Joachim Bröcher

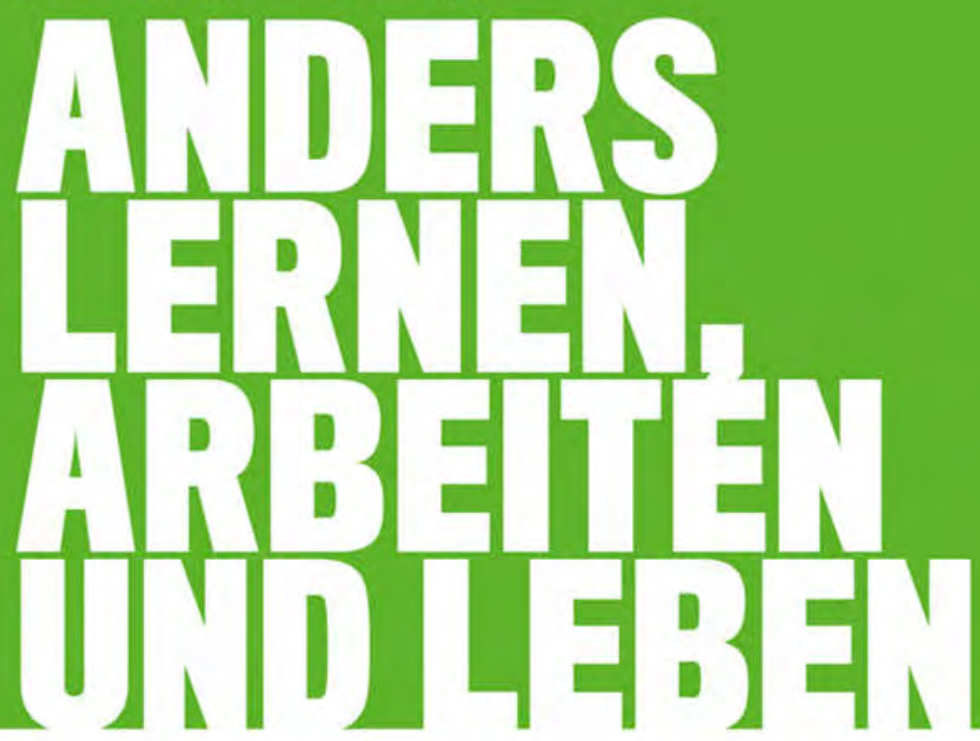

Für eine Transformation von Pädagogik und Gesellschaft

[transcript] Pädagogik 
Joachim Bröcher

Anders lernen, arbeiten und leben

Pädagogik 
Joachim Bröcher lehrt an der Europa-Universität Flensburg. Er erforscht den urbanen Raum Berlins aus pädagogischer Sicht sowie die weitere Entwicklung eines transformativen Community-Projekts, das er in einer ländlichen Region von Sachsen-Anhalt gegründet hat. 
Joachim Bröcher

\section{Anders lernen, arbeiten und leben}

Für eine Transformation von Pädagogik und Gesellschaft

[transcript] 
Der Autor bedankt sich beim Ministerium für Bildung, Wissenschaft und Kultur des Landes Schleswig-Holstein für die finanzielle Förderung dieser Publikation.

\section{Bibliografische Information der Deutschen Nationalbibliothek}

Die Deutsche Nationalbibliothek verzeichnet diese Publikation in der Deutschen Nationalbibliografie; detaillierte bibliografische Daten sind im Internet über http:// dnb.d-nb.de abrufbar.

\section{(c) $(1)(\Theta \Theta$}

Dieses Werk ist lizenziert unter der Creative Commons Attribution-NonCommercial-NoDerivs 4.0 Lizenz (BY-NC-ND). Diese Lizenz erlaubt die private Nutzung, gestattet aber keine Bearbeitung und keine kommerzielle Nutzung. Weitere Informationen finden Sie unter https://creativecommons.org/licenses/by-nc-nd/4.o/deed.de Um Genehmigungen für Adaptionen, Übersetzungen, Derivate oder Wiederverwendung zu kommerziellen Zwecken einzuholen, wenden Sie sich bitte an rights@transcript-publishing. com

Die Bedingungen der Creative-Commons-Lizenz gelten nur für Originalmaterial. Die Wiederverwendung von Material aus anderen Quellen (gekennzeichnet mit Quellenangabe) wie z.B. Schaubilder, Abbildungen, Fotos und Textauszüge erfordert ggf. weitere Nutzungsgenehmigungen durch den jeweiligen Rechteinhaber.

\section{(ㄷ) 2021 transcript Verlag, Bielefeld}

Umschlaggestaltung: Maria Arndt, Bielefeld

Satz: Michael Rauscher, Bielefeld

Druck: Majuskel Medienproduktion $\mathrm{GmbH}$, Wetzlar

Print-ISBN 978-3-8376-5651-0

PDF-ISBN 978-3-8394-5651-4

https://doi.org/10.14361/9783839456514

Gedruckt auf alterungsbeständigem Papier mit chlorfrei gebleichtem Zellstoff. Besuchen Sie uns im Internet: https://www.transcript-verlag.de Unsere aktuelle Vorschau finden Sie unter www.transcript-verlag.de/vorschau-download 


\section{Inhalt}

1. Transformation von Pädagogik und Gesellschaft ................................ 7

Die Idee und die Menschen auf dem Weg zu ihrer Realisierung ........................... 7

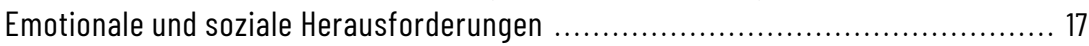

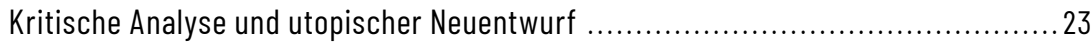

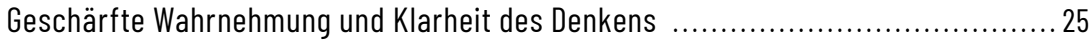

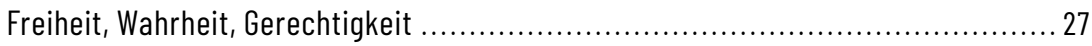

Potenzial der Demokratie .................................................................... 30

2. Das Wissen, seine Strukturen und seine Produktion ............................. 33

Emotionales und soziales Lernen: Der Wissensstand .....................................33

Emanzipatorische, transdisziplinäre Bildungs- und Sozialwissenschaft ..................38

Kulturelle Geografien, Cultural Mapping, Creative City .................................... 39

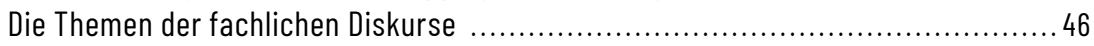

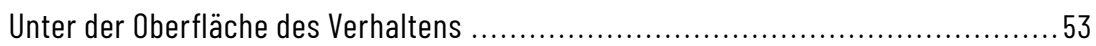

Theorieentwicklungen, Paradigmen, Spannungsfelder .....................................61

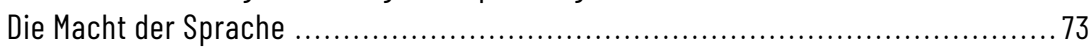

Strategisches Publizieren und das Verfehlen des State of the Art ........................ 84

3. Lern- und Bildungsprozesse anders entwerfen .................................... 103

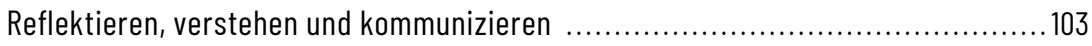

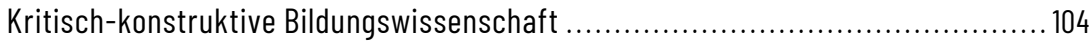

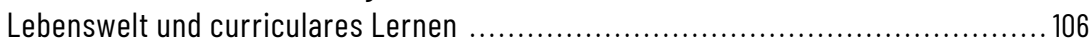

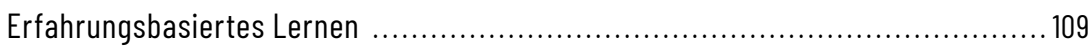

Transformative pädagogische Beziehungen ........................................................ 110

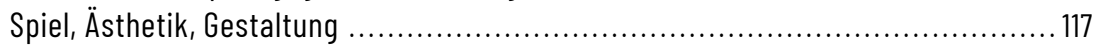

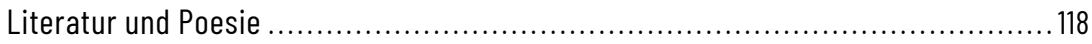

\section{Transdisziplinäre Studien in der Metropole Berlin:}

Visuelle Spiegelungen

5. Filmanalyse als Kultur- und Gesellschaftsanalyse .............................. 153

Aspekte emotionaler und sozialer Entwicklung in Filmen ............................... 153

»Sie küssten und sie schlugen inn«: Herzlose Erziehungsmethoden .................... 156

»Christiane F.«: Jugend in Berlins Schattenwelten ....................................... 159

»Billy Elliot«: Männlichkeitskonzepte und soziale Klasse .................................161

»Räuber Kneiß|«: Gefangen im sozialen Herkunftsmilieu ................................... 164

»Game of Thrones« und »Vikings«: Identität und Schicksal ............................. 166

»Der kalte Himmel«: Überwindung der orthodoxen Psychiatrie .......................... 176

»Fack ju Göhte«: Resonante pädagogische Beziehungen ................................. 178 


\section{Das ländliche Westdeutschland zur ersten Hälfte}

des 20. Jahrhunderts: Soziokulturelle Rekonstruktionen ...................... 183

Generationenübergreifendes, narratives Lernen in einer dörflichen Community ..... 183

Ein Landarbeiter, eine Müllerstochter und ihre sieben Kinder ............................. 185

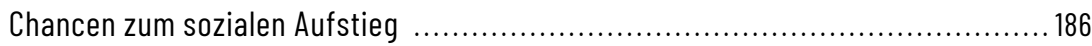

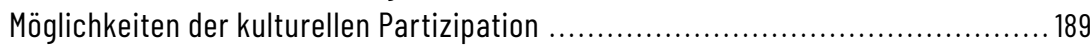

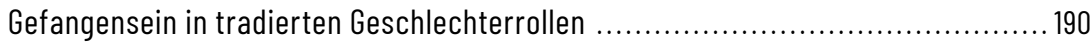

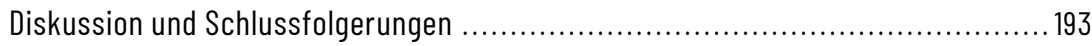

7. „Bodies under Glass«: Erkundungen in virtuellen Räumen .................... 209

Masculinities zwischen Hegemonialität und Vulnerabilität ............................. 209

Körper, Identität, Emotion und Sehnsucht in der digitalen Welt ......................... 214

8. Europäische Lernräume: Pädagogischer Austausch zwischen

Polen und Deutschland zur Zeit des Kalten Krieges ............................ 223

Die Ursprünge einer zukunftsweisenden pädagogischen Philosophie .................. 223

Die Vergegenwärtigung der besonderen Historie

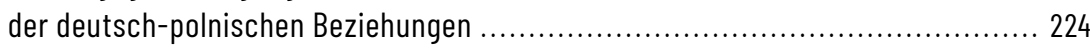

Die Achse Köln-Warschau während der Zeit des Kalten Krieges ....................... 229

Das Aufspannen von europäischen Lernräumen über Sommerworkshops

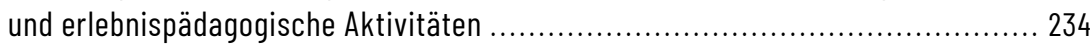

Deutsch-polnische Lernerfahrungen und Community-Projekte der Zukunft .......... 237

9. Von der Kontrollgesellschaft zur Zivilgesellschaft

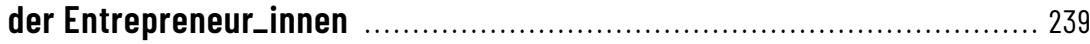

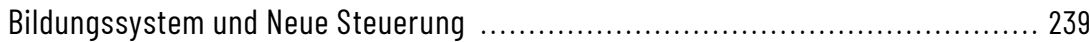

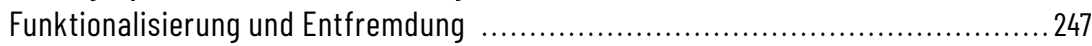

Von der Kontrollgesellschaft zur aktiven Zivilgesellschaft ............................. 255

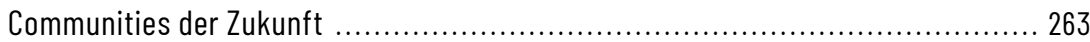

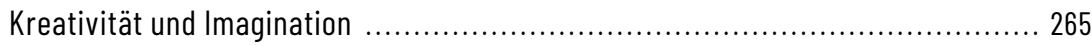

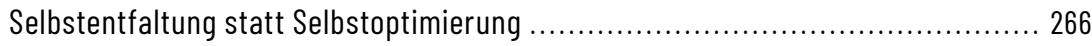

Gesellschaftliche Transformation, globale Veränderung

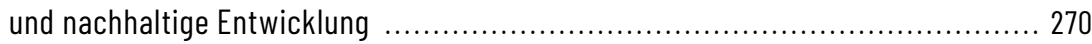

Offene, variable Strukturen in Lern- und Lebensräumen .................................277

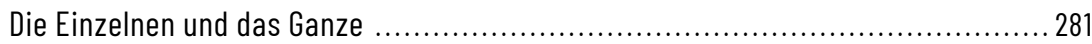

10. Ein Community-Projekt im ländlichen Raum Ostdeutschlands:

Dokumentation des Anfangs

Epilog: Mit Zuversicht und Optimismus die Zukunft gestalten ................... 297

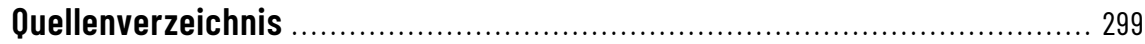

Literatur aus Inklusions-, Sozial- und Sonderpädagogik ............................... 299

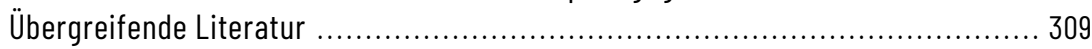

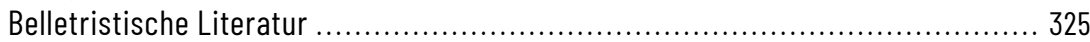

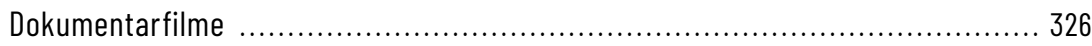

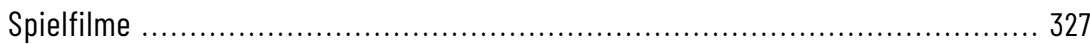




\section{Transformation von Pädagogik und Gesellschaft}

\section{Die Idee und die Menschen auf dem Weg zu ihrer Realisierung}

»Es gibt keine schlimmere Ausschweifung als das Denken. Dieser Übermut wuchert wie windbestäubtes Unkraut auf einem Beet, das für Gänseblümchen bestimmt war«, notierte Wisława Szymborska (1996 b, S. 53) in einem ihrer Gedichtbände. Würde mich jemand darum bitten, in aller Kürze zum Ausdruck zu bringen, was ich bei der Niederschrift dieses Buches letztlich getan und erlebt habe, dann möchte ich diese beiden Zeilen der, von mir sehr verehrten, polnischen Lyrikerin und Nobelpreisträgerin rezitieren, mehr nicht. Für wen habe ich dieses Buch geschrieben? Zum einen für die jungen Studierenden, die ihren pädagogischen Weg jetzt vor sich haben, um ihnen etwas an die Hand zu geben, was sie nehmen können, um daraus eine zukunftsorientierte Pädagogik, sei es in Schulen, sei es in freieren pädagogischen Kontexten jenseits des Schulsystems, um die es mir ja zunehmend geht, zu entwickeln. Zum anderen schreibe ich für schon länger, in den derzeitigen Bildungssystemen tätige, Lehrer_innen und Pädagog_innen, die möglicherweise in der institutionellen Enge ihrer Arbeitskontexte mit dem Rücken zur Wand stehen und vielleicht sogar seelisch und körperlich leiden. Ich möchte, dass sie wieder mehr Handlungsmöglichkeiten sehen, aus dem Leiden am System herauskommen, neu in die Aktivität gehen und sich wieder Spielräume verschaffen. Dieser Prozess beginnt mit einem anderen Denken und mit einem Zulassen von anderen Vorstellungen. Ich spreche hier rückblickend auch aus meiner eigenen Erfahrung im Schulsystem, im Hinblick auf das, was ich, zu einigen kritischen Zeitpunkten, speziell in meiner Laufbahn als Lehrer, gebraucht hätte. Es gibt einzelne, hervorragende, hoch entwickelte Schulkulturen, darin sind auch ausgeprägte Philosoph_innen mit viel Gespür sowie Weitblick und verantwortungsvolle Führungskräfte anzutreffen, aber es gibt auch Schulen, wo ein Klima der geistigen Enge, eine regelrecht beklemmende Atmosphäre herrscht, wo sich die Denkhorizonte verfinstert haben, wo eine zwanghafte Kleinkariertheit und Kleinbürgerlichkeit regiert, wo die Menschen keine reflexive Distanz mehr zu sich selbst und zu ihrem eigenen Tun haben, wo Angst, Misstrauen, Egoismus und Aggression die Oberhand haben, oder wo sich die Menschen an Trivialitäten und oberflächlichen Dingen festhalten und unnötig viel damit aufhalten. Dasselbe kann auch für Universitäten gelten. Der Übergang ist zunehmend fließend. Wir sollten uns nicht mehr damit abfinden und jetzt die grundlegenden Strukturen ändern. Wir haben in erster Linie mit strukturellen Problemen und Herausforderungen zu tun, und mit menschlichen Schwächen. Unter besseren Bedingungen, so jedenfalls ist meine persönliche Auffassung, können sich auch die 
Menschen anders, rücksichtsvoller, nachhaltiger, verantwortungsvoller und reflektierter verhalten, als sie es teils jetzt, unter den gegebenen Bedingungen, tun. Wenn die Strukturen besser sind, können die Menschen sich auch zu der Qualität von Person entfalten, wie sie Carl Rogers, unter den Leitideen des neuen Menschen, der Selbstaktualisierung oder der Kraft des Guten, schon vor etlichen Jahrzehnten, entworfen hat.

Drittens schreibe ich für die jungen politischen Aktivist_innen, wie sie sich jetzt etwa unter dem Namen Fridays for Future formieren, damit sie neben allen global bedeutsamen Fragen auch den Themenzusammenhang von Lernen, Schule, Universität, Arbeit, Leben und Gesellschaft mit auf ihre Agenda setzen und in ihre Veränderungsbemühungen einschließen. Der Klimawandel ist ein fundamental wichtiges Thema. Aber wenn wir eine Bewusstseins- und Verhaltensveränderung im großen Stil bei den Menschen erreichen wollen, müssen wir auch für andere Verhältnisse beim Lernen, Arbeiten und Leben sorgen. »It is all connected«, sagte Edgar Klugman, ein weiser, hochbetagter Professor am Wheelock College, jetzt Boston University, ausgewandert aus Deutschland, im Dritten Reich. Viertens schreibe ich für die Entscheider_innen in Politik und Wirtschaft, damit sie zum einen verstehen, warum sich jetzt etwas ändern muss und damit sie sehen, dass veränderte Formen des Lernens, Arbeitens und Lebens zugleich mit Innovation und Produktivität verbunden sind, dazu noch mit einer ganz neuen Qualität auf all diesen Gebieten. Es geht mir natürlich nicht darum, dass ganz Deutschland nur noch in der Hängematte liegt, wenn ich für die Einführung eines bedingungslosen Grundeinkommens eintrete. Das Gegenteil ist der Fall. Ich will dafür werben, dass mehr Menschen zu aktiven Entrepreneur_innen werden, dass mehr Menschen ihr Leben selbstbewusst in die Hand nehmen, dass sie ihr Leben schöpferisch gestalten und auf eine neue, vernünftige, gesunde, nachhaltige Weise arbeiten, ohne sich aber in fremdbestimmten Systemen schikanieren und ausbeuten zu lassen, oder, ab einer bestimmten Hierarchie- oder Karrierestufe, und so funktioniert das derzeitige System ja, dasselbe mit anderen zu tun.

Dazu muss den Menschen aber der Druck und die Existenzangst genommen werden. Ihre Existenz muss gesichert sein, ohne dass sie zu Bittstellern werden. Das haben wir doch als Gesellschaft gar nicht nötig, einzelne Mitglieder so herabzuwürdigen und wir sollten es aus ethischen Gründen auch nicht tun. Genauso sinnlos ist es, Menschen, die sich an den Rand der Gesellschaft gedrängt fühlen und die teils extreme Auffassungen entwickelt haben, zu beschimpfen und ihnen zu drohen. So werden wir diese Menschen nicht erreichen. Das ist nach der Art eines hilflosen Schulmeisters, der einfach wütend gegen eine rebellische Schüler_innenschaft anschreit, ohne sich zu fragen, was sich wirklich in den Köpfen und in den Herzen der Jugendlichen, die vor ihm sitzen, abspielt. Wenn wir einen anderen Menschen herabwürdigen, würdigen wir auch uns selbst herab. Denn der andere ist unser Spiegelbild. Nur ein oberflächlich denkender Mensch kann sich ernsthaft einreden, dass er damit davon kommen wird. Sicher, im Alltag kommt er erst einmal scheinbar mit seiner Negativität davon. Aber diese Negativität wird ihn irgendwann in seinem Leben einholen. Das Problem ist ja auch, dass auf diese Weise die sozialen Spannungen und Spaltungen, über die tagtäglich in den Medien geklagt wird, weil wieder irgendetwas Neues vorgefallen ist, an Ausschreitungen, Angriffen, Übergriffen, Beleidigungen oder Hetzaktionen, immer weiter vorangetrieben werden. Wir sollten hier einfach mutig, und zwar in der vollen Breite der Gesellschaft, aussteigen, und diesen Roten Ozean, um es mit Kim und Mauborgne zu sagen, diese konflikthaften sozialen Gewässer verlassen und uns alle 
gemeinsam in einen Blauen Ozean der neuen Möglichkeiten hineinbewegen und endlich etwas Anderes versuchen. Das bedeutet, Menschen einzubinden, sich in ihre Lage hineinzudenken und mit ihnen gemeinsam etwas zu entwickeln, nicht aber sie zu beschimpfen, zu pathologisieren oder zu dämonisieren.

Auch sind die finanziellen Mittel ja vorhanden, nach der Einschätzung von Finanzund Wirtschaftsexpert_innen. Sie müssen nur anders, das heißt auch gerechter, klüger und nachhaltiger verteilt werden. Die Zivilgesellschaft sollte sich nicht länger abspeisen lassen. Das Geld, um das es geht, ist ja nicht das Eigentum der Politik oder das Geld der öffentlichen Verwaltungen. Es handelt sich ja um das Geld, das die Zivilgesellschaft selbst erwirtschaftet hat und das auch stärker nach den Vorstellungen eben dieser Bürger_innen eingesetzt werden sollte. In den nächsten Jahren wird es daher auf mutige Stimmen aus der Zivilgesellschaft ankommen, auf Menschen, die eine andere, bessere Entwicklung vorantreiben. Doch nun will ich auf mein eigenes pädagogisches Fachgebiet zu sprechen kommen, das Gebiet, von dem ich zunächst ausgehe, auch wenn ich immer wieder darauf drängen werde, das gesamte Bild der Gesellschaft in den Blick zu nehmen und, darüber hinaus, auch die globale Situation als Ganzes zu betrachten, denn die Pädagogik der emotionalen und sozialen Entwicklung ist doch gar nicht von gesellschaftlichen und globalen Fragen zu trennen. Sie ist ihr Spiegelbild. Der Gegenstand dieses Faches ist durch und durch ein gesellschaftlicher Gegenstand. Dieser Band bietet zunächst eine kritische Bestandsaufnahme der im pädagogischen Schwerpunkt der emotionalen und sozialen Entwicklung, national wie international, vorhandenen Modelle und Konzepte, auch in ihrer Gegensätzlichkeit und Problematik, in ihrer Begrenztheit und in ihren Chancen. Ich werde diese Theorien und Handlungsansätze in einen größeren gesellschaftlichen Zusammenhang stellen und im Hinblick auf ihre Zukunftsbedeutsamkeit diskutieren, wobei mir zum einen die Agenda 2030 für nachhaltige Entwicklung als Kompass dient, zugleich aber auch die Idee der Freiheit, die jeder Mensch auf diesem Planeten, egal wo er/sie lebt, für sich und das eigene Leben verwirklichen können sollte, selbstverständlich mit Rücksichtnahme, Achtsamkeit und Empathie für den anderen. Neben der Freiheit geht es mir um die Werte der Wahrheit und der Gerechtigkeit. Zusätzlich zu dieser Bestandsaufnahme und kritischen Diskussion von vorhandenen Theorien und Modellen habe ich einige ergänzende Forschungen unternommen, in der Metropole Berlin, in einer ländlichen Community in Südwestfalen, im Bereich der Filmanalyse und der Erkundung von virtuellen Welten, durchaus im disziplinüberschreitenden und transdisziplinären Sinne, denn ich denke nicht in den engen Bahnen einer einzigen Disziplin, insbesondere dann nicht, wenn diese von vielen eher eng definiert und entworfen wird.

In der theoretischen Auseinandersetzung um den adäquaten pädagogischen Umgang mit den anwachsenden emotionalen und sozialen Thematiken oder Problematiken in Pädagogik und Gesellschaft stehen sich, ausgehend von Gilles Deleuze' Kritik der Kontrollgesellschaft, zunehmend konfrontativ, der Diskurs der Kontrolle und der Diskurs der Freiheit gegenüber. Ein Teil der Sonder- und Inklusionspädagogik engagiert sich in der Entwicklung immer subtilerer Strategien des Behavior Ratings und Behavior Managements und arbeitet somit der, das Bildungssystem zunehmend dominierenden, datenbasierten, kompetenzorientierten Neuen Steuerung zu. Auf diese Weise lässt sich das, an der Vorstellung einer überkommenen Leistungsgesellschaft festhaltende, Schulwesen, auch unter den angespannten Bedingungen der Inklusion, am Laufen halten. Doch auf der anderen Seite formieren sich Kräfte, die das Fach mit 
interdisziplinären und transdisziplinären Strömungen verbinden und als Teil der gesellschaflichen Transformation in seiner alten Gestalt überwinden und neu entwerfen. Die auf dieser Seite befindlichen Protagonist_innen bilden jedoch eine sehr heterogene, zersplitterte Szene. Der größere Teil von ihnen dürfte wiederum auch noch an der alten inklusions- und sonderpädagogischen disziplinären Identität festhalten, wie es scheint. $\mathrm{Zu}$ wenig Alternativen sind in Sicht, gemessen an den Reflexions- und Ideenhorizonten in deren Texten. Eine eher kleine Gruppe ist nun auch bereit, darunter ich selbst, den letzten Schritt zu machen und die Disziplin, quasi an einem historischen Wendepunkt, zu überwinden und in etwas anderes zu transformieren. Dabei leben bestimmte Erkenntnisse, Erfahrungen und Ideen fort, doch es ist eben eine Verwandlung in etwas qualitativ Neues. Viele Wissenschaftler_innen suchen fieberhaft nach etwas Neuem, aber sie suchen immer in demselben Raum, oder in demselben Gebäude, statt einfach einmal nach draußen zu gehen und die Augen zu öffnen und durch die Landschaft zu streifen. Der größte Teil dessen, was wir seit Jahrzehnten auf dem Gebiet der Förderung der emotionalen und sozialen Entwicklung in Schule und Unterricht zu lesen bekommen, basiert auf der unhinterfragten Vorstellung, dass diese Art von Schule, auf die hin wir dies ja alles entwickeln, quasi nach übergeordnetem Gesetz, in alle Ewigkeit so fortbesteht. Wieso eigentlich? Es hat doch nicht zu allen Zeiten eine Schulpflicht gegeben, auch nicht in allen Ländern. Es hat auch nicht immer diese Art der Schule gegeben. Warum glaubt der Staat über die einzelnen Bürger_innen in dieser Weise verfügen zu können? Ich werde noch an verschiedenen Stellen auf diese entscheidende Frage zurückkommen, denn wenn wir hierzu einmal anfangen wirklich frei zu denken, hat das eine ganze Reihe von Konsequenzen auch für die Forschung und Theoriebildung des eigenen fachlichen Schwerpunkts. Es entstehen plötzlich ganz neue Perspektiven.

Dasselbe gilt für die Verteilung der finanziellen Mitteln innerhalb der Gesellschaft. Auch das muss nicht weiter nach dem Muster geschehen, wie wir es jetzt haben. Um aber eine höhere Qualität von Pädagogik für Kinder und Jugendliche mit einer emotionalen und sozialen Thematik zu erreichen, um dies bereits hier vorwegzunehmen, sollte die Schulpflicht in eine eigenständig zu gestaltende Bildungspflicht umgewandelt und ein bedingungsloses Grundeinkommen (zur Diskussion vgl. Adamo, 2012; Ketterer, 2019; Meyer und Vornholt, 2017; Precht, 2020; Schloen, 2019) für jeden Menschen bereitgestellt werden. Deutschland könnte sich das leisten, aufgrund seiner Wirtschaftskraft, und da wo es mit den finanziellen Mitteln aus heutiger Sicht noch eng wird, könnte durch einige strukturelle Veränderungen noch mehr an Finanzkraft freigesetzt werden. Auf dieser Basis können sich, und darauf komme ich im Laufe des Buches genauer zu sprechen, den Diskurs der Freiheit verwirklichende, transformative Community-Projekte entwickeln, in denen zugleich gearbeitet, gelebt und gelernt wird, alternativ und ergänzend zu den jetzigen, zunehmend engmaschiger werdenden, Schulen und Universitäten. So entstehen nicht nur neue Lern-Settings und neue Formen des Lernens, sondern zugleich neue Möglichkeiten, mit den emotionalen und sozialen Thematiken von jungen Menschen in adäquaterer Weise pädagogisch umzugehen, als es bislang in den staatlichen Schulen, die auf immer mehr Monitoring, kompetenzorientiertes Lernen und Steuerung setzen, überhaupt möglich ist. Dadurch dass auch zugleich neue Formen des Arbeitens entstehen, wird auch ein anderes Lernen möglich, weil die Perspektive der jungen Menschen auf das Thema Arbeit verändert wird. Arbeit wird attraktiver werden in dem Moment, wo sie schöpferischer, 
selbstbestimmter und weniger entfremdet ist. Der Druck, unter dem die öffentlichen Schulen auch stehen, weil sie derzeit, aufgrund der noch geltenden Gesetze, ja gar nicht befugt sind, formale Erstarrung, Bürokratisierung, übertriebene Regulierung und curriculare Enge hinter sich zu lassen, würde dadurch, dass niemand mehr gezwungen ist, gegen den eigenen Willen dort zu sein, zum einen enorm verringert. Zum anderen würden sich die Schulen und Universitäten selbst mit der Zeit verändern, wenn sie in Zukunft noch fortbestehen wollen, in Anbetracht der Vielzahl lebendiger Community-Projekte, die dann entstehen und in die Kinder und Jugendliche, auf bestimmten Gebieten wie den Gesellschafts-, Sozial- und Bildungswissenschaften auch Studierende, alternativ gehen können, um zu lernen und sich zu entwickeln. Auch viele Denker_innen und Forscher_innen, die sich mehr ihren Interessensgebieten und dem direkten Gespräch mit jungen Menschen widmen wollen, als modularisierten, standardisierten Lerncurricula, und die es wenig erbaulich finden, im Monopoly der Academia mitzuspielen, könnten sich mit der Zeit in den Community-Projekten ansiedeln und dort entfalten.

Das Grundeinkommen dürfte auch die Bedeutung von Schulabschlüssen stark relativieren, weil unsere bisherigen Vorstellungen von eindimensionalen Erwerbsbiografien zumindest teilweise überholt wären, wie auch die Bedeutung von Bachelor- und Masterabschlüssen relativiert würde. Trotz allem wird sich ein großer Teil der Menschen ja für bestimmte, auch aufwändigere berufliche Wege qualifizieren wollen, die durchaus ein Universitätsstudium beinhalten können. Doch es wird nicht mehr der Normalfall sein, dass ein Universitätsstudium absolviert wird, weil dies auch gar nicht erforderlich ist und so oder so gar nicht angemessen erscheint. Es gilt den übertriebenen Akademisierungswahn der vergangenen Jahre wieder zurückzufahren. So oder so entsteht mehr Spielraum für diejenigen Heranwachsenden, die intensiv mit der Klärung emotionaler und sozialer Thematiken oder Problematiken zu tun haben oder die keine Passung zwischen sich und den spezifischen Lernräumen und Lernformen, wie sie staatliche Schulen bislang bieten, erkennen können. Statt immer noch mehr soziale Fragmentierung und Institutionalisierung, werden diese jungen Menschen durch das handlungsorientierte Miteinander in technischen, landwirtschaftlichen, handwerklichen, sozialen oder künstlerischen Projekten Resonanz, Anerkennung und Bestätigung erfahren. Die dort gelebten pädagogischen Beziehungen weisen eine philosophische Grundierung auf. Statt dass sich die Jugendlichen in virtuelle Welten, auf Streamingplattformen oder in Online-Communities begeben, um dort oftmals vergeblich nach dem wahren Leben zu suchen oder der Öde ihres Alltags zu entfliehen, wachsen sie unter den Bedingungen der transformativen Community-Projekte sozial eingebettet und geerdet auf. Sie lernen dort aktiv zu gestalten, sich einzubringen und ihr Leben in die Hand zu nehmen. Jenseits der apparativen, oftmals bevormundenden und depotenzierenden Systemsteuerung, die wir jetzt überwiegend in den Schulen, an den Universitäten und im Arbeitsleben haben, werden sich die jungen Menschen als handelnde Subjekte neu finden, neu entwerfen, aktiver und zufriedener werden und optimistischer in die Zukunft gehen. Auch können sie, im Rahmen von Wanderjahren, in verschiedenen Projekten leben und lernen, irgendwann weiterziehen, und so zu geistig unabhängigen, nachhaltig und global denkenden Menschen werden, die tatsächlich bereit und in der Lage sind, für sich selbst, für andere und für diesen Planeten als Ganzes Verantwortung zu übernehmen. 
Es gibt einige Personen in meinem akademischen oder persönlichen Umfeld, teils auch in meiner beruflichen und persönlichen Vergangenheit, denen ich eine ganze Reihe von Impulsen und Anregungen im Hinblick auf die Ideenentwicklung in $\mathrm{Zu}-$ sammenhang mit diesem Buch verdanke, sei es auf mehr theoretischer oder mehr praktischer, pädagogischer, unternehmerischer, teils auch menschlicher Ebene. Ich werde einige von ihnen im Laufe der Kapitel nennen, je nach Themenzusammenhang. Es gibt auch eine Reihe von Personen, die Teile des Manuskripts, das heißt frühere Entwurfsfassungen, gelesen oder die mich in erkenntnisreiche Debatten über die in diesem Buch abgehandelten Themen verwickelt haben, die mir hilfreiches Feedback, auch zu früheren Versionen dieses Buches, gegeben haben oder die bloß geistreiche Gespräche mit mir geführt haben. Sie alle haben, jede und jeder auf ganz eigene Weise, teils auch durch Widerspruch und argumentative Konfrontation, zu einer Weiterentwicklung und Präzisierung meiner Gedanken und zur Herausbildung dieses Neuentwurfs beigetragen. Dafür möchte ich mich an dieser Stelle recht herzlich bedanken bei Jan Bröcher, Berlin; Philipp Bröcher, Aachen; Prof. Dr. Friedhelm Decher, Ottfingen und Siegen; Leonie Delfs, Flensburg; Prof. Dr. Eberhard Grüning, Berlin und Flensburg; Runa-Malin Hübner, Flensburg; Prof. Dr. Wolfgang Jantzen, Bremen; Karin Anna Jung-Bröcher, Niederbreidenbach; Dr. Roland E. Koch, Köln; Dr. Regina Künzler-Knufinke, Pulheim bei Köln und Flensburg; Sylvia Mandt, Solingen; Priv.-Doz. Dr. Arwed Marquardt, Loccum und Lüneburg; Hans-Walter Putze, Gießen; André Rempel, Den Haag; Dr. Katja Luckhardt-Seebaum, Köln; Siggi Neuhaus-Omintara, Hofheim bei Frankfurt; Dr. Julia-Maria Siebert, Lingen und Flensburg; Anette Steimann, Klein Rönnau und Flensburg; Prof. Dr. Karlheinz Thimm, Berlin; Prof. Dr. Piotr Toczyski, Warschau; Oliver Werner, Nümbrecht; Priv.-Doz. Dr. Christian Wevelsiep, Essen und Flensburg, Kveta Wiesner, Schwaig b. Nürnberg und Rolf Zander, Niederbreidenbach.

Klaus Peters, Viersen, selbst lange Zeit Lehrer im Feld der schulischen Erziehungshilfe und gleichzeitig Künstler, war 1989 bis 1991 mein Fachleiter im Studienseminar Düsseldorf. Dieser Mann war aus einem ganz besonderen Holz geschnitzt, ein Querdenker und Querkopf sondergleichen, ein Freigeist, der unbequeme Fragen stellte. Die meisten in meiner Gruppe kamen von der Universität zu Köln, denn das Studienseminar in Köln nahm nur alle zwei Jahre Referendar_innen auf, eben im Wechsel mit Düsseldorf. So kamen wir nach Düsseldorf. Empfangen wurden wir hart und rau, ja schroff, vielleicht so, als säße da James Delaney, aus der Filmserie Taboo. Er hielt uns für schlecht vorbereitet, weil wir eben aus Köln kamen. Aus seiner Sicht verfügten wir weder über eine gesellschaftskritische Theorie, noch über eine handlungsorientierte Pädagogik und Didaktik. Er sagte uns voraus, dass wir einen schweren Einstieg haben würden, weil wir, mit so wenig Handwerkszeug und so wenig Wissen, nicht weit kommen würden, auf dem harten Pflaster der schulischen E-Pädagogik, und wir gingen ja alle in zumeist urbane separierte, spezialisierte Brennpunktschulen, in Düsseldorf, Duisburg, Wuppertal oder Solingen. Was für ein Einstieg! Das Studium ging also weiter, parallel zum Referendariat. Klaus Peters hatte jedoch, in der Tat, eine gesellschaftskritische, handlungsorientierte, schülerorientierte, lebensweltorientierte, bindungsorientierte, projektorientierte Pädagogik im Gepäck. Diese Pädagogik war rau, aber sie hatte Herz. Sie hatte mit Material zu tun und mit dem Reflektieren und Einordnen von gesellschaftlicher Erfahrung. Peters verbrachte mit uns ein Wochenende auf Schloss Gnadenthal in Kleve, damit wir uns nicht immer nur, für die wöchentlich zwei Stunden, in Düsseldorf trafen, eingezwängt zwischen Schulunterricht und all 
den Autobahnfahrten, und auch nicht nur bei den Unterrichtsbesuchen miteinander sprechen konnten.

In Schloss Gnadenthal lernten wir das Schweißen. Aus früheren Tätigkeiten in der Metallindustrie hatte ich gewisse Grundkenntnisse und einige Vorerfahrungen. Eisen und Stein waren Peters' Materialien, auch als Künstler. Wir sammelten Eisenteile bei Schrotthändlern in Köln-Ehrenfeld und wo sonst die beteiligten Referendar_innen lebten. Wir schweißten daraus eine gigantische Skulptur, die dann im Schlosspark stehen blieb. Abends und nachts wurde debattiert, über die Pädagogik und die Gesellschaft, über Menschen, ihr Verhalten, ihre Muster, ihre Abgründe, bei einem Fass Kölsch. Über das, was heute in der Sonderpädagogik der emotionalen und sozialen Entwicklung los ist, hätte er glaube ich nur müde gelächelt und abgewunken. Vermutlich hätte er unter Hinweis auf Niklas Luhmann gesagt, dass er von dem ganzen selbstreferentiellen Zeug aus dem Elfenbeinturm wenig halten würde. Peters hatte vor allem zwei theoretische Bezugspunkte: Theodor Adorno und Hartmut von Hentig. Von hier aus entwickelte er zum einen seine Gesellschaftskritik, zum anderen seine pädagogischen Entwürfe und Zielsetzungen. Natürlich hatte er nichts gegen Rogers' klientenzentrierten Ansatz an sich einzuwenden, wie er von Karl-Josef Kluge in den 8oer Jahren, an der Universität zu Köln, im Schwerpunkt emotionales und soziales Lernen, gelehrt wurde. Doch Klaus Peters reichte das nicht. Nicht für dieses anspruchsvolle Arbeitsfeld. Wie sollte man auch nach Rogers Unterricht in einer E-Schule planen und durchführen? Rogers lieferte mehr eine philosophische Haltung, eine Anleitung für eine Kommunikation und eine Beziehungsgestaltung, die anderen Menschen helfen sollte, sich selbst zu entfalten. Rogers' Texte beinhalteten keine Didaktik. Also fuhr Peters mit uns zur Laborschule Bielefeld. Dort wurden wir herumgeführt, schauten uns alles an und sprachen mit Annemarie von der Groeben, die die Nachfolge von Hartmut von Hentig in der Leitung der Schule angetreten hatte. »Die Menschen stärken, die Sachen klären«, das war so ein Hentig Bonmot, identisch mit einem seiner Buchtitel, das öfter bei Klaus Peters zu hören war. Das war 1989 bis 1991. Von Hentig war noch nicht demontiert worden. Das passierte erst 2011. Für viele ist er jetzt eine persona non grata. Doch die heutigen Bildungs- und Erziehungswissenschaften können ihn schlecht aus ihrer Geschichte herausspalten. Da hilft auch nicht erbittertes Verschweigen, Ignorieren, Weglassen. Was soll das auch?

Hartmut von Hentigs in den 6oer, 70er und 8oer Jahren erschienene Bücher Systemzwang und Selbstbestimmung, Wie hoch ist die höhere Schule?, Schule als Erfahrungssraum, Was ist eine humane Schule? waren doch allesamt wichtige Meilensteine auf dem Weg zu einer besseren, gerechteren, schülerorientierten, demokratischen Schulpädagogik. Es ist unaufrichtig, wenn wir das jetzt verschweigen und absichtsvoll vergessen. Natürlich war es problematisch und nicht akzeptabel, wie Hartmut von Hentig sich zu den Vorgängen in der Odenwaldschule und dem Treiben von Gerold Becker geäußert hat, mit dem er in Berlin-Charlottenburg in ein und demselben Haus, allerdings auf verschiedenen Etagen wohnte, mit dem er befreundet war und mit dem er, wie viele meinen, vor etlichen Jahrzehnten einmal eine engere Liaison gehabt haben soll. Darüber ist schon viel geschrieben und spekuliert worden. Doch von Hentig war 86 Jahre alt, als der Fall der Odenwaldschule 2011 eskalierte, das heißt als lange unterdrückte, verdrängte Dinge, die mit dem systematischen sexuellen Missbrauch an Schülern zu tun hatten, mit voller Wucht in die Öffentlichkeit und in die Medien drangen. Von Hentig ist 1925 geboren. Man muss seine Autobiografie, am besten alle drei Bände lesen, dann 
versteht man mehr. Ich werde noch an einigen anderen Stellen auf dieses Thema zurückkommen. Hier gilt es vorläufig festzuhalten, dass Klaus Peters sehr viel von den Schriften und der praktischen Pädagogik von Hartmut von Hentig hielt. Interessant ist allerdings, dass seine Texte an der Universität zu Köln, speziell im Bereich der Sonder- und Inklusionspädagogik der von mir studierten Schwerpunkte emotionale und soziale Entwicklung und Lernen aber ganz und gar keine Rolle spielten. Einmal, das war aber schon in meiner Zeit als Doktorand, saß ich bei einem Vortrag zur Neubesetzung einer Professur neben einem streng und ausschließlich empirisch-quantitativ ausgerichteten Kollegen, damals waren das ja nur einige wenige, die in Köln so dachten und arbeiten. Jedenfalls ließ ich, zwischen zwei Vorträgen, im Zweiergespräch auf den harten hölzernen, überaus unbequemen, Klappsitzen des Hörsaal 1, in der Frangenheimstraße, den Namen von Hentig fallen.

$\mathrm{Zu}$ dem Namen von Hentig sagte der genannte Professor nun: »Ach, das ist ein alter Quatschkopf!« Das Thema war auf der Stelle für ihn erledigt und ich musste etwas Neues ansprechen, damit die informelle Kommunikation weiterging und ihre Leichtigkeit behielt. Natürlich hat mich von Hentig also auch beeinflusst. Im Juli 2017 besuchte ich ihn in seiner Wohnung in Charlottenburg, auf dem Kurfürstendamm. Ich wollte mit ihm über die Zukunft der Pädagogik sprechen, wie er sie eben entworfen hatte, natürlich, wenn möglich, auch über das Thema Odenwaldschule und über die gesellschaftlichen Veränderungen und wie wir als Bildungs- und Erziehungswissenschaftler darauf reagieren sollten. Ich hatte zu der Zeit eine Wohnung direkt hinter dem Alexanderplatz gemietet, im Osten der Stadt. Die U2 brauchte natürlich eine ganze Weile, um in den Westen der Stadt zu gelangen. Ich hatte die Fahrtzeit ein wenig unterschätzt und kam vielleicht zwei, drei Minuten zu spät. Das war für einen ehemaligen Ostpreußen von 92 Jahren gerade noch entschuldbar. Wir saßen auf dem schmalen Balkon einer, recht weit oben im Gebäude gelegenen, stilvollen Altbauwohnung, im Gartenhaus. Hinter einigen hohen Bäumen sah man die Fasenenstraße. Ein wunderbarer Ort zum Leben, zum Denken, zum Schreiben. Über von Hentigs Schreibtisch hing ein historischer Stadtplan von Rom. So tranken wir Jasmintee und saßen auf einer gepolsterten Bank auf dem Balkon und tauschten uns aus. Ich fing an mit der Wildenburg, um eine Basis für das Gespräch zu legen. Diese Burg liegt einen Steinwurf von Schloss Crottorf und Friesenhagen entfernt, in Nordrhein-Westfalen. Ich wusste aus seiner Autobiografie, dass von Hentig dort seit Jahrzehnten einen Gebäudeteil gepachtet hatte, diesen als Refugium und Gegenwelt $\mathrm{zu}$ Charlottenburg genutzt und dort Bücher geschrieben hatte. Als Kinder und Jugendliche gehörte die Gegend zu unserem erweiterten Streifraum, denn ich bin in einem nicht allzuweit entfernt liegenden Dorf aufgewachsen. In Friesenhagen befindet sich auch das Grab von Marion Gräfin Dönhoff, die 2002 verstorben ist und mit der Hartmut von Hentig in vielerlei Hinsicht eng verbunden war. Marion Gräfin Dönhoff hat mit ihren gesellschaftsbezogenen Analysen und Stellungnahmen, in der von ihr mitherausgegebenen Wochenzeitung Die Zeit, in den 9oer Jahren ganz entscheidene Impulse gegeben und Perspektiven eröffnet, auch mir. Eine solche Stimme fehlt in der Gegenwart. Es ist alles sehr komplex. Ich lasse die Dinge nach und nach einfließen.

Es gibt natürlich noch weitere Personen, denen ich bedeutsame Anregungen und Impulse verdanke, darunter auch Teilnehmer_innen der von mir geleiteten Weiterbildungen im Rahmen der erew-Akademie Viersen, wo ich über sechs Jahre hinweg (1989-1995) im monatlichen Rhythmus Wochenendseminare oder Intensivwochen im 
Bereich Creative Arts gegeben habe, zumeist im oberbergischen Eckenhagen, teils auch in Aachen, am Niederrhein oder im Hochsauerland. Ich kam hier mit lebens- und berufserfahrenen Menschen aus den verschiedensten gesellschaftlichen Kontexten in Kontakt, die mich oftmals tief beeindruckt und in mancherlei Hinsicht geprägt und bis heute in meiner Ideenentwicklung beeinflusst haben. Ich war hier in so vielem der Schüler oder der Lernende. Ich bin es, der diesen Menschen für den Erfahrungsaustausch, die gemeinsam erlebten schöpferischen und reflexiven Prozesse und die darin gewonnenen Erkenntnisse und geistigen Erweiterungen zu danken hat. Sodann bekam ich etliche Anregungen und Impulse von den Studierenden der Universitäten Köln, Gießen, Halle, Hamburg, München, Magdeburg-Stendal und Flensburg sowie von den Kindern, Jugendlichen, Eltern, Netzwerkpartner_innen und Kolleg_innen, mit denen ich während meiner Jahre in den inklusiven Sommerworkshops und kreativen Sommercamps (1983-1988) und später in der schulischen Praxis in NordrheinWestfalen (1989-2008), als Lehramtsanwärter in Solingen, als Lehrer in Eckenhagen, Waldbröl, Wiehl, Gummersbach, Nümbrecht und Köln, als Konrektor in WendenSchönau und schließlich als Schulleiter in Siegen gearbeitet habe. Es ist kaum möglich, sie alle zu nennen. Besonders den Schülern, es waren ja zumeist Jungen oder junge Männer, mit denen ich an den, teils inklusiven, zumeist aber an spezialisierten, Schulen gearbeitet habe. Ihnen allen verdanke ich sehr viel an pädagogischer und menschlicher Erfahrung, an Erkenntnis, an geistiger Transformation. Sie haben mir oftmals viel abverlangt, mich gelegentlich an meine Belastungsgrenzen gebracht, wenn sie mir etwa damals, als ich als frischer Referendar in Solingen Kunst unterrichten wollte, und aufgrund meiner Fächerkombination auch musste, die Zeichenblätter, die ich verteilt hatte, unbearbeitet und zusammengeknüllt als brennende Papierkugeln nach vorne warfen oder bei einem späteren Schulwechsel zu meiner Begrüßung nahezu das komplette Klasseninventar aus dem vierten Stock des Kölner Altbaus nach unten auf den Schulhof warfen. Aber sie haben mich auch in ein Gelände hineingeführt, wo es um das Menschliche und Existenzielle in einem tieferen Sinne geht und nicht um die bloßen gesellschaflichen Konventionen, die institutionellen Abläufe, all diese unbedeutenden Oberflächen.

Gregory Michie hat das einmal sehr schön auf den Punkt gebracht, als er seine Erfahrungen in den Schulen Chicagos niederschrieb, in seinem Buch Holler, if you hear $m e$, dass nämlich auch wir von unseren Schüler_innen lernen und diese uns bilden. Ich hatte die Gelegenheit Michie live zu erleben, als er im Frühjahr 2009 als Key Note Speaker auf einem Kongress der Association for Childhood Education International im Westin Hotel, in Chicago, auftrat und von seinen noch recht frischen Schulerfahrungen berichtete. Eine der Universitäten in Chicago hatte ihn aufgrund dieses Buches, das in den USA ein Beststeller wurde, zum Professor berufen. Michie ging noch ganz in dem während der vergangenen Jahre an den Schulen Erlebten auf. Man muss sich das mal vorstellen, wenn man erst mal weiß, welche abenteuerlichen Berufungsverfahren wir hier in Deutschland durchlaufen müssen, um auf eine Professur zu gelangen. Universitäten tut so etwas sehr gut, das mit Michie, meine ich natürlich. Auf die Abgründigkeit der deutschen Verfahren komme ich noch zu sprechen. Besonders zu danken habe ich Prof. Dr. Karl-Josef Kluge und Prof. Dr. David P. Weikart, die mir die Möglichkeit gaben, in den von ihnen in Deutschland bzw. in Michigan gegründeten internationalen Sommerworkshops pädagogische Verantwortung zu übernehmen und Erfahrungen zu sammeln. Das, was ich von hier aus mitnahm, hat mich durch 
all die Jahre des Schuldienstes begleitet und mich niemals vergessen lassen, dass das Lernen auch in offeneren, schöpferischen Kontexten vonstatten gehen kann, die sich deutlich von der curricularen Enge der Schule abheben. Ich habe auch zu danken Prof. Dr. Jan-Hendrik Olbertz, der mich in seiner Eigenschaft als Kultusminister des Landes Sachsen-Anhalt an die Hochschule Magdeburg-Stendal berief und mir dadurch einen ganz neuen Weg der Weiterentwicklung eröffnete, ebenso Prof. Dr. Andreas Geiger, der als Rektor der von mir dort geleisteten Aufbauarbeit im Schwerpunkt Pädagogik, in den Angewandten Kindheitswissenschaften, sehr viel Wertschätzung entgegenbrachte, insbesondere was das Feld der transatlantischen Hochschulbeziehungen anbelangt. Selten zuvor hielten sich so viele amerikanische Studierende und Wissenschaftler_innen in Stendal auf, wie in diesen, noch durch Barack Obama geprägten, Jahren. Etliche deutsche Studierende konnten für ein Semester an die beiden privaten Universitäten in den USA gehen, mit denen wir dann regen Austausch hatten.

Natürlich wäre dies alles nicht ohne die tatkräftige Unterstützung von Prof. Dr. Fritz-René Grabau gegangen, den Dekan des Fachbereichs Wirtschaft. Er half mir, die Partnerschaften mit der Lenoir-Rhyne University, Hickory, North Carolina und dem Wheelock College Boston, heute zur Boston University gehörend, aufzubauen, weil innerhalb meines eigenen Bereichs Vorbehalte gegenüber den Vereinigten Staaten bestanden und alles abgeblockt wurde. Hierzu mussten regelrechte Verträge ausgehandelt werden, in denen die, von beiden Seiten zu erbringenden, Leistungen niedergeschrieben wurden. Prof. Dr. Werner Schulz, ursprünglich in Ostpreußen geboren, nach dem Zweiten Weltkrieg in ein kleines Dorf bei Stendal gekommen und dort aufgewachsen, und schließlich in die Vereinigten Staaten ausgewandert, war eine Schlüsselperson in alldem, von Seiten North Carolinas. Gute, lebendige internationale Universitätspartnerschaften leben immer vom Engagement von einzelnen Menschen. Insofern verdanke ich auch Prof. Dr. Joyce Davis und Prof. Dr. Janet F. Painter, beide Lenoir-Rhyne University, North Carolina, ebenfalls sehr viel. Janet Painter, Joyce Davis und ich haben auch in den Jahren später, teils bis heute, gemeinsame Studien unternommen und Publikationen erstellt. Jackie Jenkins-Scott, der damaligen Präsidentin von Wheelock, bin ich sehr dankbar, dass sie mich im Frühjahr 2010 als Visiting Scholar nach Boston eingeladen und mir dort einen Studienaufenthalt ermöglicht hat. Es war für mich von großer Bedeutung, von der anderen Seite des Atlantiks zurück nach Deutschland zu schauen und reflexive Distanz zu den davor liegen Jahrzehnten in den Schulen zu gewinnen, ebenso zu den Erfahrungen, die ich bis dahin an deutschen Universitäten gesammelt hatte. Prof. Dr. Petra Hesse hat auf dem, inzwischen zur Boston University gehörenden, Wheelock Campus viel für mich ermöglicht. Das war eine wunderbare, erkenntnisreiche Zeit, die ich nicht missen will. Schließlich muss ich hier Ernst von Borries und Dr. Ursula Berktold nennen, die mir 2014 und 2015 seitens der Münchner Schulstiftung die Gelegenheit gaben, Schulentwicklungsworkshops mit ihren Schulleitungen, Lehrkräften und Schulsozialpädagog_innen zum Thema School-wide Positive Behavior Support (PBIS) durchzuführen. Durch die gemeinsamen Seminare und die darin stattfindenden Prozesse der Aneignung und der Auseinandersetzung mit diesem, aus den Vereinigten Staaten stammenden, verhaltensbezogenen Interventionssystem, lernte ich die unterschiedlichen Sichtweisen kennen, die in deutschen Schulkollegien diesbezüglich existieren können.

Die Leitungskräfte und Kolleg_innen der Münchner Schulen bestachen einerseits durch den Enthusiasmus, sich mit neuen pädagogischen Handlungsmöglichkeiten zu 
beschäftigen, wenngleich es auch einige amerikanische Lehrkräfte gab, die PBIS bereits aus ihrem Studium in den USA kannten und das Ganze ja initiiert hatten, zum anderen durch ihre argumentative Klarheit in der kritischen Auseinandersetzung mit PBIS. Was hier an Kritik, speziell in einem der Gymnasien, geäußert wurde, in Richtung apparativer Systemsteuerung, zugleich auch das Einfordern der Möglichkeit, die verhaltensbezogenen Interventionen im Sinne von PBIS mit anderen Ansätzen und Modellen zu kombinieren, hat mich nachhaltig geprägt. Die Münchner Lehrer_innen wollten auch weiterhin auf ihre bewährten Methoden zurückgreifen können, statt lediglich evidenzbasierte Methoden verwenden zu dürfen. Ich würde heute sagen, dass der Münchner Schulstiftung und den Kolleg_innen in ihren Schulen tatsächlich die Vorreiterrolle, in der Auseinandersetzung mit PBIS in Deutschland, zukommt. Insofern waren diese Münchner Workshops historisch. 2014 gab es in ganz Deutschland noch keine Schulen, die sich mit PBIS auf der schulweiten Ebene beschäftigten, und dann eben auch differenziert, einerseits offen, anderseits aber auch kritisch an das Thema herangingen. Ich habe das in einem englischsprachigen Buchkapitel (vgl. Broecher, 2015 a) festgehalten. Ich danke all diesen Menschen, auch wenn es mich manchmal ganz schön gefordert hat, für Zuspruch, Ermutigung und Wegbegleitung, fürs Mitdenken und auch für konstruktiven Widerspruch, für das gemeinsame Durchstehen von Herausforderungen und Grenzsituationen, für das Erobern von neuen geistigen und humanen Welten. Der Mensch komme immer vor dem System, gab Karl-Josef Kluge uns Studierenden mit auf den Weg, bevor wir die Universität zu Köln in Richtung Schule verließen und dieser Grundsatz war ja durchaus kompatibel mit dem, was uns Klaus Peters dann in Düsseldorf vermittelte. Doch wie weit sind wir, das heißt meine Generation von Studierenden, damit gekommen? Wenn die Systeme immer enger und mächtiger werden und wenn diese von Menschen am Laufen gehalten und teils immer rigider gemacht werden, von Akteur_innen, die mit den Jahren die reflexive Distanz zu eben diesen Systemen und zu ihrem eigenen Tun verlieren, von Protagonist_innen, die sich oftmals von den Systemen vereinnahmen, regelrecht kaufen und korrumpieren lassen, dann wird die Herausforderung immer größer, diesen Grundsatz beizubehalten, wenn man nicht aufgerieben werden will. Nun, ich habe es einige Male darauf ankommen lassen, trotz allem, und in dieser Tradition steht auch dieses Buch.

\section{Emotionale und soziale Herausforderungen}

Es gibt diese Schüler, insbesondere Jungen, die in einer zweiten Grundschulklasse einfach aufstehen und ein Mädchen, das brav gearbeitet hat und womöglich gerade von der Klassenlehrerin gelobt worden ist, ohrfeigen. Es gibt Jungen, ebenfalls in dem Alter, die dann von einem Sonderpädagogen während eines Ausflugs in die benachbarte Großstadt begleitet werden müssen, Jungen, die den Rucksack voller Süßigkeiten haben, während der Zugfahrt unentwegt davon essen, sich vor dem ersten Tiergehege im Zoo übergeben, dann bei der Rückfahrt, im dichten Gedränge des Berufsverkehrs am Kölner Bahnhof aus lauter Übermut, hinunter ins Gleisbett springen, um zu zeigen, wie schnell sie wieder herausklettern können und die dann im Zug sich hinter einen Polizisten setzen, der, nach beendetem Dienst, zu seinem Häuschen auf dem Land zurückfährt, den Mann von hinten im Kopfhaar kraulen und plötzlich »Ich will ficken!« 
durch den ganzen Nahverkehrszug schreien. Und es gibt Grundschullehrerinnen, die dann ratlos im Zug sitzen und das mitansehen müssen und die nicht wissen, ob sie das auf Dauer in den Griff bekommen, auch weil der Sonderpädagoge nur punktuell zur Unterstützung dabei ist und sie meistens mit den Kindern alleine sind. Der Förderschwerpunkt der emotionalen und sozialen Entwicklung im Kontext Schule und Unterricht bekommt in der aktuellen gesellschaftlichen Situation mehr und mehr Bedeutung. Auf die Gründe für diese Entwicklung gibt es keine einfache Antwort. Sind die jungen Menschen anders geworden? Haben sich die Erziehungsstile ihrer Eltern und sonstigen Bezugspersonen geändert? Ein Pflegevater aus einer urbanen Förderschule machte mich dafür verantwortlich, dass unter anderem sein Pflegesohn größere Mengen an Klassenmobiliar aus dem vierten Stock runter auf den Schulhof geworfen hatte, weil ich nicht in der Lage gewesen sei, es zu verhindern. Oder sind es die sozialen, kulturellen und ökonomischen Lebensbedingungen? Ist es die zunehmende Fragmentierung oder Spaltung der Gesellschaft? Einmal tauchte ein Stiefvater, zusammen mit einem Kumpel, auf dem Schulhof der genannten urbanen Förderschule auf, mit Pitbull T-Shirts und Schlagringen an den Fingern. Sie wollten mal nachschauen, wer denn da den Stiefsohn des einen immer so drangsalierte und da mal für Ordnung sorgen.

Sind es die Medien, die Digitalisierung und die virtuellen Welten? Einer meiner Schüler fragte mich, ob ich denn wüsste was Animal Sex sei, er hätte da so einige Internetseiten gesehen, auch Filme, und ging sogleich in die Details, die ich hier aber nicht über die Lippen bringe. Auf einer anderen Seite ging es um Nekrophilie, ob ich denn wüsste, was das sei? Auch hier ging der 16-jährige in die Details. Sind es die globalen Entwicklungen? Ein sich mit rechtsgerichteten Ideologien identifizierender Jugendlicher schrieb in das kollektive Klassentagebuch: »Husch, husch, husch - Neger in den Busch!« Das wirkte sogleich wie ein Sprengsatz und erforderte meinerseits höchsten Einsatz, um ein Blutvergießen unter den jungen Männern zu verhindern. Werden auch deshalb mehr Kinder und Jugendliche mit emotionalen und sozialen Problemen wahrgenommen, weil sich die Kontexte und Bedingungen schulischen Lernens verändert haben, oder weil sich die Arbeitswelt verändert hat und schon ihre Schatten weit in die Schulzeit vorauswirft? Werden im Zuge der Veränderung der Bildungssysteme andere Erwartungen an die Heranwachsenden gestellt? Welche Rolle spielt bei alldem der Wissenschaftsbetrieb und die dort angesiedelte Produktion von Wissen und die Art des dort praktizierten Lernens? Ist das RTI-Dreieck mit seinen sog. evidenzbasierten Interventionen, wie es jetzt von immer mehr inklusions- und sonderpädagogischen Instituten und Abteilungen in Deutschland verbreitet wird, da nun wirklich die Lösung? Die pädagogischen Handlungsfelder, in denen emotionale und soziale Entwicklungsförderung stattfindet, können, je nach Bundesland und Landespolitik, zum einen inklusive Settings in Grundschulen und Sekundarschulen sein, zum anderen aber auch spezialisierte und separative Settings, etwa Förderschulen, Heimschulen oder Förderzentren. Zwei Argumentationslinien beherrschen in dieser Hinsicht derzeit die Debatte: Auf der einen Seite das unbedingte Herstellen eines, vermutlich utopischen, inklusiven gesellschaftlichen Idealzustandes. Auf der anderen Seite eine pragmatischere Denkweise, wonach die pädagogischen Settings so gewählt und arrangiert werden sollen, dass zum einen die sich unproblematisch verhaltenden Schüler_innen etwa vor Regellosigkeit, Aggression und Gewalt, Phänomene, wie sie eben mit der als problematisch eingeschätzten Gruppe von Heranwachsenden assoziiert werden, ge- 
schützt werden, durch Separierung und Spezialisierung. Zum anderen sollen die, als problematisch eingeschätzten, Kinder und Jugendlichen tatsächlich gefördert werden.

Die eine Gruppe will also am liebsten alle Förderschulen, die bis vor einigen Jahren noch Sonderschulen hießen, schließen, die andere will sie offen halten, in einem zweigleisigen System, neben den inklusiven Settings. Es gibt auf diesen Gebieten mittlerweile erbitterte Auseinandersetzungen, in denen Menschenbilder, Gesellschaftsbilder, teils auch Ideologien, eine Rolle spielen. Oftmals stößt Pragmatismus auf Idealismus, Flexibilität auf Starrsinn. Hehre Ziele werden durch unzureichende Mittelbereitstellung, mangelhafte Ausstattung und pädagogische Konzeptlosigkeit der Schulen konterkariert, denn oftmals fällt den Schulen ja nicht mehr ein, als etwa das Trainingsraumprogramm einzuführen. Elternvertreter_innen, Schulkollegien, pädagogische Institute und Fakultäten sind mittlerweile mehr als uneins. Inklusion ist zu einem Reizwort geworden, sobald es um die Schule geht, und ganz besonders, wenn es um Kinder und Jugendliche in den allgemeinen Schulen geht, die einen mittelschweren oder gar einen gravierenden Förderbedarf im Bereich der emotionalen und sozialen Entwicklung, wie es ja derzeit heißt, aufweisen. Schon in den 9oer Jahren ging das nicht ohne Konflikte ab. 1996 wurde ich zum ersten mal in den sog. Gemeinsamen Unterricht abgeordnet. Das war zu der Zeit eine Auszeichnung. Die Schulrät_innen fragten da nicht jeden. Man musste schon über ausreichend pädagogische Erfahrung und kommunikatives Geschick verfügen, um diesen Schritt aus der spezialisierten Förderschulwelt in die Grundschul-, Hauptschul- oder Sekundarschulwelt zu machen und dort zu bestehen und etwas zu bewirken. Aber leicht war es nicht. Auch wenn ich, in der Summe, eher positive Erfahrungen in diesem Arbeitsfeld machte, so schlugen einem gelegentlich ziemliche Vorurteile entgegen. Mein Vorgänger hätte »immerzu neben den Problemschülern gesessen und ständig, wenn auch leise, in den Unterricht reingequatscht. «Auf »sowas« hätten sie »jetzt hier keinen Bock mehr«. Oder mein Vorgänger hätte sich immer nur vier Schüler zusammengesucht und hätte mit denen »den ganzen Tag im Werkraum gesessen und an Holzstücken herumgefeilt«. Ich könnte ein Buch mit solchen Dingen füllen. An einer Grundschule wollte die Lehrerin mit mir kein Wort sprechen und ließ mich auch nicht in ihre Klasse, um mit dem Jungen, um den es ging, zu sprechen. Der Schulleiter nahm mich verständnisvoll zur Seite und erläuterte mir, dass die Kollegin »einfach nicht mit Männern könne«. Sie habe eine Scheidung hinter sich, lebe jetzt mit einer Frau zusammen und gemeinsam zögen die beiden jetzt, in einer Patchwork-Familie, ihre mitgebrachten Kinder groß. Die Kollegin habe wohl auf eine weibliche Betreuung des Jungen gehofft, wir sollten das einfach akzeptieren. »Kein Problem« sagte ich, »wenn Sie das der Schulaufsicht auch so, natürlich diskret, vermitteln können, nicht dass ich da noch dienstrechtlich belangt werde. Dann scheint die Kollegin ja mit dem Jungen gut klar zu kommen« erwiderte ich und nahm die verbleibenden Stunden für die drei anderen Jungen, die ich an der betreffenden Schule noch betreute. Die Kollegin, die nicht mit Männern konnte, sprach in dem Schuljahr, das ich an dieser Grundschule verbrachte, kein einziges Wort mit mir. Ich erfuhr nichts über den Jungen, seine Problematik und seine Lernfortschritte. Es gab nicht einmal den geringsten Austausch darüber.

An einer Hauptschule weigerten sich gleich fünf Lehrerinnen mit mir zu sprechen und ließen mich, an meinem ersten Tag an der Schule, einfach im Lehrerzimmer sitzen. Ich ging zum Schulleiter und schilderte ihm die Situation. Der verließ sein Büro gar nicht mehr, rauchte Kette und sagte zu mir, ich solle es nicht persönlich nehmen, aber 
ich sei als Sonderpädagoge, der an dieser Schule Integration, wie es damals noch hieß, betreiben wolle, eine »unerwünschte Person«. Ich kam mir vor wie in einem Theaterstück von Dario Fo. Sie hätten gehofft, die insgesamt fünf jungen Männer, um die es hier ging, »einfach nur loszuwerden«. Folglich sei es doch konsequent und verständlich, dass die betreffenden Lehrerinnen nicht mit mir zusammenarbeiten wollten. Es gab noch etliche Debatten dazu, auch eine Art Krisengespräch mit Schulrät_innen. Hinter deren Nervosität, ja Gereiztheit, spürte man die Hilflosigkeit und Überforderung. Man redete ja eigentlich immer über Schüler, die renitent sind, die die Regeln nicht einhalten, aber hier waren es eben die Lehrerinnen, die sich quer stellten, die gegen die Regeln verstießen, und die Schulrät_innen waren machtlos. Wer hier immer noch wie der preußische Obrigkeitsstaat denkt, ist verloren. Nur wer zum Philosophen wird, bleibt weiter handlungsfähig. Dazu muss ich aber einen entscheidenden Schritt nach hinten treten, um Abstand zu gewinnen zu dem Ganzen, und das, was ich da sehe und erlebe, in der Tat wie ein absurdes Theaterstück betrachten. Die Lehrerinnen sagten wörtlich und wie aus einem Munde: »Jetzt sind wir schon auf diesen schwierigen Schülern sitzengeblieben und jetzt haben wir auch noch einen Sonderschullehrer am Hals! « Am Ende vereinbarten wir, dass ich mit allen fünf Jungs eine Art Einzelförderung unternahm, um meinen Dienstpflichten an dieser Schule nachzukommen, aber niemals eine der Klassen betrat. Gespräche mit den Lehrerinnen fanden nicht statt. Das lehnten sie ab, denn es hätte Mehrarbeit bedeutet. Dazu waren sie nicht bereit. Wozu sie sich aber etwas später, als die Schulrät_innen wieder über alle Berge waren und auch niemals wiederkommen sollten, in dem Schuljahr, bereit fanden, war, mich in ihren Aufsichtsplan einzutragen und zwar sollte ich, an zwei von den drei Tagen, wo ich an der Schule war, jeweils eine sog. Toilettenaufsicht übernehmen. Dazu musste man während der gesamten Pause in der Jungentoilette stehen und darauf aufpassen, dass dort hinter den Klotüren keiner rauchte. Nun war ich ja an insgesamt fünf Schulen tätig, was die Kolleg_innen auch wussten und ich musste in den Pausen oftmals zwischen fünf und fünfundzwanzig Kilometern mit dem Auto fahren, $a ß$ mein Butterbrot und trank meinen Tee während der Fahrt, weil ich es anders gar nicht geschafft hätte, bei den weiten Wegen. Ich fand das also sehr einfühlsam, mich in dieser Weise einzuteilen und über meine Zeit zu verfügen, über eine Zeit, die ich selbst gar nicht hatte.

Auf dem Niveau lief das also. Der ketterauchende Schulleiter nahm darauf keinen Einfluss und hatte auch keine Macht mehr. Er betrat das Lehrerzimmer, in dem sowieso nur dicke Luft herrschte, gar nicht mehr. Konferenzen und Dienstbesprechungen fanden folglich nicht statt. Der Schulleiter hatte die Nerven dazu nicht mehr, der Konrektor auch nicht. HilfDir selbst, sagte ich zu mir und teilte den Kolleg_innen, die die Pausenaufsichtspläne erstellt hatten, mit, dass ich das zeitlich nicht leisten könne und folglich nicht zur Verfügung stehe. Sie mussten es wohl oder übel schlucken. Ich fand diese Art von Aufsicht ohnehin problematisch. Wie oft hatte ich sogar Schüler, die kurz davor waren auszurasten, jemand anders zusammenzuschlagen oder Stühle aus dem Fenster zu werfen, diskret gebeten, einmal zur Toilette zur laufen und dabei tief durchzuatmen. Und jetzt sollte ich mich da hineinstellen und Kontrolle in diesem allerletzten Refugium der Jugendlichen ausüben und mich nachher womöglich als Spanner beschimpfen lassen, der den Jungs beim Pinkeln zusieht? Wie dumm muss ein Lehrerkollegium sein, das auf solche Ideen kommt? Ich hatte wirklich gute Gespräche mit den Jungs und sah in den erzwungenen kontinuierlichen Einzelberatungen eine 
große Chance zu erproben, was ich in beratender Hinsicht drauf hatte und bewirken konnte. Sagen wir, nachdem ich endlich einen vernünftigen Raum dafür gefunden hatte. Zuerst saßen wir in einer Ecke auf einem Flur, hinter einem Kopierer. Das Kollegium verweigerte mir einen angemessenen Raum. Der Schulleiter stellte sich hilflos und rauchte nur in einem fort weiter, in seinem Büro, bis dass er schließlich kollabierte und in ein Sanatorium eingeliefert wurde. Er kehrte niemals zurück. Dem reichlich überforderten Konrektor ging es nicht anders. Er erkrankte nach einigen Monaten schwer, und blieb auch weg. Zwei von den Lehrerinnen, die mich so schroff abgewiesen hatten, brachen mitten im Unterricht zusammen und mussten von einem Notarzt versorgt und in ein Krankenhaus gebracht werden. Eine von den beiden hatte sich auch noch ganz besonders mit mir angelegt, weil ich versuchte, mit den 15 Stunden, die ich an dieser Schule, über mehrere Tage verteilt, gab, in dem sog. Streitschlichtungsraum unterzukommen und dort mit meinen Schützlingen zu sitzen und zu arbeiten.

Das war auch der einzige Raum in dem riesigen Schulgebäude, der hierfür geeignet erschien und der eigentlich fast immer leer stand. Diese Kollegin hatte also den Hut auf in Sachen Streitschlichtung an der betreffenden Hauptschule. Sie verfügte über ein entsprechendes Zertifikat, aus irgendeiner Weiterbildung, und meinte dann zu mir, als ich nach dem Raum fragte: »In diesem Raum findet nur Streitschlichtung statt!« Ich erwiderte: »Das was ich mache, ist ja auch nicht so weit davon entfernt.« Darauf die Streitschlichterin: »Sie sind nicht in Streitschlichtung zertifiziert, folglich sind Sie nicht qualifiziert und haben somit keinen Zutritt zu dem Raum!« Ich ließ aber nicht locker: »Wenn Sie oder eine andere zertifizierte Kollegin zu einem Streitschlichtungsgespräch kommen, könnte ich ja den Raum gerne freiräumen, das wird ja nicht täglich sein.« Darauf abschließend, reichlich gereizt und schon im Gehen begriffen, die Lehrerin: „Sie werden den Raum nicht betreten, denn sie sind nicht qualifiziert! Punkt.«Wie auch immer, diese Kollegin gehörte zu den zweien, von meinen fünf Bezugslehrerinnen, die in ihrer Klasse, irgendwann im Herbst war es, kollabierten und die das ganze Schuljahr nicht wieder zurück an die Schule kamen, denn nach dem Krankenhaus folgten Aufenthalte in Reha-Kliniken und Sanatorien. Nun machte mir niemand mehr diesen Beratungsraum streitig und die Jungs und ich mussten nicht mehr in der Ecke auf dem Flur, hinter dem Kopiergerät sitzen, sondern konnten uns in einem adäquaten räumlichen Ambiente unterhalten. Ich will es erst einmal dabei belassen, wir befinden uns ja erst in der Einleitung des Buches. Es wird noch einiges folgen. Auch wenn wir 2020 vielleicht weiter sind als diese Schule in den Jahren 1999-2000, so spiegelt sich hier doch ein sehr grundsätzliches Problem wider, das wir noch nicht abschließend gelöst haben. Wir befinden uns mitten in einem Red Ocean, in einem durch und durch konflikthaften Gewässer, um es mit Kim und Mauborgne zu beschreiben.

Im weiteren Verlauf dieses Buches werde ich Ideen und Vorstellungen entwickeln, wie wir aus diesem Dilemma herauskommen können. Bisher wird nicht mutig genug gedacht. Es hilft ja nichts, sich über überforderte Schulleiter und Lehrer_innen und unzureichend entwickelte Schulkulturen aufzuregen und mit dem Finger auf diese zu zeigen. Mir taten diese Menschen eher leid. Dass sie mich mit Füßen traten, habe ich nicht wirklich persönlich genommen, obwohl ich am Anfang, das gebe ich zu, wirklich unter der Situation gelitten habe. Vor allem dass ich dann auch noch vom Konrektor attackiert wurde, beim runden Tisch mit den Schulrät_innen. Er behauptete dort, ich sei ja selbst für meine Ablehnung verantwortlich. Schließlich hätte ich den Lehrerin- 
nen ungefragt Papiere in ihr Fach gelegt. Sowas würde immer als »übergriffig« erlebt. Hatte ich auch. Weil sie nicht mit mir sprachen, hatte ich auf einigen Seiten meine handlungs- und projektorientierte Pädagogik skizziert und Beispiele für mögliche Unterrichtsreihen oder Projekte gegeben, in der Hoffnung, einige von den Lehrerinnen würden das vielleicht aufgreifen und zumindest mal darüber nachdenken. Das wurde mir nun als unverzeihlicher »Übergriff« ausgelegt. Auch die fünf Lehrerinnen entrüsteten sich. Das wäre ja wohl der Gipfel, dass ich mich erdreisten würde, ihnen solche Vorschläge zu machen. Co-Teaching? Fehlanzeige. Aber diese Menschen haben mir auch plastisch vor Augen geführt, was dabei herauskommen kann, wenn man/ frau sich so hart macht, ganz in die Abwehr geht, völlig starr wird im Wahrnehmen, Denken und Handeln - bis zum völligen Zusammenbruch. An der Frage der Inklusion scheiden sich bis heute die Geister, ein Reizthema sondergleichen. Aber die Situation ist keineswegs so alternativlos, wie es oftmals dargestellt wird. Es muss mehr Möglichkeiten geben, als zwischen diesen beiden skizzierten Alternativen zu wählen, als immer nur von links nach rechts zu schauen, als zwischen schwarz und weiß entscheiden zu sollen. Wieso wird bisher so wenig über einen vollständigen Systemwechsel nachgedacht, über eine grundlegende Veränderung der derzeitigen Bildungs- und Sozialsysteme? Was wir jetzt brauchen, ist ein Denken, das uns aus den alten, überholten Systemen herausführt, ein Denken, das Neuland erschließt, ein Denken im Sinne der Blue Ocean Strategie (vgl. Kim und Mauborgne, 2016, 2018). Mir geht es allerdings mit diesem Rückgriff auf die Blue Ocean Strategie nicht um das Erschließen von neuen Märkten im Sinne eines strategischen Managements, sondern um das Erschließen von neuen Denk- und Handlungsräumen jenseits der konfliktträchtigen, rivalisierenden Theoriesysteme, Bildungssysteme, sozialen Systeme usw. André Rempel war es, der mich, im Laufe unserer Gespräche, auf Red Ocean und Blue Ocean aufmerksam machte. Ich hatte mich in früheren Jahren schon viel mit Edward de Bono und dem von ihm geprägten Lateralen Denken beschäftigt, insbesondere in Zusammenhang mit meiner Dissertation, in der es ja um kreatives Denken und Handeln ging, aber was Kim und Mauborgne hier machen, geht ja noch einmal weit darüberhinaus, und ließe sich letztlich sicher gut mit dem Lateralen Denken de Bonos zusammenbringen. In den 9oer Jahren reichte ich einmal einen Artikel zur Bedeutung von de Bonos Denkwerkzeugen, insbesondere dem Lateralen Denken, bei einer sonderpädagogischen Fachzeitschrift ein. Das waren diese Jahre, wo ich solche Erfahrungen in Schulen machte und dann versuchte, diese auf der theoretischen Ebene zu verarbeiten und in etwas Konstruktives zu transformieren.

Der Artikel wurde abgelehnt mit dem Hinweis, dass de Bonos Denkmodelle nicht Teil der sonderpädagogischen Theoriewelt seien. Das ist es auch bis heute nicht und das ist auch der Grund, warum ich der Disziplin der Sonderpädagogik, zumindest in ihrer bisherigen Form, keine besonderen Zukunftschancen mehr gebe. Nur die wirklich zukunftsweisenden Ideen werden überleben, nicht aber diese alten überkommenen Strukturen, nicht die Netzwerke und Seilschaften, die sich krampfhaft an die einmal erreichten Pfründe klammern. Wenn wir also nun diese geschlossenen, reichlich konflikthaften Systeme, die wir im Sinne von Kim und Mauborgne als Red Ocean bezeichnen können, nicht verlassen, haben wir keine Chance, zu relevanten gesellschaftlichen und globalen Veränderungen und Verbesserungen zu kommen. Statt unsere Energie weiter in ideologische, durch Konkurrenz geprägte Debatten, Machtkämpfe und fruchtlose Auseinandersetzungen zu stecken, sollten wir lieber ganz aus diesen 
Strukturen aussteigen und etwas Neues entwerfen. In diesem etwas freieren Sinne verwende ich in diesem Buch die Konzepte Blue Ocean und Red Ocean. Die Bücher von Kim und Mauborgne wurden in Dutzende von Sprachen übersetzt und das Modell wird weltweit in den verschiedensten gesellschaftlichen Bereichen aufgegriffen, variiert und adaptiert, oftmals ähnlich frei, wie ich es hier tue. Wenn mir Menschen schreiben und mich zu engagieren versuchen, um einzelnen Schulen oder ganzen Schulbezirken zu helfen, die anwachsenden Verhaltensprobleme, unter den Bedingungen der politisch forcierten Inklusion, und zusätzlich unter den Bedingungen des standardisierten, kompetenzorientierten Lernens, in den Griff zu bekommen, dann ist meine heutige Antwort darauf, dass wir endlich aufhören müssen mit dieser Flickschusterei. Wir sollten jetzt etwas anderes versuchen. Wir müssen heraus aus den sozialen und institutionellen Gewässern, die sich durch teils unmögliche pädagogische Settings und Rahmenbedingungen einerseits und durch aggressive ideologische Debatten und rivalisierende Diskurse mittlerweile zu einem roten Ozean verfärbt und eingetrübt haben. Ein Buch wie dieses Open Access zur Verfügung zu stellen, ist für mich persönlich mit einigen finanziellen Aufwendungen verbunden. Die Ideenentwicklung in diesem Buch, die Niederschrift, einschließlich der vielen Überarbeitungen und Präzisierungen, ferner die besonders kostenaufwändige Art der Veröffentlichung sind nun mein Beitrag zum Ganzen. Ich bin dem transcript Verlag sehr dankbar für die Möglichkeit, dass dieses ganz spezielle Buch eben hier erscheinen kann, in einem Verlag, wo die Autor_innen unsere Gesellschaft und ihre sozialen und kulturellen Bezüge so brillant analysieren und mutig und innovativ in die Zukunft hinein entwerfen. Insbesondere danke ich Dr. Dagmar Buchwald, die das Manuskript, auch in einer noch etwas rohen und unfertigen Fassung, schon voll unterstützt, sozusagen an Land gezogen, und das geistige Potenzial darin erkannt hat.

\section{Kritische Analyse und utopischer Neuentwurf}

Emotionale und soziale Problematiken von Heranwachsenden weiten sich aus, in einer zunehmend fragmentierten, entfremdeten Gesellschaft. Doch diese Gesellschaft hat offenbar in weiten Teilen den Mut verloren, ihr wahres demokratisch verankertes Potenzial auszuschöpfen. Auch kann diese Gesellschaft weithin nicht mehr als ethischmoralisches Vorbild dienen, weil sie selbst durch eine ungerechte Ressourcenverteilung, ungelöste soziale Konflikte und vielfältige emotionale und soziale Auffälligkeiten, auch in ihrer Mitte, in ihrer Breite, in ihren etablierten Schichten, gekennzeichnet ist, sich äußernd in Egoismus, Rücksichtslosigkeit, Konkurrenzdenken, Gleichgültigkeit und emotionaler Verflachung. Dabei geht es nicht einmal in erster Linie um den Bereich der Schule und dahinterstehend der Familie, sondern um Politik, Wirtschaft, Unternehmenswelt, Medien und das öffentliche Leben als Ganzes. Wieviele erwachsene Menschen missachten Regeln, konstruieren die Realität um, verbreiten Aggressionen und treten die Rechte anderer mit Füßen und versuchen damit durchzukommen? Wieviele Menschen auf der Welt denken in erster Linie an sich selbst und selten einmal an andere? Wieviele Menschen behandeln andere Menschen respektlos und kaum mit der notwendigen Wertschätzung und das auf allen nur denkbaren gesellschaftlichen Ebenen? Ich weiß, ich klinge jetzt sehr schulmeisterlich, aber wir reden ja nun mal auch über pädagogische und damit über gesellschaftliche Belange. Ich bekomme viele 
Klagen zu hören, wie es um die deutsche Gesellschaft hinsichtlich des Verhaltens von Kindern und Jugendlichen bestellt sei. Nun, ich werde meine Vorschläge unterbreiten und meine Rückmeldungen dazu geben.

Geschäftsleute, die in Zügen pausenlos laut telefonieren, selbst dann, wenn, direkt in Sichtweite gegenüber, jemand versucht, in einem Buch zu lesen. Sogar in den so genannten Ruheabteilen passiert dies immer wieder. Junge Männer, die sich auf dem Berliner Kurfürstendamm ein Autorennen liefern und dabei das Leben anderer Menschen aufs Spiel setzen. Dörfer, auf denen Rottweiler, die ausgeführt werden, nicht angeleint werden, selbst wenn, nicht weit entfernt, Kinder spielen. Dorfbewohner_innen, die ihr am Hang gelegenes Grundstück um zwei bis drei Meter tief ausschachten lassen, weil sie plötzlich die Idee zu einem Hausanbau haben, obwohl sie noch nicht einmal eine Baugenehmigung eingeholt und noch gar keinen handfesten Plan haben und dann die überrumpelten Nachbarn ganze fünf Jahre auf dieser Kliffkante wohnen lassen. Behörden, die sich als unfähig erweisen, einen solchen Zustand zu beenden. Oder Zäune, die einfach, ohne sich weiter um Grenzsteine zu kümmern, auf das Grundstück des Nachbarn gesetzt werden, als dieser verreist ist. Oder nehmen wir die Kinder, die, obwohl der Wald nicht weit wäre, auf dem Grundstück eines Nachbarn eine Bude bauen und dazu mehrere Heckensträucher, direkt über dem Boden absägen, als diese Familie nicht zu Hause ist. Der Vater des federführenden Jungen antwortete nur, das seien eben »Jungssachen«, als die geschädigte Familie das Neupflanzen der Heckensträucher verlangte, und kümmerte sich aber weiter nicht mehr darum. Weder der Vater noch der Sohn rührten sich, auch nicht als der Wunsch nach Wiedergutmachung ein zweites Mal vorgebracht wurde. Ein arbeitslos gewordener Autoverkäufer denkt sich, dass er einen eigenen Business aufbaut und beginnt mit dem Abspritzen von Motoren. Dazu verwendet er einen Kompressor, der eine enorme Lautstärke hat. Die alten Motorenöle und Schmutzteilchen werden durch den Wasserstrahl umhergewirbelt. Das Ganze aber nun zwischen eng gebauten Häusern auf einem Dorf. Rücksicht auf die Nachbarn oder die Umwelt? Fehlanzeige. Nachdem die Nachbarn sich beim Ordnungsamt beklagt haben, beginnen Jahre einer eisigen Nachbarschaft. Der ehemalige Autoverkäufer hat eine Tochter und einen Sohn im Grundschulalter. Was lernen diese Kinder durch ein solches väterliches Vorbild? Was lernen sie durch das mütterliche Vorbild, wenn die Mutter, seit diesem Ereignis, laut über die Nachbarn schimpft und diese nicht mehr grüßt?

Jede und jeder von uns hat eigene Geschichten, Beispiele, Erfahrungen aus dem persönlichen Umfeld, die auf dieser anscheinend so trivialen, banalen Ebene liegen, und wir alle haben zusätzlich vielerlei Informationen aufgenommen aus den diversen Medien, in denen es um derlei Dinge geht. Jeder einzelne Tag ist voll davon. Es ist sogar so viel, dass wir anfangen, uns gegen all diese destruktiven Meldungen abzuschotten. Doch wen wundert es, dass unter solchen Bedingungen, bei solchen Einflüssen und bei solchen Vorbildern viele Kinder und Jugendliche immer rücksichtsloser und egoistischer werden oder sich nicht mehr in die gesellschaftlich vorgegebenen Bahnen einfügen, dass sie keine Verantwortung mehr übernehmen für ihr eigenes Tun, dass sie aggressiv ihre eigenen Sachen durchziehen, ohne jede Empathie? Doch sollen das jetzt alles die Schulen richten? Sollen das jetzt alles die Lehrkräfte ausgleichen und etwa korrigierend auf die Kinder und beratend auf die Eltern einwirken? Dort wo der Vater, ein Physiotherapeut mit eigener Praxis, seinen Sohn nicht zur Ordnung ruft und mit ihm gemeinsam das Neupflanzen der Heckensträucher, womöglich an 
einem Samstag, in einer gemeinsamen Vater-Sohn-Aktion, umsetzt, wie wir es vielleicht erwarten würden, von einem engagierten, verantwortungsvollen, nach vorne denkenden Mittelschichtsvater, einem Mann, der sich selbst als Teil einer funktionierenden, dörflichen Community sieht und der seinem Sohn vermittelt, dass es immer ums Ganze geht und nicht nur um das eigene, kleine persönliche Ding. Doch dort, wo der Vater das eben nicht tut und nicht auf dem Schirm hat, wie wir heute sagen, ist für die Gesellschaft insgesamt viel verloren. Jetzt solche Eltern allerdings moralisch $\mathrm{zu}$ verurteilen, hilft uns natürlich auch nicht weiter. Es sind noch keine wirklichen Erwachsenen, die uns da begegnen. Es sind noch keine wirklichen Bürger_innen, die Verantwortung übernehmen können für sich und für das Ganze. Ihre eigene familiäre Sozialisation und auch die Schule, die sie durchlaufen haben, sind ihnen entweder etwas schuldig geblieben oder haben etwas an ihnen angerichtet, was sie eben auch als Erwachsene noch so wenig verantwortungsbewusst sein lässt, was sie auf so eine seltsame Art infantil bleiben lässt. Zwar sausen sie mit einem schnittigen BMW über die Straßen, aber sie sind offenbar in all den Jahren, die sie in ihren Herkunftsfamilien und in den Klassenzimmern verbracht haben, nicht zu klar denkenden und bewusst handelnden Menschen geworden.

\section{Geschärfte Wahrnehmung und Klarheit des Denkens}

Vor einer Weile las ich die Protokolle der Gespräche, die Jiddu Krishnamurti mit den Schüler_innen an der, von ihm gegründeten, Schule Brockwood Park, in Großbritannien, geführt hat. Er konfrontiert die jungen Leute in diesen Gesprächen mit einem solchen geistigen Scharfsinn, zugleich mit einer enorm starken Wertschätzung und mit einem ungeheuren Vertrauen, dass sie das geistige Potenzial, um das es ihm geht, in sich haben. Außenstehende könnten seine Rückmeldungen, Fragen und Gedanken vielleicht als unbequem empfinden, doch wenn die jungen Menschen einen solch klaren und wahrhaftigen Stil von Seiten ihres Lehrers gewohnt sind, dann fangen sie an, sich auf ganz neue geistige Höhen emporzuschwingen. Als Student hatte ich ein Taschenbuch von Krishnamurti in meiner Büchersammlung und hatte mich nie wieder genauer mit seinen Ideen und Gedanken beschäftigt, wenngleich ich immer wieder in den Büchern von anderen geistigen Lehrern, insbesondere Muktananda, Goenka oder Osho gelesen habe. Katja Luckhardt-Seebaum war es, die mir bei unseren Gesprächen über das vorliegende Buch und die darin behandelten Themen, empfahl, einmal genauer in die, in den letzten Jahren übersetzten, Werke Krishnamurtis hineinzulesen. Diese Texte sind eine Fundgrube für Pädagog_innen. Sie können uns helfen, das eigene Bewusstsein bezogen auf das, was wir eigentlich in der Pädagogik tun und bewegen wollen, zu erweitern und sie können uns helfen, die Kommunikation mit Kindern und Jugendlichen und mit all den Menschen drum herum, mit denen wir ja auch sprechen, zu verfeinern. Ja es ist in der Tat ein Verfeinern der Kommunikation und eine Präzisierung unserer Sprache. Es geht um die Schärfung der Wahrnehmung und die Klarheit des Denkens, und dann auf der Basis, auch um die Klarheit des Handelns. Wir können als Pädagog_innen und Lehrer_innen, je nach Kontext, natürlich einiges tun, aber wir sollten auch nicht versuchen, jetzt alles für die Gesellschaft zu lösen, dazu sind die Aufgaben zu groß, dazu sind unsere Kräfte zu begrenzt. Was wir aber tun können, ist Impulse zu geben, Klärungsprozesse anzustoßen, die Schärfung der Wahrnehmung 
und klares Denken zu fördern. Dazu müssten wir aber anders arbeiten, als es jetzt zumeist von uns erwartet wird. Insbesondere stehen strukturelle Veränderungen an. Wir brauchen jetzt andere Kontexte, andere Rahmenbedingungen für eine gute Pädagogik, wenn diese wirklich etwas bewegen und verändern soll.

Wir arbeiten in, teils völlig überholten, institutionellen Strukturen, unter, teils sehr ungesunden, kontraproduktiven Bedingungen, in denen die Menschen oftmals aufgehört haben, genau hinzusehen, Fragen zu stellen, klar zu denken. So lässt sich aber kein Boden für eine andere, für eine bessere Zukunft für alle bereiten. Wir sollten uns nicht weiter von der Neuen Steuerung, wie sie derzeit immer stärker die öffentlichen Bildungssysteme beherrscht, instrumentalisieren lassen. Es kann doch nicht darum gehen, dass wir uns eben diesen Systemen, in einer solch reformbedürftigen Gesellschaft, trotz allem als Reparaturbetrieb andienen und dazu die Entwicklung effektiver Anpassungsinstrumente, bezogen auf Kinder und Jugendliche, die nicht ohne Weiteres in der vorgesehenen Bahn laufen, in Aussicht zu stellen. Die Sonder- und Inklusionspädagogik des Schwerpunkts emotionale und soziale Entwicklung sollte sich jetzt eher auf ihren systemkritischen Auftrag besinnen und Teil der gesellschaftlichen Transformation werden, wie sie derzeit auf den verschiedensten Ebenen begonnen hat. Denn alles andere wird nur immer weiter wegführen von einer wirklich freiheitlichen, in sich zufriedenen, ausgeglichenen, nachhaltigen und zukunftsorientierten Gesellschaft und einer besseren Welt als Ganzes. Um aber den Weg in eine veränderte gesellschaftliche Zukunft freizumachen, müsste zunächst die Schulpflicht aufgehoben, diese in eine offener und freier auszugestaltende Bildungspflicht umgewandelt und jeder Einzelne mit einem bedingungslosen Grundeinkommen ausgestattet werden. Heranwachsende, die unter den leistungs- und kompentenzorientierten schulischen Standards nicht mehr lernen wollen oder können, und Eltern, die das Joch der 9-to-5Jobs, die sie oftmals in entfremdeten Arbeitskontexten vor Bürobildschirmen verbringen, abstreifen wollen, können sich dann in selbstorganisierte, disziplinen- und generationenübergreifende, an Nachhaltigkeit, globaler Gerechtigkeit, kultureller Vielfalt und prosozialen Werten orientierte, digital vernetzte Communities und Projekte einschreiben, einbringen und diese gemeinsam mit anderen voranbringen. Jenseits der auf Abhängigkeit und Entfremdung zielenden Erwerbsarbeit, und zugleich befreit von den einengenden kompetenzorientierten Rahmenbedingungen und immer rigider gewordenen Standards staatlich vorgegebener, überregulierter Bildungscurricula, können dann, in einer gesünderen Balance für alle Beteiligten, neue Formen von Arbeiten und Wirtschaften, von Technik-Entwicklung, Handwerk, Acker- und Gartenbau, von Leben, Kunst, Musik und Philosophie, von Lernen und wissenschaftlichem Denken erprobt und entwickelt werden. Mit der Zeit wird dies, in der Rückwirkung, auch zu einer Reform und zu einem Neuentwurf der Schulen und Universitäten selbst führen.

Bei aller Dramatik, die mit der Ankunft des Corona-Virus in der Mitte unserer Zivilisation verbunden war und noch ist, sind immerhin digitales Lernen, Studieren und Arbeiten in Gestalt von Home-Schooling, Online-Lehre und Home-Office plötzlich zu realen Optionen geworden. Damit ist die Gesellschaft bereits teilweise von der alten, reichlich überholten, Vorstellung abgerückt, dass schulisches Lernen, Studieren und Arbeiten nur unter durchgängiger Kontrolle in dafür bereitgestellten Räumen, quasi unter direkter Aufsicht, zu erfolgen hätten. Sobald es solche alternative, zu Bildungszwecken, zugleich aber auch zum Arbeiten und zum Leben aufgespannte, Freiheitsräume gibt, werden die bisher geschlossenen, veränderungsresistenten Bildungssys- 
teme, mit all ihren bürokratischen Überbauten, vor der Frage stehen, wie auch sie sich verändern können und sich auf die veränderte gesellschaftliche Situation einstellen wollen. Dadurch, dass weniger Menschen in die noch verbleibenden staatlichen Bildungsinstitutionen strömen, wird es auch zu einer Umverteilung der finanziellen Ressourcen kommen, weg von den staatlichen Institutionen hin $\mathrm{zu}$ den zivilgesellschaftlich getragenen Projekten. Anders als unter den in der Gegenwart dominierenden Bedingungen institutionalisierter Kindheiten in Krippen und Tagesstätten und oftmals eintöniger und fader Jugendjahre in standardisierten Klassenzimmern, die flächendeckende Ausstattung der Klassenräume mit Tablets und Laptops allein wird daran überhaupt nichts ändern, haben die Heranwachsenden in den neuen transformativen Zukunftsprojekten mehr Kontakt zu ihren, ebenfalls dort lebenden und tätigen Eltern, Geschwistern oder sonstigen Bezugspersonen und zu ihrer erweiterten sozialen Community. Es besteht dann auch nicht mehr die, im Verlauf der CoronaPandemie deutlich gewordene, Abhängigkeit der im beruflichen Hamsterrad laufenden Eltern von Kindertagesstätten und Schulen, die dazu führt, dass diese Institutionen zunächst einmal als bloße Aufbewahrungsorte für die Kinder benötigt werden. Wollen sich die Heranwachsenden im Jugendalter lieber in andere Projekte einbringen, die ihren inhaltlichen Interessen vielleicht mehr entsprechen, als das Projekt, in dem sie zunächst aufgewachsen sind, auch um sich emotional und geistig von ihren Eltern abzulösen und eine stärkere Selbstständigkeit zu erlangen, können sie sich auf Wanderschaft begeben, ganz wie es in früheren Jahrhunderten gemacht wurde und im Rahmen solcher Wanderjahre ihre Bildung vervollkommnen. So werden sie, von früh an, nicht nur in signifikantes Lernen und nachhaltiges Wirtschaften und in interessante urbane oder ländliche Umgebungen aktiv eingebunden, sondern auch diejenige emotionale und soziale Beziehungsqualität erfahren, die sie für eine natürliche und ausgeglichene Persönlichkeitsentwicklung brauchen.

\section{Freiheit, Wahrheit, Gerechtigkeit}

In einer ersten Fassung dieses Buches hatte ich noch viele Zitate von großen Denkern wie John O'Donohue, aus seinen Werken Anam Cara und Eternal Echoes, in meinen Text eingefügt. Sodann lagen da mit der Zeit, ausgelöst durch die Gespräche mit Katja Luckhardt-Seebaum und die dann von mir unternommenen Krishnamurti-Lektüren, eine ganze Reihe weiterer Zitate aus seinen Büchern Vollkommene Freiheit und Wahre Bildung. Auch Nassim Nicholas Taleb steuerte durch sein Buch Antifragilität, das im englischsprachigen Untertitel eigentlich viel treffender Things That Gain from Disorder heißt, und auf das mich Rolf Zander hingewiesen hatte, viele neue, inspirierende Gedanken und Überlegungen zu meinen Reflexionen bei. Doch meine ersten Leser_innen hatten dringend davon abgeraten, so viele Zitate $\mathrm{zu}$ bringen und wollten mehr narrative Elemente, die ich aus meinen pädagogischen und wissenschaftlichen Erfahrungshintergründen schöpfen sollte. Diese erste Version war auch voller Fußnoten und hatte ein gigantisches Literaturverzeichnis. Wer also jetzt kritisch einwendet, ich hätte zuwenig Literaturverweise, so kann ich nur sagen, dass in der ersten Version ca. $1400 \mathrm{Fußnoten} \mathrm{enthalten} \mathrm{waren.} \mathrm{Fast} \mathrm{zu} \mathrm{jeder} \mathrm{Theorie,} \mathrm{zu} \mathrm{jedem} \mathrm{Modell,} \mathrm{zu} \mathrm{jeder} \mathrm{De-}$ batte, gab es Literaturhinweise. Es war nicht ganz einfach, mich von alldem wiederum zu lösen. Auch begann ich damit, an den verschiedensten Stellen narrative Passagen 
einzufügen. Wenn ich hier also über Freiheit, Wahrheit und Gerechtigkeit schreibe, dann möchte ich zugleich auf die Originaltexte der oben genannten Autoren verweisen, insbesondere auf die Texte von O'Donohue und Krishnamurti. Selbst wenn diese von ganz unterschiedlichen Hintergründen kommen, so geht es doch beiden darum, uns etwas an die Hand zu geben, um uns aus unseren inneren und äußeren Käfigen zu befreien und etwas zu einer besseren, gerechteren Welt beizutragen. Dieses Erlangen von Freiheit und Unabhängigkeit von Autoritäten und Systemen, ist für beide Autoren ganz zentral. Taleb hingegen ist ein spritziger Querdenker. Seine Gedankenexperimente können dazu dienen, uns geistig beweglicher zu machen. Er tritt ein für selbstbestimmtes, autodidaktisches Lernen und lehnt alle Formen standardisierten Lernens ab. Sehr erfrischend! Eine hübsche Provokation für Leute, die sich allzu sehr daran gewöhnt haben, in den Bildungswissenschaften und in der pädagogischen Praxis in irgendwelchen engen Kompetenzrastern zu denken, diese empirisch zu überprüfen und darüber hinaus nichts mehr gelten zu lassen.

Dass ich Freiheit, Wahrheit und Gerechtigkeit als übergeordnete Maßstäbe in Lehre, Forschung und Theoriebildung meines pädagogischen Schwerpunkts verwende, versuchte ich vergeblich einer Kommission zu erklären, die vor nicht allzu langer Zeit zusammengetreten war, um eine Professur zu diesem Fach an einer kleinen Universität zu besetzen. Man hatte einen Kollegen von einer anderen Universität, quasi als externen Experten, hinzugebeten. Interessant war nun, dass dieser Kollege, obwohl er nicht einmal exakt dasselbe Fach lehrte, sondern ein Nachbargebiet, selbst wenn es Überschneidungen mit seinem eigenen Gebiet gab, so konnte er selbst aber im engeren Sinne doch nichts zum Thema Schule und Unterricht sagen. Aber nicht das ist das Kuriose, eher ist so etwas ja gang und gäbe. Interessant war, dass dieser Mann zu 95 Prozent der gesamten Redezeit, die nach meinem Vortrag zur Diskussion blieb, für seine vielen Fragen und Einwände verwendete und alle anderen sich eher knapp äußerten und sich allenfalls auf wesentliche Nachfragen beschränkten. Ich habe derlei öfter erlebt, dass also gerade die von außen hinzugeholten Kolleg_innen, sich wegen ihrer fachlichen Expertise, wie es immer so schön heißt, und wie man sie ihnen also bei diesem institutionellen Spiel zuschreibt, ganz besonders geehrt und somit zu erhöhtem Einsatz in der praktischen Kommissionsarbeit veranlasst sehen. An einer anderen Universität, deren Namen ich hier natürlich aus Gründen der Pietät verschweigen muss, war diese betreffende externe Kollegin, selbst gerade erst mit dem politischen Rückenwind des Professorinnenprogramms berufen, denn auch immer wieder damit beschäftigt, mir unter die Nase zu reiben, dass ich ja keine Drittmittel in größerem Umfang eingeworben hätte, obwohl das ja nun auch bereits aus meinen Bewerbungsunterlagen ersichtlich war. Nein, sie hatte sich also vorgenommen, diese Karte immer mal wieder zu ziehen. »Wo, sind denn nun Ihre Drittmittel?« Und: »Wann kommen denn endlich Ihre Drittmittel? « warf sie in Abständen in die Diskussion ein, rümpfte dabei die Nase, warf ihren Kopf nach hinten und schaute triumphierend in die Runde. Es gibt ja mittlerweile auch genug Kritik an diesem Drittmittel-Kult. Wollte dieser Personenkreis allen Ernstes meine geistigen Qualitäten als Universitätsprofessor an den Geldsummen messen, die ich aber nicht eingeworben hatte? Ja, man/frau bekommt einen Marktwert zugewiesen, wenn wir bei diesem Wissenschaftsmonopoly mitspielen. Ladenthin (2020, S. 829) formuliert es so: »Je teurer die drittmittelgeförderte Forschung, desto mehr verzerrt sich der Wahrheitsdiskurs einer Gesellschaft. Als wahr gilt dann, was finanziert wurde - nicht aber, was erforscht werden könnte.« 
Doch zurück zu dem extern, wegen seiner Expertise, herbeigeholten Kollegen. Als ich nun eine Serie wissenschaftstheoretischer Poster vorgestellt und die Komplexität der beteiligten Wissensschaftsdiziplinen, der gegensätzlichen Strömungen innerhalb des Fachgebiets, die für die Zukunft meines Erachtens relevanten Kernthemen und die Konsequenzen für die Hochschullehre, die Forschung und die pädagogische Praxis aus alldem aufgezeigt und abgeleitet hatte, neigte er seinen Kopf nach links, nach rechts, immer wieder, noch während ich sprach und schien so ausdrücken zu wollen, dass er meine Gedankengänge nicht billigte und innerlich auf Widerspruch gestimmt war. »Man weiß ja nun gar nicht, wofür Sie wirklich stehen«, konfrontierte er mich dann. Mich erinnerte seine Art zu sprechen an die intriganten Bischöfe in Ken Folletts Kingsbridge-Romanen. Als ich dann sinngemäß sagte, dass es aus meiner Sicht das Wichtigste sei, sämtliche vorhandenen, für das Fachgebiet relevanten Theorien und Modelle zu analysieren und zugleich der Kritik zu unterwerfen und dabei als Maßstab ein freiheitliches Menschenbild und ein emanzipatorisches Bildungsideal zugrundezulegen, da schüttelte der externe Experte immer noch den Kopf und sagte: „Was mir von Ihnen fehlt ist, dass Sie einmal ein eindeutiges Glaubensbekenntnis ablegen, wo Sie wirklich stehen? Sie berichten von all diesen Theorien und Modellen, aber wo stehen Sie denn persönlich?« Ich sagte sinngemäß, dass die Zeiten doch vorbei seien, wo die Professor_innen des Fachs sich entweder psychoanalytisch, individualpsychologisch, klientenzentriert, marxistisch, sozialphilosophisch, behavioristisch, lösungsorientiert, systemisch usw. positionierten und identifizierten, das wären die 8oer und 9oer Jahre gewesen, das sei Vergangenheit. Jetzt ginge es darum die nationalen und internationalen theoretischen Landschaften insgesamt in den Blick zu bekommen und das Ganze im interdisziplinären und transdisziplinären Sinne auf eine neue Stufe zu heben. Und als Maßstab bei der Analyse, Evaluation und Weiterentwicklung eben übergreifende Werte wie Freiheit, Wahrheit, Gerechtigkeit herangezogen werden müssten. Wieder dieses seltsame, Widerspruch signalisierende, Hin- und Herwiegen des Kopfes. Auch machte sonst aus der Kommission keiner Anstalten etwas zu sagen, bis auf einen Kollegen aus der dortigen Sonderpädagogik, der die Sorge äußerte, ich könnte die traditionellen Strukturen des Faches aus den Angeln heben. Ich versuchte ihn zu beruhigen, auch war das ja wirklich nicht meine Absicht, zu dem Zeitpunkt jedenfalls noch nicht. Doch vor allem dem externen Kollegen und seiner geistigen Brillanz gehörte die Bühne und er setzte noch ein weiteres Mal mit diesem Glaubensbekenntnis an, ja in der Tat, er sagte immer wieder Glaubensbekenntnis, und dass er das bisher immer noch nicht von mir gehört hätte und dass er da nun ein wenig ungeduldig würde.

Durch das Verfahren war er mir gegenüber natürlich mit einer situativen Macht ausgestattet. Womöglich war das alles ein abgekartetes Spiel. Während ich seiner Maskerade zuschaute, ohne allzu viel von meinen Gedanken zu verraten, visualisierte ich das Hintergrundgeflecht von schon längst getroffenen Absprachen, aber auch die möglicherweise noch nicht ganz festgezogenen Stellschrauben, wie sie eben für die deutschen Professur-Besetzungsverfahren typisch sind. In mir ratterten Erinnerungen an vergleichbare Situationen, die ich zur Entschlüsselung und Deutung blitzschnell durchfilterte. Noch einmal schnell die Machtspiele in Kingsbridge durchgehen. Was würde Machiavelli hierzu sagen? Welche Strippen hätten die Medici bei sowas gezogen? Was wären die Schachzüge der Borgia oder der Sforza gewesen? Während der externe Experte also immer noch weiter redete und redete und immerfort das 
Wort Glaubensbekenntnis darin wiederholte und variierte, platzte dem Dekan, der die Kommission leitete, schließlich der Kragen: »Ach Glaubensbekenntnisse! Es geht doch hier nicht um Glaubensbekenntnisse!« Das hatte etwas Befreiendes und Wohltuendes. Sicherlich saßen in der Kommission auch einige sehr gute, wache, weitdenkende Menschen, wenn auch eine Kollegin aus dem Mittelbau der betreffenden Abteilung, wo die Professur angesiedelt war, vor allem daran interessiert war, wie es schien, dass es inhaltlich genauso weiterging, wie der scheidende Professor den Lehrstuhl hinterlassen hatte, also bloß nichts Neues. Das Schweigen der anderen und die passive Rolle des Dekans, dem meine Veröffentlichungen, gemessen an seinen eigenen Arbeiten, die ich teils kannte, eigentlich ganz gut gefallen haben müssten, konnte ich mir im Nachhinein nur so erklären, dass, im Hintergrund des Ganzen, die mit goldenen Talern gefüllte Schatulle des Professorinnenprogramms schon bereit stand und die vielen Dukaten darin allzu verführerisch glitzerten. So wurde eine Kollegin berufen, die nicht einmal das pädagogische Fach, um das es ja ging, studiert und folglich auch niemals in dem zugehörigen pädagogischen Feld gearbeitet hatte. Was hätte ich darum gegeben, wenn Meister Eckhart, den ich, wegen seiner Schriften und seiner geistigen Weite, sehr verehre, und den ich nun ganz besonders mit diesem Landstrich verbinde, warum genau, weiß ich nicht, vermutlich ist es ein Bild, das bei der Lektüre eines seiner Bücher in mir entstanden ist, wenn Meister Eckhart also nun mit uns in diesem Raum gesessen hätte, wenn er dieses Spiel aus der Nähe mitangesehen hätte und wir beide, nur wir beide versteht sich, abends in ein rustikales Lokal, in jener denkwürdigen Stadt, zum Essen hätten einkehren und einen guten Krug Wein dazu leeren können. Dort hätten wir uns über diese Ereignisse und ihre Bedeutung austauschen und philosophieren können. So aber blieb mir nichts anderes, als den Intercity Express zurück nach Berlin zu nehmen und diesen, der nationalen Gesellschaftspolitik und den mikropolitischen Spielchen der sonderpädagogischen Szene zum Opfer gefallenen, Landstrich, inklusive des Lehrstuhls dort, hinter mir zu lassen.

\section{Potenzial der Demokratie}

Unsere demokratische Gesellschaftsordnung bietet mehr Möglichkeiten, als wir bisher ausgeschöpft haben. Gemessen an dem, was wir, historisch betrachtet, hinter uns gebracht haben, sind wir als Gesellschaft sicher weit entwickelt. Deutschland hat sich von einem feudal regierten Flickenteppich über ein nationalistisches, imperialistisches Kaiserreich schließlich, in den 1920er Jahren, zu einer ersten, wenn auch noch instabilen, Demokratie entwickelt. Nach dem Zusammenbruch der Weimarer Republik, und den dann folgenden Jahren der Diktatur, schließlich der völlige Zusammenbruch, und der Neuanfang, im Osten Deutschlands allerdings mit mehreren Jahren Verzögerung. Deutschland lässt sich mittlerweile als ein weltoffenes, pluralistisches Land beschreiben. Auf europäischer Ebene gehört es zu den impulsgebenden Ländern, trotz aller Herausforderungen, die es auch gibt. Aber es geht noch mehr. »In den letzten Jahren haben manche in diesem Land befürchtet, die zweite deutsche Demokratie werde den Weg der ersten gehen. Ich habe dies nie geglaubt. Ich glaube dies heute weniger denn je. Nein: Wir stehen nicht am Ende unserer Demokratie, wir fangen erst richtig an « (Regierungserklärung von Willy Brandt, vom 28. Oktober 1969, zit. n. Frei 2008, S. 209). Was Willy Brandt 1969 sagte, muss uns auch 50 Jahre später 
noch Ansporn sein, unsere demokratische Gesellschaft weiter zu entwickeln und zu verbessern, denn wir sind noch lange nicht am Ziel. Freiheit und Selbstbestimmung, Gerechtigkeit und Menschenwürde, Mitbestimmung und Solidarität, in prosozialen Gemeinschaften sind, unter den gegenwärtigen Bedingungen, noch lange nicht im erforderlichen Maße verwirklicht. Dies hängt in vielfacher Weise nicht nur mit dem momentanen Zustand der Gesellschaft, sondern auch mit dem Zustand unseres staatlichen Bildungssystems zusammen, das sich, seit einiger Zeit, in einigen, sehr entscheidenden, Aspekten in die falsche Richtung entwickelt. Doch dürfen wir nicht darauf warten, dass die nun notwendigen Veränderungen gerade von staatlicher Seite aus initiiert werden. Eher müssen wir, als aufgeklärte, denkende Bürger_innen, mutig sein und selbst die Veränderung anstoßen und darauf vertrauen, dass wir, durch mehr zivilgesellschaftliches Handeln, unsere Demokratie letztlich stärken werden. Es kann daher in Zukunft nicht mehr darum gehen, Kinder und Jugendliche, die sich in die, immer engeren, Bahnen und Stukturen unserer Bildungsinstitutionen und unserer Arbeitswelt nicht mehr einfügen können oder wollen, mit immer raffinierteren pädagogisch-psychologischen Maßnahmen in die Spur zu bringen. Es wird auch nicht funktionieren. Dasselbe gilt für die Arbeitswelt. Wir können die Menschen nicht immer weiter optimieren und sämtliche Prozesse immer weiter rationalisieren. Auf der einen Seite haben wir die Diskurse der Freiheit und der signifikanten Lernerfahrung, auf der anderen Seite die Diskurse der Steuerung und der Kontrolle. Beide Diskurse ringen derzeit um die Vorherrschaft in den Bildungsinstitutionen, wie auch in der Gesellschaft als Ganzes. Eine Pädagogik der emotionalen und sozialen Entwicklung, die das gesellschaftliche Ganze im Blick hat, sollte den Diskurs der Freiheit führen. 



\section{Das Wissen, seine Strukturen und seine Produktion}

\section{Emotionales und soziales Lernen: Der Wissensstand}

Mit dem Definieren der, in der Gegenwart dominierenden, pädagogischen Settings, ist freilich noch nicht beantwortet, welche Handlungsmodelle, in den jeweiligen Kontexten, tatsächlich Anwendung finden können und was die Wissenschaft diesbezüglich im Angebot hat. Viele inklusive Schulen haben, in Ermangelung besserer Ideen, seit 2003 etwa auf das Trainingsraumprogramm (vgl. die affirmativen Beschreibungen dieses Programms bei Balke, 2003; Bründel und Simon, 2013; Claßen und Nießen, 2006) zurückgegriffen, auch wenn es seitens der Wissenschaft dafür keine nennenswerten Empfehlungen gegeben hat, sondern eher Bedenken geäußert wurden. Als aussichtsreicher erscheint derzeit School-wide Positive Behavior Support (SW-PBIS oder etwas kürzer: PBIS) (vgl. die resümierende Übersicht bei Broecher, $2015 \mathrm{a}$, ferner die für diese Theoriewelt repräsentativen Veröffentlichungen von Lewis und Newcomer, 2004; Sailor et al., 2009) zu sein. Bei PBIS handelt es sich um ein evidenzbasiertes Interventionssystem, das sich seit gut 15 Jahren rasant entwickelt und weltweit an Bedeutung gewonnen hat. Die diesbezügliche Debatte in Deutschland hat, seit etwa 2014, begonnen und es werden sicher Adaptierungen und Weiterentwicklungen notwendig sein, wenn dieses System des Verhaltenstrainings und der Verhaltenssteuerung überhaupt die Zukunft in den deutschen Schulen bestimmen soll. Eine 1:1 Übertragung, aus den USA auf deutsche Verhältnisse, erscheint derzeit aber kaum möglich, aus Gründen des Menschenbildes und des Bildungsideals. Die deutsche behavioristische Forschungscommunity scheint hier allerdings weniger Bedenken an den Tag zu legen und greift PBIS, wie auch andere Response-to-Intervention-Modelle (RTI), bei denen es ja stets um schulweite, datenbasierte Mehrebenensysteme der Diagnostik, der Förderung und der Intervention, bezogen auf Verhalten, bezogen auf Lernen, oder beides kombiniert, geht (vgl. etwa Blumenthal und Voß, 2016; Huber und Grosche, 2012; Voß et al., 2016), recht enthusiastisch auf. Generell, und dann auch mit Blick auf die spezialisierten schulischen Settings, haben wir im genannten Förderschwerpunkt in Deutschland jedoch mit einer enormen theoretischen und methodologischen Vielfalt, auch mit Gegensätzlichkeiten und Spannungsverhältnissen zu tun, auf die ich noch genauer zu sprechen komme. Zum einen lassen sich im Fachgebiet der emotionalen und sozialen Entwicklungsförderung historisch-hermeneutische Arbeiten ausmachen, sodann empirisch-erfahrungswissenschaftliche, das heißt qualitative und quantitative, Ansätze bis hin zu gesellschaftskritischen und ideologiekritischen Diskursen. Der transatlantische Ideenaustausch zwischen Deutschland und Nordamerika war bei 
all dem immer zentral, schon seit den 6oer Jahren, angefangen bei den behavioristischen Arbeiten von Skinner, über Rogers' klientenzentrierte Arbeiten im Sinne der Humanistischen Psychologie, bis hin zur psychoanalytischen Pädagogik von Bettelheim oder Redl. Dies alles waren Modelle, Ideen, Erfahrungen und Erkenntnisse, die in Deutschland aufgegriffen und weiterentwickelt wurden. Die einen betrieben dann im pädagogischen Feld eine Verhaltensmodifikation, früher auch Verhaltenstherapie genannt, die anderen eine klientenzentrierte Gesprächstherapie oder Erziehungstherapie, wie es etwa Karl-Josef Kluge an der Universität zu Köln eine Reihe von Jahren getan hat. Wieder andere entwickelten psychoanalytisch ausgerichtete Pädagogiken, etwa Bernd Ahrbeck an der Berliner Humboldt-Universität.

Umgekehrt finden wir in den USA Einflüsse der deutschen Reformpädagogik wieder, vor allem im Bereich Experiential Education, wo etwa Kurt Hahn in der Gegenwart als Leitfigur gilt. Doch auch in den USA hat der verhaltensorientierte Ansatz seine Kritiker_innen, speziell in denjenigen Communities in Wissenschaft und Praxis, die an Experiential Education, Urban Education oder Teaching for Social Justice orientiert sind. So stand ich 2016 mit meinem Poster in Minneapolis auf dem Jahreskongress der Association for Experiental Education, auf dem ich eine Art Synthese erfahrungsbezogener, qualitativer und evidenzbasierter Handlungsansätze versuchte. Die AEE-Protagonist_innnen, die zu mir kamen und ein Gespräch mit mir darüber führten, schüttelten aber den Kopf, wenn sie sich vorstellen sollten, ihre Handlungsmodelle mit behavioristischem Wissen zu verknüpfen. Niemand auf dieser Szene wollte etwas davon wissen. Behavior war für diese Leute kein relevantes Kriterium. Die Überzeugung der AEE-Stakeholder_innen ist, dass wir nur bedeutsame pädagogische Erfahrungen ermöglichen und die Kontexte hierfür bereitstellen müssen. Wenn die Kinder und Jugendlichen Erfahrungen machen, sagen wir im Outdoor und Adventure-Bereich, im Hochgebirge, in Nationalparks oder auf dem Meer, dann trägt sie das aus ihren bisherigen Lebenskontexten hinaus. Diese Erfahrung hilft ihnen, ihre bisherigen Verhaltensmuster zu überschreiten und hinter sich zu lassen. Vor meiner intensiven Beschäftigung mit PBIS, hatte ich es ja ähnlich gesehen und, in all den Jahren in den Sommercamps und in den vielen verschiedenen Schulen, auch eher wie die $\mathrm{AEE}$-Leute gemacht. $\mathrm{Zu}$ wenig wird noch von Deutschland aus wahrgenommen, was sich in Nordamerika in diesen Feldern tut, oftmals allerdings außerhalb der akademischen Sonder- und Inklusionspädagogik, denn diese ist überwiegend sehr stark behavioristisch und evidenzbasiert dominiert. Oftmals haben Wissenschaftler_innen und Praktiker_innen in Deutschland sehr stark vereinfachte Bilder der Situation in den Vereinigten Staaten. Die theoretischen Landschaften in der Pädagogik dort sind viel verzweigter, differenzierter und heterogener, als viele hier in Deutschland glauben. Wir haben mit mindestens drei großen Communities zu tun, in Nordamerika wie auch in Deutschland. Diese Theoriewelten entfalten sich um die Kernkonzepte Behavior, Justice und Experience. Sie fächern sich vielfach auf, verzweigen sich, mischen sich, brechen sich, wie Lichtstrahlen in einem Kristall und sie sind gekoppelt an bestimmte wissenschaftstheoretische Denkweisen. Empirie und Evidenzbasierung, soziale Gerechtigkeit oder signifikante Lernerfahrungen in subjektzentrierter Perspektive werden jeweils zu Leitmotiven, nach denen sich diese Forschungscommunities auf beiden Seiten des Atlantiks konstituieren und voneinander abgrenzen. Der Begriff der Empirie wird jedoch insbesondere von denjenigen Protagonist_innen, und das ist in Deutschland genauso wie in den USA, vereinnahmt, die die Evidenz- 
basierung und quantitativ-statistische Methoden auf ihre Fahnen geschrieben haben. $\mathrm{Zu}$ Unrecht, denn empirisch heißt erfahrungsbasiert und beinhaltet damit auch all jene methodologischen Zugänge, die wir unter dem Begriff der qualitativen Forschung zusammenfassen.

Eine Reduzierung des Empiriebegriffs auf alles Quantitativ-Statistische erscheint daher weder zulässig noch sinnvoll. Schon Wolfgang Klafki (1985) hat aufgezeigt, wie bedeutsam es für das Auffinden vorhandener Probleme und das Formulieren von relevanten Fragestellungen ist, dass wir qualitative und quantitative Methoden miteinander verknüpfen, unter gleichzeitiger Einarbeitung von historisch-hermeneutischen und gesellschaftskritisch-ideologiekritischen Perspektiven. Müsste es nicht eher darum gehen, die Theorielandschaften insgesamt in den Blick $\mathrm{zu}$ nehmen und nach Synergien und neuen Entwicklungsstufen für das Ganze Ausschau zu halten? Wissenschaft ist doch letztlich Wahrheitssuche, und vor allem freies, zweckfreies Denken und Forschen! »Es indiziert nicht die Qualität einer Wissenschaft, Erwartungen zu bedienen. Die Erwartungen könnten falsch sein, partikular, unsinnig, wenig zukunftsweisend«, lesen wir bei Volker Ladenthin (2020, S. 829). Doch die Bildungspolitik und die Gesellschaftspolitik regieren auf vielfältige Weise in unser Fach hinein, versuchen Richtungen vorzugeben und zu steuern, was wir tun, was wir forschen und was wir an Ergebnissen finden. Hinzu kommt die Lagerund Netzwerkpolitik, die sich als universitäre und deutschlandweite Mikropolitik in Form der Beeinflussung von Institutsstrukturen, durch Mittelzuweisung oder Mittelvorenthaltung, durch die Politik der Forschungsförderung, durch die Politik der Berufungsverfahren, durch die Politik der Frauenquoten, durch die Politik des Professorinnenprogramms, oder durch die Politik der Konzipierung und Akkreditierung von Studiengängen, realisiert. Oftmals werden Denk-Zäune um die universitären Institute und Abteilungen herum errichtet, zumindest sprechen Berichte von Insider_innen aus ganz Deutschland dafür, dass es an vielen Orten des Landes genauso ist. Oftmals wird dabei vor allem auf den Machterhalt des eigenen wissenschaftlichen Netzwerks abgezielt. Dies ist zwar aus der Eigenlogik der diversen Netzwerke und Seilschaften heraus verständlich, erscheint, mit Blick auf eine bessere Zukunft für alle, jedoch wenig sinnvoll, wenn wir eine nachhaltige, demokratische Weiterentwicklung des gesellschaftlichen Ganzen, inklusive der Bildungs- und Sozialsysteme, im Blick haben und tatsächlich erreichen wollen. Protagonist_innen im Fachbereich Game Design könnten in Kürze ein neues Brettspiel, vermutlich auch eine Multiplayer-Online-Version dazu entwickeln, eine Art Wissenschaftsmonopoly, wo sich Spielfiguren übers Feld bewegen, im Kampf um Lehrstühle und universitäre Abteilungen, Drittmittel und wissenschaftliche Großprojekte, Senatssitze und Vizepräsidentschaftsposten.

Interessant dabei ist, dass es aktiv im Feld laufende Figuren und eine Reihe von Figuren gibt, die aus dem Hintergrund agieren und das Spielgeschehen beeinflussen. Über Ereigniskarten und Gemeinschaftskarten, die gezogen werden, wenn man/frau durch Würfeln auf bestimmte Felder vorrückt, wird das Spielgeschehen zusätzlich beeinflusst. Dies können bestimmte politische Entscheidungen, auf nationaler oder europäischer Ebene, bezüglich neu propagierter Forschungsthemen oder, durch die DFG oder das BMBF bereitgestellte, Drittmittel sein. Dies können auch Interventionen der Gleichstellungs- oder Diversitätsbeauftragten sein. Wenn Mitspielerinnen etwa die Ereigniskarte Professorinnenprogramm ziehen, sie ist in der Tat nur weiblichen 
Spielerinnen vorbehalten, kommen sie in den Genuss einer beträchtlichten steuerfinanzierten Mitgift, die ihnen das unmittelbare Vorrücken auf einen hochdotierten Lehrstuhl ermöglicht und ihnen, allein dadurch, dass sie weiblichen Geschlechts sind, zugleich weitere personelle und finanzielle Ressourcen zuweist. Diese Mittel sind so erheblich, dass kaum eine Universität, in dem Moment, noch einen Mann auf die ausgeschriebene Professur berufen wird. Wir erinnern uns noch an den Bischofvon Kingsbridge, der mich, in jenem zauberhaften Meister-Eckhart-Land, unter Druck zu setzen versuchte, Glaubensbekenntnisse abzulegen, während im Hintergrund schon eben diese Schatulle mit Goldtalern verheißungsvoll strahlte und glitzerte. Oder die Spielerinnen, die diese Ereigniskarte gezogen haben, bekommen ein Uprade aus dieser Schatulle, um einen kleineren gegen einen besser dotierten Lehrstuhl einzutauschen. Männer müssen bei diesem Wissenschaftsmonopoly die strategischen Vorteile der Frauen durch höheren Einsatz beim Publizieren und Geld Einwerben ausgleichen, oder vermutlich sogar öfter, einfach nur aushalten, hinnehmen und in intellektuelle Brillanz transformieren, so gut es eben geht, also subliminieren, kompensieren auf anderen Feldern, wie auch immer. Aber so wird ja, aufs Ganze gesehen, auch die Wissenschaft vorangebracht, Denken geht immer, auch mit weniger Talern in der Tasche und weniger nationalen Bewegungsmöglichkeiten. Durch solche Einschränkungen werden dann oft ganz andere Dinge möglich, die man vielleicht vorher niemals in Betracht gezogen hat, etwa in Berlin eine pädagogisch motivierte Metropolenforschung zu betreiben oder im ehemaligen Fürstentum Anhalt-Zerbst ein altes Gehöft zu kaufen und dort ein transformatives Community-Projekt aufzubauen.

Auch Einengung kann also Kreativität hervorbringen, vielleicht sogar mehr Kreativität als es bei Menschen der Fall ist, die, aufgrund günstiger politischer Rahmenbedingungen und vorteilhafter Seilschaften und Netzwerke, immer nur über vor ihnen ausgerollte Teppiche laufen und von allen Seiten mit guten Gaben zugeworfen werden. Oft genug entsteht dabei auch mehr ein professorales Jetset-Gehabe, mehr Hybris als wissenschafliche, reflexive, hermeneutische, philosophische Tiefe. Das betreffende Game Design Team entwirft derzeit noch Ereigniskarten, die insbesondere Männern mit Migrationshintergrund, vor allem aber homosexuellen Männern, bessere Spielchancen im Kampf um die Lehrstühle bescheren sollen, denn diese beiden Gruppen haben es im Moment überaus schwer und sie können kaum auf den Spielfeldern vorrücken. „Der kam ja nun auch wirklich etwas schwuchtelig rüber« hörte ich eine Frau in einer Berufungskommission über einen männlichen Bewerber sagen, und draußen war er. Volker Ladenthin (2020, S. 828) schreibt zu solchen Sekundärfaktoren, wie sie auf den Ereignis- oder Gemeinschaftskarten des Wissenschaftsmonopolys notiert sind und wie sie schon jetzt das reale Geschehen in der Welt der Academia beeinflussen: »Man kann Wahrheit nicht als regulative Idee von Wissenschaft ausweisen und bei der Bewertung ein anderes Kriterium heranziehen.« Gerechtigkeit gibt es vorläufig so oder so nicht, auch wenn die Urheberinnen des Professorinnenprogramms dies noch so oft behaupten. Höchstens könnte aus den vergangenen Jahrhunderten heraus argumentiert werden, im Hinblick auf die historisch ja nachgewiesene Einschränkung der Bildungschancen und beruflichen Selbstentfaltungsmöglichkeiten von Frauen. Aus der Gegenwart unserer Gesellschaft heraus glaubwürdig zu argumentieren, dürfte dagegen mehr als schwer sein. Denn das Professorinnenprogramm benachteiligt nicht nur Männer, die sich qualifiziert haben, indem Frauen allein wegen ihres Geschlechts vorrangig berufen werden, selbst dann, wenn sie 
geringer, teilweise nicht einmal fachspezifisch qualifiziert sind. Das Programm ist, auch aus der Sicht der Gender- und Queer Studies, vollkommen überholt und nicht mehr auf dem aktuellen Stand der Forschung und der Theoriebildung. Wir wissen heute doch gar nicht mehr, wieviel Mann oder Frau in einer Person tatsächlich drin steckt. Da wo oberflächlich Frau dransteht, kann in Wahrheit, vielleicht zu 90 Prozent, ein Mann drin stecken und wo eigentlich noch Mann dransteht, kann es sich in Wahrheit um, sagen wir zu 85 Prozent, um eine Frau handeln. In Zusammenhang mit den von mir unternommenen Studien in der virtuellen Welt wird dies sicher noch ein wenig konkreter werden, plastischer noch als in Judith Butlers theoretischen, abstrakten Abhandlungen.

Vieles, was sich hier abspielt, ist also Geschlechter-, Identitäts- und Gesellschaftspolitik, oder es dreht sich um Selbsterhalt, Machterhalt, Ressourcenvermehrung, Statusvermehrung, oder beides kombiniert. Es wird, zumindest in vielen pädagogischen Feldern, nicht mehr danach gefragt, wer die umfassendste Erfahrung und Kenntnis des Gebietes hat, auf dem ein Lehrstuhl besetzt werden soll, sondern es wird in erster Linie nach sekundären Faktoren gesehen, die dann der abschließenden Entscheidungsfindung dienen. Somit handelt es sich um selbstreferentielle Spiele im Elfenbeinturm, um es mit Luhmann zu sagen, fernab von den Dingen, die sich draußen in der Gesellschaft vollziehen, ganz zu schweigen von den enormen finanziellen Ressourcen, die das alles kostet und die teils besser auf anderen, innovativeren, nachhaltigeren und zukunftsorientierteren Gebieten investiert würden. Einige denken vielleicht in diesem Zusammenhang an den in den 9oer Jahren von Dietrich Schwanitz veröffentlichten Roman Der Campus, für den er, der ja selbst als Professor gearbeitet hatte, als Nestbeschmutzer gescholten wurde. Doch wie harmlos erscheinen die Dinge, die Schwanitz damals beschrieb, im Vergleich zu dem, was heute in der Welt der Academia geschieht. Ich sprach damals mit dem von mir sehr geschätzten Hans-Günther Richter, von der Universität zu Köln, der mich beim Verfassen meiner Habilitationsschrift beriet und der leider schon nicht mehr lebt, über den Roman, den ich gerade las, als wir in Bremen auf einer Tagung beide mit Vorträgen aufgetreten waren und mit anderen abends bei einem Drink zusammensaßen. Richter, der auch sehr viel belletristische Literatur las, und eine Zeitlang in Köln Dekan war, kannte Der Campus bereits und als ich, als junger, angehender Privatdozent, mein Staunen über solche Enthüllungen zum Ausdruck brachte, sagte er nur müde abwinkend, ach in Wahrheit sei es doch alles noch viel schlimmer. Dabei war es doch wichtig, dass jemand wie Schwanitz diese merkwürdigen, selbstreferentiellen, mikropolitischen Dinge auf humorvolle Weise thematisierte. Darin lag doch eine Chance zur Veränderung, zur Verbesserung, zur Transformation. Doch die Gesellschaft war noch nicht so weit. Bald wird sie jedoch so weit sein. Die Zivilgesellschaft, wenn wir hierunter einmal die Gesamtheit aller nichtstaatlichen Organisationen und engagierten Bürger_innen sowie das demokratische Gemeinwesen dieses Landes insgesamt verstehen, wird, so hoffe ich, bald mehr Mitspracherechte einfordern, was tatsächlich mit den von ihr aufgebrachten Steuermitteln geschehen soll, und was nicht, und ob sie weiterhin solche Spielchen finanzieren will, oder nicht. 


\section{Emanzipatorische, transdisziplinäre Bildungs- und Sozialwissenschaft}

Was würde ein Denker vom Range Egon Friedells über unsere Zeit sagen? Friedell zeigte in seiner Geschichte der Neuzeit die großen kulturellen Themen auf, wie sie sich über die Jahrhunderte hinweg entwickelt, ausgeprägt und wieder verändert haben. Was waren die dominierenden Themen der zweiten Hälfte des 20. Jahrhunderts, das heißt nach 1945? Das Erkämpfen und Sichern von Freiheit, das Überwinden von Machtsystemen, das Aufbauen einer soliden Demokratie und das Erreichen von Chancengleichheit für Kinder und Jugendliche aus allen Sozialschichten. Doch was ist das Thema nach der Jahrtausendwende? Die Neue Steuerung? Die schrittweise Unterhöhlung der Demokratie? Die Verwandlung der Demokratie in einen subtilen, auf Fremdkontrolle, die aber als Selbstkontrolle und Selbstdisziplinierung konzeptualisiert wird, basierenden Machtapparat? Was ich hier versuche, steht im Dienste einer Erziehung zur Mündigkeit (vgl. Adorno, 1971) und einer emanzipatorischen Sozialwissenschaft (vgl. Wright, 2017). Es ist zum einen interdisziplinäre Forschung (vgl. z. B. Schoolman et al., 2012), in Teilen auch transdisziplinäre Forschung (vgl. Hirsch Hadorn et al., 2008; Lang et al., 2012). Im Sinne von Paul Feyerabend (2010) verwende ich eine pluralistische, offene und weite Methode. Welche Texte muss ich dazu in die Hand nehmen? Die in der Pädagogik der emotionalen und sozialen Entwicklungsförderung vorhandenen Einführungen und Übersichtswerke (vgl. z. B. Ahrbeck und Willmann, 2010; Blumenthal et al., 2020; Hillenbrand, 2003, 2008; Müller, 2018; Mutzeck, 2000 b; Myschker und Stein, 2018; Stein, 2008), Handbücher (vgl. z. B. Clough et al., 2005; Cole et al., 2013; Garner et al., 2014; Gasteiger-Klicpera et al., 2008; Goetze und Neukäter, 1993; Rutherford, 2004; Walker und Gresham, 2014 usw.), Tagungsdokumentationen, Praxisanleitungen, Übungsmaterialien und historischen Rekonstruktionen wirken einerseits breit gefächert, fast uferlos. Zum anderen lässt sich das ganze veröffentlichte Material aber auch recht schnell auf bestimmte Kernthemen und Grundfiguren zurückführen. Es gilt zum einen heranzuziehen, was im Fachgebiet vorliegt, und dann Erweiterungen vorzunehmen, um so das Wissen voranzubringen, durch Analyse, Reflexion und Neuentwurf. Die kritisch-konstruktive, erziehungswissenschaftliche Forschung in der Tradition von Wolfgang Klafki, in ihrer Verbindung von historischhermeneutischen, empirischen sowie gesellschaftskritischen und ideologiekritischen Perspektiven, dient mir dabei als Ausgangspunkt. Von hier aus unternehme ich eine Bestandsaufnahme, ein Review und eine kritische Analyse. Ich selbst habe in den vergangenen Jahrzehnten überwiegend Feldforschung, ethnografische Forschung, Handlungsforschung, kulturgeografische Forschung betrieben, auch in subkulturellen urbanen Räumen. War ich als Lehrer und Schulleiter über nahezu zwei Jahrzehnte hinweg im Kontext von Praxisforschung tätig, hierbei natürlich selbst in das pädagogische und didaktische Geschehen verwickelt, in Klassenzimmern, auf Pausenhöfen, in Lehrerzimmern, so unternahm ich zuletzt meine Forschungen aus Außenperspektiven auf Schulen im urbanen Raum. Ich begann die sozialen und kulturellen Räume zu erkunden, die die Schulen umgeben, in der Metropole Berlin.

Dazu gehörte am Ende auch, mich mit zwei ausgewählten Berliner Schulen eingehender zu beschäftigen. Die eine, eine inklusive Sekundarschule, liegt in einem multikulturellen Hotspot, nicht weit vom Görlitzer Park, die andere, eine international ausgerichtete Schule mit Grundschule und Sekundarstufen, liegt im eher bürgerlichen, gediegenen Südwesten. Größer könnte der Kontrast auch nicht sein. In beiden Fällen 
habe ich die Schulprogramme und die verwendeten pädagogischen Konzepte und Methoden analysiert und auch intern Gespräche geführt. Zusätzlich habe ich, nachdem ich 18 Jahre im Schuldienst Nordrhein-Westfalens tätig war, als Lehrer, Schulleiter und Fortbildner, einige weitere Innenperspektiven zum Berliner Schulwesen gewonnen in den Bereichen Educational Governance, Schulleitung, Schulverwaltung und Schulentwicklung sowie Training und Coaching von zukünftigen schulischen Führungskräften, durch Teilnahme an Workshops und Seminaren. Nun, ich wäre um ein Haar zum zweiten Mal Schulleiter geworden, nach zwölf Jahren Universität, doch sprang ich kurz vorher wieder ab. Auch die aus diesem Prozess mitgenommenen Eindrücke und Erkenntnisse fließen in dieses Buch ein. Worum geht es am allermeisten? Um die Befreiung des Denkens aus den, mittlerweile immer einengender wirkenden, Institutionalisierungen. Wir sollten die junge Generation ermutigen, vorauszudenken und zu entwerfen, statt diese in erster Linie anzuleiten, lediglich Regeln zu befolgen. Odile Decq, ich sah sie zuerst in einem Dokumentarfilm von Marcus Fitsch (2019) zum Thema Flexible Räume - Die Zukunft des Bauens, leitet das Confluence Institute for Innovation and Creative Strategies in Architecture, Paris. Wer nach einem lebendigen Beispiel für gelebte Inter- und Transdisziplinarität sucht, schaut sich das am besten einmal an.

\section{Kulturelle Geografien, Cultural Mapping, Creative City}

Was ich zuletzt in Berlin unternommen habe, ist aber noch ein wenig weiter gespannt, im Sinne von Passagen (vgl. Benjamin, 2015), von transdisziplinären Erweiterungen. Ich bewege mich im Feld der kulturellen Geografien (vgl. Berndt und Pütz, 2007; Scherle, 2016), der emotionalen Geografien (Wood, 2013) und betrachte den städtischen Raum als gelebten Raum. Bei diesen Forschungen verwende ich die Methode des Cultural Mapping, des Mapping Urban Spaces (vgl. Duxbury et al., 2015; Roberts, 2012). Ich verbinde meine pädagogische Konzeptentwicklung mit Metropolenforschung (vgl. Eckardt, 2014). Dabei geht es darum, die Dynamiken der Creative City, auch ihre Historie, denken wir an die West-Berliner Experimentierräume der 8oer Jahren (vgl. Tannert, 2018) auszuloten. Es wird später, in Zusammenhang mit der Beschreibung der transformativen Community-Projekte deutlich werden, warum ich gerade in den West-Berliner 8oer Jahren, soweit sich diese Zeit von heute aus rekonstruieren lässt, einen schöpferischen Humus sehe. Es ging mir darum, die Protagonist_innen, Entrepreneur_innen und Szenen der Creative City (vgl. z. B. Florida, 2002, 2005; Lange, 2006, 2007, 2010), die Co-Working Spaces, Cafés und Orte kreativen Tuns, die Creative Industries (vgl. z. B. Lange et al., 2008), die Musikszenen, die diversen alternativen und subkulturellen Szenen (vgl. Lanz, 2013), die urbanen Räume auch bei Nacht (vgl. z. B. Schwegmann, 2016), in Augenschein zu nehmen. Ich baute hier auf Stadterkundungen auf, die ich schon in früheren Jahren, insbesondere in Köln, in meinen Jahren als nächtlicher studentischer Taxifahrer, über einige Jahre hinweg, unternommen habe und die ich später insbesondere in Paris und New York, teils auch in Chicago fortgesetzt habe.

Man gewinnt schon Einblicke, wenn man mehrere Jahre, insbesondere Samstagnacht, durch das nächtliche Köln fährt. Man kommt mit Menschen über ihr Leben und ihre verborgenen Wünsche ins Gespräch. Man lernt, auf welch komplexe Weise urba- 
ne Infrastrukturen und menschliche Bedürfnisse miteinander verwoben sind. Man lernt etwas über soziale Milieus, über kulturelle Welten. Es ist schon ein Unterschied, ob ich ein gebildetes Ehepaar von der Oper abhole und etwas von der allerneuesten La Traviata-Aufführung zu hören bekomme und die beiden elegant gekleideten Menschen zurück in ihr Haus nach Marienburg fahre, oder ob ich ein paar Ganoven in der Drachenburg am Heumarkt auflade und am nächsten Morgen direkt von der Polizei ausgefragt werde, wann genau ich in dem Unterwelt-Schuppen war, wo ich dann mit den Männern hingefahren bin, wer alles dabei war und was die Männer sonst noch dabei hatten. Allerdings machte ich bei einer meiner Bewerbungen auf Professuren, es war wohl Ende der 9oer Jahre, den unverzeihlichen Fehler, zu erwähnen, in welchen gesellschaftlichen Bereichen ich, durch solche studentischen Nebentätigkeiten, soziokulturelle Erfahrungen gesammelt hatte. Ich dachte, dass es doch gut zum Ausschreibungstext der Professur passen würde, solche Dinge einmal durchblicken zu lassen, dass ich also nicht ein rundum mit Geld versorgter Komplett-Stipendiat gewesen war, der nur Stiftungen, Seminarräume, Schreibaufenthalte in Gründerzeitvillen, Archive und Bibliotheken kannte, sondern der auch in das Leben der Metropolen, die Subkulturen oder die raue Männerwelt in den metallverarbeitenden Fabriken eingetaucht war, der das verruchte Kölner Hotel Timp und die Drachenburg von innen kannte, der den schwarzen Staub einer Flanschenschmiede, im Siegerland, im Gesicht gehabt hatte.

Eine Kollegin, die es gut mit mir meinte, und die von den Interna dieses so genannten Berufungsverfahrens gehört hatte, die also offenbar die externen und internen Gutachten über mich und meine Bewerbung gelesen hatte, oder der man bloß davon erzählt hatte, warnte mich jedenfalls: »Mach das bitte nie wieder! Sonst schaffst $\mathrm{Du}$ es niemals auf eine Professur! « Nun, ich habe es mir gut gemerkt. Es gab noch andere Gründe, warum es für mich schwer war, allein schon die viele schulische Praxiserfahrung! Wie hinderlich! »Der ist doch so praxisverhaftet, der ist einfach ein paar Jahre zuviel in den Schulen gewesen « hatte eine andere Kommission festgestellt, später dann, und mich gleich aussortiert. Man erfährt fast alles, nur zeitversetzt. Es gibt immer Menschen, die Gesprächsbedarf haben und irgendwann ihr Gewissen erleichtern wollen, durch das Teilen solch internen Wissens, das sie anscheinend belastet. Doch nun zurück zu den Feldforschungen in Berlin. »Forschung auf Abwegen« sagte Karlheinz Thimm zu mir, aber im Spaß. Er sympathisiert ja mit sowas und war immer für das Authentische, das Wahrhaftige zu haben. So stand ich etwa vor der rund um die Uhr geöffneten Blue Boy Bar in Schöneberg, wo allerlei junge Männer, Stricher und Taschendiebe um dickere und ältere Daddies herumstreichen, sich von ihnen zum Frühstück, an schönen Tagen auch draußen an den Tischen, und zu sonst allerlei Dingen einladen lassen. Ich ging aber dennoch nicht hinein und beschränkte mich hier aufs Recherieren. Forschung begibt sich also auf Abwege, wenn sie solche Orte, solche Szenen aufsucht und in den Blick nimmt. Aber Karlheinz Thimm, Professor für Sozialpädagogik, früher in der Entwicklung und Koordinierung von Projekten im Bereich Schulverweigerung, in der Qualitätssicherung von Heimerziehung und anderen Kinder- und Jugendhilfemaßnahmen, meinte das ja im Grund aufmunternd und sagte das mit einem Schmunzeln. Er war es ja auch gewesen, der mich über die Jahre, wenn ich wieder einmal in Berlin war, in die Bars und Kneipen ausgeführt hatte und mir die Läden zeigte, die gerade besonders angesagt waren. Dort hatten wir dann bei einigen Drinks gesessen, einige Male auch zusammen mit Mathias Schwabe, einem Kollegen 
von ihm, der auf Heimerziehung spezialisiert war, an der Evangelischen Fachhochschule in Berlin-Zehlendorf, und hatten über den Zustand der Gesellschaft und über die neuesten Entwicklungen in den Bildungs- und Sozialsystemen Deutschlands und die sich hier stellenden Herausforderungen debattiert.

Die Buchungsplattform Airbnb spielte hierbei, zunächst über zwei Jahre hinweg, eine wichtige Rolle, denn hier entstehen nicht nur kommunikative und kulturelle Beziehungen und transformative Erfahrungen für alle Beteiligten, sondern zugleich neue Formen der sozialen und ökonomischen Kreativität. Gemeinsam mit Janet Painter habe ich eine kleine Studie darüber veröffentlicht (vgl. Broecher und Painter, 2021). Man kann die Viertel und kulturellen Szenen immer wieder wechseln, kann tief eintauchen, in die Kieze und Lebensformen, und gewinnt ungeheure Einblicke, auch in die diversen Subkulturen und die schrillsten Szenen, die Berlin zu bieten hat. So buchte ich mich, ohne es zu ahnen, etwa bei einem aus Bayern zugewanderten Studenten des Event Management ein, der darauf spezialisiert war, britische Professoren oder andere Männer, die seine Väter hätten sein können, das Gehorchen zu lehren und sie in allen, wirklich allen Dingen gefügig zu machen. Dazu trug er schwarzes Leder, das imposant an seiner Garderobe hing. Ein sehr erkenntnisreicher Aufenthalt war das, in Schöneberg. Ich schlief in einem riesigen, schweren Metallbett, das auf allen vier Seiten allerlei Ösen zum Festschnüren hatte, wirklich sehr stabile Metallringe, umringt von einigen metallenen Schränken, wie man sie in Fabriken findet, und vor denen sich sonst Arbeiter den Ruß und den Staub von den Armen wuschen. Ich lernte dazu. Allerdings verblieb ich konsequent auf der Gesprächsebene, etwa über die emotionalen Qualitäten von uniformähnlichen Mützen, Ledermänteln, Lederstiefeln, über den Reiz der Dominanz und den Reiz der Unterwerfung. Während der bayrische Student heiter plauderte, er hatte ein sonniges, Leichtigkeit ausstrahlendes, Gemüt, fragte ich mich, wie es dann wohl sei, wenn er den Schalter plötzlich umlegte und der strenge Meister war. Ich zog auch eine Querverbindung zu der Schulleitern der Förderschule Schwarzegg ${ }^{1}$, die ja, nach den Berichten von Insider_innen, auch viel in schwarzem, engem Leder herumlief. Sie trat auf wie eine Domina, auf hackigen Schuhen, die wie gefährliche Sporen eines aggressiven Reiters aussahen. Sie ritt ja auch.

Über den rotplüschigen, gezackten Stuhl, der ihrem Rektorinnenthron gegenüberstand, hing ein ein Paar Handschellen. Auf dem Tisch kräuselte sich roter, transparenter Tüll. Auf ihrem Schreibtisch stand ein in Pelz gerahmter Computerbildschirm. Es stellte sich also die Frage nach den emotionalen Qualitäten der Materialien Pelz, Leder und Tüll. Fetischismus dachte ich, das wird die Verbindung sein, aber auch das Spiel mit Dominanz und Unterwerfung. Doch es gab einen großen Unterschied zwischen beiden Welten. Der bayrische Student betrieb das als Spiel, zumindest stellte er einen gut gelaunten, netten Rahmen bereit, und ich hatte ja die Wahl, ob ich auf die dezent ausgestreuten Einladungen einging oder nicht, wenngleich ich ja in der Tat keine Vorstellung davon hatte, wie es dann, nach Umlegen des Schalters tatsächlich weitergehen würde. Die Schulleiterin in Schwarzegg hingegen betrieb das ernsthaft. Spiel und Realität waren eins. Sie war die einzige, der das Lust bereitete und natürlich ihrer engsten Entourage. Die anderen bissen ins Gras. Man muss also Feldstudien in der Schöneberger Fuggerstraße, an der Grenze des Transdisziplinären, unternehmen, um besser $\mathrm{zu}$ verstehen, was in der Förderschule Schwarzegg das Besondere war. So eröffnen

1 Es handelt sich um einen fiktiven Namen. 
sich die tieferen Bedeutungsebenen, vielleicht auch die Sinngehalte von vielen Machtspielen in der Academia, wo immer auch solche Abgründigkeiten zum Tragen kommen. Universitäre Berufungsverfahren könnten nicht nur wissenschaftlich begleitet, sondern auch von Filmteams minutiös dokumentiert werden, einschließlich all der Strippenzieherei aus dem Hintergrund und von entfernten Orten, was natürlich mehr oder weniger unmöglich erscheint. Da käme jedenfalls Material für einige Staffeln und Episoden zusammen, die es durchaus mit Game of Thrones aufnehmen könnten.

Doch zurück zur Creative City. Auch die Schattenseiten von sozialen und kulturellen Innovationen, wie sie durch Airbnb repräsentiert werden, gilt es in den Blick zu nehmen. In Creative Labs und Urban Living Labs (vgl. Marvin et al., 2018) geht es nun einerseits um das Experimentieren mit gesellschaftlichen Zukünften, das Entwickeln von neuen Formen des Wohnens, des Transports, der Energieversorgung, des Herstellens von Nachhaltigkeit. Doch auch die Risiken und Widersprüche der Creative City (vgl. z. B. Pratt, 2010, 2011; Ratiu, 2013; Vivant, 2013), speziell im Kontext der Gentrifizierung (vgl. z. B. Florida, 2017), müssen diskutiert werden. Ich nehme also zum einen die Transformation von kreativen Distrikten, die Ansätze inklusiver und nachhaltiger Stadtentwicklung in den Blick, zugleich geht es mir um die Erforschung der, die urbanen Räume umspannenden und überwölbenden, digitalen Welt. Auch das Universum der technischen Bilder, wie es Vilem Flusser genannt hat, verlangt nach Aufmerksamkeit seitens der Bildungswissenschaften. Dazu gehört im weitesten Sinne ebenfalls die Auseinandersetzung mit Filmen, als bedeutsamen kulturellen Produktionen, wobei ich die Filmanalyse als Kulturanalyse (vgl. Wende und Koch, 2010) verstehe. Zum anderen werden wir auch die intimen Räume der virtuellen Welt erkunden müssen und das ist die Welt, die Flusser auch meinte, soweit dies eben möglich und vertretbar ist. Erst hierdurch werden wir in die Lage versetzt, zumindest annähernd zu verstehen, was sich derzeit in der Gesellschaft abspielt. Dabei wende ich Narrative Inquiry (vgl. z. B. Chase, 2011) und intensives Zuhören bzw. Listening (vgl. Bennett et al., 2015) an. Somit kommt der Hermeneutik bzw. dem Verstehen ein zentraler Stellenwert bei den eigenen Forschungen zu, aber auch der Kommunikation und der Imagination. Während dieser Prozesse sind, über die Jahrzehnte hinweg, Forschungstagebücher, teils traditionell in schriftlicher Form, teils in Bildern und Filmfragmenten, entstanden. Diese Aufzeichnungen beinhalten eigene Standortbestimmungen, Entschlüsselungen von Sinn, das Hinterfragen eigener bisheriger Sichtweisen und das Entwerfen von neuen Perspektiven. Eine repräsentative Auswahl von Photografien, die mit der in jüngster Zeit in Berlin unternommenen Metropolenforschung in Verbindung stehen, habe ich in dieses Buch eingearbeitet.

Angetrieben hat mich dabei die tiefe Überzeugung, dass mein Unbehagen an der Schulpädagogik wie auch an der Sonderpädagogik der emotionalen und sozialen Entwicklung tiefere Ursachen hat, Ursachen, die außerhalb von mir liegen und die viel mit dem Thema der geistigen Enge und Beschränkung zu tun haben. Dies gilt zum einen für viele der Schulen, auch wenn es hier immer Ausnahmen und Lichtblicke, und sei es nur im Gespräch mit einzelnen Kolleg_innen oder anderen beteiligten Personen gab, etwa mit meiner Kollegin Eva Wiegold, die eine wahre Philosophin war und die dann in ihren wohlverdienten Ruhestand nach Spanien ging und jetzt schon nicht mehr lebt, oder mit der wunderbaren Schulrätin Magna Becker in Köln, die mit ihrer geistigen Weite dem ganzen abgründigen Geschehen an der Schule, an der ich arbeitete, den Schrecken nahm. Zum anderen wurde diese geistige Enge ganz besonders in den uni- 
versitären Kontexten und akademischen Diskursen und Spielen erfahrbar. Natürlich gab es auch hier immer wieder Ausnahmen und Lichtblicke, einzelne Personen, die mich inspirierten. Aber zu oft war das genaue Gegenteil der Fall. Osho lehrt uns in seinen Texten alte Konditionierungen abzustreifen. Ich entdeckte seine Texte zuerst in Ischia-Ponte, in einem Buchladen. Die Italiener scheinen Oshos Texte zu lieben, denn sie haben seinen kompletten Nachlass in ihre wunderbare Sprache übersetzen lassen. Osho liest sich auf Italienisch ganz besonders schön. So saß ich in Ponte, wo ich eigentlich ein pädagogisches Buch zuende schreiben wollte, in Oshos Texte über das Überwinden von Konditionierungen vertieft. Nun kannte ich die Sanyassins noch aus der Kölner Studentenzeit. Sie liefen in ihren orangefarbenen Gewändern, teils auch auf dem Campus der Erziehungswissenschaftlichen und Heilpädagogischen Fakultät, herum. Ich fand sie damals ein wenig suspekt. Im Belgischen Viertel in Köln hatten sie eine Art Zentrum, wo Workshops und dergleichen stattfanden. Man hörte von Gruppensex in ihrem Ashram im indischen Puna und in einem Wochenendseminar zum Thema Sexualitätspsychologie, das nach Art der von Carl Rogers begründeten Encountergruppen, auf dem Land stattfand, schlug ein Student eine aktivierende Interaktionsübung aus dem Repertoire der Sanyassins vor, wobei wir uns alle ausziehen sollten. Dann sollten wir die Augen schließen und langsam in die Raummitte gehen und dann einfach sehen, was passiert. Die Mischung aus Verwunderung, Aufregung, teils Entsetzen, aber auch unterschwelliger Lust, je nachdem, je nach Charakter, Naturell, Vorgeschichte, Erfahrungshintergrund der Studierenden, war spürbar in der Gruppe. Es war bewundernswert, wie unser Dozent ruhig und gelassen dasaß und einfach nur abwartete, ohne etwas zu sagen. Er war der Fels in der Brandung und schien durch nichts zu erschüttern.

Jedenfalls wurde lebhaft diskutiert, die von dem Sanyassin vorgeschlagene Übung aber schließlich mehrheitlich, sagen wir: glücklicherweise, als undurchführbar verworfen. Auf die Art brachen aber auch vielerlei Emotionen unter den Studierenden auf. Teils kamen Aggressionen zur Sprache, andere standen plötzlich auf und nahmen irgendeinen anderen in den Arm. Einige weinten und andere verliebten sich gar ineinander. In den frühen 8oer Jahren hatte die Universitätslehre also noch eine ganze andere Dynamik als heute. Niemand interessierte sich für Module, Prüfungsanmeldungen oder Credits. Unseren Namen hatten wir am schwarzen Brett auf eine Liste geschrieben. Den Leistungsnachweis bekamen wir fürs bloße Mitmachen und für das Verfassen eines zweiseitigen selbstreflexiven Erfahrungsberichtes, über den es dann noch ein Gespräch mit Karl-Josef Kluge oder seinem Mitarbeiter Klaus Fitting gab. In Verbindung mit dem Seminaraushang hatte es auch Literaturempfehlungen gegeben. Die Inhalte dieser Literatur flossen in die Seminarsitzungen ein und schlugen sich auch in unseren Texten nieder, aber unter anderem. Die persönlichen Reflexionen standen bei Kluge immer an erster Stelle. Die Perspektive war immer vom studentischen Subjekt aus in Richtung der wissenschaftlichen Literatur, etwa so: „Und, sagte Ihnen das denn was?«, oder: „Gab es in dieser Publikation etwas, was Sie ansprach?«, oder: »Wie ging es Ihnen denn beim Lesen?« Es gab niemals dieses bloße Abprüfen von Wissen. Kluge interessierte sich in erster Linie für das innere Erleben der Studierenden. Damit erzeugte er einen ziemlichen Kontrast zu den anderen Kölner Professor_innen, selbst zu den geisteswissenschaftlich orientierten Kolleg_innen. Den allergrößten Kontrast gab es allerdings zu den, damals allerdings zahlenmäßig eher wenigen, Empirikern in der Heilpädagogik, wie es damals noch hieß, ja Empirikern, 
zu der Zeit waren es Männer. Heilpädagogik, was für ein problematisches Wort, das heben wir uns für ein späteres Kapitel auf.

In einem anderen Seminar, es war in den Erziehungswissenschaften im Teilgebiet Psychologie angesiedelt und es fand in drei Wochenendblöcken in einem Tagungshaus außerhalb von Köln statt, pikanterweise auch noch auf dem Gelände eines Frauenklosters, wurden gerade durch den psychoanalytisch geschulten und im Psychodrama spezialisierten Professor studentische, biografische Konditionierungen zum Thema gemacht. Ein ungeheuer intensives Seminar. Diesmal wurde das Tabu der Nacktheit tatsächlich überwunden, denn an jedem der Seminartage gingen wir, in einer stark verlängerten Mittagspause, in ein, auf dem Gelände befindliches, Schwimmbad und spielten dort Wasserball, nackt. Der das Seminar leitende Professor schaffte es vorher, alle Studierenden darauf vorzubereiten. Wer nicht bereit war sich auszuziehen und mitzumachen, musste, nach seiner Theorie, noch gravierende Blockaden in sich haben, die er/sie nun hier unter seiner fachkundigen Anleitung und Begleitung bearbeiten und überwinden konnte. Dazu war auch nicht jeder aufgelegt. Also hieß es abwägen zwischen Seelenstriptease oder körperlichem Striptease. Es galt auch abzuwägen zwischen der Frage, was man bereit war, für den, hier in Aussicht gestellten, Leistungsnachweis zu tun. An mehreren Tagen nackt Wasserball zu spielen, wobei der Professor immer mitten im Geschehen war, oder ein langatmiges Referat vorbereiten und halten, in irgendeiner anderen Lehrveranstaltung, die man sich freilich dann erst mal neu suchen musste, im nächsten Semester. Nun, diese Seminarreihe galt vielen auch als Geheimtipp, wobei ich keine näheren Vorinformationen hatte. Ich weiß nur, dass ich zumeist recht müde war, weil ich Samstag Nacht in Köln Taxi fuhr, bis Sonntag Morgen um 6.00. Das Seminar begann drei Mal sonntags um 9.00, draußen vor den Toren von Köln, und man musste noch eine Stunde fahren. Ich hatte also gerade Zeit unter die Dusche zu gehen und ordentlich zu frühstücken. Insofern war es mir Recht, nicht den ganzen Tag in einem Seminarraum sitzen zu müssen. Das Herumspringen im Wasser machte mich wach und erfrischte ja regelrecht. Die ans Schwarze Brett gehängte Teilnehmer_innenliste war immer im $\mathrm{Nu}$ voll. So lief das ja damals. Wer sich rechtzeitig draufgeschrieben hatte, war drin. Ich komme später noch einmal auf dieses denkwürdige Seminar zurück und was dort geschah. Vorläufig geht es mir ja um das Thema des Auflösens von Konditionierungen. Dieser Professor gab vor, uns aus alten familiären, sozialisationsbedingten Zwängen befreien zu wollen und errichtete selbst neue Zwänge. Das Ganze war natürlich problematisch, weil mit einem subtilen, teils offenen Druck gearbeitet wurde. Das würde heutzutage vermutlich alles unter dem Vorzeichen des sexuellen Missbrauchs wahrgenommen werden, aber Anfang bis Mitte der 8oer Jahre war das kein Thema. Ganz Köln, zumindest der etwas lebhaftere Teil der Academia, so schien es, war auf Ausleben, Erproben, Erkunden eingestellt. Über meiner Ehrenfelder Altbauwohnung lebte zeitweise die Chansonsängerin Beate Radermacher und probte da auf dem Klavier mit Hubertus Tölle, was sinnliche, inspirierende Atmosphären erzeugte. Später dann lebte dort eine dompteurartig gekleidete Frau, in engem schwarzen Leder. Sie feierten dort oben queere Parties, zu denen auch Berühmtheiten aus der Medien- und Filmwelt erschienen, Events, die manchmal bis in den frühen Morgen gingen. Es war die Atmosphäre, wie wir sie heute noch in Berlin-Neukölln haben. Einmal ging ich morgens um vier nach oben, im Schlafanzug, um zu sehen, ob die Musik ein wenig heruntergedreht werden könnte. Die Tür stand auf und ich stieg über die Geschöpfe der Nacht hinweg, um zur Stereoanlage durchzu- 
kommen. Ein Arm griff nach mir und versuchte mich zu sich herunterzuziehen. Aus dem hinteren Zimmer hörte man leise Stimmen und Geräusche. So muss sich Gereon Rath gefühlt haben, wenn er in die untere Etage des Moka Efti kam. Keiner beachtete mich weiter, einige schliefen schon, andere lagen zu Paaren oder zu dritt zusammengerollt, im Halbdämmer des Kerzenlichts. Da kam doch keiner mit solch kleinbürgerlichen, kleinkarierten Einwänden, was hier das Wasserballspielen anging. Ich war auch recht entspannt in solchen Dingen. Ich war zwar mal katholischer Messdiener gewesen, aber das war nun auch schon einige Jahre her und das Köln der frühen 8oer war eine Welt, in der es so einiges zu entdecken gab. Das Seminar war daher in vielerlei Hinsicht erkenntnisreich.

Nur was ich in diesen Jahren nicht so recht auf dem Schirm hatte war, dass ich doch langsam aber sicher auf ein berufliches Leben, unter recht engen Systembedingungen, zusteuerte. Einige Kommiliton_innen sammelten die vielfältigen Erfahrungen und Impulse des Kölner Studiums ein und sprangen noch rechtzeitig wieder ab, aus der Sonderpädagogik. Ein Studienfreund, der schon früher wieder aufgehört hatte und nach Indonesien gegangen war und dort einen Business in der Touristikbranche aufgezogen hatte, sagte mir vor einer Weile, als wir nach einigen Jahrzehnten wiederum in Kontakt kamen, dass er niemals in solche Systeme habe einsteigen wollen und froh sei, dass er es nicht getan hätte. Die Künstlerin Claire Nagle, in deren Pensionszimmer mein ältester Sohn und ich im Sommer 2004 übernachteten, in Dunquin, an der felsigen Westküste von Irland, dem westlichsten Punkt Europas, in einem zauberhaften Cottage, als wir über den Dingle Way mit dem Rucksack wanderten, sagte zur mir, als ich von den Herausforderungen meiner pädagogischen Arbeit berichtete: »You must feel very confined. "Dieser Satz von Claire hallt noch heute in mir nach. Er hatte etwas Therapeutisches und Befreiendes. Es war der Sommer meiner Zwangsversetzung, was ich Claire, die eine Zeitlang in New York gelebt und dort Theater am Broadway gespielt hatte, allerdings nicht sagte. Ich ließ es bei allgemeinen Beschreibungen. Der Grund, der diese Zwangsversetzung ausgelöst hatte, war, dass ich mich geweigert hatte, beim Trainingsraum-Programm mitzumachen, in dem Raum Aufsicht zu führen und die spezielle Methode, wie sie beim TRP vorgesehen ist, anzuwenden. Das TRP war, nach langen Debatten, an der Förderschule, wo ich tätig war, eingeführt worden. Ich gehörte zu der Minderheit, die dagegen war. Die Kolleg_innen hatten mich bei der Eröffnung als allererstes in den Plan eingetragen. Ausgerechnet ich, der Hauptkritiker des TRP, sollte, so war dieser Schachzug wohl zu verstehen, das Programm eröffnen. Der Kollege, der den Plan gemacht hatte, und der schon aufgeregt im Stechschritt über die Schulflure ging, jetzt da endlich mehr Kontrolle über die aufmüpfigen Schüler_innen in Aussicht stand, schien seinen Spaß an meiner misslichen Lage zu haben und stand mir gegenüber im Lehrerzimmer, als wolle er mir sagen: Nun beweg Dich und Wir haben jetzt hier das Sagen. So muss es sich für die kritischen Intellektuellen bei der Machtergreifung 1933 angefühlt haben. Aber ich ging stattdessen als zweite Kraft in meine eigene Klasse und verbrachte die Stunde dort, der Dinge harrend, die jetzt auf mich zukamen. Der Trainingsraum blieb unbesetzt. Niemand konnte während dieser ersten Stunde seiner Eröffnung Kinder oder Jugendliche dorthin schicken. Für mich hatte das ein Nachspiel, weil der, neu an die Schule gekommene, jüngere, aber sehr dominante, Flügel des Kollegiums Druck auf die Schulleiterin machte. Störung des Schulfriedens hieß es, als mich die Schulrätin anrief und sie kündigte mir die Versetzung in einen anderen Landkreis an. Ich sagte ihr, ich würde mich nur in die nächst gelegene 
Metropole versetzen lassen, sonst würde ich juristisch gegen das Ganze vorgehen. So kam ich immerhin wieder an den Rhein, was auch sein Gutes hatte. Andere mussten dafür zehn Jahre Versetzungsanträge stellen, um das zu erreichen. So fing ich in allem wieder von vorne an, na ja, nicht ganz von vorne. Doch sammelte ich hier ganz neue Erfahrungen und Erkenntnisse. Ich habe über diese Zeit ein Tagebuch verfasst.

\section{Die Themen der fachlichen Diskurse}

Wer sich dem unübersichtlichen und zerklüfteten Gebiet der emotionalen und sozialen Entwicklungsförderung nähert, steht einer weitgefächerten Publikationslandschaft gegenüber, in der eine Fülle von Einzelfragen abgehandelt werden. Eine überzeugende Gesamtdarstellung des Ganzen wird man vergeblich suchen und auch nicht finden. So verliert man/frau sich in vielen Einzelthemen, etwa Angst, aggressives und gewalttätiges Verhalten, sexuelle Auffälligkeiten, der Einfluss der Medien auf die psychosoziale Entwicklung, moralische Erziehung und Charakterbildung oder der Zusammenhang zwischen hoher Begabung, Intelligenz und Kreativität und der Entwicklung einer emotionalen, sozialen Thematik. Karl-Josef Kluge machte das etwa in Köln zu einem seiner Arbeitsschwerpunkte. Es ist aufschlussreich, dass Kluge als Experimentierfeld für die Entwicklung einer anderen Pädagogik eben außerschulische Sommercamps aufspannte, für all die Kinder und Jugendlichen, die mit ihrer hohen Lernmotivation im Schulsystem nicht zurande kamen, die dort schikaniert wurden, die ihr Potenzial nicht leben konnten. Er ging mit seinen Ideen und Forschungen eben nicht in das curricular geprägte Schulsystem hinein, um sich dort womöglich an den gegebenen Strukturen, Vorgaben und Restriktionen abzuarbeiten, wie ich es dann all die Jahre später, wohl oder übel, tun musste. Ähnlich war es ja bei David Weikart in Michigan. Auch die HighScope Foundation versuchte außerhalb des Schulsystems zu Erkenntnissen über andere Formen des Lernens zu kommen, ebenfalls in Sommercamps, die in Michigan in den 6oer und 70er Jahren zunächst ganze acht Wochen dauerten. Erst später, in den 8oer Jahren reduzierten David Weikart, seine Frau Phyllis und Charles Hohman die Länge des International Summer Workshop for Teenagers auf sechs Wochen. Das HighScope Camp wurde, über viele Jahrzehnte hinweg, zu einem weltweit geschätzten pädagogischen Experimentierfeld, über das allerdings viel zu wenig in schriftlicher Form festgehalten worden ist (vgl. dazu Broecher, 2015 b). Es war in erster Linie eine angewandte pädagogische Forschung, wie auch in den, später in Deutschland durch Karl-Josef Kluge begründeten, Kreativen Sommercamps. Auch hier gibt es viel zu wenig Dokumentation.

So wird auch schnell deutlich, wie es einem in diesem Fachgebiet gehen kann. Ich greife ein Thema heraus und sogleich fächert sich ein weiter Horizont an Hintergründen und möglichen Vertiefungen dazu auf. Ich beginne zwar in der Sonderpädagogik der emotionalen und sozialen Entwicklung und lande am Ende bei der nordamerikanischen Gifted Education oder der außerschulischen Experiential Education. Oder ich greife mir das Thema Angst heraus und am Ende lande ich bei kinder- und jugendpsychiatrischen Forschungen aus irgendeinem klinischen Kontext. Andere, in diesem, nahezu endlosen, Fachgebiet aufzufindende Themen sind die Bedeutung biografischen Lernens für Kinder und Jugendliche, die Frage, wie offen oder wie geschlossen der Unterricht im Bereich emotionalen und sozialen Lernens sein sollte, die Frage, ob 
es eine spezielle Didaktik für dieses Feld gibt, oder die Frage, wie sich Eltern und andere Erziehungsberechtigte aktiv in die pädagogischen Bemühungen einbinden lassen. Wieder andere Publikationen befassen sich mit der Frage, wie die Situation der eher wenigen Mädchen und jungen Frauen in diesem Handlungsfeld aussieht und was mit ihnen geschehen kann oder es geht um den Übergang von der Schule ins Berufsleben. Frühere Arbeiten beschäftigten sich mit den Möglichkeiten der Re-Integration von zuvor separierten und spezialisiert beschulten Heranwachsenden in Regelschulen. Andere Forschungsarbeiten befassen sich mit der Frage, welche Möglichkeiten des TeamTeachings oder Co-Teachings unter den Bedingungen der Inklusion bestehen und wie sich ein gemeinsames Verständnis von Sonderpädagog_innen und Regelschullehrkräften entwickeln lässt. Oder es wird der Frage nachgegangen, wie die Kooperation in interdisziplinären Teams, zu denen ja auch außerschulisch tätige Berufsgruppen gehören, in inklusiven Schulen gelingen kann, was die Haltungen und Einstellungen von Lehrkräften im Kontext Inklusion sind, was ihre Erfahrungen sind, wie sich inklusive Lerngruppen schaffen lassen, was fördernde und hemmende Faktoren für die Inklusion sind, wie sich das Thema Inklusion im Feld der emotionalen und sozialen Entwicklungsförderung den oftmals sehr skeptischen oder gar ablehnend eingestellten Eltern vermitteln lässt, wie sich Studierende im Rahmen der Lehramtsbildung an Universitäten auf das Thema vorbereiten lassen und schließlich mit der Frage, wie sich die Ergebnisse der inklusiven Bemühungen evaluieren und messen lassen. In einigen Texten wird zu belegen versucht, dass es auch in Zukunft eine separierte, spezialisierte Beschulung im Feld der emotionalen und sozialen Entwicklungsförderung geben muss (vgl. z. B. Ahrbeck, 2020), weil das, was heutzutage unter dem Namen der schulischen Inklusion betrieben wird, als fragwürdig erscheint, oder es wird nach Möglichkeiten gesucht, Kinder und Jugendliche, die traumatische Erfahrungen, teils im Kontext Flucht und Migration, gemacht haben, im Feld der Pädagogik zu unterstützen.

Ein weiterer Teil der Literatur beschäftigt sich mit Traumatisierung durch sexuellen Missbrauch, speziell auch mit dem Missbrauch an Jungen, teils in reformpädagogischen Schulen, wie der Odenwald-Schule, oder im kirchlichen Raum. Die ohnehin schon breit gefächerte Literatur zeigt nun noch zahllose Übergänge in die Bereiche Kinder- und Jugendhilfe, Heimerziehung, Sozialarbeit, Kinder- und Jugendpsychiatrie oder Gefängnispädagogik. Das Fachgebiet der emotionalen und sozialen Entwicklungsförderung hat sich bei alldem in einer Fülle von Einzelfragen verloren, so scheint es. Es gibt kein übergreifendes Modell. Ein solches kann es vermutlich auch niemals geben. Das gesamte Berufsleben vieler Forscher_innen hat sich in Nischen abgespielt, die sich teils durch eine sehr enge Themenwahl auszeichnen. In der Vergangenheit hat es Kolleg_innen gegeben, die, über nahezu zwei Jahrzehnte hinweg, nur von der lösungsorientierten Beratung, der Bindungstheorie oder der systemischen Beratung gelebt und quasi ihre komplette Tätigkeit in Forschung und Lehre aus solch einem singulären Ansatz abgeleitet haben. Als ich 2000 für ein Jahr die Vertretung einer Professur in einem anderen Bundesland übernahm, war ich dort mehr als überrascht zu sehen, dass all die vielen Studierenden, die zu mir kamen, um sich für mündliche oder schriftliche Prüfungen anzumelden, bei meinem Vorgänger ausschließlich zwei Themen bearbeitet hatten und auch unbedingt genau darin geprüft werden wollten. Das eine Thema lautete Erlebnispädagogik und das andere Thema lautete interessanterweise Magersucht. Ich riet den Studierenden unbedingt, sich noch ein wenig mehr mit Didaktik zu beschäftigen, wollten sie doch alle als Lehrer_innen für Sonderpädagogik 
ins Referendariat des betreffenden Bundeslandes gehen. Ich ließ einen ganzen Stapel meiner Aufsätze zur Lebensweltorientieren Didaktik vervielfältigen und drückte allen Studierenden, die zur mir in die Sprechstunde kamen, es waren ziemlich viele, weil es in diesem Institut zu der Zeit nur zwei Professuren gab, zwei, drei Aufsätze in die Hand und riet dazu, sie zu lesen und sich damit zu beschäftigen. Einige Studierende begrüßten das auch. Ein weiterer Teil zog gleich zum Dekan weiter und beklagte sich, ich würde sie unter Druck setzen, jetzt kurz vor der Prüfung noch etwas anderes zu lesen, und dann auch noch von mir selbst verfasste Texte, das sei eine Zumutung!

Ich wurde dringend vom Dekan des Fachbereichs, der sich sogleich schützend vor die Studierenden stellte, gebeten, auf so etwas zu verzichten. Meine erste studentische Kampagne. In diesem mikropolitischen Scharmützel wurde ich als aggressiver Feeder konstruiert, der die auf Magersucht eingestellten Studierenden übermäßig mit unnötigem Wissen mästen wollte. Ja es ist wahr, wenn ich koche, wird meistens recht viel aufgetischt, aber letztlich ist ja alles ein Angebot. Ich führe ja niemand noch den Löffel mit Essen an den Mund. Also ließ ich diese Gruppe von Studierenden ziehen, mit Spezialwissen zur Magersucht und zur Erlebnispädagogik. Spätestens im Referendariat würden sie schon noch andere Sachen lesen und sich aneignen. Es war nicht länger meine Verantwortung. Andererseits, vielleicht war Magersucht wirklich ein zentrales Thema auf diesem Fachgebiet, aber mehr auf der Ebene, dass es eine Weigerung gibt, Wissen und Ideen in sich aufzunehmen. Mittlerweile lasse ich auch Masterstudierende in ihrer Abschlussarbeit über die philosophische, weltbetrachtende Bedeutung des Angelns schreiben und dränge sie nicht, sich mit den Niederungen der Unterrichtsplanung zu befassen. Wer weiß, ob sie dadurch nicht sogar besser auf die Arbeit in den Schulen vorbereitet sind. Das Problem bei der Vertretungsprofessur war eben, dass mein Vorgänger die Komplexität des Faches und seiner vielen Verzweigungen in einer solchen Weise reduziert hatte und dadurch ja diese missliche Lage überhaupt entstanden war. Komplexität ist eben nicht jedermanns Sache. Natürlich hätte man/frau da unter anderem über Magersucht sprechen können, aber hätte man nicht genauso über das gezielte Ansetzen von Körperfett oder Muskelmasse reden müssen, wir wir später bei den Erkundungen der virtuellen Welten sehen werden? Komplexität ist eben doch eine ziemliche Herausforderung für die Academia. Ich war an einer Universität ins Rennen um eine Professur gegangen und hatte dort sieben Theorielandkarten aufgehängt, im Kongress-Poster-Format. Ich wollte meiner Zuhörer_innenschaft das ständige Scannen immer neuer Powerpoint-Folien ersparen. Insofern griff ich auf das didaktische Mittel der Komplexitätsreduktion zurück. Jedes der Plakate enthielt andere, wissenschaftstheoretische Aspekte, teils grafisch aufgelockert, teils mit Photos bebildert.

Trotz allem waren die Poster vollgepackt mit Wissensbausteinen, auch mit Literaturhinweisen. Insofern war das wiederum eine Komplexitätserhöhung. Ich war ja immerhin an einer Universität, dachte ich, und ich bewarb mich ja auf eine Professur. Theoretische Komplexität müsste da doch für alle Beteiligten eine selbstverständliche Sache sein. Ich hatte der Kommission die sieben Wissenslandkarten auch im Vorfeld per E-Mail geschickt, schöne bunt leuchtende digitale Überblicke, damit die Mitglieder vorher schon mal einen Blick darauf werfen konnten. Ich war um 8.00 Uhr dran. Niemand, außer der Kommission selbst, war so früh dort. Meine Poster hingen schon am Whiteboard als die Kommission hereinkam. Einleitend erläuterte ich, warum ich auf das lineare Zeige von Powerpoint-Folien verzichtet und was ich mir bei dieser Art 
von Präsentation gedacht hatte. Ich würde versuchen, vor dem Hintergrund dieser Theorielandkarten, die großen Zusammenhänge in der Pädagogik der emotionalen und sozialen Entwicklung, in wissenschaftstheoretischer Perspektive, aufzuzeigen und dann auszuführen, wie ich, von dort aus, die Lehre und die Forschung an der betreffenden Universität voranzubringen gedächte. Alle Kommissionsmitglieder hatten, wie gesagt, die Poster in ihrer Mail-Box, das hatte mir der Kommissionsvorsitzende bestätigt. Doch was passierte dann? Zwei Frauen, die zur Kommission gehörten, machten mir, quasi als Warm-Up eine ungeheure Szene, dass sie sich von der durch die Poster erzeugten Komplexität regelrecht »erschlagen« fühlten und dass sie das unzumutbar fänden, dass ich diese dort so aufgehängt hätte, statt das linear, eins nach dem anderen vorzustellen und zu erläutern. Ein wirklich schöner Einstieg, der mir zugleich klar machte, dass ich bei diesem Verfahren nur pro forma eingeladen war und man vermutlich schon wusste, wer berufen werden sollte, jedenfalls nicht ich. Dies kam auch genauso, wie alle Kenner_innen der Szene vorausgesagt hatten. Als Hebel wurde hier also zuviel Komplexität verwendet, um mich zu verunsichern und rauszukicken. Die Challenge war für mich, cool zu bleiben und weiter brav im Verfahren mitzuspielen, so dass ein direktes, authentisches, wahrhaftiges Feedback an diese Personen in der Kommission leider nicht in Frage kam. Dann wäre ich nun auch wahrlich sofort aus dem Verfahren herausgeflogen. So einfach wollte ich es dieser Kommission aber nun doch nicht machen. Kaum jemand hat einmal den größeren gesellschaftlichen Zusammenhang und die tatsächliche Breite der Theoriewelten vor Augen bekommen, tatsächlich erfasst und niedergeschrieben und die großen Überblick versprechenden Handbücher sind oftmals sehr aus Sicht der Psychologie und weniger aus einer pädagogischen Perspektive verfasst und geben somit auch kein objektives oder übergreifendes Bild (z. B. Gasteiger-Klicpera et al., 2008). Bei all der inhaltlichen Vielfalt wird aber auch deutlich, welche hohe Last an psychosozialen Schwierigkeiten in dieser pädagogischen Spezialdisziplin verhandelt wird und wie groß der Druck der Schulen und anderen pädagogischen Einrichtungen mittlerweile geworden ist, mit alldem zurechtkommen zu müssen. So problematisch die separierte Beschulung im Feld des emotionalen und sozialen Lernens auch war und noch ist, so gehen mit ihr doch immerhin erweiterte, freiere pädagogische Handlungsräume einher, die unter den inklusiven, durch rigide Lerncurricula und enge institutionelle Abläufe gekennzeichneten, Bedingungen oftmals kaum gegeben sind. Die politisch forcierte Inklusion, auch dieser Gruppe von Kindern und Jugendlichen, hat vor allem zwei Dinge an den Grund- und Sekundarschulen erhöht: Den Druck und die Ratlosigkeit, wenngleich es natürlich immer auch einzelne Schulen und einzelne Naturtalente unter den Lehrer_innen gibt, die das recht gut hinbekommen.

Aus diesen zuletzt genannten Themen lässt sich schon erkennen, dass sich durch die weltpolitische Kehrtwende in Richtung Inklusion eine ganz neue Situation ergeben hat. Die inklusive Beschulung erscheint jetzt nicht mehr als eine Möglichkeit, sondern ist einfach politisch gesetzte Realität. Die Schulen müssen damit klarkommen. Die pädagogischen Wissenschaften haben die passenden Konzepte in Forschung und Lehre zu liefern und die Landesregierungen erwarten im Gegenzug zu den Drittmitteln, die sie zu diesem Zweck an bestimmte Forschungsteams, vorzugsweise in ihren eigenen Bundesländern, versteht sich, ausschütten, dass der Effekt und die Effizienz des Ganzen unter Beweis gestellt wird. Was für eine Wissenschaft! Was für eine Forschungsförderung ist das? Es ist mehr Auftragsforschung, wo das gewünschte Er- 
gebnis vorher mitgeteilt wird bzw. schon auf den Internetseiten des Auftraggebers nachgelesen werden kann. Ziehen wir an der Stelle wiederum das Modell von Kim und Mauborgne heran, so haben sich diese politischen, administrativen und akademischen Gewässer mittlerweile zu einem roten Ozean eingetrübt. Gereiztheit, Unzufriedenheit, Kritik, aggressive ideologische Debatten. Man weiß oft nicht wo es am schlimmsten ist, in der Politik, in der Wissenschaft oder in der pädagogischen Praxis an den Schulen. Es wird Zeit für einen Kurswechsel, hinein in den blauen Ozean der Ideen, der Neuentwürfe, ganz in dem Sinne, wie es Karl-Josef Kluge und David Weikart mit ihren Sommercamps gemacht haben. Zugleich gehen die Studierendenzahlen im Fach Sonder- und Inklusionspädagogik zurück. Es hat sich offenbar herumgesprochen, dass das kein leichter Weg sein wird. Wir sollten daher jetzt umdenken und neuartige Lernräume aufspannen, neue Strukturen schaffen, neue und andere Erfahrungen ermöglichen. Natürlich können wir heute nicht mehr Sommercamps in der Art der 8oer Jahre aufziehen. Welche heutigen Jugendlichen würden auch in den landschaftlichen Weiten Michigans sechs Wochen freiwillig auf ihr Handy und auf jede Art von Medienkonsum verzichten? Das war aber in den 8oer Jahren so. Es gab auch noch gar keine Handys und kein Internet. Es war eine große geistige Freiheit, zu der wir jedoch vermutlich nicht mehr zurückkehren können. Doch wie lässt sich die, nur in Ansätzen aufgezeigte, Vielfalt an Themen und Problemen, die wir im sog. Förderschwerpunkt der emotionalen und sozialen Entwicklung vorfinden, wie lässt sich all das nun ordnen? Wie könnte eine Systematik aussehen?

Grundsätzlich können wir auf dem Fachgebiet der emotionalen und sozialen Entwicklungsförderung analytisches Wissen bzw. Reflexionswissen, auf der einen Seite, und Handlungswissen, auf der anderen Seite, unterscheiden. Wenngleich auch diese Einteilung am Ende keinen Bestand haben kann, denn eine Analyse vorzunehmen und eine Reflexion zu betreiben sind, für sich betrachtet, bereits Formen von pädagogisch relevantem Handeln. Zumindest wird ein praxisbezogenes Handeln durch Analyse und Reflexion vorbereitet. Auch die Veröffentlichung solcher Analysen und Reflexionen kann überaus handlungsrelevant werden, weil andere, die im pädagogisch praktischen Feld tätig sind, oder die sich an Universitäten oder in Studienseminaren darauf vorbereiten, sich davon leiten oder anregen lassen. Dieses Wissen wird nun generiert durch Soziologie, Psychologie, innerhalb dieser Disziplin, vor allem durch Entwicklungspsychologie, Persönlichkeitspsychologie, klinische Psychologie und Pädagogische Psychologie. Sodann von der Pädagogik, hier vor allem durch die Schulpädagogik, die Sozialpädagogik, teils auch durch die Medienpädagogik, die Sexualpädagogik, die Umweltpädagogik usw. Auch die Medizin ist beteiligt, vor allem die Psychiatrie oder die Hirnforschung, schließlich die Philosophie, speziell die Politische Philosophie und die Sozialphilosophie. Weiterhin greifen wir auf die Sozialökologie, die Sozial- und Humangeografie, die Politikwissenschaft, die Kriminologie, die Metropolenforschung, die Gender- und Queer Studies und die Kulturwissenschaften und das, in diesen Feldern, generierte Wissen zurück. Das analytische Wissen reicht von durchaus sehr unterschiedlichen Annahmen und Theoretisierungen, inklusive der dekonstruierenden Analysen zu Aufmerkamskeits- und Hyperaktivitätsproblematiken, über Annahmen zu entwicklungsförderndem oder abträglichem Bindungsverhalten von Erziehungsberechtigten, bis hin zu Annahmen zu den Wirkungen bestimmter sozioökonomischer Verhältnisse auf das Verhalten oder emotionale Erleben von Kindern und Jugendlichen. Es geht dabei um das Rekonstruieren von biografischen, familiä- 
ren, sozialen, ökonomischen, kulturellen Hintergründen, Lebenswelten, Zusammenhängen, Kontexten bezogen auf das soziale Verhalten und emotionale Erleben und die diesbezüglichen Auseinandersetzungs- und Bewältigungsprozesse von Kindern und Jugendlichen mit Förderbedarf in der emotionalen und sozialen Entwicklung. Analytisches Wissen zielt ferner auf eine breit angelegte Untersuchung der schulischen Lehr- und Lernprozesse, von Schulleben und Schulkultur, der Beziehungen zwischen Schule und umgebender Community, auch des Zusammenhangs zwischen Politik, Kultur und Pädagogik.

Das vorhandene Handlungswissen fokussiert auf die Gestaltung förderlicher pädagogischer Beziehungen, den Aufbau prosozialen Verhaltens, das Entwerfen einer handlungsorientierten Projektpädagogik, das pädagogische Arrangieren von förderlichen neuen sozialen und emotionalen Erfahrungen, das angeleitete Reflektieren über diese Erfahrungen oder das Verarbeiten von psychosozialen Konfliktthemen. Weitere Aspekte des Handlungswissens können sein die Gestaltung von förderlichen Lernumgebungen und hilfreichen pädagogischen Beziehungen in Klassenzimmer, Schulleben, Schulkultur bis hin zu interprofessioneller Kooperation, die förderliche didaktische Gestaltung und besondere Strukturierung der Lernprozesse durch Berücksichtigung der Prinzipien der Handlungsorientierung, der Erfahrungsorientierung, Prozessorientierung, der Lebensweltorientierung, der Variabilität, Flexibilität, Individualisierung und Differenzierung eingeschlossen. Dabei kann das Wechselspiel von Selbstorganisation auf der einen Seite und Impulsgebung und Lenkung durch die Lehrkraft auf der anderen Seite eine wichtige Rolle spielen. Handlungswissen gibt auch Hinweise zum Einbauen von metakommunikativen oder reflexiven Phasen in das Lerngeschehen, das Anbieten von Feedback und Impulsen, von Raum für die Klärung und Bearbeitung von psychosozialen Themen oder konflikthaften Lebensthemen, stets eng verschränkt mit dem Vorantreiben fachlicher, inhaltlicher Fragestellungen und Problemlösungsprozesse, integriert in den Unterricht oder in andere kommunikative Formate. Weitere Aspekte des Handlungswissens sind Trainings sozialer Fähigkeiten, integriert in den Unterricht oder in spezielle Gruppenaktivitäten, sowie schulübergreifende Systeme der Verhaltenssteuerung und des sozialen Lernens, wie sie mit School-wide Positive Behavior Support (PBIS) vorliegen. Sodann gehören zum Handlungswissen Modelle der, auf einzelne Kinder und Jugendliche bezogenen, kollegialen Beratung, Fallberatung und Modelle zur Weiterentwicklung des Schulganzen als eines sich selbst reflektierenden und lernenden Systems. International betrachtet sind Großbritannien und die USA immer die wichtigsten Impulsgeber für die Inklusions- und Sonderpädagogik des Schwerpunkts der emotionalen und sozialen Entwicklung in Deutschland gewesen. In Großbritannien waren es besonders die Bindungstheorie und die daraus abgeleitete Bindungspädagogik, aber auch Modelle zu Community-School Relationships. In den USA reicht das Spektrum von Behavior Management und Social Skills Training über Teaching for Social Justice und Urban Education bis hin zur Experiential Education.

Historisch betrachtet sind die Klassiker der deutschen Pädagogik im Schwerpunkt emotionales, soziales und verhaltensbezogenes Lernen die Bindungspädagogik, die humanistische und psychoanalytische Pädagogik, die Erlebnispädagogik, die handlungs- und lebensweltorientierte Pädagogik sowie Modelle zur engen Kooperation mit der Jugendhilfe. Trotz der politisch vorangetriebenen Schwerpunktsetzung auf Inklusion muss das Fach auch weiterhin spezialisierte, separative schulische Kontexte im 
Blick behalten und, je nach Bundesland, auf die Arbeit dort vorbereiten und zugleich die Separation, wie auch, wenig ausgereifte oder gar inakzeptable, Formen der Inklusion, hinterfragen. Die Entwicklungen in Theorie und Praxis folgten, in den letzten 100 Jahren, bestimmten wissenschaftstheoretischen Paradigmen, im Sinne von handlungsleitenden Modellen, beginnend mit dem medizinischen, störungsorientierten Paradigma, seit dem 19. Jahrhundert, dem tiefenpsychologisch-sozialisationstheoretischen Paradigma, seit den 6oer Jahren, dem sozialwissenschaftlich-interaktionstheoretischen Paradigma, seit den 70er Jahren, dem lerntheoretisch-behavioristischen Paradigma, seit den 6oer Jahren, und dem systemökologisch-lebensweltorientierten Paradigma, seit den $80 e r$ Jahren. Sodann folgten konstruktivistische, systemische, klientenzentrierte, stärken- und resilienzorientierte, postmoderne, heterogenitätsund inklusionstheoretische Strömungen, ferner die Disability Studies, schließlich erweiterte kulturgeografisch-ökologische Ansätze bis hin zu, zumindest im Ansatz, Gender Studies und Queer Studies. Es ist jedoch schwer zu beantworten, wann wir wirklich von einem neuen Paradigma sprechen sollten und wann von einem neuen Modell oder einer neuen theoretischen Strömung. Das Fach ist durch ein enormes Spannungsfeld zwischen historisch-hermeneutisch, qualitativ-philosophisch und gesellschaftskritisch fundierten Forschungen, Theoriebildungen und Handlungsmodellen, auf der einen Seite, und empirisch-quantitativen, evidenzbasierten Forschungen und Interventionssystemen, auf der anderen Seite, gekennzeichnet. Kontroverse fachliche Debatten gab es in den vergangenen Jahrzehnten zum Trainingsraum-Programm (vgl. die Selbstdokumentationen von Balke, 2003; Bründel und Simon, 2013; Claßen und Nießen, 2006), das mit schulinterner Exklusion arbeitet, und zu der den Willen von Jugendlichen brechenden, durchaus rabiate Methoden anwendenden, konfrontativen Pädagogik (vgl. die Selbstdokumentationen von Kilb et al., 2013; Weidner und Kilb, 2010, 2011).

Ebenfalls kontroverse Sichtweisen gibt es derzeit zu Response-to-Intervention (RTI) Modellen (vgl. z. B. die affirmativen Darstellungen von Hawken et al., 2008; Huber und Grosche, 2012; Jimerson et al., 2015), etwa School-wide Positive Behavior Support oder bezogen auf das Rügener Modell (vgl. z. B. die Selbstdokumentationen von Blumenthal und Voß, 2016; Hartke, 2017; Voß et al., 2016). Störungsbegriffe und entsprechende Kategorisierungen werden in kritischen Diskursen, die jedoch interessanterweise zumeist außerhalb der akademischen Sonder- und Inklusionspädagogik stattfinden, in Frage gestellt, ausgehend von einem, an Freiheit orientierten, Menschenbild und Bildungsideal. Wissenschaftliche Theorien werden dabei teils als Herrschaftswissen betrachtet. Vorhandenes Wissen sollte daher nicht affirmativ vermittelt, sondern einer kritischen Analyse unterworfen werden. Als gesichert gilt mittlerweile, dass Schulen, in denen Dominanzkulturen herrschen, die einzelne Jugendliche ausschließen und so in ihrer Handlungsautonomie einengen und möglicherweise gar in ihrer Identität und in ihrem Selbstwertgefühl beschädigen, zu gefährlichen Gegenreaktionen provozieren können. Die Columbine High School, in Littleton, Colorado, hat sich in diesem Zusammenhang, durch die hochdestruktiven Ereignisse in Zusammenhang mit den, dort vorgekommenen, School Shootings, tief ins kollektive Gedächtnis eingebrannt. In der diesbezüglichen Literatur zeigt sich nicht nur die Notwendigkeit der interdisziplinären Analyse, um gewalttätiges Verhalten diesen Ausmaßes als Resultat von situativen Bedingungen sehen zu können. Es wird auch deutlich, dass wir die Bedeutung der kulturellen Kontexte, etwa der Waffenkultur 
in einem individualistischen Land wie den USA, in Betracht ziehen müssen. Auch mediale Darstellungen und Debatten zu den School Shootings, und ihre Rückwirkungen auf das Erleben und Verhalten von Menschen, müssen bedacht werden. Mehr Sicherheit an Schulen scheint es indes nicht in erster Linie durch bessere technische Systeme, sondern vor allem durch gute Bindungen zwischen Jugendlichen und ihren pädagogischen Bezugspersonen sowie durch die Bindekräfte einer unterstützenden sozialen Community zu geben. Dieser Wirkungszusammenhang hat weitreichende Konsequenzen für das Entwerfen der neuen transformativen Community-Projekte, in denen in der Zukunft nicht nur gelernt, sondern auch gearbeitet und gelebt werden könnte.

\section{Unter der Oberfläche des Verhaltens}

Ja es gibt sie, Jungen, die im Schwimmunterricht plötzlich neben mir stehen und fragen, ob aus meiner Brust auch Milch käme, wenn sie daran trinken wollten, oder Jungen, die im Stuhlkreis immer nah bei mir sitzen wollen, sich dann nah an mich schmiegen und in mein Flanellhemd verbeißen und irgendwann versuchen, mein Hemd aus der Hose zu ziehen, um mit der Hand oder dem Mund darunter zu gelangen, oder männliche Jugendliche die, wenn ich meinen klientenzentrierten Kommunikationsstil hervorkehre, mich anraunen: »Schwulen Sie mich nicht so an!« Zu einem anderen Zeitpunkt kommt derselbe Jugendliche mit einem, prall mit Wasser gefüllten und zugeknoteten, Kondom zu mir, während ich Eintragungen am Lehrerpult mache und streicht mir damit, während ich schreibe, sanft über meinen Nacken und meine Wangen. Würden wir uns nun allein auf die Oberfläche des Verhaltens konzentrieren, bräuchten wir uns keine Gedanken über all das zu machen, was sich darunter befindet, nur dass wir als Pädagog_innen dann nicht weit kommen würden, weder im Verstehen und Begreifen, noch im Handeln und Verändern. Im Wettstreit der großen psychologischen Schulen, das heißt der Psychoanalyse, des Behaviorismus und der Humanistischen Psychologie, war speziell die Psychoanalyse nicht nur impulsgebend in der Psychotherapie mit Erwachsenen, der Kindertherapie oder im Bereich der Kultur, sondern auch in der Pädagogik. Die Psychoanalytische Pädagogik entwickelte sich unter anderem auch in der Sonderpädagogik der emotionalen und sozialen Entwicklung, in der schulischen wie der außerschulischen pädagogischen Arbeit, in der Heimerziehung und Fürsorgeerziehung. Psychoanalytische Theorien und Modelle zeigten die Besonderheiten der kindlichen und jugendlichen Identitätsentwicklung auf oder lieferten Erklärungen, wie Rechtsradikalismus und Fremdenfeindlichkeit bei Jugendlichen entstehen können. Trotz allem spielt die Psychoanalyse in der Gegenwart der akademischen Inklusions- und Sonderpädagogik nur noch eine eher untergeordnete Rolle, ähnlich der Humanistischen Psychologie, während zugleich behavioristische, verhaltensorientierte Theorien und Modelle, sowie die daraus abgeleiteten evidenzbasierten Interventionssysteme, immer stärker beherrschend sind. Diese Situation könnte damit zusammenhängen, dass psychoanalytische Theorien auf qualitativen Grundlagen, vor allem auf Fallstudien, beruhen und insofern ein anderes Wissenschaftsverständnis erfordern, als es etwa in evidenzbasierten, verhaltensorientierten Forschungen zum Ausdruck kommt, wo es um mathematisch genaue Operationalisierungen und statistische Berechnungen geht. Diese Situation könnte aber auch mit der generellen 
Vereinnahmung der Erziehungs- und Bildungswissenschaften durch eine, bisher so nie dagewesene, apparative Systemsteuerung zusammenhängen, bei der nur noch das Operationalisierbare, Messbare, Sichtbare, Quantifizierbare und Vergleichbare zählt. Auf dem Gebiet der Psychoanalyse geht es dagegen eher um Tiefenhermeneutik und Interpretation, um Subjektivität und Körperlichkeit, um das Ungesagte, Verschwiegene, Angedeutete oder Ambivalente. Wie sollten auch Traumbilder, um deren Entschlüsselung es Sigmund Freud unter anderem ging, mit quantitativen Mitteln erforscht werden?

Doch die verhaltensorientierten Ansätze haben eben auch ihre Grenzen. Wir lesen dazu bei Wolfgang Jantzen (2012 c, S. 9), dass die »Konzepte der Verhaltenstherapie und Verhaltensanalyse, die zweifelsohne gegenüber traditionellen psychiatrischen und psychometrischen Konzepten den Vorteil hatten, Menschen als lern- und entwicklungsfähig zu betrachten, auf der anderen Seite deren Subjektlogik als solche nur setzen, jedoch nicht verstehen können.«Um also eine Vorstellung von dieser Subjektlogik zu bekommen, könnte es also durchaus von Bedeutung sein, sich im Schwerpunkt der emotionalen und sozialen Entwicklung mit psychoanalytischen Theorien und Konzepten zu beschäftigen, selbst wenn diese Tiefenschichten des Menschen so schwer greifbar, messbar und quantifizierbar sind. Einmal vorausgesetzt, wir akzeptieren die theoretischen Grundlagen der Psychoanalyse, so lernen wir zu unterscheiden, dass es ein bewusstes und ein unbewusstes psychisches oder seelisches Leben im Menschen gibt. Der größere Teil unseres Seelenlebens dürfte sich im Bereich des Unbewussten abspielen, dem Reich der verborgenen Wünsche. Oftmals handelt es sich um verdrängte Bewusstseinsinhalte, die sich dann und wann im Traum, in der Kunst, im Spiel, teils auch in der Körpersprache, auch in Krankheitssymptomen, oder in zufälligen Gesten und Versprechern, die uns unreflektiert über die Lippen gehen, äußern können. Als dritte, zwischen dem Unbewussten und dem Bewussten liegende Kategorie existiert das Vorbewusste. Hiermit werden Bewusstseinsinhalte bezeichnet, die generell ins Bewusstsein gebracht werden können, etwa durch gezielte Erinnerung, schöpferisches Arbeiten oder in der Psychotherapie. Unbewusste und vorbewusste Inhalte können sich miteinander mischen. Wir können dies sehr schön an James Delaney, in der britischen Serie Taboo, beobachten, wie er durch Kindheitserinnerungen eingeholt wird, wie sein Bewusstsein von, teils sehr starken, Bildern regelrecht geflutet wird, ohne dass er den gesamten Zusammenhang schon kennen und verstehen würde.

Das psychoanalytische Persönlichkeitsmodell gehört heutzutage zum Allgemeinwissen. Danach befindet sich im Zentrum der Person das Ich, das die eigenen Wünsche, Bedürfnisse, Triebe (Es), die verinnerlichten Normen, Verhaltensregeln und ethischen Gebote (Über-Ich) und die Anforderungen der Umwelt miteinander in Einklang bringen muss. Diese Aufgabe gelingt dem Ich, je nach Entwicklungsstand und Reifegrad eines Menschen, unterschiedlich gut. Problematisch ist zum einen, wenn das Über-Ich zu schwach ausgebildet ist, das heißt es gibt zu wenig oder gar keine verhaltensregulierenden Internalisierungen. Psychoanalytisch orientierte Autor_innen sprechen in diesem Fall von Dissozialität. Ebenfalls problematisch kann sein, wenn das Über-Ich zu stark ausgebildet ist und das Ich durch zu strikte Gebote und Regeln quasi ständig unter Druck gesetzt wird. Hier wird dann von Neurose gesprochen. Das Ich muss also die Balance halten und bildet dazu eine Reihe von Ich-Funktionen aus, die mal mehr und mal weniger geeignet sind, diese Balance auch tatsächlich herzu- 
stellen. Diese Ich-Funktionen können mehr auf aktive Bewältigung oder auf Abwehr, im ungünstigsten Fall auf Fragmentierung, wie bei der Psychose, die durch Realitätsverluste gekennzeichnet ist, hin angelegt sein. Es zeigen sich hier Übergänge zur Coping- oder Bewältigungsforschung, wo es um Daseinstechniken oder Bewältigungsstrategien geht, auch zu Modellen der Emotionsregulierung, bei der die betreffende Person bestimmte Strategien anwendet, die sich im Rahmen der pädagogischen Arbeit verbessern und weiterentwickeln lassen. Teils müssen geeignete, das heißt effektive und sozial verträgliche Daseinstechniken oder Bewältigungsstrategien aber erst einmal vermittelt und aufgebaut werden.

Ein für die Inklusions- und Sonderpädagogik sehr wesentliches psychoanalytisches Konzept ist die Übertragung, wonach Kinder und Jugendliche emotionale Muster, Verhaltensmuster, bindungsgestaltende oder bindungserschwerende Muster, in die Interaktion mit ihren männlichen oder weiblichen pädagogischen Bezugspersonen einbringen, die eigentlich von ihren familiären Bezugspersonen her stammen und dort, eben in den frühesten Beziehungen mit den Eltern, ausgeprägt wurden. Es gehört zur pädagogischen Professionalität im Bereich der emotionalen und sozialen Entwicklung, diesen Hintergrund zu kennen und sich folglich nicht persönlich durch das Verhalten eines Kindes oder Jugendlichen provoziert oder angegriffen zu fühlen. Von Bedeutung ist auch das Konzept der Gegenübertragung, wobei wir als Pädagog_innen auf das Verhalten eines Kindes oder Jugendlichen mit eigenen Emotionen, Erwartungen, Vorannahmen oder Wünschen reagieren. Auch dieses Phänomen gilt es sorgsam in den Blick zu nehmen, weil sonst eigene unverarbeitete biografische Erfahrungen, verinnerlichte und automatisierte Skripte und sich hieraus entwickelnde seelische Strukturbildungen das eigene pädagogische Verhalten leiten. Dies kann sehr problematische Formen annehmen, wenn die betreffenden Themen, Muster und Skripte nicht erkannt werden. So etwas kann sogar in einer universitären Berufungskommission eine Rolle spielen, wenn ein junger Bewerber einen älteren Professor emotional um den Finger wickelt und dieser ihn dann auf den ersten Platz der Berufungsliste zu bringen versucht, obwohl der junge Mann bis dahin das exakte Gegenteil von dem veröffentlicht hat, wofür der ältere Professor wissenschaftlich steht. Doch der junge Mann hat in ihm vielleicht irgendeine verborgene, emotionale Tiefenschicht berührt, so dass sich der ältere Mann in dem jüngeren Mann wiedererkannt oder gespiegelt hat. Vielleicht hat er sich, als der Jüngere seinen Bewerbungsvortrag hielt, an die Zeit erinnert, als er selbst in jenem Alter war und versuchte im Wissenschaftsbetrieb weiterzukommen. Er achtete also kaum noch auf den Inhalt und die wissenschaftliche Einrahmung des Gesagten. Auf diese Weise wird vielleicht verständlich, wie es kommen kann, dass der Ältere nun plötzlich eine ganz andere Sichtweise auf die Arbeiten des Jüngeren einnimmt, zur Verwirrung einiger anderer und zur freudigen Überraschung noch anderer, die jetzt mit ihren Argumentationen und mikropolitischen Strategien wieder Oberwasser gewinnen, weil sich da jemand, der in der Kommissionsarbeit eine zentrale Rolle spielt, unverhofft, um 180 Grad gedreht hat.

Die von Sigmund Freud begründete Psychoanalyse erfuhr schon früh Weiterentwicklungen und Verzweigungen. Sein Schüler Alfred Adler, der Begründer der Individualpsychologie, betonte etwa den Zweck von Verhalten, während Freuds Forschungen eher auf die Ursache des Verhaltens ausgerichtet waren. Adler fragte also danach, was ein Kind mit seinem Verhalten erreichen möchte. Rudolf Dreikurs hat Alfred Adlers Ideen für die Pädagogik fruchtbar gemacht. Ein weiteres, von Adler entwickeltes, 
Konzept bezieht sich auf die Position, die ein Kind in der Geschwisterreihe einnimmt. Hieraus können sich lebenslang wirksame Verhaltensmuster ergeben, mit Jungen oder Mädchen, und später mit Männern oder Frauen, zu rivalisieren, etwa in einem Team aus Lehrer_innen oder Hochschuldozent_innen, Muster, die im besten Fall irgendwann erkannt und in der Vergangenheit zurückgelassen werden. Ein weiteres, durch Alfred Adler geprägtes, individualpsychologisches Konzept ist der Minderwertigkeitskomplex, der sich auf irgendeinen Mangel bezieht, den ein Mensch subjektiv empfindet und der zu einem lebenslangen, oftmals übersteigerten Kompensationsstreben führen kann. Ein überhöhtes Geltungsstreben oder gar der Wille zur Macht stellen für Alfred Adler eine seelische Überkompensation eines verstärkt erlebten Minderwertigkeitskomplexes dar. Schulen, Ministerien, Universitäten, wenn wir einmal die Bildungs-, Erziehungs- und Sozialwissenschaften in den Blick nehmen, stellen exzellente Bühnen und Handlungsarenen für das Inszenieren und Ausagieren solcher Skripte dar. So kann es sein, dass eine Professorin Privatdozent_innen, die sich noch unter der Supervision ihres Vorgängers qualifiziert haben, und die ihre Titellehre in der betreffenden Abteilung erbringen, vom übernommenen Lehrstuhl abzudrängen versucht, selbst wenn es dann weniger theoretische Vielfalt in der Abteilung gibt. Wie so etwas dann praktisch aussieht? Es waren die späten 9oer Jahre und es war ja noch vor der Zeit des Internets. Die Privatdozent_innen reichten jedes Semester einen, recht frei gewählten, Lehrveranstaltungstitel ein. Es gab ja noch keine Modulpläne und nicht diese engen Vorgaben. Nun kamen aber interessanterweise die mehrfach gesandten Briefe niemals im Sekretariat des Lehrstuhls an. Wenn man dann versuchte dort anzurufen, um das zu klären, hob niemand ab, und kam man endlich durch und schlug man vor, den Titel noch einmal per Fax zu senden, war da auch nichts durchgekommen usw. Die betreffende Professorin hatte ja selbst früher in der Abteilung, quasi als untergeordnete Professorin, gearbeitet und besonders mit einer speziellen Privatdozentin rivalisiert. Jetzt mussten einfach alle raus. Es sollte nur noch sie geben. Der Privatdozent suchte sich ein anderes Institut, sogar in einer anderen Fakultät, ging also ganz raus aus diesem Red Ocean. Hier wurden seine Seminarangebote auch sehr geschätzt. Die Privatdozentin warf das ganz hin und konzentrierte sich fortan auf ihre psychotherapeutische Praxis. Später dann, als das von der Professorin vertretene Spezialfach die Wertschätzung bei der Mehrheit der betreffenden Fakultät verloren hatte und man/frau ihre Professur nicht mehr neu besetzen, sondern vielmehr streichen wollte, wurde sie plötzlich aktiv, besann sich des genannten Privatdozenten und versuchte, auf die Schnelle, das Publikationsvolumen ihrer Abteilung aufzurüsten, indem sie ihn nach seinen veröffentlichten Forschungsarbeiten der vergangenen Jahre fragte und diese in ihr Plädoyer für den Erhalt des Lehrstuhls einbaute. So versuchte sie deutlich zu machen, von welcher Bedeutung das themenübergreifende Fach für die Fakultät sei. Sie wollte es in seiner thematischen Breite präsentieren. Das Problem war, dass sie selbst in den Jahren, die sie dann auf der Professur verbracht hatte, kaum etwas veröffentlicht hatte. Ob sie es jemals bereut hat, dass sie die beiden Privatdozent_innen Jahre zuvor regelrecht vergrault hatte? Über viele Jahre hinweg hätte die betreffende Abteilung natürlich in viel größerer inhaltlicher Breite laufen können, als sie es dann tat. Ich glaube dennoch nicht, dass es den Lehrstuhl erhalten hätte, denn der Zeitgeist hatte sich geändert. Trotz allem leben die betreffenden Theorien und Modelle nun an einem anderen Ort weiter, wenn auch in bescheidenerem Format, d. h. auf der Ebene einzelner Module. Hier verketteten sich also zwei nachteilige Dinge: Zum einen 
die Verschiebung wissenschaftstheoretischer Sichtweisen und die Herausbildung anderer Mehrheitsverhältnisse, zum anderen persönliche Schwächen, die aus einem übertriebenen Geltungsstreben, übersteigerten Narzissmus und einem sehr unklugen Umgang mit Positionsmacht resultierten. Was für eine Verschwendung von Energie und Lebenszeit, wenn Menschen dann gezwungen sind, mit solchen Situationen und Verhaltensweisen umzugehen! Wie nachhaltig ist das alles?

Manchmal denke ich, es könnte zu einer substantiellen Verbesserung beitragen, wenn in der Wissenschaftswelt ganz auf akademische Titel verzichtet würde, denn dann würden all diejenigen Personen, die sich mehr aus narzisstischen Gründen von der Academia angezogen werden, vielleicht gar keine Ambitionen mehr haben, dort hineinzugehen. Es würden in erster Linie dort Menschen sein, die Interesse an der Vertiefung in Sachthemen haben und weniger Menschen, die an so sekundären Dingen, etwa als Professor_in XY irgendwo aufzutreten, orientiert sind und daraus eine Selbstbestätigung ziehen. Aufschlussreich ist auch das durch Adler geprägte Konzept der privaten Logik, das heißt der Mensch konstruiert sich seine eigene Realität und konzeptualisiert von hier aus seine Handlungsstrategien und Erlebnisweisen. Auch dieses Phänomen lässt sich auf allen Ebenen des Bildungssystems, wie auch in der Politik, in der weiteren Gesellschaft und in den Medien, tagtäglich beobachten. Carl Gustav Jung, ein anderer Freud-Schüler, begründete die Theorie des kollektiven Unbewussten. Jung untersucht kulturelle und symbolische Ausdrucksformen in weitgespannter Perspektive und macht in ihnen tiefliegende Themenkomplexe, das heißt Archetypen aus, etwa Anima und Animus, die männlichen und weiblichen Anteile des Menschen, die teils im Widerstreit miteinander liegen, oder den Schatten, zur Bezeichnung all dessen, was verdrängt, verborgen, abgespalten ist, weil es unserem positiven Selbstbild nicht entspricht oder weil wir es nicht in unser Alltagsbewusstsein integrieren können. In George R. R. Martins Buchserie A Song of Ice and Fire und der darauf basierenden Filmserie Game of Thrones sind diese Dinge eventuell durch die Wildnis jenseits der Mauer aus Eis symbolisiert worden. Indem die Filmhelden, denken wir etwa an Jon Snow, sich diesen Gefahren stellen und diese besiegen, entwickeln sie sich weiter. Sie befreien sich von alten Ängsten und erobern Neuland. Wichtige Weiterentwicklungen der Psychoanalyse sind ferner De Masis (2018) Forschungen zu Sadismus und Masochismus, auf deren Grundlage wir manche Phänomene, die uns speziell in Zusammenhang mit vulnerablen jungen oder älteren Männern in virtuellen Welten begegnen, besser verstehen können. Von Bedeutung sind auch die, von Anna Freud entwickelte, Kinder-Spieltherapie, auch psychoanalytische Anwendungen in den künstlerischen Therapien und Creative Arts. Schließlich wären Erweiterungen ins Systemische, auch ins Familientherapeutische, zu nennen. Wichtig erscheinen auch die Übergänge in die Gesellschaftskritik, speziell wenn es um die Untersuchung von autoritären Persönlichkeiten geht, insbesondere bei Adorno (2019).

Seitens der Gender- und Queer-Studies gibt es noch einige notwendige Auseinandersetzungen und nicht abgeschlossene Klärungen bezüglich der Psychoanalyse, denn zum Thema des Weiblichen und zum Thema der Homosexualität lesen wir in den psychoanalytischen Texten durchaus viel Problematisches. Überhaupt dürften die Zeiten vorbei sein, wo die Psychoanalyse eine Art religiösen Kultstatus hatte, der nicht hinterfragt oder angezweifelt werden durfte. Vorbei sind Dogmatismus, patriarchalisches Denken oder die theoretisch-männliche Hegemonialität bestimmter Glaubenssätze. Trotz allem liefern die vorhandenen Theorien und Modelle zur Psy- 
choanalyse und zur Psychoanalytischen Pädagogik eine Fülle von thematischen Anknüpfungspunkten für eine Pädagogik und Didaktik zur Förderung der emotionalen und sozialen Entwicklung, die auch unter die Oberfläche des Verhaltens blickt. Auf diese Weise lassen sich Themen wie Identität, Autonomie und Symbiose, oder Macht und Unterwerfung, zum Gegenstand einer pädagogischen Reflexion machen. Eine solche Reflexion dürfte auch Übergänge ins Therapeutische aufweisen, wenngleich wir ab einem bestimmten Punkt an hauptamtliche Psychotherapeut_innen abgeben und delegieren werden, um unsere eigene Rollenklarheit als Lehrer_innen an Schulen oder als Pädagog_innen in Projekten der verschiedensten Art nicht aufzuweichen und aufrecht zu erhalten. Lehrkräfte machen auch keine Trauma-Therapie in der Schule. Die von Zimmermann (2016) progagierte Traumapädagogik erscheint daher fragwürdig, zumindest für den Kontext der Schule. Von der Psychoanalyse her lässt sich auch begründen, warum Väter und Männer wieder eine aktivere Rolle beim Aufwachsen speziell von Jungen, die wir ja im Feld der emotionalen und sozialen Entwicklungsförderung in erster Linie antreffen, haben sollten. Väter und Männer sind für die Identifikationsprozesse, die Jungen durchlaufen, von hoher Bedeutung (vgl. z. B. Trowell und Etchegoyen, 2002). In der gegenwärtigen Gesellschaftspolitik wird dies nicht unbedingt angemessen berücksichtigt. Kapitel 7, in dem es um exemplarische Einblicke in virtuelle Welten geht, wird zeigen, was passieren kann, wenn Väter, insbesondere für ihre Söhne, nicht in der notwendigen Weise präsent und verfügbar sind. Doch diese Männer bzw. Väter müssen auch tatsächlich geeignete Rollenvorbilder sein. Aus, wenn auch etwas in die Jahre gekommenen, Studien ist etwa bekannt, dass Jungen eine weibliche Identifikation mit der Mutter vorziehen, wenn sie einen gewalttätigen Vater haben (vgl. z. B. Dank, 1971). Die maskuline Rollenidentität eines Jungen hängt auch nicht von der vermeintlichen Maskulinität des Vaters ab, sondern von der Intensität der Vater-Sohn-Beziehung (vgl. Mussen und Distler, 1959) konkretisiert als Kombination seiner Versorgungshaltung, Dominanz und Teilhabe in der pädagogischen Hinwendung zu seinem Sohn (vgl. Lynn, 1976).

Die transformativen Projekte der Zukunft, um die es mir geht, sehen eine solch aktive Rolle von Vätern und Männern im pädagogischen Umgang vor, zugleich eingebettet in ökonomische und kulturelle Kontexte. Mir geht es um Väter und Männer, die, statt irgendeiner entfremdeten Berufstätigkeit in einer separierten Bürowelt nachzugehen und sich dort die Flügel stutzen zu lassen, in den transformativen Projekten tätig sind und darin ihre Erfüllung finden. Solche Projekte, in denen zugleich Jungen wie Mädchen aufwachsen und in denen sie ein breiteres Spektrum an erwachsenen Bezugspersonen zur Verfügung haben, werden die jüngere Generation in ganz anderer Weise prägen, als dies derzeit bei den institutionalisierten, auf Aufgabenteilung beruhenden, und oftmals vor allem durch Frauen dominierten, Kindheiten und Jugendjahren der Fall ist, in den standardisierten, kompetenzorientierten pädagogischen Einrichtungen. Psychoanalytisches Wissen hilft auch das tiefergehend $\mathrm{zu}$ verstehen, was sich in der Gesellschaft, in der Welt des Internets, in den sozialen Medien und Dating-Apps, im Sinne einer kompensatorischen Gegenwelt zum pädagogischen und gesellschaftlichen Alltag, derzeit abspielt. Psychoanalytisches Wissen hilft ferner zu entschlüsseln, was sich auf der Organisationsebene in Schulen, Universitäten, Verwaltungen, politischen Institutionen usw. vollzieht (vgl. z. B. Lohmer, 2008; Lohmer und Möller, 2019; Sievers et al., 2003), denn auch hier agieren Menschen, diejenigen mit den akademischen Abschlüssen mindestens genauso intensiv wie die 
Heranwachsenden ohne jeglichen Studienabschluss, viele Dinge aus, die sie unbewusst, unerkannt und unreflektiert, quasi als Schatten, mit sich herumtragen. Kein akademischer Titel schützt vor blindem Ausagieren von teils skrupellosem Machtstreben oder Narzissmus (vgl. z. B. Wirth, 2011) vor der autoritären, sadistischen, gefühllosen Unterwerfung anderer Menschen, Mechanismen, wie sie ja von Milgram (2012) und Zimbardo (2017) erforscht worden sind. Solche Problematiken ließen sich etwa an der Förderschule Schwarzegg ausmachen, wo Schüler_innen und ein Teil der Lehrkräfte schikaniert, degradiert oder eliminiert wurden, wie man/frau es dort nannte, wo Schulgesetze umgedeutet, missachtet oder ausgehebelt wurden, wo die Regeln demokratischer Partizipation durch Schüler_innen, Eltern und Lehrkräfte nicht mehr galten, wo Schüler_innen, gemeinsam mit ihren Eltern auf den heißen Stuhl gesetzt und in aggressiver Weise von der Führungsclique dieser Förderschule konfrontiert wurden, wo die despotisch regierende Schulleiterin, eine Clique von Lehrer_innen um sich geschart hatte, die sie mit großzügigen Privilegien, in Form von Arbeitserleichterungen, zusätzlichem Personal in deren Klassen oder finanziellen Befugnissen, ausgestattet hatte und im Gegenzug von dieser Gruppe von Lehrkräften gegen interne und äußere Kritik verteidigt und in ihrer Machtposition gefestigt wurde (vgl. ausführlich dazu Bröcher, 2011, 2016). Es bleibt eine offene Frage, ob die abgründigen Vorgänge an der Förderschule Schwarzegg eher im Charakter der Menschen begründet lagen, wie Adorno meint, oder ob die Destruktivität der Akteur_innen bloß situativ ausgelöst wurde, dass also eigentlich gute Menschen zu bösen Menschen werden, wie Zimbardo meint. Ich bin, nach eingehender Auseinandersetzung mit dem Fall Schwarzegg, ein Anhänger der Charaktertheorie Adornos.

Vermeintliche akademische Bildung schützt also nicht vor einem solch rücksichtslosen Ausleben von Aggressionen. Diese Lehrkräfte hatten ja alle Universitätsabschlüsse. Das Geschehen spielte sich noch deutlich nach dem Jahr 2000 ab, es war also nicht in einem fernen, weit zurückliegenden, Jahrhundert angesiedelt. Das bloße Durchlaufen von Modulen und das Einsammeln von Credits beinhaltet also keinerlei Garantien, dass diese Art von Bildung, wie wir sie seit einigen Jahrzehnten an den Universitäten in Szene setzen, überhaupt dazu beiträgt, dass die Menschen insgesamt besser werden, charakterlich betrachtet. Auch in den Universitäten selbst werden ja endlose Machtspiele und Intrigen in Gang gesetzt (vgl. auch Fehrenbach, 2020), das ist also kein alleiniges Problem der Schulen. Es gibt zahlreiche Insiderberichte, die belegen, dass wir es in der Welt der Academia teils mit einer Neuen Despotie (vgl. Keane, 2020) und oftmals auch mit einer erneuten Errichtung höfischer, feudaler Strukturen zu tun haben. Nicholas Taleb (2018, S. 40 f.) schreibt dazu: »... für diejenigen, die der Meinung sind, an der Universität gehe es ruhiger zu und sie sei eine emotional erholsame Abwechslung nach dem unsteten, riskanten Business-Leben, habe ich eine Überraschung parat ... Akademiker ... vor allem diejenigen in den Gesellschaftswissenschaften ... leben offenbar in einem Zustand ständigen gegenseitigen Misstrauens; sie sind von kleinlichen Zwangsvorstellungen, von Neid bis zu eiskaltem Hass besessen ... Ein vergleichbares Ausmaß an Neid habe ich während meiner Jahre als Geschäftsmann nie erlebt.« Niccolo Machiavelli (2018) hat uns eine Analyse dieser Machttechniken und Strategien hinterlassen. Allerdings beschrieb er, was er um sich herum sah und erlebte und was er für empirisch feststellbar hielt. Es ging ihm nicht darum, diese Techniken zu propagieren. Für ein Machiavelli-Consulting zu werben, wie Bolz (2000) es, in einem von Jens Weidner, dem Begründer der konfrontativen Pädagogik, heraus- 
gegebenen Buch macht, erscheint als unethisch. Da Machiavelli aber nun eben nicht die mikropolitische Boshaftigkeit propagiert, sondern bloß dokumentiert und analysiert hat, erscheint diese gesamte Bezugnahme auf Machiavelli zusätzlich als sachlich und historisch falsch. Es gibt also eine ganze Reihe von Gründen, warum wir gerade in der Lehrer_innenbildung und in den Bildungswissenschaften kontinuierlich die psychoanalytische Literatur und andere, damit verknüpfte, kritische Literaturen lesen und die darin auffindbaren Konzepte und Erkenntnisse in unser professionelles Handeln einfließen lassen sollten.

Zugleich existiert eine Literatur, die dazu ermutigt, unter die Oberfläche des Verhaltens zu blicken, die über die psychoanalytischen Theoriegebäude aber noch weit hinausgeht, in der Gestalt der Philosophie John O'Donohues etwa. In seinen Büchern Anam Cara und Eternal Echoes finden sich zum einen stoisch-platonische Einflüsse, zum anderen spekulativ-imaginative Rückgriffe auf keltische Traditionen. Friedhelm Decher und ich hatten darüber eine ausführliche Debatte, in deren Verlauf es auch um die Frage ging, welche schriftlichen Überlieferungen die Kelten denn tatsächlich hinterlassen hätten? Was O'Donohue hier macht, ist also zu weiten Teilen Spekulation und Imagination und trotz allem ein großer Wurf. Der ehemalige katholische Priester, der, nach einem halben Berufsleben in der Kirche, eben diese Institution verlassen hat und sich in die Einsamkeit der westirischen Landschaft zum Schreiben und zu philosophischer Kontemplation zurückgezogen hat, macht den Iren auf diese Weise, nach der Unterdrückung der keltisch-gälischen Sprache und Kultur durch die kolonialistische Politik der Briten, ein Identifikationsangebot von der Art, wie es mit der keltischen Überlieferung eben hätte gewesen sein können. Was O'Donohue vor allem mit Bravour gelingt, ist die Auffächerung der Welt des Seelischen und die Verknüpfung der menschlichen Existenz mit den großen, ungelösten universalen Fragen. Man/frau findet in diesen Texten wunderbare, suggestive Metaphern und Beschreibungen, etwa dass wir uns dem Seelenleben eines anderen Menschen besser in einer Atmosphäre des Kerzenlichts nähern, wo auch noch schützende Schatten im Raum bestehen bleiben, nicht aber im Neonlicht der wissenschaftlichen Analyse. Schon in meiner Zeit als praktisch tätiger Lehrer habe ich sehr viel aus diesen Büchern, die ich zunächst bei Wanderungen in Südwestirland entdeckte, in einer Pension in Kerry, schöpfen können. Ich lege also einmal diese Bücher von O'Donohue, Anam Cara und Eternal Echoes, neben eine Fachzeitschrift wie Behavioral Disorders oder das Journal of Positive Behavior Support und um den Kontrast noch weiter zu erhöhen und noch mehr Verwirrung anzurichten, ziehe ich nun noch Elsa Morantes Roman Arturos Insel oder Jean Genets Querelle aus dem Bücherregal. Unterschiedlicher könnten die Literaturen und Textsorten gar nicht sein und doch stehen alle drei Textsorten in einer Beziehung zu meiner pädagogischen Arbeit. Spekulative Philosophie, quantitativ-empirische Forschung und belletristische Literatur, in der die Komplexität des menschlichen Lebens, in all ihrem Tiefgang, aufgefächert wird. Wie komplex diese Beziehungen sind, werde ich nun Schritt für Schritt, im Laufe der kommenden Kapitel versuchen darzulegen. 


\section{Theorieentwicklungen, Paradigmen, Spannungsfelder}

In Anlehnung an Thomas Kuhn (2012) über Paradigmen und Paradigmenwechsel in den diversen Wissenschaftsdisziplinen zu sprechen, ist heutzutage sehr verbreitet und gelegentlich wird vielleicht ein wenig schnell ein solcher Paradigmenwechsel ausgerufen (z. B. durch Huber und Grosche, 2012). Der Paradigmenbegriff, wie ihn Kuhn entwirft und verwendet, erscheint teils vieldeutig und schwer greifbar (vgl. Lueken, 2010, S. 166), doch lassen wir diese feinsinnigen Details einmal beiseite. Für den Schwerpunkt des emotionalen und sozialen Lernens hat Georg Theunissen (1992) schon früher eine solche Systematisierung erstellt und dabei Abgrenzungen solcher wissenschaftstheoretischer Strömungen vorgenommen. Nach dem, etwa seit dem 19. Jahrhundert auszumachenden, psychiatrischen oder medizinischen Paradigma liegen die verhaltensbezogene oder emotionale Störung und ihre Ursache allein im Kind oder Jugendlichen. Es wird quasi ein Defekt der menschlichen Persönlichkeit unterstellt. Nach dem tiefenpsychologisch-sozialisationstheoretischen Paradigma, das sich in etwa seit den 6oer Jahren abzeichnet, wenngleich sich solche Erkenntnisse auch schon viel früher angebahnt haben, sind das Verhalten und die damit einhergehenden emotionalen Erlebnisweisen als Resultat von Interaktionserfahrungen in der Familie und zusätzlich als Ergebnis von sozioökonomischen und soziokulturellen Rahmenbedingungen oder Prozessen zu verstehen. Aus Sicht des behavioristisch-lerntheoretischen Paradigmas, das sich ebenfalls seit den 6oer Jahren etabliert hat, wurde problematisches Sozialverhalten gelernt, durch Verstärkung und Modell-Lernen. Das fehlende prosoziale Verhalten wurde dagegen, nach dieser Auffassung, noch nicht gelernt. In diesem Theorienspektrum finden wir zunächst die frühen Formen der Verhaltenstherapie oder Verhaltensmodifikation, wie sie in den 6oer und 70er Jahren entwickelt wurden, bis hin zu komplexeren Systemen wie School-wide Positive Behavior Support (PBIS), die etwa seit den späten 9oer Jahren in den USA an Bedeutung gewonnen haben und in der Gegenwart immer dominanter hervortreten, in Nordamerika, wie auch in den eher nördlichen europäischen Ländern, insbesondere in Norwegen, Island, Dänemark oder in den Niederlanden. Nach dem sozialwissenschaftlich-interaktionstheoretischen Paradigma, auch Labeling Approach genannt, wurde auffälliges Verhalten seit den 7oer Jahren als Resultat von Zuschreibungsprozessen in sozialen oder pädagogischen Institutionen aufgefasst.

Seit den 8oer Jahren bestimmte dann zusätzlich das systemökologisch-lebensweltorientierte Paradigma den Fachdiskurs, das auch für mich, während meiner Jahre in der Schulpraxis und der dort unternommenen Forschungen, handlungsleitend war. Verhalten, und damit verknüpft auch das emotionale Erleben, wird hier als Resultat von individuellen Faktoren, Umweltfaktoren und systemischen Wirkungen und Wechselwirkungen betrachtet. Dabei wird das Kind oder der Jugendliche als Akteur_ in in der eigenen gelebten Welt, als einer subjektiven Erlebnis- und Erfahrungswelt, konzeptualisiert. Diese individuelle Welt oder Lebenswelt lässt sich in Anlehnung an Schütz und Luckmann in ihren räumlichen, sozialen und zeitlichen Aufschichtungen verstehen und beschreiben. Verwandte Modelle und Konzepte sind die Poetik des Raumes oder das sozialökologische Modell Bronfenbrenners, bei dem Zonen und Systemwirkungen unterschieden werden, die das jeweilige kindliche oder jugendliche Leben beeinflussen. Beim konstruktivistischen Modell, seit den 9oer Jahren in der Debatte, geht es um die soziale Konstruktion von Auffälligkeiten. In der Konsequenz sollen 
zuschreibende und etikettierende Störungsbegriffe dekonstruiert, das heißt wieder aufgelöst und letztlich beseitigt werden. Statt etikettierende Zuschreibungen an die Heranwachsenden vorzunehmen, soll die Beziehung zwischen lernendem Organismus und Umwelt betrachtet werden. Unter dem Vorzeichen der Postmoderne wurde in den 9oer Jahren, etwa von Fredric Jameson oder Paul Virilio, das fragmentierte, auf sich selbst zurückgeworfene Subjekt in einer unübersichtlicher gewordenen, beschleunigten Welt, in einer zunehmend das gesamte Leben beherrschenden, elektronischen Medienwirklichkeit ausgemacht. Solche Diskurse wurden in der Sonderpädagogik der emotionalen und sozialen Entwicklung allerdings eher selten aufgegriffen. Ich habe es etwa getan, im Rahmen meiner Arbeiten zur Lebensweltorientierten Didaktik. Unter dem Banner der Resilienz wurden seit den 9oer Jahren ferner Stärke, Widerstandskraft und Prävention, statt der vorhergehenden Fokussierung auf Defizite, betont. Die seit den $80 e r$ Jahren in den USA und Großbritannien, etwa seit 2000 auch in Deutschland, in den Blick rückenden Disability Studies konzeptualisieren Behinderung und Benachteiligung als soziale, historische und kulturelle Konstruktion. Forschung soll in interdisziplinärer Perspektive, mit emanzipatorischer Intention, in Partizipation und möglichst Eigenregie der betroffenen Zielgruppen, erfolgen. Im Bereich des emotionalen und sozialen Lernes hätten wir hier freilich noch einen weiten Weg vor uns, was die Umsetzung dieser Maxime anbelangt. Schließlich das seit etwa 2000 auszumachende, mittlerweile sehr umstrittene Heterogenitäts- und InklusionsModell, wonach Besonderheiten im sozialen Verhalten und emotionalen Erleben als Ausdruck von Verschiedenheit im Kontext Inklusion betrachtet werden.

Die sich in der Gegenwart abzeichnenden Strömungen sind natürlich noch nicht wirklich abschließend erkennbar, in ihrer genauen Zielrichtung noch nicht greifbar und beschreibbar. Wo bewegt sich das Ganze also derzeit hin? Wir könnten vielleicht von einem kultur- bzw. humangeografisch-sozialökologischen, transdisziplinären Paradigma sprechen. Soziales Verhalten und emotionales Erleben erscheinen dabei als Ausdruck von Verwundbarkeit bzw. Resilienz im Kontext regionaler und globaler Raum- und Gesellschaftsordnungen, Ökonomien, Teilhabemöglichkeiten bezüglich natürlicher Ressourcen, vor allem Boden, Wasser, Bodenschätze sowie im Kontext sozialer bzw. kultureller Konflikte, bis hin zu Klimaveränderungen, Kriegen und weltweiten Wanderungsbewegungen, Flucht und Migration (vgl. Huntington, 2002; Mitchell, 2000; Norton, 2006). Doch konsensfähig ist eine solche vorläufige Einschätzung sicher nicht, wenn ich an die wissenschaftstheoretische Ausrichtung von vielen deutschen und nordamerikanischen Universitätsinstituten auf dem Gebiet der Sonder- und Inklusionspädagogik des Schwerpunkts emotionale und soziale Entwicklung denke, denn dort gibt es auch Strömungen und Bestrebungen, die eher auf ältere Paradigmen verweisen, die wir ja keineswegs überwunden haben. In der Gegenwart zeichnen sich auf nationaler Ebene in unserem Fach vor allem zwei Strömungen ab. Auf der einen Seite existiert eine, in sich wiederum heterogene, gesellschaftskritisch orientierte Community, gespeist aus kritischer Theorie, Sozialphilosophie, Anerkennungstheorie, Machtkritik, Gender- und Queer Studies, Disability Studies, Biografieforschung, Sozial- und Kulturgeografie, Cultural Studies, Media Studies oder kritischer Diskursanalyse. Forschung ist hier zumeist qualitativ fundiert und arbeitet Subjektperspektiven heraus. Teils handelt es sich um konzeptionelle oder historisch-hermeneutische Ansätze. Menschenbild und Bildungsideal sind an Freiheit, Emanzipation und Solidaritätsfähigkeit orientiert. Gesellschaftsbilder orientieren sich an Chancengleichheit, 
sozialer Gerechtigkeit und Teilhabe, sozialer Inklusion und einer positiven Sicht auf Diversität. Im Umgang mit den pädagogischen Zielgruppen werden teils sprachliche Sensibilität, De-Etikettierung und De-Kategorisierung eingefordert.

Das Erheben von Daten durch eine klinisch-psychologisch fundierte Diagnostik und sämtliche Formen der apparativen Systemsteuerung, wie sie unter dem Vorzeichen von RTI-Modellen betrieben und verbreitet werden, wird von Teilen dieser Community kritisch gesehen oder rigoros abgelehnt. Ein Teil dieser Szene verwendet aber auch all das, was Georg Theunissen einmal kritisch als orthodoxe Heilpädagogik bezeichnet hat, teils noch sehr affirmativ, unhinterfragt, routiniert, in endloser Wiederholung, das heißt diagnostische Tests, kategorisierende Schemata, Inventare, Ratingtools, Kompetenzraster, Förderpläne und dergleichen, als müsste das alles immer so fortgeführt werden in den Konzept- und Modellentwicklungen, in den Universitätsinstituten, in den akademischen Communities und Netzwerken, wie sie sich nunmal herausgebildet und etabliert haben. Auf der anderen Seite hat sich eben eine Community in der Forschung und Lehre unseres Faches etabliert, die an quantitativ-statistischen, evidenzbasierten Maßstäben orientiert ist, in Fortführung des sich seit den 6oer Jahren konstituierenden behavioristisch-lerntheoretischen Paradigmas. Behavior Rating, Behavior Management, RTI-Modelle, datenbasierte Intervention oder Verlaufsdiagnostik sind hier die Schlüsselkonzepte. Diese Strömung erweist sich als kompatibel mit der test- und datenbasierten, kompetenzorientierten Steuerung von Bildungssystemen, auch bezeichnet als Neue Steuerung oder Educational Governance. Diese Community war zuletzt sehr erfolgreich in Deutschland, in der Eroberung immer neuer Lehrstühle, in der Gewinnung der Kontrolle über immer mehr Institute und gar ganze Fachbereiche oder Departments. Ich erinnere an das bereits angesprochene Wissenschaftsmonopoly-Spiel, dass in Kürze seitens des Forschungsbereichs Game Design entwickelt und auf den Markt gebracht werden könnte.

»Jede Forschungsmethode schließt Erkenntnisse aus, die mit anderen Methoden gewonnen werden könnten: Wer nur quantitative Empirie fördert, schließt alles das, was mittels qualitativer Empirie erkannt werden könnte, aus dem Wahrheitsdiskurs einer Gesellschaft aus, « notierte Ladenthin (2020, S. 829). Natürlich gilt auch der umgekehrte Fall. Die Einseitigkeit und die Ausschließlichkeit, die Rigidität im Denken sind das Problem. Teils hat es bereits kritische Auseinandersetzungen gegeben, bezüglich der Dominanz der evidenzbasierten Forschung in vielen sonder- und inklusionspädagogischen universitären Instituten und Abteilungen. Dabei wurden auch ungewöhnliche Formen und Methoden gewählt. Ein Zeitschriftenartikel unter dem harmlosen Namen »Kuno bleibt am Ball« schlug in der Szene ein wie eine Bombe. Hier wurde von einem mutigen Team von Autor_innen ein Text, nach der typischen Art einer sonder- und inklusionspädagogischen, quantitativ-empirischen Studie, frei komponiert und einer nationalen Fachzeitschrift zur Publikation eingereicht. Die Herausgeber_innen bemerkten das ganze Spiel aber nicht und wurden durch den Text, den sie dann veröffentlichten, regelrecht vorgeführt, nachdem die Absicht der Aktion seitens der Autor_innen durch einen, in einem anderen Journal veröffentlichten, Artikel offen gelegt wurde, nämlich überkommene und ideologisch verengte Praktiken der Wissensproduktion der Kritik zu unterwerfen. Bei diesem Komplott wirkten also noch weitere Personen mit. Einerseits lässt sich das nun als überaus gelungenen Geniestreich betrachten, denken wir einmal an den Skandal, den das Ganze ausgelöst hat, allerdings auch nur in der überaus engen der Welt der deutschen Inklusions- und 
Sonderpädagogik. Die meisten anderen Wissenschaftsdisziplinen dürften wohl auch recht erstaunt sein, zu sehen, woran sich da noch abgearbeitet wird. Jedenfalls befinden wir uns, wenn wir einen Schritt von dem genannten Geschehen zurücktreten, inmitten eines tiefroten Ozeans der Ressourcen- und Revierkämpfe.

Aufschlussreich ist an dieser Stelle ein vergleichender Blick in die Vereinigten Staaten, um zu sehen, welche Entwicklungen dort in den führenden internationalen Fachgesellschaften sichtbar werden. Die Association for Childhood Education International (ACEI) folgt etwa einer ausgesprochen politischen Agenda. Es wird eine Vielzahl an Projekten in allen Erdteilen unterstützt. Das Wissenschaftsverständnis ist breit, und vor allem: wertegeleitet. Armut und Gewalt soll begegnet werden durch Bildung für alle und durch Chancengleichheit. Ich nahm 2009 am ACEI-Kongress in Chicago teil und hatte die Gelegenheit, mich mit Menschen aus der Politik, aus NGOs, aus Wissenschaft und pädagogischer Praxis auszutauschen, die sich, überall auf der Welt, für die Belange von Kindern und Jugendlichen engagierten. ACEI gibt allen Mitgliedern stets ein starkes Gefühl der Anerkennung für das eigene gesellschaftliche und globale Tun. Karen C. Liu, die 2009 Präsidentin von ACEI war, lud etwa alle internationalen Vortragenden in ihre Suite im Westin Hotel zu einem Empfang. Von jeder und jedem einzelnen wollte sie genau wissen, woran wir arbeiteten, was genau wir zu bewegen versuchten und wie wir mit den sich uns stellenden Herausforderungen umgingen, alles begleitet von sehr viel persönlichem Interesse, Anteilnahme und Wertschätzung. Der Council for Children with Behavioral Disorders (CCBD) ist dagegen ausschließlich auf die Generierung und Verbreitung von evidenzbasierten, verhaltensbezogenen Interventionen fokussiert. 2013 besuchte ich einen der CCBD-Kongresse, der im Marriott O'Hare, in Chicago, stattfand. Diese Tage waren in mehrfacher Hinsicht sehr aufschlussreich. Gemeinsam mit Nicola Kluge, wir arbeiteten dann und wann zusammen, hatte ich ein Proposal für eine Posterpräsentation eingereicht. Das Poster war auch akzeptiert worden, erstaunlicherweise, denn von den 50 Postern, die dort aufgehängt wurden, war es das einzige, das qualitativ gewonnene Daten präsentierte, wie sich später herausstellte. Es ging bei unserem Poster um die Auswertung von Tagebüchern von Lehrkräften, im Feld der emotionalen und sozialen Entwicklung, und um die schulinterne Beratung und Unterstützung der Lehrkräfte auf der Basis von solchen, reflexiven Texten. Hinzu kam, dass wir die maximale Postergröße in der Tat ausgeschöpft und in Deutschland ein Poster von gigantischen Ausmaßen und in auffälligen Pastellfarben hatten drucken lassen, während die anderen Wissenschaftler_innen zumeist, eher pragmatisch, mehrere kleinere Poster zu einem größeren Ensemble zusammengestückelt hatten. Zum Glück fanden die aufmerksamen Flugbegleiterinnen einen geeigneten Schrank in der Kabine, in dem die übergroße Rolle den Atlantik überqueren konnte. Unser Poster fiel also in mehrfacher Hinsicht ziemlich aus dem Rahmen. Trotz allem hatten wir einige sehr interessierte Gespräche mit anderen Kongressteilnehmer_innen, während wir mit Drinks und Häppchen vor dem Poster standen und unsere Arbeit erläuterten.

Wer sich genauer dafür interessiert, kann das in dem Buch Creating Learning Spaces (vgl. Broecher, 2019), im ersten Kapitel, nachlesen. Doch die echten CCBD-Koryphäen, die Leading Figures der Behavior-Szene, würdigten unser Werk mit keinem einzigen Blick. Sie kamen nicht einmal in unsere Nähe, während sie an den anderen Postern, selbst wenn sie diese nicht im Detail lasen, aber doch immerhin den betreffenden Wissenschaftler_innen, die sie erstellt hatten, anerkennend und wohlwollend 
zunickten. Ich sagte im Scherz zu Nicola, dass sie bezogen auf uns wohl eher dachten, dass jemand bei den Peer Reviews geschlafen haben musste. Nun hat jede dieser Wissenschafts-Communities ihre eigenen internen Regeln, ihre Rituale und Spiele. Ein bestimmter Personenkreis wird dabei als ranghoch konzeptualisiert und positioniert. Dies macht sich fest an der Vergabe bestimmter Redezeiten, am Schaffen von spezifischen Formaten, die solchen Inszenierungen dienlich sind. Etwa, indem eine Art Panel aufgesetzt wird, wo diese Expert_innen dann hinter Namensschildern, die ihren akademischen Status ausweisen, Platz nehmen und Fragen beantworten. Zwei Lehrerinnen aus den USA waren, wie sie sagten, nach Chicago angereist, um von diesem CCBD-Kongress einige Anregungen mit in ihre Schule zurückzunehmen, wo sie, nach eigenen Angaben, sehr viel mit herausforderndem Verhalten von Kindern und Jugendlichen zu tun hatten. Auch hatten sie vor einigen Jahren selbst in den USA Pädagogik studiert und suchten jetzt quasi nach Auffrischung und neuen Anregungen. Diese Veranstaltung lag eher am Ende des Kongresses, so dass die Lehrerinnen schon eine ganze Reihe von Workshops besucht und einiges gehört hatten, was dort an neuen Interventionsmöglichkeiten dargelegt worden war. Irgendwie schien ihnen das alles aber nicht gereicht zu haben und sie beharrten darauf, dass es da noch mehr geben müsse, außer dem, während des CCBD-Kongresses pausenlos propagierten, evidenzbasierten Wissen. Eine Professorin aus Ohio, ich finde heute noch, dass sie das sehr plastisch auf den Punkt gebracht hat, erklärte den Lehrerinnen, dass sie zunächst einmal unterscheiden müssten zwischen evidence-based practices, research-based practices und feel good practices. CCBD propagiere eben ausschließlich evidence-based practices. Wenn sie wieder von Chicago zurückfliegen würden, erläuterte sie den Lehrerinnen, würden sie ja auch Wert darauf legen, dass der Pilot die Maschine nach genau den Instruktionen fliegen würde, wie es von der Forschung für das Fliegen von Flugzeugen vorgegeben sei und nicht irgendwie kreativ oder experimentell. Diese Argumentation hatte etwas ungeheuer Durchschlagendes. Ich hörte plötzlich auf zu denken und war eine Zeitlang voll davon überzeugt, dass diese Kollegin aus Ohio absolut Recht habe. Wer will sich schon sagen lassen, dass er/sie mit feel good practices arbeitet. Hier waren endlich Menschen, die Farbe bekannten und eine klare Richtung vorgaben. Danach sagte aus dem Auditorium auch keiner mehr was. Research-based sei nur in einer Art Übergangsstadium und unter Versuchsbedingungen zu tolerieren, so die Kollegin aus Ohio weiter, wenn sich bestimmte Interventionen also noch in der Erprobung befänden. Feel good practices seien aber in keiner Weise akzeptabel. Und was für das Fliegen von Flugzeugen gelten würde, das müsse eben auch für die Pädagogik gelten.

An der Stelle könnte man freilich argumentativ einsteigen, denke ich heute, aus dem zeitlichen Abstand heraus. So bestechend die Flugzeugmetapher auf den ersten Blick ja ist, so problematisch ist doch der direkte 1:1 Transfer auf die Pädagogik. Natürlich können wir auch nicht Räucherstäbchen in einem Klassenzimmer anzünden und dann behaupten, das würde das Verhalten der Schüler_innen positiv beeinflussen. Wir können auch nicht Tarot-Karten legen bei Fallberatungen, auch wenn sich das vielleicht für einzelne Kolleg_innen gut anfühlt und die Wahrnehmung erweitern und Impulse geben kann. Was die Kollegin aus Ohio hier gesagt hat, das heißt die Flugzeugmetapher, die sie im Marriott O'Hare in Chicago in den Raum gestellt hat, ist aber doch produktiv. Wir können uns sehr schön damit auseinandersetzen und Klarheit gewinnen. Soweit hat CCBD hier eben einen sehr klaren Standpunkt, an dem man sich abarbeiten kann. In der Kaffeepause plauderte ich ein wenig mit den, immer noch ein 
wenig aufgebrachten, in gewisser Weise ja regelrecht zum Schweigen gebrachten, Lehrerinnen und sagte zu ihnen, dass sie in den USA doch auch noch ganz andere Wissenschaftscommunities hätten und dass sie ja, zum Vergleich und zur Erweiterung der Handlungsmöglichkeiten, auch einmal in andere Theoriewelten eintauchen könnten. Ich berichtete ihnen ferner ein wenig von den diesbezüglichen Auseinandersetzungen und Debatten in Deutschland. Auf einer ähnlichen Ebene wie der Council for Children with Behavioral Disorders (CCBD) ist die Association for Positive Behavior Support (APBS) angesiedelt. APBS ist die internationale, zunehmend auch europäische Plattform, auf der School-wide Positive Behavior (PBIS) entwickelt wird, ein System zur Prävention und Intervention bei schulischen Verhaltensproblemen, welches ineinander verschränkte, pädagogische, didaktische, sozialpädagogische und interprofessionelle Komponenten enthält. Im Grunde gibt es eine sehr große Schnittmenge zwischen APBS und CCBD. Beide sind am Verhalten orientiert, beide verwenden evidenzbasierte Interventionen. Die Idee der schulweiten Intervention ist unter anderem auch Thema bei CCBD. APBS bearbeitet zugleich aber noch mehr als das Thema Schule und entwickelt auch Konzepte für außerschulische Felder und für die Arbeit mit Familien.

Ich machte es stets so, dass ich für mehrere Jahre Mitglied in den genannten Gesellschaften wurde, dadurch auch deren Fachzeitschriften bezog und regelmäßig las und immer mindestens einen der größeren Kongresse besuchte, um die Akteur_innen aus den jeweiligen Communities live zu erleben und mit einigen von ihnen auch persönlich in Kontakt zu kommen, auch um fachliche Fragen zu klären. Meine Teilnahme am PBIS-Kongress in Boston im Frühjahr 2015 war ebenfalls mit einer Reihe aufschlussreicher Beobachtungen und Erkenntnisse verbunden. Ich hatte mich schon im Vorfeld dieser Reise sehr intensiv mit PBIS beschäftigt. So waren die Inhalte der Workshops und Vorträge für mich nicht wesentlich neu. Trotz allem konnte ich mein Wissen vertiefen und Einzelheiten besser verstehen. Auch besuchte ich, dem Kongress vorgelagert, eine Reihe von skill-building workshops, die man gegen einen Aufpreis, über zwei Tage hinweg, belegen konnte. Da ich ja in Kooperation mit der Münchner Schulstiftung angefangen hatte Schulentwicklungsworkshops und Lehrertrainings zum Thema PBIS durchzuführen, hielt ich es für eine gute Idee, solche Workshops bei den Koryphäen dieses Gebiets, etwa bei George Sugai oder Rob Horner, zu belegen. Das waren auch sehr gut gemachte Seminare und ich sah manches noch viel deutlicher und klarer als zuvor. Beide genannten Wissenschaftler sind außerdem exzellente Kommunikatoren und gut im Storytelling, aber auch klar in der Sache, um die es ihnen im Kern geht. Einen solchen skill-building workshop belegte ich auch zum Thema Function-based Assessment und Function-based Intervention. Wir arbeiteten dort mit Fallmaterial und diversen Formblättern. Am meisten aber waren wir mit den Händen beschäftigt, flochten Bänder und fädelten Perlen auf. Die Moderatorin, eine freiberufliche Verhaltenstrainerin und Beraterin, hatte einen einzigartigen didaktischen Stil, der das an sich etwas trockene Thema farbig und lebendig werden ließ. Ich würde sagen, dass sie ingesamt drei Komponenten verwendete. Das eine war, wie schon gesagt, der ausgeschriebene Kerninhalt. Das zweite war ein kontinuierliches Storytelling, was uns alle bei Laune und bei hoher Motivation hielt. Sie teilte etliche Geschichten aus ihrer umfangreichen pädagogischen und beratenden Arbeit mit uns. Drittens kam noch hinzu, der beschäftigungstherapeutische hands-on approach. Unvergesslich, wie sie uns im Seminarraum mit all diesen Taschen empfing, die vor ihr auf den Tischen standen und darin schimmerten bunte Perlen, Bänder, Schnüre, allerlei kleine, inte- 
ressante Gegenstände, etwa gelbe Polster, die man in die Hand nehmen und auf denen man herumkneten konnte. Das machte die Leute neugierig und kam den taktilen, spielerischen Bedürfnissen entgegen. Und dann diese Geschichte, wie sie das alles durchs Check-in und durch die Sicherheitskontrollen gebracht hatte und welche Debatten es da mit dem Flughafenpersonal gegeben und wie sie das alles erklärt und transparent gemacht hatte. So wurden die bunten Perlen, die Figürchen und all der andere Tand, mit dem wir hantieren durften, während die Moderatorin dies alles in drastischen Schilderungen erzählte, mit einer enormen Bedeutung, eben über das Storytelling, aufgeladen.

Auch wurde das alles mit pädagogischen Überlegungen bezüglich ADHS und anderen Themen, aus dem Feld der emotionalen und sozialen Herausforderungen, verknüpft, auch mit dem Bedürfnis von Kindern und Jugendlichen mit Material umzugehen. Mir leuchtete das alles sehr ein, weil der Umgang mit Material, und auch spielerische Elemente, stets Teil meiner Pädagogik und Didaktik gewesen waren. So lief das eigentliche Thema, das ja Function-based Assessment und Function-based Intervention lautete, zwar immer auch mit, rückte aber phasenweise in den Hintergrund, und dann wieder in den Vordergrund. Das eigentlich zentrale Thema wurde jedenfalls farbig und hands-on angereichert. Unsere Moderatorin nahm hier eine Art enrichment vor, wie es Joseph Renzulli, der große Ideenentwickler der amerikanischen Gifted Education genannt hat. Doch die offene Frage, die für mich bis heute im Raum steht, lautet, warum diese an sich wertvollen Komponenten, wie Hands-on Learning oder Storytelling, keinerlei Eingang in die Theoriewelt von APBS finden? Deren Fachzeitschrift Journal of Positive Behavior Support bringt keine Beiträge über Storytelling und auch nicht über den handelnden Umgang mit Material, auch nichts über Hands-on Learning. Hier müsste man/frau doch einmal einsetzen mit kritischen Diskussionen, wenn es darum geht, die Theoriewelt, an der APBS ja nun mal arbeitet, weiter voranzubringen und womöglich mit anderen Theoriewelten zu verbinden. Nur so kann es doch eine Weiterentwicklung geben. Mein für Boston eingereichtes Poster zu den Münchner Erfahrungen mit PBIS, auf dem ich die Herausforderungen darstellen wollte, die mit der Einführung dieses Interventionssystems in Deutschland verbunden sein würden, wurde denn auch von dem zuständigen Auswahlkomitee nicht angenommen. So konnte ich die, sich in Deutschland herauskritallisierende, Situation bezüglich PBIS in Boston leider nicht zur Diskussion stellen. Als ich mir die akzeptierten 50 Poster eins nach dem anderen anschaute, war auch kein einziges darunter, dass PBIS, oder einzelne Komponenten daraus, in irgendeiner Form in Frage gestellt oder kritisch reflektiert hätte. Es war alles affirmativ, das vorhandene System weiter ausarbeitend und stabilisierend. "Wissenschaft wird einseitig; sie erforscht nur das Pro, nicht das Contra, weil der Abnehmer nur am Pro interessiert ist«, schreibt Ladenthin (2020, S. 829). So war es auch hier. APBS war zum Zeitpunkt der Ablehnung meines Posterbeitrags nur am Pro interessiert, nicht an der gleichzeitigen Ausleuchtung der anderen Seite.

Wenn ich, zwischen den Workshops und Vorträgen, durch das am Bostoner Hafen gelegene Westin Hotel ging oder den Gesprächen während der Kaffeepausen lauschte, drangen immer wieder Wörter und Satzteile an mein Ohr: ... tier I, tier II ... data-based decision-making ..., evidence-based practices, ... Oh, this was really a tier IV kid, I can tell you ... Das Ganze wirkte wie eine einzige geschlossene Theorieblase. Dadurch, dass man die key words aufgriff und diese rege, und selbstverständlich enthusiastisch, verwendete, wurde man unmittelbar zum Teil dieser Sprachgemeinschaft und Wissenschaftscommunity. Besonders interessant die inoffizielle Wendung tier IV kid, die immer dann 
verwendet wurde, wenn jemand auf einen regelrechten Kracher, wie es in Deutschland oftmals heißt, oder neuerdings, nach Erscheinen des Films von Nora Fingscheidt, auch Systemsprenger, hinweisen wollte, mit dem man/frau da im pädagogischen Feld zu tun gehabt hatte. Sowas sicherte einem sofortige Aufmerksamkeit. Wie gerne wäre ich hier einmal mit Norman Fairclough an der Seite herumgelaufen. Danach hätten wir uns auf einen Drink zusammen an die Bar setzen und dies alles analysieren können. Das Eintauchen in diese sprachliche Blase der PBIS-Welt während des Kongresses in Boston war, als Selbsterfahrungsübung vielleicht, einmal recht unterhaltsam, begann mich aber nach einigen Tagen zu langweilen, weil mir das alles als zunehmend flach erschien. Mir fehlte jetzt einmal ein Vortrag mit weitergespannten Perspektiven, ein Diskurs mit mehr philosophischem, soziologischem oder kulturellem Tiefgang. Sicher, diese Leute hier machten oftmals exzellente Karrieren an ihren Universitäten, wie es schien, aber wie nachhaltig war das alles? Ich vermisste auch Gespräche, die die komplexe Situation unserer Gesellschaften, auch in transatlantischer Hinsicht, reflektierten. Ich joggte durch die Straßen von Boston, obwohl es an den Seiten teils noch hohe Schneeberge gab, doch die Märzsonne setzte sich schließlich im Laufe der Tage durch. Auch fuhr ich zum Campus des Wheelock College, einmal lief ich sogar dort hinüber, wo ich, einige Jahre zuvor, ganz andere pädagogische Erkenntnisse gewonnen hatte, im Vergleich zu diesem PBIS-Kongress, mehr in Richtung Teaching for Social Justice und Urban Education. Ich dachte an Confratute zurück, ein legendärer Mix aus Kongress und Intensiv-Workshops auf dem Gebiet der Gifted Education und des Creativity Trainings, mit Joseph Renzulli und seinen Leuten, an dem ich 1988 auf dem Campus der University of Connecticut, in Hartford, teilgenommen und auch etwas über die Kreativen Sommercamps in Deutschland vorgetragen hatte. Zehn Tage lang kreative Power! Man verbrachte die Tage bei inspirierenden Vorträgen und in aktivierenden Workshop Sessions. Das Ganze ging an etlichen Abenden in Parties über.

Es hat schon Auswirkungen auf die Menschen und die entstehenden Atmosphären, welche Art von Konzepten wir im Kopf haben. Lege ich den Fokus auf Verhaltenstraining und Verhaltenssteuerung oder lege ich ihn auf das Stimulieren von Kreativität? Ich würde immer das Thema Kreativität wählen. Niemand zwingt mich, immer nur auf das Verhalten zu starren, auch dann nicht, wenn andere vor mir gemeint haben, diese Kinder oder Jugendlichen hätten aber in erster Linie ein Verhaltensproblem. Wirklich? Vielleicht gibt es ja auch einen Mangel an kreativer Stimulation in ihrem Leben. So unterschiedlich können jedenfalls Kongressatmosphären sein. Im Bostoner Hafen fiel ich abends in mein Hotelbett, wenig inspiriert, draußen die schmutzigen Schneeberge an den Straßenrändern. Ich lag in meinem King Bed und erinnerte mich an den aufregenden Sommer in Connecticut, und träumte von dem Dreieck mit den drei Interventionsebenen, dass man hier beim APBS-Kongress pausenlos auf Power-Point-Folien oder Postern zu sehen bekam. Auch ist dieses, Wissenschaftlichkeit suggerierende, Dreieck immer wieder an Pinnwänden, auf Fluren von deutschen Universitätsinstituten der Inklusions- und Sonderpädagogik, anzutreffen. Man geht nur, um sich einmal einen Tee zu kochen, und schon kommt man an irgendetwas vorbei, wo so ein Dreieck drauf ist. Jetzt ist die komplexe pädagogische Welt jedenfalls endlich wieder beherrschbar. Man schaut am besten immer wieder meditierend auf diese drei Ebenen des Response-to-Intervention Modells, bis dass man plötzlich völlig davon überzeugt ist, dass unsere pädagogische Welt an den Schulen so klar zu beschreiben und zu beeinflussen ist, wie dieses Dreieck einem nahelegt. Ich stellte mir vor, auch mein 
eigenes Leben nach einem solchen Modell aufzubauen. Das und das waren dann meine Tier I-Aktivitäten, das und das meine Tier II-Aktivitäten usw. Mir kam das Bild eines Ameisenhaufens, wenn ich an diese RTI- und PBIS-Welt dachte und all die geschäftigen Menschen darin, wie sie mit ihren Posterrollen und Vortragsskripten herumliefen. Der Kontrast zum Confratute-Kongress in Connecticut hätte gar nicht größer sein können. Ich hatte dort ad hoc Gespräche und Workshop-Erlebnisse, die bis heute in mir nachwirken und meine eigene kreative Power beflügeln. Joseph Renzulli, der dies alles in Gang gebracht hat, sei nochmal nachträglich für diese Erfahrung gedankt.

Eine bemerkenswerte Erfahrung machte ich auch bei einer kleineren PBIS-Tagung, im Juni 2017, an der Universität Amsterdam. Hier waren Teilnehmer_innen aus den USA, aus Holland und verschiedenen skandinavischen Ländern vertreten. Eingangs explizierte ein Stakeholder aus der amerikanischen Behavior Community, ein Kollege aus Texas, was er unter evidenzbasiert verstehe und dass zum Erreichen dieses Status', bei der wissenschaftlichen Prüfung von Interventionen, ganz bestimmte Kriterien erfüllt werden müssten. Das bedeutete, dass verschiedene Forscher_innen, an verschiedenen Orten, bei Stichproben von einer bestimmten Größe und unter Einhaltung ganz bestimmter Spielregeln, sowohl bei der Datenerhebung selbst, als auch bei der statistischen Auswertung, zu ein- und demselben Ergebnis gekommen sein müssten. Das klang selbstverständlich alles sehr einleuchtend, insbesondere natürlich bezogen auf die Medizin, aus der der Kollege ja seinen Denkansatz abgeleitet hatte. Aber ähnlich wie bei der Kollegin aus Ohio beim CCBD-Kongress in Chicago wurde dies wiederum mit einer ziemlichen Ausschließlichkeit dargelegt, so dass es neben den evidenzbasierten Interventionen in diesem Denkhorizont auch nichts anderes mehr an pädagogischen Handlungsmöglichkeiten gab. Als Metapher, die der Kollege aus Texas der Medizin entlehnte, verwandte er das Thema des Blutdrucks. Hier wollten wir zunächst ein genaues Messergebnis, eben mit einer wissenschaftlich geprüften Methode und auch wissenschaftlich geprüfte Medikamente, die dann einen erhöhten Blutdruck wirksam absenken können. Das wirkte natürlich zunächst ungeheuer überzeugend auf alle Teilnehmenden der Tagung, ähnlich der Flugzeug-Metapher der CCBD-Kollegin aus Ohio. Es ist ja auch erst einmal zutreffend, um eine Soforthilfe $\mathrm{zu}$ schaffen und den Gesundheitszustand der betreffenden Menschen zu stabilisieren und weitere Probleme zu verhindern, die aus einem dauerhaft zu hohen Blutdruck resultieren können. Trotz allem muss natürlich die Frage nach den unterschiedlichen Gründen für einen erhöhten Blutdruck gestellt werden, wenn wir den angebotenen Vergleich einmal wirklich ernst nehmen und dem genauer nachgehen. Es kann organische Ursachen für einen Bluthochdruck geben. In den meisten Fällen, wie wir aus der Forschung wissen, sind es jedoch nervliche Gründe, die für eine Ausschüttung von Stresshormonen sorgen und die Blutgefäße sich anspannen lassen. In beiden Fällen muss auch nach den Komponenten im Lebensstil eines Menschen gefragt werden, die den Blutdruck ansteigen lassen, das heißt die Art wie er/sie lebt und arbeitet, wie die Ernährung und das Bewegungsverhalten ist usw. Gute Kardiolog_innen raten daher zusätzlich zur medikamentösen Behandlung auch zu Veränderungen im Lebensstil, der Ernährungsweise, auch zur Aneignung von meditativen Praktiken usw. Es ist daher doch ein wenig komplexer. Die Medizin zieht durchaus auch Maßnahmen in Betracht, die nicht im engeren Sinne als evidenzbasiert und in vielen Fällen nur als research-based gelten. Insofern ist es doch immerhin fraglich, ob eine evidenzbasierte, verhaltensorientierte Sonderpädagogik so ohne Weiteres in der dargelegten Art und 
Weise unter Bezugnahme auf die Medizin argumentieren kann, wie es der Kollege aus Texas, bei der PBIS-Tagung in Amsterdam, eben getan hat.

In ziemlicher Abgrenzung zur Behavior-Welt geht es der Association for Experiential Education (AEE) um soziales und persönliches Lernen durch Erlebnis und Erfahrung, bevorzugt bei Gruppenaktivitäten in der Natur, auf dem Meer, auf Flüssen und Seen, im Gebirge, in den Nationalparks der USA und Nordamerikas. Das Wissenschaftsverständnis ist breit und schließt quantitative wie qualitative und gesellschaftskritische Zugänge ein. Ich hatte die Gelegenheit, an dem Jahreskongress von AEE in Minneapolis teilzunehmen, im Herbst 2016. Die Workshops reichten von Hochgebirgswandern mit straffällig gewordenen Jugendlichen, über die Geschichte der amerikanischen Sommercamps, bis zu Storytelling. Kongressteilnehmer_innen kommen hier vielfach in Outdoor-Kleidung und weniger im Jacket, teils mit dem Rucksack und weniger mit einem Rollkoffer. Unter dem Dach von AEE versammelt sich eine große Vielfalt von Forscher_innen und Praktiker_innen, sicher mit Schwerpunkt auf den USA und Kanada, doch auf den Namenschildern war zu lesen, das auch Menschen aus allen Teilen dieser Welt nach Minneapolis angereist waren, um neue Ideen vom Ufer des Mississippi mit nach Hause zu nehmen und sich auszutauschen. Die Workshops bei den AEE-Kongressen sind oftmals hands-on, das heißt es gibt häufig etwas zu tun, sich $\mathrm{zu}$ bewegen, untereinander in kleinen Gruppen oder zu zweit etwas auszuprobieren, jedenfalls mehr, als einfach nur auf dem Stuhl zu sitzen und zuzuhören und PowerPoint-Folien anzuschauen. Richard Louv hielt den Hauptvortrag, über die Bedeutung der Naturerfahrung in einer zunehmend digitalisierten Welt, und er erhielt stürmischen Applaus. Nach dem Kongress in Minneapolis habe ich eine ganze Reihe seiner, sicherlich sehr bedeutsamen, Bücher gelesen. Sie sind sehr engagiert geschrieben. Louv ist Journalist, verarbeitet jedoch eine Vielzahl von wissenschaftlichen Theorien in seinen Büchern und er ist ein exzellenter Storyteller. Er kann, ohne Übertreibung, als ein globaler Akteur angesehen werden, der weltweit gelesen wird und somit Impulse geben kann. Er ist ein regelrechter Influencer. Für jede Stunde, die ein Kind oder Jugendlicher vor einem Bildschirm verbringt, sollte es eine Stunde Naturerfahrung geben, so Richard Louv. Außerdem hat Louv ein wunderbares, sehr enagiertes Buch über die Bedeutung der Vater-Kind-Beziehung geschrieben.

Die Urban Affairs Association (UAA) schließlich lenkt den Blick auf die sozial- und humangeografischen Räume, in denen Menschen leben. Themen sind hier etwa Segregation, Armut oder eingeschränkte Lebens- und Partizipationsmöglichkeiten, durch ungeeignete Modelle der Stadtentwicklung und fehlende Community-Strukturen, in ihrer Rückwirkung auf die Sozialisationsverläufe von Heranwachsenden. Ich nahm im Frühjahr 2019 an der Annual Conference von UAA in Los Angeles teil, ausgerichtet in einem Konferenzhotel auf dem Gelände der UCLA, der University of California. Es war faszinierend einer chinesischen Forscher_innengruppe zuzuhören, wie sie Karten von, am Gelben Fluss gelegenen, Städten und Regionen an die Wand warfen und aufzeigten, wie sich die Infrastrukturen dieser Siedlungen und Städte, über die Jahrhunderte, verändert hatten und wie dies alles die Lebensbedingungen der dort lebenden Menschen geprägt und beeinflusst hatte und auch die Art, wie sie arbeiteten, lernten und lebten. Der Blick weitet sich noch einmal beträchtlich, wenn ich mich in eine solche Theoriewelt begebe. Es gibt eine engagierte Untergruppe in der Urban Affairs Association, mit der ich mich während der Kongresses traf, engagierte Menschen aus Wissenschaft und Praxis, die speziell Fragen der Pädagogik und der Schulentwick- 
lung im Blick haben, darunter Universitätsleute, aber auch einige Schulleiter und Menschen aus regionalen Verwaltungen, die sich Gedanken über die sozialgeografischen Strukturen und Herausforderungen in den Gebieten machen, in denen ihre Schulen liegen. Ein Teil der sozialen Problematiken, die sich in den Schulklassen manifestieren, steht ja in Zusammenhang mit der Art, wie Stadtviertel und ländliche Gebiete geplant und entwickelt werden. Je nachdem, wie dort gebaut wird und was dort gebaut wird, können sich ganz unterschiedliche sozialgeografische Kontexte herausbilden, in denen sich bevorzugt die einen oder die anderen sozialen Gruppierungen ansiedeln, mit allen Folgen, die dieses Zoning, das Aufteilen von Land in Nutzungszonen, für die Nachbarschaften, für die Communities, für das kulturelle Leben, für das Aufwachsen von Kindern und Jugendlichen, für ihr Lernen, für ihre Zukunft hat.

Was mich in Zusammenhang mit diesem UAA-Kongress in Los Angeles aber noch lange beschäftigte war das Folgende. Vor Kongressbeginn hatte ich noch ein wenig Zeit und ich wollte mir das Getty Center und die dort untergebrachten Kunstsammlungen ansehen. Auch lag es ja eigentlich nur einen Steinwurf vom UCLA Campus entfernt, zumindestens wenn man auf den Stadtplan schaute. In Wahrheit war es jedoch ein wenig komplizierter. Auch hatte ich bereits einiges darüber gelesen, dass Los Angeles nicht unbedingt eine Stadt für Fußgänger_innen sei. Trotz allem machte ich mich zu Fuß auf den Weg, denn der Himmel war blau, und kam bis auf einige Engpässe, wo kaum ein Streifen für zu Fuß Gehende entlang der Straße vorhanden war, einigermaßen gut durch, bis zu dem Punkt, wo dann ein Shuttle-Zug zum Getty Center verkehrt, das auf einem Berg, hoch über Los Angeles, liegt und an eine geheimnisvolle Location aus einem James-Bond-Film erinnert. Unterwegs traf ich zwei Mal junge Männer an, die jeder für sich, an verschiedenen Orten, einen Einkaufswagen mit ihren Habseligkeiten vor sich herschoben und ziemlich abgerissen aussahen. Von Gesicht und Gestalt her zu urteilen, waren sie beide Mitte bis Ende zwanzig. Die Haut von beiden jungen Männern war dunkel getönt, von der vielen Sonne, obwohl es eigentlich hellhäutige Menschen waren. Ich fühlte mich sehr schuldig in Anbetracht eines solchen Kontrastes. Ich selbst hatte in einem komfortablen King Bed geschlafen und hatte ein reichhaltiges Frühstück in meinem Zimmer im Kongress Center eingenommen. Diese jungen Männer wirkten so als seien es ehemalige Studenten, die aus der Bahn geraten sind und sie waren offensichtlich in einer sehr desolaten Lebenssituation. Es sah so aus, als hätten sie in irgendeinem kleinen Parkabschnitt, zwischen Büschen und unter Bäumen, übernachtet. Einer von ihnen kam mir mit seinem Einkaufswagen auf einem, wirklich nur noch vierzig, fünfzig Zentimeter breiten, Asphaltstreifen in einer Straßenkurve entgegen. Ich wich auf die Straße aus, um an ihm vorbeizukommen. Einen kurzen Blickkontakt gab es aber trotz allem. Ein Blick, in dem so vieles transportiert wurde, bis hin zum heutigen Tage, wo ich darüber schreibe.

Das Getty Center ist sicherlich ein Ort von einzigartiger Schönheit. Es geht auf die Kunstsammlung des Öl-Tycoons Jean Paul Getty zurück und wurde in den 9oer Jahren gebaut. Betreiber ist der J. Paul Getty Museum Trust. Getty galt zu seiner Zeit als reichste Person der Welt. Nun, es wurden hier offenbar im großen Stil Geschäfte gemacht, um ein Vermögen einer solchen Größenordnung zusammenzubekommen. Es wird dazu auch Schattenseiten und kritische Stimmen geben. Doch es ist aus diesen Gewinnen immerhin etwas Wunderbares an die Menschheit zurückgegeben worden. Niemand braucht Eintritt zu zahlen, auch der Shuttle-Zug und das Parken, wenn man mit dem Auto kommt, sind kostenlos, ebenso die Garderoben und das Trinkwasser 
an den sprudelnden Maschinen, überhaupt ein großer Vorteil in den USA. Die Kunstsammlungen sind exzellent. Man/frau braucht nur den Stadtbus, was in Los Angeles auch erstaunlich preiswert ist, bis zum Startpunkt des Shuttle-Zugs zu bezahlen und kann dann den ganzen Tag in schönen Gärten, auf sonnenbeschienenen Terrassen und zwischen erlesenen Kunstwerken verbringen und kann zwischendurch hinunter, auf die pazifische Küste und auf Santa Monica schauen. Ganz Los Angeles liegt einem hier zu Füßen, wenngleich die entfernteren Viertel der, endlos in die Breite, kaum aber ins Vertikale ausgedehnten, Metropole im Dunst verschwimmen. Ich saß eine ganze Weile in einem Raum vor venezianischen Meistern und schaute auf diese wunderbaren Bilder der Lagunenstadt, lauschte auch einer Grundschullehrerin, die ihre Schüler_innen in eine erlebnisorientierte, interaktive, imaginative Bildbetrachtung zu verwickeln suchte, bis das die Gruppe wieder weiterzog und irgendwo im Hintergrund der vielen Kabinette verschwand und ich den Raum eine Zeitlang für mich ganz allein hatte. Ich dachte an Venedig, an die Renaissance, an die Toskana, aus der die hellen Marmorsteine für die äußeren Wände dieser Museumsgebäude, bis hierher nach Los Angeles, geholt worden waren. Ich dachte an die beiden jungen obdachlosen Männer, an den reichen Öl-Tycoon und Stifter Getty, an Deutschland, und was wir dort an Möglichkeiten hätten, solchen aus dem Takt gekommenen jungen Männern zu helfen, ihnen unter die Arme zu greifen. Es kann uns als zivilisierte Gesellschaft doch nicht zufriedenstellen, dass es Menschen unter uns gibt, die so stranden, dachte ich. Und diese ganze Schönheit des Getty Centers steht doch im allergrößten Kontrast zu der desolaten Situation, in der die beiden obdachlosen jungen Männer waren.

Bei meinen Erkundungen des UCLA Campus, der vielerlei stilistisch ansehnliche Gebäude, auch im historischen Stil, und auch eine Menge Grünflächen, Parks, Baumbestände usw. aufweist, kam ich auch durch mehrere Bibliotheksgebäude, wo etliche Studierende arbeiteten und über Büchern und Laptops saßen. In einem dieser Räume hielten sich vielleicht gut hundert Studierende auf. Teils schliefen sie auf den dort befindlichen Sofas oder recherchierten an den Tischen. Einige checkten ihre Nachrichten auf dem Smartphone oder hörten Musik oder Podcasts. Ich las auch irgendwo, dass viele Studierende der UCLA in den Zimmern, in denen sie oftmals zu dritt oder zu viert schlafen, weil sie ein Einzelzimmer nicht bezahlen können, nicht genug Schlaf bekommen und natürlich auch nicht konzentriert arbeiten können und daher an solche Orte, wie diesen Raum, gehen müssen, um zu schlafen oder konzentriert zu arbeiten. So schön der UCLA Campus auch ist, so sehr erzeugte diese Szene hier für mich den Eindruck, dass es sich auch um eine Art Lernfabrik handelt. Hatten die beiden jungen Männer, mit den dunkelgebräunten Gesichtern, der abgerissenen Kleidung und den Einkaufswagen, die sie auf den schmalen Asphaltstraßen vor sich herschoben, auch einmal hoffnungsvoll als Studenten auf dem UCLA Campus begonnen? War dann vielleicht eins nach dem anderen gekommen, das Schlafen in einem solchen Zimmer, die Schwierigkeit beim Erwerb der Credits mitzuhalten, vielleicht noch ein Zerwürfnis mit den Eltern, die irgendwo draußen in Wyoming oder Oregon lebten, Leute, die keinen weiteren Kredit mehr aufnehmen wollten oder konnten, um das Studium ihrer Söhne zu finanzieren? Sodann die Schwierigkeit, Aushilfsjobs und Studium unter einen Hut zu bringen, dann noch eine enttäuschte Liebe, persönliche Krisen und das Einsetzen einer Abwärtsspirale, die Unmöglichkeit noch die eigenen Rechnungen zu bezahlen, der endgültige Bruch mit den Eltern, Drogen, vielleicht Prostitution, dann der Absturz. So saß ich vor den venezianischen Meistern und dach- 
te an solche möglichen Zusammenhänge und imaginierte mögliche Hintergrundszenarien. Und die Urban Affairs Association?

Haben die Leute in dieser Wissenschaftscommunity Lösungen für derlei Situationen und Herausforderungen? Natürlich haben sie auch keine Sofortlösungen, aber doch immerhin theoretisches und methodisches Werkzeug, um zu einer erweiterten Perspektive zu gelangen. »It is all connected«, sagte Edgar Klugman, bei unserem Gespräch in der Lobby eines Bostoner Hotels. Eine weitere Richtung mit starker Repräsentanz im schulischen und universitären Bildungssystem Nordamerikas ist Teaching for Social Justice (vgl. z. B. Michie, 2005, 2009), eine politisch motivierte Pädagogik, deren Wurzeln bis zur amerikanischen Bürgerrechtsbewegung zurückreichen. Forschungsarbeiten sind hier oftmals qualitativ ausgerichtet. Schlüsselthemen sind Student Voice, Partizipation, produktiver Umgang mit Diversität oder die integrative Kraft der sozialen Communities. Die gesellschaftskritischen Strömungen finden sich in Deutschland, wie auch in den USA, gleichermaßen. Experiential Education wird dagegen in den deutschen Abteilungen des Faches derzeit kaum abgebildet. Dafür bestehen rege transatlantische Austauschbeziehungen zwischen der deutschen und der amerikanischen Behavior-Community. Was passiert darüber hinaus in Europa? Während in den Niederlanden und den skandinavischen Ländern seit einigen Jahren intensiv mit School-wide Positive Behavior Support gearbeitet wird, steht in Großbritannien nach wie vor die, teils auch im deutschsprachigen Raum geschätzte, durch John Bowlby entwickelte Bindungstheorie hoch im Kurs. Die britischen Nurture Groups, wie sie insbesondere von Marjorie Boxall begründet und entwickelt wurden, als pädagogische Anwendungen der Bindungstheorie im Schulkontext, in Vorschulen, Grundschulen und teils gar in Sekundarschulen, haben sich allerdings bisher in Deutschland kaum durchsetzen können. Ein weiterer wichtiger Impuls aus Großbritannien, schauen wir etwa auf die politische und pädagogische Arbeit der Social, Emotional, and Behavioral Difficulties Association (SEBDA), ist die Etablierung von kooperativen Beziehungen zwischen Schule und Community, wenn in der Schule die emotionale und soziale Förderung von Kindern und Jugendlichen gelingen soll. Eine besonders lebendige, motivierende Darstellung, aus der Sicht einer Schulleiterin, verfasste Reva Klein (2000), am Beispiel von Newcastle. SEBDA integriert wissenschaftliche Ansätze und Methodologien in der vollen Breite.

\section{Die Macht der Sprache}

In den Bildungswissenschaften, wie auch in den zugehörigen pädagogischen Handlungsfeldern hängt alles von der Sprache ab. Sprache ist in jeder Hinsicht fundamental. Sie bietet uns enorme Denk- und Handlungsmöglichkeiten und kann doch auch überaus problematisch, destruktiv und damit kontraproduktiv sein. Diskurse lassen sich nun, wie Weisser (2010, S. 284) es beschreibt, verstehen als »Praxen der Verständigung, also alle möglichen Formen und Wege des Austausches von Wissen oder allgemeiner, von Sinn«. Thema der Analyse von Diskursen ist dann die Frage, wie es Jan Weisser formuliert hat, "was auf welche Weise von wem zum Thema gemacht wird und wie das behandelte Thema mit seinen Kontexten interagiert (vgl. Weisser, 2010, S. 285). Das gesamte Gebiet der Diskursanalyse erscheint heute als sehr komplex und hat sich immer weiter verzweigt. Besondere Bedeutung haben, während der frühen Entwick- 
lung dieses Theoriefeldes, die Publikationen von Michel Foucault erlangt. Ich werde im Folgenden insbesondere die Arbeiten von Norman Fairclough (1989, 1992, 2013) emeritierter Professor an der Lancaster University, Großbritannien, zum Ausgangspunkt nehmen. Fairclough hat in seinen Arbeiten auf dem Gebiet der angewandten Linguistik insbesondere den Zusammenhang von sprachlichem Diskurs und sozialen Ordnungen untersucht. Die von Fairclough betriebene Soziolinguistik richtet ihren analytischen Blick vor allem auf den Zusammenhang von Macht bzw. Hegemonialität und Sprache, denn die Welt des Sozialen wird mithilfe von Sprache konstruiert. Hegemonialität wird hier, abgeleitet von den Arbeiten von Antonio Gramsci, im Sinne von Vorherrschaft oder Überlegenheit, speziell von sozialen Institutionen oder Organisationen, verstanden. Die Critical Discourse Analysis, wie sie von Fairclough, seit Erscheinen seines Buches Language and Power (1989), theoretisch und methodologisch breit entworfen worden ist, will nun einerseits analytisches Werkzeug liefern, um Macht und Diskurs als Kernelemente des sozialen Geschehens herauszuarbeiten. Zum anderen tritt die Critical Discourse Analysis mit dem Anspruch auf, unmittelbar auf soziale, politische und pädagogische Veränderungen hinzuwirken. Insofern versteht sie sich nicht als rein deskriptiv, sondern auch als normativ, indem sie auf die Beseitigung von sozialen Missständen, Ungleichheiten oder Benachteiligungen abzielt. Fairclough unternimmt außerdem eine Kapitalismuskritik, wie auch eine Kritik an neoliberalen gesellschaftlichen, wirtschaftlichen und administrativen Strukturen und verarbeitet in seinen Texten Gedanken von Marx, Gramsci, Arendt, Butler, Bourdieu oder Bernstein, bis hin zu Foucault und Habermas.

Worin ist nun der Zusammenhang mit dem Thema der emotionalen und sozialen Entwicklung zu sehen? Zum einen lassen sich in den Fachdiskursen auf diesem Gebiet zahlreiche kategorisierende, etikettierende, oftmals pathologisierende sprachliche Wendungen ausmachen, die mit Hilfe der Critical Discourse Analysis problematisiert und in Frage gestellt werden können, das heißt Begriffe und Konzepte wie Verhaltensstörung (z. B. bei Casale et al., 2014; Goetze, 1994; Goetze und Neukäter, 1993; Hillenbrand, 2003, 2008; Mutzeck, 2000a; Mutzeck und Pallasch, 1992; Myschker, 1989; Myschker und Stein, 2018; Stein, 2008; Wittrock und Vernoij, 2008), Entwicklungsstörung (z. B. bei Blumenthal et al., 2020), Gefühlsstörung (z. B. bei Opp 2000), Entwicklungspsychopathologie (z. B. bei Fingerle, 2008), Aufmerksamkeits- und Hyperaktivitätsstörung (z. B. bei Abelein und Stein, 2017; Opp, 2000), Angststörung (z. B. bei Stein, 2012), Unterrichtsstörung (z. B. bei Claßen und Nießen, 2006) oder Störungsbilder (z. B. bei Heilmann et al., 2015). Im Englischen finden sich Begrifflichkeiten wie behavioral dis$\operatorname{order}$ (z. B. bei Bakken et al., 2012; Bowman-Perrott, 2009; Eber und Keenan, 2004; Ennis und Jolivette, 2014; Gresham, 2007; Kavale et al., 1997, 2004; Landrum 2000; Lane et al., 2010; Simpson 2004; Trout et al., 2003; Walker und Gresham, 2014), oft auch in Kombination damit emotional disorder (z. B. bei Gresham und Elliott, 2014; Kalberg et al., 2011; Kavale et al., 2004; Rutherford et al., 2004; Wehby et al., 2003) oder emotional disturbance (z. B. bei Burns und Goldman, 1999; Levendoski und Cartledge, 2000; Reid et al., 2004), gelegentlich auch disruptive behavior (z. B. bei Reinke et al., 2008) oder disruptive behavior disorders (z. B. bei Tsai et al., 2015). Selbst die, 2019 gegründete, Zeitschrift ESE, verwendet den Störungsbegriff noch, indem sie sich den folgenden Untertitel gegeben hat: »Emotionale und Soziale Entwicklung in der Pädagogik der Erziehungshilfe und bei Verhaltensstörungen." Ein ziemliches Wortungeheuer im Deutschen ist sicher Verhaltensgestörtenpädagogik (z. B. bei Mutzeck 2000 b). Oftmals 
begegnen wir einer medizinischen oder paramedizinischen Sprache, etwa Begriffen wie Ko-Morbidität (z. B. bei Opp, 2000) oder Klassifikationssystemen zu psychischen Störungen (z. B. bei Dilling et al., 2015; Falkai und Wittchen, 2018; Stein und Kranert, 2020). Selbst in Publikationen, in denen in erster Linie gar kein störungsbezogenes Menschenbild vorherrscht, wurde in der Geschichte des Faches immer wieder der Begriff verhaltensgestört verwendet (z. B. bei Fitting und Kluge, 1982). Emotionale und soziale Entwicklungsförderung, wie es in der Gegenwart heißt, auch das wird sicher nicht der letzte Stand bleiben, denn diese sprachliche Wendung beinhaltet immer noch eine Reihe von Schwierigkeiten, auf die ich mit der Zeit noch eingehen werde. Jedenfalls gab es zum Gebrauch solcher Fachtermini in den 8oer Jahren kaum eine kritische Auseinandersetzung in der Sonder- und Inklusionspädagogik. Als weniger diskriminierend erscheint vielleicht der Begriff challenging behavior (z. B. bei Emerson und Einfeld, 2011; Kaiser und Rasminsky, 2012; Lever, 2011), wenngleich er jedoch in demselbem $\mathrm{Maße}$, wie die anderen genannten Begriffe auch, zu Zwecken der Kategorisierung und der Zuweisung eines Status als förderbedürftig dient. Problematisch erscheint dagegen, wenn diese Bezeichnung auf die gesamte Person ausgeweitet wird. Statt lediglich ein bestimmtes Verhalten als herausfordernd zu bezeichnen, wird dann von challenging students (z. B. bei Minahan und Rappaport, 2012) gesprochen.

Zum anderen haben verhaltenstheoretisch, klinisch-psychologisch ausgerichtete Wissenschaftscommunities, im Verbund mit denjenigen Institutionen, die die Bildungs- und Sozialsysteme zu weiten Teilen kontrollieren oder repräsentieren, ein Gebäude aus praxisbezogenen Diskursen und sozialen oder (sonder-)pädagogischen Praktiken errichtet, in denen mithilfe einer speziellen Diagnostik Entwicklungsabweichungen, Entwicklungsrückstände oder Entwicklungs- bzw. Verhaltensstörungen festgestellt werden, auf die hin dann spezifische, datenbasierte, evidenzbasierte Interventionen oder Maßnahmen eingesetzt werden. Teile der behavioristischen Community sprechen gar von Konditionierung (z. B. Linderkamp, 2008) in Zusammenhang mit Kindern und Jugendlichen. Dabei wäre es erforderlich, statt Menschen zu Objekten solcher Interventionen, Maßnahmen und diagnostischer Prozeduren zu machen, sie in ihrer eigenen Geschichte, in ihren sozialen, kulturellen, ökonomischen und biografischen Verhältnissen und Kontexten zu sehen und zu verstehen, wie Wolfgang Jantzen (2012 c, 2018) in seinen Arbeiten zur rehistorisierenden Diagnostik gezeigt hat. Eine vergleichbare Zielrichtung verfolgt auch Georg Theunissen in zahlreichen Texten (z. B. 2003, 2013). Theunissen wendet sich gegen Dogmatismus und Orthodoxie, gegen starre Übungsbehandlungen und funktionalistische Therapien. Stattdessen plädiert er für Empowerment, Subjektbezug und Partizipation, in der pädagogischen Praxis wie auch in der Forschung. Es gibt also Ausnahmen im sonderpädagogischen Feld, Autor_innen, die genau das machen und veröffentlichen, was auch Fairclough im Sinn hat. Doch vielfach ist eben das Gegenteil davon der Fall. Akademisch gebildete Menschen üben nun, aus der Sicht der Critical Discourse Analysis, in einem sich modern gebenden demokratischen Staat, in Universitäten, Ministerien, Aufsichtsbehörden und Schulen die soziale Kontrolle über gesellschaftlich zumeist marginalisierte Personengruppen aus, indem sie deren vermeintliche Probleme definieren, benennen, einschätzen und diese Heranwachsenden zum Objekt ihrer beurteilenden und kategorisierenden Praktiken und Diskurse und, zumeist klinisch-psychologisch hergeleiteten, Interventionen machen. Denkt man das konsequent im Sinne der Kritischen Diskursanalyse weiter, müssten sich Sonder- und Inklusionspädagogik fragen lassen, ob sie sich nicht auf 
dem Rücken der Zielgruppen, für die sie beanspruchen dazusein, professionalisiert und speziell im Wissenschaftsbetrieb enorme personelle und finanzielle Ressourcen angehäuft haben und ob das, was sie da tun oder zu tun behaupten, tatsächlich immer im Sinne der Zielgruppen ist und ob das ethisch und gesellschaftlich überhaupt vertretbar ist (vgl. dazu auch Hänsel und Schwager, 2003).

Selbst wenn wir zu dem Ergebnis kommen sollten, dass diese Form der Professionalisierung, Akademisierung und Ressourcengenerierung, historisch betrachtet, eine Zeitlang notwendig gewesen ist, so ist dies für die Zukunft des Förderschwerpunkts der emotionalen und sozialen Entwicklung, um den allein es hier geht, keineswegs eindeutig zustimmend zu beantworten. Vieles spricht eher dafür, sich nun schrittweise ins Interdisziplinäre und Transdisziplinäre zu bewegen und einzubringen, mit anderen theoretischen Strömungen und gesellschaftlichen Initiativen sich zusammenzutun und zu verschmelzen und die eigenen Erfahrungen und Erkenntnisse nun in etwas Neues, Größeres und Übergeordnetes einzubringen. Als eigenständige Wissenschaftsdisziplin würden wir uns dann in der Tat auflösen, was nicht ein Verlust, sondern, gesellschaftlich betrachtet, sogar ein Gewinn wäre. Mit der bisherigen Disziplin könnten wir dann auch all die überholten Störungsbegriffe, die überkommenen Zuschreibungen, die reduzierten Menschenbilder, die verengten, rigiden Handlungssysteme, die geistig wenig ansprechenden, wenig motivierenden, oftmals kaum inspirierenden, Theorien und Modelle, die uns über die Jahrzehnte teils offeriert worden sind und noch werden, und damit zugleich all diese negativen sprachlichen Konstrukte und Begriffsungetüme, in der Vergangenheit zurücklassen und höchstens dort, wo diese Theorien und Modelle noch brauchbar erscheinen, diese weiterentwickeln, aber eben in einem neuen transdisziplinären Zusammenhang. Doch die Realität ist noch eine andere. Aus der Sicht der kritischen Diskursanalyse werden die marginalisierten Personengruppen in der gesellschaftlichen Gegenwart zu Adressaten sozialer, administrativer und (sonder-)pädagogischer Praktiken und erfahren somit eine soziale Statuszuweisung. Das Ganze geht einher mit der Implementierung (vgl. z. B. Netzel und Eber, 2003) übergeordneter schulischer Steuerungssysteme, in denen zwar individuelle Förderung propagiert wird. Allerdings erfolgt diese nach relativ rigiden Kategorisierungen, kompetenzorientierten Standards und standardisierten Lerncurricula, unter denen die heranwachsenden Subjekte in ihrer Autonomie verloren zu gehen drohen. Statt einer gesellschaftskritischen, subjektzentrierten Pädagogik stehen nunmehr Classroom Management (z. B. bei Brozio, 2015; Eichhorn und Sucholetz, 2019; Klaffke, 2018; Marzano, 2003; Marzano et al., 2005; Reinke et al., 2011) als Kernbegriffe einer betriebswirtschaftlich geprägten Sprache, und kompetenzorientierte Förderung, als Inbegriff einer an sichtbaren und messbaren Fähigkeiten orientierten Pädagogik, im Vordergrund. Hierdurch werden aus Sicht der Critical Discourse Analysis aber institutionell abgesicherte Herrschaftsbeziehungen von Menschen über Menschen etabliert. Während die eine Gruppe ihren sozialen Status und ihre monetären Pfründe sichert, wird die andere Gruppe immer weiter stigmatisiert, marginalisiert und geschwächt, selbst wenn die wissenschaftlichen Rhetoriken das genaue Gegenteil davon behaupten.

In den sozialen Institutionen bilden sich dabei ideologisch-diskursive Formationen. In der Regel gibt es eine deutlich dominierende ideologisch-diskursive Formation in einer Einrichtung, in einer Schule, in einem Universitätsinstitut, in einem Fachbereich, wenn es nicht gar ein Gegeneinander annähernd gleich starker Formationen 
gibt, was dann natürlich ein Konfliktpotential beinhaltet und angespannte Atmosphären produziert. Jede dieser Formationen bildet nun eine Art Sprachgemeinschaft mit ihren eigenen diskursiven und ideologischen Normen. Eine solche Formation kann sich etwa um die Empirie drehen oder um den gesellschaftskritischen Auftrag der Bildungswissenschaften. Alles das, was in den sozialen oder pädagogischen Institutionen geschieht, an Thematisierungen, Konzeptentwicklungen usw. ist mehr oder weniger durch eine solche ideologisch-diskursive Formation geprägt. Mit der Zeit entwickelt sich das häufig in der Weise, dass seitens der Beteiligten eine solche Akzeptanz gegenüber einer dominierenden Formation aufgebaut wird, wenn es nicht gar zu einer vollständigen Verschmelzung mit den Inhalten dieser Formation kommt, dass die hier agierenden Personen, seien es Schulleitungen und Lehrkräfte oder Wissenschaftler_innen und Studierende, den Eindruck haben, es handele sich um eine allgemein als vernünftig akzeptierte und um die vermutlich einzig wahre und richtige Vorgehensweise. Fairclough (2013, S. 30) nennt diesen dann angelegten Maßstab common sense. Es geht der Critical Discourse Analysis nun um das Aufdecken solcher Ideologien, auf denen wissenschaftliche Diskurse und sich hieraus ergebende soziale und (sonder-) pädagogische Praktiken beruhen, Ideologien, die mit der Zeit als common sense auftreten und oftmals gar nicht mehr hinterfragt werden. Doch solche Ideologien müssen eben, trotz allem, hinterfragt werden. Auch dann, wenn sie durch die Politik, durch mächtige Instanzen, dominante Kolleg_innen oder durch eine bestimmte Art der Ressourcenverteilung vorangetrieben werden. »Macht und Geld sind aber keine regulativen Ideen von Wahrheit und damit Wissenschaft«, schreibt Ladenthin (2020, S. 829). Für Fairclough (2013, S. 46) beinhaltet eine Ideologie die Repräsentation der Welt aus der Perspektive eines bestimmten Interesses. Auch die sonder- und inklusionspädagogischen Diskurse müssten dann, gehen wir nach der Critical Discourse Analysis, andere werden, geht es doch um ein vertieftes Bewusstsein und das Entwickeln eines kritischen Sprachbewusstseins. Fairclough (2013, S. 527-543) spricht hier von critical language awareness. Was sind also die dominierenden ideologisch-diskursiven Formationen auf unserem Fachgebiet? Welche Sprachgemeinschaften existieren hier und an welchen diskursiven Normen sind diese ausgerichtet?

Psychoanalytische und verhaltensorientierte Modelle markieren hier sicherlich die allergrößten Gegensätze. Jede dieser Theoriewelten stellt eine eigene Sprachgemeinschaft mit bestimmten diskursiven Normen dar. Mit dem verstehenden Blick unter die Oberfläche des Verhaltens kontrastieren Sichtbarkeit, Messbarkeit und Operationalisierbarkeit. Die konfrontative und paramilitärische Schulkultur in Schwarzegg war durch einen totalitären und manipulativen Sprachgebrauch gekennzeichnet. Das Plastisch-Drastische, das permanente Wiederholen, das Einbrennen von griffigen Phrasen und Floskeln in das pädagogische Alltagsbewusstsein derjenigen, die Teil dieser Schule waren (vgl. hierzu auch die sprachkritischen Analysen von Victor Klemperer, 2018), gehörte hier zum Kerngeschehen. Den »Hammer kreisen lassen«, Schüler_innen »zusammenfalten« oder »eliminieren«. Oder: »Wir braten hier keine Extrawürste.« Eine solche Sprache war tagtäglich in der Förderschule Schwarzegg zu hören (vgl. zu diesem Fall ausführlich Bröcher, 2011, 2016). Ein Kollege, dessen vermeintliche Verstöße gegen die schulinternen Regeln, durch den, um die despotisch herrschende Schulleiterin versammelten, loyalen Kreis an Kolleg_innen akribisch notiert wurden, der also regelrecht bespitzelt wurde, »kriegte«, so der kollegiale Diskurs, »einfach nichts auf die Kette«. Die Schulleiterin berichtete triumphierend von ihren 
aggressiven Auseinandersetzungen mit einer Heimleiterin, die einen schülerorientierten, individualisierten Unterricht gefordert hatte. Am Ende hatte diese Heimleiterin allerdings »in eine Tischplatte gebissen«, und sie die Schulleiterin, ließe sich hier auch »von gar niemandem mehr hinten rumheben. Ende Gelände.«Ihren Sitzplatz im Lehrerzimmer hatte sie mit allerhand buntem Tand dekoriert, darunter ein, zu den Lehrkräften gewandtes, Mini-Flipchart mit einer darauf gepinnten Postkarte. Auf dieser war zu lesen: »Hier kann jeder machen was ich will.« Stand man/frau vor ihrer Bürotür, blickte man geradewegs auf die folgende Spruchkarte: »Jeder hat ein Recht auf meine Meinung."

Wieviel critical language awareness zeigt die Leiterin der Förderschule Schwarzegg, wenn sie von einer Schulleitersitzung berichtet, die »wieder einmal fürs Gesäß«war, wenn sie die Schüler_innen draußen auf der Terrasse antreten und geradestehen lässt, und sie anschreit, ihnen »ginge hier gleich der Arsch auf Grundeis«, wenn sie nicht sofort erfahren würde, wer die Toiletten so verdreckt hätte. Auf ihrem, mit rotem Tüll bekräuselten, Gesprächstisch, in einer Halterung schwebend, die "goldene Arschkarte« oder wechselweise das "goldene Popo-Kärtchen«. Der Leiter einer anderen Förderschule lebte wiederum in seiner ganz eigenen, freilich harmloseren, aber trotz allem unreflektierten Sprachwelt. Er begann fast jede Besprechung, jede Konferenz, wobei er zumeist eher moderierte, was die dominanten kollegialen Flügel vorbrachten und vorhatten, mit Sätzen wie: „Was ist denn hier der Sachstand? « Und später dann, wenn das Ganze ausreichend ausgebreitet und analysiert worden war: „Gut, was ist jetzt hier die Stoßrichtung? « Doch noch einmal zurück in die Welt der Academia. Über alle wissenschaftstheoretischen Gegensätze hinweg, haben sich in der Gegenwart, in den deutschen sonder- und inklusionspädagogischen Instituten und Abteilungen, in Studiengängen, Modulbeschreibungen, Akkreditierungspapieren, Publikationen, Konzeptentwicklungen, Modellentwicklungen, Forschungsprojekten und Forschungsberichten, entsprechend auch in ministeriellen Handreichungen, Schulgesetzen und Schulprogrammen, und damit wieder auf die Praxis an Schulen zurückwirkend, Begrifflichkeiten wie Diagnose, Förderung oder Intervention durchgesetzt. Diese Begriffe beherrschen den Fachdiskurs und die pädagogische Alltagspraxis in einer ungewöhnlich dominanten Weise, mittlerweile auf allen Ebenen des schulischen und außerschulischen Bildungssystems. Sie prägen nicht nur das pädagogische Wahrnehmen von Kindern, Jugendlichen, von schulischen und unterrichtlichen und sozialen Kontexten. Sie sind zum integralen Bestandteil der pädagogischen Denkweise von Lehrenden und Studierenden geworden, im Sinne von common sense, wie Fairclough es nennt.

Ich halte diese Entwicklung für eine ungeheure Verkürzung, Verflachung, Reduzierung, ja Verzerrung, in der gesamten pädagogischen Hinwendung zu Kindern und Jugendlichen. Deren tatsächliches Leben, in seiner tieferen Bedeutungshaftigkeit, deren realen soziokulturellen Lebenshintergrund, bekommen wir mit solchen vereinfachten, schematischen Rastern, die Wissenschaftlichkeit, Theoriebezug, Evidenzbasierung letztlich nur suggerieren und im Grunde eine unzulässige Vereinfachung, ein Aufpressen eines Schemas darstellen, nicht wirklich in den Blick. Wir gelangen so nicht zu einem tieferen Verständnis dessen, was das Leben dieser jungen Menschen, für die wir ja mit unserer Pädagogik da sein wollen, ausmacht. Die Begriffe Diagnose, Diagnostik, diagnostizieren, diagnostisch, die in der akademischen Sonder- und Inklusionspädagogik in einem fort zu hören sind und den Fachdiskurs bestimmen, gehen auf die griechischen Wörter diágnosis, gleichbedeutend mit Unterscheidung, Beurtei- 
lung, Erkenntnis, besonders die Beurteilung einer Krankheit durch den Arzt, sowie diagignoskein, gleichbedeutend mit genau erkennen, durch und durch erkennen, unterscheiden bzw. beurteilen zurück. Dabei hat sich der Begriff der Diagnose vor allem im Hinblick auf die Erkennung und Bestimmung von Krankheiten, Diagnostik entsprechend als Lehre von der Bestimmung und Erkennung der Krankheiten eingebürgert (vgl. Pfeifer, 2004, S. 221). Doch die Sammlungen von diagnostischen Tests in den sonderpädagogischen Instituten werden gehütet, als seien sie der Heilige Gral dieser Wissenschaft. Hier lagert der Kern des sonderpädagogischen Wissens, aber auch die Definitionsmacht und die Macht über Menschen in Problemlagen.

Fragwürdig erscheinen hier nun mehrere Dinge. Zum einen, dass sich die Sonderund Inklusionspädagogik hier so eng an die Medizin anlehnt und sich dieser gerne zur Seite stellt. Sie positioniert sich gleich neben der Medizin, um in einem Akt der parallelen Selbstdefinition Wissenschaftlichkeit zu generieren und zu behaupten, indem sie sich so aufstellt, als sei sie eine Art medizinisches Teilgebiet. Dies geschieht zumeist im Zuge der Betonung von quantitativ-statistischen und evidenzbasierten Modellen und Standards. Der unreflektierte Sprachgebrauch findet sich trotz allem auch in eher qualitativ orientierten Forschungscommunities. Pädagogik und Medizin sind jedoch sehr unterschiedliche Disziplinen. Die Pädagogik, die immerhin eine lange geisteswissenschaftliche und auch, wenigstens seit dem 19. Jahrhundert, eine gesellschaftskritische Tradition hat, könnte sich genauso von der Soziologie oder Philosophie her definieren. Aber gerne wird vor allem die klinische Psychologie, mit ihren Übergängen zur Psychiatrie, seitens der Pädagogik der emotionalen und sozialen Entwicklung zur Selbstdefinition dieser Sparte der Sonder- und Inklusionspädagogik herangezogen. Natürlich ist es wichtig, dass wir als Pädagog_innen erkennen, ob etwa ein problematisches Verhältnis zur äußeren Realität bei einem Kind oder Jugendlichen vorliegt, ob ein Heranwachsender möglicherweise sich und andere in Gefahr bringen könnte. Wir werden in solchen Fällen andere Fachleute hinzuziehen, müssen aber nicht selbst als inoffzielle Psychiater_innen oder klinische Psychotherapeut_innen agieren, auch werden wir ja nicht als solche tätig sein. Trotz allem sollten wir wissen, woran in der Psychologie und der Psychiatrie geforscht wird, mit welchen Methoden dies geschieht und was die Ergebnisse sind. Was spräche also dagegen, sich auf das pädagogische Handwerk zu beschränken, und zugleich die Erkenntnisse der genannten Wissenschaften zu beachten und $\mathrm{zu}$ integrieren in unser pädagogisches Handeln? Trotz allem betreiben wir aber eine Pädagogik, im eigentlichen Wortsinne, zum einen als Wegbegleitung, zum anderen als Anstoßen von relevanten Lernprozessen, als Aufspannen von Lernräumen.

Es gibt jedoch immerhin ein Modell, auch wenn es den Diagnostikbegriff noch in seinem Namen führt, das eine substantiell andere Richtung einschlägt: Die rehistorisierende Diagnostik, wie sie durch Wolfgang Jantzen geprägt worden ist. Jantzen (2018, S. 152) schreibt dazu: »Rehistorisierende Diagnostik rekonstruiert mit den Mitteln des je verfügbaren Erklärungswissens die einzelne Geschichte dort als sinnvoll und systemhaft, wo diese bisher auf Natur und Schicksal, Pathologie und Devianz reduziert wurde.« Rehistorierende Diagnostik unterscheidet sich auch von den allermeisten anderen im Feld der Inklusions- und Sonderpädagogik anzutreffenden Diagnostiken dadurch, dass ihr ein dialogisches und partizipatorisches Verständnis zugrundeliegt, indem es eine »Teilhabe der Diagnostizierten am Prozess der Diagnostik« gibt. Es wird nicht über die Menschen gesprochen, wie es in den allermeisten sonderpädagogischen 
Diagnostiken der Fall ist, sondern mit ihnen (vgl. Jantzen und Lanwer, 2012, S. VIII). Der kritische, emanzipatorische Ansatz, der in der rehistorisierenden Diagnostik enthalten ist, richtet sich gegen die Verdinglichung von Menschen, die sich im Feld der Macht, hier greift Jantzen auf Pierre Bourdieu zurück, kaum behaupten können (vgl. Jantzen und Lanwer, 2012, S. XIV). Rehistorisierende Diagnostik richtet sich auch gegen diagnostischen Reduktionismus (vgl. Jantzen, 2012 c, S. 15) und gegen die Abspaltung der Menschen von ihrer eigenen Geschichte (vgl. Jantzen und Lanwer, 2012, S. 3). »Es gibt in diesem Prozess keinen festen Punkt des abschließend erklärt oder verstanden Habens « (vgl. Jantzen, 2018, S. 152). Es handelt sich vielmehr um einen »nie abgeschlossenen Prozess mit dem Zweck, zu erkennen, zu erklären, zu begreifen, $\mathrm{zu}$ übersetzen, warum behinderte Menschen so geworden sind, wie sie sind « (vgl. Jantzen und Lanwer, 2012, S. VI). Auch eine kritische Selbstreflexion desjenigen, der eine solche Diagnostik betreibt, gehört zum Verständnis der rehistorisierenden Diagnostik dazu. Es geht ihr um die »Rekonstruktion der Gesamtsituation einschließlich der Rolle des Beobachters« (vgl. a. a. O., S. VIII). Jantzen (2018, S. 144 f.) unterscheidet nun weiter zwischen Erklären und Verstehen. Beim Erklärungswissen geht es um die »Rekonstruktion einer inneren Ordnung der Befunde «, beim Verstehen um einen »Akt der Anerkennung der Würde des anderen« (vgl. a.a.O., S. 151 f.). Wenngleich Befund ein ebenfalls sehr stark medizinisch geprägter Begriff ist, den ich persönlich in der Pädagogik der emotionalen und sozialen Entwicklung gar nicht mehr verwenden würde, denn in einer Pädagogik brauchen wir nicht notwendigerweise Befunde, wie in der Medizin.

Diagnostik als Rehistorisierung ist eine »dialogisch orientierte, gegen Unterdrückung gerichtete gesellschaftliche Praxis« (vgl. Jantzen und Lanwer, 2012, S. VI). Insofern handelt es sich um ein politisches Verständnis von Diagnostik, denn diese "zielt auf neue und egalitäre Formen menschlicher Praxis, weder auf Integration noch auf Inklusion, sondern auf eine gegen Ausschluss gewendete gesellschaftliche Transformation« (vgl. ebd.). Bei Franco Basaglia, auf den sich Wolfgang Jantzen in vielfacher Hinsicht bezieht, ist das »Verstehen eingebettet in einen politischen Prozess der Dechiffrierung jeder Form von Ausschluss als antihuman« (vgl. Jantzen und Lanwer, 2012, S. 5) und bei Alexander Romanowitsch Lurija, auf den Jantzen sich ebenso bezieht, in einen "psychologischen Prozess der Dechiffrierung jeder Tätigkeit als sinnvoll und systemhaft« (vgl. ebd.). Das Diagnostikverständnis, wie wir es bei Jantzen finden, steht vom Anliegen her betrachtet sicherlich im Einklang mit meinen eigenen Zielsetzungen, wenngleich ich, wie bereits oben gesagt, Begriffe wie Diagnostik und Befund gar nicht mehr in einer Bildungswissenschaft bzw. Pädagogik verwenden würde. Es muss jedoch bedacht werden, dass Wolfgang Jantzen teils über sehr schwere, körperliche und geistige Behinderungen schreibt und in diesem Zusammenhang medizinische Klärungen schon von wesentlicher Bedeutung sein können. Dies ist ja im Bereich der emotionalen und sozialen Entwicklung, bis auf wenige Ausnahmefälle, durchaus anders. Trotz allem bleibt aber immer zu unterscheiden, was Sache der Medizin ist und was Sache der Pädagogik ist.

Schauen wir uns nun das Konzept der Förderung ein wenig genauer an. Auch auf dieses sollte, in dem neu zu entwerfenden, mehr pädagogisch-philosophischen Theoriezusammenhang, verzichtet werden. Rein etymologisch bringt der Begriff der Förderung zwar keine Schwierigkeiten mit sich, bezieht er sich doch auf das Voranbringen eines Menschen. Doch brauchen wir diesen, mittlerweile reichlich abgenutzten, 
bis zur geistigen Abstumpfung aller Beteiligten, gebetsmühlenartig wiederholten und überall, mit solcher Massivität und Alternativlosigkeit propagierten und verwendeten, Begriff in der Pädagogik der Zukunft wirklich? Der Begriff Förderung (vgl. z. B. Popp et al., 2017; Ricken, 2013), so wie er eben all die Jahre verwendet worden ist, impliziert doch immer, dass Entwicklungsrückstände und dergleichen vorliegen und bringt das Kind und den Jugendlichen in die Position der Abhängigkeit gegenüber den Pädagog_innen bzw. gegenüber einem pädagogischen System, wie wir es früher schon bei den Termini Hilfsschule und Hilfsschulpädagogik hatten. Jemandem zu helfen oder jemanden zu fördern, liegt weder sprachlich, noch vom pädagogischen Verhältnis her betrachtet, weit auseinander. Diese andere, nämlich die pädagogische, Seite weiß, so wird unterstellt, wo es mit der Förderung hingehen soll. Egal, ob sie nun hilft, fördert oder unterstützt, es ist immer nur ein neues Wort für denselben überholten Sachverhalt, für dasselbe hierarchische, paternalistische, auf Abhängigkeit beruhende, pädagogische Verhältnis. Die Ziele der, zumeist eng gefassten, Förderbemühungen leiten sich nun aus dem schulischen Curriculum ab und lassen oftmals kaum Spielraum für selbstbestimmtes und partizipatives Lernen seitens der Heranwachsenden. Der kompetenzorientiert durchstruktuierte Lernapparat, mit dem Kinder und Jugendliche hier, indirekt natürlich auch ihre Eltern und Erziehungsberechtigten, zu tun bekommen, ist doch sehr machtvoll, und aufs Ganze gesehen wirkt er entmündigend. Selbst wenn beständig betont wird, dass dies alles doch zum Besten des Kindes oder Jugendlichen geschehen soll.

Ein weiteres Problem besteht darin, dass genau das gefördert wird, was man/frau mit der nunmal zur Verfügung stehenden und angewandten diagnostischen Methode erkannt zu haben glaubt, und leider auch nichts anderes. Ich verfüge über ein bestimmtes Repertoire an diagnostischen Verfahren, aber eben über keine weiteren, die darüber hinausgehen würden. Aber welche Logik liegt in diesem Ablauf und in einer solchen Verengung und Reduzierung? In der pädagogischen Realität kann ich mich auf so einer Basis vollständig neben den eigentlich wichtigen Dingen herbewegen, ohne dass es mir selbst oder irgendjemandem auffällt. Aber ich arbeite auf vermeintlich anerkannten Grundlagen, jedenfalls auf der Basis von Grundlagen, die eine der dominanten Sprachcommunities für richtig, wahr und effektiv erklärt hat. Das muss zur Legitimation ausreichen. Genauso problematisch ist der Begriff Intervention (vgl. z. B. bei Killu, 2008; Vaughn et al., 2003), der, im Verbund mit Diagnostik und Förderung, den zentralen Dreiklang des, im sonderpädagogischen Milieu in Endlosschleifen gesungenen, Mantras bildet und immer wiederkehrt und sich in unser Denken eingebrannt hat. Doch auch das gebetsmühlenartige Aufsagen kann nicht darüber hinwegtäuschen, dass das Ganze nicht mehr als eine überwiegend leere Schablone darstellt, die dazu dient, Professionalität und Wissenschaftlichkeit zu suggerieren und Status und Deutungsmacht über die Situation zu gewinnen und zu behaupten. Auch wird dieses Schema, seiner leichten Überschaubarkeit wegen, gerne von allen Beteiligten aufgegriffen, überall im Lande verbreitet und nachgesprochen. Doch im Grunde werden auf diese Weise sehr komplexe Zusammenhänge auf sehr simple Formeln reduziert, um sie beherrschbar und, im eng getakteten Schulalltag bzw. im Rahmen von universitären Modulen, Verwaltungsabläufen und Akkreditierungen, handhabbar $\mathrm{zu}$ machen. In Wahrheit wird jedoch, mit Blick auf den Bereich der emotionalen und sozialen Entwicklung, der größere Teil der gesellschaftlichen und kulturellen Wirk- 
lichkeit, um die es eigentlich geht, ausgeblendet. Was sich in diese Modelle nicht reinpressen lässt, bleibt einfach draußen.

Schauen wir noch ein wenig genauer auf das Wort Intervention. Das lateinische Wort interventio und das französische Wort intervention standen hier, etymologisch betrachtet, Pate und gehen mit den inhaltlichen Bedeutungen einschreiten, dazwischen kommen, vermittelnd eingreifen, dazwischen treten, vermitteln oder eingreifen einher (vgl. Pfeifer, 2004, S. 589). Natürlich ist diese Denkweise in gewissem Sinne auch verständlich. Etwas läuft schief und wir greifen ein, um die Dinge zum Besseren $\mathrm{zu}$ wenden, nachdem wir vorher eine genaue Diagnose gestellt und darauf aufbauend einen Förderplan entwickelt haben. Aber dieses Eingreifen und dazwischen Treten ist nur eine von vielen möglichen Blickrichtungen, nur eine mögliche Lesart von Situationen und Kontexten. Genauso kann ich mich als Pädagoge in eine herausfordernde Situation hineinbegeben und Schritt für Schritt einen Lernraum aufspannen, ohne zunächst, bezogen auf ein Kind oder einen Jugendlichen, einzugreifen. Wie oft wird, aus dem Stand, von Sonderpädagog_innen ein Aktionismus entfaltet, nur um Engagement oder Professionalität zu demonstrieren. Dabei wäre es oftmals besser, erst einmal genau zu beobachten und gar nichts zu tun und den Beteiligten zu sagen, dass es hier sicher keine schnellen Lösungen geben wird. Natürlich wird es auch Situationen geben, wo ich unmittelbar handeln muss, etwa wenn dem Kind oder einem anderen Kind, bedingt durch das zuerst genannte Kind, Schaden droht. Diese Fälle meine ich hier jedoch nicht und sie sind auch nicht Gegenstand der sonder- und inklusionspädagogischen Diagnostiken, Förderplanentwicklungen und Interventionsplanungen. Ich wage zu behaupten, dass es der Pädagogik und allen, die mit ihr, unter den Aspekten der emotionalen und sozialen Entwicklung, zu tun haben, überaus gut tun würde, ganz auf die Begrifflichkeiten Diagnose, Förderung und Intervention zu verzichten, ferner auch auf Inklusion, was zusätzlich für viele zu einem ambivalenten Reizwort geworden ist. Vor allem sollten wir endlich auf das Präfix Sonder vor Pädagogik verzichten, im Bereich emotionalen und sozialen Lernens brauchen wir es nicht mehr. Ebenfalls verzichten sollten wir auf das Präfix Heil, da es zusätzlich medizinische Unterströmungen transportiert und auch nahelegt, dass es sich um Krankheiten handelt, die da geheilt werden müssen. Wir sind mit unserem Anliegen in der Mitte der Pädagogik, wie in der Mitte der Gesellschaft, angekommen. Haben wir aber erst einmal die, teils dogmatischen und orthodoxen, Systeme der Heil-, Sonder- und Inklusionspädagogik hinter uns gelassen, gilt es, das eigene Schiff vorsichtig zu navigieren, um nicht in die Strudel gezogen zu werden, die unterdessen durch Educational Governance und Neue Steuerung in den Erziehungs- und Bildungswissenschaften, wie auch im schulischen und universitären Bildungssystem, erzeugt werden.

In welcher Art von Fachdiskurs wollen wir also unser professionelles Handeln verankern? Welche Sprache wollen wir sprechen, wenn wir über unser Handlungsfeld und die Menschen, die wir darin antreffen, reden? Welche Modelle und Konzepte wollen wir dabei anwenden? Welche pädagogischen und gesellschaftlichen Ziele wollen wir verfolgen? Wollen wir affirmativer Teil eines sozialen Kontroll- und Steuerungsapparats werden und uns in die, in Zusammenhang mit Educational Governance und Neuer Steuerung praktizierten, Sprachgewohnheiten und Routinen einfügen und Begrifflichkeiten wie Leistungsstandards, Evaluation, Kompetenzraster etc. fortwährend aufsagen? Oder wollen wir gemeinsam mit den uns anvertrauten Menschen die wahrgenommenen und erkannten Themen, Herausforderungen, aber auch die, uns 
alle miteinander umgebenden institutionellen Strukturen und Prozesse, einer philosophischen Reflexion und kritischen Analyse unterwerfen? Das wiederum wird auch auf das Sprechen einer anderen Sprache hinauslaufen. So ließen sich die oftmals in ihren Lebens- und Handlungsmöglichkeiten eingeschränkten Kinder und Jugendlichen und ihre Familien doch immerhin stärken und zugleich ließe sich auf die notwendigen sozialen Veränderungen hinwirken. Aber wie könnte das nun konkret gelingen? Was wären hier die Ziele und in welchen Schritten ließen sie sich erreichen? Welchen Beitrag können wir als Lehrkräfte im schulischen Förderschwerpunkt der emotionalen und sozialen Entwicklung im Sinne der Critical Discourse Analysis leisten? »Wir werden die Worte, die laut sind, verlernen, und von uns reden wie Sterne von Sternen, alle lauten Worte verlernen ...« dichtete Rainer Maria Rilke (vgl. Schönherz und Fleer, 2002). Das wäre doch etwas, in einer solch poetischen Sprache zumindest schon mal zu denken, wenngleich wir sie, in dieser genauen Form, im bildungswissenschaftlichen oder pädagogisch-praktischen Feld nicht so aussprechen werden.

Bernd Ahrbeck (2020, S. 306) argumentiert vorläufig noch gegen die Dekategorisierung und gegen die damit einhergehende Auflösung der Wissenschaftsdisziplin der emotionalen und sozialen Entwicklungsförderung in einem allgemeinen Heterogenitätsdiskurs und will an einer fachspezifischen Sprache, die eine klare Benennung der Probleme beinhaltet, festhalten. Bei einer Auflösung in einen allgemeinen Heterogenitätsdiskurs, so Ahrbecks Sorge, will ich auch nicht herauskommen. Denn es geht hier keineswegs um bloße Heterogenität oder Vielfalt. Es geht eher um Komplexität und Tiefgang, um die Gesellschaft als Ganzes und um die Tatsache, dass sich diese Gesellschaft auch als Ganzes ändern muss, weil wir die anwachsenden emotionalen und sozialen Schwierigkeiten, nicht nur diejenigen der Kinder und Jugendlichen, sondern auch die der mittleren und älteren Generationen, sonst nicht wirkungsvoll und nachhaltig beeinflussen können. Es beginnt mit dem kritischen Hinterfragen einer funktionalisierenden Sprache in der Inklusions- und Sonderpädagogik, zugleich in der Gesellschaft insgesamt. Das Problem ist, dass es dieser funktionalisierenden Sprache an Tiefe fehlt, an Differenziertheit. Wir brauchen etwa Worte, die die Rätselhaftigkeit unserer Existenz zum Ausdruck bringen, wie in der Poesie, und wir sollten achtsamer werden, was wir überhaupt wie benennen. Wir sollten die Dinge und die Personen und alles das, was mit ihnen zu tun hat, wenn ich erneut die Bücher von John O'Donohue in die Hand nehme, kann ich lesen, wie das geht, auf eine wertschätzende und raumgebende Art und Weise benennen. Poise ist etwa so ein Wort. Es ist zunächst einmal zu übersetzen mit Haltung, doch für O’Donohue bezeichnet es noch mehr, nämlich die innere Zentriertheit, das tief im Innern verankerte, natürliche Selbstbewusstsein, eine Art inneres und, damit verbunden, ein äußeres Standing. Sodann longing, womit er die Sehnsüchte bezeichnet, die uns antreiben, ferner belonging, die Lebensbereiche und Beziehungsformen also, wo wir Zugehörigkeit spüren und erleben. Wir sollten in Zukunft in der Pädagogik mehr mit solchen Begriffen arbeiten, also poise, longing und belonging, aber auch mit threshold, loving eye, presence, reverential mind und transfiguration, ich komme später noch einmal genauer auf diese Konzepte zu sprechen, statt Diagnostik, Förderung und Intervention, statt Rating-Tool, Behavior Screening, Förderplan und Kompetenzraster. Über die Konzepte des irischen Philosophen öffnen sich doch ganz andere Räume, um Menschen zu begegnen und mit ihnen gemeinsam $\mathrm{zu}$ lernen und $\mathrm{zu}$ arbeiten, und letztlich mit ihnen zu leben. 


\section{Strategisches Publizieren und das Verfehlen des State of the Art}

Die zunehmend durch Funktionalisierung, Entfremdung und Verflachung gekennzeichnete Wissenschaftswelt in weiten Teilen der Inklusions- und Sonderpädagogik spiegelt sich auch in einer bestimmten Art der Textproduktion und Publikationskultur wider. Es scheint zunehmend weniger darum zu gehen, den Dingen, nach bestem Wissen und Gewissen, wirklich auf den Grund zu gehen, Fragen aufzuwerfen, zu denken und Systemstrukturen zu verändern, sondern darum, Netzwerkpolitik zu betreiben, Gelände zu besetzen, Ressourcen zu generieren und die eigene strategische Position im Monopoly der Academia kontinuierlich zu verbessern. Nur was ist, wenn dabei die Sinnhaftigkeit des eigenen Tuns abhanden kommt? Welch umfangreiche personelle und finanzielle Ressourcen fließen auch in eine solche Studie und was davon kommt am Ende zur Gesellschaft, die diese Ressourcen bereitgestellt hat, zurück? Wie nachhaltig ist eine solche Wissenschaftskultur und Textproduktion also? Und wie wirkt sich das alles auf die jungen Menschen aus, die sich in inklusions- und sonderpädagogische Studiengänge einschreiben? Welches Bild von Wissenschaft und Theorieentwicklung wird ihnen da vermittelt? Im Folgenden nehme ich einmal eine solche Veröffentlichung exemplarisch genauer unter die Lupe. Da die betreffende Studie sich zum freien Download auf der Verlagsseite befindet, hat die kritische Leser_innenschaft die unmittelbare Möglichkeit, sich selbst ein Bild zu machen und gegebenenfalls meine kritischen Einwände wiederum zu hinterfragen. Das allein ist lebendige Wissenschaft.

»Und bist du nicht willig, so brauch ich Gewalt.< Der Trainingsraum: Empirische Befunde, theoretische Perspektiven, pädagogische Alternativen« ist ein Artikel von Dennis C. Hövel, David Zimmermann, Barbara Meyer und Stephan Gingelmaier überschrieben. Dieser ist in Heft 3, 2020 (S. 291-305), in der Zeitschrift Sonderpädagogische Förderung heute, im Verlag Beltz Juventa, erschienen. Beginnen wir mit dem Titel des Artikels. Es ist zu beachten, bei aller Kritik am Trainingsraumprogramm, im Folgenden nur noch TRP genannt, dass es nicht mit körperlicher Gewalt arbeitet. Diese Überschrift könnte dies jedoch suggerieren. Sie ist daher als problematisch einzuschätzen. Soweit es sich aber, in der Sichtweise von Hövel et al., beim TRP um psychische Gewalt handeln soll, müssten hier entsprechende Differenzierungen in ihrem Artikel vorgenommen werden. Nach der Auswertung der wenigen vorhandenen empirischen Untersuchungen zum TRP wollen die Autor_innen (S. 291) ein »Alternativkonzept«, einen »Freiraum für die schulische Auseinandersetzung mit Verhaltensstörungen« vorstellen. Dieser Satz, an das Ende des Abstracts gestellt, ist in mehrfacher Hinsicht kritisch zu sehen. Aus fachlicher Sicht ist es zunächst problematisch, den Begriff »Verhaltensstörungen« so unkommentiert zu verwenden. Das entspricht nicht heutigen sprachlichen Standards und humanen Werten, auch nicht den theoretischen Wissensständen, nicht nachdem wir den Labeling Approach, schon in den 7oer Jahren, als theoretische Hintergrundfolie hatten, nicht nachdem wir die Disability Studies, seit 2000, zur Verfügung haben und uns ebenfalls mit dem Konstruktivismus beschäftigt haben, schließlich auch nicht, nachdem wir die Critical Discourse Analysis, seit den 9oer Jahren, an der Hand haben.

Der Begriff Verhaltensstörungen, ohne dass er in Anführungszeichen oder kursiv gesetzt wird, um Distanz zu dieser Art der Sprache und Statuszuweisung, zu dieser Art der Machtdemonstration gegenüber marginalisierten oder in der Defensive be- 
findlichen jungen Menschen anzuzeigen, gilt als stigmatisierend, etikettierend und pathologisierend. Und es kann schon allein deshalb kein »Freiraum« mehr sein, der hier am Ende als Alternative zum TRP präsentiert werden soll, weil das ganze Unternehmen unter der Maßgabe einer solchen Zuschreibung, auf einer solchen Verengung, Vereinseitigung und Verzerrung der komplexen pädagogischen und gesellschaftlichen Realität beruht, wie sie eben in der Etikettierung Verhaltensstörung zum Ausdruck kommt. Es wird also »ein Freiraum für die schulische Auseinandersetzung mit Verhaltensstörungen" geschaffen. Wieviel Freiheit wird es denn da für einen Jugendlichen geben? Schließlich wird er dort ja als ein Mensch mit Verhaltensstörung empfangen und betrachtet, so oder so. Es müssen vermutlich doch noch ganz andere Dinge stattfinden, als dass wir uns bloß mit den vermeintlich störenden oder gestörten Verhaltensweisen eines Kindes oder Jugendlichen beschäftigen. Dazu ist auch schon viel geschrieben worden, von Göppel (2002), Jornitz (2004) oder Pongratz (2010) und anderen, unter anderem auch von mir (vgl. Bröcher, 2005 a, b; 2007 b; 2010, 2011 a, b; 2014 a, b; 2019 c). Hövel et al. werden mir womöglich in dem Punkt sogar zustimmen, weil vieles in ihrem Artikel darauf hindeutet. Nur warum schreiben sie dann einen solchen Satz wie den oben genannten? Und wieso kommen all die Dinge, die bereits Göppel, Jornitz, Pongratz und Bröcher, und noch andere, zur Analyse des TRP geschrieben und veröffentlicht haben, in der Einleitung (Hövel et al., S. 291-293) zu dem Artikel nicht vor? Diese gesamte Einleitung verliert sich auf Nebengleisen und führt nicht zum Thema der Studie hin.

Lesen wir uns also in den Text ein: ")Und bist du nicht willig, so brauch ich Gewalt erscheint gleichwohl als durchaus präzise Metapher eines erzieherischen Paradigmas, das sowohl in der schulischen als auch außerschulischen Pädagogik eine wieder zunehmende Form von Popularität genießt und gleichsam popularisiert wird« schreiben Hövel et al. (S. 291). Was genau macht dieses vermeintliche Paradigma denn aus? Wie lässt es sich charakterisieren oder definieren? Wo können wir etwas darüber lesen? Von wem wird darüber geschrieben? Mir ist ein solches Paradigma aus der Literatur bisher nicht bekannt. In welcher Form äußert sich dieses vermeintliche Paradigma denn in der pädagogischen Praxis? Gehört auch das TRP dazu? Gehört die konfrontative Pädagogik Jens Weidners dazu? Gehört die paramilitärische Schulkultur von Schwarzegg dazu, über die ich ja auch schon geschrieben habe (vgl. Bröcher, 2011, 2016)? Oder die Glenn Mills Schools in den USA? Diese wurden inzwischen wegen zahlreicher Qualitätsmängel und pädagogischer Missstände geschlossen. Bei wem in Deutschland genießt dieses vermeintliche Paradigma also »Popularität « und durch wen, wie und wo wird es "popularisiert«? Das müsste doch konkret aufgezeigt und belegt werden. Was genau sollen wir auch unter popularisieren verstehen? Heißt es vielleicht verbreiten, also unters Volk bringen? Ist »Und bist du nicht willig, so brauch ich Gewalt« also wirklich eine »präzise Metapher«, wie Hövel, Zimmermann et al. schreiben, zur Beschreibung eines vermeintlichen Paradigmas, über dessen konkrete Gestalt wir als Leser_innen aber im Dunkeln bleiben und das wir gar nicht greifen können? Oder ist das vielleicht gerade die Absicht? Etwas Dunkles, Bedrohliches anzudeuten, womöglich die, tief unten in uns liegenden, Erinnerungen an die Zeiten der Schwarzen Pädagogik, an Prügelstock, Lederriemen und dunkle Kellerräume, wachzurufen, ohne dies jedoch genau zu benennen, und dann mit einer scharfsinnigen wissenschaftlichen Analyse, wie man/frau sie hier nun erwarten könnte, Licht in all das hineinzubringen? Können wir aber etwas so Unklares und Ungenaues "präzise« nennen? 
Schauen wir uns den folgenden Abschnitt einmal genauer an: »Denn die Kernklientel des Förderschwerpunkts Emotionale und soziale Entwicklung wird von schulischen und außerschulischen Fachkräften systemübergreifend als besonders herausfordernd wahrgenommen (Korpershoek, Harms, de Boer, van Kuijk \& Doolaard, 2016). Auch hier liefert der >Erlkönig \ durchaus brauchbare Metaphern: Mitglieder dieser Gruppe zeigen häufig rational scheinbar nicht erklärbare oder angstdominierte Verhaltensweisen (>birgst so bang dein Gesicht ), wirken dissoziativ (`Mein Vater, und hörest du nicht?) und agieren nicht selten übergriffig. Lehrkräfte reagieren häufig mit abrupt wechselnden Formen der Zuwendung ('gar schöne Spiele spiel ich mit dir), von Angeboten >Goldener Fantasien< (Cohen, 2004, S. 51-65) im Sinne des dyadischen Beziehungsangebots ('willst feiner Knabe du mit mir gehen?) und den damit unhintergehbar verbundenen Formen der Entwertung und des Ausschlusses (>und bist du nicht willig, so brauch ich Gewalt ) (Überblick bei Stein \& Müller, 2015, S. 37-40)« (a.a. O., S. 292). Beginnen wir mit dem ersten Satz. Das könnte jede $x$-beliebige Person, die etwas über die Situation in heutigen Schulen weiß, gesagt haben. Der Verweis auf Korpershoek et al. erscheint zum einen beliebig und austauschbar, zum anderen auch nicht präzise, denn Korpershoek et al. haben eine Metaanalyse zu den Effekten von Strategien des Classroom Managements unternommen. Eine so allgemeine Feststellung, dass diese Gruppe von Heranwachsenden von allen Sparten an Fachkräften als »herausfordernd wahrgenommen « wird, liegt ja in der Natur der Sache und ist zum anderen gar nicht Thema des Artikels von Korpershoek et al., auf den sich Hövel et al. aber beziehen. Korpershoek et al. verfolgen in ihrem Text in erster Linie das Anliegen, die Effekte von Strategien des Classroom Managements metaanalytisch zu vergleichen. Warum verweisen Hövel et al. dann aber auf diese Publikation? Lässt sich so der Eindruck von Wissenschaftlichkeit erzeugen?

Der zweite Satz soll nun vermutlich eine Überleitung schaffen, aber von was wird dabei ausgegangen und zu was soll hingeführt werden? »Auch hier liefert der >Erlkönig، durchaus brauchbare Metaphern«, schreiben Hövel et al. Was steckt in dem »hier«? Bezieht sich das hier auf die »Kernklientel des Förderschwerpunkts Emotionale und soziale Entwicklung« oder auf die »Wahrnehmung « der "schulischen und außerschulischen Fachkräfte« der »Kernklientel« als »besonders herausfordernd«? Es geht also jetzt um Charakterisierungen der »Kernklientel«, denn Hövel et al. sagen nun, dass »Mitglieder dieser Gruppe« »häufig rational scheinbar nicht erklärbare oder angstdominierte Verhaltensweisen « zeigen und setzen in Klammern dahinter »birgst so bang dein Gesicht", ein Element aus dem Erlkönig also, quasi zur Illustration ihrer recht allgemeinen und hypothetischen Aussage, die sie zuvor in den Raum gestellt haben. Vereinfacht gesagt ließe sich das vielleicht so ausdrücken: Jugendliches Verhalten ist häufig rational nicht erklärbar und durch Ängste gekennzeichnet und diese Passage aus dem Erlkönig bringt das zum Ausdruck. Aber kann diese Ballade das überhaupt widerspiegeln? Hatte Goethe, der Erlkönig wurde 1782 veröffentlicht, so etwas im Sinn? Nun verfügen wir über eine Vielzahl von Interpretationen zum Erlkönig. Es scheint jedoch am ehesten in die Richtung zu gehen, dass sich in der Ballade naturmagische, gefühlshafte, teils verführerische, teils bedrohliche, Daseinselemente in ihrem Ringen mit einer mehr aufklärerisch-rationalen Haltung manifestieren. Was Goethe in lyrische Bilder kleidete, bildet also geistige, emotionale Prozesse im Bewusstsein ein- und derselben Person ab. Können wir Goethes Ballade also einfach so simplifizierend heranziehen, um bestimmte Phänomene, die uns in der heutigen pädagogi- 
schen Wirklichkeit begegnen oder begegnen könnten, zu illustrieren? Ist das einem Kulturgut wie dem Erlkönig angemessen? Hövel et al. fahren fort: »Mitglieder dieser Gruppe ... wirken dissoziativ«. Doch was ist hier genau mit dissoziativ gemeint? Nur ein Teil der Leser_innen dürfte unmittelbar eine inhaltliche Vorstellung davon haben, was Hövel et al. mit diesem Begriff tatsächlich meinen könnten. Ist damit das Auseinanderfallen, eigentlich zusammenhängender, psychischer Funktionen gemeint? Und wieso steht jetzt dahinter in Klammern die Passage aus dem Erlkönig "Mein Vater, und hörest du nicht?« Verweist das dann, in dem von Hövel et al. angedachten pädagogischen Transfer, auf mögliche Halluzinationen des Kindes? Oder soll dieser Satz aus dem Erlkönig auf eine bestimmte Beziehungsthematik zwischen Vater und Kind hindeuten? Das bleibt aber unbeantwortet. Goethes literarisches Anliegen, selbst wenn Hövel et al. nun solche Dinge in den Erlkönig hineininterpretieren, kann das aber kaum gewesen sein. Es geht folgendermaßen weiter: »Mitglieder dieser Gruppe ... agieren nicht selten übergriffig«. Hier haben Hövel et al. offenbar kein passendes, zur Illustration taugendes, Versatzstück im Erlkönig gefunden. Diese Behauptung muss also ohne assoziative Verknüpfung mit einer spannungserzeugenden Erlkönig-Passage auskommen. Als Leser_innen stehen wir daher ratlos da, so oder so. Auch erscheint »Kernklientel« nicht gerade als ein sehr wertschätzendes Wort für die Kinder und Jugendlichen, mit denen wir pädagogisch arbeiten. Diese Bezeichnung drückt eher eine kühle Distanz zu den jungen Menschen aus. Was heißt dann auch »Kernklientel«? Stecken da Kategorisierungen drin? Geht es um Häufigkeiten von bestimmten Phänomenen, die uns in den pädagogischen Feldern begegnen können? Wir erfahren das nicht. Der Sprachgebrauch von Hövel et al. wirkt an der Stelle sehr ungenau.

Doch zurück zur Analyse des Textabschnitts. Die also zu dieser »Kernklientel« gehörenden Heranwachsenden agieren nun »übergriffig«. Wie häufig? »Nicht selten.« Ich versuche einmal zu übersetzen: Also das kommt vor, zwar nicht oft, aber immer mal wieder. Das sind erneut sehr vage Angaben, die hier von Hövel et al. in den Raum gestellt werden. Aber vor allem: Was heißt »übergriffig« denn? Was meinen die Autor_ innen damit? Gibt es dazu eine Theorie, wo dieses Wort vorkommt? Ich kenne selbst keine solche Theorie, auch kein Modell, oder ist das pädagogisch-populistische Alltagssprache? Ist das wissenschaftlicher Populismus? Ist das Wort übergriffig hier vielleicht sogar ironisch gemeint? Aber dann hätten Hövel et al. es doch sicher kursiv oder in Anführungsstriche gesetzt. Das Wort übergriffig steht hier aber einfach so. Geht es da um körperliche Streitereien oder gar Attacken? Nehmen die betreffenden Heranwachsenden anderen etwas weg? Geht es vielleicht sogar um sexuell inakzeptables, grenzüberschreitendes Verhalten? Wir können lange darüber rätseln, was Hövel et al. hier wirklich meinen. Im Folgenden geht es nun um die Lehrkräfte: »Lehrkräfte reagieren häufig mit abrupt wechselnden Formen der Zuwendung.« Dieser Satz stellt eine Behauptung dar, die weder von Hövel et al. belegt wird, noch wird sie sich überhaupt anhand dessen, was wir an Forschungsliteratur zur Verfügung haben, belegen lassen. Ich war ja nun selbst 18 Jahre in Schulen tätig und habe auch, in den Jahren danach, noch etliche Schulen beratend begleitet. Solche »abrupten Wechsel« in der pädagogischen Beziehungsgestaltung, wenn ich "Zuwendung « einmal so übersetze, mag es in Einzelfällen geben, aber häufig ist das sicherlich nicht. Ließe sich diese Aussage bezüglich der »abrupten Wechsel« also anhand von Forschungsergebnissen belegen? Lehrkräfte, die professionell und selbstreflektiert arbeiten, praktizieren, in der Regel, eher eine durchgängige, verlässliche, für die Schüler_innen berechenbare, Haltung im 
Rahmen ihrer pädagogischen Beziehungsgestaltung. Zur Illustration des gerade Behaupteten packen Hövel et al. die folgende Erlkönig-Passage in Klammern dahinter: "gar schöne Spiele spiel ich mit dir«. Das dürfte aber nun den Anschein erwecken, dass hier ziemliche Willkür seitens vieler Lehrkräfte herrscht. Sie »spielen gar schöne Spiele« mit den Heranwachsenden. Die Text-Montage von Hövel et al. legt nahe, dass die Kinder und Jugendlichen der Herrschaft der Lehrkräfte nun völlig ausgeliefert sind. Manchmal können die Lehrer_innen sehr freundlich und zugewandt sein, manchmal ist das exakte Gegenteil davon der Fall. Durch das aus dem Zusammenhang der Ballade gerissene Erlkönig-Element steht plötzlich die Vorstellung im Raum, dass hier Menschen ihre Macht, die sie durch ihr Amt verliehen bekommen haben, ausnutzen könnten, um andere, Abhängige und Untergebene nicht näher definierten "Spielen« $\mathrm{zu}$ unterziehen. Ein Horrorszenario klingt tief unten in mir, als Leser und ehemaliger Schüler, an. Es werden Assoziationen in Richtung körperlicher Gewalt geweckt, an sadistische Spiele, die gar auch sexuelle Komponenten enthalten könnten. Natürlich steht das nicht explizit da, aber solche Assoziationen können durchaus entstehen, wenn die Sätze und Bilder so, aus dem eigentlichen Zusammenhang des Erlkönigs herausgerissen, mit Versatzstücken einer pädagogischen Theorie zusammengefügt werden, wie Hövel, Zimmermann et al. es tun.

Es bleibt weiter rätselhaft, wenn Hövel et al. schreiben: »...von Angeboten >Goldener Fantasien (Cohen, 2004, S. 51-65) im Sinne des dyadischen Beziehungsangebots (১willst feiner Knabe du mit mir gehen?).« Schon grammatikalisch liegt dieser Satz von Hövel et al. jenseits dessen, was wir eine durchgetaktete Grammatik nennen. Ich habe den Satz einmal auf seine Grundstruktur reduziert, um etwas klarer zu sehen: »Lehrkräfte reagieren häufig mit abrupt wechselnden Formen der Zuwendung ..., von Angeboten >Goldener Fantasien .... im Sinne des dyadischen Beziehungsangebots ... und den damit unhintergehbar verbundenen Formen der Entwertung und des Ausschlusses.« Grammatik ist, nach den allermeisten Definitionen, die Lehre vom inneren Aufbau einer Sprache. In diesem Detail aus dem Aufsatz von Hövel, Zimmermann, Meyer und Gingelmaier zeigt sich aber der ganze Mangel an Durcharbeiten, an Durchdenken, an Debattieren, der Mangel an Ringen um die letztendliche Formulierung, zugleich auch der Mangel an klarer Argumentation und Gedankenentwicklung, mit dem wir hier zu tun haben. »Goldene Fantasien« werden also von Lehrer_innen »angeboten«? Was aber sind diese "goldene Fantasien«? Wir werden auf eine Publikation von Cohen verwiesen. Schauen wir auf der Literaturlise nach, ob wir dort Aufschluss über dieses, uns aufgegebene, Rätsel finden können. Cohen hat 2004 ein Buch herausgegeben mit dem Titel »Das mißhandelte Kind«. Der Untertitel lautet »Ein psychoanalytisches Konzept zur integrierten Behandlung von Kindern und Jugendlichen«. Diese "goldenen Fantasien« müssen also etwas mit Misshandlungen zu tun haben. Verwenden erwachsene Menschen, die Kinder misshandeln, also "goldene Fantasien«? Dienen diese womöglich der Verführung und Überrumpelung von Kindern? Nun wird da noch das theoretische Versatzstück »im Sinne des dyadischen Beziehungsangebots« drangehängt, wohl ein Baustein aus der psychoanalytischen Pädagogik. Kann denn das Spiel mit den »goldenen Fantasien« tatsächlich ein »dyadisches Beziehungsangebot« sein? Eher ist es doch eine Verzerrung und Verkehrung desselben, wenn wir ja zugleich den Hinweis bekommen, dass die "goldenen Fantasien« mit Kindesmisshandlung in Verbindung stehen. Das hinter das »dyadische Beziehungsangebot« gesetzte Erlkönig-Element »willst feiner Knabe du mit mir gehen?« weckt, ähnlich wie schon das "gar schöne Spiele spiel 
ich mit dir«, hier auf den pädagogischen Kontext übertragen, Assoziationen, die ins Dunkle, Irrationale, Unterschwellige gehen und die sich auch um Verführung, alle nur denkbaren Formen der Misshandlung, vielleicht auch sexuelle Perversionen und was noch alles, drehen könnten. Hövel et al. gehen dem aber nicht weiter nach, überlassen die Leser_innenschaft ihren eigenen Assoziationen und klären das auch nicht auf.

Der Textabschnitt endet so rätselhaft, wie er begonnen hat: "Lehrkräfte reagieren häufig mit ... und den damit unhintergehbar verbundenen Formen der Entwertung und des Ausschlusses«. Was bedeutet »unhintergehbar«? Soll mit diesem Wort philosophische Tiefe suggeriert werden? Aber wird dadurch nicht eher ein Nebel der Unklarheit erzeugt? Und wer oder was wird »entwertet«? Das Kind oder der Jugendliche als Person? Das Lernanliegen, die Lebenssituation, die Autonomie, der Selbstwert der jungen Menschen? Und wer wird »ausgeschlossen«? Geht es jetzt schon um das Trainingsraumprogramm (TRP), wo Schüler_innen ja vorübergehend hingeschickt werden, um über ihr Verhalten nachzudenken und Besserung zu geloben? Geht es also um den "Ausschluss « der Kinder und Jugendlichen aus dem Klassenunterricht? Direkt dahinter wurde erneut das, schon im Titel des Aufsatzes zu lesende, ErlkönigElement gesetzt: »und bist du nicht willig, so brauch ich Gewalt«. Doch durch diese drohende Zeile werden viele Leser_innen erneut an den Prügelstock, Lederriemen usw. denken. Das ist aber nicht Teilbestandteil des TRP. Im Gegenteil, Balke bzw. Bründel und Simon, die ja nun so massiv für das TRP geworben haben, wollten ja gerade weg von den cholerischen Wutausbrüchen von überforderten Lehrer_innen, die auch mal eine Ohrfeige gaben oder mit dem Schlüsselbund nach einem Schüler warfen. Sie wollten eben versachlichen. Trotz allem könnten wir die Hypothese aufstellen, dass das TRP mit seinen rigiden Frageritualen, die den Schüler_innen keine Chance auf Eigensinn lassen, Anteile von psychischer Gewalt enthält. Hövel et al. differenzieren hier aber nicht. Körperliche und psychische Gewalt werden in ihrem Artikel nicht unterschieden. Auch fehlen die dazu notwendigen theoretischen Bezüge. Am Ende dieses Abschnitts, mit dem ich mich jetzt so detailliert beschäftigt habe, kommt noch ein Literaturhinweis: »(Überblick bei Stein \& Müller, 2015, S. 37-40)«. Bezieht sich der Hinweis auf den ganzen Abschnitt oder nur auf den letzten Satzteil? Und welche Art von Überblick erhalten wir dort, in der genannten Bezugsquelle? „Verhaltensstörungen und emotionale-soziale Entwicklung: zum Gegenstand«, lautet der Titel des betreffenden Kapitels, das Roland Stein und Thomas Müller für ein Buch verfasst haben, das sie selbst herausgegeben haben. Bekommen wir dort einen Überblick zu den »Formen der Entwertung und des Ausschlusses « oder zu sämtlichen in diesem Abschnitt abgehandelten Themen? Der letzte Teil des betreffenden Absatzes ging doch über die Lehrkräfte. Das zitierte Buch befasst sich aber nicht mit der Einstellung oder dem Handeln von Lehrkräften, sondern es gibt einen Überblick zu »Verhaltensstörungen«, wohl von Heranwachsenden. Dient dieser Literaturverweis also nur zur vagen Einrahmung des Ganzen, ohne dass es dabei auf konkrete Fragestellungen oder inhaltliche Bezüge ankommt? Auch handelt es sich ja um ein Buch mit dem Titel »Inklusion im Förderschwerpunkt der emotionalen und sozialen Entwicklung«, das Stein und Müller herausgegeben haben. Die Leser_innen sollen eventuell noch einmal daran erinnert werden, dass wir uns nicht im Feld der Literaturwissenschaft, sondern in der Inklusionspädagogik befinden? Wird so auch Wissenschaftlichkeit bloß demonstriert? Werden nach solchen Mustern wissenschaftliche Texte zusammenmontiert? Oder ging es mehr darum, an irgendeiner, halbwegs passend 
erscheinenden, Stelle des Textes, die Namen Roland Stein und Thomas Müller fallen zu lassen? Könnte der dem zugrundeliegende Subtext dann lauten: Seht, das ist unser wissenschaftliches Netzwerk!? Angenommen das träfe zu: Was würde das über den Zustand der Wissenschaftscommunity in diesem pädagogischen Gebiet aussagen? Was sagt das über die Formierung von wissenschaftlichen Netzwerken und die Art, wie sie dann arbeiten? Geht es am Ende also mehr um Netzwerkpolitik als um den eigentlichen Inhalt von solchen Studien? Geht es mehr um ein strategisches Name Dropping, wer hier also wen zitiert und wen man, aus mikropolitischen Gründen, weglässt und verschweigt?

Nun leiten Hövel et al. (S. 292) zum Thema der Inklusion über: »Wie lässt sich diese hoch und - aus literaturwissenschaftlicher Sicht - unprofessionelle Interpretation einer epochenverbindenden Ballade nunmehr mit aktuellen Fragen der schulischen und außerschulischen Förderung von Kindern und Jugendlichen mit erheblichen psychosozialen Beeinträchtigungen verbinden?« Das ist in der Tat eine wichtige Frage. Es folgt jetzt seitens Hövel et al. eine eher allgemeine Einführung zu den Problematiken der Inklusion und zu der Herausforderung, die diese für Lehrkräfte darstellt. Es handelt sich um eine Art von Textbaustein, der auch in zahllosen anderen Texten zu, im weitesten Sinne, inklusionspädagogischen Themen, zu finden sein könnte. Gegen Ende dieses ersten Teils kommen Hövel et al. (S. 293) nun noch einmal auf den Erlkönig zurück: "Eine heftige emotionale Verwicklung aller Beteiligten, so wie in der Ballade >Erlkönig beschrieben, zeigt sich nahezu regelhaft als Ergebnis dieses komplexen Bedingungsfelds (Zimmermann, 2019).« Können wir denn wirklich das tiefgründige Geschehen in Goethes Erlkönig in der Weise heranziehen, dass wir darin eine Beschreibung der »emotionalen Verwicklung« von Menschen, das heißt Lehrkräften und Schüler_innen, im Kontext Schule und Unterricht, wiedererkennen wollen? Und hilft uns da der selbstzitierende Verweis auf eine Publikation von Zimmermann zum Thema »Professionalisierung für Unterricht und Beziehungsarbeit mit psychosozial beeinträchtigten Kindern und Jugendlichen« wirklich weiter? Ist dadurch, dass Zimmermann an der Stelle seine eigene Publikation ins Feld führt, eine Art Legitimierung geschaffen, dass der Erlkönig so verwertet werden darf?

Ganz zum Schluss dieses Textteils kommt auch, endlich, die Rede auf das TRP. »Um dem Bildungs- und Erziehungsauftrag der Schule gerecht zu werden, suchen Lehrkräfte jedoch nach einfach handhabbaren und effektiven Konzepten, um mit Unterrichtsstörungen und Disziplinkonflikten umzugehen, wobei sich die Methode des Trainingsraums seit einigen Jahren zunehmender Beliebtheit erfreut (Wollenweber, 2013)«, so zu lesen bei Hövel et al. (S. 293). Dieser Satz ist in mehrfacher Hinsicht aufschlussreich. "Seit einigen Jahren« ist allerdings nicht ganz zutreffend. Es war genau genommen das Jahr 2003, als das TRP Einzug in viele deutsche Schulen hielt, also 17 Jahre vor dem Erscheinen der hier diskutierten Studie. Stefan Balke unterhielt damals eine Internetseite, auf der sich immer neue Schulen selbstbewusst präsentierten und öffentlich bekannten, dass sie jetzt auch das TRP verwendeten. Warum Hövel et al. sich hier allerdings auf Wollenweber beziehen, erschließt sich nicht, denn dieser unternimmt eine Vergleichsstudie und interessiert sich für die Wirksamkeit des TRP, nicht aber für die bildungshistorische Einordnung und Herleitung des TRP. Solche Literatur, die aber genau darauf abzielt, hier einleitend heranzuziehen, hätte dem Artikel von Hövel et al. sicher überaus gut getan, also die Publikationen von Göppel, Jornitz, Bröcher oder Pongratz und noch weiteren Autor_innen, die dazu 
geschrieben haben. Mit heranziehen meine ich allerdings nicht, solche Texte kurz einmal oberflächlich zu erwähnen, wie es Hövel et al. ja einige Male tun, quasi als eine Art Pflichterfüllung am Rande, sondern diese Texte tatsächlich in der Tiefe zu lesen, auszuwerten, $\mathrm{zu}$ analysieren, diese auf vielleicht neue Art zu kategorisieren, zu systematisieren, mit aktuellen Entwicklungen zu verknüpfen, diese Texte gerne auch $\mathrm{zu}$ kritisieren und das Ganze zur Basis neuer, weitergehender, zukunftsweisender, realitätsbezogener Forschungen zu machen. Interessanterweise hatte Wollenweber (2013, S. 1) selbst in seiner Dissertation geschrieben: »Vor diesem Hintergrund ist es verständlich, dass Schulleitungen und Lehrkräfte nach einfach handhabbaren und effektiven Konzepten suchen, um in ihren Schulen während des Unterrichts ein positives Lernklima zu ermöglichen (Bröcher, 2005 b).«Wollenweber verwendet also einen Text von mir als einen, eher allgemein die Situation in Zusammenhang mit dem TRP beschreibenden, Literaturbezug, der daher auch ein wenig vage erscheint. Es handelt sich offenbar nicht um ein wörtliches Zitat, sondern Wollenweber fasst zusammen, was er bei mir insgesamt gelesen und gefunden hat. Das ist ja auch legitim. Hövel et al. dagegen verwenden nun denselben Gedanken wie Wollenweber, nur verweisen sie jetzt nicht mehr auf mich, sondern auf Wollenweber. Das heißt sie transportieren ein Gedankengut von 2013 nach 2020 weiter, das Wollenweber, zumindest teilweise, zunächst aus meinem Text von 2005 (b) geschöpft hat. Wollenweber hat dieses Gedankengut also von 2005 ins Jahr 2013 mitgenommen, aber nun, beim durch Hövel et al. vorgenommenen Update auf das Jahr 2020, gehen quasi Bezugsquellen verloren, denn mein Name wird in der Vergangenheit zurückgelassen. Bei Hövel et al. (2020, S. 293) klingt das dann so: »Um dem Bildungs- und Erziehungsauftrag der Schule gerecht zu werden, suchen Lehrkräfte jedoch nach einfach handhabbaren und effektiven Konzepten, um mit Unterrichtsstörungen und Disziplinkonflikten umzugehen ... (Wollenweber, 2013)." Das Satzelement »nach einfach handhabbaren und effektiven Konzepten " wurde von Hövel, Zimmermann et al. also offensichtlich direkt von Wollenweber übernommen, allerdings ohne dieses in Anführungszeichen zu setzen. Die Lehrkräfte, die danach suchen, werden von Wollenweber vor und hinter dieses Satzelement gesetzt, von Hövel et al. nun aber komplett davor.

Im zweiten Teil des Artikels stellen Hövel, Zimmermann et al. nun über zwei ganze Heftseiten hinweg das TRP noch einmal inhaltlich detailliert dar. Das wäre aber, da wir ja die Publikationen von Balke sowie Bründel und Simon vorliegen haben, nicht erforderlich gewesen. Insbesondere Bründel und Simon (2013) arbeiten in ihrem, mehrfach aktualisierten, Buch viel mit anschaulichen Graphiken. Gleich im ersten Satz unterläuft Hövel et al. auch eine Ungenauigkeit, denn wir müssen ja nun mal voraussetzen, dass sich die vier Autor_innen gründlich in die Materie eingearbeitet haben. Das TRP wurde von Balke (2003) und Bründel und Simon (2003) fast zeitgleich, selbst wenn Balke etwas schneller gewesen ist, für den deutschen Sprachraum adaptiert, also nicht allein von Balke, wie Hövel et al. schreiben. Die beiden Parteien konkurrierten in den nachfolgenden Jahren sehr stark miteinander. Vor allem Bründel war es, die in unermüdlichem Eifer durch die deutschen Schulen reiste, aber auch Balke pflegte seine Website und listete eine Schule nach der anderen, die er wieder einmal vom TRP überzeugt hatte. Warum Hövel et al., bezüglich der Frage der deutschen Adaptierung, Wollenweber überhaupt als Quelle angeben, erscheint nicht nachvollziehbar. Wollenweber liefert, wie bereits erwähnt, mit seiner empirischen Vergleichsuntersuchung zum TRP, keine verlässliche Quelle für den historischen Vorlauf, den das TRP genom- 
men hat. Auf Quellen in einer solch ungefähren und unpräzisen Art und Weise zu verweisen, könnte mit einer wenig gründlichen Recherche in Zusammenhang stehen. Den dann in ihrem Artikel für die detaillierte Erläuterung des TRP verwendeten Raum hätten Hövel et al. für die Diskussion all dessen nutzen können, was Göppel, Jornitz, Bröcher, Pongratz und andere bereits über die Problematik des TRP an theoretischen Analysen zusammengetragen haben, denn wie das TRP geht, können wir, wie bereits erwähnt, ja gut bei Balke bzw. Bründel und Simon nachvollziehen. Was allerdings erstaunlich ist, dass ich nun, da ich erstmalig als Autor von Hövel et al. (S. 293) erwähnt werde, der etwas zum TRP gesagt hat, in einer Weise zitiert werde, die den Eindruck erweckt, als ließe sich anhand meines Textes erfahren, was das TRP überhaupt will. »Übergeordnete Ziele dieser Maßnahme sind die Entlastung der Lehrkräfte von Streit- und Konfliktgesprächen im Unterricht sowie die Gewährung eines störungsfreien Unterrichts für die lernwilligen Kinder (Bröcher, 2010).« Mein Text ist aber eine kritische Auseinandersetzung mit dem TRP und keine Einführung in das TRP. Mein eigentliches Anliegen kommt hier im Text von Hövel et al. zunächst somit nicht zur Sprache. Um das, was Hövel et al. hier sagen wollten, mit fundierten Quellen zu unterlegen, hätten sie besser Bründel und Simon zitiert, aber nicht mich, denn ich habe hier nur kurz zusammengefasst, was Bründel und Simon oder Balke mit dem TRP im Sinn haben. Meine Texte hätten sicher viel anderes, für eine detaillierte Analyse des TRP auch sehr viel Relevantes, beinhaltet, was aber von Hövel et al. unbeachtet bleibt.

Im dritten Teil geben Hövel et al. (S. 295-300) nun einen Überblick über den Forschungsstand zum TRP. Dabei fällt auf, dass sie einem sehr stark verkürzten Forschungsverständnis folgen. Sie interessieren sich lediglich für das »Konstrukt der Evidenz« und halten sich über Gebühr mit den Evidenzstufen auf, wie sie vom »Oxford Centre for Evidence-Based Medicine« definiert worden sind. Es stellt sich auch die Frage, ob ein solches, für die Medizin entwickeltes, Modell, überhaupt auf das Feld der Pädagogik übertragen werden kann. Die in aller Ausführlichkeit von Hövel et al. dargelegten und dann verwendeten Auswahlkriterien reduzierten die, ursprünglich 469 zum Thema des TRP angezeigten, Publikationen auf bloße fünf. Teils handelt es sich dabei um qualitative, teils um quantitative Studien, von Bründel und Simon, Balz, Spohn, Rynberg und Wollenweber. Es war zu erwarten, dass sich keine überzeugenden Hinweise für die Wirksamkeit des TRP in diesen, teils auch sehr fragwürdigen, Studien finden würden. Trotz allem werden sie, in aller Ausführlichkeit, aufgeführt und quasi zum empirischen Herzstück des Artikels gemacht. Dies erscheint umso unverständlicher, als ja von vorneherein klar ist, dass nichts dabei herauskommen wird, was die Wirksamkeit des TRP belegen könnte. Bezogen auf die Studien von Bründel und Simon, Balz und Wollenweber habe ich diese negativen Ergebnisse bezüglich der Wirksamkeit des TRP ja auch schon mehrfach in meinen Publikationen diskutiert, schon vor etlichen Jahren. Warum sollten die Leser_innen all diese Details denn nun trotzdem noch oder wieder lesen?

$\mathrm{Zu}$ einer umfassenderen erziehungs- und bildungswissenschaftlichen Forschung, wenn wir einmal auf die Arbeiten von Wolfgang Klafki zurückgreifen, gehören ja auch historisch-hermeneutische sowie gesellschafts- und ideologiekritische Perspektiven. Bezogen auf das TRP ließen sich etwa Bezüge zu den philosophischen Texten von Adorno, Arendt, Fromm oder Foucault herstellen, auch zur aktuell veröffentlichten Kritik an den Funktionalisierungstendenzen in unseren Bildungssystemen, an der zunehmenden Dominanz von kompetenzorientierten, standardisierten Bildungs- 
programmen, in Zusammenhang mit Neuer Steuerung und Educational Governance. Zusätzlich sollten wir immer auch diskursanalytisch, das heißt auch sprachkritisch, arbeiten, etwa unter Rückgriff auf die Arbeiten von Fairclough oder anderen. Weil Hövel et al. diese Perspektiven aber nicht, zusätzlich zur empirischen Perspektive, einnehmen, selbst wenn diese letztere Perspektive ja immerhin schon einmal in quantitativ und qualitativ ausdifferenziert wurde, kommen die Autor_innen nicht auf den Gedanken, dass es bei solchen Programmen, wie dem TRP, gar nicht allein um ihre Wirksamkeit gehen kann. Selbst wenn ein Programm, wie das TRP, als wirksam befunden würde, müssten wir es ja dennoch ablehnen, aus Gründen des Menschenbildes, des Gesellschaftsbildes und des mit beidem verbundenen Bildungsideals. Auch die Konzentrationslager im Dritten Reich waren effektiv. Effektivität allein ist also ein irreführendes Kriterium in Zusammenhang mit pädagogischen und sozialen Programmen. Um aber eine solche kritische Denkhaltung einnehmen zu können, muss ich eben nicht nur empirisch, sondern auch historisch-hermeneutisch, gesellschaftskritisch und ideologiekritisch bzw. diskursanalytisch denken und arbeiten. Das alles hätte aber nun in die Zusammenfassung des Forschungsstandes, in die Darlegung des State of the Art, hineingehört. In dieser Hinsicht haben Göppel, Jornitz, Pongratz und ich, und noch andere, bereits sehr viel zusammengetragen. Meine sämtlichen Texte zum TRP (Bröcher 2005 a, b; 2007 b; 2010; 2011 a, b;2014 a, b; 2019 c) sind ja fast alle zum freien Download auf ResearchGate verfügbar, einige wenige zumindest aber in Bibliotheken. Vor allem lautet der Untertitel des Artikels von Hövel et al. ja auch: »Der Trainingsraum: Empirische Befunde, theoretische Perspektiven, pädagogische Alternativen«. Doch die theoretischen Perspektiven hätten hier dann auch einmal detailliert aufgefächert werden müssen.

Was dann im vierten Teil unter dem Titel »pädagogische Kritik« folgt, liefert immerhin, teils noch nachträglich, einige Aspekte davon: »Kritische Stimmen beziehen sich auf die vage theoretische Basis, die nötigen Ressourcen, die gegen die Inklusion stehende Praxis des Ausschlusses, die Reduktion vielschichtiger unterrichtlicher Realitäten auf ein Disziplinproblem und die defizitäre Sichtweise auf die Schülerinnen und Schüler (Bröcher, 2010; Dettmar, 2010; Pongratz, 2010)«, schreiben Hövel et al. (S. 300). Und weiter zitieren sie (ebd.) das Folgende: »Aus einer pädagogischen Warte ist eine strukturelle Herrschaftspraxis (Pongratz, 2010) ein wesentlicher Kritikpunkt am Trainingsraum« (ebd.) sowie »Kritisiert wird ebenfalls, dass Lehrkräfte nicht reflektieren, ob das Störverhalten eines Kindes in einer mangelnden Vorbereitung, Differenzierung oder ganz grundlegend in einer schlechten Klassenführung begründet liegt (Bröcher, 2010)« (Hövel et al., S. 301). Immerhin haben es diese Argumentationen geschafft, in den Text von Hövel et al. aufgenommen zu werden. Eine systematische Verknüpfung der zitierten Argumentationen mit dem Forschungsstand findet aber nicht statt. Das zuletzt genannte Thema des Unterrichts ist nun auch ein ganz wesentlicher Punkt, dem Hövel et al. aber nicht weiter nachgehen. Wir reden ja hier in der Tat über Schulunterricht, den es in erster Linie weiterzuentwickeln und zu verbessern gilt. Immerhin ist es doch abenteuerlich, wie Balke (2003) das Thema des »Flows« in der Klasse sieht. Da ist also ein Flow, der die Mehrheit der Klasse begeistert lernen lässt. Einer stört nun den Flow der Mehrheit, im Diskurs von Balke, und der geht, nach den Regeln des TRP, dann eben raus. Der wird nun draußen kognitiv diszipliniert und zur Selbstanpassung gedrängt und darf erst dann wieder rein, wenn er Besserung gelobt hat. Dieser Jugendliche, es sind ja zumeist Jungen, hat dann schon viel vom 
Lernprozess der anderen, die ja alle im Flow zu sein scheinen, verpasst und findet nun schwer erneuten Anschluss an den Inhalt, der gerade im Unterricht verhandelt wird. Dadurch wird es noch schwieriger für ihn, in einen solchen Lern-Flow zu gelangen. Es dürfte für einen aus der Klasse verwiesenen und dann zurückkehrenden Jugendlichen auch fast unmöglich sein, da schnell wieder hineinzufinden. Noch weiter nach unten kann die Schulpädagogik auch nicht sinken. Aber zugleich stehen die Lehrkräfte immer mehr unter Druck, durch standardisierte Lerncurricula und kompetenzorientierte Standards, die mit Macht seitens der Ministerien und Landesregierungen in die Schulen hineingedrückt werden. Neben der fehlenden geistigen, pädagogischen Flexibilität von Lehrkräften und den unzureichend entwickelten Schulkulturen, sind diese politisch forcierten Standards ein wesentlicher Treiber dafür, dass auch in der Gegenwart immer noch, und immer wieder neu, auf das TRP, in all seinen Varianten, zurückgegriffen wird.

Wir müssen daher unsere Kritik an die Bildungspolitik auf der Ebene der Landesregierungen adressieren. Die Schulen haben oftmals kaum Spielräume, eigene Wege $\mathrm{zu}$ gehen, wenngleich sie trotz allem gewisse Spielräume haben. Diese Ebene haben Hövel et al. aber nicht im Blick. Lieber verheddern sie sich in dieser Jonglage mit Missbrauchs- und Gewaltbildern, die sie sich aus dem Erlkönig herausgreifen. Sie können doch nicht ernsthaft den, unter immer höherem Druck stehenden, Lehrkräften so etwas zuschreiben? Ich hatte in meinem Text von 2011 (S. 86) das Folgende dazu geschrieben: »Die alten überholten Unterrichtskonzepte, deren Erfolg sich allein am Durchnehmen von Stoff bemisst, treten wiederum deutlich in Erscheinung, völlig gleichgültig, ob dieser Stoff intern auch beim Lernenden angekommen, verankert und mit eigenen subjektiven Motivationen, Gedanken, Interessen verknüpft worden ist«. Und die ganze Misere wird noch nicht wirklich nachhaltig besser, wenn dort draußen, weit weg von den Klassenzimmern, freiere, subjektzentrierte Reflexionen stattfinden, wie es Hövel, Zimmermann et al. am Ende ihrer Studie vorschlagen. Wichtiger ist doch der Lern-Flow in der Klasse, auch für den vermeintlichen Störenfried. Ich kann aus meiner Erfahrung an Schulen sagen: Das geht auch. Hier muss angesetzt werden. In meinen Büchern Lebenswelt und Didaktik oder Anders unterrichten, anders Schule machen habe ich einiges zu der Frage niedergeschrieben, wie das praktisch gelingen kann. Es folgen seitens Hövel et al. (S. 301-302) noch eine Reihe weiterer Überlegungen bis zum Ende dieses vierten Teils, die sich durchaus mit dem decken, was Göppel, Jornitz, Pongratz und ich bereits früher veröffentlicht haben, ohne dass dies im Text von Hövel et al. jedoch weiter erwähnt oder im Detail auf all diese publizierten Analysen und Argumentationen verwiesen oder Bezug genommen würde. Sie präsentieren ihre Gegenargumente, bezogen auf das TRP, die nach dem gerade genannten Zitat auf ca. einer Heftseite folgen, anscheinend als neu, so als hätte noch keiner vor ihnen all diese, bereits bekannten, kritischen Einwände aufgeführt. Interessanterweise wird nun selbst das rigide Frageritual, das beim TRP praktiziert wird, von Hövel et al. mit dem Erlkönig verknüpft. Hövel et al. (S. 302) zitieren hier exemplarisch einen Teil dieses Fragerituals nach Balke:»Bist du bereit, dich an die Klassenregeln zu halten? Wie willst du uns zeigen, dass du nicht mehr in den Trainingsraum geschickt werden willst? « Ich stimme Hövel et al. ja zu, wenn sie schreiben, dass es sich bei diesem Frageritual um eine »Entrechtung«der Schüler_innen und um eine »Auflösung des Rechts auf Bildung und Erziehung« handelt. Dasselbe habe ich ja bereits früher auch schon mehrfach geschrieben. Ich überschrieb Absatz 46 meiner 2011 (S. 82) veröffentlichten kritischen 
Thesen zum TRP mit dem Titel »Das Recht auf Bildung verwirkt?« An einer anderen Stelle schrieb ich: »Ich kann ihnen (den Schüler_innen, Ergänz. J. B.) dann (statt dieses problematische Frageritual des TRP zu verwenden, Ergänz. J. B.) aufrichtig und wahrhaftig sagen, dass ich sie unter den gegebenen Bedingungen nicht mehr unterrichten kann und werde. Aber ihr Recht auf Unterricht haben sie deshalb keineswegs verwirkt « (Bröcher 2005 b, S. 177). Ein wenig später, aber immer noch sechs Jahre vor Hövel et al., schrieb ich: „Eine Schule, die so verfährt, missachtet das Menschenrecht auf Bildung« (Bröcher 2014 a, S. 29). Inhaltlich ist es dasselbe, was Hövel et al. jetzt hier 6, 9 bzw. 15 Jahre später schreiben. Trotz identischer Argumentation ist eine Bezugnahme auf meine Texte seitens Hövel et al. jedoch nicht gegeben.

Das einzige, was an den Ausführungen von Hövel et al. in diesem Textteil wirklich neu ist, ist die wiederholte, allerdings problematische Bezugnahme auf den Erlkönig. Dass dies, wenn Hövel et al., zum wiederholten Mal, das Satzelement »Und bist du nicht willig, so brauch ich Gewalt« in ihren Text einstreuen, eine fragwürdige Verknüpfung darstellt, weil hierdurch Assoziationen an körperliche Gewalt und Misshandlung geweckt werden, was beim TRP aber keineswegs vorgesehen ist, habe ich ja bereits angemerkt. Was in diesem vierten Teil nun noch, wenn auch wissenschaftlich wenig überzeugend, was die Literaturrecherche und was das Zitieren von Quellen anbelangt, mit Blick auf die schon vorhandenen Texte, im konkreten Fall von Bröcher (2005 b, 2011), in loser Ordnung und ohne Systematik nachgereicht wird, hätte aber unbedingt in die Zusammenfassung des Forschungsstandes zum TRP gehört. Auch diese kritischen Analysen sind ja Teil der Forschung. Allerdings wäre es erforderlich gewesen, die schon vorhandene Literatur systematisch auszuwerten und dann die Autor_innen dieser früheren Texte auch präzise zu benennen, also die Quellen auch systematisch zu dokumentieren. Kommen wir nun zum fünften und letzten Teil des Artikels. Im Zuge der wissenschaftlichen Begleitung einer Förderschule haben die Autor_innen mit den Pädagog_innen und Schüler_innen in der betreffenden Schule gemeinsam aus dem, anscheinend noch original nach Balke konzeptualisierten, Trainingsraum einen sog. »Freiraum« gemacht. Das wird den Leser_innen nun als krönender Abschluss des Ganzen präsentiert. Nicht aber Überlegungen wie der Unterricht in der Klasse umstrukturiert oder verändert werden könnte, damit nicht mehr so viele Schüler_innen überhaupt nach draußen geschickt werden (müssen) oder diesen freiwillig verlassen wollen. Das wäre doch auch einmal eine Gelegenheit gewesen, über die Lebensweltorientierte Didaktik, wie ich sie seit den 9oer Jahren in einer ganzen Serie von Texten entwickelt und dargelegt habe (vgl. z. B. Bröcher, 1997) nachzudenken, weil diese ja die Lebensthemen der Kinder und Jugendlichen gezielt aufgreift und dann mit curricularem Lernen verschränkt, durchaus in einer partizipativen, projekt- und handlungsorientierten Art und Weise. Da dieses Modell allerdings nicht evidenzbasiert ist und lediglich auf qualitativ erhobenen Daten und Erfahrungen basiert, ist es vielleicht nicht jedermanns Sache. Immerhin ist das Modell, über viele Jahre hinweg, praxiserprobt, denn ich habe es unter den Bedingungen einer sehr herausfordernden schulischen Realität entwickelt.

Dem schulischen Rahmen und dem Rollenverständnis von Lehrkräften erscheint die Lebensweltorientierte Didaktik auch angemessener als die ansonsten von Zimmermann (2016) propagierte »Traumapädagogik«, da diese die Lehrkräfte hinsichtlich ihrer Kompetenzen überfordert, nicht mit ihrer unterrichtsbezogenen Rolle vereinbar ist und sich auch nicht in den curricular geprägten Lernraum der Schule glaubhaft 
einbetten lässt. Natürlich hätte an dieser Stelle, als Alternative zum TRP, unbedingt auch über School-wide Positive Behavior Support, kurz PBIS, diskutiert werden müssen. Selbst wenn es vieles an diesem evidenzbasierten Modell zu kritisieren gibt, so wäre es doch, im Vergleich zum TRP, ein enormer Fortschritt, denn hier wird ja gezielt etwas an der Verbesserung des Unterrichts getan und bis auf einige vorübergehende Maßnahmen, die auch einmal außerhalb des Klassenverbandes stattfinden können, bleibt der Fokus von PBIS aber doch im Wesentlichen auf dem Geschehen im Klassenzimmer. Beide Modelle bleiben aber in dem Text von Hövel, Zimmermann, Meyer und Gingelmaier außen vor. Es wird der Blick stattdessen auf den Raum im Draußen gerichtet, wo jetzt die entscheidenden Dinge laufen sollen. "So ergab sich die Idee eines freundlichen, aufnehmenden Raums, der im Konfliktfall bedingungslos, aber am besten freiwillig aufgesucht werden könnte. In diesem sollte es die Möglichkeit geben, die eigenen Bedürfnisse zu bemerken (z. B. Ruhe und Runterkommen mit Musik aus dem eigenen Handy, in Ruhe arbeiten, für die eigene Geschichte Gehör finden oder sich z. B. am Boxsack auspowern) und Zusammenhänge zwischen den Verhaltensweisen, den darunterliegenden mentalen Zuständen und ihrer Funktion interpretieren zu lernen. Der Trainingsraum wurde passend zu seiner neuen Ausrichtung umfirmiert in Freiraum. Dies sollte anzeigen, dass es sich jetzt um einen Raum zum Verstehen von inneren und äußeren Dynamiken handelt, also ein realer äußerer Raum, der den Rahmen für identitätsrelevante Austauschprozesse (Straus \& Höfer, 1997) zwischen Innen und Außen anbietet. Je nach Anlass konnte der Raum nun aus unterschiedlichen Motiven aufgesucht werden. Durch verschiedenfarbige Karten symbolisiert, gab es für die Kinder die Möglichkeit, im Konfliktfall selbst dorthin zu gehen, dort ungestört an etwas $\mathrm{zu}$ arbeiten oder im $>$ Notfalk von der Lehrperson dorthin geschickt zu werden. Eine klare Priorität lag aber darauf, dass die Schülerinnen und Schüler ein Gespür dafür entwickeln sollten, wann es für sie besser wäre aus einer Situation hinauszugehen. Darin sollten die Lehrkräfte die Lernenden unterstützen« (Hövel et al., S. 302).

Etwas durchaus Vergleichbares habe ich bereits 2005 (a) veröffentlicht. Allerdings nur für den Fall sollte es, nach meiner damaligen Auffassung, so ein Draußen geben, wenn zuvor wirklich alle erdenklichen Versuche, einen besseren, anderen, adäquateren Unterricht, der auch jeden einzelnen Schüler und jede Schülerin in den didaktischen Flow einschließt, inklusive der vermeintlichen Störer_innen, gescheitert waren. Ich schrieb 2005 (a, S. 145) in dem, in Päd Forum: erziehen, unterrichten, veröffentlichten Artikel das Folgende: "Doch versuchen wir abschließend eine mögliche Transformation der Trainingsraum-Idee ins Produktive ... Angenommen, die didaktischen Variationen ..., die vielleicht helfen könnten, in der Klasse mit unerwarteten Verhaltensweisen und besonderen Lernausgangslagen von Schülern klarzukommen, angenommen diese didaktischen Variationen könnten von bestimmten Lehrkräften oder auf Grund besonders stark verfestigter Schwierigkeiten bezüglich bestimmter Schüler nicht geleistet werden und es müsste wirklich daran gedacht werden, Kinder und Jugendliche vorübergehend aus der Klasse herauszunehmen, wäre nicht auch die Einrichtung einer sozialpädagogisch-therapeutischen Werkstatt oder Auffangstelle möglich ...?« Hövel et al. (S. 302) nennen das nun einen »freundlichen, aufnehmenden Raum« und konzeptualisieren diesen durchaus ähnlich, in vielen Punkten fast identisch, wie ich es 2005 (a) getan habe. Weiter schrieb ich: »... eine Werkstatt oder Auffangstelle ..., in der vielleicht die Schulsozialarbeiter präsent sind, in der auch eine Lehrkraft bereit steht, die sich mit Kommunikation, Entwicklung, individueller Potenzialförderung/ 
Coaching und Veränderung auskennt und in der subjektiv relevante Gespräche mit den Kindern und Jugendlichen geführt werden, die im Augenblick nicht im Unterricht zurechtkommen? Möglich wäre auch ein situatives gestaltungs-, spiel- oder beschäftigungstherapeutisches Angebot für die Kinder, eine Art Teestube mit Musik für die Jugendlichen. Es ginge dabei um eine Anlaufstelle, die parallel zum gesamten Schulvormittag geöffnet wäre, wie der Trainingraum auch, eine Anlaufstelle, in die Schülerinnen und Schüler in Krisen auch freiwillig kommen könnten und die sie, nach erfolgter Stabilisierung, wiederum verlassen könnten. Dies alles ginge vonstatten, ohne die vielen Formulare und Passierscheine auszufüllen und $\mathrm{zu}$ archivieren und ohne neue Spannungen in den Familien zu erzeugen« (Bröcher, ebd.).

Hövel et al. beschreiben diesen "Freiraum« so, dass er »im Konfliktfall bedingungslos, aber am besten freiwillig aufgesucht werden könnte.« Auch das hatte ich ja bereits 2005 (a) geschrieben: »...eine Anlaufstelle, in die Kinder und Jugendliche in Krisen auch freiwillig kommen könnten« (Bröcher, ebd.). Hövel et al. fahren fort: »... In diesem sollte es die Möglichkeit geben, die eigenen Bedürfnisse zu bemerken (z. B. Ruhe und Runterkommen mit Musik aus dem eigenen Handy, in Ruhe arbeiten, für die eigene Geschichte Gehör finden oder sich z. B. am Boxsack auspowern).« In meinem Text hatte ich ziemlich parallel geschrieben: «Eine Teestube mit Musik für die Jugendlichen« und ein »bewegungsorientiertes Angebot « (Bröcher, ebd.). In dem von Hövel et al. entworfenen »Freiraum « geht es ferner darum »Zusammenhänge zwischen den Verhaltensweisen, den darunter liegenden mentalen Zuständen und ihrer Funktion interpretieren $(\mathrm{zu})$ lernen.« Im Vergleich zu meiner Skizze finden wir bei Hövel et al. also einige weitere theoretische, freilich schon recht anspruchsvolle, Spezifizierungen, die mit dem »Freiraum« verknüpft werden. Es stellt sich allerdings die Frage, ob die, tagtäglich dort arbeitenden und sich vermutlich abwechselnden, Lehrkräfte solche psychoanalytisch-pädagogischen Hintergründe und Konzeptualisierungen (z. B. Innen und Außen) tatsächlich alle zur Verfügung haben und da wirklich professionell mit arbeiten können? Von einem systematischen Training des Schulkollegiums in dieser Richtung war im Text jedenfalls nicht die Rede, so dass bei meiner eigenen Kenntnis dessen, was an Schulen in der Regel möglich ist, die Alltagsrealität in diesem »Freiraum « nicht ganz so anspruchsvoll und theoriegeleitet ablaufen dürfte, wie die Autor_innen hier nahelegen, es sei denn sie sorgen für systematische und nachhaltige schulinterne Weiterbildung. Auch müssten die theoretischen Bezüge, wenn denn schon so hohe Ansprüche mit den in diesem »Freiraum« zu unternehmenden Klärungsprozessen verbunden werden, genauer angegeben werden. Zwei Mal in dem Artikel ist die Rede von Prozessen zwischen Innen und Außen, aber theoriegeleitet zu arbeiten hieße ja, da genauere Angaben zu machen, wo diese Konzeptualisierungen herkommen, auf welchen Theorien sie beruhen und wie sie ganz konkret im schulischen Alltag umgesetzt werden sollen. Zwar liegt der Gedanke an eine Publikation von Ahrbeck et al. (2016) nahe, zum Thema »Innere und äußere Grenzen«, aber diese wird hier nicht genannt. Worauf jedoch verwiesen wird, ist eine Publikation von Straus und Höfer (1997), zum Thema »Entwicklungslinien alltäglicher Identitätsarbeit«. Aus diesem Modell soll also vorläufig für die Arbeit im »Freiraum« geschöpft und mit den Heranwachsenden an ihrer »Identität « gearbeitet werden.

Es ist allerdings auch zu bedenken, dass es sich bei diesem »Freiraum« um einen offenen, ungeschützten Raum handelt, in dem jederzeit Schüler_innen, aus allen Richtungen des Schulgebäudes, aus wirklich allen Klassen der Schule, ankommen können. 
Sollen jedoch ernsthaft »identitätsrelevante Austauschprozesse zwischen Innen und Außen « und ein »Verstehen von äußeren und inneren Dynamiken« ermöglicht werden, damit die Schüler_innen, die im Unterricht nicht zurechtgekommen sind, den »Zusammenhang zwischen den Verhaltensweisen, den darunter liegenden mentalen Zuständen und ihrer Funktion interpretieren lernen«, so konzeptualisieren ja Hövel, Zimmermann et al. diesen »Freiraum«, dann wird hierfür sicherlich ein geschützter Raum benötigt, um auch ins Persönliche gehende Einzelgespräche führen zu können. In einem solchen Taubenschlag, wo ein ständiges Kommen und Gehen herrscht, mit Musik, Boxsack, Tee und was noch allem, wird das aber kaum gehen. Es ist auch erfahrungsgemäß nicht so, dass sich alle, die dort eintreten, da dürfte wohl eine recht heterogene Gruppe an Kindern und Jugendlichen zusammenkommen, sich nun automatisch harmonisch, brav und empathisch in einen Stuhlkreis setzen werden. Wie die betreffende Schule damit dann tatsächlich zurechtkommt, wissen wir nicht. $\mathrm{Ob}$ wirklich alle Lehrkräfte die Schüler_innen jederzeit einfach aus dem Unterricht weggehen lassen? Was ist, wenn es in diesem »Freiraum« übervoll wird? Was sind dann die Regelungen der Schule? Fragen über Fragen. Es ist verwunderlich, dass Hövel et al. (S. 295 f.) in ihrem Artikel seitenlang über »Evidenzstufen«, den »Goldstandard« des »randomisierten Kontrollgruppendesigns« und die »Standards der Cochrane Collaboration « referieren, uns am Ende aber ein Modell als richtungsweisend empfehlen, das noch nicht einmal an einer einzelnen Schule längerfristig erprobt und evaluiert worden ist und das, hinsichtlich seiner theoretischen Bezüge und seiner praktischen Umsetzungen, nur vage beschrieben worden ist.

Das Modell des »Freiraums« hatte sich, wie Hövel et al. es darstellen, ganz neu und originell, aus einem halbjährigen Beratungsprozess herauskristallisiert, obwohl es längst in meinem Päd Forum Artikel von 2005 (a) vorentworfen worden ist. Dieser Artikel befindet sich auch seit einigen Jahren, mit Erlaubnis des Schneider Verlages Hohengehren, zum freien Download auf ResearchGate. Er wird dort offenbar auch sehr rege aus ganz Deutschland heruntergeladen. Bisher lassen sich über 5000 Downloads erkennen. Dieses, also in einer Einzelschule, aufgrund der eigenen Beratungsleistungen von Hövel et al., neu entwickelte und für zukunftsweisend befundene Modell befindet sich, wie es scheint, aber gerade erst im allerersten Entwurf. Dieser »Freiraum« befindet sich noch nicht einmal im Versuchsstadium, denn vorher müssten ja die Theoriebezüge und die tatsächlich zu verwendenden Beratungskonzepte noch genauer angegeben und definiert werden. Trotz allem wird der pädagogischen Fachwelt dieser »Freiraum« nun als Lösungsweg und als Alternative zum TRP empfohlen. »Goldstandard RCT« und »Cochrane-Standards« sind plötzlich kein Thema mehr. Hövel et al. fügen noch das Folgende hinzu: »Der starre und rigide Ablaufplan, durch den sich die Schülerinnen und Schüler geschleust fühlten, wurde zugunsten eines individuellen Settings aufgebrochen. « Bei mir hieß das so: „Dies alles ginge vonstatten, ohne die vielen Formulare und Passierscheine auszufüllen und zu archivieren und ohne neue Spannungen in den Familien zu erzeugen« (Bröcher, ebd.). Hövel et al. schreiben weiter: "Das Ziel einer gelingenden Rückführung in den Klassenraum blieb bestehen, allerdings nicht mehr durch ein formales Schuldeingeständnis, sondern über behutsame Verstehensprozesse eigener und fremder Anteile am Entstehen dysfunktionaler Dynamiken. «Ich schrieb: »... eine Anlaufstelle ..., die sie nach erfolgter Stabilisierung wiederum verlassen könnten« (Bröcher, ebd.). Wenn Hövel et al. schreiben: »... nicht mehr durch ein formales Schuldeingeständnis « so notierte ich »ohne die 
vielen Formulare und Passierscheine auszufüllen« (Bröcher, ebd.), denn auch im Trainingsraum wird ja, unter Anleitung, ein vorgefertigter Rückkehrplan, eben mit einem solchen Schuldeingeständnis, ausgefüllt.

Abzüglich einiger von Hövel, Zimmermann et al. hinzugefügter, weiterer, teils für schulische Verhältnisse sehr anspruchsvoller, Theoretisierungen, handelt es sich bei deren »Freiraum« und meiner »Werkstatt bzw. Auffangstelle« doch im Wesentlichen um ein und dasselbe Konstrukt, dass sich auf die folgenden Komponenten herunterbrechen lässt: Freiwilligkeit, Niedrigschwelligkeit, angenehme Atmosphäre, Bezug zur Jugendkultur, Bewegungsmöglichkeiten, sinnstiftende Gespräche, Bedürfnisorientierung, fernab von den zwanghaften Ritualen des TRP, mit dem Ziel der Rückkehr in die Klasse. Nun lässt sich natürlich einwenden, was schon dabei gewesen sei, eine solche, nicht einmal außergewöhnliche, Idee $\mathrm{zu}$ formulieren und dass es doch fast schon naheliegend sei, eine solche Alternative zum TRP zu entwerfen und dass doch jeder, jederzeit auf so etwas kommen könnte. Sicher. Aber es wäre für Hövel, Zimmermann, Meyer und Gingelmaier doch auch ein Leichtes gewesen, auf diesen frühen Aufsatz von mir hinzuweisen und etwa zu schreiben. Etwas, diesem "Freiraum" Vergleichbares, hat Bröcher bereits 2005 formuliert und entworfen und zwar in dieser Art und Weise ... Eine seriöse Neuformulierung des State of the Art zum TRP hätte jedenfalls anders ausgesehen, inklusive der Anerkennung dessen, was Kolleg_innen bereits zum Thema an Vorarbeiten geleistet haben. Hinzu kommt, dass der Artikel zwar durch die mehr als fragwürdige Bezugnahme auf den Erlkönig Aufmerksamkeit auf sich zieht, letztlich aber dunkle, unklar bleibende Unterströmungen erzeugt. Dadurch irritiert und verwirrt dieser Text mehr als er auf klärt. Auch wird das Ganze nicht überzeugend in einen theoretischen Rahmen eingeordnet. Empirische Detailversessenheit und lose Versatzstücke einer psychoanalytisch-pädagogischen Theorie bleiben unverbunden nebeneinander stehen und werden in keiner Weise überzeugend mit einem erziehungs- und bildungswissenschaftlichen Diskurs verknüpft, der auch die besonderen schulischen, curricularen Belange und die übergreifenden aktuellen Strömungen in den Bildungsystemen, sich drehend um die Neue Steuerung, sowie auch die realen schulischen Umsetzungsmöglichkeiten, berücksichtigen würde. Auch hat die Montage, die Hövel, Zimmermann et al. unter Verwendung von Teilen aus dem Erlkönig, zusammengefügt haben, mit dem Erlkönig an sich nichts mehr zu tun. Der Erlkönig wurde lediglich als Materialfundus benutzt, um dann daraus eine ganz eigene Story zu kreieren. Trotz allem versuchen Hövel et al. eine sehr simplifizierende, fragwürdige Erlkönig-Interpretation der eigenen wissenschaftlichen Story zugrundezulegen, die mit der »emotionalen Verwicklung« der am Schulleben Beteiligten zu tun haben soll. Es wird suggeriert, dass das TRP etwas mit Gewalt und Misshandlung zu tun hat. Die Debatte über das TRP wird von Hövel et al. mit einer abgründigen Folie unterlegt, die das Ganze dunkel einfärben soll. Den Erlkönig für all das als Illustration, oder gar als Beleg, heranzuziehen, ist abenteuerlich und lässt sich nicht durch Erkenntnisse der Literaturwissenschaft legitimieren. "Eine erziehungswissenschaftliche Diskussion aus einer Gedichtzeile heraus zu entwickeln, hier aus Goethes `Erlkönig‘, ist zweifelsohne gewagt«, schreiben Hövel et al. (S. 291). Sie scheinen schon selbst zu ahnen, wie riskant ihr Unternehmen ist.

Ich fasse zusammen: Die von Hövel et al. eingesetzten Suchfilter waren sicher zu eng gefasst, so dass keiner meiner Texte in dem Netz von Hövel et al. hängen blieb, um es in die Analyse des Forschungsstandes zum TRP zu schaffen. Dabei hatte Wollen- 
weber (2013, S. 35), auf dessen Text Hövel et al. ja sonst öfter zurückgegriffen haben, doch immerhin das Folgende geschrieben: »Bröcher (2005 b, 2010) untersuchte die Programmkonzeption qualitativ und kommt zu dem Ergebnis, dass ... Immerhin war Wollenwebers Suchfilter nicht ganz so eng, wie der von Hövel et al. Die Autor_innen stellten sich das Thema »Der Trainingsraum: Empirische Befunde, theoretische Perspektiven, pädagogische Alternativen«. Die wenigen, überdies wenig aussagekräftigen, empirischen Befunde zum TRP so eng zu filtern und das wenige Gefundene dann aber so detailliert auszubreiten, erscheint kaum zielführend. Diesen Teil hätte man in drei, vier Sätzen abhandeln können, ohne all die evidenzbasierten Details derart ausführlich darzulegen. Zugleich hätten alle diskursanalytischen, historisch-hermeneutischen, gesellschafts- und ideologiekritischen Texte, die zum TRP bereits seit 2002 erschienen sind, systematisch ausgewertet werden müssen. So erreicht das Erörtern theoretischer Perspektiven zum TRP seitens Hövel et al. nicht einmal das Niveau der Texte, die wir schon, teils seit ca. 15 bis 18 Jahren, vorliegen haben. Was Hövel et al. aber in den, schon damals erschienenen, Texten hätten finden können, sind Auseinandersetzungen mit der Frage, was ein adäquater Unterricht innerhalb des Klassenzimmers ist, sind Erörterungen des Zusammenhangs von Menschenbild, Bildungsideal und Gesellschaftsbild, sind Diskurse zur Funktionalisierung in den Bildungsinstitutionen, sind Überlegungen zur Schulentwicklung, Schulkulturentwicklung und schulischen Organisationsentwicklung, sind Überlegungen zu schulrechtlichen Fragen, zu kollegialen, kommunikativen Prozessen, zu Führungsfragen in Schulen bis hin zum Aufzeigen von echten Alternativen, was wir den Schulen eben statt des TRP empfehlen können. Auch der dritte Punkt wird nicht eingelöst, schon mal gar nicht im Plural, denn dort steht »pädagogische Alternativen«. Das einzige, was im Text von Hövel et al. als Alternative angeboten wird, ist der »Freiraum « im Draußen des Klassenzimmers und am Ende wird dort lediglich mit den Kindern und Jugendlichen, die Probleme haben, gearbeitet, während in der Schule ja höchstwahrscheinlich Entwicklungsarbeit auf der kollegialen Ebene anstehen dürfte. Davon ist aber in dem Artikel nicht die Rede. Der letzte Satz im Abstract sagte es ja auch schon: »Ein Alternativkonzept, ein Freiraum für die schulische Auseinandersetzung mit Verhaltensstörungen, wird vorgestellt.« Damit wären aber die viel weiterreichenden, von Hövel, Zimmermann et al. vorgenommenen, Theoretisierungen zum Freiraum wiederum größtenteils hinfällig. »Verstehensprozesse eigener und fremder Anteile am Entstehen dysfunktionaler Dynamiken «wie die Autor_innen es ganz am Ende des Artikels ambitioniert nennen, passen erstens nicht zu der einseitigen Etikettierung »Verhaltensstörung« und zweitens können sie wohl kaum von den Heranwachsenden allein bewerkstelligt werden. Da müssten ja sicherlich die Lehrkräfte, die sich am anderen Ende des unterrichtlichen Geschehens befinden, oder noch weitere Akteur_innen, miteinbezogen werden.

Auch dürften inzwischen viele Schulen, die ursprünglich einmal mit den OriginalModellen des TRP, im Sinne von Balke oder Bründel und Simon, angefangen haben, diesen Raum längst in ihrem eigenen Sinne abgewandelt oder erweitert haben. Die meisten Schulen gehen da mittlerweile recht autonom mit um und dürften eben genau das machen, was sie im Moment für richtig und machbar halten. So furchtbar innovativ ist es also nicht, im Jahr 2020, wo das Thema schon seit 17 Jahren in den Schulen präsent war, einen solchen »Freiraum« vorzuschlagen, den es wahrscheinlich schon hundertfach und noch öfter im deutschsprachigen Raum geben wird, nur unter jeweils anderem Namen. 2005 war das vielleicht ein wenig anders, weil zu der Zeit noch 
so eine Programmgläubigkeit bei vielen Schulen herrschte. Die bedeutsamste Baustelle der heutigen Schulen ist aber der Unterricht in der Klasse und wie dieser umgestaltet werden kann, trotz, immer enger werdender, curricularer Vorgaben und Zwänge, damit darin alle, wirklich alle zurechtkommen, jedenfalls solange wir noch diese Art der, längst zu reformierenden, Schule haben. Da verfügen wir ja nun über eine ganze Reihe von Möglichkeiten, wie sich anhand der nationalen und internationalen Literatur sehen lässt, von der Lebensweltorientierten Didaktik bis hin zu School-wide Positive Behavior Support. Die zweite Baustelle, die auch bei Hövel et al. leider keine Rolle spielt, ist die übergreifende Schulentwicklungsarbeit mit einem ganzen Kollegium. Diese Arbeit ist aber fundamental wichtig. Allein Klärungsprozesse irgendwo jenseits des eigentlichen unterrichtlichen Geschehens mit den Schüler_innen in Gang zu bringen, dürfte wenig Veränderungseffekte nach sich ziehen und ist daher nicht nachhaltig. Da nützt es auch nichts, so einen »Freiraum« mit eloquenten Theoretisierungen auszustatten, wenn nicht gar zu überfrachten. Das wird am Ende im schulischen Alltag alles verpuffen, wenn es nicht mit dem kollegialen und organisatorischen Ganzen einer Schule verknüpft wird. Allerdings müssen wir, wenn wir mit Schulkollegien in dieser Art und Weise arbeiten möchten, selbst über umfassende eigene Erfahrungen aus Schule und Unterricht verfügen, sonst werden wir keine Chancen haben, etwas zu bewegen.

Entsprechend wirft auch das Fazit am Ende dieses Artikels mehr Fragen auf als es beantwortet. Unter Bezugnahme auf eine Veröffentlichung von Kautter (2003), aus einem Band zur "sonderpädagogischen Diagnostik«, sagen Hövel et al. (S. 303), wie wichtig es sei das "Thema des Kindes « zu ergründen. Sicher. Für mich ist das allerdings eher Sache einer guten Pädagogik und Didaktik, nicht in erster Linie Angelegenheit der »sonderpädagogischen Diagnostik«. Statt des TRP sollen also »schulische Maßnahmen « Anwendung finden, die eine "realistische und vor allem multifaktorielle Sicht von Verhaltensstörungen unterstützen, die auf eine fundierte Diagnostik zurückgreifen ...« (Hövel et al., S. 303). Was bedeutet hier denn »realistisch«? Wir erfahren es nicht. Hövel et al. gebrauchen zum Abschluss des Artikels noch einmal den Begriff »Verhaltensstörungen«, wiederum ohne Distanz. Damit wird quasi eine Klammer um den ganzen Artikel gelegt, denn er wurde ja auch genauso, mit diesem Begriffsgebrauch, eingeleitet. Welche genauen schulischen Maßnahmen und welche Form von Unterricht denn nun Anwendung finden sollen, bleibt auch unklar. Wir haben als einziges, konkretes Modell aber den »Freiraum«, an dieser einen Schule, vor Augen. Auch der vage Verweis auf eine Publikation von Lindsay (2007), in der es um die Effektivität der inklusiven Beschulung geht, erschließt sich nicht. Es wird nicht präzise gesagt, warum hier Lindsay überhaupt zitiert wird und was in seiner Metaanalyse denn jetzt, für das Thema des TRP und seine Einordnung und bezüglich des Schaffens von Alternativen, das Entscheidende war. Schon seit der Reformpädagogik haben engagierte Lehrer_innen, auf der Basis von Aufsätzen, Zeichnungen und Gesprächen, versucht, die Lebensthemen von Kindern und Jugendlichen zu verstehen und dieses Wissen mit curricularem Lernen verschränkt. Schule ist und bleibt in erster Linie eine pädagogische und didaktische Angelegenheit. Die sonderpädagogische Diagnostik kann höchstens unterstützend hinzukommen. Die von mir in zahlreichen Büchern und Aufsätzen entworfene Lebensweltorientierte Didaktik macht ja genau dies zu ihrem Kernthema, aufbauend auf vielen anderen, die vor mir schrieben und entwickelten. Selbst wenn im Werk von Kautter auch viel Hilfreiches enthalten sein mag, was sprach 
also dagegen, an dieser Stelle zusätzlich die Lebensweltorientierte Didaktik heranzuziehen? Die hierzu von mir verfassten Texte werden viel anbieten, um Alternativen zum TRP anzubieten und zu schaffen, selbst wenn das, was ich in dem Zusammenhang niedergeschrieben habe, weiterer Entwicklung bedarf. Niemals würde ich behaupten, dass ich da etwas Fertiges veröffentlicht hätte. Im Gegenteil. Trotz allem denke ich, dass in diesen Texten Anhaltspunkte enthalten sind, die aufgegriffen und mit anderen Dingen verknüpft werden könnten.

Wollten Hövel et al. nun nach bestem Wissen und Gewissen den State of the Art erfassen? Eher sieht es so aus, dass wir uns, um es mit Kim und Mauborgne (2018) zu sagen, mitten im Red Ocean der sonderpädagogischen Academia befinden. Dieser Red Ocean ist voller Rivalität und durchsetzt mit einer bestimmten Art der parteiischen, strategischen Textproduktion. Diese Art des Publizierens bewegt sich, sehenden Auges, an dem vorbei, was wir einen guten, soliden, seriösen State of the Art nennen würden. Wir müssen also allmählich hinein in den Blue Ocean der Möglichkeiten und der zukünftigen Entwicklung zu etwas Besserem, zu mehr Erkenntnis, zu mehr Wahrheit, auch zu mehr Nachhaltigkeit, zu mehr großem und weitem Denken. Eine fundierte Zusammenfassung des Forschungsstandes hätte sicherlich auch eine präzisere, der Realität heutiger Schulen angemessenere, Fragestellung hervorgebracht. Möglicherweise hätte das Ganze dann auch zu relevanten Erkenntnissen geführt. Was diesen Artikel aber so einzigartig macht, sind die dramatisierenden Anspielungen, die ins Dunkle und Irrationale gehen und die von den unterschwelligen Themen Gewalt und Misshandlung ihren Ausgang nehmen. Das alles bildet einen seltsamen Kontrast zu den zaghaften Versuchen der wissenschaftlichen Analyse, die sich aber auf Nebenschauplätzen und in unwichtigen Details verliert. Die gewählten wissenschaftlichen Zugänge sind kaum geeignet und die theoretischen Bezüge sind unzureichend, um das Thema TRP für die Gegenwart neu zu erschließen. Ich bin kein besonderer Freund des Peer Reviews in den Bildungs- und Gesellschaftswissenschaften, denn zu oft werden hier geistige Enge, ideologisches und parteiisches Denken erfahrbar, wodurch der Weiterentwicklung dieser Wissenschaften oftmals mehr geschadet wird, als dass solche Peer Reviews etwas nützen. Trotz allem mag ein Peer Review oder Editorial Review manchmal hilfreich sein, wenn es verantwortlich gemacht wird, wenn da jemand genau hinsieht und Fragen stellt, wenn da jemand weit und offen und zugleich klar und präzise denkt. Doch was ist, wenn einer der Autoren zugleich der geschäftsführende Herausgeber der betreffenden Fachzeitzeitschrift ist, wie bei dieser Studie? Wie viel kritische Distanz ist dann noch gegeben? 


\section{Lern- und Bildungsprozesse anders entwerfen}

\section{Reflektieren, verstehen und kommunizieren}

Wollen wir das verstehen, was uns im pädagogischen Feld begegnet, können wir zum einen qualitative Beobachtungen und Rekonstruktionen in Unterricht und Schulleben unternehmen, auch Dokumentenanalysen, indem wir etwa Zeichnungen, selbst verfasste Texte, mediale oder alltagsästhetische Produktionen der Kinder und Jugendlichen gemeinsam mit diesen betrachten und besprechen. Auf diese Weise können lebensweltlich-biografische Hintergründe schrittweise zugänglich werden, in der pädagogisch-didaktischen Arbeit mit den Kindern oder Jugendlichen, auch in der beratenden Arbeit mit Eltern. Bei alldem können Tagebücher oder Portfolios, in denen die pädagogischen Erfahrungen und Prozesse festgehalten werden, eine wichtige Hilfe sein. Solche Materialien lassen sich auch als Grundlage für Supervision oder Fallberatung heranziehen. In der schulischen Praxis spielt das Fallverstehen durch schulinterne, kollegiale Beratung und Reflexion eine sehr wichtige Rolle. Die Anwendung solcher Methoden variiert jedoch sehr stark, je nach Schulkultur und Schulklima. Solche kommunikativen Formate können Übergänge in die Bereiche Supervision und Coaching aufweisen. Sie können zum einen lösungsorientiert, zum anderen auch sinnverstehend ausgerichtet sein, oder beides. Die theoretischen Einrahmungen der jeweiligen Modelle können etwa psychoanalytisch, humanistisch bzw. klientenzentriert oder systemisch orientiert sein. Es sind hier eine Fülle von Modellen auf dem Markt, von der kollegialen Fallberatung oder Fallbesprechung, bis zur kooperativen Beratung, mit einzelnen Pädagog_innen, mit Teams oder in Gruppen, sodann die kollegiale Supervision, die Intervision, das reflektierende Team, bis hin zum Fallverstehen der Sozialpädagogik bzw. der Kinder- und Jugendhilfe. In der Literatur finden sich ferner Coaching-Adaptierungen für den Bereich der Schule. An den Schulen der USA wird ein resilienz- und stärkenorientieres School Counseling betrieben, was auch als eigener Studiengang an Universitäten belegt werden kann. Viele Pädagog_innen im Bereich emotionalen und sozialen Lernens arbeiten mit der, durch Ruth Cohn entwickelten, Themenzentrierten Interaktion oder sie beziehen sich auf mehrdimensionale Kommunikationsmodelle, auf Mindfulness, Mentalisieren oder Streitschlichtung.

Teils handelt es sich um umfassendere Modelle oder um einzelne Methoden und Techniken, wie das aktive Zuhören und das Verwenden von Ich-Botschaften im Sinne von Thomas Gordon oder das einfühlende Verstehen, Empathie zeigen und Paraphrasieren im Sinne von Carl Rogers. Im Coaching wird speziell dem Pacing und Leading eine hohe Wirksamkeit zugerechnet, aber auch dem zirkulären Fragen, dem Einset- 
zen von Metaphern, dem gezielten Arbeiten mit Verneinungen oder hypnotherapeutischen Techniken. Erstaunlicherweise lesen wir eher selten vom Einsetzen von Humor und auch nicht sehr oft vom gelegentlich notwendigen Setzen von Grenzen, einer Art wohlwollender Konfrontation, wobei Konfrontieren hier nicht im Sinne der konfrontativen Pädagogik Weidners zu verstehen ist. Es geht dabei mehr um ein direktes $\mathrm{Zu-}$ rückspiegeln von Dingen, die mir im pädagogischen Prozess auffallen und die auch einmal mit etwas mehr Deutlichkeit, Präzision und Bestimmtheit ausgesprochen werden müssen. Dieses Zurückspiegeln sollte immer von Wertschätzung für das jeweilige Kind oder den Jugendlichen geprägt sein und auch seine Autonomie und sein Selbstbestimmungsrecht und seine Integrität als Mensch achten. Trotz allem muss ich als Pädagoge manchmal auf die Grenzen hinweisen, wenn die Rechte oder die Integrität von Dritten durch ein bestimmtes kindliches oder jugendliches Verhalten eingeschränkt oder in Frage gestellt werden. Auch diese pädagogischen Handlungen beruhen auf verbaler Kommunikation, sicherlich unterstützt durch Körpersprache.

\section{Kritisch-konstruktive Bildungswissenschaft}

Wolfgang Klafki (1985, S. $47 \mathrm{ff}$.) spricht in seinen Studien zur Bildungstheorie und Didaktik von drei Perspektiven, die von einer kritischen Bildungswissenschaft eingenommen und miteinander verschränkt werden sollen. Aus der historisch-hermeneutischen Perspektive stehen pädagogische Sinngebungen und Sinnbeziehungen in umfassenderen erziehungsgeschichtlichen Zusammenhängen sowie in darüber hinausreichenden geschichtlich-gesamtgesellschaftlichen Kontexten. Nehmen wir etwa Michel Foucaults Arbeiten zur Disziplin oder zur Normalität, Erich Fromms Erörterungen zum Thema Normalität, Pierre Bourdieus Analyse der sozialen Klassen bzw. Milieus, Niklas Luhmanns systemtheoretische Arbeiten, Ulrich Becks Analyse der Risikogesellschaft oder Judith Butlers Dekonstruktion des heteronormativen Modells einer binären Geschlechtlichkeit. Alle diese Texte haben unser Verständnis davon verändert, was eine verhaltensbezogene Norm ist, was eine soziale Klasse ist, was ein soziales System ist, was eine Gesellschaft ist oder was eine geschlechtliche Identität ist. Diese Diskurse, auch wenn die allgemeine Bevölkerung die Originaltexte gar nicht gelesen hat, sind trotz allem handlungsrelevant geworden und über die Jahre in die Politik, in die Wissenschaft, in die Pädagogik und in die Kultur, etwa in die durchaus pädagogisch zu verstehende Filmproduktion des öffentlich-rechtlichen Fernsehens, wo sich dies besonders anschaulich nachvollziehen lässt, eingeflossen. Vor diesen diskursiven Hintergründen vollziehen sich die aktuellen gesellschaftliche Debatten zur Zukunft der Bildung, zur gesellschaftlichen Integration, zur sozialen Gleichheit bzw. Ungleichheit oder zu gesellschaftlichen Werten. Betrachten wir das erziehungs- und bildungswissenschaftliche Handlungsfeld aus einer erfahrungswissenschaftlichen, das heißt empirischen Perspektive, so lässt sich mit Klafki feststellen, dass empirische Forschung von Hermeneutik durchzogen und umklammert ist. Dieser Zusammenhang und diese Wechselwirkung muss beim Entwickeln von Fragestellungen, beim Analysieren der Gegenstände, beim Interpretieren und Einordnen der Ergebnisse berücksichtigt werden. Empirische Forschung muss daher mehr sein als neutrale Effektivitätsforschung, indem Sozialisationsprozesse und institutionalisierte Bildungsprozesse in kritischkonstruktiver Perspektive untersucht und analysiert werden. Empirische Forschung 
versteht sich ferner als pädagogische Innovationsforschung, die an humanen und demokratischen Zielsetzungen orientiert ist, speziell bezogen auf Kinder und Jugendliche aus sozial schwächeren oder marginalisierten Bevölkerungsgruppen (vgl. Klafki, 1985, S. 50 ff.).

Betrachten wir unser pädagogisches Handlungsfeld ferner aus einer gesellschaftskritisch-ideologiekritischen Perspektive, so geht es zunächst darum, sich der historischen Grundlagen zu versichern, die wir heranziehen können, um unsere Kritik auf eine solide Basis zu stellen. Klafki (1985, S. $57 \mathrm{ff}$.) beginnt mit den Bildungskonzepten der Aufklärungszeit, festgemacht an Jean-Jacques Rousseau, John Locke und Immanuel Kant. Er geht dann weiter zu Ansätzen der freiheitlichen Bildung und Volksbildung um 1770-1830, wie sie von Pestalozzi, Diesterweg, Fröbel oder Schiller entwickelt worden sind. Bildung lässt sich von hier aus bestimmen als ein Unterfangen, bei dem es um Freiheit, Selbstbestimmung, Emanzipation und Solidaritätsfähigkeit geht. Klafki spannt den historisch-rekonstruktiven Bogen bis hin zur kritischen Theorie der Gesellschaft, wie sie von der Frankfurter Schule entwickelt worden ist, einschließlich Jürgen Habermas' Erkenntnisinteressen und Theorie des kommunikativen Handelns, Axel Honneths Kritik der Macht, Anerkennungstheorie und seinen Analysen zur zerrissenen Welt des Sozialen. Doch auch im internationalen Feld finden sich Bezüge in Theorien und praktischen Handlungsmodellen, die sich aus einer gesellschaftskritischen Perspektive heranziehen lassen. $\mathrm{Zu}$ denken ist hier an Participatory Citizenship Education, Student Participation, Student Voice, Teaching for Social Justice und Teaching through Social Cohesion. Bei all diesen internationalen Strömungen geht es um emanzipatorische, freiheitliche Bildungsideale und gesellschaftliche Utopien, die sich um die Aufhebung von gesellschaftlicher Desintegration und die Überwindung von sozialer Ungleichheit drehen. Stets geht es um ein positives Menschenbild, wie es etwa von John Locke entworfen wurde, um die Vorstellung eines Menschen, der in der Lage ist, sein Leben zu ergreifen, sich zu verwirklichen und frei zu sein. Niemals geht es bei den genannten pädagogischen Strömungen jedoch um ein negatives Menschenbild, wie es etwa Thomas Hobbes entworfen hat, wonach sich Menschen, ohne starke staatlich regulierende Hand wie egoistische Bestien aufführen. Neue Steuerung und Educational Governance, die derzeit in unserer Gesellschaft und in unseren Bildungsinstitutionen immer mehr die Oberhand gewinnen, implizieren jedoch, dass die Menschen sich nicht aus eigener innerer Verantwortlichkeit selbst steuern können. Wir können dies auch daran erkennen, dass die Schulpflicht bisher nicht in eine selbst gestaltete Bildungspflicht umgewandelt worden ist, obwohl diese Forderung ja keineswegs neu ist und in einigen anderen Ländern längst praktiziert wird. Folglich geht es auch nicht um die bloße Wirksamkeit von pädagogischen Maßnahmen, schon gar nicht um reines institutionelles Funktionieren, nicht um bloße Statistiken, Metaanalysen, Effektstärken oder Evidenzbasierung. Diese pädagogischen Handlungsansätze wollen Chancengleichheit, soziale Inklusion, eine positive Sicht auf Diversität und eine gerechtere, lebenswertere Welt für alle. Es geht nicht um das bloße Steuern von Verhalten, sondern um ein freiheitliches Bildungsideal, um die Stärkung von solidarischen Kräften in der Gesellschaft, um den sozialen Zusammenhalt, um die Stärkung der Zivilgesellschaft, um die Stärkung der Rechte der Bürger_innen. Insofern handelt es sich hier um gesellschaftspolitisch motivierte pädagogische Ansätze, die für den Förderschwerpunkt der emotionalen und sozialen Entwicklung von hoher Relevanz sind. 


\section{Lebenswelt und curriculares Lernen}

Ich habe die Lebensweltorientierte Didaktik seit Anfang der 90er Jahre, aus der pädagogischen Praxis an spezialisierten Förderschulen heraus, entwickelt, später auch mit Blick auf die inklusiven Settings an Grund- und Hauptschulen. Die Modell- und Konzeptentwicklung vollzog sich in hohem Maße dialogisch-partizipativ, das heißt unter maximaler Einbindung und Mitgestaltung der von mir unterrichteten Kinder und Jugendlichen, denen ein Förderbedarf in der emotionalen und sozialen Entwicklung zugeschrieben worden war, oftmals zusätzlich ein Förderbedarf im Lernen. Das Modell ist von der Forschungsmethodik her qualitativ fundiert, subjektzentriert ausgerichtet und orientiert sich an Feldforschung, ethnografischer Forschung und Handlungsforschung. Theoretisch basiert die Lebensweltorientierte Didaktik auf der am Bildungsideal der Freiheit, der Emanzipation, der Selbst- und Mitbestimmung und der Solidaritätsfähigkeit des Einzelnen ausgerichteten kritisch-konstruktiven Erziehungs- und Bildungswissenschaft, wie sie von Klafki formuliert und ausgearbeitet worden ist. Zugleich werden Elemente aus der Reformpädagogik, insbesondere der demokratischen Pädagogik Fritz Gansbergs und Celestin Freinets integriert, ebenso Elemente der Projektpädagogik, der handlungsorientierten Pädagogik, der Schule als eines demokratisch verfassten Erfahrungsraums, wie ihn Hartmut von Hentig konzeptualisiert hat, aber auch Elemente und Erfahrungen aus den freien Schulen der 70er Jahre. In meinen Forschungsbemühungen habe ich eine Subjektperspektive eingenommen, eine Haltung, wie wir sie nicht nur aus der Reformpädagogik kennen, sondern auch aus der neuen Kindheits- und Jugendforschung. Ziel ist dabei, das Kind bzw. den Jugendlichen in seiner individuellen Welt wahrzunehmen und zu verstehen. Dazu habe ich nicht nur Lebenswelt-Modelle, sondern auch sozialökologische Modelle herangezogen, die sich eignen, die jeweiligen Lebensräume, von ihren Strukturen bzw. inhaltlichen Komponenten her, zu begreifen und zu beschreiben. Die Lebensweltorientierte Didaktik versteht sich nicht nur als pädagogisches Handlungsmodell, sondern will selbst auch Beiträge zu einer kritischen bildungswissenschaftlichen und sozialwissenschaftlichen Forschung leisten, indem sie die, wie Honneth es genannt hat, zerrissene Welt des Sozialen mit der Absicht einer positiven Veränderung ausleuchtet. Gemeinsam mit den Kindern und Jugendlichen werden ihre Lebenswelten und die hierin liegenden Daseins- und Lebensthemen, die sich zu einem großen Anteil aus ihren zu bewältigenden Entwicklungsaufgaben und Daseinsthemen ergeben, sowie die dazu von ihnen eingesetzten Daseinstechniken bzw. Auseinandersetzungsstrategien untersucht. In diesen Prozessen werden von den Heranwachsenden seit der frühesten Kindheit, teils in emotional stark betonten Situationen, interne kognitive Schemata, Repräsentationen bzw. Skripte oder Drehbücher ausgebildet, die fortan das Denken, Fühlen und Handeln der jungen Menschen prägen.

Damit diese Themen und Skripte zum Ausdruck kommen können, gilt es einen pädagogisch-didaktischen Raum aufzuspannen. Bei alldem spielen symbolbildende Prozesse wie Spielen, Zeichnen, Malen und Gestalten, Jugendkultur, Körperkulte und Körperkonzepte, ferner die Entwicklung spezieller Jugendsprachen und der Umgang mit Medien, Musik oder Computerspielen, eine wesentliche Rolle. Doch auch das freie, expressive Schreiben, mit seinen Übergängen zu Hip Hop und Rap Produktionen, kann hier von hoher Bedeutung sein. Arwed Williams, der eine Zeitlang in der Flensburger Abteilung mitgearbeitet hat, hat mir hier wertvolle Einblicke gegeben. In 
der internationalen Literatur finden wir solche pädagogischen und didaktischen Entwürfe unter Titeln wie Youth Culture or Popular Culture as a Bridge, Hip Hop Pedagogy, Connecting Hip Hop and Social Justice oder auch Critical Literacy. Eine Reihe von Publikationen beschäftigt sich auch mit der Frage, wie wir Studierende an Universitäten auf eine solche pädagogische Arbeit vorbereiten können. Themen sind hier Preparing Teachers for Multicultural Classrooms oder Hip Hop, Justice and Working with College Students (vgl. auch Broecher et al., 2017). Wenn Jugendkulturen für einen pädagogisch-didaktischen Handlungsansatz als wesentlich oder zentral angesehen werden, so müssen wir natürlich in Betracht ziehen, dass sich diese in einem fortwährenden Veränderungsprozess befinden. In den 70er und 8oer Jahren dominierten widerständige Jugendkulturen, die ihre Vorbilder teils aus der Arbeiterklasse bzw. der britischen working class (vgl. Willis, 1979, 1981, 2017) ableiteten. In den 90er Jahren dominierten teils rechtsradikale Kulturen, auch die Kultur der Skinheads. In den vergangenen Jahren ging es zunehmend um Techno-Szenen und digitale Jugendkulturen. Teils bewegen sich die Jugendlichen in neuen Lernwelten und betreiben längst eine selbstorganisierte Bildung, jenseits der etablierten Bildungsinstitutionen (vgl. z. B. Wahler et al., 2008). Einen besonderen Stellenwert nehmen hier Computerspiele bzw. Games, insbesondere die Multiplayer-Online-Rollenspiele ein, etwa World of Warcraft, Destiny, Battlefield, Counter-Strike, The Division oder Borderlands. Selbst wenn das Eintauchen in solche Spiele und Online-Rollenspiele mit vielen problematischen Aspekten einhergehen kann, mir sind Fälle bekannt, wo junge Männer von Mitte zwanzig noch immer in den Dachzimmern leben, in denen sie als Kinder aufgewachsen sind, und die ganze Nacht über in ihr Mikrophon schreien, in wilder Spielaktion, so dass Nachbarn, die dicht an solch einer gebeutelten Familie wohnen, sogar ihre Häuser verkauft haben. Doch lässt sich auf der anderen Seite nicht leugnen, dass sich Kinder und Jugendliche während des Spielens zahlreiche technische Fähigkeiten, je nach Spiel, inhaltliche Kenntnisse, und im Falle von Multi-Player-Spielen, auch soziale Fähigkeiten aneignen. Es hat zuletzt zahlreiche Bemühungen gegeben, unter dem Titel Gamification, eben dieses Potenzial von Computerspielen für pädagogische Zwecke zu nutzen. Es gibt dazu mittlerweile eine anwachsende Literatur. Für die Zukunft des Bildungssystems und seiner curricularen Binnenstruktur könnten daher Game Design und Game Narrative bzw. Storytelling von hoher Bedeutung sein. Die Lebensweltorientierte Didaktik sucht dann im nächsten Schritt nach Übergängen und Anknüpfungspunkten für curriculares, sachbezogenes Lernen in den Unterrichtsfächern. Subjektzentriertes Arbeiten wird mit sachorientiertem Lernen verschränkt. Darin könnten in Zukunft Games und Gamification eine hervorgehobene Rolle spielen, insbesondere dann, wenn Lernprozesse mehr und mehr auf digitale Ebene gebracht werden.

Winfried Kuhn und Ulrike Kocks, die damaligen Leiter_innen des Düsseldorfer Studienseminars, entwickelten ab 1989 das Konzept des fächerübergreifenden Handlungsrahmens. Speziell Kuhn griff dabei auf seine umfangreichen Erfahrungen aus der einklassigen Dorfschule zurück. Dabei handelt es sich um längerfristige, projektartige didaktische Einheiten, in denen, im Sinne von Klafki, mal mehr die Subjektanliegen geklärt und mal mehr die Sachanliegen weiter vorangebracht werden, je nach Situation, je nachdem, was möglich ist. Gleichzeitig wurde eine Beratung zum Lern-, Arbeits- und Sozialverhalten in den didaktischen Prozess integriert. Problematisch wäre allerdings, wenn wir jetzt Gamification einsetzen, um ein, immer enger und ri- 
gider werdendes, schulisches Lernen bloß digital anzureichern. Es müssen, wenn wir schon die virtuellen Spiele in unsere pädagogischen und didaktischen Bemühungen einbeziehen, offene Lernräume entstehen, in denen von den Kindern und Jugendlichen durchaus Neuland entdeckt werden kann, in welche Richtung auch immer. Wir müssen nicht alles im kompetenzorientierten Sinne, in Form von didaktischen LehrLern-Zielen vorgeplant und vorgedacht haben. Parallel zur praktischen Arbeit an den nordrhein-westfälichen Schulen, konnte ich das Material und die pädagogisch-didaktischen Entwürfe an der Justus-Liebig-Universität Gießen, an der Universität zu Köln, an der Martin-Luther-Universität Halle-Wittenberg, an der Universität Hamburg und an der Ludwig-Maximilians-Universität München in meine Lehrtätigkeit einbringen, während der Jahre 1998 bis 2008. Die Studierenden dieser Universitäten waren interessiert und motiviert, wenn es darum ging, die Lebensweltorientierte Didaktik, ihre Möglichkeiten und die sich stellenden Herausforderungen zu diskutieren und für ihre eigenen pädagogischen und didaktischen Versuche aufzugreifen, abzuwandeln oder weiterzuentwickeln. Insofern waren auch die Beiträge und Gedanken dieser Generation von Studierenden für die weitere Entwicklung des Modells von großer Bedeutung. Sie wirkten als Treiber und erzeugten Motivation, weiterzumachen.

Ferner ergaben sich während dieser Jahre eine Reihe von Kooperationen mit der Welt der Kinder- und Jugendhilfe bzw. Sozialpädagogik, insbesondere mit Karlheinz Thimm und Katrin Kantak von der Landeskooperationsstelle Schule-Jugendhilfe Potsdam, dem Deutschen Verein für öffentliche und private Fürsorge, in Frankfurt a. M., dem Institut für soziale Arbeit, Münster und den durch Birgit Warzecha, inzwischen Birgit Herz, angeleiteten Hamburger Bahnhofsprojekten. Allen genannten Organisationen und Projekten ging es um den produktiven Umgang mit, den Schulunterricht verweigernden, Jugendlichen, um verstehende, ethnografische, subjektzentrierte $\mathrm{Zu}$ gänge, nicht aber um deren Anpassung an schulische Routinen und nicht um deren bloße Anwesenheit an Schulen. Im Verlauf dieser Kooperationen wurde die Lebensweltorientierte Didaktik zum Bestandteil der Konzeptentwicklung auch im Schnittfeld zur Kinder- und Jugendhilfe, zur Sozialpädagogik. Möglichkeiten des Neuentwurfs könnten darin liegen, die Lebensweltorientierte Didaktik mit den internationalen Modellen Teaching for Social Justice, Urban Education, Experiential Education, Citizenship Education, Student Voice, Hip Hop und Rap Pedagogies und Place Pedagogies zu verknüpfen sowie das Ganze zeitgemäß zu aktualisieren, denn auch die beständige Weiterentwicklung der Medien, sozialen Netzwerke, Jugendkulturen etc. erfordert neue, vor allem auch digitale didaktische Formen. Aber die Lebensthemen, an denen sich die jungen Menschen oftmals aufreiben und dabei durch Einsatz problematischer Daseinstechniken auffällig werden, dürften noch dieselben sein. Mit Bezug auf Paolo Freire lässt sich hier auch von generativen didaktischen Themen sprechen, das heißt Themen, die, aus existenzieller und gesellschaftlicher Notwendigkeit und Dringlichkeit heraus, aufgefunden und bearbeitet werden müssen. Generative Themen sind Themen, die für die Kinder und Jugendlichen, für ihre Familien und Communities von besonderer Bedeutung sind. Diese Themen haben immer eine soziale und kulturelle Komponente. Auch Wolfgang Jantzen (2012 d) hat diesen Zusammenhang der, von ihm entwickelten, kulturhistorischen Didaktik zugrundegelegt. Hierbei werden die historischen, kulturellen und sozialen Kontexte, in denen die Lernenden, aber auch die Lehrenden, sich befinden, reflektiert und zum Ausgangspunkt des pädagogischen Denkens gemacht. Es findet eine, in den didaktischen Prozess integrierte, pädagogische 
Reflexion zu den Daseinsthemen, Lebenskonflikten, um diese von Hans Thomae geprägten Begrifflichkeiten hier aufzugreifen, inklusive ihrer sozialen und kulturellen Hintergründe etc. statt, wie auch zu den Daseinstechniken, die sich unter anderem als Lern-, Arbeits- und Sozialverhalten zu erkennen geben. Auch die von Jean-Paul Sartre in Das Sein und das Nichts explizierten existentialistischen Konzepte, die Art der Beziehungsgestaltung, um solche Reflexionen überhaupt in Gang zu bringen, die Gespräche über Vergangenheit, Faktizität und Transzendenz, das Überschreiten des Alten und das Entwerfen des Neuen, gingen in die Lebensweltorientierte Didaktik ein.

\section{Erfahrungsbasiertes Lernen}

Nicht immer helfen verbale Kommunikationen, um im pädagogischen Prozess voranzukommen. Oftmals erscheint es sinnvoller, Kindern und Jugendlichen konkrete, handelnde, körperbasierte Erfahrungen zu ermöglichen und ihnen Räume, Medien und Materialien erschließen zu helfen, um das eigene Innenleben zu erkunden, zum Ausdruck zu bringen und dann gegebenenfalls neu zu strukturieren. Modelle zum erfahrungsbasierten Lernen, die speziell auch mit Aspekten der emotionalen und sozialen Entwicklung verknüpft werden können, sind etwa Adventure oder Wilderness Education. Hierbei können beispielsweise die Themen Resilienzförderung oder Selbstkonzept, Selbstwertgefühl und Identitätsentwicklung im Vordergrund stehen. Andere Modelle sind unter Titeln wie Outdoor Education, fokussierend etwa auf das Thema Selbstwahrnehmung, sodann unter Outdoor Education und Pedagogy of Place, oder unter Outdoor Education und Social Justice zu finden. Wieder andere Publikationen kombinieren die Konzepte Outdoor und Adventure im Hinblick auf emotionales und soziales Lernen. In Deutschland vertraut ist die Erlebnispädagogik, die sich historisch betrachtet, teils auf Schiffen vollzogen hat. Bekannt ist ferner das Modell Outward Bound, in der Tradition von Kurt Hahn. Im internationalen Feld werden dagegen die Begriffe Experiential Learning oder Experiential Education verwendet. Erfahrungsbasiertes Lernen hat sich vielfach in den Sommercamps Nordamerikas entwickelt, auch mit Impulsen und Wirkungen für Deutschland. Bestandteil von Experiential Learning können intensive Naturerfahrungen sein, gerade im Kontext der Digitalisierung. Richard Louv, der auf einem der großen Kongresse der Association for Experiential Education, 2016 in Minneapolis, als Keynote Speaker aufgetreten ist, gilt auf diesem Gebiet als wichtiger Impulsgeber. Was Experiential Education ist, und warum diese so bedeutsam für das pädagogische Feld der emotionalen und sozialen Entwicklung ist, wird sehr prägnant seitens der Association for Experiential Education (AEE) ausgeführt und dargelegt ${ }^{1}$. AEE ist die führende internationale Gesellschaft für Erlebnispädagogik, Outdoor- und Adventure-Pädagogik, Adventure Therapy, Wilderness Therapy etc. Experiential Education wird auf der genannten Internetseite folgendermaßen definiert: »Challenge and experience followed by reflection leading to learning and growth.« Dahinter steht eine pädagogische Philosophie, die auf einer Vielfalt an Methodologien basiert, die gezielt Lernanlässe herstellt und Möglichkeiten der fokussierten Reflexion, um Fähigkeiten zu entwickeln und Wissen aufzubauen,

1 vgl. https://www.aee.org/ (12.10.2020) 
Werte zu klären und Kinder und Jugendliche in die Situation zu bringen, positive Beiträge zur ihren sozialen Communities machen zu können.

Dies geschieht auch durch die aktive Einbindung der Heranwachsenden in Entscheidungsprozesse und in kreative Problemlösungsprozesse. Gelernt wird aus natürlichen Konsequenzen und Abläufen, auch aus Fehlern, ebenso aus Erfolgen, durch vertiefte, gemeinsame Reflexion. Auch über mögliche Risiken und Erfahrungen des Scheiterns wird sich ausgetauscht und reflektiert. Die verantwortlichen Pädagog_innen sorgen für Sicherheit und adäquate, der jeweiligen Entwicklung der Heranwachsenden angemessene, Lernräume. Dies fördert zugleich auch die Weiterentwicklung und Vertiefung der pädagogischen Beziehungen. Während des HighScope Summer Camps wanderten wir mit den Jugendlichen drei Tage durch einen Nationalpark in Michigan, über den Potawatomi-Trail. Wir gingen jeweils in Gruppen von etwa fünfzehn Jugendlichen und zwei Begleitpersonen, mit Zelten, Decken, Kochgeschirr und Proviant auf dem Rücken. Die Zelte konnten an bestimmten Lagerplätzen im Nationalpark aufgestellt werden, wo es Wasserleitungen mit Trinkwasser und Feuerstellen, zumeist in der Nähen von Seen, gab. Wir hatten teils mit sehr widrigen Verhältnissen zu kämpfen. Einerseits war es sehr warm, doch tags wie nachts flogen Heerscharen von Moskitos. Einen ganzen Tag lang gingen wir in strömendem Regen. Gemeinschaftlich galt es die Zelte aufzuschlagen und Essen auf einem Lagerfeuer zuzubereiten. Etliche Jugendliche, die bis dahin nur ein behütetes, zivilisiertes oder urbanes Leben kannten, gerieten unterwegs in ziemliche Krisen und mussten kontinuierlich ermutigt werden, weiter zu machen, speziell an dem Tag, als es soviel regnete und wir teils über aufgeweichte Wege gingen, teils regelrecht durch Schlamm wateten. Es gab gar keine Alternative, als den Zielpunkt zu erreichen, an dem David Weikart uns wiederum mit dem gelben HighScope Bus abholte. Doch es gab auch unvergleichlich schöne Augenblicke, als wir etwa abends am Ufer eines Sees um ein kleines Feuer saßen, die Zelte im Halbkreis hinter uns, in den Sternenhimmel schauten und dem Konzert von Fröschen lauschten. Ähnliche Erfahrungen machten die Kölner Studierenden der Sonderpädagogik in den 8oer Jahren, die durch die enge Zusammenarbeit zwischen Karl-Josef Kluge und Andrzej Jaczewski, von der Universität Warschau, nach Polen kamen und mit Jaczewski und den dortigen Pfadfindern auf den Masurischen Seen segelten oder in den Beskiden, einem Vorgebirge der Karpaten, wanderten und dann zumeist in Ropki übernachteten, einem kleinen Ort in Südpolen, wo Andrzej Jaczewski bis ins hohe Alter von 91 Jahren lebte.

\section{Transformative pädagogische Beziehungen}

Das Aufbauen und Unterhalten von pädagogischen Beziehungen, speziell wenn es um die Förderung der emotionalen und sozialen Entwicklung geht, gilt als eine der wichtigsten Komponenten des pädagogischen Handelns. Wenn ich mir bei einer erfahrenen Sonderpädagogin anschauen durfte, wie das geht, dann war das meine damalige Mentorin Sylvia Mandt, an einer Förderschule in Solingen. Worin jedoch eine hilfreiche pädagogische Beziehung besteht und durch welche Eigenschaften diese gekennzeichnet ist, bedarf genauerer Definition. Um diese Konkretisierung vorzunehmen, müssen Theorien herangezogen werden, die etwas zum Thema der förderlichen wie auch der abträglichen pädagogischen Beziehung aussagen können, direkt oder indi- 
rekt. Wieviel Empathie, Mitfühlen oder Pacing ist nötig und wieviel Versachlichung, Abgrenzung oder gar Konfrontation? Eine einheitliche und mit empirisch-quantitativen Methoden geprüfte Theorie existiert auf dem Gebiet der pädagogischen Beziehungsgestaltung im Feld der emotionalen und sozialen Entwicklungsförderung bisher nicht. Dieses Gelände dürfte auch so viele, schwer zugängliche Tiefenschichten beinhalten und berühren, dass die empirisch-evidenzbasierte Forschung hier nicht weit kommen wird. Auch lassen sich therapeutische Konzepte, und ich spreche noch gar nicht von ihrer genauen Ausrichtung, nicht automatisch auf pädagogische Kontexte, auf die ja vielfältige Faktoren einwirken, übertragen. Beim Trainingsraumprogramm soll etwa eine demonstrative Freundlichkeit die pädagogische Beziehung kennzeichnen. Doch diese Freundlichkeit erscheint mechanisch und auch nicht glaubwürdig, weil kein echtes Interesse am Lebenskontext des Kindes oder Jugendlichen gezeigt wird, zumindest sieht das Modell dies nicht vor. So dürfen die eigentlich bedeutsamen Fragen ja gar nicht gestellt werden. School-wide Positive Behavior Support (SW-PBIS) dürfte sich glaubhaft um eine Berücksichtigung der pädagogischen Beziehung bemühen, eben durch die grundsätzlich positive Haltung zum Kind oder Jugendlichen. Dieses Modell lässt jedoch trotz allem wenig Spielraum für die Reflexion von all den komplexen emotionalen und seelischen Vorgängen, für die es eben keine theoretischen Konzepte hat. Die Reichweite von SW-PBIS ist daher, unter dem Aspekt der pädagogischen Beziehungsgestaltung, als eher begrenzt einzuschätzen, weil diese bisher nicht konsequent in das Theoriegebäude eingearbeitet worden ist.

Wesentliche Erkenntnisse lassen sich aus der, von John Bowlby begründeten, Bindungstheorie und auf dieser basierenden Forschungsarbeiten ableiten, ebenso aus Verknüpfungen von Bindungstheorie und Neurowissenschaften (vgl. z. B. Gebauer und Hüther, 2012), bis hin zu den Forschungen bezüglich der bindungsbasierten Nurture Groups, die in der Tradition von Marjorie Boxall an britischen Schulen eingerichtet und teils auch, im Sinne einer Nurtering School, zur pädagogischen Gestaltung ganzer Schulen herangezogen worden sind. Doch die Fähigkeit von Pädagog_innen, sichere von unsicheren Bindungsmustern zu unterscheiden und das Bemühen, sichere Bindung im Nachhinein wenigstens ansatzweise durch eine gute Pädagogik herzustellen, dürfte allein noch nicht ausreichen, um tatsächlich etwas Nachhaltiges zu bewirken. Weitere Bezugspunkte lieferte die Psychoanalyse bzw. die psychoanalytische Pädagogik, indem sie etwa für das Thema Übertragung und Gegenübertragung in der pädagogisch-therapeutischen Beziehung sensibilisierte. Dieses Wissen wird uns helfen, durch ein negatives oder destruktives Verhalten zum emotionalen Erleben bzw. Seelenleben des Kindes oder Jugendlichen hindurchzusehen und uns nicht durch provokative Worte oder negative Verhaltensweisen irritieren zu lassen. Vor allem bewahrt uns dieses Wissen davor, eigene, womöglich ungeklärte und unverarbeitete Konfliktthemen in die Wahrnehmung des pädagogischen Geschehens hineinzuprojizieren. Wichtige Impulse für eine pädagogisch-therapeutische Beziehungsgestaltung gab auch der von Carl Rogers begründete klientenzentrierte Ansatz, wie er etwa von Karl-Josef Kluge und seinen Mitarbeiter_innen in den 8oer Jahren an der Universität zu Köln auf die Sonderpädagogik der emotionalen und sozialen Entwicklung bezogen, gelehrt und praktiziert wurde, bis hin zu den spieltherapeutischen Weiterentwicklungen, die der klientenzentrierte Ansatz erfahren hat.

Ausgeprägte beziehungsgestaltende Komponenten finden sich ferner in der historischen Reformpädagogik. Es dürfte jedoch noch nicht abschließend geklärt sein, ob 
wir die Reformpädagogik generell als missbrauchsanfällig und missbrauchsbegünstigend ansehen müssen, wie Jürgen Oelkers dies getan hat. Weitere Anknüpfungspunkte finden wir in der Urban Education und unter dem Titel Teaching for Social Justice, ebenso in der materialistischen Behindertenpädagogik, wie sie Wolfgang Jantzen (vgl. 2012 a, b; 2019; 2020 b) geprägt hat, durch die Hervorhebung des Dialogs im Lernprozess, durch das Geben und Erfahren von Anerkennung, Bestätigung und Resonanz im Rahmen dialogischer Beziehungen, wodurch alles Soziale überhaupt erst möglich wird (vgl. Jantzen, 2012 b, S. 119 ff., S. 148 f.). Im Feld der, recht umstrittenen, konfrontativen Pädagogik lassen sich durchaus härtere, teils den Willen brechende, Umgangsarten, speziell mit sehr widerständigen Jugendlichen, beobachten. Dieses Modell würde quasi den radikalen Gegenpol zu den bindungsorientierten oder klientenzentrierten Ansätzen darstellen, wenn wir auf das Thema der pädagogischen Beziehungsgestaltung schauen. Jens Weidner und seine Co-Autoren schildern Situationen und Fallbeispiele, bei denen, nach deren eigener Auffassung, bloße Empathie nicht mehr ausreichen soll, um etwas an den sehr destruktiven Verhaltensmustern der Heranwachsenden zu ändern. Einen fachlichen Konsens hierzu dürfte es aber kaum geben. Pädagogische Erfolge mit Jugendlichen, die sich extrem herausfordernd verhalten, lassen sich nachweislich, ich greife hier auf eigene, langjährige pädagogische Erfahrungen aus Förderschulen für emotionale und soziale Entwicklung zurück, auch mit weniger rabiaten, dominanten und erniedrigenden, das heißt mit akzeptierenden und wertschätzenden, Methoden erreichen.

Das Problem ist oftmals die institutionelle Vorgeschichte eines Verhaltens, die die biografischen, familiären, peerweltbezogenen Hintergründe und Einflussfaktoren noch verschärfen kann. Je länger die Historie fachlich unprofessioneller, falscher oder kontraproduktiver pädagogischer Entscheidungen und Einflussnahmen und damit einhergehend, die Ansammlung von negativen Erfahrungen eines Jugendlichen ist, desto massiver und herausfordernder verhält er sich schließlich in den pädagogischen Kontexten, in die er als nächstes kommt. Daraus ist aber nicht abzuleiten, dass die Pädagogik auch, in demselben Maße, an Härte zunehmen müsste. Das war ja der große Irrtum der Leitung und des Kollegiums an der Förderschule Schwarzegg, wo Schüler_ innen, gemeinsam mit ihren Eltern, auf den heißen Stuhl gesetzt und dann die Familie vom versammelten Kollegium verbal aggressiv konfrontiert wurde, wo Schüler_innen, die nur in der Nähe eines rauchenden Schülers gestanden hatten, gleichermaßen bestraft wurden, wo Jugendliche gezielt provoziert und körperlich in die Enge getrieben wurden, um sie dann, wenn sie sich wehrten, wegen Selbst- und Fremdgefährdung komplett vom Schulleben auszuschließen und zu psychiatrisieren. In einigen Fällen, als sich eine bestimmte Heimleiterin, die eine ganze Reihe von Schützlingen an der betreffenden Schule hatte, weigerte, die Jugendlichen während des Unterrichts abzuholen und stattdessen von der Schulleiterin eine andere, geeignetere Pädagogik gefordert hatte, bestellte die Schulleiterin einen Notarztwagen, ließ den betreffenden Jugendlichen Beruhigungsspritzen geben und sie in eine psychiatrische Klinik einweisen, ohne weitere Rücksprache mit der betreffenden Heimleitung zu nehmen. Daraus wurde ein ziemlicher Eklat, das heißt die Heimleiterin reichte eine Dienstaufsichtsbeschwerde gegen die Schulleiterin ein, die Schulleiterin wiederum diffamierte die Heimleiterin usw. Wir befinden uns an so einer Stelle tief im roten Ozean, um erneut das Modell von Kim und Mauborgne heranzuziehen. Nach meiner eigenen Erfahrung muss die Pädagogik in solchen Kontexten, wenn sich die Dinge schon so zugespitzt haben, eher 
philosophischer und freier werden. Aber es können dann auch neue Gefahren drohen. Diese Erzeugung eines anderen Klimas, einer anderen kommunikativen Atmosphäre, kann gelegentlich von einigen männlichen Jugendlichen nicht eingeordnet werden, was, zumindest am Anfang, zu weiteren Irritationen führen kann. Eine Metakommunikation über pädagogische Beziehungsverhältnisse kann von einigen Jugendlichen zunächst fehlinterpretiert werden, etwa vereinfacht gesagt in der folgenden Weise: Wer plötzlich so freundlich und verständnisvoll mit mir spricht, der muss irgendetwas von mir wollen. Es gilt also, je nach Situation, die passenden Worte und das passende Gesprächssetting zu finden. Besser in solchen Fällen also am Anfang etwas raubeiniger auftreten, zumindest als Mann, aber von der inneren Haltung her wertschätzend und verhalten herzlich sein, aber eben nicht $z u$ herzlich. Sagen wir in etwa so, wie Heino Ferch das in den allermeisten Kriminalfilmen tut, in denen er mitspielt, etwa als Richard Brock in der Serie Spuren des Bösen. An der Stelle brauchen Pädagog_innen gute Nerven, Durchhaltevermögen und am besten auch kollegiale Rückendeckung, selbst wenn es manchmal, je nach Schulkultur, auch ohne gehen muss.

Nun hat es in der Vergangenheit extreme Ausformungen pädagogischer Beziehungen gegeben, von erotisierten Nähebeziehungen, die in einigen Fällen in mannmännliche, sexuelle Beziehungen übergingen. Die Namen der beiden Pädagogen bzw. Schulleiter Gustav Wyneken und Gerold Becker, wenngleich Becker eigentlich Theologe war und nicht einmal Pädagogik studiert hatte, sind in diesem Zusammenhang eng mit sexuellen Beziehungen zu Jungen im frühen Jugendalter verknüpft. Dem unangemessenen Herstellen von körperlicher und emotionaler Nähe steht das eiskalte Eliminieren von jungen Menschen innerhalb von totalitären Schulkulturen gegenüber, wie im Fall Schwarzegg. Beide Formen des pädagogischen Missbrauchs haben eigene ideologische Überbauten. In der paramilitärischen, an der konfrontativen Pädagogik und den Glen Mills Schools ausgerichteten und in vielerlei Hinsicht an Philip Zimbardos Gefängnisexperiment erinnernden, Schulkultur von Schwarzegg wurde sich zwar einerseits auf die konfrontative Pädagogik Jens Weidners bezogen. Doch die weiblichen Führungspersonen und zumeist fachlich inkompetente oder von der Persönlichkeit her wenig entwickelte Lehrkräfte und Sozialpädagog_innen, die dieses inhumane System als Co-Konstrukteur_innen oder Mitläufer_innen trugen, hatten sich von schulrechtlichen und wissenschaftlichen Grundlagen vollständig losgelöst, selbst von der konfrontativen Pädagogik. Deren Methoden dienten hier nur noch als Inspirationsquelle für weitergehende, entwürdigende Praktiken. Auch die Glen Mills Schools dienten der Führungsclique in Schwarzegg als Vorbild. Ihr Begründer Ferrainola war ein ehemaliger Gangster, der seine pädagogische Methode von der street gang her entwickelte. Er arbeitete vor allem mit Gruppendruck, allerdings ohne das Zulassen von körperlichen Schlägereien. Im April 2019 wurden den Glen Mills Schools, durch das Pennsylvania Department of Human Services, sämtliche Lizenzen entzogen, wegen der fachlichen Imkompetenz der Mitarbeiter_innen und wegen der emotionalen Vernachlässigung und Misshandlung der Jugendlichen dort. Schieben wir diese abgründigen Dinge, diese Entgleisungen und Verzerrungen nun wieder beiseite. Sie zeigen was es teils auch geben kann auf dem Gebiet, doch wir dürfen uns davon nicht beirren lassen. Es muss konsequent gegen solche Missstände in der Pädagogik, gegen eine solche Zerstörung des Vertrauens von Menschen in pädagogische Einrichtungen gearbeitet werden. Dazu muss auf sehr vielen Ebenen agiert und etwas unternommen werden. Es müssen Netzwerke hergestellt und Bündnisse geschmiedet werden. Es 
gilt mutige Personen in einer solchen Schule und im Umfeld der Schule zu finden, die Schritt für Schritt an der Überwindung einer so destruktiven Situation, wie wir sie an der Schule Schwarzegg hatten, vorgehen.

Doch warum haben viele heutige Kinder und Jugendliche eigentlich einen solchen Mangel an verlässlicher, stabiler, positiver und entwicklungsförderlicher Bindungserfahrung? Wir haben es mit dem rapiden Verfall traditioneller sozialer Communities zu tun, mit dem Verfall von Familien, insbesondere auch dem Niedergang der Großfamilien, von Kirchen und Dorfgemeinschaften. Durch die veränderten gesellschaftlichen Bedingungen ist vieles nicht mehr in der alten Form vorhanden oder nur noch in Ansätzen. Hinzu kommen noch Migrationshintergründe und, oftmals damit verbunden, soziale Konflikte oder Entwurzelungserfahrungen. Die einzigen wirklich stabilen und verlässlichen Communities, wenn wir einmal von einigen nicht-deutschen Kulturen absehen, sind noch die Schulen. Sie sorgen für Mittagessen und betreuen Kinder und Jugendliche nun fast über den ganzen Tag hinweg. Doch diese schulischen Communities sind auch von vielen als sehr ambivalent erlebte Communities, handelt es sich doch letztlich um leistungsorientierte Gebilde, in denen den Kindern und Jugendlichen, je nachdem, welche schulische Leistung sie nun mal zeigen, ein bestimmter Status und ganz bestimmte Zukunftschancen zugewiesen werden, immer abhängig von eben dieser Leistung. Wenn Eltern und dahinterliegende Communities aber keinen stabilen Halt mehr geben können, kommt der Peergroup eine besonders wichtige Rolle zu. Speziell Jungen und männliche Jugendliche können hier allerdings schnell in einen Zwiespalt geraten. Auf der einen Seite wird durch die vielfach weiblichen Bezugspersonen, die das Geschehen in weiten Teilen des Schulsystems definieren, ein eher angepasstes und braves Verhalten erwartet, um im schulischen Ablauf Gratifikationen zu bekommen und vorzurücken. Andererseits wird von den männlichen Peers, insbesondere im Bereich der Sekundarstufe I, eher unangepasstes Verhalten propagiert und erwartet, um bei ihnen Akzeptanz zu finden. Jungen, die wirklich zu 100 Prozent die schulischen Erwartungen erfüllen, werden oftmals als Streber etikettiert und Opfer von Attacken und Mobbing auf Schulhöfen und schulischen Hinterbühnen, ohne dass die Lehrkräfte und Schulleitungen dies wirksam verhindern könnten.

Ein Junge, der ein Gymnasium besuchte, wurde nach dem Sportunterricht, als er sich wieder angekleidet hatte, von seinen Klassenkameraden unter eine Dusche gezerrt, stand dann durchnässt da und konnte nicht weiter am Unterricht teilnehmen. Ein anderes Mal wurde sein Mofa in einen Graben gestoßen und angezündet. Doch damit sind wir noch nicht am Ende. Eines nachts tauchte eine Gruppe vermummter Jugendlicher vor dem Haus der Familie auf und besprühte Garagentor und Hauswand mit destruktiven Parolen. Dies alles geschah an einem Gymnasium in einer Kleinstadt bzw. im Umfeld dieser Schule. Der Schulleiter lebte noch in der alten gymnasialen Bildungswelt und neigte dazu, solche Vorgänge einfach zu verdrängen. Folglich kamen seitens der Schule auch keine Reaktionen auf diese Ereignisse. Viele Jungen fahren daher zum eigenen Schutz ihr schulisches Engagement nach unten und bleiben so bedauerlicherweise unter ihren intellektuellen Möglichkeiten. Unter den Mädchen besteht dieses Problem in aller Regel nicht, wodurch sie nun, zusätzlich zu der besseren Passung mit der Erwartungshaltung der überwiegend weiblichen Lehrkräfte, wesentlich leichter durch das staatliche Schulwesen kommen als Jungen. Auch aus diesem Grund müssen Alternativen zum jetzt bestehenden Schulsystem geschaffen werden, alternative Räume, in die gestresste Jungen und männliche Jugendliche, ohne Weite- 
res und aufgrund eigener Initiative, rechtzeitig wechseln können, bevor sie aus dem natürlichen Takt motivierenden Lernens herausfallen, um dann dort auf eine ganz andere Art und Weise zu lernen und sich zu entfalten. Wir haben also eine ganze Reihe von Gründen, die der heutigen Schule zugewiesenen Aufgaben und Verantwortlichkeiten neu und anders zu verteilen und das System zu öffnen und zu erweitern. Es müssen eben neue und andere Arten von sozialen Communities entwickelt und aufgebaut werden, ich nenne sie einmal vorläufig transformative Community-Projekte. Denn in vielen Bereichen sieht es nicht danach aus, als könnte die derzeitige Schule das tiefe Bedürfnis insbesondere vieler männlicher Heranwachsender nach belonging, wie es John O'Donohue nennt, tatsächlich erfüllen, auch wenn dies in Einzelfällen so sein mag. Es gibt nun eine, nicht zu kleine, Gruppe von Jugendlichen, die sich im curricular geprägten und kompetenzorientierten Schulsystem mit seinen besonderen Verhaltenserwartungen nicht widerfindet, teils auch dagegen rebelliert oder gleich ganz der Schule fernbleibt. Trotz allem hat auch diese Gruppe von Heranwachsenden ein berechtigtes Bedürfnis nach Zugehörigkeit und Wertschätzung, nach Bestätigung und Resonanz. Teils kommt es dann zu Verhaltensweisen, die in dieser Hinsicht eher kontraproduktiv erscheinen und vielfältige weitere Probleme verursachen, bis hin zu Delinquenz. Sich ausgeschlossen zu fühlen, verändert auch die Person in ihrem Selbsterleben. Die von mir entworfenen transformativen Community-Projekte der Zukunft bieten mehr Spielraum Jugendlichen das zu geben, was sie wirklich am allermeisten suchen und brauchen, mehr als unter den Bedingungen der heutigen Schule möglich ist.

Als Pädagog_innen sind wir hier vor eine besondere Verantwortung gestellt. Bei allem ist die Achtung gegenüber dem anderen wesentlicher Bestandteil bei der Gestaltung von pädagogischen Beziehungen. Im Hinblick auf die teils destruktiven Beziehungsverhältnisse, die wir in Schulen, denken wir einmal an den Fall Schwarzegg, gelegentlich auch in der Welt der Academia antreffen, lässt sich vermuten, dass diese angetrieben sind von ungefilterten, unreflektierten Impulsen, von Geltungssucht, Machtstreben, Größenwahn, oftmals gekoppelt an fachliche Inkompetenz und persönliche Schwierigkeiten der verschiedensten Art. Eine genauere Analyse des Falls Schwarzegg zeigte etwa zwei Dinge: Erstens hatten sich in diese abgelegene Gegend, in jenen Jahren, Lehrkräfte hinbeworben, die auf dem Markt, wegen ihrer studierten Fächerkombinationen, bis dahin keine oder nur sehr schlechte Chancen hatten. An der betreffenden Förderschule herrschte aber ein Mangel an Lehrkräften. Alle Bewerber_innen bekamen dort Stellen als Beamt_innen, obwohl keine der Personen Sonderpädagogik mit Schwerpunkt emotionale und soziale Entwicklung studiert hatte. Diese, fachlich im eigentlichen Sinne nicht qualifizierten, Lehrkräfte wurden also leichte Beute einer autokratisch agierenden Schulleiterin, die ihnen suggerierte, dass sie ihrem radikalen pädagogischen Kurs nur brav zu folgen brauchten, um an der betreffende Schule gut über die Runden zu kommen. Tatsächlich sorgte sie mit den massenhaften Eliminierungen, das heißt langfristigen, auf Psychiatrisierung hinauslaufenden Suspendierungen und dem rabiaten Vorgehen gegen die Schüler, es waren ja zumeist Jungen bzw. männliche Jugendliche, auch für erträgliche, fast bequeme Arbeitsbedingungen, allerdings auf Kosten der jungen Menschen, mit denen nicht in der notwendigen Weise pädagogisch gearbeitet wurde. Zweitens: Teile dieses Kollegiums trugen neben der fachlichen Inkompetenz, wie sich in späteren Jahren zeigen sollte, auch einige nicht zu unterschätzende psychosoziale Problematiken in sich. Ein Kol- 
lege, der sich während der besonders destruktiven Phase in Schwarzegg als überaus aggressiv gegenüber den Kritiker_innen der Schulleiterin zeigte, verhielt sich zugleich überaus loyal, ja devot der herrisch auftretenden Schulleiterin gegenüber. Sie sorgte im Gegenzug für kontinuierliche personelle Unterstützung in seiner Lerngruppe, so dass er, der kaum etwas über das pädagogische Fachgebiet der emotionalen und sozialen Entwicklung wusste, und bei Dienstbesprechungen und in den Pausen mit Sätzen glänzte wie »Der gehört in die Psych«, trotz allem leicht durch das Schuljahr kam. Als schließlich die Schulleiterin vom Dienst suspendiert wurde, wegen ihrer zahlreichen Verstöße gegen das Schulgesetz, und als ein Schulleiter von außen in Schwarzegg eingesetzt wurde, der die Geschäfte kommissarisch führte, wurde der genannte Kollege dienstunfähig wegen Burnout, wie es hieß. Es lässt sich vermuten, dass er die dienstlichen Anforderungen der Lehrerstelle, die er besetzte, bei Normalisierung der fachlichen Anforderungen, nicht mehr erfüllen konnte. Er kam ein ganzes Jahr lang nicht wieder an die Schule zurück. Eine Geistesverfassung, wie sie O'Donohue als reverential mind charakterisiert, ist in diesem tiefroten Ozean, der sich hier vor uns ausbreitet, nicht sichtbar und auch nicht spürbar. Die Leiterin der Schule Schwarzegg ist bei all der aufgezeigten Dunkelheit sicherlich als Schlüsselperson anzusehen, eine Superspreaderin, wie es heute in Corona-Zeiten heißt, allerdings für Destruktivität, Gleichgültigkeit gegenüber anderem Leben und Hass, wenngleich weitere Faktoren, die in anderen Personen, im Umfeld und in den Strukturen des Systems liegen, hinzukommen. Das Problem ist nur, dass es in spiritueller Hinsicht nicht gelingen kann, andere Menschen, die womöglich noch von einem abhängig sind, ungerecht, unfair, ausbeuterisch oder entwürdigend zu behandeln und dann noch zu glauben, dass man/ frau bei der ganzen Sache irgendetwas erreicht oder sich einen Vorteil verschafft hätte. Diese Rechnung wird, spirituell betrachtet, niemals aufgehen. Allerdings werden solch spirituelle Sichtweisen in der, derzeit in den pädagogischen Institutionen dominierenden, funktionalistischen Betrachtung zumeist für irrational erklärt. Wenn ich aber nicht lerne für den anderen mitzudenken und mich in seine Lage hineinzuversetzen, werde ich auch langfristig für mich nichts erreichen, selbst wenn es mir gelungen ist, mir vordergründig materielle Vorteile, Statusvorteile, Definitionsmacht, situative Macht usw. zu verschaffen. Was wir also dringend im pädagogischen Feld und auch in der Gesellschaft entwickeln sollten, wäre eine Haltung, wie sie O'Donohue mit reverential mind beschreibt, das heißt Achtsamkeit und Empathie für den anderen zu praktizieren. In seinen Büchern Anam Cara und Eternal Echoes verwendet er darüberhinaus weitere Schlüsselkonzepte, die sich zur vertiefenden Gestaltung von pädagogischen Beziehungen heranziehen lassen, insbesondere belonging, im Sinne von Zugehörigkeit und Bezug aufeinander, poise, im Sinne von innerem Zentriertsein, innerer Klarheit, transfiguration, im Sinne der Umwandlung und Überwindung von Negativität, von Destruktivität, Eifersucht, Neid und Angst und threshold, im Sinne der Schwellen und Stufen, die wir im Leben und in seiner weiteren Entwicklung überschreiten und überwinden. Schließlich loving eye, in dem Sinne, dass ich den anderen mit innerem Wohlwollen und mit Wertschätzung betrachte. Sodann zieht sich die Vorstellung durch seine Bücher, dass wir uns dem Seelenleben des anderen eher im warmen Schein von Kerzenlicht nähern als im grellen Neon-Licht wissenschaftlicher Analyse. An einer Stelle zieht O'Donohue den Vergleich zu den Bildern, wie sie Rembrandt gemalt hat, um uns zu zeigen, welche Art von Licht-Schatten-Relation er meint. Durch die Lektüre dieser Bücher bekommen wir gehaltvollere Begrifflichkeiten und Konzepte an die 
Hand, als wir sie in der traditionellen sonder- und inklusionspädagogischen Literatur finden. Wir sollten daher mit der Revision und Überarbeitung unserer Theorien und Handlungsmodelle beginnen.

\section{Spiel, Ästhetik, Gestaltung}

Die kognitive sowie die emotionale und soziale Entwicklung sind in den frühen Lebensjahren zum einen an verlässliche, förderliche Bindungsbeziehungen und zugleich an sinnliche Wahrnehmung, an den handelnden Umgang mit den Dingen und die damit verbundene Materialerfahrung gebunden. Wenn Kinder spielen, malen und gestalten, eignen sie sich neues Wissen an und bilden interne kognitive Repräsentationen und Schemata aus. Zugleich bringen sie ihre Erlebnisse und Emotionen und all das, was verbalsprachlich noch nicht mitgeteilt werden kann, symbolisch zum Ausdruck. Eine Reihe von psychosozialen, kulturellen und gesellschaftlichen Faktoren können diese Prozesse beeinflussen, unterstützen oder erschweren. Bezogen auf Kinder und Jugendliche mit einer emotionalen oder sozialen Thematik, lassen sich spezielle schöpferische Aktivitäten in den Kontext Schule und Unterricht, aber auch in vorschulische und außerschulische pädagogische Handlungsfelder einbringen, als Impulse für eine ausgeglichene Entwicklung. Die an Spiel, Kunst und Gestaltung orientierten Lernangebote haben dabei einerseits eine, auf ein tiefergehendes Verstehen der kindlichen oder jugendlichen Welt gerichtete, Bedeutung, weil wir in den entstehenden Bildresultaten und Gestaltungen der Kinder und Jugendlichen formale Besonderheiten erkennen können, die Rückschlüsse auf die jeweilige Problematik erlauben. Zum anderen erzählen die Kinder und Jugendlichen in ihren Bildern und Gestaltungen von ihrem besonderen Lebensgeschehen. Hans-Günther Richter, lange Jahre an der Universität zu Köln tätig, hat die Erforschung der Kinderzeichnung in besonderem Maße vorangebracht. In den Zeichnungen lässt sich viel über die kognitive, die geistige, die emotionale und soziale Entwicklung, aber auch über die gesamte Lebenssituation eines Kindes erkennen. Auf der formalen Ebene der Zeichnung können wir etwa sehen, ob ein Kind sich einigermaßen natürlich entwickelt. In der Theorie der Kinderzeichnung wird hier eine frühe Kritzelphase, eine dann folgende Schemaphase und schließlich eine mehr oder weniger naturalistische, realistische Phase unterschieden, bevor es dann mit der Jugendzeichnung weitergeht. Manche Kinder durchlaufen diese, als mehr oder weniger kulturunabhängig geltenden, Stufen eher langsam, andere schneller. Diese Unterschiede ergeben sich zum einen aus den kognitiven Voraussetzungen eines Kindes, zugleich auch durch den Anregungsreichtum des jeweiligen soziokulturellen Milieus und der familiären Umgebung. Auch die inhaltliche Ebene einer Kinderzeichnung liefert vielerlei Aufschlüsse, weil wir sehen können, mit welchen Themen sich ein Kind auseinandersetzt. Dabei spielt sich manches auf einer bewussten Ebene ab, anderes liegt eher im Verborgenen und erschließt sich nur durch Interpretation. Eine Reihe von Studien haben belegt, dass emotionale Belastungen, Angst, Schmerz oder traumatische Erfahrungen, sich unmittelbar in der Kinderzeichnung niederschlagen und sowohl auf der formalen wie auch auf der inhaltlichen Ebene zum Ausdruck kommen.

Die besondere Bedeutung all dessen für die emotionale und soziale Entwicklung liegt nun darin, dass wir Kinderzeichnungen heranziehen können, um die individu- 
ellen Themen eines Kindes oder Jugendlichen besser einschätzen zu können und seine Lebenskontexte tiefergehend zu verstehen. Je nachdem, können thematisch etwa Aggressionen und destruktive Tendenzen, Aspekte der Auseinandersetzung mit Sexualität, oder anderer Entwicklungsaufgaben des Kindes- oder Jugendalters, in den Vordergrund treten. Teils wurden in der Vergangenheit auch spezielle Verfahren, etwa Familie in Tieren, von Brem-Gräser entwickelt, eingesetzt. Von hier aus lassen sich pädagogische Angebote entwerfen, die in den Unterricht oder das allgemeine Schulleben integriert werden können. Der Schwerpunkt solcher Aktivitäten kann auch auf dialogischem Lernen zu zweit oder auf der symbolischen Kommunikation in Gruppen liegen. In manchen Situationen kann es sinnvoll sein, Kindern und Jugendlichen Ausdrucks- und Gestaltungshilfen, etwa das collage-unterstützte Zeichnen bzw. Mobile Layout, anzubieten, wie ich es über viele Jahre hinweg entwickelt habe (vgl. z. B. Bröcher, 2012, 2019b). Die Prozesse des Spiels und des bildhaften Gestaltens, teils auch in jugendkulturellen und alltagsästhetischen, medialen Kontexten, werden in den vorhandenen Theorien und Handlungsansätzen zum einen mehr psychologischtherapeutisch, zum anderen stärker pädagogisch-didaktisch betrachtet. Zum anderen können curriculare Lernprozesse durch das Spiel unterstützt werden. Im Sinne emotionalen und sozialen Lernens lässt sich die Bedeutung des Spiels aus einer psychoanalytisch-therapeutischen, einer personenzentriert-therapeutischen oder einer philosophischen Perspektive einschätzen. Wenn wir Kindern und Jugendlichen die Möglichkeit geben, künstlerisch oder gestalterisch tätig zu sein, bringen wir sie in ihrer psychosozialen Entwicklung voran. In, eher freien oder thematisch angeleiteten, künstlerischen oder gestalterischen Prozessen können dann etwa Phänomene wie der Rückzug von der Realität, die Auseinandersetzung mit dem eigenen Status als Adoptivkind, mit Angst, innerer Leere, Delinquenz, Gewalt oder Familienbeziehungen an die Oberfläche kommen. In solchen Prozessen kann es zu Klärung und Spannungsabbau kommen, doch auch zu einer vorläufigen Dominanz von Abwehr. Auf der anderen Seite wird eine Verknüpfung mit den schulischen, curricularen Inhalten und Lernzielen hergestellt. Die Übergänge zwischen diesen beiden Herangehensweisen sind fließend. Die Archivierung, Dokumentation und Analyse von künstlerischen Gestaltungen von Kindern und Jugendlichen, wie ich sie etwa in dem Buch Bilder einer zerrissenen Welt veröffentlicht habe, kann Beiträge zu kulturkritischen, sozialphilosophischen Forschungen und Diskursen liefern.

\section{Literatur und Poesie}

Literatur kann, auf so vielen Ebenen, im Feld der Erziehungs- und Bildungswissenschaften, zu einer wichtigen Komponente historisch-hermeneutischer Forschung wie auch von praktischer Pädagogik werden. Literatur kann uns etwa helfen, den Aufbau und die Dynamiken von, in sich geschlossenen, Gesellschaften, von bestimmten sozialen Mileus oder sozialgeografischen Räumen zu verstehen und, darin eingebettet, die Konstituierung von sozialen Normen und Werten, Verhaltensmustern, Geschlechterrollen, von Vorstellungen und Konzepten bezüglich Arbeit und Kultur sowie des Umgangs mit Regel- und Normabweichungen im Verhalten von einzelnen oder Gruppen. Literatur kann verdeutlichen, wie dies alles auf die Charaktere, auf die Menschen und ihre Lebensgeschichten einwirkt, denken wir etwa an Wladislaw Reymonts 
Roman Die Bauern, der kurz nach 1900 erschienen ist und im ländlichen Polen, während der zweiten Hälfte des 19. Jahrhunderts, angesiedelt ist. Literatur kann jedoch auch gesellschaftliche Transformationsprozesse widerspiegeln, also Gesellschaften im Umbruch zeigen, und darin die Lebensläufe einzelner Akteur_innen, nehmen wir zum Beispiel Michail Scholochows Roman Der stille Don, der 1928 erschienen ist und der die innere Zerrissenheit des nachrevolutionären Rußland thematisiert. Jede Zeit und jede Gesellschaft produziert ein bestimmtes Repertoire an Verhaltensweisen und sanktioniert andere Verhaltensweisen, je nach politischen Gegebenheiten, je nachdem, welche Lebens- und Wirtschaftsformen in der jeweiligen Gesellschaft dominierend sind. Jede Zeit und jede Kultur bringt ihre ganz eigenen Charaktere hervor. Neben diesen mehr theoretischen Bezügen, bietet die pädagogisch-didaktische Arbeit mit Kinder- und Jugendliteratur im Bereich emotionalen und sozialen Lernens eine Fülle an praktischen Möglichkeiten. Literatur kann eine pädagogische Reflexion und ein Durcharbeiten von emotionalen Erfahrungen, Lebenserfahrungen und seelischen Problematiken oder sich stellenden Lebens- und Entwicklungsaufgaben ermöglichen. Hierbei kann es etwa um Themen aus dem Bereich des Familienlebens, der Peerbeziehungen oder der Schule gehen. Wenn ich etwas ganz besonders gerne, mit Ausdauer und Leidenschaft getan habe, dann war das die Haus- und Volksmärchen der Gebrüder Grimm meinen eigenen Kindern, aber auch den Kindern an den inklusiven Grundschulen, an denen ich tätig war, vorzulesen und auf der Basis dann schöpferische, gestalterische Prozesse in Gang zu setzen. Durch die Texte von Bruno Bettelheim und Verena Kast wissen wir, welche Art von psychosozialen Themen Kinder, speziell anhand der Märchen, verarbeiten können, von Symbiose und Individuation bis Autonomie und Loslösung. Andere thematische Bezüge in literarischen Werken können erste Erfahrungen mit der Berufswelt sein oder kommunikative Erfahrungen, etwa Mobbing in den sozialen Netzwerken. Julien Dupuy (2020) zeigt in seinem Filmportrait, dass die von King bediente Sparte gewalttätiger Horror-Literatur möglicherweise dazu dienen kann, Menschen eine symbolische Auseinandersetzung mit ihren dunklen und abgründigen Seiten zu ermöglichen. In zahlreichen Interviews macht Stephan King deutlich, dass es ihm, im Kern, um die Förderung der Imaginationsfähigkeit, des Denkens und der Bildung geht. Dazu gehört, seiner Aussage nach, auch die Auseinandersetzung mit dem Thema Gewalt, da diese Bestandteil der amerikanischen Gesellschaft sei.

Weitere Themen sind Prozesse der Identitätsfindung, ziehen wir einmal Robert Musils Roman Die Verwirrungen des Zöglings Törleß heran. Oder es geht um Prozesse jugendlichen Aufbegehrens gegen Autoritäten oder Machtstrukturen, denken wir etwa an Hermann Hesses Unterm Rad, Friedrich Torbergs Der Schüler Gerber, J. D. Salingers Fänger im Roggen oder Alan Sillitoes Die Einsamkeit des Langstreckenläufers. Andere Themen, die sich in der Literatur widerspiegeln, sind Angst und Einsamkeit oder die Verarbeitung von Migrations- und Fluchterfahrungen. Der Umgang mit Kinder- und Jugendliteratur kann auch globales, kulturübergreifendes Lernen ermöglichen, wenn Lebenswelten wertschätzend, differenziert, ohne Klischees und stereotype Bilder dargestellt und erschlossen werden. Kinder- und Jugendbücher können Anregungen geben, kritisch über gesellschaftliche Themen und Spannungsfelder, etwa Ungerechtigkeit, Ausgrenzung und Diskriminierung, nachzudenken. In einem Buch oder literarischen Text vorkommende Charaktere und Figuren bieten die Möglichkeit, diese als Stellvertreter für eigene emotionale Befindlichkeiten und Auseinandersetzungs- 
prozesse zu verwenden. Literatur kann aber noch mehr, denn auch das probeweise Hineinschlüpfen in andere und neue Rollen beinhaltet viel Entwicklungspotential. Literatur kann Kinder und Jugendliche in phantastische Welten hineinführen, die über die realen sozialen und seelischen Gegebenheiten hinausführen. Nehmen wir, als ein herausragendes Beispiel, Otfried Preußlers Jugendroman Krabat. Mit diesem Buch habe ich einigermaßen erfolgreich an Schulen gearbeitet, auch mit jungen Männern, die sich sehr herausfordernd verhalten haben und teils noch nicht richtig lesen konnten. Durch die Beschäftigung mit einem solchen literarischen Werk entstehen Bilder, wie das Leben noch sein könnte. Es entstehen imaginative Räume und Vorstellungen davon, was noch alles ginge. Dies kann gerade auch für konfliktbelastete Kinder und Jugendliche etwas sehr Wertvolles sein, im Sinne eines Gegenpols, einer neuen Perspektive, einer Überschreitung des Faktischen. Die Auseinandersetzung mit der Faktizität, wie Jean-Paul Sartre in Das Sein und das Nichts die gegebene Lebenssituation eines Menschen nennt, und die Erschließung von Transzendenz, im Sinne der Überschreitung des Gegebenen hin zu etwas Neuem, etwas Offenerem und Weiterem, lassen sich, in pädagogischer Perspektive, durchaus miteinander verbinden.

Je nach Altersstufe, konkreter Lerngruppe, individuellen Lernvoraussetzungen, Lernsetting und curricularem Kontext, erscheint es sinnvoll, handlungsorientierte, produktionsorientierte und fächerübergreifende didaktische Prinzipien einzuarbeiten, auch Elemente des Spiels und der musikalischen oder künstlerischen Gestaltung, bis hin zu medialen, filmischen Bearbeitungen und Theaterinszenierungen. Für den Unterricht mit Zielgruppen, die zugleich Lernprobleme, Leseschwierigkeiten oder Probleme beim Schreiben aufweisen, gibt es seitens der Sprachdidaktik, der Deutschdidaktik und des Bereichs Deutsch als Zweitsprache eine Fülle von praktischen Handlungsempfehlungen, etwa das Prinzip der Textentlastung, wobei die Lehrkraft Zusammenfassungen des Inhalts gibt, um allen eine inhaltliche Auseinandersetzung zu ermöglichen, auch denen, die den Text nicht selbstständig im vollen Umfang zu lesen vermögen. Es lassen sich Schlüsselszenen aus den Texten heraussuchen und diese mit besonderer Aufmerksamkeit bearbeiten. Handlungsorientierter Leseunterricht kann auch das Verfassen von Lesetagebüchern oder das Erstellen von Lesewänden beinhalten, einmal in herkömmlicher Papier-Print-Form, zum anderen mithilfe einer digitalen Portfolio-Software, wo eine Gruppe von Schüler_innen gemeinsam an einem Dokument schreibt. Lesen und Schreiben greifen bei allem ineinander. Die reformpädagogischen Modelle etwa von Fritz Gansberg, der schon in der Zeit des wilhelminischen Deutschlands, kurz nach 1900, von seinen Schüler_innen freie erlebnisorientierte Texte verfassen ließ und diese dann in pädagogischer Perspektive mit ihnen reflektierte, lassen sich hier zur Orientierung heranziehen. Seit den 1920er Jahren führte Celestin Freinet die Schuldruckerei ein und experimentierte mit offenen, schülerorientierten, werkstattartigen didaktischen Formen. Freinets Pädagogik kann uns auch heute noch Impulse für die handelnde Beschäftigung mit Kinder- und Jugendliteratur geben, auch im digitalen Zeitalter.

Für O'Donohue stehen Natur, Stille und Poesie in einem engen Zusammenhang. Speziell der Poesie kommt hier noch einmal ein besonderer Stellenwert zu. Es gibt wunderbare Texte im Bereich Rap und Hip Hop, einer sehr zeitgemäßen Weiterentwicklung der älteren Formen von Poesie. Intensiv in sich hineinzuhorchen und aus dem Inneren Worte zu schöpfen, hat etwas Klärendes und Reinigendes. Poesie in soziale und kulturelle Kontexte einzubringen, erzeugt für alle Beteiligten eine bedeut- 
same Resonanzerfahrung. Sprache schafft Zugänge sowohl zur Realität wie auch zum Traum, beides fließt in Form der Phantasie ineinander. Das Lesen von Literatur ermöglicht auch Selbsterkundung. Dabei geht es vorallem darum, die eigene Stimme $\mathrm{zu}$ finden, denn ist das nicht das Ziel aller Bildung, junge Menschen zu ermutigen, in sich hineinzuhorchen und dort mit der Zeit ihre eigene Stimme zu vernehmen, wo doch die allermeisten unentwegt Dinge hersagen, die sie von dominierenden Gruppen oder übergeordneten Stellen oder diversen Medien übernommen haben? Auch im Hinblick auf die menschlichen Konflikte, Machtkämpfe, Intrigen und Ränkespiele, in den sozialen und pädagogischen Institutionen und Organisationen, können Literatur und Poesie aufklärend wirken, Themen widerspiegeln und Impulse geben. »Piranhas zweifeln nicht am Sinn ihrer Taten. Die Klapperschlange akzeptiert sich ohne Vorbehalt. Einen selbstkritischen Schakal gibt es nicht«, notierte Wisława Szymborska (1996b, S. 68). 



\section{Transdisziplinäre Studien in der Metropole Berlin: Visuelle Spiegelungen}

Ich war nicht mehr davon überzeugt, dass eine Forschung, die sich mit der Zukunft des Lernens befasst, und damit auch mit dem Arbeiten und Leben, insbesondere in Zusammenhang mit emotionalen und sozialen Aspekten, sich auf Erkundungen in Klassenzimmern beschränken darf. Natürlich transportieren die dortigen Akteur_innen vielerlei kulturelle und gesellschaftliche Bezüge in den Raum der Schule hinein. Doch alles das, was dort hineingebracht wird, wird auf eine spezifische Art, unter dem Vorzeichen des schulischen Curriculums und der unhinterfragt dominanten Position des Schulsystems, gefiltert und eingerahmt. Wenn wir aber immer nur die Perspektive der Schule einnehmen, und von hier aus, nach draußen in die Gesellschaft schauen, dann übernehmen wir stillschweigend bestimmte Setzungen, etwa die Überzeugung, dass es grundsätzlich sinnvoll sei, Schulen und standardisiertes Lernen, in der jetzigen Form, fortbestehen zu lassen. So kommt es, dass ich schließlich andere Wege ging, dass ich in den urbanen Raum Berlins eintauchte und dort, im Herbst 2015, mit Feldstudien und ethnografischen Erkundungen begann. Das war zunächst noch eine vorsichtige Suchbewegung, doch war ich überzeugt, dass sich in dieser Metropole die gesellschaftliche Zukunft Deutschlands, wie kaum in einer anderen Stadt, vorbereitet. Ich sah Berlin und seine ungeheure Dynamik, auf sozialen, wirtschaftlichen und kulturellen Gebieten, als eine Art Treibhaus für zukünftige gesellschaftliche Entwicklung. Es gibt dort Impulse auf so vielen Ebenen. Ich habe versucht, diese photografisch einzufangen. Dieses Kapitel zeigt eine kleine Auswahl an Bildmaterial. Es geht nicht um die direkte Verwertbarkeit, nicht um den sofortigen Transfer, sondern darum, geistig beweglich zu werden, die Wahrnehmung zu erweitern und freier zu denken, im Sinne von Transdisziplinarität. 

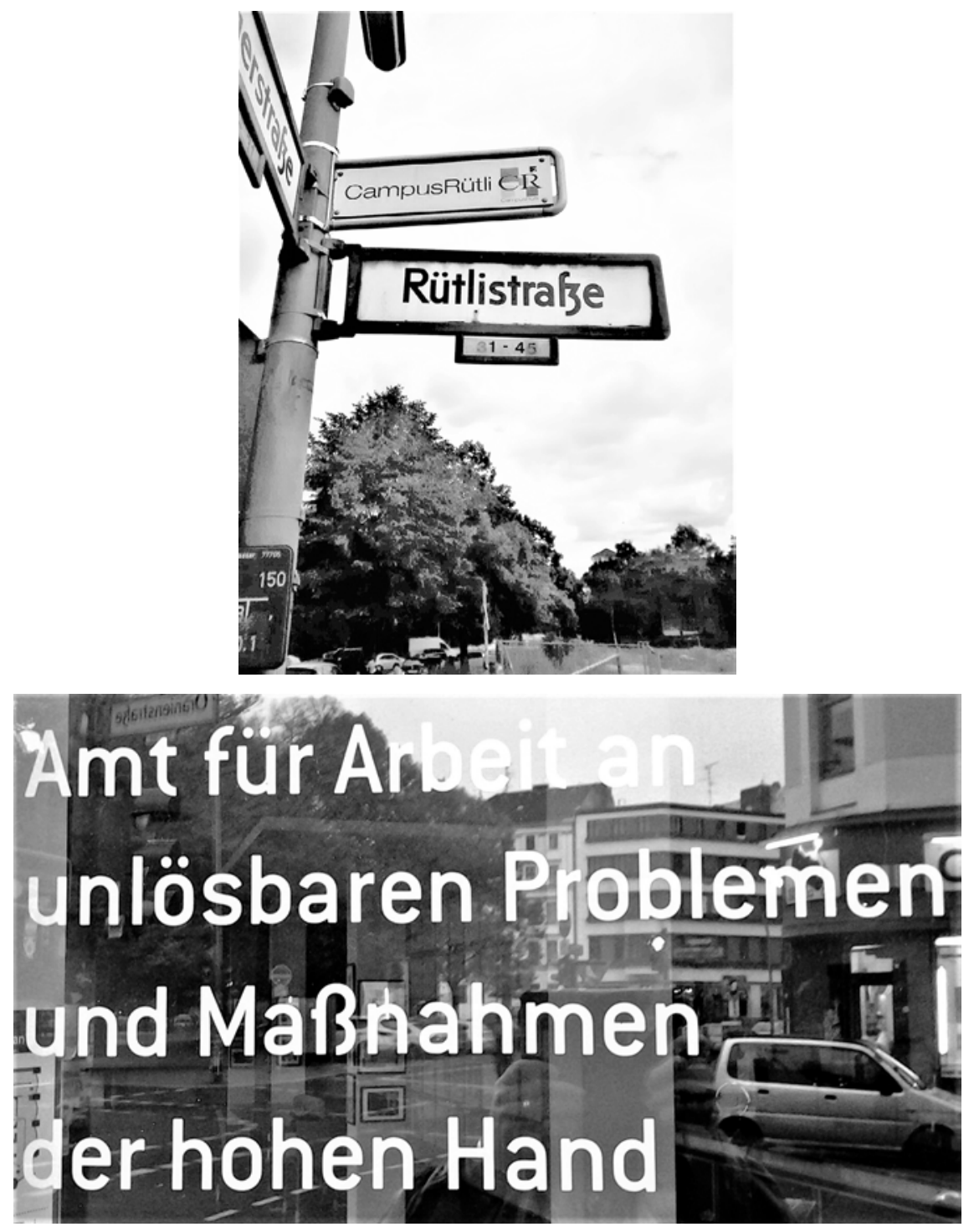

Abb. 1 und 2: Sie ist uns als nationales Sinnbild der Überforderung des Schulsystems, im Hinblick auf die heranwachsende Ceneration, besonders in multikulturell geprägten urbanen Räumen, in Erinnerung geblieben: Die Rütli-Schule in Berlin-Neukölln. Das obere Photo zeigt uns das Straßenschild, nicht weit vom Schulgebäude. Manifestierten sich hier Coolness, Chetto-Stolz und Wut als Antwort auf eine entmündigende Pädagogik in neoliberalen Zeiten? Eskalierte die Situation schließlich auch deshalb, weil die Lehrkräfte nicht in der Lage waren, ihre pädagogische Arbeitsweise an die neuen gesellschaftlichen Bedingungen anzupassen? Inwiefern waren auch längst überholte schulische Rahmenbedingungen für diese Krise verantwortlich? Es gäbe Lösungen für die, sich derzeit in Pädagogik und Cesellschaft stellenden, Probleme, wenn wir nur neu und anders dächten und aus dem geistigen Käfig der Alternativlosigkeit heraustreten würden. Das Photo unten zeigt einen Ausschnitt aus dem Schaufenster einer Denkfabrik in Berlin-Kreuzberg, die hier Impulse geben könnte. 

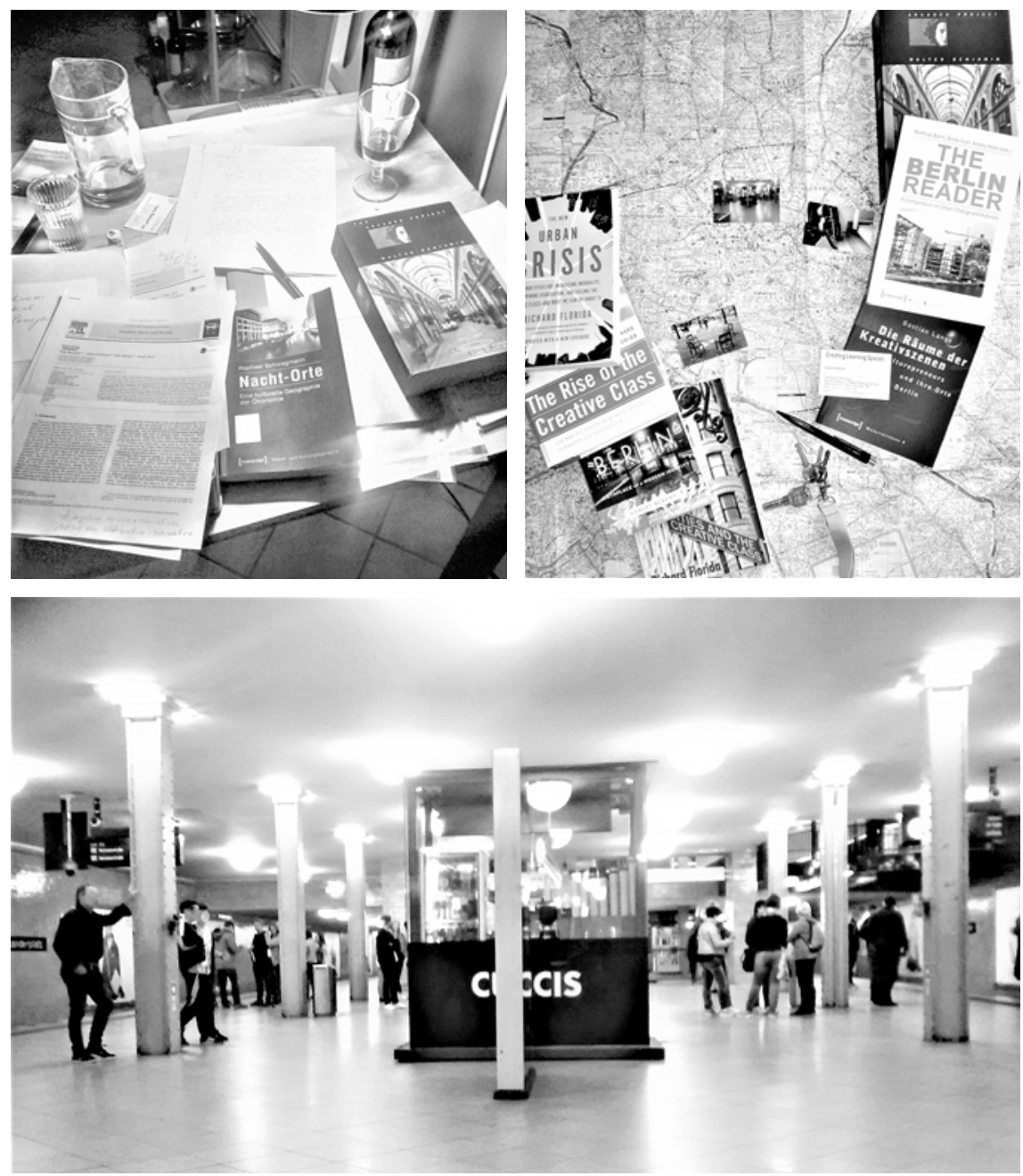

Abb. 3-5: Ich suchte nach Veränderungsimpulsen für das Schulsystem, außerhalb der Schulen, und zwar gezielt in Berlin, weil diese, in rasanter Veränderung befindliche, Metropole zeigt, zu welcher Entwicklung unsere Gesellschaft fähig ist. Die oberen Photos dokumentieren Planungsprozesse und Hintergrundarbeiten in Zusammenhang mit meinen sozial-und kulturgeografischen Feldstudien. Walter Benjamins, in der Metropole Paris entstandenes, Passagenwerk lieferte mir zunächst den Impuls, das Leitmotiv und die Motivation. Dieses Jahrhundertwerk war nicht nur Quelle der Inspiration, es diente auch als Handlungsmodell für meine eigenen Erkundungen in Berlin. Das untere Photo ist eine Momentaufnahme von meinen Streifzügen durch die Stadt. Es zeigt eine U-Bahn-Plattform am Alexanderplatz, in Berlin-Mitte. 

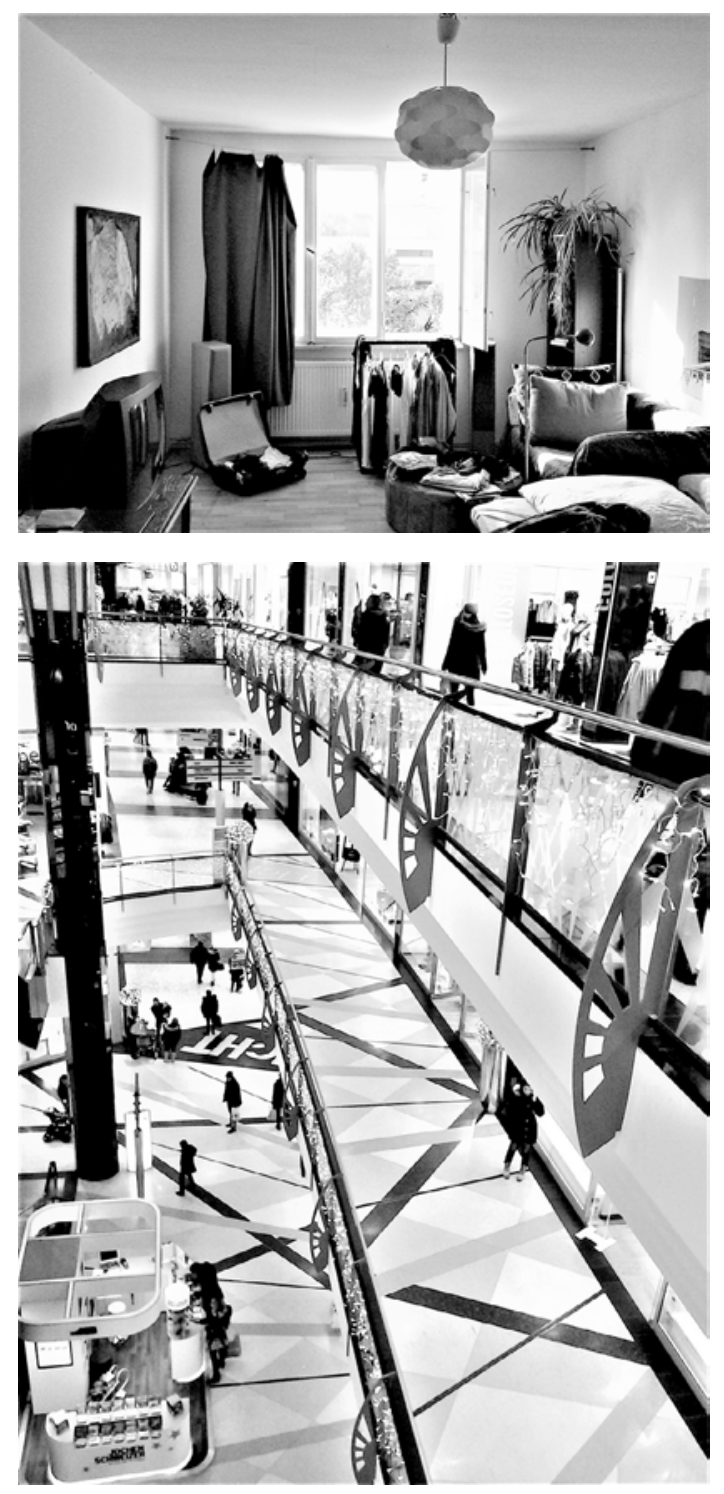

Abb. 6 und 7: Das obere Photo zeigt eine, über die Plattform Airbnb gebuchte, Wohnung in Berlin-Kreuzberg. Mein Host war in den Creative Industries tätig. Er hatte einen deutschfranzösischen Hintergrund und war in Paris aufgewachsen. Diese Wohnung wurde zum Ort eines weitreichenden, philosophischen Diskurses, über den zeitgenössischen Menschen im urbanen Raum, auf der geografischen Achse Berlin-Paris. Dieser spontane Diskurs ist repräsentativ für viele andere Begegnungen, im Rahmen meiner Berliner Feldstudien. Das Photo unten zeigt die Shopping Mall Alexa, am Alexanderplatz, in Berlin-Mitte. Es versinnbildlicht, auf sehr helle und moderne, auch auf repräsentative Weise, die Idee der Passagen. Die Passagen, die Walter Benjamin in Paris erkundete, waren allerdings dunkler, schmuddeliger, geheimnisvoller, als diese hier am Alexanderplatz. Fast alles Dunkle hat sich jetzt ins Internet verlagert, wie es scheint, einmal abgesehen von den Nachtclubs der Metropole. 

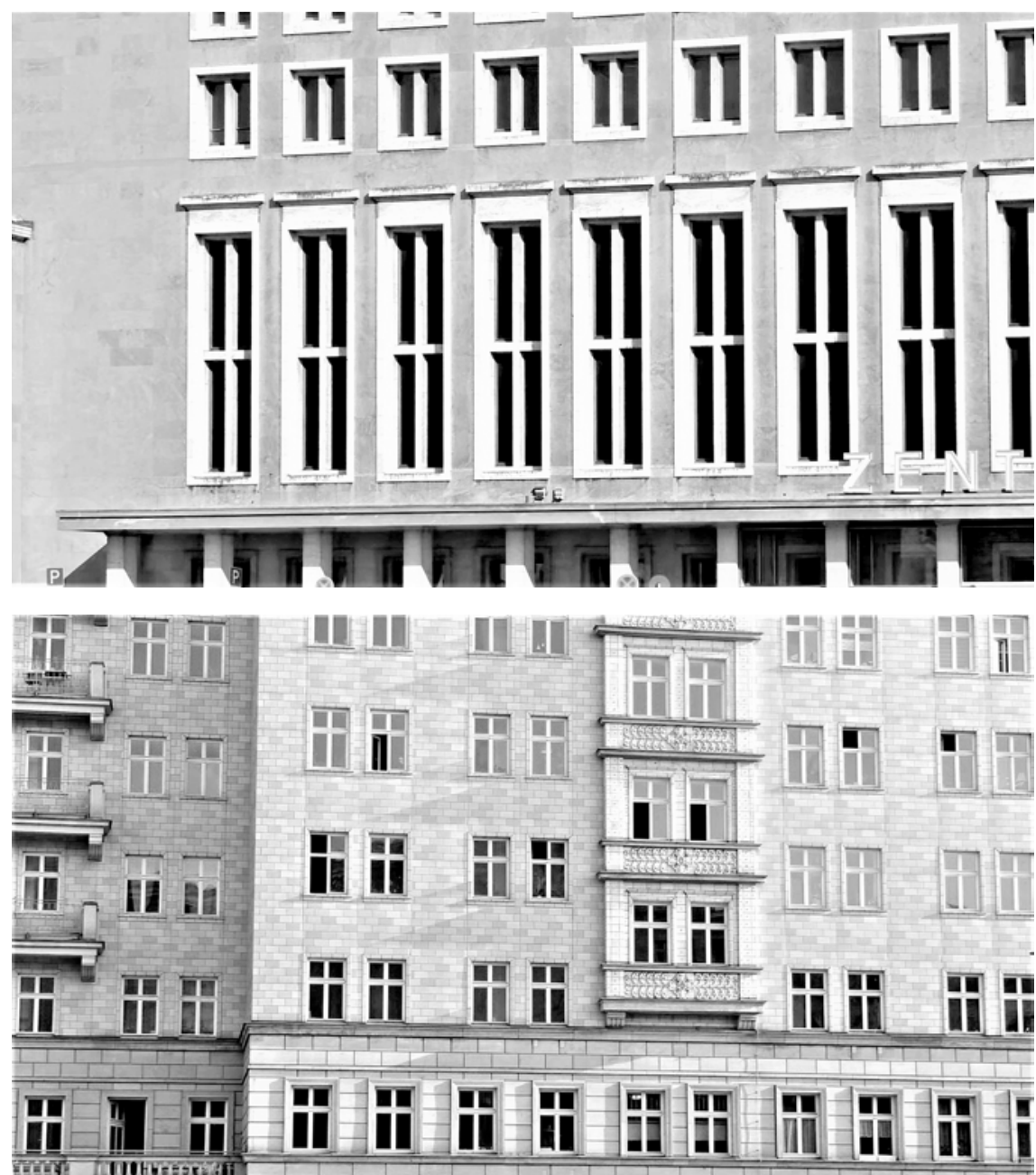

min! itItrintimill

Abb. 8 und 9: Das erste Photo zeigt einen Fassadenausschnitt vom Flughafengebäude in Berlin-Tempelhof. Dieser, von den Nationalsozialisten erbaute, Flughafen, sollte das Drehkreuz von Germania werden. Zum anderen sehen wir einen Ausschnitt der kolossalen Wohnblöcke, wie sie die Karl-Marx-Allee und die Josef-Stalin-Allee, nach dem Zusammenbruch der DDR umbenannt in Frankfurter Allee, säumen. Diese, in Berlin-Friedrichshain gelegene, Prachtstraße, wurde für die Aufmärsche, Militärparaden und Machtdemonstrationen der DDR und des Ostblocks genutzt. Ideologisierungen, wie sie sich in der Architektur und in der Städteplanung, in den historischen Kontexten des Nationalsozialismus, wie auch der DDR-Diktatur, zeigen, können sich auch in bildungs- und sozialwissenschaftlichen Theoriesystemen und pädagogischen Alltagspraxen widerspiegeln, von der Zwangserziehung in den Jugendwerkhöfen der DDR, bis hin zu der abgründigen, paramilitärischen, mit Schikanen, Eliminierungen und Bespitzelungen arbeitenden, Förderschule Schwarzegg, wo sich die Schulleiterin als eine, für gesellschaftliche Ordnung sorgende, Führungskraft in Szene setzte (vgl. die ausführliche Dokumentation und Analyse bei Bröcher, 2011, 2016). 

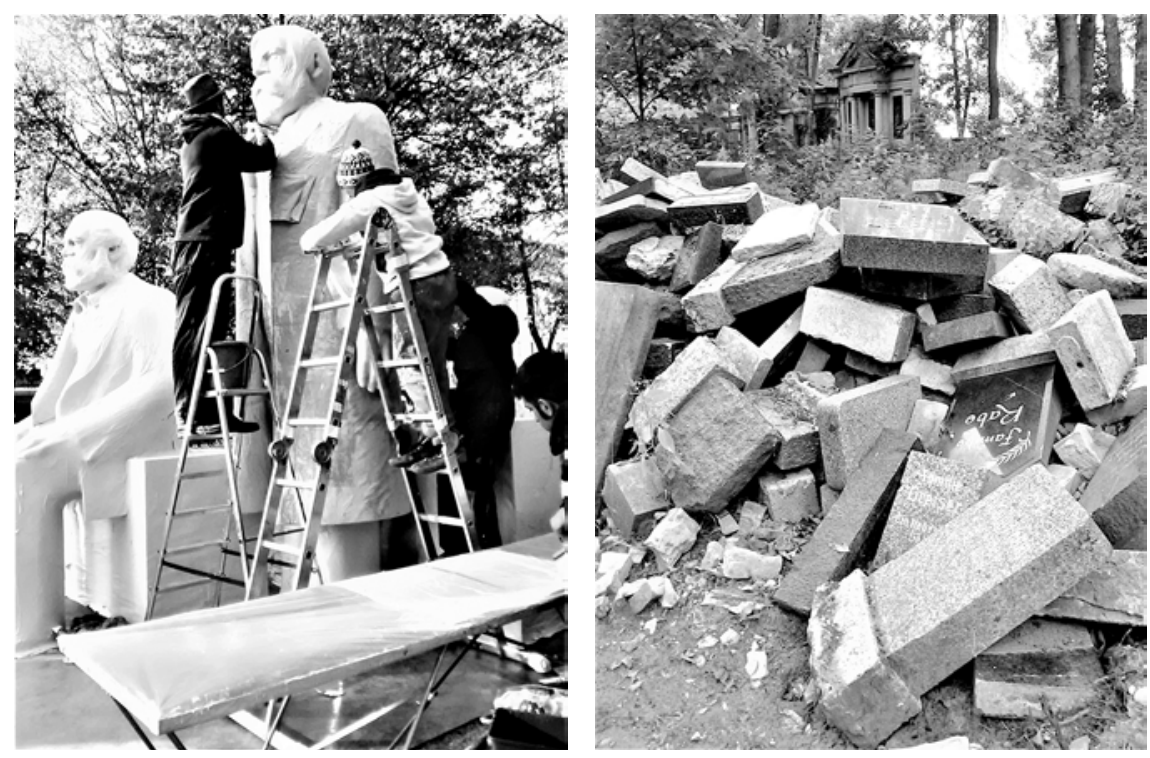

Abb. 10 und 11: City Skins war eine Kunstaktion von Various \& Could, in Berlin, vom 28. April bis 3. Mai 2017, wobei es um die Papiermaché-Abformung von Marx und Engels-Skulpturen in Berlin-Mitte ging. ' Diese Aktion lässt sich zum Anlass nehmen, neu über die Zukunftsbedeutsamkeit der Analysen, Ideen und Theorien von Karl Marx nachzudenken, speziell was die Themen der Entfremdung, der gerechteren Ressourcenverteilung und der sinnvolleren Organisation der Arbeit anbelangt. Dabei müssten wir freilich Entstellungen der marxistischen Crundlagen, wie wir sie in Cestalt des real existierenden Sozialismus in der DDR und im Ostblock erlebt haben, als solche erkennen und der Kritik unterwerfen. Nur so ließen sich größere Teile der, nunmehr selbst unter entfremdeten Bedingungen arbeitenden und lebenden, Mittelschicht für die Öffnung gegenüber marxistischem Cedankengut gewinnen und dann, im nächsten Schritt, auch für eine aktive Mitwirkung bei der, dringend erforderlichen, gesellschaftlichen Transformation. Die auf dem Photo rechts gezeigte Szene setzte bei mir den folgenden Impuls frei: Das bildungs- und gesellschaftstheoretische Wissen, seine Produktion und seine Vermittlungsformen, befinden sich im Umbruch. Viele ältere Texte, mit ihren spezifischen Begrifflichkeiten, Konzepten, Modellen und Schlussfolgerungen, halten heutigen Sichtweisen, Maßstäben und Erwartungen an gute, zukunftsweisende, nachhaltigkeitsfördernde Theorie nicht mehr Stand. Die ausrangierten Grabsteine auf einem Friedhof in Berlin-Friedrichshain könnten diesen Transformationsprozess symbolisieren.

1 Abdruck mit freundlicher Genehmigung des Urban Art Duos Various \& Gould, Berlin; Projekt im Rahmen von Kunst im Untergrund 2016/17, nCbK, https://variousandgould.com/ 

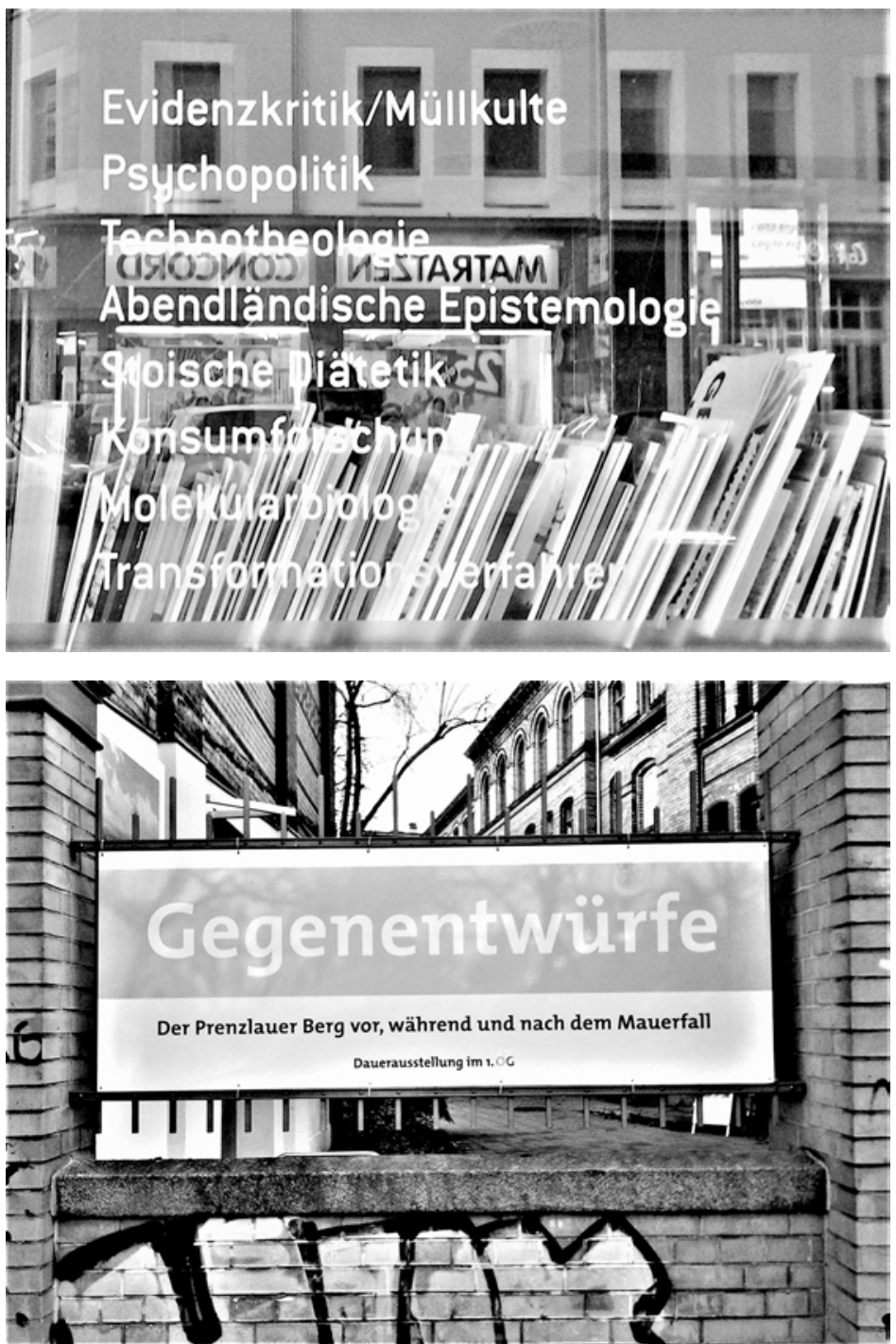

Abb. 12 und 13: Wer sich mit Fragen des emotionalen und sozialen Lernens befasst und zusätzlich all die gesellschaftlichen Aspekte in den Blick nimmt, die damit verknüpft sind, wird sich mit vielerlei Diskursen, Theorien und Modellen beschäftigen müssen, um die Komplexität des Ganzen zu erfassen. Diskurse und Theorien, und die darin aufscheinenden Leitkonzepte, sind aber in ständiger Veränderung, wie der, im oberen Photo dokumentierte, Ausschnitt aus einer Schaufensterpräsentation einer Denkfabrik in Berlin-Kreuzberg zeigt. Vor allem brauchen wir Gegenentwürfe, ähnlich dem Leitthema einer, in BerlinPrenzlauer Berg gesehenen, Ausstellung, wie sie im unteren Photo festgehalten ist. Dies gilt besonders dann, wenn die vorhandenen Theorien und Modelle, und die aus ihnen resultierenden pädagogischen Alltagspraktiken, starr und unbeweglich geworden sind. 

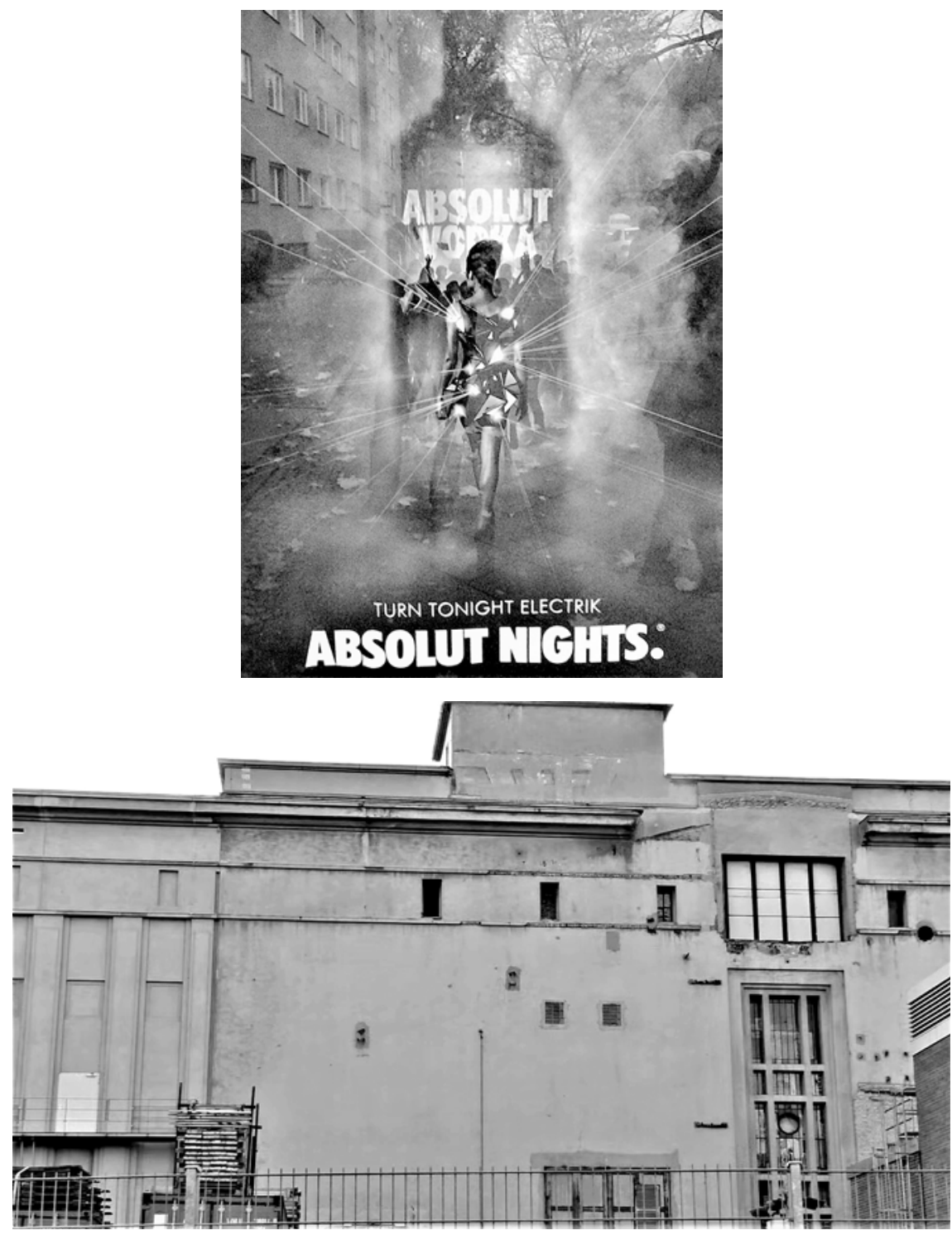

Abb. 14 und 15: Clubnächte in Berlin bieten jungen Menschen Möglichkeiten, über die Grenzen des Üblichen und Alltäglichen hinauszugehen. Körper und Seelen begegnen sich, häufig in industriell vorgeprägten Räumen, die nun mit Musik geflutet werden. Es gibt Zonen des Lichts und der Dunkelheit, wo vieles möglich wird. Die gemachten Erfahrungen können dabei sehr ambivalent sein. Wieviel Freiheit hier im Spiel ist, wieviel Eskapismus und wieviel Ausagieren innerer, teils bewusster, teils unbekannter Skripte, aber auch wieviel longing, im Sinne von O'Donohue, könnte eine produktive Frage für pädagogische Cespräche mit Jugendlichen sein. Das obere Photo zeigt ein Werbeplakat, aufgenommen in BerlinKreuzberg. Es bringt deutlich zum Ausdruck, welche Rolle Wodka, Rauschmittel und Drogen, besonders bei nächtlichen Transgressionen und Ekstasen, spielen. Das untere Photo zeigt eine seitliche Ansicht des Clubs Berghain, in Berlin-Friedrichshain, dem Heiligen Gral der Techno-Welt. 

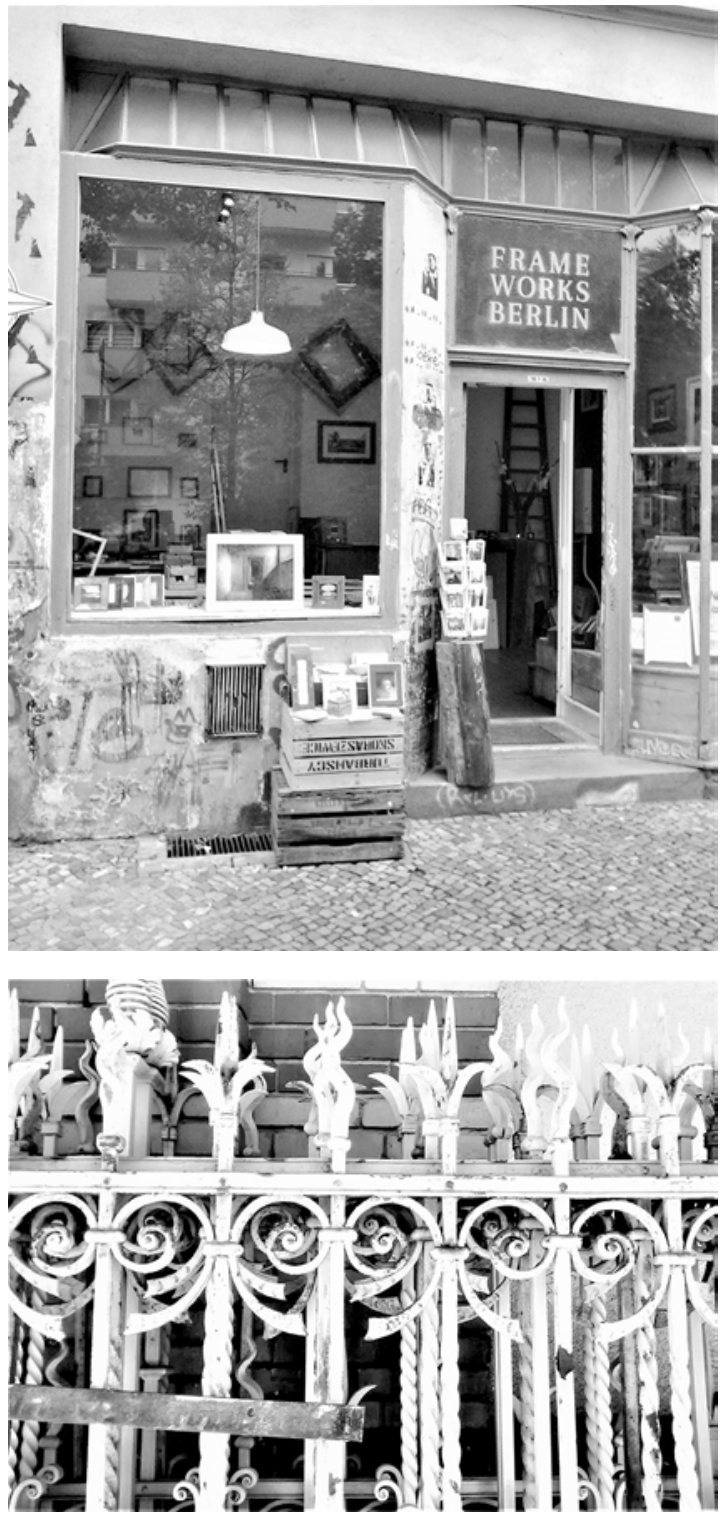

Abb. 16 und 17: Welche Perspektiven haben wir auf die Cegenstände? Was sind unsere Wahrnehmungs- und Denkmuster? Welche theoretischen Rahmen schaffen wir uns und durch welche Setzungen sind unsere theoretischen Diskurse charakterisiert? Gibt es bei alldem Denkblockaden und Denkverbote? Welche Auswirkungen hat dies für unser pädagogisches und gesellschaftliches Denken und Handeln? Das Ladenlokal Frameworks, auf dem Photo oben zu sehen, aufgefunden in Berlin-Kreuzberg, nicht weit vom Kottbusser Tor, bringt diese Fragen auf symbolische Art und Weise auf den Punkt, ebenso die ausrangierten Metallzäune, auf dem Photo unten, die in einem Hinterhof in Berlin-Wedding lagerten. Was sind also die Rahmen und was sind die Zäune bzw. Begrenzungen in unserer Wahrnehmung und in unserem pädagogischen und wissenschaftlichen Denken und Handeln? 

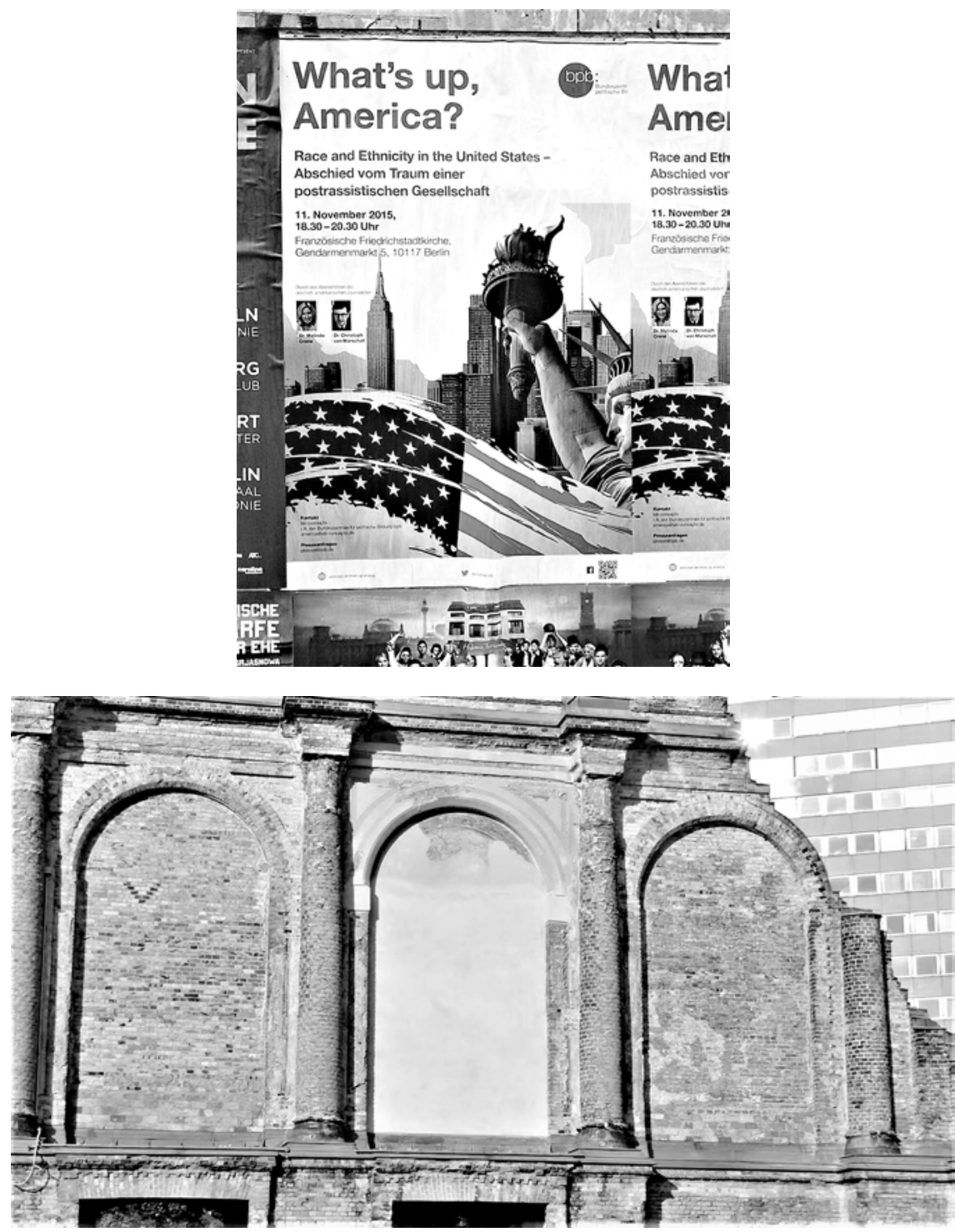

Abb. 18 und 19: Die Cesellschaften der beiden Einwanderungsländer Deutschland und USA befinden sich auf dem Gebiet der emotionalen und sozialen Entwicklungsförderung bzw. des Verhaltenstrainings und der Verhaltensteuerung im fortwährenden Vergleich. Der transatlantische Ideenaustausch war hier stets zentral und hat sich immer wieder verändert, je nach den gesellschaftlichen und politischen Rahmenbedingungen, in beiden Ländern. What's up America? wird auf dem Veranstaltungsplakat, das in Berlin-Neukölln an einer Mauer hing, gefragt. Auf dem unteren Photo sehen wir Überreste der Fassade des Anhalter Bahnhofs in Berlin-Kreuzberg, die stark mit den Neubauten im Hintergrund kontrastieren. Das Alte und das Neue kommen gleichzeitig in den Blick, das alte Europa, die Neue Welt, das alte Deutschland und das neue Deutschland der Gegenwart und der Zukunft. 


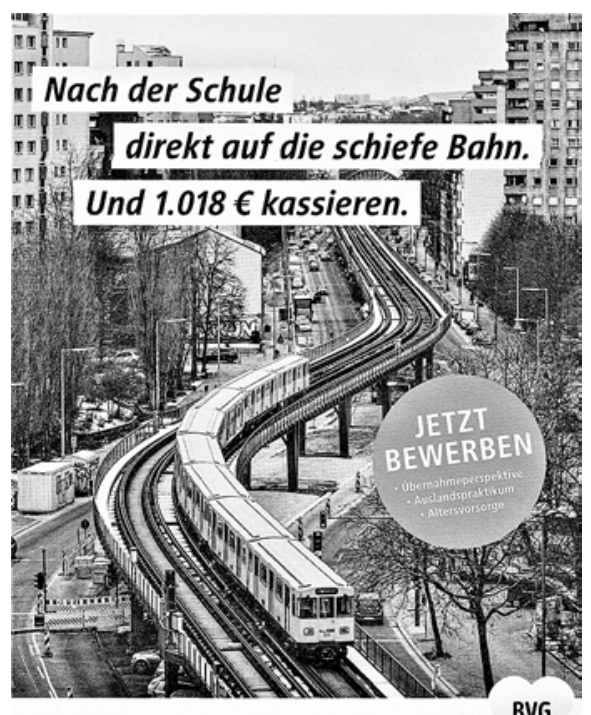

BVG

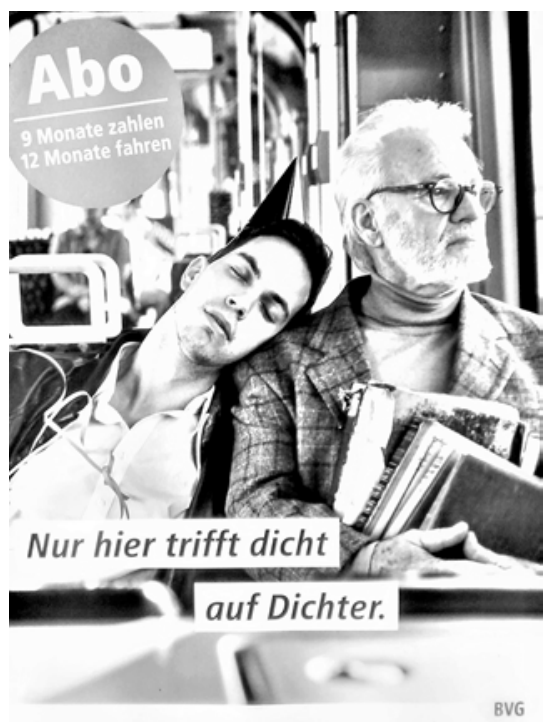

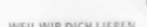

WEIL WIR DICH LIEBEN.

Abb. 20 und 21: Allein schon der Werbeslogan der Berliner Verkehrsbetriebe zieht die Bürger_innen dieser Stadt in den Bann: Weil wir dich lieben. Bei dieser überaus schöpferischen Kampagne wird deutlich, welche Macht Sprache hat, wie suggestiv Sprachbilder sein können, wieviel Imagination freigesetzt werden kann, durch die gekonnte Verknüpfung von Bildmetapher und Slogan. So entsteht erst die Metapher, im Kopf des Betrachters. Die beiden ausgewählten Plakate zeigen, wie sich jugendliches Lebensgefühl wertschätzend und humorvoll spiegeln lässt, wie mit Devianz, Ekstase, Experiment gespielt wird und wie das Ganze doch in einen übergreifenden gesellschaftlichen Zusammenhang eingebettet wird, wo dies alles verstanden und akzeptiert wird, nicht nur toleriert, sondern auch anerkannt und geschätzt wird. Aus dieser Kampagne der BVG lässt sich viel für eine gute Pädagogik lernen, auch in dem Sinne, wie Richard Sennett und Pablo Sendra ihre Vision für die urbanen Räume der Zukunft veröffentlicht haben, unter dem Titel Designing Disorder. 

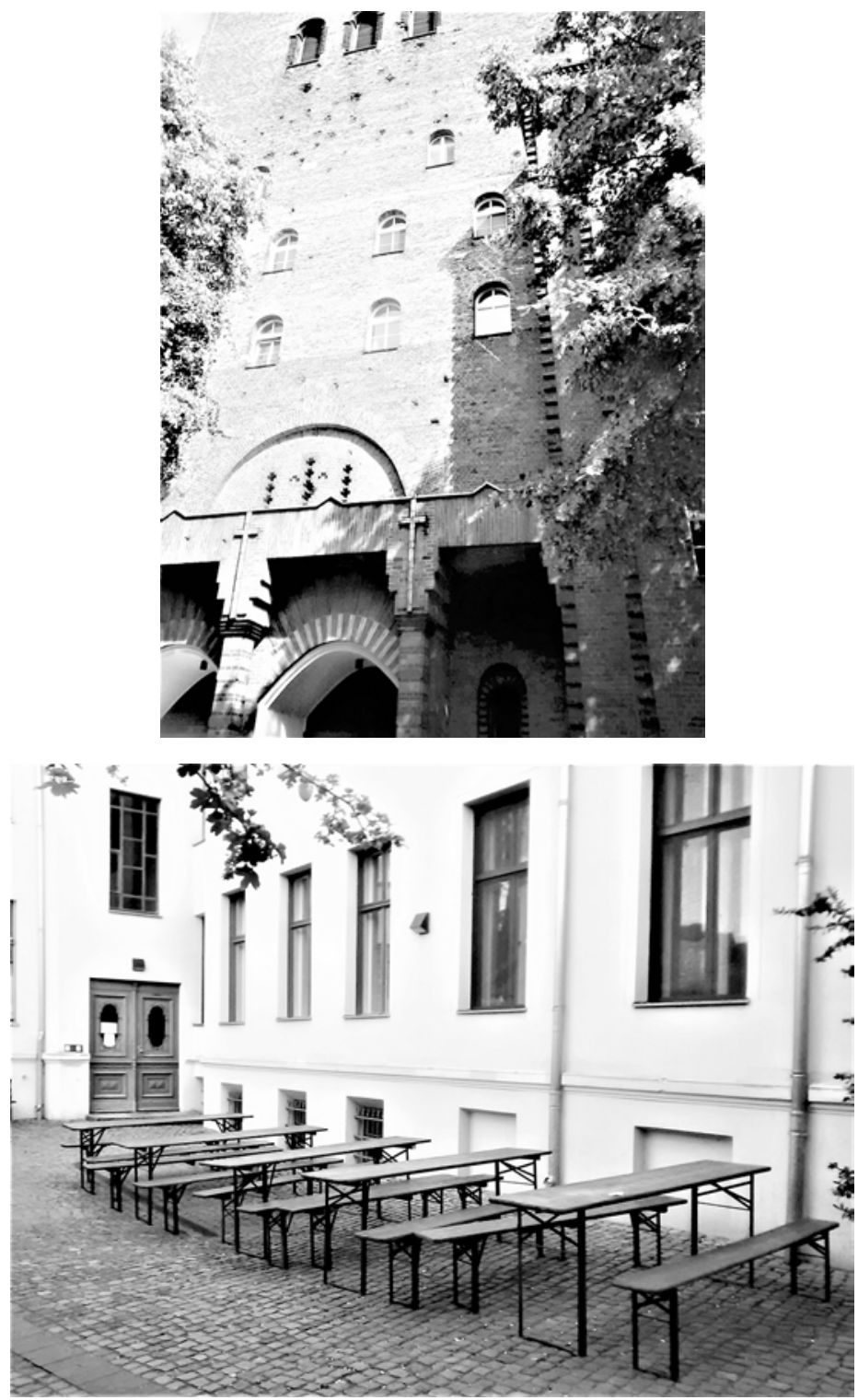

Abb. 22 und 23: Loslassen, Zulassen, für die Menschen, ihre Sorgen und Nöte da sein, so beschreibt eine katholische Kirchengemeinde in Berlin-Neukölln, ihre Philosophie. Zu den Protagonist_innen der Kirche im sozialen Brennpunkt gehört auch, die aus dem südwestfälischen Ottfingen stammende, Lissy Eichert. Dann und wann versorgt sie die deutsche Bevölkerung, auf recht erfrischende und stets wahrhaftige Art und Weise, mit dem Wort zum Sonntag. Der Kirchturm auf dem oberen Photo wirkt wie ein mittelalterliches Bollwerk der Menschlichkeit, in einer, durch vielerlei soziale Herausforderungen charakterisierten, urbanen Umgebung. Teilen, im Sinne einer humanen Existenz für alle, ist die Philosophie einer weiteren Klostergemeinschaft, in Berlin-Pankow. Dazu gehört nicht nur eine Kleiderkammer, sondern auch ein kostenloser Mittagstisch für Obdachlose, den wir auf dem unteren Photo sehen können. 

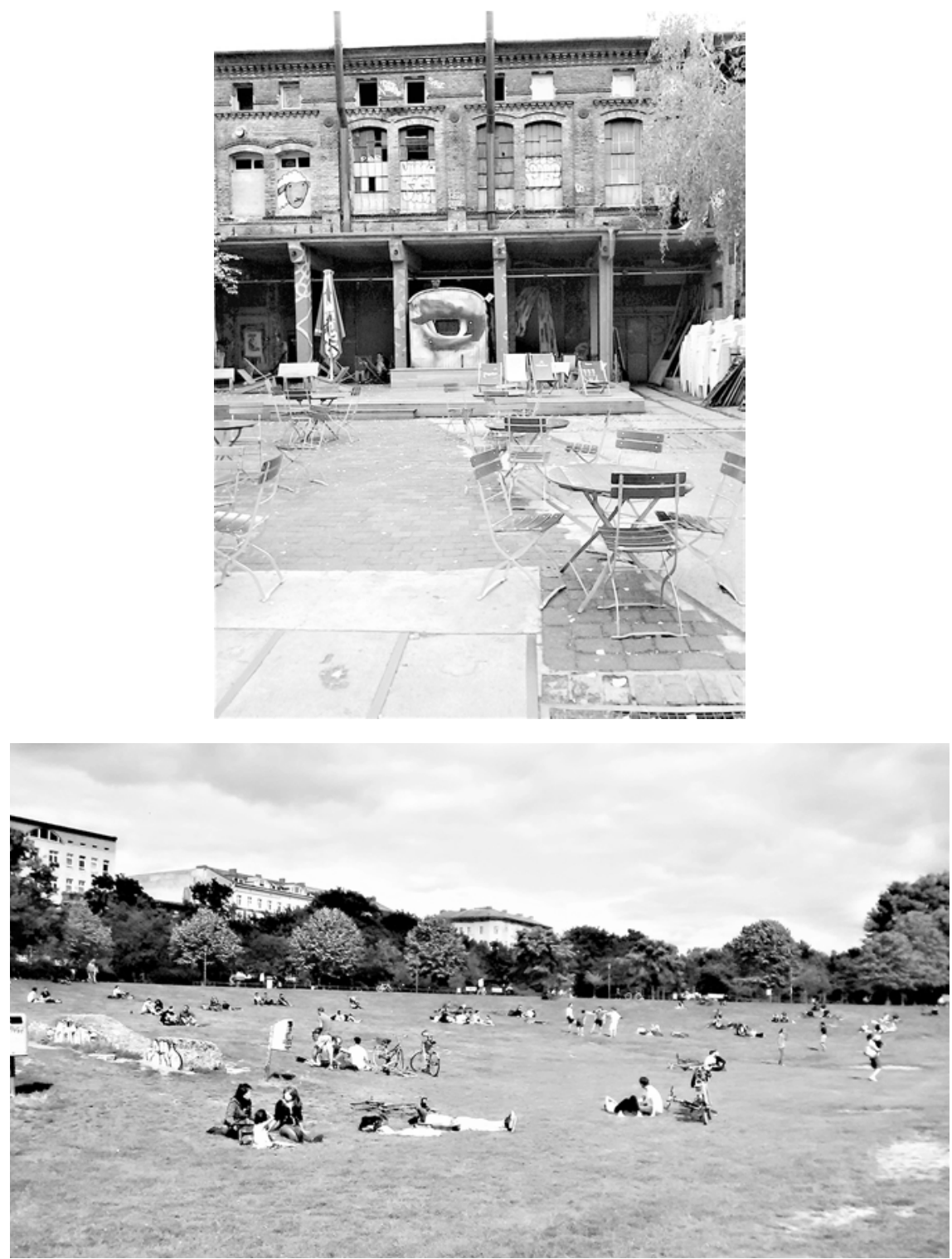

Abb. 24 und 25: Im Zuge der politischen Umbrüche, auch bedingt durch die sozialen und wirtschaftlichen Veränderungen, standen in Berlin viele Gebäude leer. Dazu gehörte auch das Gelände des ehemaligen Reichsbahnausbesserungswerks, in Berlin-Friedrichshain, unter Insider_innen RAW-Gelände genannt. Heute befinden sich darin kulturelle und pädagogische Projekte, eine Kletterhalle und Bars. Das obere Photo dokumentiert einen repräsentativen Ausschnitt davon. Das untere Photo zeigt den, wegen des mehr oder weniger geduldeten Drogenverkaufs immer wieder in die Schlagzeilen gekommenen, Cörlitzer Park, in Berlin-Kreuzberg, eine Art Aushandlungsbühne der offenen Cesellschaft, würde Karl Popper vielleicht dazu sagen. 

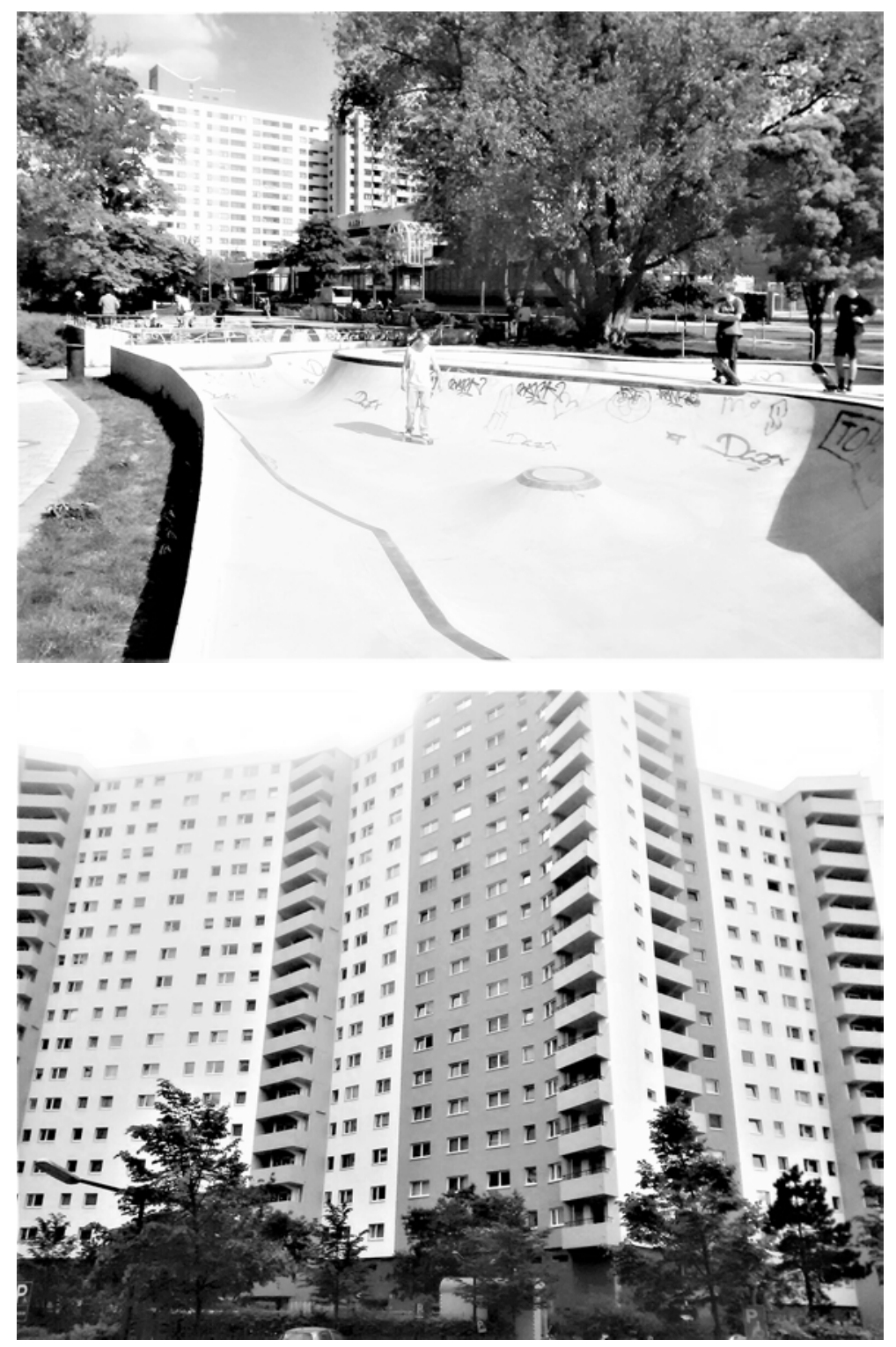

Abb. 26 und 27: Welche Arten von Cebäuden und welche Art von urbaner Raumgestaltung bieten Möglichkeiten der Partizipation, der Umgestaltung und der Transformation? Welche Architektur und Stadtgestaltung fördert das Wohlbefinden der Menschen? Die Photos zeigen eine Halfpipe und ein typisches Wohngebäude in der Schlafstadt Berlin Märkisches Viertel. In Zukunft sollten wir nicht mehr so bauen. Diese Art der Architektur und Stadtgestaltung trennt Wohnen von Arbeiten und kulturellem Leben. Sie erzeugt Uniformität und sie macht die Menschen zu kleinen Rädchen, die sich einzufügen haben. 


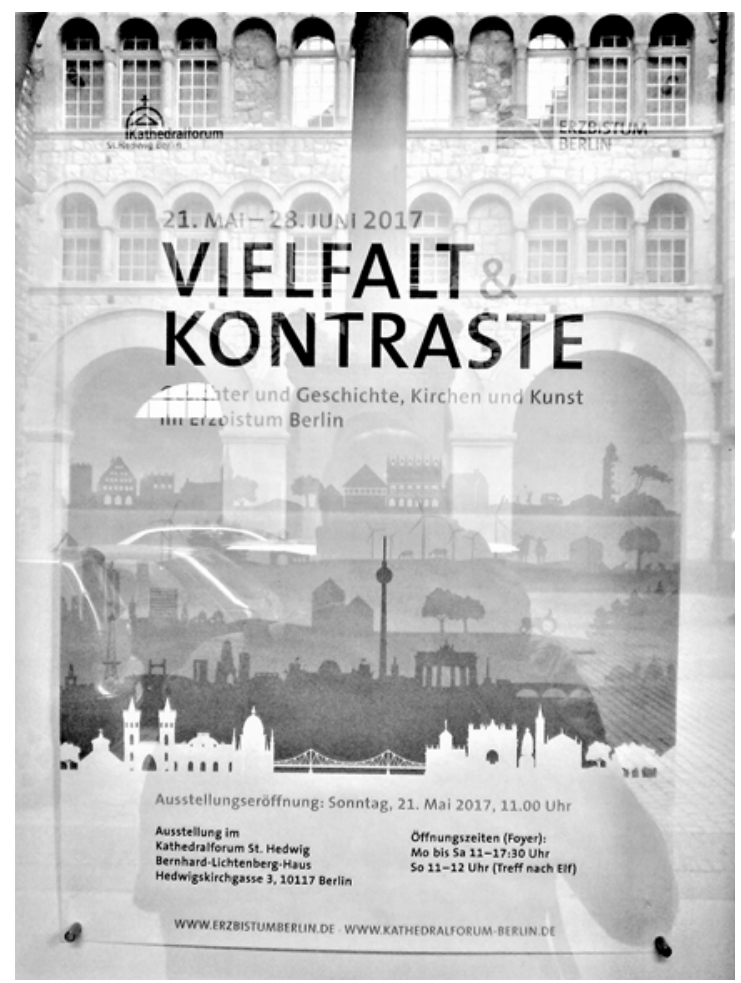

Abb. 28: Berlin ist ein Schmelztiegel der Kulturen, ähnlich wie London. Nehme ich die U2 vom Olympia-Stadion im Westen, bis nach Pankow im Osten, dann wird das immer eine kulturell vielfältige Fahrt durch die Tunnel, über die unterirdischen Bahnsteige hinweg und später, über die Gleise der Hochbahn, die mich stets an New York oder Chicago erinnern. Dann bekomme ich Menschen aus allen Bereichen der Erde zu sehen und ich höre vielerlei Sprachen. Nehme ich dabei auch noch Henry Thoreaus Buch Walden oder Erich Fromms To Have or to Be mit auf die Reise, um unterwegs darin zu lesen, wird sich, mit hoher Wahrscheinlichkeit, auf dem Weg durch die Tunnel, irgendein interessantes Cespräch ergeben. Umgekehrt, stand ein chinesischer Student, mit Thomas Bernhards Buch Verstörung in der Hand, mir direkt gegenüber, während der Zug über die Gleise ratterte. Wir kamen miteinander ins Cespräch, stiegen schließlich beide am Alexanderplatz aus und diskutierten eine ganze Weile über das Werk von Bernhard, seine Bedeutung und seine Rezeption in China. Die U3, sie geht ja von der Krummen Lanke, über das Kottbusser Tor, bis zur Warschauer Straße, weckt zugleich die Sehnsucht nach der Weite des Ostens. Die U2 und die $U_{3}$, das sind die wahren, die globalen und universalen Universitäten in dieser Stadt, wo noch relevante Debatten stattfinden, ganz ohne Module und Credits. Bummele ich durch Neukölln betören mich die Aromen fremdländischer Kochkünste. Über die Spannungsverhältnisse, die sich hieraus ergeben können, hören und lesen wir täglich. Es gilt produktiv und schöpferisch umzugehen mit Fremdheit, mehr Neugier zu entfalten. Auch das, auf diesem Photo zu sehende, in Berlin-Kreuzberg entdeckte, für diesen ganzen Themenzusammenhang exemplarische, Ausstellungsplakat, mit dem Titel Vielfalt $\&$ Kontraste, legt dies nahe. Durch das vermeintlich Fremde bekommen wir auch wieder das abgründige Eigene zurückgespiegelt, wenn ich an den chinesischen Studenten, mit Thomas Bernhards Romanen im Rucksack, denke. Bernhard hat ja, wie kaum ein anderer, das Dunkle in unserer eigenen Kultur ausgeleuchtet. 


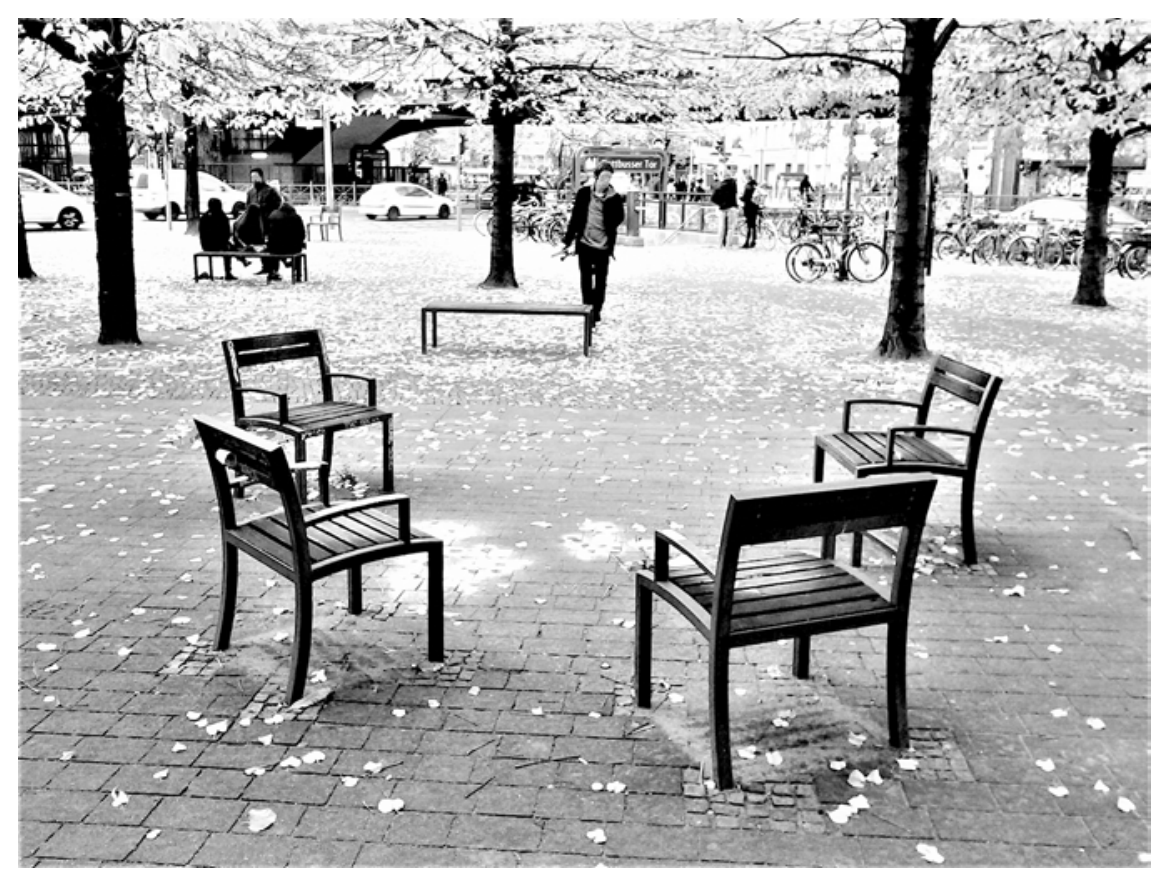

Abb. 29: Das Photo zeigt einen fest installierten, aus robustem Metall gefertigten, Stuhlkreis am Kottbusser Tor, einem als Brennpunkt geltenden U-Bahn-Drehkreuz in BerlinKreuzberg. Welche Kommunikationen, welche Reflexionen wären hier denkbar? Auch eine Einladung innezuhalten und nachzudenken, seine Gedanken schweifen zu lassen. Hier wären in Zukunft geistreiche Gespräche möglich, etwa mit chinesischen Studierenden, die Thomas Bernhard lesen, oder mit Menschen aus Neuseelandland, die sich gerade mit Thoreaus Walden beschäftigen. Dieser offene Stuhlkreis könnte zum erweiterten Raum der U3 gehören, zu der globalen, der eigentlichen und universalen Universität. Ich stelle mir einen chinesischen Studenten vor, der dort sitzt und auf seinem Smartphone in der digitalen Version dieses Buches hier liest, und der mich zwischendurch anschreibt, weil er mit mir über das Celesene sprechen will. Das ist die Zukunft der Universität. Auf solche Art könnten die entscheidenden Veränderungen auf den Weg kommen. 


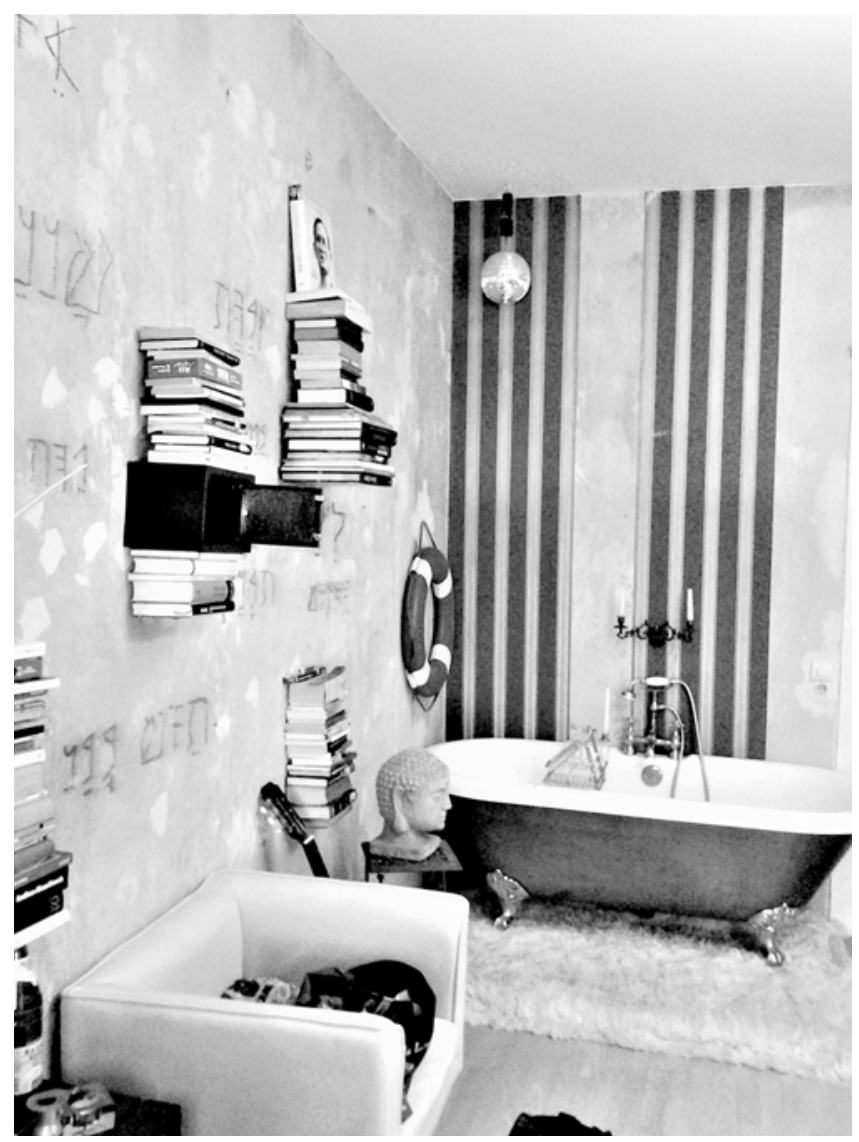

Abb. 30: Escape the Ordinary, so lautete das Motto einer spezifischen Airbnb-Erfahrung, in Berlin-Prenzlauer Berg. Diese Wohnung bot Raum für einen, um die Creative City kreisenden, komplexen, philosophischen Diskurs. Mein Host, im Feld der Creative Industries tätig, hatte einen amerikanisch-deutsch-israelischen Hintergrund. Er pendelte, in Abständen, zwischen New York, Berlin und Tel Aviv. Dies war eine Wohnung zum Eintauchen in Marcel Prousts Aufder Suche nach der verlorenen Zeit. Gemeinsam mit Janet Painter habe ich, in Progress in Education, eine kleine Studie zu den spezifischen Airbnb-Erfahrungen in Berlin veröffentlicht, unter dem Titel Throwing out a net over Berlin: Educators in search of the metropole's creative potential (vgl. Broecher und Painter, 2021). 


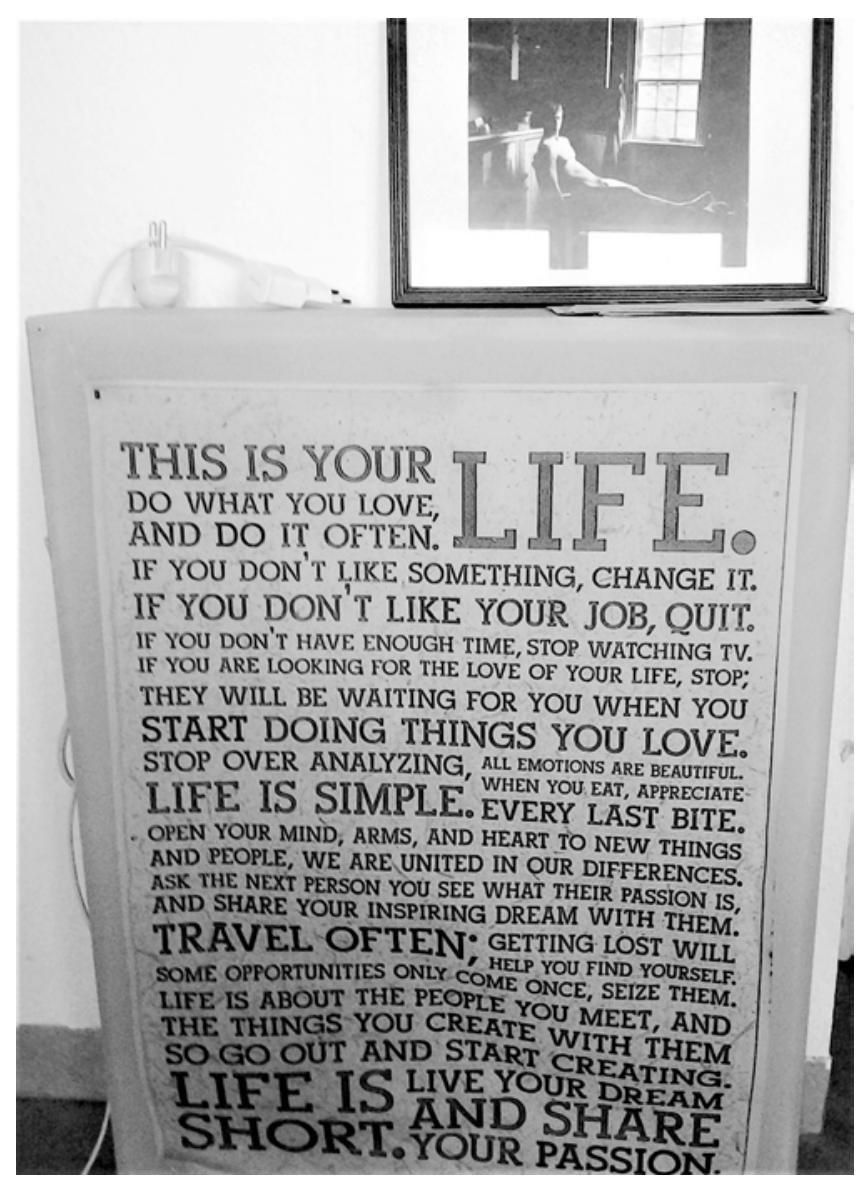

Abb. 31: This is your life, do what you love and do it often ... Anhand des, über den ganzen Clobus verbreiteten, Holstee Manifestos ${ }^{2}$, brachten zwei schöpferische junge Männer, bei denen ich mich über Airbnb in Berlin-Prenzlauer Berg eingemietet hatte, ihre Lebensphilosophie zum Ausdruck. Der eine der beiden Hosts, ursprünglich aus Polen stammend, war dabei, ein Startup zu gründen. Er hatte einen alten Bus gekauft und wollte ihn als fahrende Werbefläche vermarkten. Der andere war ein Naturwissenschaftler aus Südamerika, der erst einmal an einer Berliner Privatschule unterrichtete. Alles war in Bewegung. Die beiden hatten noch mehr als das halbe Leben vor sich. 

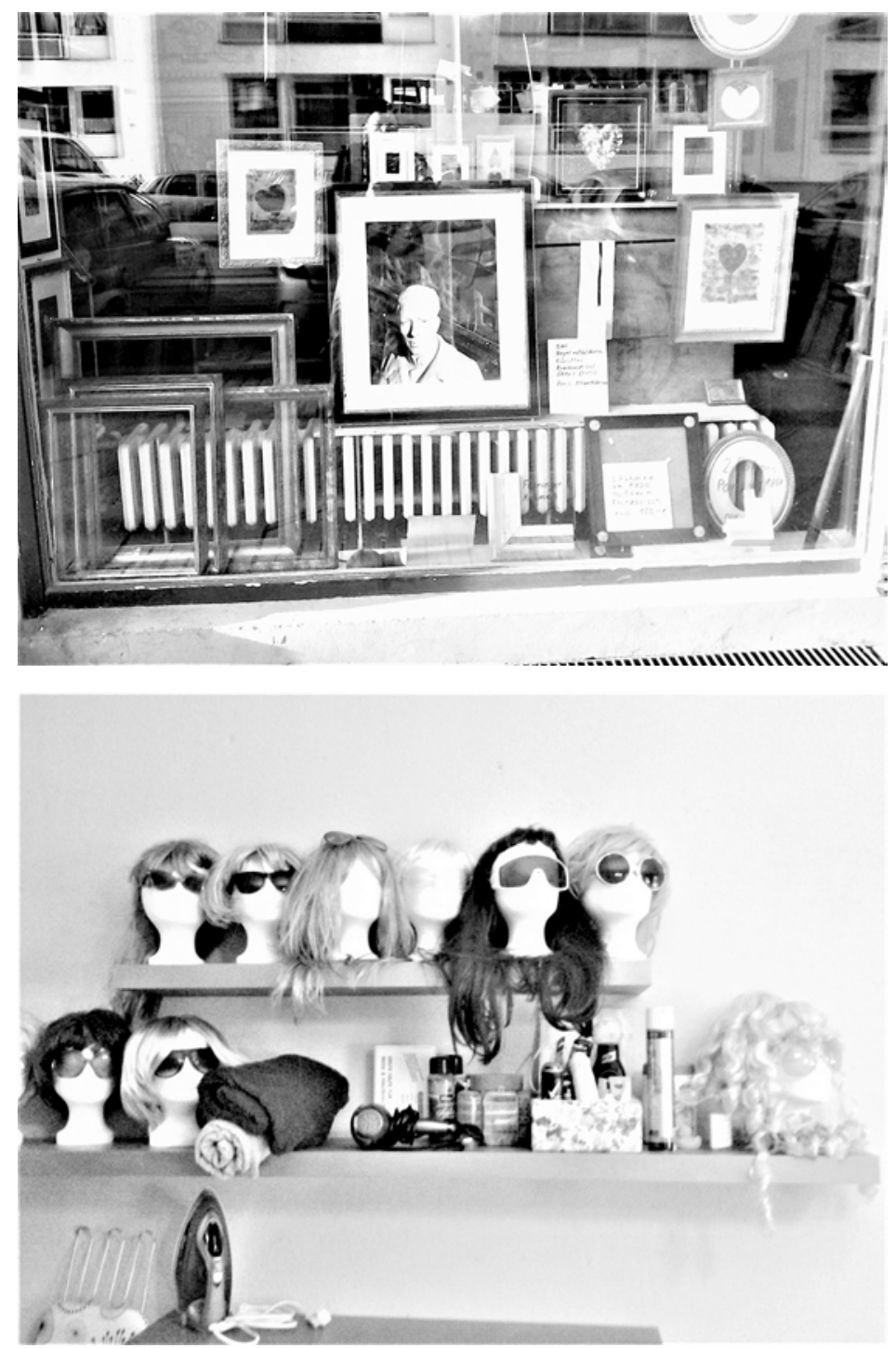

Abb. 32 und 33: Das Leben in einer Metropole wie Berlin bringt mich immer auch zu der Frage, wer ich selbst bin, nach den durch berufliche und familiäre Verantwortlichkeiten ausgefüllten Jahren, jetzt, wo ich vieles mehr aus der Distanz betrachten kann. Das Photo oben zeigt das Schaufenster einer Werkstatt in Berlin-Schöneberg, in der erlesene Bilderrahmen hergestellt werden. Das eingerahmte Portrait in der Mitte machte mich sehr nachdenklich. Welchen Rahmen habe ich meinem Leben bisher gegeben und was könnte jetzt ein passender Rahmen sein? Oder auch die Frage, ob ich überhaupt noch einen solchen Rahmen um mich herum benötige? Geben solche Rahmen mehr soziale Sicherheit und seelische Stabilität oder engen sie auch ein? In einer, über Airbnb gebuchten, Unterkunft in Prenzlauer Berg, befand sich eine, auf dem unteren Photo zu sehende, Sammlung von Perücken, die die Gäste verwenden konnten, um beim Eintauchen ins Nachtleben, einmal versuchsweise mit einer anderen Identität zu experimentieren. 


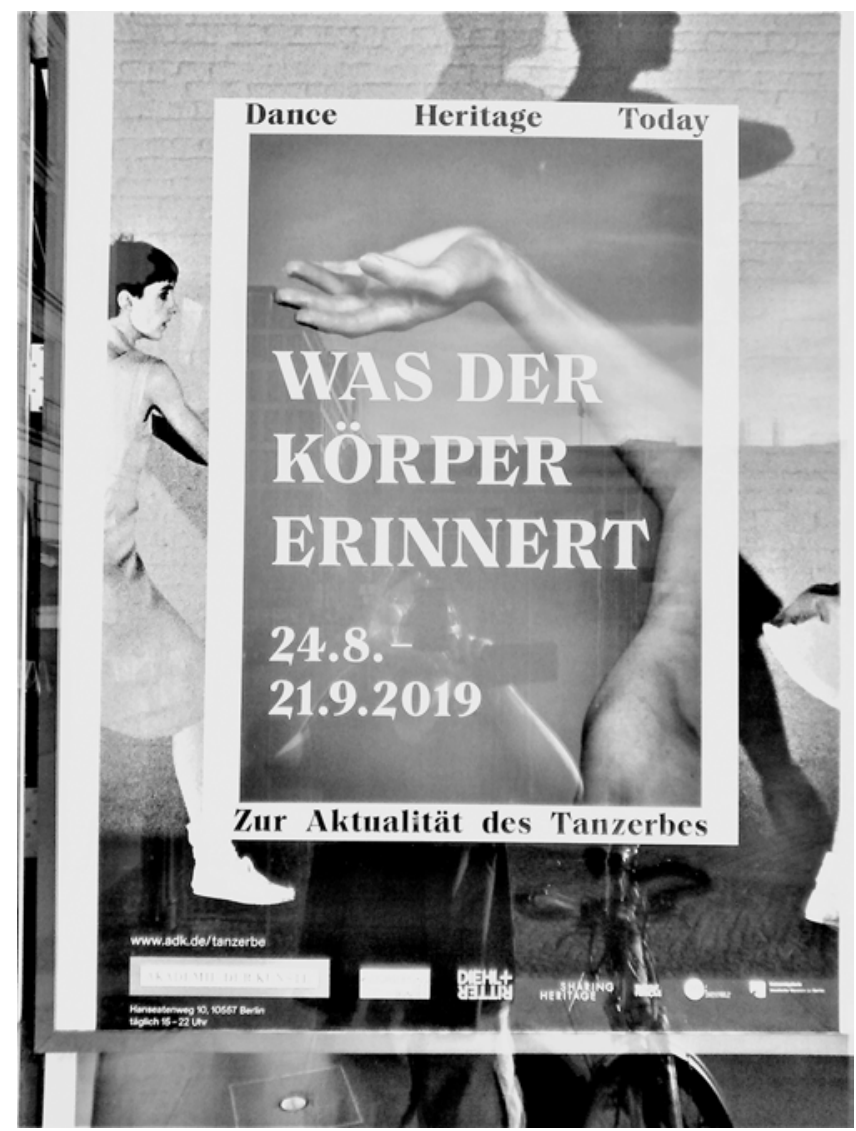

Abb. 34: Vieles, ja das Allermeiste, was wir in den Bildungs-, Sozial- und Cesellschaftswissenschaften tun, hat mit kognitiven, intellektuellen Dingen zu tun. Wir sind fast immer im Kopf, im Denken und Entwickeln, im verbalen Kommunizieren und Schreiben. Dabei waren wir immer auch Körper, in Unterrichtsstunden und in Seminarräumen, in Sitzungen und Konferenzen und bei der Arbeit am Schreibtisch. Doch wer spricht davon und wer denkt daran, was unsere Körper aus all den Jahren mit sich nehmen und was sie erinnern? Dieses, in der Kunstausstellungshalle, neben dem Hotel Adlon, gesehene Plakat machte mich sehr nachdenklich. Was erinnert der Körper eines jugendlichen Fabrikaushilfsarbeiters, Pädagogikstudenten, Kellners, Taxifahrers, Lehrers, Vaters, Seminarleiters, Schulleiters und Universitätsprofessors? Ich könnte wohl ein ganzes Buchkapitel von hier aus entwerfen und mit Inhalt füllen. 

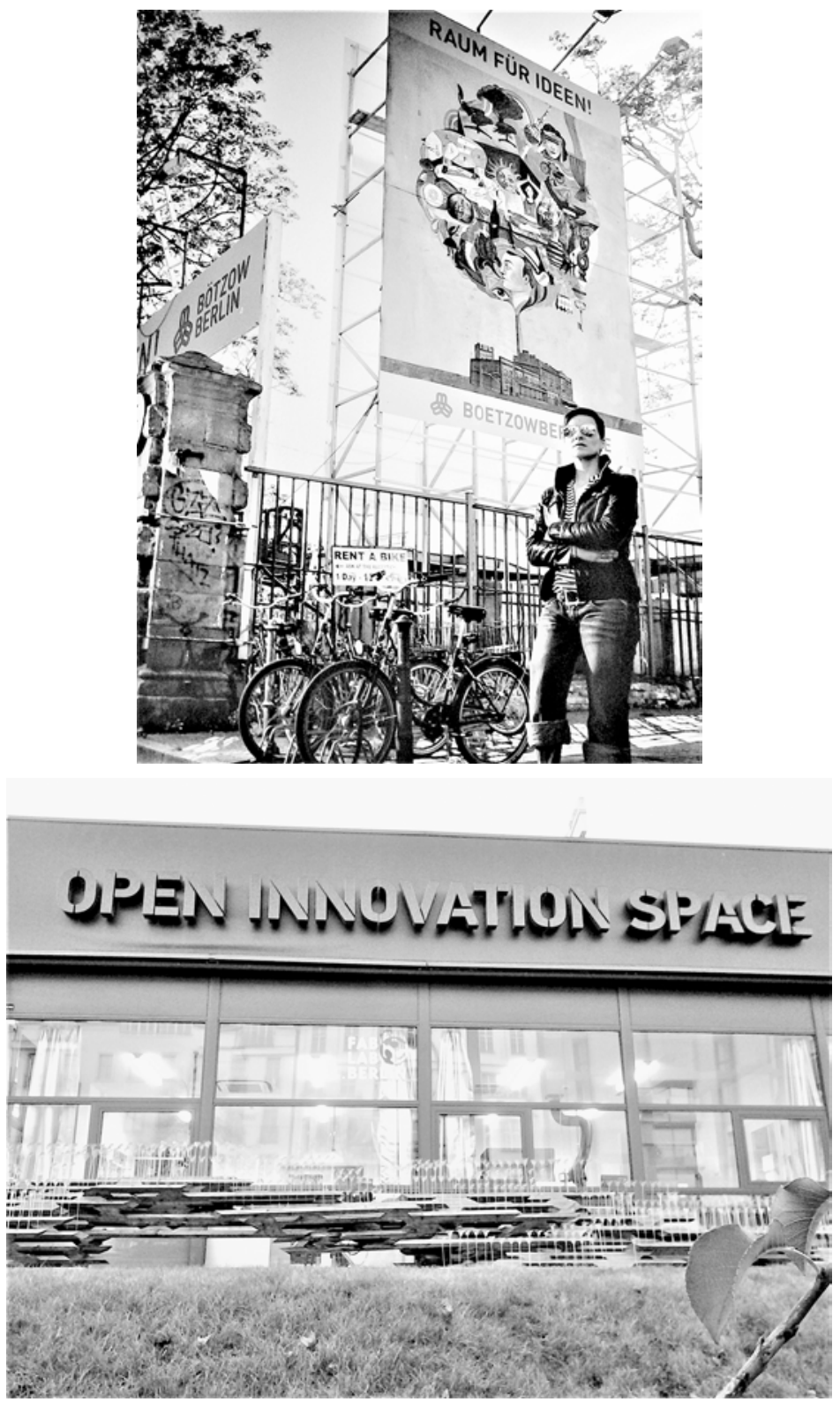

Abb. 35 und 36: Der Transformationsprozess des staatlichen Schul- und Universitätswesens bereitet sich längst vor, erst einmal in den, die Schulen und Universitäten umlagernden, urbanen Räumen, sodann in den verschlungenen, digitalen und virtuellen Welten. Die Photos zeigen Ausschnitte von ehemaligen Brauereigebäuden in Berlin-Prenzlauer Berg, die mittlerweile in Denkfabriken, Co-Working Spaces und Creative Labs umgewandelt worden sind. Das könnten die Prototypen für die neuen sozialen Formationen der Zukunft sein, in denen, und um die herum, gearbeitet, gelernt und gelebt wird. 

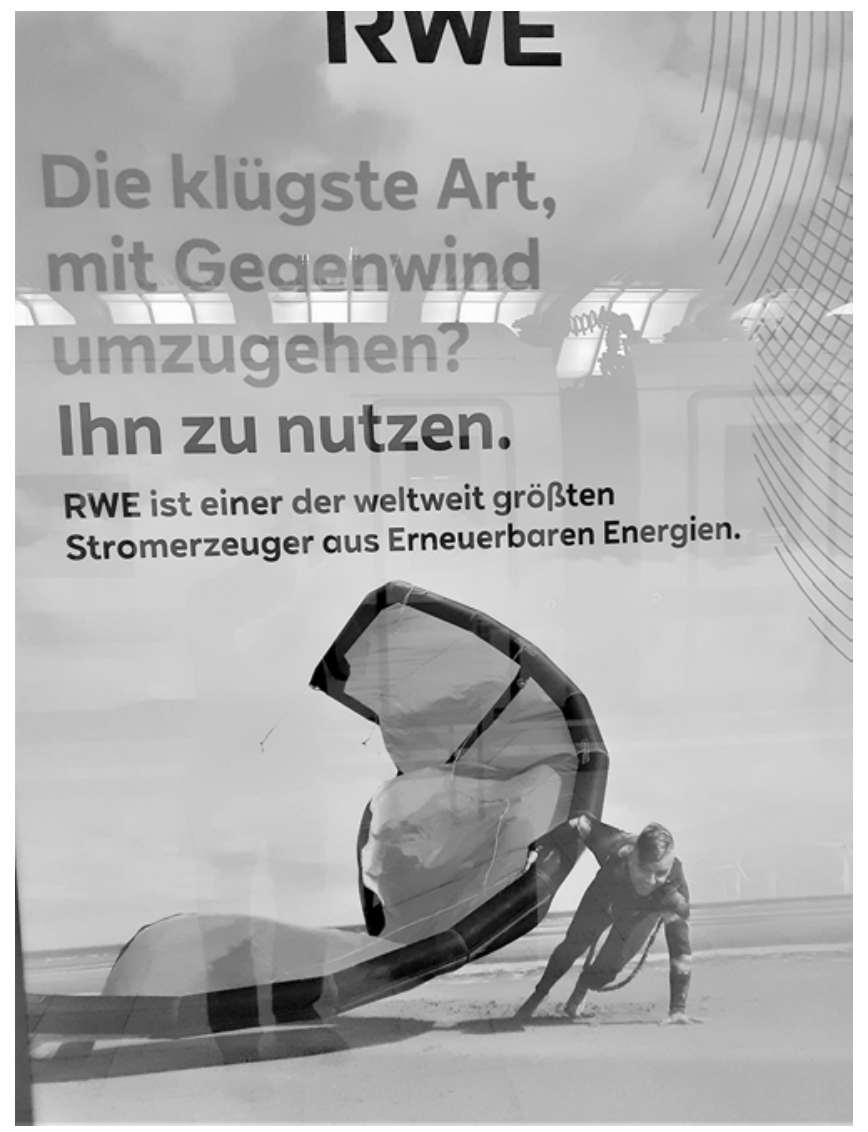

Abb. 37: Dieses markante Werbeplakat habe ich auf dem ICE-Bahnsteig, in Berlin-Cesundbrunnen, photografiert, im Zuge meiner Pendelei zwischen Flensburg, Niederbreidenbach und Berlin. Als ich, mit Rucksack und Koffer, vor dem Plakat stand, realisierte ich plötzlich, dass es, wie kaum eine andere bildhafte Symbolisierung, mein Lebensgefühl zum Ausdruck brachte, wenn ich an all die Jahre in den Schulen und Universitäten denke. Ich hatte fast immer das Gefühl, bis auf wenige kürzere Abschnitte vielleicht, wo ich einmal Rückenwind hatte, einen so kräftigen Cegenwind vor mir zu haben, wie der Kiter auf dem Strand, den wir hier auf diesem Plakat sehen können. Trotz allem folgte ich immer dem Crundsatz, aus den Steinen etwas zu bauen, die man/frau mir vor die Füße warf. Auch das vorliegende Buch ist in diesem Zusammenhang zu verstehen. 


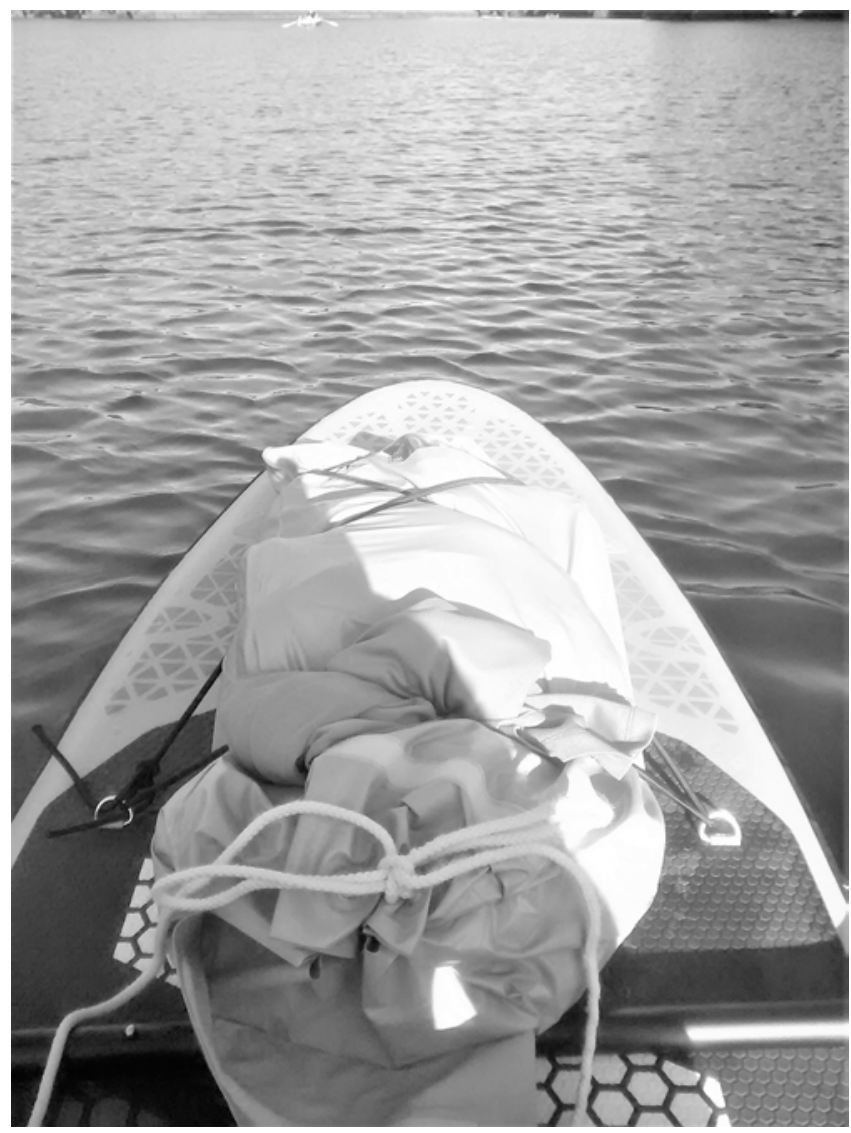

Abb. 38: Ich führte über viele Jahre hinweg ein sehr eng getaktetes Leben. Da ich meine Familie nicht entwurzeln und nicht dazu drängen wollte, hinter mir her, an die Orte zu ziehen, wo ich ab 2008 Professuren angeboten bekam, pendelte ich viele Jahre zwischen Rhein und Elbe, später gar bis zur dänischen Grenze und wieder zurück. 2015 begann ich damit, mir Berlin, aufbauend auf meinen ersten Erkundungen 1981, und den dann wiederkehrenden Berlinaufenthalten, als Forschungsfeld zu erschließen. Ich führte einen Ordner mit Flugtickets, Zugtickets, Airbnb-Buchungen, denen entlang ich dann alles, Schritt für Schritt, umsetzte. Seminare, Verwaltungsarbeit, Feldstudien, konzeptionelle Arbeiten, Veröffentlichungen, Praxiskooperationen. Der Terminkalender war immer randvoll. Erst eine feste Wohnung in Berlin brachte vita activa und vita contemplativa wieder besser in Einklang. Ich begann auch die Berliner Muße-Räume zu entdecken. Das Photo zeigt mein Stand-upPaddling-Board auf dem Wannsee. 


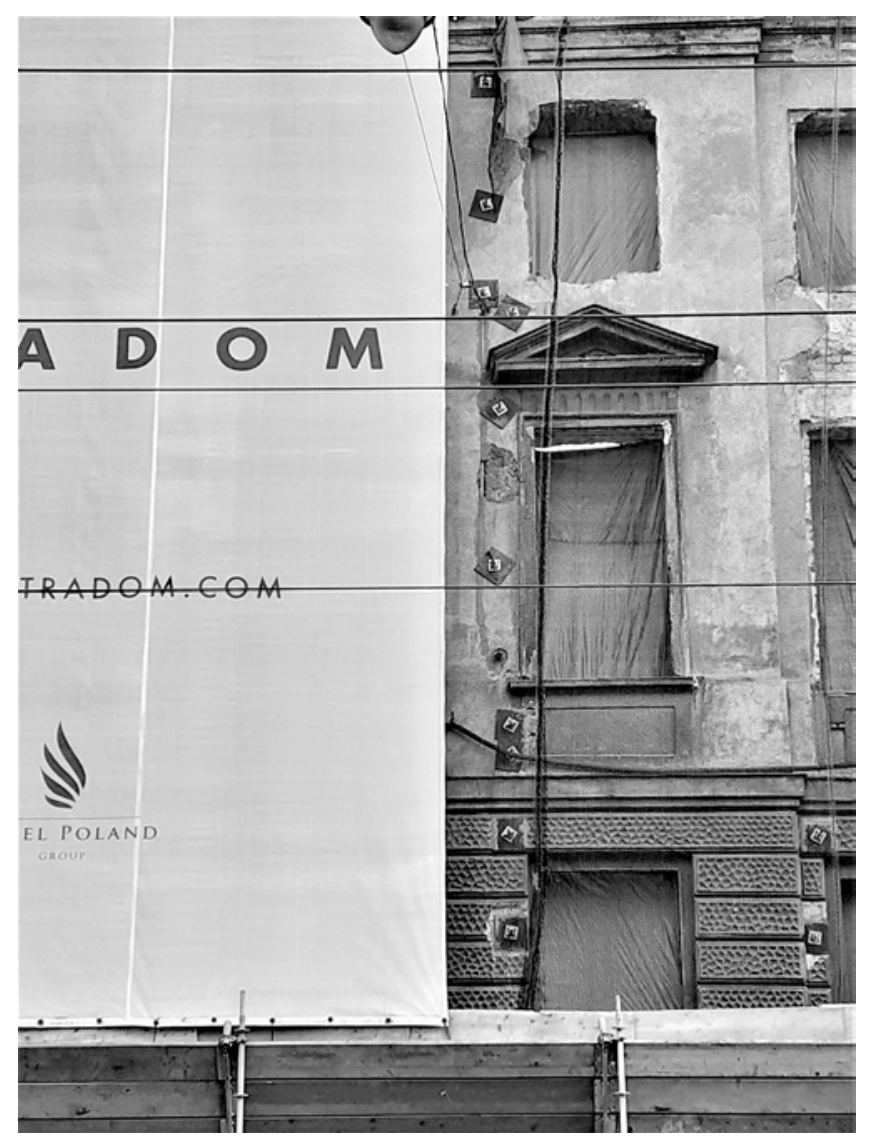

Abb. 39: Im Januar 2020 unternahm ich eine Reise nach Krakau und Südpolen. Dort traf ich Piotr Toczyski, einen Kollegen aus Warschau. Wir unternahmen Recherchen zunächst in Krakau und besuchten dann Andrzej Jaczewski, der früher Kinderarzt und Professor der Universität Warschau war und später Ehrenprofessor der Universität Krakau. Wir trafen ihn an seinem Wohnort in Ropki, in Südpolen, in einem abgelegenen Gebirgsdorf in den Beskiden. Dort führten wir Gespräche zum deutsch-polnischen Austausch auf dem Gebiet der Sonder- und Inklusionspädagogik, zur Zeit des Kalten Krieges. Cemeinsam mit Karl-Josef Kluge, von der Universität zu Köln, war er ein Pionier der europäischen Pädagogik, 1969 bis 1990, lange bevor all die institutionalisierten Austauschprogramme geschaffen wurden, die wir heute haben. Andrzej Jaczewski, geboren 1929, war ein Jahrhundert-Mensch. Schon als jugendlicher Pfadfinder beteiligte er sich am Widerstand gegen die deutsche und die sowjetische Besatzung in Warschau. Er ist am 13. Oktober 2020 verstorben, im Alter von 91 Jahren (vgl. auch Kapitel 8). Alles ist jetzt im Umbruch in Polen. Wir sind Zeuge von sozioökonomischen, kulturellen und urbanen Erneuerungen und Veränderungen. Dieses, in der Altstadt von Krakau aufgenommene, Photo bringt dies für mich in besonders anschaulicher Weise zum Ausdruck. 

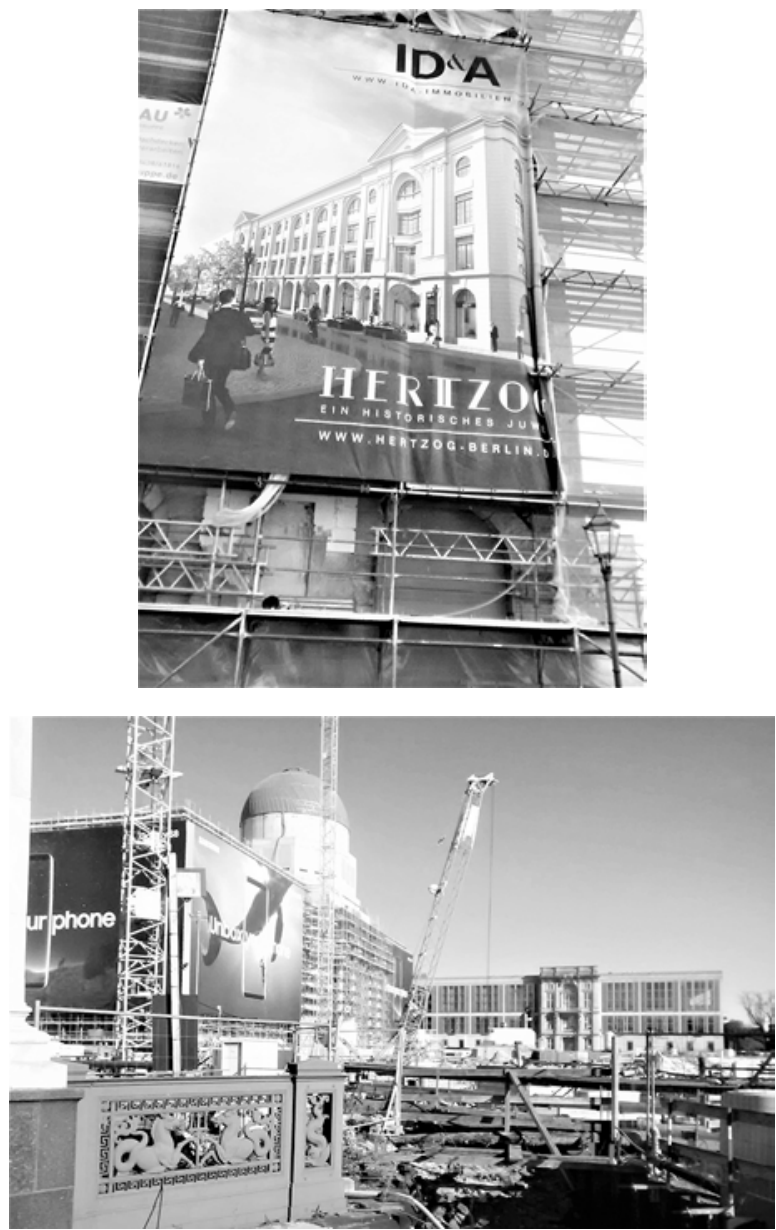

Abb. 40 und 41: Der urbane Raum Berlins ist voller Verweise auf historische Hintergründe, auf soziale, politische, kulturelle Auseinandersetzungen. Alles befindet sich in ständiger Veränderung. Wir selbst, die Bürger_innen dieser Stadt, sind Teil dieser Veränderung. ${ }^{3}$ Schicht um Schicht ist alles übereinander gelagert. Das Photo oben zeigt das ehemalige Kaufhaus Hertzog, in der Brüderstraße, in Berlin-Mitte, nicht weit vom derzeit entstehenden Humboldt Forum, das wir auf dem Photo unten sehen. Im August 2003 wohnte ich in der Brüderstraße, in einer kleinen Plattenbauwohnung, gemeinsam mit meinem Sohn Philipp. Wir hatten die Wohnung von einer Russin gemietet. Es war noch weit vor Airbnb und viel schwieriger so etwas zu finden. Wir unternahmen Stadterkundungen, die auch in dem Band Creating Learning Spaces, in Kapitel 5, zusammenfassend dokumentiert sind. Von unserer Wohnung aus schauten wir auf das leerstehende Ceschäftsgebäude und rätselten über seine Geschichte. Inzwischen wird es saniert und aufpoliert. Philipp und ich rekonstruierten auch das frühere Leben in der Brüderstraße, anhand von Büchern, teils auch anhand von Exponaten im Märkischen Museum. Einst gab es dort viele kleine Läden, Werkstätten und ein buntes, sinnliches Treiben. So sollten Städte nach Ansicht von Richard Sennett und Pablo Sendra wieder werden. Jetzt wirkt die Brüderstraße dagegen aufgeräumt, ordentlich, schick, aber nicht mehr sinnlich oder lebhaft. 

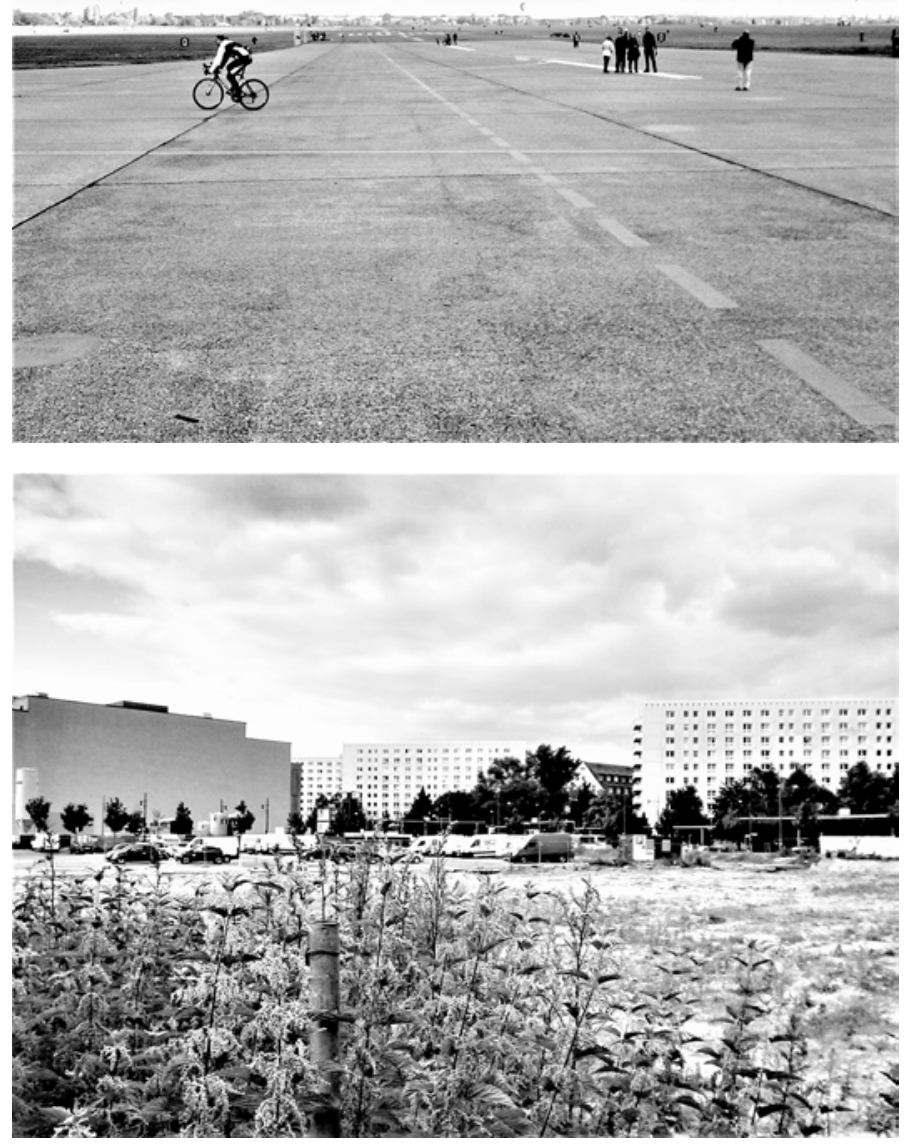

Abb. 42 und 43: Die materiellen Strukturen von Städten lassen sich als Spiegelbild von sozialen, ökonomischen und kulturellen Systemen ansehen. Brachen stellen Räume dar, die eine Zeitlang keine besondere Strukturierung oder Nutzung erfahren, und in denen sich dadurch ein ganz eigenes, oftmals eigensinniges, Leben entfalten kann. Das untere Photo zeigt eine Brache hinter dem Alexanderplatz, Berlin-Mitte. Berlins Brachen haben einen besonderen Reiz und hatten eine spezielle Bedeutung, ökologisch, sozial und kulturell. Auch Kinder und Jugendliche fanden hier ihre Streifräume, wenn wir einmal an die Forschungen von Martha Muchow denken. Aber durch das kontinuierliche Bauen schwinden die Brachen allmählich. ${ }^{4}$ Das Tempelhofer Feld, wie wir es auf dem Photo oben sehen, ist eine offen gelassene Fläche der ganz besonderen Art. Es bietet den Berliner_innen Raum für individuelle Aneignungsprozesse, sportliche Aktivitäten, die Cestaltung von MußeStunden bis hin zu Urban Gardening. 

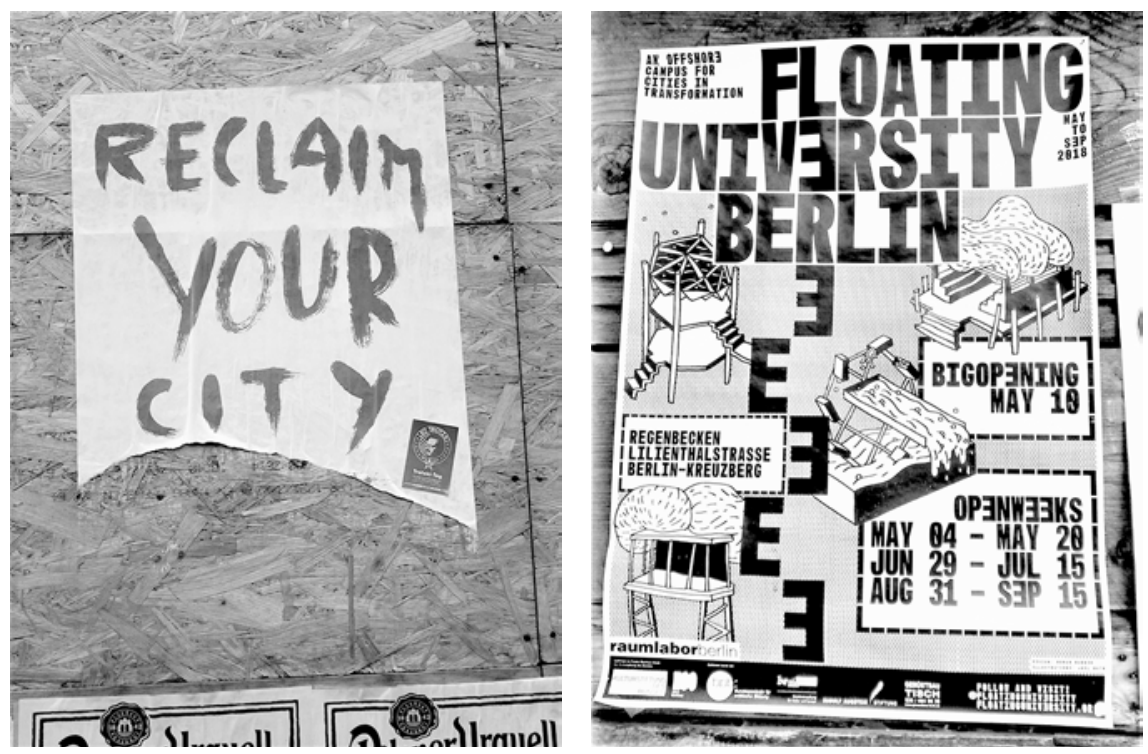

Abb. 44 und 45: Natürlich gibt es in einer Stadt wie Berlin, wie auch in anderen großen Metropolen, emanzipatorisch geprägte Bewegungen, politische Initiativen und engagierte Akteur_innen, die auf allen Ebenen der Politik versuchen, den Ausverkauf der Stadt an internationale Investor_innen, wenn nicht zu verhindern, dann doch immerhin abzubremsen und der, immer weiter fortschreitenden, Centrifizierung entgegenzusteuern. Das Problem ist inzwischen, in der Literatur, gut analysiert. Ideen, wie sie Richard Sennett und Pablo Sendra in den Büchern Building and Dwelling oder Designing Disorder niedergeschrieben haben, sollten stärker in die Debatte gebracht, in den Alltag der Menschen übertragen und dort erfahrbar werden. Das in Berlin-Neukölln gesehene Plakat, dokumentiert im Photo links, bringt diesen ganzen Problemzusammenhang sehr plastisch zum Ausdruck. Aber es geht nicht nur um die internationalen Finanzmärkte, um die Investor_innen aus China, Russland, Skandinavien, London und Paris, die immer mehr Häuser, teils ganze Straßenzüge in Berlin aufgekauft haben, es geht auch um die Bildungsinstitutionen in ganz Deutschland, die ungeheure Geldmengen an sich ziehen. Eine aktiver gewordene Zivilgesellschaft wird diese enormen Finanzmittel sicherlich eines Tages selbstbestimmter und nachhaltiger verwenden wollen, als es jetzt der Fall ist. Noch können sich Projekte, wie die Floating University Berlin, kaum behaupten, aus Mangel an Finanzkraft. Doch sollten Open Education (vgl. dazu Deimann, 2019) und Open Space (vgl. Owen, 2011) bald mehr Bedeutung bekommen. 


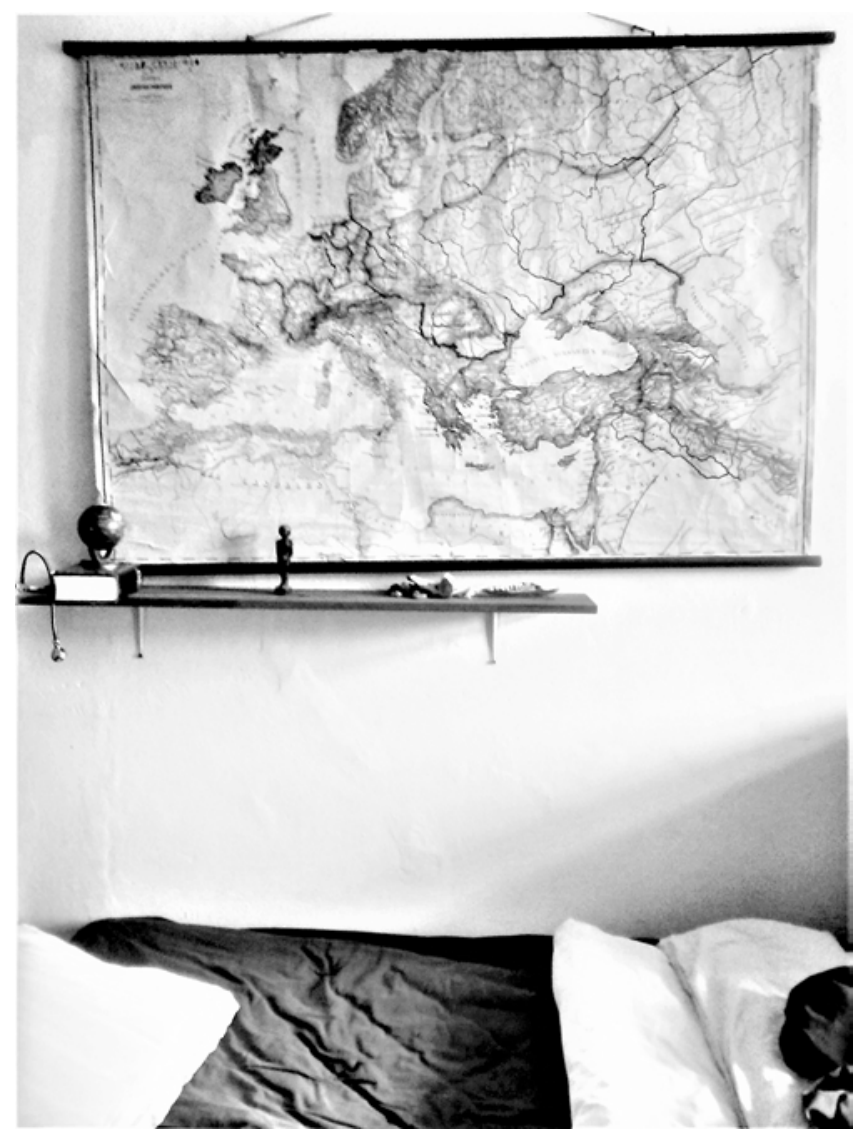

Abb. 46: Als ich diese historische Karte, in einer über Airbnb gebuchten Wohnung, in Berlin-Prenzlauer Berg, sah und ich mich, über zwei Jahre hinweg, in all den, multikulturell geprägten, urbanen Kontexten der Berliner Quartiere und Kieze bewegte, wurde mir mit einem Mal die Tragweite des Ganzen bewusst, was derzeit in den meisten europäischen Cesellschaften geschieht. Wir haben mit ungeheuer weitreichenden Migrations- und Wanderungsbewegungen zu tun. Auch wenn sich Landesgrenzen nur noch selten verändern, so verschieben sich aber doch Bevölkerungen und Kulturen, innerhalb der gegebenen Grenzen. Alles mischt sich auf neue Art und Weise. Zum anderen, wenn wir uns einmal in historische Atlanten vertiefen, ist es, über die vergangenen viertausend Jahre hinweg, fast immer so gewesen. Alte Nationalstaaten mit stabiler demokratischer Ordnung und ausreichend Wirtschaftskraft, allen voran Deutschland, bieten eine solide äußere Struktur, in der sich die Transformation der Weltgesellschaft nun vollziehen kann. Zugleich bleiben, in einigen Bereichen von Europa und der Welt, die national geprägten Cesellschaften und Kulturen vorläufig noch bestehen, nämlich dort, wo eine Abschottung nach außen erfolgt. Anstatt jedoch wehmütig Oswald Spenglers Untergang des Abendlandes zu lesen, sollten wir lieber auf der Welle der Transformation, die jetzt alles zu ergreifen beginnt, surfen. Wir sollten aktiv mitgestaltende Protagonist_innen dieser Transformation sein. 

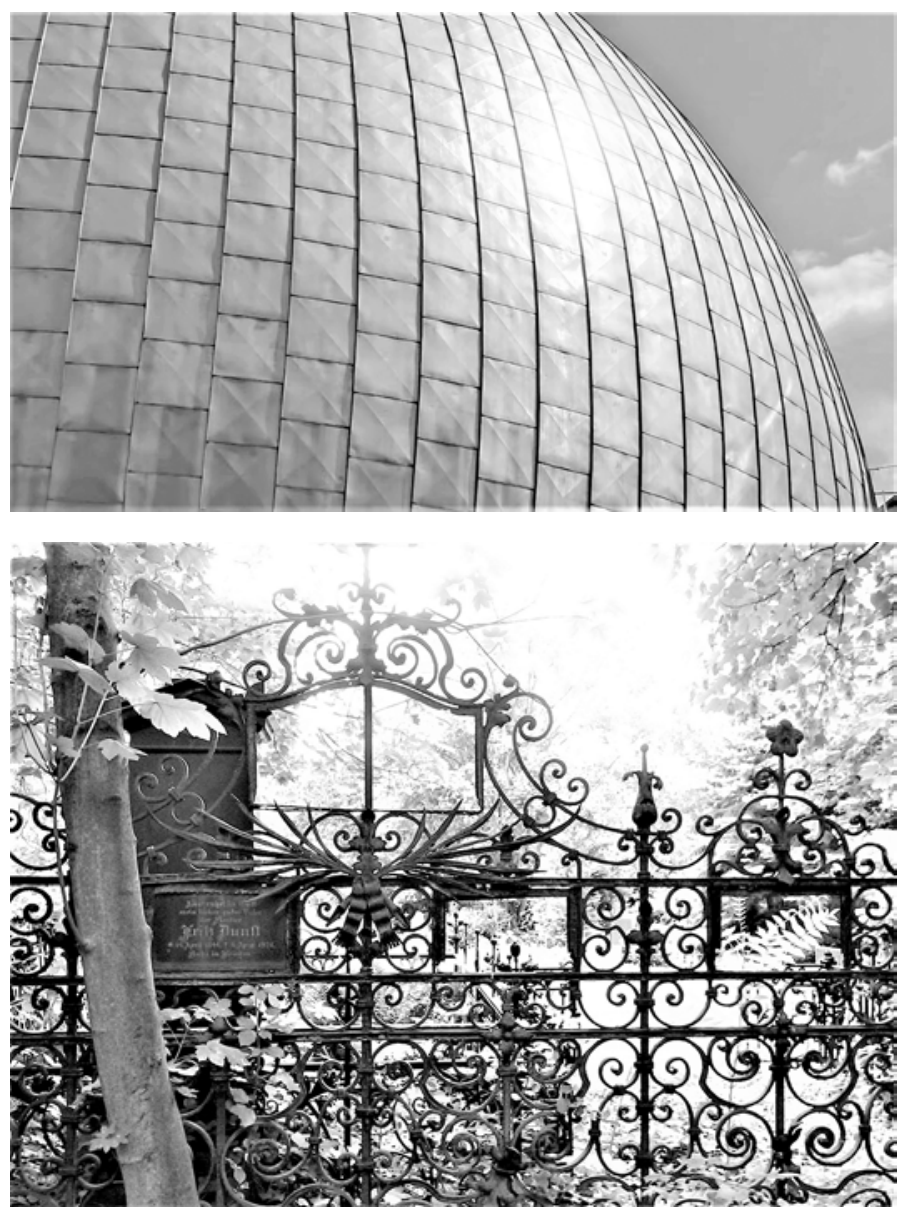

Abb. 47 und 48: Lesen wir in dem Buch Eternal Echoes, das der irische Philosoph John O'Donohue in einer poetischen Sprache verfasst hat, so bekommen wir die Begrenztheit unseres irdischen Daseins vor Augen. Es entsteht das, teils irritierende, Bild eines unendlichen, letztlich unergründlichen, Universums, eines flirrenden Ozeans von leuchtenden Sternen, von dem wir umgeben sind. Im Zeiss-Planetarium, in Berlin-Prenzlauer Berg, wir sehen seine Kuppel auf dem oberen Photo, werden uns, das Alltagsbewusstsein erweiternde, virtuelle Reisen in dieses Universum ermöglicht. Aufs Ganze gesehen, bleibt unsere Existenz auf dem Planeten Erde, der bloß ein verschwindend kleines Cebilde in all den Galaxien aus Sternen darstellt, überaus rätselhaft. Lebenskunst im Sinne von Seneca heißt den Augenblick zu leben und den Tod jederzeit zu antizipieren. Der philosophische, fast nihilistische Sound, wie er aus dem 4500 Jahre alten Buch Kohelet spricht, sensibilisiert uns, für das beständige Entstehen und Vergehen, dem auch wir unterliegen. Das untere Photo zeigt eine verwitterte Grabumzäunung, auf einem Friedhof in Berlin-Friedrichshain, nicht weit vom Techno-Tempel Berghain, ein repräsentatives Bild für all die alten Friedhöfe in der Stadt, die zu einer solchen Kontemplation und geistigen Erweiterung einladen. Auch der Berliner Elektro-Sound antizipiert bereits die universale Ewigkeit. 



\section{Filmanalyse als Kultur- und Gesellschaftsanalyse}

\section{Aspekte emotionaler und sozialer Entwicklung in Filmen}

Filme haben eine enorme Bedeutung für den schulischen Förderschwerpunkt der emotionalen und sozialen Entwicklung. Dies in mehrfacher Hinsicht. Zum einen können sie komplexe, psychosoziale und soziokulturelle, Zusammenhänge ausleuchten oder überhaupt vorstellbar machen, etwa das Aufwachsen in Armut, die verhängnisvolle Wirkung von fehlenden Bildungs- und Arbeitsperspektiven (Tanz in die Freiheit), die Ausbeutung der unteren Sozialschichten in der Klassengesellschaft der Vorkriegszeit (Gosford Park), oder das Aufwachsen mit einem emotional kalten Vater, der dann auch noch auf der falschen Seite steht, in der Zeit des Nationalsozialismus (Deutschstunde). Filme können uns auch bestimmte Entwicklungsphasen der Wissenschaften, etwa der Psychoanalyse und der Philosophie, näher bringen (Lou Andreas-Salomé). Dabei kommt es nicht darauf an, dass die Filme, im strengen Realitätssinn, etwas dokumentieren. Sie können unsere Vorstellungskraft steigern, und unsere Fähigkeit zur Imagination auf höhere Entwicklungsstufen bringen. Gute Filme können dazu beitragen, die eigene Wahrnehmungsfähigkeit zu erweitern, und insgesamt mehr Hintergrund zu gewinnen, um die komplexen Phänomene, mit denen wir in Pädagogik und Gesellschaft, aber auch im Wissenschaftsbetrieb, konfrontiert sind, besser entschlüsseln und tiefergehend verstehen zu können. Filme, die auf literarischen Vorlagen aufgebaut sind, bieten auch den Vorteil, dass breitere Bevölkerungsschichten, die nicht selbst zum Buch greifen würden, Zugang zu diesen Themenbearbeitungen, Inszenierungen und Klärungsprozessen bekommen. Eine andere Möglichkeit besteht darin, Filme unmittelbar mit pädagogischer oder didaktischer Zielsetzung einzusetzen, an der Universität, in der Schule oder in der außerschulischen Bildungsarbeit, wenngleich hier immer sorgfältig abgewogen werden muss, ob ein Film, und der Kontext seiner Bearbeitung, das heißt der institutionelle Rahmen, die Altersstufe, die psychosoziale Situation der Zielgruppe, und die curricularen Vorgaben einer Bildungsinstitution wie der Schule, miteinander kompatibel sind. Teils ist es so, dass Drehbuchautor_innen oder Regisseur_innen Themen aufgegriffen haben, die für unser Arbeitsgebiet, direkt oder indirekt, von Bedeutung sind, etwa die Ausleuchtung der Zusammenhänge zwischen der psychosozialen Entwicklung des einzelnen Menschen und den sozioökonomischen Lebensbedingungen und soziokulturellen Hintergründen (Billy Elliot, Christiane F., Räuber Kneißl, Schlafes Bruder). Auch die kritische Hinterfragung bürgerlicher Milieus, etwa bei Claude Chabrol (Die Blume des Bösen), kann uns Einblicke in das komplizierte Geflecht aus Psyche und soziokulturellem und sozioökonomischem Kontext geben. 
Alfred Hitchcocks filmische Auseinandersetzung mit dem Unbewussten, mit den menschlichen Trieben (Die Vögel), oder die Thematisierung von problematischen, abgespaltenen Persönlichkeitsanteilen (Psycho), vermögen unser Verständnis von menschlichem Verhalten, und den dahinterliegenden Beweggründen, zu erweitern. Ingmar Bergman sensibilisiert in seinen Filmen für das Thema der menschlichen Beziehung. Er zeigt das oftmals vergebliche Ringen um echte Nähe (Schreie und Flüstern). Menschliche Daseinsthemen oder Lebenskonflikte stehen im Mittelpunkt unzähliger Filme, etwa das Thema der Mutter-Sohn-Beziehung (Hühnchen in Essig), die Entfremdung zwischen Eltern und Kindern (Amerikanisches Idyll; Exit Marrakech), die Ambivalenz der Beziehung zwischen zwei Brüdern (Solino), die Verstrickung junger Menschen in teils riskante sexuelle Beziehungen (Die Brautjungfer), der Umgang mit Homosexualität (Maurice; Nicht der Homosexuelle is pervers, sondern die Situation, in der er lebt; Querelle), dies speziell auch im Umfeld der Universität (A Single Man), oder in, von traditionellen Männlichkeitskonzepten, geprägten Umwelten (Freier Fall, Brokeback Mountain). Auch der Universitätscampus selbst, eigentlich als Ort der geistigen Freiheit und persönlichen Entfaltung gedacht, kann voller Untiefen und Gefahren sein (A Single Man, Der menschliche Makel). Bei zugleich hochbegabten Studierenden können sich psychische Besonderheiten und daraus resultierende Probleme zeigen (A Beautiful Mind). Oder es prallen auf dem Universitätscampus verschiedene soziokulturelle Welten, Lebensentwürfe und Denksysteme aufeinander (Empörung). Der filmische Versuch, die Kindheit, die Erinnerung an die eigene Schulzeit, die Familie, das gesellschaftliche Umfeld, das politische Zeitgeschehen und das Erwachen der jugendlichen Sexualität einzufangen, kann dramatisch (Fanny und Alexander) oder melancholisch (Nostalgia) ausfallen, oder eine heitere Grundierung aufweisen, wie in Fellinis Amarcord. In unmittelbar pädagogisch gerahmten Filmen werden Kindheiten erkundet ( $\mathrm{Ta}$ schengeld) oder Sozialisationsverläufe von Kindern oder Jugendlichen rekonstruiert, die mit einem Risiko des Scheiterns belastet sind (Billy Elliot, Der kalte Himmel, Kaspar Hauser, Precious). Francois Truffaut verfolgte, bedingt durch sein eigenes, problembelastetes Aufwachsen, bis hin zu einigen Jahren in besonderen Erziehungsinstitutionen, ein ausgeprägtes pädagogisches Interesse in vielen seiner Werke, nicht nur in dem Film Der Wolfsjunge, sondern auch in seinem gesamten Antoine-Doinel-Zyklus, in dem er die Entwicklung eines jungen Mannes, über viele Jahre hinweg, darstellt, immer in Zusammenarbeit mit ein- und demselben Schauspieler (Sie küssten und sie schlugen ihn, Geraubte Küsse). Auch das destruktive Verhalten von pubertären Jungen (Die Unverschämten), oder die Risiken, die ein junger Wissenschaftler eingeht, wenn er die Distanz zum Forschungsfeld verliert (Ein schönes Mädchen wie ich), machte Truffaut zum Thema. Pier Paolo Pasolini widmete sich in seinen Büchern Ragazzi di Vita und Una Vita Violenta dem Überlebenskampf von Jugendlichen, die in sozial desintegrierten Vorstadtmilieus aufwachsen. Bolognini brachte dieses Material auf die Leinwand (Wir von der Straße). Pasolini selbst war es, der filmisch die verschiedenen Spielarten der Sexualität erkundete (Erotische Geschichten aus 1001 Nacht, Teorema). Andere Filme handeln von einer bestimmten Art der pädagogischen, beratenden oder therapeutischen Beziehungsgestaltung im Verhältnis zu jungen Menschen. Fast immer geht es dabei um Jungen oder junge Männer, gelegentlich aber auch um Mädchen oder junge Frauen, die sich sehr herausfordernd verhalten und eine besondere Art der kommunikativen Resonanz einfordern (Die Kinder des Monsieur Mathieu, Good Will Hunting, Fack ju Göhte). Ein Teil der Filme thematisiert das Ringen einer engagierten Lehrkraft um 
wahre Bildung und echtes Menschsein, um Poesie, Wahrhaftigkeit und menschliche Tiefe (Der Club der toten Dichter) oder die Filme setzen sich, in pädagogischer bzw. psychologischer Perspektive, mit Unterrichtsversuchen an Schulen oder wissenschaftlichen Experimenten auf einem Universitätscampus, sich drehend um die Themen Macht und Unterwerfung, auseinander (Das Experiment, Die Welle, The Stanford Prison Experiment) oder es geht um das Thema der menschlichen Freiheit, in einem totalitären System wie der DDR (Das schweigende Klassenzimmer). Weitere Filme erkunden Bereiche jenseits des kulturell und gesellschaftlich noch Erlaubten, in denen sich Macht, Unterwerfung und Sexualität miteinander vermischen (Die 120 Tage von Sodom) oder es geht um das Ringen zwischen Wahrhaftigkeit und Intrigen bzw. Machtansprüchen (Der Buchladen der Florence Green).

Interessant, im Hinblick auf die Entwicklung der neuen, transformativen Communities, sind auch filmische Auseinandersetzungen mit fragwürdigen Gemeinschaften, in denen Menschen festgehalten, unterdrückt, indoktriniert und missbraucht worden sind (Colonia Dignidad). Wieder andere Filmwerke drehen sich um die, teils konfliktanfälligen, jugendlichen Peerbeziehungen (Einfach zu haben, Lord of the Flies), um das Thema der Vater-Sohn-Beziehung (Billy Elliot, The Pursuit of Happyness), auch die Frage erkundend, wie eine Wiederannäherung zwischen Vater und Sohn, nach einer langen Zeit des Getrenntlebens, gelingen kann (Exit Marrakech). Weitere, pädagogisch relevante, Themen sind das Zurechtfinden von Migrant_innen in der deutschen Gesellschaft (Solino) oder die Rolle als Lehrer_in und die Gefahr der emotionalen oder sexuellen Verstrickung mit Schüler_innen (Half Nelson). Neben Lehrer_innen-Komödien (Der beste Lehrer der Welt, Die Feuerzangenbowle, Frau Müller muss weg!) finden wir ernsthafte Auseinandersetzungen mit den Herausforderungen des Daseins als Lehrer_in (Chalk, Die Klasse, Die Klassenfahrt, October Sky, Stand and Deliver, Teacher, Teacher of the Year), ebenso Thematisierungen des herausfordernden Verhaltens von Schüler_innen (Ferris macht blau), von sozialen Lernprozessen von Schüler_innen (The Breakfast Club), die Auseinandersetzung mit Mobbing in der Schule (The Dirties), oder mit delinquentem Verhalten von Jugendlichen (Die kleine Diebin). Wieder andere Filme versuchen sich an der Verarbeitung des Themas des sexuellen Missbrauchs an Schulen (Die Auserwählten), oder an einer Analyse des Problems, dass auch ein unschuldiger Pädagoge des Missbrauchs verdächtigt werden kann (Die Jagd). Teils geht es um eine dokumentarische Auseinandersetzung mit den Verhaltensweisen von Kindern und Jugendlichen, die im Rahmen Schule kaum noch tragbar erscheinen (Systemsprenger), dann wieder um Lehrer_innen, die mit unkonventionellen Methoden zu, sich herausfordernd verhaltenden, Heranwachsenden durchzudringen versuchen (Dangerous Minds, Die Grundschullehrerin, Die Schüler der Madame Anne, Freedom Writers, Precious, Sein und haben). Das Genre der Teacher Hero Movies lässt sich der Kritik unterwerfen, wenn allzu sehr auf stereotype Charaktere und Handlungen gesetzt wird. Gelegentlich kommt in, pädagogisch motivierten, Filmen der Musik ein besonderer Stellenwert zu (Die Kinder des Monsieur Mathieu, Rhythm Is It!, School of Rock).

Im folgenden werde ich einige ausgewähle Filme, aus den letzten sechzig Jahren, $\mathrm{zu}$ verschiedenen Themen und Problematiken, die mit der emotionalen und sozialen Entwicklung zu tun haben, genauer besprechen und diskutieren. Es dürfte deutlich werden, dass jedes Verhalten, und jede damit verbundene emotionale und soziale Thematik, in einem ganz besonderen, sozialen und kuturellen, auch historischen, Kontext steht. Filmanalyse lässt sich dabei als Kulturanalyse (vgl. Wende und Koch, 
2010) verstehen. Oftmals geht es in den Filmen um die Konstruktion von sozialen Normen und Abweichungen davon. Für das Gebiet der emotionalen und sozialen Entwicklung erscheint die Auseinandersetzung mit Randbereichen der Gesellschaft, mit ausgeschlossenen oder marginalisierten Gruppen besonders interessant, Themen wie sie auch Rainer Werner Fassbinder aufgegriffen hat (Berlin Alexanderplatz, Querelle). Ferner interessiert mich die Art, wie Geschlechterrollen in Szene gesetzt und somit kulturell konstruiert werden, besonders im Hinblick auf die, für das Feld der emotionalen und sozialen Entwicklung besonders relevanten, Masculinities. Das Schreiben von Drehbüchern könnte für die Pädagogik der Zukunft bedeutsam werden, weil Filme für die Heranwachsenden mit hoher Motivation besetzt sind. Ich verweise an dieser Stelle etwa auf die Filmserie Game of Thrones (GoT), die nicht nur bei der Bevölkerung insgesamt, sondern speziell auch bei den Heranwachsenden, auf eine enorme Resonanz gestoßen ist. Exposition, Aufbau der Story, Entwurf der Figuren, Entwicklung der Charaktere, Entfaltung von Szenen und Dialogen, Platzieren des Ganzen auf einem Hintergrund (Backstory), Einfügen von Wendepunkten (Plot Points), Hürden, die Held oder Heldin überwinden müssen, schließlich die ersehnte Auflösung. Diese filmischen Komponenten lassen sich, in vielfacher Weise, fruchtbar machen, etwa bei der Planung und Durchführung von pädagogischen oder kulturellen Projekten, aber auch in der pädagogischen Reflexion von biografischen Ereignissen, im Nachdenken über die eigene Lebensgeschichte. Eine solche biografische Standortbestimmung ist schon deshalb bedeutsam und hilfreich, damit weder die Heranwachsenden, noch wir selbst, unbewusst einem verborgenen Script folgen, das uns, scheinbar unausweichlich, biografisch auferlegt ist. Besser ist, selbst zu gestalten, die Dinge zu verändern und selbst, soweit wie möglich, Regie zu führen.

\section{„Sie küssten und sie schlugen ihn«: Herzlose Erziehungsmethoden}

Francois Truffaut war einer der maßgeblichen Akteure der Nouvelle Vague, einer Erneuerungsbewegung im französischen Film, die Ende der 1950er Jahre einsetzte, gemeinsam mit Claude Chabrol, Jean-Luc Godard und einigen anderen. Es ging dieser Gruppe von Regisseuren darum, neue cineastische Erzähl- und Ausdrucksformen zu entwickeln. Truffaut hat sich in seinen Filmen auch mit pädagogischen Fragen befasst, denn seine eigene Sozialisation verlief alles andere als einfach. Er wurde als Kind in eine Einrichtung für Schwererziehbare eingewiesen. Der Film Sie küssten und sie schlugen ihn, der Originaltitel lautet Les quatre cents coups, kam 1959 in die Kinos. Er wurde nicht nur in Frankreich, sondern auch international, ein Erfolg. Gedreht wurde vor allem in Paris, in der Nähe des Montmartre. Im Zentrum steht der 13-jährige Antoine Doinel, gespielt von Jean-Pierre Léaud. Truffaut sah den Jungen als eine Art Doppelgänger seiner selbst und drehte mit ihm später, als er schon ein junger Mann war, eine Reihe weiterer Filme (Antoine Doinel-Zyklus). Der Film beginnt mit Einblicken in eine rigide und seelenlose Schulpädagogik, die nicht dazu geeignet ist, den Jungen für das Lernen zu begeistern. Der Lehrer spricht überwiegend in einem gereizten Befehlston. Die Schüler, es handelt sich um eine reine Jungenklasse, vertreiben sich die Zeit mit lausbubenhaften Streichen, während der Lehrer Texte an die Tafel schreibt, die die Jungen in ihre Hefte kopieren sollen. Um sich, in Anbetracht dieser öden Unterrichtsatmosphäre, ein wenig zu unterhalten, reichen die Jungen etwa das Bild einer leicht 
bekleideten Frau von Tisch zu Tisch weiter. Als das Bild schließlich bei Antoine ankommt, dreht sich der Lehrer gerade um. Er wird nach vorne zitiert, zurechtgewiesen und muss das Bild abgeben. Zur Strafe muss er, während der Hofpause, in der Klasse bleiben. Verärgert schreibt er einige kritische Reime an die Wand des Klassenzimmers, was neuen Ärger mit sich bringt. Antoine muss Putzsachen holen und die Wand säubern, verpasst dadurch einen Teil des Unterrichts und soll außerdem zu Hause noch eine Strafarbeit verfassen zum Thema Narrenhände beschmutzen Tisch und Wände.

Antoine lebt mit Mutter und Vater in einer kleinen, engen Wohnung. Er schläft auf einer Liege auf dem Flur, direkt vor der Wohnungstür. Die Mutter hat nicht einmal Bettwäsche für ihn gekauft, obwohl der Stiefvater ihr das Geld dafür gegeben hat. Antoine schläft in einem Schlafsack und gibt sich damit zufrieden. Überhaupt ist die Art, wie die Mutter mit dem Jungen umgeht, sehr speziell. Zwar kann sie sich ihrem Sohn auch einmal emotional zuwenden, doch diese Zuwendung wirkt niemals echt. Die Mutter schaut seltsam starr ins Leere, wenn sie mit dem Jungen spricht. Überwiegend spricht sie in einem kühlen Befehlston mit dem Kind. Immerfort verlangt sie etwas von ihm, dass er den Tisch deckt, Einkäufe erledigt, den Müll runterbringt und dann in seinem Zimmer verschwindet, wenn man das Eckchen auf dem Flur, vor der Wohnungstür, wo er schläft, so nennen will. Die Mutter arbeitet als Schreibkraft, bleibt aber oft länger weg, weil sie einen Liebhaber hat, was Antoine, an einem Tag, wo er mit René, einem Schulkameraden, die Schule schwänzt, zufällig herausfindet. Kommt sie dann zurück in die Wohnung, kritisiert sie Antoine, weil er nichts zum Essen eingekauft hat. Es fehlt die konstante mütterliche Wärme bei diesem Familienleben. Sogar der Stiefvater geht noch warmherziger mit dem Jungen um, wenn die beiden sich zusammen Eierkuchen machen. Doch er sagt auch halb scherzhaft, halb ernsthaft: »Du bist ein Nagel zu ihrem Sarg.« In einer anderen Szene sprechen Stiefvater und Mutter recht gefühllos über das Kind: »Was machen wir mit ihm im Sommer? «Stecken wir ihn doch ins Ferienlager."Als Antoine, mit René zusammen, die Schule schwänzt, treiben sich die beiden in einer Spielhalle und auf einem Jahrmarkt herum. Sicherlich von hoher Symbolkraft ist die Szene, in der Antoine eine Art Karussell, einen sich drehenden Zylinder, besteigt. Als dieser immer schneller rotiert, wird der Junge mit dem Rücken an die Außenwand gedrückt und verliert gar den Kontakt zum Boden. Schließlich hat er gar keine Orientierung mehr. Renés Vater ist ein wohlhabender Unternehmer. Hier scheint es eher eine Art Wohlstandsverwahrlosung zu sein, die diesen Jungen aus der Spur geraten lässt. Renés Familie lebt in einer geräumigen, großbürgerlichen Wohnung, etwas dekadent und nachlässig das Ganze und mit vermutlich zu vielen, unstrukturierten Freiräumen. Die Jungen spielen auf Renés Bett Backgammon, rauchen, trinken Wein. Der Vater, er ist beschäftigt mit Pferderennen, interveniert nur zum Schein, in Anbetracht der Rauchwolke im Zimmer seines Sohnes. Die Mutter »kokst«, sagt René. Auf diese Weise baut Truffaut einen scharfen Kontrast zwischen den sozialen Milieus auf. Aber es gibt auch etwas Gemeinsames: Beiden Jungen fehlt es an familiärem Halt, wenn auch auf unterschiedliche Art und Weise, und beide sehen in der wenig motivierenden, ja rigiden Schulpädagogik, die ihnen zwangsweise zukommt, keinen Sinn. Beide Jungen bedienen sich heimlich aus den Bargeldverstecken der Eltern. Beide halten es nicht so genau mit der Wahrheit.

Das Unheil nimmt seinen Lauf. Wegen der versäumten Schultage müssen Entschuldigungen gefälscht werden. Einmal sagt Antoine, er habe nicht kommen können, weil seine Mutter gestorben sei. Der Lehrer, erstmalig eine emotionale Reaktion, 
außer Ärger freilich, zeigend, lässt ihn zunächst gewähren, doch das Ganze fliegt auf. Der Stiefvater ohrfeigt Antoine vor der gesamten Klasse. Die Mutter kommt spät nachts zurück. Der Stiefvater macht ihr eine Szene und verdächtigt sie, dass sie eine Affäre hat. Die beiden schreien laut in der Wohnung herum. Antoine beschließt von zu Hause wegzulaufen. René bringt ihn zunächst in einer Druckerei unter, die zum Unternehmen seines Vaters gehört. Bis die Maschinen still stehen, soll er spazieren gehen. Er streunt durch das nächtliche Paris. Morgens stiehlt er eine Flasche Milch vor einem Café, ein trauriges Bild. Dennoch geht er nach dieser schlaflosen Nacht zur Schule, wo ihn die Mutter, nach dem Unterricht, in Empfang nimmt. Nun kümmert sie sich, badet ihn, reibt ihn ab, steckt ihn ins Bett. Sie versucht auch schulische Lernmotivation aufzubauen, indem sie ihm 1000 Francs bietet, wenn sein nächster Aufsatz unter den ersten fünfen sein sollte. Auch sagt sie, dass sie und ihr Partner es heute büßen müssten, dass sie keinen höherwertigen Schulabschluss hätten. Doch dabei bleibt es auch. Es gibt nicht das durchgängige Unterstützen einer Bildungslaufbahn. Hausaufgaben macht der Junge am Essenstisch. Soll gegessen werden, müssen die Schulhefte stets schnell verschwinden. Ist Antoine allein in der Wohnung, liest er Romane von Balzac und raucht. Er verehrt Balzac so sehr, dass er ihm eine Art Schrein gebaut hat. Einmal zündet er eine Kerze an in dem Kasten und hängt ein Stück Stoff davor, während er mit Mutter und Stiefvater am Tisch sitzt, um zu essen. Es gibt beinahe einen Wohnungsbrand.

Antoine bekommt beim nächsten Aufsatz die schlechteste Note der ganzen Klasse, weil ihm der Lehrer unterstellt, von Balzac abgeschrieben zu haben. Der geistig eng gestrickte, misstrauische Schulmeister sieht bedauerlicherweise nicht die Möglichkeit, die Balzac-Begeisterung des Jungen pädagogisch fruchtbar zu machen. Gemeinsam mit René stiehlt Antoine eine Schreibmaschine aus dem Büro des Vaters, um diese $\mathrm{zu}$ Geld zu machen, was aber misslingt, so dass er sie wieder zurückbringt, wobei er allerdings erwischt wird. Nun bringt ihn der Stiefvater zur Polizei und will ihn, einvernehmlich mit der Mutter, in ein Erziehungsheim geben, was dann auch geschieht. Der Junge wird erkennungsdienstlich behandelt, wie ein Verbrecher. Gemeinsam mit Kriminellen und Prostituierten, die nachts irgendwo in Paris aufgegriffen worden sind, wird er in einen Käfig gesperrt und, in einem vergitterten Wagen, durch die Stadt gefahren. Die Erziehungsmethoden in der Institution, wo er sich nun befindet, sind paramilitärisch und herzlos. Weil Antoine, vor dem offiziellen Beginn des Essens, sich ein wenig von seinem Stück Brot genommen hat, wird er vor dem gesamten Speisesaal geohrfeigt. Die Mutter kommt noch einmal zu Besuch und sagt sich kühl von ihrem Sohn los. Sie habe ihn ohnehin nie gewollt, sagt er später zur Fürsorgerin. Ein anderer Junge klärt Antoine über die Kontrollpraktiken der sozialen Institutionen auf und rät ihm, bei der Fürsorgerin vorsichtig zu sein, denn alles was er sage, lande nachher in seiner Akte. Antoine will wissen, was eine Akte sei. »Wo alles über dich drinsteht, was Doktor und Richter denken«, erwidert der andere Junge. Dieser hatte es geschafft in seine Akte Einblick zu bekommen: »Ich gehöre zu der Gattung frühreifer Psychopathen mit perversen Tendenzen.« René will ihn besuchen, wird aber abgewiesen. Antoine entflieht aus der Besserungsanstalt. Er läuft und läuft, bis ans Meer. Er wollte immer ans Meer. Der Film übt Kritik, an einem überkommenen Schulwesen, an überholten, inhumanen Erziehungspraktiken, an den geringen Aufstiegschancen der unteren Sozialschichten, an den Kontroll- und Stigmatisierungspraktiken und den pathologisierenden Etikettierungen der sozialen Institutionen. Das großbürgerliche Milieu 
hat dagegen mehr Handlungsspielraum. Renés Eltern geben ihren Sohn schließlich nicht in die Hände der staatlichen Fürsorge. Sie haben sicher ihre Probleme mit dem Jungen, aber sie verfügen doch über einen weiteren geistigen Horizont, und auch über die finanziellen Mittel, um ihren Sohn, selbst wenn er vorübergehend aus der Spur gerät, auf irgendeine andere Art gesellschaftlich wieder einzubinden, oder immerhin aufzufangen und über Wasser zu halten. Truffaut hat später in Interviews gesagt, dass er in diesem Film eigene schulische und familiäre Erfahrungen verarbeitet hat. Alles sei authentisch, und wenn er irgendetwas von dem Dargestellten nicht selbst erlebt habe, dann hätten es Freunde oder Bekannte von ihm erlebt.

\section{"Christiane F.»: Jugend in Berlins Schattenwelten}

Die männlichen Jugendlichen trugen Hosen mit weitem Schlag, Schuhe mit erhöhten, breiten Absätzen und langes Haar. Die 7oer Jahre propagierten, in der gegenkulturellen Welt des Pop und Rock, androgyne Männertypen, etwa verkörpert durch David Bowie, wie wir ihn in dem Film Wir Kinder vom Bahnhof Zoo, in einem Konzertmitschnitt in Berlin, sehen können. Doch so innovativ die späten 70er Jahre, in ihrem experimentierfreudigen Spiel mit Identitäten, und in der Abkehr von den sozialen und kulturellen Traditionen der alten Bundesrepublik, auch waren, so groß waren auch die sozialen Spannungsfelder und die Schwierigkeiten, die Kinder und Jugendliche mit problematischen soziokulturellen Hintergründen zu bewältigen hatten. Hat dieser, 1981 in die Kinos gekommene, Film noch eine aktuelle Bedeutung? Können wir auch für die Gegenwart noch etwas daraus lernen? Ja, denn dieser Film, der letztlich auf den autobiografischen Aufzeichnungen einer Jugendlichen mit dem Pseudonym Christiane F. basiert, lässt sich, im Sinne des Cultural Mapping, als eine sozialkritische, kulturgeografische Studie betrachten, die Ausschnitte aus der West-Berliner Soziokultur der späten 7oer Jahr einfängt, genauer gesagt, aus den Teilen der West-Berliner Bevölkerung, die eher am Rande der bürgerlichen Gesellschaft, in den Trabantenstädten, wie etwa in Gropiusstadt, lebte. Christiane ist zu Filmbeginn ganze 13 Jahre alt, fast noch ein Kind, aber eben auch eine frühreife Jugendliche. Wie sie dann im Laufe des Films morgens, etwas blass, über der Geburtstagstorte mit den 14 Kerzen sitzt, und diese auspustet, neben ihr die Freundin Babs, die schon seit einiger Zeit auf dem Kinderstrich am Bahnhof Zoo anschaffen geht, um ihren Bedarf an Drogen finanzieren zu können, ist schon dramatisch zu nennen. Sieben Freier in einer Stunde hat Babs an einem Tag geschafft. Sie verfügt dadurch über reichlich Geld. Später wird sie, auf der Titelseite der Berliner Zeitung, als erste Drogentote der Stadt abgelichtet werden. Christiane gerät nun, nach und nach, immer weiter in diesen Sumpf aus Prostitution und Drogen. Noch ist Heroin das große Mysterium. Zunächst konsumiert sie nur leichtere Drogen, zumeist in einer bestimmten Diskothek, die das Zentrum dieser Szene darstellt. Doch sie will mit ihrem Freund Detlef »auf einer Höhe sein", wie sie es nennt. Das Mädchen schlägt alle Warnungen der Peers vor Heroin in den Wind. "Findick echt Scheiße wat de da machst«, sagt ihr der Bekannte, als sie sich auf der Toilette den ersten Schuss setzen will, aber die Technik des Spritzens noch nicht richtig beherrscht. Am Ende hilft er ihr doch. Das ist etwa in der Mitte des Films. Christiane verteilt ihre Butterbrote am Bahnhof Zoo an die Jungs, die dort ihren Körper gegen Geld an Männer verkaufen, darunter Detlef, ihr Freund. Die Kamera zeigt S-Bahnen 
und U-Bahnen, die sich durch das, abweisend wirkende, graue Meer aus Hochhäusern bewegen, dunkle Tunnel und U-Bahn-Schächte, dazu psychedelischer Sound. Von der Schule sieht man während des ganzen Films nichts.

Der Film behandelt die Schulwelt nicht als relevanten Ort, von dem positive Veränderungen oder Hilfestellungen für die in Krisen befindlichen Jugendlichen ausgehen könnten. Es wird impliziert, dass Schule und Lehrkräfte nicht wissen, wie es um diese Jugendlichen in Krisen steht, und wenn sie es wüssten, ohnehin nichts daran ändern könnten. Die Erwachsenen, etwa Christianes getrennt lebende Eltern, sind zu sehr mit sich selbst beschäftigt, als dass sie wirklich Verantwortung für ihre Kinder übernehmen und die Signale in deren Verhalten entschlüsseln könnten. Man möchte die Mutter, bei der sie ja doch immerhin lebt, schütteln und ihr zurufen: Schau doch hin! Und dem Vater, der sich gar nicht kümmert: Übernimm Verantwortung! Christiane leiht sich die High Heels der Mutter aus, um angeblich bei einer Freundin zu übernachten. In Wahrheit tauchen die Teenager ins Nachtleben Berlins, in Peer- und Drogenwelten, ab. Die Zwangslage, über Prostitution an Geld kommen zu müssen, wird schließlich zum alles beherrschenden Thema. Die Angst auf Turkey zu kommen, der Druck Geld auftreiben zu müssen. Die Sorge den anderen durch Sex mit Freiern emotional zu verletzen. Christiane peitscht Stottermax aus, einen Mann mit masochistischem Verhaltensmuster, gegen Geld, in dessen Wohnung. Im Hintergrund flattern Vögel in einem Käfig. Ein Bild, das auf den Zusammenhang von sexuellen Obsessionen, Gefangensein in den eigenen Lebensverhältnissen und sexuell-erotischen Erlebnismustern verweist. Am Ende sind sie alle gefangen in ihren Lebenswelten, Mustern und Zwängen, egal ob Stricher oder Freier. Es gibt keine Freiheit, wie auch die Vögel in der Szene zwar wild flattern, in ihrem Käfig, aber niemals frei sein werden. Dann Atzes Tod. An einer Wand in seiner Wohnung steht mit der Hand gepinselt: Can you dream about anything? Sehnsucht nach einem anderen Leben? Doch es gibt im Leben dieser Jugendlichen niemanden, der ihnen den Weg dorthin weisen könnte, der ihnen helfen würde, es am besten selbst herauszufinden, und sie dabei konsequent zu ermutigen. Detlef und Christiane fliehen bestürzt aus Atzes Wohnung. Erneut das Bild der Vögel im Käfig, in Atzes Wohnung. Christiane gibt ihnen Wasser, nimmt den Käfig mit und lässt die Tiere später, irgendwo in der Stadt, stehen. Der natürliche Kreislauf des Sorgens und Versorgens funktioniert nicht mehr. Wer nie verlässlich gehalten wurde, kann einem anderen auch keinen verlässlichen Halt geben, so scheint die Botschaft des Films zu sein.

Wenngleich es innerhalb der Peerwelt einige prosoziale, wenn auch ambivalente, Verhaltensmuster zu geben scheint: »Den nächsten Freier mache ich nur für Dich.» Die Szene, in der Christiane, die 50 D-Mark, die sie von der Mutter zum 14. Geburtstag bekommen hat, mit zum Bahnhof Zoo nimmt, um dann Drogen, für sich und die Freunde, davon zu kaufen, schmerzt besonders, wenn man selbst Kinder großgezogen hat und sich sowas vorstellt: »Hier, meine Mutter hat gemeint, ich soll mir was Schönes davon kaufen!«Warum braucht das Mädchen soviel Bestätigung und Halt seitens der Peers? Die Peers erscheinen einerseits als überlebenswichtige neue Familie, doch die moralische und praktische Unterstützung, die von ihnen ausgeht, beinhaltet hohe Risiken. In der Drogenszene an Rang zu gewinnen bedeutet zugleich, sich und das eigene Leben großen Gefahren auszusetzen. Später gibt sich Christiane einen Schuss, im Bad der mütterlichen Wohnung, morgens vor der Schule. Sie liegt nahezu bewusstlos auf dem Boden, vor der verriegelten Tür. »Was machst Du so lange im Bad?«, will die Mutter nervös wissen. Sie muss zur Arbeit. Christiane schafft es noch, die Tür zu 
öffnen. Endlich begreift die Mutter, hält das Kindergesicht zwischen ihren Händen, und doch hält sie es nicht mit der nötigen Konsequenz. Immerhin drängt die Mutter auf einen Entzug, zusammen mit Detlef, in der eigenen Wohnung. Zusammengekauert liegen die Jugendlichen im Bett, sie bibbern, zittern, schwitzen, von Schmerzen geplagt, und betäuben sich mit Wein und Tabletten. Detlef reißt vor lauter Verzweiflung die Tapeten von den Wänden. Schicht für Schicht legt er frei. Ein suggestives Bild, das auch zu biografischen Reflexionen, zur Analyse des Ineinanders von soziokulturellem Umfeld, Lebensthemen und Daseinsstrategien einlädt. Sie haben es erst einmal geschafft, vom Heroin wegzukommen, doch werden sie schon bald rückfällig. Detlef zieht zu einem Freier. Einmal nimmt er Christiane dorthin mit. Doch sie erträgt es nicht, wenn er im Nebenzimmer mit dem Mann schläft. Sie geht nach nebenan und konfrontiert ihn. "Was soll ich denn machen?« ruft er verzweifelt, umklammert von dem Mann. Schließlich schafft die Mutter ihre Tochter auf ein Dorf, weit weg von Berlin. Hier gelingt es der Jugendlichen ein neues Leben zu beginnen. Und in der Gegenwart? Jugendliche haben mehr Informationen über die Risiken solcher Praktiken. Der städtische Raum wird inzwischen besser überwacht. Straßensozialarbeit und Schulsystem sind besser vorbereitet, doch durch Digitalisierung und Globalisierung hat sich vieles in schwer zugängliche Bereiche verschoben. Die Art der Drogen, und die kulturellen Kontexte ihres Konsums, haben sich verändert. Die seelischen Probleme der Jugendlichen dürften denen jener Zeit jedoch teils vergleichbar sein.

\section{»Billy Elliot«: Männlichkeitskonzepte und soziale Klasse}

Wer an Schulen, im Schwerpunkt der emotionalen und sozialen Entwicklung, gearbeitet und vor allem Jungen unterrichtet hat, weiß wie fragil männliche Identitäten sein können, und wie heikel es für einen Jungen oder für einen jungen Mann sein kann, wenn er etwa gerne tanzt, wenn er sich also zu musisch-künstlerischen Dingen hingezogen fühlt, die, von großen Teilen der Gesellschaft, eher Mädchen und Frauen oder aber, durchaus klischeehaft, homosexuellen Männern, zugerechnet werden. Stephen Daldrys, im Jahr 2000 in die Kinos gekommener, auf einem Drehbuch von Lee Hall basierender, Film Billy Elliot: I Will Dance setzt sich mit dieser Thematik auseinander. Billy bekommt Boxunterricht und wird von seinem Vater angefeuert, auf diesem Gebiet Fortschritte zu machen. Mit seinen Handschuhen und dem Helm im Ring wirkt er jedoch verloren und unglücklich. Er verhält sich auch nicht aggressiv und offensiv genug, um in dieser, traditionell männlichen, sehr rauen und hemdsärmeligen, Welt $\mathrm{zu}$ bestehen, während in einem anderen Teil der Sporthalle die Mädchen Ballett üben. Irgendwann zieht es Billy in die Nähe der dort, unter der Regie von Mrs. Wilkinson, zu Klaviermusik übenden Gruppe. Ein bestechendes Bild, wie der Körper des Jungen, auf natürliche Weise, in die Formation von Mädchen, und die dort praktizierten Bewegungsabläufe, hineinfindet, ohne dass dies durch irgendeine verbale Kommunikation vorbereitet worden wäre. Die Tanzlehrerin integriert ihn, ohne dies sonderlich zu thematisieren. Sie leiht ihm schließlich ein Paar Ballettschuhe, die er mit nach Hause nimmt, und unter seinem Bett versteckt. Aus dem Büchereibus stiehlt Billy ein Werk über die Grundlagen des Ballett, nachdem die Bibliothekarin ihn schroff zurechtgewiesen hat, dass er das Buch, in dem er zuvor geblättert hatte, sowieso nicht ausleihen 
könne. Billy hat keinen leichten Weg vor sich. Der, an traditionellen Männlichkeitskonzepten der Arbeiterklasse orientierte, Vater verliert komplett die Selbstbeherrschung, als er bemerkt, dass Billy heimlich an der Ballettklasse teilnimmt, und dass er nicht mehr zum Boxtraining geht. Er übt einen enormen Druck auf seinen jüngsten Sohn aus, weiter zu boxen und verbietet ihm rigoros das Tanzen. Die Tanzlehrerin glaubt jedoch weiter an Billy. Der irgendwo in Durham, Nordengland, liegende Ort ist geprägt durch den Bergbau. Wir sehen einfache, eng aneinander gebaute, Reihenhäuser der working class. Es sind die wirtschaftlich harten Jahren der Thatcher-Zeit, Mitte der 8oer Jahre. Die Bergleute streiken, auch um den Preis, dass sie kaum noch Geld haben, um zu leben. Es sind stolze Männer, die um ihre Selbstachtung kämpfen. Der Daseinskampf hat sie hart gemacht. Diese Haltung kommt im Boxsport, und im Konsum von Alkohol, zum Ausdruck. Billys älterer Bruder ist, genau wie der Vater, in dieser Welt verhaftet. Die einzige Fluchtmöglichkeit, die der Bruder hat, ist die Rockmusik. Sein ganzer Stolz ist der Plattenspieler neben seinem Bett. Unter seinem Kopfhörer kann er, dann und wann, abtauchen. Zugleich neigt er zu hochaggressiven und militanten Verhaltensweisen, im Kontext des Bergarbeiterstreiks, in der Auseinandersetzung mit sog. Streikbrechern, ebenso gegenüber seinem jüngeren Bruder.

Billys Mutter ist schon vor Jahren gestorben. Das Klavier erinnert an die Mutter. Darauf steht ein Familienbild, gemeinsam mit der Mutter, als sie noch lebte. Alles Künstlerische wird, in dieser sozialen Welt, als weiblich konstruiert. Auch die bereits ein wenig verwirrte, mit im Haushalt lebende, Großmutter, wollte früher einmal Tänzerin werden, wie sie sagt, fand jedoch weder Gelegenheit, noch Unterstützung, einen solchen künstlerischen Weg zu gehen. Billy kümmert sich liebevoll um sie. Der Vater erträgt es nicht, wenn Billy am Klavier sitzt, und versuchsweise einige Töne anschlägt. Klavierunterricht bekommt der Junge nicht. Es wäre auch kein Geld dafür vorhanden. Mitten im Winter, als die finanziellen Mittel der Familie, durch den Streik, immer enger werden, zerschlägt der Vater das Klavier, um damit zu heizen. Drastischer hätte es gar nicht kommen können. Billy bekommt unterdessen Einzelunterricht im Tanzen von Mrs. Wilkinson, ohne dass er dafür zahlen muss, weil die Ballettlehrerin sein Talent erkannt hat. Der erste Versuch ihn zu einem Vortanzen zu bringen, sie will ihn persönlich hinfahren, scheitert am Widerstand von Vater und Bruder, denn Billy kommt nicht zum vereinbarten Treffpunkt. Die Lehrerin setzt sich mutig mit den beiden auseinander. Es kommt zu sehr dramatischen und aggressiven Szenen. In der Neujahrsnacht übt Billy gemeinsam mit Michael einige Ballettschritte, in der eiskalten Turnhalle. Der Freund hat sich ein Ballettröckchen angezogen. Bei früherer Gelegenheit sehen wir, wie Michael in ein Mädchenkleid geschlüpft ist, wie er sich und Billy dann spielerisch ein wenig Lippenstift aufträgt. Einer der Männer hat das Licht in der Turnhalle brennen sehen. Der Vater wird verständigt, sich die Tanzübungen seines Sohnes, mit Michael im Ballettröckchen, anzusehen. Der aggressiven Drohkulisse des, entsetzt in die Turnhalle drängenden, Vaters setzt Billy nun einen Tanz des Widerstands entgegen. Vielleicht ist das der dramaturgische Höhepunkt des Films und zugleich der entscheidende Wendepunkt. Endlich bewegt sich etwas im Vater, auch weil ihm Mrs. Wilkinson klar gemacht hat, dass Billy durch das Tanzen den Weg in eine andere Zukunft finden kann, jenseits der abhängigen Lohnarbeit im Bergbau. Um das Geld für die Fahrt nach London aufzutreiben, ist der Vater, wo diese lang ersehnte Einstellungsänderung endlich erreicht ist, nun sogar dazu bereit, auf die Seite der Streikbrecher zu wechseln. Wir sehen nun einen emotional bewegten, regelrecht 
zerrissenen Mann. Doch der ältere Sohn kann sich nicht damit abfinden, den Vater auf der Seite der Streikbrecher zu sehen. Er und seine Kollegen von der Gewerkschaft suchen eine Alternative. Es wird schließlich Geld gesammelt und Schmuck verkauft, damit der Vater mit Billy nach London fahren und sich im Erfolgsfall, sollte er die Aufnahme an der nationalen Ballettschule bestehen, dort einschreiben kann. Es ist schön zu sehen, wie Billys Zukunft jetzt zum Projekt der erweiterten Community wird und wie auch die anderen Männer den Vater, materiell wie moralisch, unterstützten, jetzt den einzig richtigen Weg zu gehen.

Die Jury erkennt Billys Talent und ahnt auch seinen Konflikt, die soziale Hintergrundproblematik, die Tiefenschichten seines unbeherrschten Auftretens, als er einen anderen Jungen, in der Umkleidekabine, geohrfeigt hat, nur weil ihm dieser gut zusprechen will, in einer Situation, unmittelbar nach dem Vortanzen und dem Interview, wo Billy unter emotionaler, seelischer Hochspannung stand, und er diese ungewohnte Art von positiver Zuwendung fehlinterpretiert haben dürfte. Die Ballettlehrerin hatte auch ein Empfehlungsschreiben an die Jury gerichtet und darin etwas zu Billys sozialen Hintergründen gesagt. Nun steht der Vater ganz hinter seinem Sohn, weil er die Chance erkannt hat, die in der Verwirklichung seines Traumes liegt. Jetzt ist er derjenige, der der Jury sagt, dass Billy jeden Abend tanzt. Wir sahen den Jungen zuvor, tanzend, auf Straßen, Plätzen, im Haus, wo auch immer, bis dass er irgendwann, von einer rostigen Wand aus Metallplatten, ein intensives Filmbild, gestoppt wird, während Billy selbst, durch sein wortkarges Auftreten, drauf und dran ist, seine Chancen vor der Jury zu verspielen. Eine Frau aus dem Auswahlgremium ruft ihn noch einmal zurück. Sie will wissen, wie er sich fühlt, wenn er tanzt. Zögernd kommt es aus ihm heraus, dass er dann in einer anderen Welt ist, dass es sich anfühlt wie Elektrizität ... Für die Ohrfeige in der Umkleide wird er zwar unmittelbar gerügt, doch Billy wird schließlich von der Londoner Ballettschule aufgenommen. Die Familie sitzt, voller Spannung, um den Brief, als dieser endlich kommt. Vater und Sohn fahren im Aufzug in die Grube, als der Streik schließlich beendet wird. Vorbei die Straßenschlachten mit der Polizei, die Attacken auf die Streikbrecher. Das Gitter des Grubenaufzugs rastet vor ihnen ein. Es ist ein regelrechter Käfig, in dem sie, dicht gedrängt mit den anderen Minenarbeitern, in die Tiefe fahren. Ihre Lebensbahn ist damit endgültig besiegelt. Am Ende fahren Vater und Bruder aber doch stolz nach London, und sehen den nun erwachsenen Billy auf der Bühne. Im Zuschauerraum treffen sie auf Michael. Dieser trägt femininen Kopfschmuck und hat einen farbigem Freund an seiner Seite. Billy hatte ihm zum Abschied einen Kuss auf die Wange gedrückt, damals. Über Billys Sexualität verliert der Film klugerweise kein Wort. Billy ging weder auf die erotisch-sexuellen Einladungen der Tochter der Ballettlehrerin ein, noch ging er weiter auf den, definitiv homosexuellen, Michael zu. So gelingt die Betrachtung seines künstlerischen und beruflichen Weges, ohne ihn dabei, womöglich klischeehaft, sexuell festzulegen. Das Thema der männlichen Homosexualität wird, in einer Art filmischem Kunstgriff, auf eine der wichtigsten Nebenfiguren, nämlich auf Michael, verlagert. Dieser Film beinhaltet sicherlich enorme Chancen. Er bietet eine Fülle von Gesprächsanlässen, für die Pädagogik, wenn es um soziales und emotionales Lernen, insbesondere von Jungen, in der Umkehrung aber auch von Mädchen, geht. Der Film Billy Elliot zeigt auf eindringliche Weise den engen Zusammenhang von Bildung und Gesellschaft, von sozialem Milieu, sozioökonomischem Hintergrund und politischen Rahmenbedingungen. 


\section{„Räuber Kneiß|«: Gefangen im sozialen Herkunftsmilieu}

Kann ein Film zum Leben des bayrischen Räubers Mathias Kneißl von pädagogischer Relevanz sein? Ja, er kann, und die erneute Verfilmung des historischen Stoffes von Marcus H. Rosenmüller, auf der Basis des Drehbuchs von Christian Lerch, stellt die Bedeutung von Filmproduktionen, für die Bildungs- und Sozialwissenschaften, erneut unter Beweis. Natürlich muss klar sein, dass ein solcher Film auslegt und variiert. Er kann und will niemals eine wissenschaftliche Dokumentation der historischen Ereignisse sein. Doch ein solcher Film beflügelt die Vorstellungskraft, wie die Dinge sich zugetragen haben könnten. Was ist die Story? Mathias Kneißl wurde 1875 in eine kriminelle, in einer Mühle im Dachauer Hinterland lebende, Familie hineingeboren. Kneißl war von 1893 bis 1899 inhaftiert. Er wurde 1902 auf der Guillotine hingerichtet. Der Film beginnt mit einer Szene, wo Pfarrer und Gendarm auf den, verlassen wirkenden, elterlichen Hof kommen. Einer von ihnen ruft: WWenn ihr nicht in die Schule geht, dann werdet ihr eingesperrt!« Einer der Jungen schießt mit einer Steinschleuder auf den Gendarmen. Der Pfarrer rät zum Rückzug. Der Vater bringt ein Gewehr mit nach Hause und drückt es seinen Jungs in die Hand. Diese üben sogleich das Schießen, für die gemeinsame Wilderei. Nachdem Vater und Mutter die Kultgegenstände aus einer nahegelegenen Kirche geraubt haben, wird der Vater, mit Messkelch und Kreuz im Rucksack, von der Polizei gestellt. Er kommt bei seinem Fluchtversuch, durch Sturz in den Mühlengraben und zusätzliche Hiebe der Gendarmen, zu Tode. Die Söhne schauen entsetzt aus dem Fenster zu. Die Mutter wird für einige Monate wegen Hehlerei eingesperrt. Die Jungen treiben die Tante vom Hof, die sich um sie kümmern wollte. Die vier Kinder sind sich nun selbst überlassen. Sie gehen auf die Jagd und stehlen Hühner, einmal in Frauenkleidern. Doch werden sie vom Bauern und dessen Söhnen erwischt und zur Abschreckung auf den Misthaufen geworfen und mit dem Ruf Saububen davongejagt. Die Bauern regeln das unter sich, so die Botschaft, ohne die Gendarmerie, der man nicht über den Weg traut. Mathias betätigt sich als Metzger. Wir sehen ihn mit blutverschmierten Armen. Als die Gendarmen schließlich kommen, um die beiden Jungen und die zwei Mädchen in die Hände der staatlichen Fürsorge zu geben, verstecken sich diese auf dem Dachboden. Bruder Alois schießt auf die Polizisten, als diese nach oben kommen und verletzt sie schwer. Die beiden Brüder entkommen zunächst, verstecken ihre Waffen im Wald, werden dann doch gefasst und ins Gefängnis gebracht. Alois bekommt 15 Jahre, Mathias sechs Jahre Haft. Der Bruder stirbt während der Haftzeit, an Tuberkulose. Mathias findet nach seiner Entlassung Arbeit bei einem Schreiner. Er will nun ein anständiges Leben führen und, gemeinsam mit seiner geliebten Cousine Mathilde, nach Amerika auswandern. Er verliert die Arbeit wieder, teils weil er so aufbrausend ist und sich auch sehr provokativ verhält, teils weil, wegen seiner Vergangenheit, gegen ihn intrigiert wird, insbesondere von dem damals durch Schüsse verletzten Gendarmen.

Weil ihm niemand mehr Arbeit gibt und auch keine sonstige soziale Sicherung existiert, lässt er sich erneut auf Raubzüge ein. Bei einem Festnahmeversuch erschießt er zwei Polizisten. Er wird nun gesucht, versteckt sich in einer alten Scheune, draußen in der Landschaft. Über seinen ehemaligen Schreinerkollegen gelingt es, Mathilde zu ihm zu bringen. Die Tante ist es, die den Gendarmen seinen Aufenthaltsort verrät, um an die ausgesetzte Belohnung von 1000 Mark zu kommen. In Wahrheit, wenn wir den historischen Quellen folgen, war es jedoch die Cousine selbst, die ihn verriet. Der Film 
weicht hier ein wenig vom überlieferten historischen Geschehen ab. Mathias Kneißl hat die Sympathie der einfachen Leute, weil er keck der verhassten Obrigkeit auf der Nase herumtanzt, so dass sie ihn zwar einerseits fürchten, ihm aber andererseits helfen, sich zu verstecken. 150 Polizisten belagern schließlich die Scheune, in der er sich, oben im Heu, versteckt hält, und schießen. Mathias wird getroffen und ist schwer verletzt. Schließlich wird er überrumpelt, abtransportiert, medizinisch versorgt und operiert. Man lässt ihn überleben, um ihm dann den Prozess zu machen. Vorher sehen wir eine emotionale Szene in der Gefängniszelle, mit seiner Mutter, nachdem die Nachricht gekommen ist, dass sein Gnadengesuch abgelehnt worden ist. Räuber Kneißl ist ein Film über die Entstehung von dissozialen und delinquenten Verhaltensweisen, aber auch über den Zusammenhang von Familie, sozialer Schicht, fehlenden Aufstiegschancen und vor allem über die Unmöglichkeit, aus dem Bodensatz der Gesellschaft herauszukommen. Die sozialen Systeme dieser Zeit boten noch keine Resozialisierungsmaßnahmen, keine sozialpädagogische Begleitung, keine geeignete Schulpädagogik. Nach innen hält diese Familie fest zusammen, das heißt die emotionalen Bindungen zwischen Eltern und Kindern und Geschwistern sind überaus eng. Doch die Umwelt wird als feindselig und ausbeuterisch erlebt und konstruiert. Also muss man sich von dort, notfalls mit Gewalt, nehmen, was man zum Überleben braucht. Dass der regelmäßige Schulbesuch zu einem sozialen Aufstieg über Bildung führen kann, ist für diese Eltern und folglich auch für die Kinder nicht vorstellbar. Man hätte Mathias Kneißl die Chance zum ersehnten Neuanfang in Amerika gewünscht. Aber wäre er dort, in dem rauen gesellschaftlichen Klima, nicht wieder auf die schiefe Bahn gekommen? Zumindest hätte ihn dort niemand auf seine Herkunft und seine Vergangenheit zurückgeworfen und dadurch erneut zu Fall gebracht. Wodurch wird also das Verhalten geprägt, durch die sozialen Umstände oder durch den Charakter, oder beides?

War Kneißl wirklich eine Art bayrischer Robin Hood, also ein Sozialrebell, oder war er doch nur ein gewöhnlicher Krimineller? Ja, es gab den Haß der einfachen Leute, der Tagelöhner, der Handwerker, Kleinbauern auf die Obrigkeit, den Prinzregenten, daher die Sympathie und die Unterstützung, die Mathias Kneißl erfuhr. Er revanchierte sich mit der Lieferung von Wildbret. Doch schon die Mutter, eine geborene Pascolini, entstammte einer Räuberfamilie. Als Mathias 1899 das Gefängnis verlässt, sieht er verwandelt und gereift aus, mit blondem Schnauzbart. Das Wiedersehen mit der Familie, in einer ärmlichen Stadtwohnung, ist überschwänglich. Die Mutter spielt auf dem Schifferklavier. Es wird Schnaps getrunken, gelacht und getanzt. Mathias und die Cousine schlafen miteinander auf dem Küchenboden, nachdem die Tante, im Schnapsdusel, am Küchentisch eingeschlafen ist. Alle laufen hier in den, durch die soziale Herkunft vorgezeichneten, engen Bahnen. Die Familie am Totenbett der Schwester, die Gendarmen Mathias auf der Spur, die Mutter stellt sich ihnen ein letztes Mal in den Weg, so dass er fliehen kann. Vor dem dramatischen Finale gibt es zwei Szenen, die voller Aufbruch sind: Mathias ist seinen Häschern ein letztes Mal entkommen, im Jauchewagen untergetaucht. Wir sehen ihn nackt, zitternd, als der Bauer ihn mit Wasser übergießt, als würde er ihn taufen, den Dreck seiner Vergangenheit von ihm abwaschen. Mathias nun, am frühen Morgen, mit Koffer, im langen Mantel aus Schafsfell, mit Hut, Mathilde an der Hand, von der Scheune kommend. Geld für die Überfahrt nach Amerika ist jetzt da, von den jüngsten Raubzügen. Allein die Hundertschaft an Gendarmen lauert im Gebüsch. Man muss diese Szene verlangsamen, um sie tatsächlich in ihrer Tiefe zu erfassen, die Filmbilder eins nach dem anderen ansehen, 
die Gesichter der beiden, die eigentlich alles vor sich haben könnten, sich vorstellen, sie schafften es, bis nach Bremerhaven oder Hamburg, auf eines der Auswandererschiffe, und sie überquerten den Atlantik, und sie gingen in New York an Land, und verlören sich dann in den Weiten des Mittleren Westens. Wären da nicht diese widrigen Umstände, die dem entgegenstehen. Diese soziale und familiäre Herkunft war ein chancenloser Käfig, aus dem es kein Entkommen gab, dafür aber einen frühen Tod auf der Guillotine.

\section{"Game of Thrones» und „Vikings«: Identität und Schicksal}

Wenn wir aus einer kulturwissenschaftlichen und zugleich aus einer pädagogischen Perspektive in die Welt des Films blicken, so bieten sich die acht Staffeln von Game of Thrones (GoT) für eine Besprechung an. Die insgesamt 73 Episoden beruhen auf Romanen von George R. R. Martin. Diese sind als Serie unter dem Titel A Song of Ice and Fire, in den Bänden A Game of Thrones, A Clash of Kings, A Storm of Swords, A Feast of Crows und A Dance with Dragons erschienen. Zugleich haben die Drehbuchautor_innen eine Reihe von Weiterentwicklungen und Fortschreibungen vorgenommen. Die Fancommunity von GoT hat selbst auch alternative Handlungen entworfen, besonders für die achte und letzte Staffel, weil hier vielen manches nicht plausibel erschien und daher als weniger zufriedenstellend erlebt wurde. Daran wird schon deutlich, mit welch hoher Motivation seitens der Rezipient_innen GoT einherging, welch hohes Maß an Emotionen und intellektuellem Interesse hier im Spiel war und noch ist. GoT zeigt uns eine, dem europäischen Mittelalter nachempfundene, mit Fantasy-Elementen angereicherte, Welt. Diese besteht, nach dem Kenntnisstand der Menschen dort, aus den Kontinenten Westeros und Essos und weiteren, noch unbekannten Kontinenten. Im Zentrum des Geschehens steht der erbitterte Kampf verschiedener Adelshäuser, insbesondere der Häuser Baratheon, Lennister und Targaryen, um den Eisernen Thron von Westeros. Von Kings Landing aus werden, seit tausenden von Jahren, die sieben Königslande regiert. Der Norden, vertreten durch das Haus Stark, ist ebenfalls in die bestehenden Konflikte involviert, kämpft aber letztlich nur um seine Unabhängigkeit. Krieg und Eroberung, Verrat und Mord, Machtkämpfe und Intrigen gehören zum Alltag und ziehen sich wie ein roter Faden durch alle 73 Episoden. Die zahlreichen, plastisch und drastisch in Szene gesetzten, Gewaltakte machen diese dunkle Seite überaus lebendig. Kämpfe und Überfälle, Plünderungen und Hinrichtungen, Vergewaltigungen und Misshandlungen werden schonungslos gezeigt. Doch auch die Tugenden der Wahrhaftigkeit, der Treue, der Zuneigung, der Liebe und der Loyalität bekommen ihren Raum. Kontrastreich werden sie gegen alles Dunkle und Destruktive gesetzt. Diese helle Seite wird insbesondere durch das Haus Stark verkörpert, aber auch durch Figuren wie Brienne von Tarth, den sich immer mehr ins ethisch-moralisch Gute hinein entwickelnden Tyrion Lennister, teils auch den späten Jaime Lennister.

GoT ist auf ein hohes Interesse, auch in den diversen Wissenschaften, gestoßen und hat als Gegenstand der theoretischen Analyse und Reflexion Eingang in zahlreiche Fachdiskurse gefunden. Veröffentlicht wurden bisher gesellschafts- und politikwissenschaftliche Interpretationen, geschichtswissenschaftliche Einschätzungen, kulturwissenschaftliche Analysen, Reflexionen zum Thema Wildheit oder zum Thema der hegemonialen Maskulinität in GoT, um einmal das, von Raewyn bzw. Robert 
Connell $(1995,2005)$ geprägte Konzept an dieser Stelle einzuführen. Es existieren auch kritische Stellungnahmen von feministischer Seite oder Analysen zu den Themen Führung und Management. Andere Autor_innen lieferten philosophische oder psychoanalytische Interpretationen. In der Literatur finden sich etwa Betrachtungen zur Mauer aus Eis, die die sieben Königslande vor Gefahren aus dem unbekannten Norden schützen soll. Ebenso können wir Erörterungen zu den permanenten Bedrohungen lesen, die von dem Unbekannten ausgehen, das nördlich der Mauer angesiedelt ist und irgendwann in der Zukunft über Westeros hereinzubrechen droht und in dem Satz Winter is coming symbolisiert wird. Viele menschlich und gesellschaftlich bedeutsame Themen werden in GoT mit dramaturgischem Geschick in Szene gesetzt. Neben Familie und Blutsverwandtschaft, Herrschaft und Macht, gesellschaftlichen Ordnungen und Sanktionierung von Regelüberschreitungen, sind das vor allem Geschlechterrollen, Identitäten, Liebe und Sexualität. Dabei wird kaum etwas ausgespart. Auch nicht das Thema Inzest, das uns, in Gestalt von Cersei Lennister und ihrem Zwillingsbruder Jaime, plastisch vor Augen geführt wird. GoT bietet den Rezipient_innen ein enormes Spektrum an unterschiedlichsten Figuren, und deckt, im Hinblick auf Männlichkeitsund Weiblichkeitskonzepte, nahezu alles ab, was derzeit vorstellbar erscheint. Wenngleich hier auch einige Begrenzungen sichtbar werden, denn in Wahrheit gibt es ja immer noch ein wenig mehr Varianten, Übergänge und Ausprägungen in diesem Bereich. Man vergleiche die derbe, feiste, joviale, hedonistische Männlichkeit von Robert Baratheon mit dem zurückhaltenden, androgynen Charm von Jon Snow, das Feuer in den Augen des Wildlings Tormund Riesentod mit dem väterlich-liebenden Gesicht von Eddard Stark. Man vergleiche das freundliche Wesen des dicklichen, von seinem Vater verstoßenen, Samwell Tarly mit dem, seinen muskulösen Oberkörper stets unbekleidet zeigenden, Dothraki-Häuptling Khal Drogo. Einige Figuren lassen sich explizit dem Spektrum von männlicher Homosexualität zuordnen, etwa Renley Baratheon und Loras Tyrell, die im Verborgenen ein Paar sind. Oberyn Martell lebt selbstbewusst eine sehr freizügige Bisexualität und schläft mit Männern wie mit Frauen, ohne dies im Geringsten zu verbergen. Der, vielfachen Anfeindungen, Verdächtigungen und Spekulationen ausgesetzte, Eunuch Lord Varys ist ein höfischer Strippenzieher ersten Ranges. Er wird, gegenüber den Zuschauer_innen, durch eine Anspielung des Bordellbetreibers Petyr Baelish geoutet: »Der erste Junge geht aufs Haus.« Weitere Figuren sind umgeben von unterschwelligen Andeutungen und Anspielungen, die zwar nichts explizit Homosexuelles beinhalten, aber dennoch Möglichkeiten offenhalten, wenn wir etwa an die Szene denken, wo Jon Snow, nach seiner Rückkehr zur Schwarzen Festung, zuerst jemand anders zu begrüßen beabsichtigt, und Tormund Riesentod es aber kaum erwarten kann, ihn in die Arme zu nehmen und recht stürmisch von der Seite anspringt.

Auch der Schluss der Serie lässt in dieser Hinsicht viele Möglichkeiten offen. Jon Snow hatte seine geliebte Daenerys Targaryen, zweifellos zum Schutz und zum Wohle der Bevölkerung, mit einem gezielten Messerstich getötet. Doch um ihre Anhänger_ innen zu besänftigen und von einem Aufstand abzuhalten, wird Jon zur Nachtwache verbannt. Die Aufgaben der Nachtwache können aber, nach dem Tod des Nachtkönigs und der Versöhnung mit den Wildlingen, nicht mehr dieselben sein. Wir sehen denn auch Jon und Tormund, mit einer Gruppe von Männern, von der Schwarzen Festung aus nach Norden reiten, einer neuen Zukunft entgegen und dabei die alte soziale Ordnung hinter sich lassend. Zuvor wurde Jon Snow in mehreren Episoden provoziert, in- 
dem ihm homosexuelle Tendenzen zugeschrieben werden, etwa durch Allister Thorn, den früheren Waffenmeister auf der Schwarzen Festung. Weil Jon sich für einen fairen, gerechten Umgang mit dem körperlich untrainierten, sich beim Schwertkampf mehr als ungeschickt anstellenden, Sam Tarly einsetzt, unterstellt Allister Thorn Jon Snow vor den anderen Männern, dass er sich in diesen dicklichen jungen Mann verliebt haben müsse. Auch Sam selbst wird, aufgrund seiner Körperfülle, von Allister Thorn stigmatisiert, entmännlicht und zu einer devoten, passiven Kreatur degradiert, die den sexuellen Trieben echter, viriler Männer zu Willen zu sein hat. Allister Thorn geht sogar noch einen Schritt weiter und führt aus, dass ein dicker Junge wie Sam, bei einem langem Aufenthalt eines Stoßtrupps der Nachtwache, im winterlichen Norden, eine wertvolle Ressource darstellt. Bevor die Männer also verhungern, so Allister Thorn, könnten sie den übergewichtigen jungen Mann schlachten, und vom seinem Fett einige Wochen überleben. Sam Tarley behauptet sich, hinsichtlich seiner Sexualität, immerhin im Gespräch mit Jon Snow. Zwar nimmt er, gegenüber Jon, freiwillig eine untergeordnete Stellung ein, was das Thema Mädchen und Frauen anbelangt, indem er unterstellt, dass der attraktive Jon doch sicherlich schon sehr viel Erfahrung hat, auf dem Gebiet, was aber nach dessen Aussagen gar nicht mal zutrifft. Doch insistiert Sam darauf, dass er dieselben Bedürfnisse habe, wie alle anderen jungen Männer auch. So nimmt er schützend das Mädchen Goldy und deren, von Craster, einem herrschsüchtigen, reizbaren Mann, der sich von der Nachtwache abgespalten hat, gezeugten, Sohn unter seine Fittiche. Weil Goldy nicht ertrug, dass der Säugling von den Weißen Wanderern geholt werden sollte, floh sie, gemeinsam mit Sam, von Crasters Hof. Wir wissen von Romanautor George R. R. Martin, dass er sich mit der Figur des Sam Tarley identifiziert hat, unter anderem auch wegen seiner eigenen Leibesfülle.

Eine Nebenfigur, die diese Thematik erneut widerspiegelt, ist der verwaiste, ebenfalls dickliche, Bäckersjunge Heiße Pasteten. Seinen Namen trägt er, weil er, die von seiner Mutter frisch gebackenen, Pasteten auf einem Holzkarren durch die Straßen von Kings Landing gefahren und immerfort »Heiße Pasteten" gerufen hat. Auch dieser Junge wird, hinsichtlich seiner Identität, aufs Essen, auf sein Körperfett, reduziert. Er wird mit etwas gleichgesetzt, was sich andere einverleiben. Mit dem selbstgebackenen Schattenwolf, den er ihr schenkt, wirbt er, trotz allem, um Aryas Zuneigung und bringt sich, darin durchaus Sam vergleichbar, als Junge mit emotionalen, und dahinterliegend, wohl auch sexuellen, Bedürfnissen ins Spiel. Schauen wir uns die Männerfiguren und die, durch diese verkörperten, Masculinities noch ein wenig genauer an, etwa diejenigen Männer, die einem traditierten Rollenbild am ehesten zu entsprechen scheinen. Männer, die geschickt mit dem Schwert umgehen können, gut trainierte, schlanke, aber zugleich kräftige, wendige, mutige Männer. Hier wären zu nennen Eddard Stark, Robb Stark, Benjen Stark, Jon Snow, Tywin Lennister, Jaime Lennister, Jorah Mormont oder Bronn. Eine Reihe von Jungen und Männern werden sich eventuell mit diesen Männerfiguren identifizieren, wenngleich die genannten Charaktere in sich wiederum sehr vielfältig sind. So gutmütig Eddard Stark auch sein mag, für viele wird er, zweifellos, ein väterliches Sehnsuchtsbild darstellen, aufgrund seiner Emotionalität, seiner Loyalität, seiner Wahrhaftigkeit, seiner emotionalen Wärme. Auf der anderen Seite erweist er sich in den Machtspielen, in die er als Hand des Königs hineingezogen wird, als schwach, hilflos und ungeschickt, weil er glaubt, dass er, allein mit Wahrhaftigkeit, Ehrlichkeit und Loyalität, in den bösen Ränkespielen, die 
ihn umgeben, bestehen kann. Doch das Gegenteil ist der Fall. Nicht nur er, sondern auch seine Frau Catelyn, wie auch sein ältester Sohn Robb, gehen dabei unter. Anderen Männern seines Alters, die vielleicht auch als väterliche Projektionsfiguren dienen könnten, insbesondere Tywin Lennister, fehlt jedoch das Emotionale, das Vertrauen Erweckende. Tywin Lennister ist zwar ein kluger Stratege, doch er wirkt kalt und berechnend. Männer wie er überleben länger, wenn auch nicht ewig. Wollen wir also im pädagogischen Feld mit Jungen und jungen Männern über Wunschväter oder gehasste Väter, über nicht gehabte Väter, real vorhandene Väter, und damit über die väterlichen Projektionsfiguren in Verbindung mit GoT, reden, dann bieten sich hier zahlreiche Anknüpfungspunkte. Dieses Themenfeld ist, je nach autobiografischem Hintergrund, sehr subjektiv eingefärbt. Es ist voller Ambivalenzen und Unterströmungen. Von daher ist bei solchen Thematisierungen im pädagogischen Feld Vorsicht geboten. Niemals dürfen männlichen Jugendlichen mit einer ausgeprägten emotionalen oder sozialen Thematik zu direkte Fragen in Verbindung mit ihrem eigenen, emotionalen Erleben gestellt werden.

Trotzdem kann ich fast alles ansprechen und auch zur reflexiven Auseinandersetzung in den pädagogischen Raum stellen. Ich muss die Dinge nur weit genug vom Jugendlichen weg platzieren und etwa auf unbeteiligte, fiktive Dritte verlegen oder diese Themen ganz im Bereich der Filmstory belassen. Sonst ist es wahrscheinlich, dass das ganze Gespräch abrupt vom Jugendlichen beendet wird oder ins Negative kippt. Während Eddard Stark und Tywin Lennister, als väterliche Projektionsfiguren beide ihre Grenzen haben dürften, erscheint Jeor Mormont, der Lord Kommandant der Nachtwache, dagegen als gerecht, erfahren und besonnen. Er zeigt sich verhalten emotional zugewandt und ist mit allen Wassern gewaschen. Er holt Jon Snow, nach dessen Ankunft in der Schwarzen Festung, als Sekretär in seinen persönlichen Bereich, führt ihn in vielerlei führungsrelevante Dinge ein, hält seine väterliche Hand über ihn und schützt ihn vor den Attacken von Allisar Thorn. Jeor Mormont wird als warmherziger, resoluter Mann gezeigt, aber eben nicht als so gutmütig und naiv wie Eddard Stark. Ein sehr empfindliches Thema, dass in GoT eine zentrale Rolle spielt, dreht sich um die Bastarde, die illegitimen Kinder, hier insbesondere Söhne. Der prominenteste Bastard in GoT ist sicher Jon Snow, wenngleich er in Wahrheit, wie wir ganz am Ende erfahren werden, gar keiner ist. Aber Jon wächst aufWinterfell eben in diesem Bewusstsein auf und entwickelt dadurch eine seelische Verfasstheit als Sohn zweiter Klasse. Jon zeigt ein gedämpftes Selbstbewusstsein, wenngleich Eddard Stark ihn liebt, und ihm dies auch gezeigt hat. Doch Catelyn, die Jon Snow für das Produkt einer Affäre ihres Mannes hält und nicht weiß, dass er den Waisen seiner ermordeten Schwester Lyanna, gezeugt von Rhaegar Targaryen, aufgenommen hat, um ihn vor den Häschern des Königs, seines Jugendfreundes Robert Baratheon, zu schützen, zeigt Aegon bzw. Jon bedauerlicherweise die kalte Schulter. Jons dunkles, in tiefste seelische Abgründe hineinreichendes, Gegenbild ist der Bastard Ramsey Bolton. Verzweifelt kämpft Ramsey um die formale, sicher auch um die emotionale, Anerkennung seines Vaters. Er hat dabei einen bösartigen, sadistischen Charakter entwickelt. Ein dritter Bastard, wiederum mit stabiler Persönlichkeit, und von gutmütigem, zwar etwas schlichtem, aber sehr liebenswertem Charakter, ist der Schmiedegeselle Gendry, ein illegitimer Sohn von Robert Baratheon. Gendry erfährt erst spät von seiner eigentlichen Herkunft. So ist er ungestört von Selbstzweifeln, ohne den Wunsch nach Anerkennung durch seinen leiblichen Vater, aufgewachsen. 
Das Thema der Bastarde ist, in pädagogischer Hinsicht, von einem besonderen Interesse, geht es dabei doch in einem tieferen Sinne um das Thema der väterlichen Anerkennung der Kinder, hier der Söhne. Wir müssen auch bedenken, dass wir im pädagogischen Feld der emotionalen und sozialen Entwicklung, mit einiger Regelmäßigkeit, mit Jungen oder jungen Männern zu tun haben, die nicht mit ihren leiblichen Vätern leben, diese teils gar nicht kennen und teils mit Stiefvätern oder wechselnden Lebenspartnern ihrer Mütter aufwachsen. Oftmals sind diese biografischen Hintergründe Teil einer besonderen Konfliktgeschichte. Mit männlichen Jugendlichen, die in komplizierten familiären Konstellationen leben oder gelebt haben, über Jon Snow, Ramsey Bolton oder Gendry zu sprechen, könnte durchaus zu Einsichten und Erkenntnissen, teils auch emotionalen Klärungen führen, die jedoch eher indirekt erreicht werden und keineswegs zu deutlich artikuliert werden sollten. Das Problem in diesem pädagogischen Feld ist ja, dass wir vieles eben nicht explizit sagen oder fragen dürfen und manches eher im Ungefähren belassen müssen, damit wir überhaupt an diese Themen herankommen, denken wir einmal an John O'Donohues philosophische Ausführungen zum Seelenleben, das keine allzu direkte, keine zu helle Ausleuchtung verträgt. Damit ist aber das Spektrum der, in den 73 GoT-Episoden auf die Leinwand gebrachten, Masculinities noch nicht erschöpfend besprochen, und die männlichen Rollenkonzepte und Identitäten sind nun mal ein zentrales Thema in dem pädagogischen Feld, um das es uns hier geht. Wenn wir einmal das Konzept der hegemonialen Männlichkeit bemühen, so erscheint Craster, der von der Nachtwache abgespaltene und nördlich der Mauer in der Wildnis lebende Einzelgänger, als eine sonderbare Steigerung derselben, eine Zuspitzung ins Extreme freilich. Craster lebt in einer Art Wald-Harem mit 19 Frauen zusammen, die größtenteils seine eigenen Töchter sind. Er schläft abwechselnd mit allen. Werden sie mit einer Tochter schwanger, erweitert sich der Harem. Gebären sie dagegen einen Jungen, so wird dieser, unmittelbar nach der Geburt, im Wald ausgesetzt und vom Nachtkönig und den Weißen Wanderern geholt. Durch diese Tributzahlungen kann Craster mit seinen Frauen draußen in der Wildnis, unbehelligt vom Nachtkönig, überleben und seinen männlichen, sexuellen Gelüsten ungestört nachgehen. Interessant ist, dass Craster sich, bei der Ankunft einer Delegation der Nachtwache, durch die Schönheit von Jon Snow, der ihn offenbar mit seinen langen dunklen Locken und seinem sinnlichen Gesichtsausdruck irritiert, so stark provoziert fühlt, dass er nahezu die Kontrolle verliert und sofort Streit beginnt. Er unterstellt Jon, dass er sich seinen Frauen annähern wolle, doch wirkt das Ganze ambivalent. Jons Reize scheinen vielmehr auch Craster nicht kalt zu lassen.

Eine wieder andere Ausformung von Masculinities repräsentiert Gregor Clegane, auch der Berg genannt, ein riesiger, physisch starker, hochaggressiver, einfältiger Hüne, ein dumpfer Muskelberg, der als Kind den Kopf seines Bruders ins Feuer gedrückt hat, weil dieser nach seinem Spielzeug griff. Nach verlorenem Turnier schlägt er seinem Pferd den Kopf ab. Gegen alle Turnierregeln versucht er Loras Tyrell, nachdem dieser über ihn gesiegt hat, vor den Augen des königlichen Hofes zu töten. GoTFans lernen also, dass auch ein homosexueller Mann ein versierter Turnierkämpfer sein kann. Gregor Clegane lässt sich später willig durch Cersei instrumentalisieren, als Leibwächter. Ein wenig anders erscheint dagegen sein Bruder Sandor Clegane, auch Bluthund genannt. Sandor ist in mancherlei Hinsicht seinem Bruder ähnlich. Auch er startet als finsterer Charakter, doch im tiefen Innern ist er ein Mann mit Emo- 
tionen und einem Gefühl für humane Werte, für richtig und falsch. Dementsprechend steht er Loras Tyrell bei, als sein Bruder Gregor, nach dem verlorenen Turnier, vor den Augen des Königshofes, mit dem Schwert auf diesen losgeht. Insbesondere durch die Interaktion mit Arya entwickelt er sich, über all die Episoden hinweg, charakterlich $\mathrm{zu}$ einem zumindest etwas besseren Menschen. Ab einem bestimmten Punkt erkennt Sandor die Sinnlosigkeit der ewigen Machtkämpfe und der nicht endenden Gewaltexzesse. Ebenfalls ein hünenhafter Mann ist der Stallbursche Hodor, später Leibwächter des querschnittsgelähmten Brandon Stark, loyal bis in den eigenen Tod und auf der Seite der Guten stehend, aber geistig zurückgeblieben. Bleiben noch die Eunuchen, allen voran Varys, Männer, die in ihrer Kindheit kastriert wurden, ebenso Grauer Wurm und die Soldaten, die sie die Unbefleckten nennen, ferner Theon Greyjoy, der im Rahmen von sadistischen Folterungen entmannt wird. Varys geht offensiv, ironisch-sarkastisch mit dem Thema seiner Kastration um, um den vielen Demütigungen, die in dieser Hinsicht aus seinem Umfeld kommen, vorzubeugen und sicherzustellen, dass ihn die verbalen Bosheiten nicht so stark treffen. Eine offen gezeigte Sexualität wird ihm, dem sämtliche Geschlechtsorgane genommen wurden, im Film nicht zugestanden. Es werden allerdings Anspielungen gemacht, wie bereits erwähnt, dass er sich, dann und wann, von jungen Männern beglücken lässt.

Grauer Wurm findet, trotz seiner Kastration, in der ehemaligen Sklavin Missandei seine große Liebe. Die beiden werden auch in körperlich hingebungsvollen Szenen gezeigt, wenngleich sie natürlich mit gewissen Einschränkungen umgehen müssen. Theon Greyjoy wirkt, nach der Kastration, völlig gebrochen, ja traumatisiert. Er findet aber teils auch zu einer ethisch guten Verfasstheit zurück, nachdem er, geleitet von Verblendung und Größenwahn, eine Zeitlang Gewaltexzessen nachgegangen ist. Das Thema der Kastration dürfte an die tiefsten Ängste von Jungen und männlichen Jugendlichen rühren. Wie wir aus der psychoanalytischen Forschung wissen, können damit erhebliche seelische Komplexe und Spannungen verbunden sein, selbst dann, wenn eine Entmannung im materiellen Sinne weder stattgefunden hat, noch als reale Gefahr droht. Eine Entmannung kann auch rein seelischer Natur sein. In sexueller Hinsicht dürfte Jaime Lennister vielleicht dem klassischen männlichen Filmhelden am nächsten kommen, zum anderen auch wieder nicht, da er im Verborgenen mit seiner Schwester Cersei schläft und drei Kinder gezeugt hat, die durch die Macht des Schicksals und möglicherweise darin verborgene moralische Kräfte, alle früh zu Tode kommen. Auch die spätere, kürzere Liaison mit der androgynen Brienne von Tarth überschreitet die Vorstellung davon, was ein männlicher Filmheld üblicherweise tut. Die Kommunikation zwischen den beiden weckt durchaus vielfältige Assoziationen, wenn Jaime vor der soeben, von ihm selbst, feierlich zum Ritter geschlagenen Brienne steht und sagt: »Ich habe noch nie mit einem Ritter geschlafen.« Entspricht Jon Snow diesem tradierten Ideal eines männlichen Filmhelden? Insgesamt wirkt er dafür zu gehemmt, denken wir an die Begegnung mit der derb auftretenden Wildlingsfrau Ygritte. Anders ist es dann mit Daenerys Targaryen. Hier entsteht mit der Zeit eine Beziehung auf Augenhöhe, die die Erwartung an einen traditionellen männlichen Filmhelden eher erfüllt, freilich erst, nachdem Jon, mutig und ausdauernd, Daenerys' Führungs- und Machtanspruch zurückgewiesen und auf einem gleichwertigen Verhältnis bestanden hat. Aber ein Frauenheld ist Jon Snow trotz allem nicht. Sein Selbstbewusstsein ist belastet durch sein vermeintliches Aufwachsen als Bastard, als Sohn zweiter Klasse, obwohl dies ja nun, wie wir später erfahren, nicht einmal der Realität 
entsprach. Vielmehr ist er sogar, ohne dass es irgendjemand weiß, außer seinem Stiefvater Eddard Stark freilich, der wahre Erbe des Eisernen Throns. Seine eher scheue Zurückhaltung gegenüber Frauen könnte ja, das wäre zumindest glaubhaft, mit der eher kühlen Behandlung durch seine Stiefmutter zusammenhängen. Dass Jon, abweichend von traditionellen männlichen Filmhelden, aber gar keine Machtinteressen hat, dürfte ihm viele Sympathien einbringen, sowohl bei den Akteur_innen im Filmgeschehen, wie auch bei den Rezipient_innen der Filmserie. Alles das, was ihm, im Sinne einer glatten Heldenstory, am Held-Sein fehlt, das Verunsicherte, Gedämpfte, Ambivalente in seinem Charakter, macht ihn letztlich zum eigentlichen Helden der ganzen Serie und umso liebenswerter und attraktiver. An Mut und Tapferkeit im Kampf fehlt es ihm dagegen nicht. Im Hinblick auf Macht-Distanz, Geschlechterrolle und Identität ist er vielleicht der modernste, der zeitgemäßeste und der zukunftsweisendste Charakter in GoT. Für Jon muss es, im Zweifelsfall, immer ehrlich, wahrhaftig und ethisch verantwortlich zugehen. Es gibt viel mit heutigen männlichen Jugendlichen zu reden über den Charakter und die Emotionalität von Jon Snow.

Spiegelbildlich lassen sich diese Perspektiven genauso für die Frauen und Mädchen einnehmen. Vergleichen wir das mütterliche, aber auch entschlossene, charakterfeste Gesicht von Catelyn Stark mit dem Gesicht der kühl berechnenden Machttaktikerin Cersei Lennister, das naiv verträumte, romantische Wesen der jungen Sansa Stark mit der burschikosen Keckheit ihrer jüngeren Schwester Arya. Vergleichen wir die, mit allen Wassern gewaschene, Großmutter Olenna Tyrell mit der sehr verhalten und verunsichert beginnenden und dann ihren Eroberungsfeldzug startenden Daenerys Targaryen. Brienne von Tarth, die irgendwo zwischen den Geschlechtern changiert, Ellaria Sand, die einerseits die Geliebte von Oberyn Martell ist, die aber auch Leidenschaft für Frauen entwickelt, etwa für die spröde und raubeinig auftretende Asha Greyjoy. Einige Mädchen weisen die traditionelle Geschlechterrolle zurück, vor allem Arya Stark, die zu einer regelrechten Schwertkämpferin wird. Die Wildlingsfrau Ygritte, die auf derbe, teils recht obszöne Weise Jon Snow aus der Reserve zu locken versucht und dies schließlich auch schafft. Zu stark ist Jons Drang, dem Geheimnis von Liebe und Sexualität auf die Spur zu kommen, wenngleich er vermutlich einen sanfteren Einstieg bevorzugt hätte, doch immerhin verhindert Ygritte, dass ihn die Wildlinge töten. Sodann die kampferprobten Töchter von Ellaria Sand, Sandschlangen genannt. Auch diese stehen für ein anderes Frauenbild. GoT präsentiert uns weiterhin Mädchen, die gebildet sind und sogar erwachsenen Männern das Lesen beibringen, etwa Sharin Baratheon. Sodann Mädchen, die anfangs naiv, romantisch und etwas dümmlich starten und dann eine enorme Entwicklung hinlegen und sich zu standfesten, resoluten Persönlichkeiten aufschwingen, insbesondere Sansa Stark. GoT bietet mütterliche Projektionsfiguren, allen voran Catelyn Stark, warmherzig, wahrhaftig und gerecht, allerdings mit Einschränkungen bezogen auf Jon Snow. Ein völlig anderer Muttertyp ist dagegen Cersei Lennister, ihre Kinder zwar liebend, bis hin zur Selbstaufopferung, jedoch ohne übergreifende humane Werte zu verkörpern, ohne die Tiefe des Gefühls. Einen weiteren, durchaus extremen Muttertyp verkörpert Lysa Arryn, Catelyns Schwester, die sich hoch in ihrer Burg verbarrikadiert hat, symbiotisch mit ihrem Sohn Robin verschmolzen ist und diesen noch mit etwa zehn Jahren, vor aller Augen, an der Brust stillt. Olenna Tyrell kann dagegen als großmütterliche Projektionsfigur gelten, weltoffen, tolerant, gefühlvoll, aber auch mit sicherem Machtinstinkt. 
Über Vieles, was Autor und Drehbuchautor_innen die Figuren in GoT sagen lassen, können wir im philosophischen Sinne lange nachdenken und mit Jugendlichen debattieren. Etwa wenn der Fechtmeister zu Arya, der jüngsten Tochter von Eddard Stark, sagt: \ou are not here, you are with your trouble« oder:»Watching is not seing.« Nachdenklich machen auch Lord Varys' Sätze: »Some doors were closed forever while others opened in unexpected places « oder "Nothing lasts." Eine besondere Rolle spielen auch weise alte Menschen, etwa Maester Aemon Targaryen in der Schwarzen Festung oder die Alte Nan in Winterfell, mit ihren mythologischen Geschichten, die zweifellos viel Wahrheit enthalten. Besonders zeitgemäß erscheint das Betonen von Figuren mit Disabilities, allen voran von Tyrion Lennister, als einem kleinwüchsigen Menschen. Sodann Brandon Stark, der, nach dem Sturz vom Turm, querschnittsgelähmt ist oder Jaime Lennister, dem eine Hand abgeschlagen wurde, auch Sharin Baratheon mit ihrem entstellten Gesicht, ferner Robin Arryn in seiner seltsamen Entrücktheit, Ramsey Bolton in seinem inneren Gefängnis aus Selbsthass und nach außen gerichteten Sadismus, Theon in seiner Traumatisierung. Besondere Aufmerksamkeit verdienen die Machttaktiker Tywin Lennister und Olenna Tyrell, aber auch die Intriganten, Hofschranzen und Strippenzieher Lord Varys, The Spider genannt, sowie Petyr Baelish, Littlefinger genannt. $\mathrm{Zu}$ reden wäre ferner über die Verstoßenen, sozial Geächteten, Ausgestoßenen oder in Ungnade Gefallenen, über Sam Tarley, Jorah Mormont, zwar beide von edlem Charakter, und doch geächtet, und all die vermeintlichen Verbrecher, Vergewaltiger, Mörder, die sich in der Schwarzen Festung versammeln. Viele von ihnen zeigen ein menschliches Gesicht, selbst unter den harten Lebensbedingungen an der Mauer. GoT arbeitet teils mit Figuren, die enorme Veränderungsprozesse durchlaufen, allen voran Tyrion Lennister, aber auch Cersei Lennister, Jaime Lennister, Theon Greyjoy, Sansa Stark, Daenerys Targaryen, aber auch Lancel Lennister, zunächst eine scheinbar unbedeutende Nebenfigur, die dem Hauptgeschehen jedoch mehrfach eine entscheidende Richtung gibt. Lancel ist verunsicherter Spielball von Kräften, die zwar andere entfachen, wird unter anderem von seiner Tante Cersei sexuell benutzt, als Jaime länger abwesend ist, doch dann erfolgen Radikalisierung, Seitenwechsel und ein früher Tod, zusammen mit vielen anderen.

Wir können in der pädagogischen Reflexion reden über gute Charaktere und über die Frage, welche Eigenschaften ein guter Charakter haben sollte. Hier können wir zunächst von Eddard Stark, Robb Stark, Catelyn Stark, Benjen Stark, Jon Snow, Jorah Mormont und Samwell Tarly, von Brienne von Tarth und Arya Stark ausgehen. Das Repertoire an bösen Charakteren ist groß, denken wir an Geoffrey Baratheon, der Eddard Stark vor den Augen seiner Töchter hinrichten lässt, oder an Ramsey Bolton, der Sansa Stark schwer misshandelt. Sodann Euron Greyjoy, ein gefürchteter Pirat, Walder Frey, der einen Teil der Starks während der roten Hochzeit abschlachten lässt, der Nachtkönig, der die größte Gefahr aus dem Norden darstellt, Aerys II. Targaryen, der begann, alle Menschen in seinem Umfeld zu verbrennen, Viserys Targaryen, der bereit ist, seine Schwester Daenarys für die Rückeroberung des verlorenen Throns zu opfern. Doch warum bezeichnen wir diese Figuren als böse, was treibt sie an und was wollen sie erreichen? Was sind ihre Rollen, ihre Identitäten, ihre Werte? Wodurch verändern sie sich und in welcher Weise? Werden sich konfliktbelastete, teils auch traumatisierte Jugendliche, die vielleicht selbst sadistische Neigungen entwickelt haben, mit Ramsey Bolton oder Theon Greyjoy, mal in der Rolle des Aggressors, mal in der Rolle des Opfers der Aggression, identifizieren? Zu sprechen wäre auch über die 
magischen Figuren, etwa Melisandre, die rote Frau, eine Priesterin, die dem Herrn des Lichts dient. Oder über Jaqen H'ghar, den Mann ohne Gesicht, der Arya eine Zeitlang hilft, sie dann aber bedroht und verfolgt, als sie nicht mehr nach den Prinzipien seines Ordens leben will. Sodann der, später durch Brandon Stark verkörperte, dreiäugige Raben, der alles Gewesene zugleich visualisieren kann und eine Art kollektives Gedächtnis der Menschheit darstellt. Ferner die Hexe im Wald, von der sich Cersei Lennister, diese Szene wird in der Retrospektive gezeigt, ihre Zukunft voraussagen lässt. Schließlich Mirriz Maz Duur, die Khal Drogo mit Blutzauber behandelt und ihn, anscheinend mit Absicht, in geistiger Umnachtung zurücklässt. Auch die Kinder des Waldes und die Weißen Wanderer lassen sich den magischen Figuren zurechnen, ferner die Drachen, teils auch die Schattenwölfe, die das Wappen der Starks zieren. Wenn wir über Magie sprechen, dann auch über Drachenglas und valyrischen Stahl. Haben heutige Jugendliche, bis hin zu Universitätsstudierenden und Universitätsprofessor_innen, denn sehr viele haben sich ja für GoT begeistert oder darüber geschrieben, also doch ein starkes Bedürfnis nach Märchen, nach Magie und überirdischen Dingen? Ist dieser Wunsch vielleicht sogar noch viel größer geworden, weil in der schnöden Realität dieser Gesellschaft nur noch naturwissenschaftliche Maßstäbe gelten? Aus der Perspektive der Academia erscheint interessant die Zitadelle, wo sich die gelehrten Maester befinden, die das historische und medizinische Wissen sammeln und bereithalten, um die Herrscher zu beraten und wo Sam Tarley später lernt und studiert. Unter politischem Aspekt erscheinen besonders interessant die zehn Freien Städte in Essos, dem im Westen liegenden riesigen Kontinent, einer Art Gegenwelt zu der mittelalterlich geprägten Welt von Westeros. Darunter die Städte Braavos, Pentos oder Volantis, in Anlehnung an die italienischen Stadtstaaten, nach dem Fall Roms. GoT wirft eine Fülle an Fragen auf. Die Motivation heutiger Jugendlicher, darüber zu sprechen und zu debattieren, wie auch immer ihre emotionalen und sozialen Thematiken gelagert sein mögen, dürfte hoch sein.

Auch die von 2013 bis 2020 ausgestrahlte kanadisch-irische Filmserie Vikings bietet enorm viel Material, das wir, durchaus GoT vergleichbar, im Rahmen pädagogischer Reflexionen mit Jugendlichen heranziehen können. Die insgesamt 89, von Michael Hirst entworfenen, Episoden drehen sich um Eroberung und Kampf, Macht und Ruhm, Wahrheit und Gerechtigkeit, Lüge und Verrat, Intrigen und Ränkespiele, Liebe und Hass. Die alles überragende männliche Figur ist der Wikinger Ragnar Lothbrok, den wir während seines abenteuerlichen Lebens begleiten. Seine Motive sind zunächst Landwirtschaft und Familienleben, dann Raubzüge und schließlich das Gründen von Siedlungen im fruchtbaren England. Wir erleben Ragnar in all seiner Ambivalenz, auch in seiner charakterlichen Veränderung, in seinen Stärken und Fähigkeiten, in seinen Schwächen und Abgründen, in seiner späteren Verlorenheit, seiner Zerrissenheit und seinen Sehnsüchten, eingebettet in einen nicht endenden Strom von Aktion und Gegenaktion, von Stabilisierung und Destabilisierung, von Erfolgen und Rückschlägen. Mal ist er der Akteur, mal ist er der Spielball irdischer Kräfte und höherer Mächte. Ragnar gegenüber steht, als starke weibliche Figur, die Schildmaid Lagertha, seine erste Frau. In moralisch-ethischer Hinsicht überstrahlt sie alle anderen um ein Vielfaches. Keine andere Figur ist von solcher Wahrhaftigkeit, Klarheit und innerer Zentriertheit. Drumherum bewegt sich eine heterogene Gruppe von teils faszinierenden Akteur_innen, die alle miteinander ein hochkomplexes Geschehen auf die Leinwand bringen, im norwegischen Kattegat, sodann in England, insbesondere in 
Wessex, in Paris, Nordafrika, Island, Grönland und Kiew. Wir können reden über soziale Ordnungen und die Rolle von Gewalt, denken wir etwa an die endlosen Schlachten, die wir hier zu sehen bekommen. Wir werden hier wahrlich nicht geschont und manche Formen der Gewalt, etwa König Aelles Schlangengrube, der von den Wikingern praktizierte Blutadler oder die Tier- und gar Menschenopfer zu Ehren Odins, stellen schon eine ziemliche Herausforderung dar. Wir können über Männlichkeitskonzepte sprechen, anhand von Ragnar, Björn Eisenseite, Prinz Oleg oder König Egbert. Wir können reden über Weiblichkeitskonzepte anhand der Frauenfiguren, denken wir an Judith, Aslaug, Helga oder Siggy. Einige von ihnen (Lagertha, Astrid, Torvi) führen das Schwert ebenso geschickt wie die Männer. Anhand von Ragnar und Rollo lässt sich über die Rivalität zwischen Brüdern reflektieren, ebenso im Hinblick auf Björn und seine jüngeren Halbbrüder Ubbe, Hvitserk und Ivar. Am Beispiel des mit einer Behinderung geborenen Ivar lässt sich über die destruktiven Folgen von emotionaler Ablehnung und Verwöhnung sprechen. Ferner lassen sich, ausgehend von Ivar, Überkompensation, Größenwahn, Realitätsverlust, diktatorischer Blutrausch und unberechenbare Despotie zum Thema machen. Ragnar erfüllt einerseits alle Anforderungen, die in seiner Kultur an einen Mann in einer Führungsposition gestellt werden. Er zeugt zahlreiche Kinder mit mehreren Frauen, doch seine tiefste emotionale Liebe gilt dem englischen Mönch Athelstan, den er einst, nach dem ersten brutalen Einfall in England, aus dem Kloster Lindisfarne entführt und mit nach Norwegen genommen hat, und der ihm die englische Kultur und Sprache nahebringt. Der sanfte Athelstan wird $\mathrm{zu}$ einer Schlüsselfigur für Ragnars charakterliche, geistige Weiterentwicklung, für seine zunehmende Sensibilierung, wenngleich der ehemalige Mönch Ragnars wiederholter Aufforderung, mit ihm auch das Nachtlager zu teilen, aufgrund seiner eigenen religiösen Überzeugungen, nicht folgt. Ragnar ist schwer getroffen, als er Athelstan durch einen brutalen Eifersuchtsmord verliert. Regisseur Michael Hirst hat mit der Figur des Ragnar, der einerseits von der allergrößten männlichen Härte, Wildheit und Rohheit ist und zum anderen diese tiefe Zuneigung zu Athelstan entwickelt, sicher einen enormen Beitrag zu einer Erweiterung der Masculinities geleistet und wichtige Impulse für breite männliche Bevölkerungsschichten gegeben, die sich genau hiermit vermutlich schwer tun und diese, in Richtung des Engländers gelebte, Seite aus ihrer persönlichen Identitätskonstruktion herausspalten und wohl zumeist durch Projektion nach außen loszuwerden versuchen. Auf Seiten der Frauen vollzieht sich die gleichgeschlechtliche Liebe dagegen ganz unaufgeregt und als natürliche Bisexualität, indem etwa Lagertha und Astrid eine Zeitlang zusammenleben. Ein spannendes Thema für pädagogische Gespräche dürfte die Frage sein, inwieweit unser Leben das Ergebnis eigener Entscheidungen und Handlungen ist und inwieweit wir einem vorgegebenen Schicksal unterliegen, das uns lenkt. Die diesbezüglichen Weissagungen des Sehers, von dem sich die Hauptakteur_innen in Abständen beraten lassen, bestehen oftmals mehr aus Andeutungen und gezieltem Verschweigen. Was der blinde, weise Mann mit den schwarzen Lippen und der wunderbar mysteriösen Stimme, preisgibt, scheint aus den Tiefen des Universums zu kommen. Es spannt sich auch ein Lernfeld auf zwischen der nordischen und der englischen Kultur, die unterschiedlichen Vorstellungen von Religion, Bildung und Wissen, Sexualität, Geschlechterrollen und Familienkonstellationen eingeschlossen. Es kommt, trotz der Kämpfe und Rückschritte, nach und nach zu geistigem Austausch, zu einem Miteinander, zu Lernprozessen. Zwischen dem Wikinger Ragnar und dem englischen König Egbert entwickelt sich 
eine hochkomplexe geistige Beziehung, durchaus mit emotionalem Tiefgang. Diese Beziehung lässt sich als Anzeichen für eine nachhaltige Annäherung zwischen den gegensätzlichen Kulturen interpretieren, selbst wenn diese bis zum Ende ambivalent bleibt. Auch wenn Ragnar es nicht mehr erlebt, und er schließlich untergeht, so kommt es in der nächsten Generation doch zu einer Art kulturellen Verschmelzung und Weiterentwicklung, die Ragnar nun mal selbst vorangetrieben hat und die zugleich durch Athelstan ermöglicht wurde. Etwas Vergleichbares findet in Paris statt, dadurch das Rollo Lothbrock seine große Liebe am französischen Hof findet und sich ihm dort ein ungeahntes Handlungs- und Lebensfeld erschließt. Auch auf diesen Ebenen bieten sich zahlreiche, pädagogisch relevante Gesprächsanlässe. Denkbar ist ferner, dass Jugendliche, nachdem sie diese sechs Staffeln zu den Wikingern gesehen haben, doch mehr darüber wissen wollen, was im 8. Jahrhundert und danach in diesen Teilen Europas genau passiert ist, bis hin zu dem mysteriösen Geschehen um die Rus-Wikinger bzw. Kiewer Rus, die ein Großreich auf dem Gebiet des heutigen Russland, Weißrussland und der Ukraine aufgebaut hatten, dass die Heranwachsenden der Gegenwart also anfangen mit historischen Rekonstruktionen und Vertiefungen. Auch diejenigen, die es sich zur Aufgabe machen, die mikropolitischen Strukturen und Prozesse in der Welt der Academia zu erforschen und tiefergehend zu verstehen, finden sowohl in GoT wie auch in den Vikings umfangreiches Anschauungsmaterial.

\section{"Der kalte Himmel«: Überwindung der orthodoxen Psychiatrie}

Oftmals sind es Spielfilme, die größeren Bevölkerungsgruppen Themen nahebringen. Der, auf einem Drehbuch von Andrea Stoll basierende, vom Regisseur Johannes Fabrick gedrehte, zweiteilige Fernsehfilm wurde 2011 erstmalig gezeigt. Im Zentrum des Geschehens: Ein Junge, der in einem ländlichen, bäuerlichen, katholischen Milieu in Bayern aufwächst, in den 6oer Jahren, und der der Norm nicht entspricht. Felix Moosbacher liebt es, mit ausgebreiteten Armen durch die, von Vater und Großvater bewirtschafteten, Hopfenfelder zu laufen, wie ein Vogel. Oder er freut sich an den, sich in Glasscherben brechenden, Lichtstrahlen, die sich auch noch bewegen, weil sich draußen eine Maschine dreht. Aber er läuft auch, ohne zu wissen, was er tut, vor einen fahrenden Lastwagen und bringt sich in Gefahr, indem er selbst große landwirtschaftliche Maschinen anschaltet, wenn sonst niemand in der Nähe ist. Er interessiert sich sehr für Zahlen und fürs Rechnen und vermittelt so den Eindruck einer durchaus hohen Begabung, unabhängig von den bereits beschriebenen Besonderheiten. Als er eingeschult wird, steigert sich das, was die Familie bisher mit dem Kind erlebt hat, zu einer ganz neuen Dramatik. Das ärztliche und schulische Personal ist zwar bemüht, aber reichlich überfordert. Die Situation eskaliert. Der Junge gilt als nicht beschulbar. Die Familie gerät immer mehr unter Druck. Paul, der Vater, wird von seiner mit im Haus lebenden Mutter kritisiert, weil seine Erziehungsmethoden zu nachgiebig seien gegenüber dem Kind. Die Großmutter faltet dem Jungen bei Tisch gewaltsam die Hände und sagt: „Wer nicht beten kann, braucht auch nicht zu essen.« Alex, die aus Berlin in die benachbarte Kleinstadt gekommene Kantorin, sie hört Rockmusik in ihrem VW-Bus, trägt hennarot gefärbtes Haar und einen Schafsfellmantel, im Stil der 68er. Allerdings wird sie vom patriarchalisch konservativen Pfarrer in dieser Position als Frau nicht geschätzt. Sie hatte sich mit dem Kurznamen Alex beworben, so dass 
der Pfarrer, als er ihr zusagte, nicht wusste, dass es sich um eine Frau handelt. Doch nun spielt sie in seiner Kirchengemeinde die Orgel und leitet einen Frauenchor.

Alex wird nun für Marie Moosbacher, Felix' Mutter, zur transformationsfördernden Schlüsselfigur. Die Berlinerin bringt Entwicklungsimpulse dadurch, dass sie einen positiven Blick auf Felix einnimmt, auf eine Abklärung seiner Probleme drängt, Marie im Rahmen der kirchlichen Chorarbeit in ihrer Freude am Gesang fördert und ihr dadurch mehr Selbstwertgefühl und zugleich eine künstlerische Ausdrucksmöglichkeit verschafft. Das Ganze gipfelt in der Szene als Marie, während der Messe, die Maria im Dornwald als Solo singt, während Felix die Münzen aus dem Sammelkörbchen in den Mittelgang wirft, so dass sie rollen und klirren. Marie fährt mit Alex nach München und gerät dort in die Mühlen einer orthodoxen, zuschreibenden und etikettierenden Psychiatrie. Morgens in der Münchner Pension wäscht Marie das durchnässte Bettlaken des Sohnes. Am Ende wird Felix in einem Hörsaal vorgeführt wie ein hochverstörtes Wesen, zu wissenschaftlichen Demonstrationszwecken, ohne jedes Interesse und ohne jede Empathie für seine tatsächliche innere Welt. Immerhin einige Studenten, es waren in der Tat ausschließlich junge Männer, die dort studierten, bemerken, dass Felix, nachdem er aus dem Rollstuhl geklettert ist, mit Kreide lauter Primzahlen auf den Boden gemalt hat. Offenbar hat man ihm in der psychiatrischen Klinik Psychopharmaka verabreicht, die dazu führen, dass er, zumindest zeitweise, nicht mehr gehen kann. Für den Professor der Psychiatrie handelt es sich jedoch einfach um eine vorpubertäre Schizophrenie. Durch eine rabiate, handgreifliche Diagnostik wird der Junge schließlich erst recht in Unruhe versetzt und muss dann zwangsweise ruhiggestellt werden. Nur mit Mühe kann Marie ihr Kind aus diesem unmenschlichen Apparat wieder herausholen. Alex macht Marie nun mit Dr. Cromer, einem jungen idealistischen Kinder- und Jugendpsychiater, mit dem sie befreundet ist, bekannt. Dieser hält sich gerade in München auf, um an einem psychiatrischen Kongress teilzunehmen. Auch in dem Café, wo sie sich treffen, eskaliert die Situation, weil Felix die konventionellen Verhaltenserwartungen beim Kakaotrinken am Tisch nicht erfüllen kann. Doch Dr. Cromer lässt sich davon nicht beirren und wendet sich dem Kind auf Augenhöhe zu. Aufgrund von rechtlichen Regelungen kann er allerdings in Bayern keine Behandlung durchführen. Er empfiehlt Marie daher mit dem Jungen nach Berlin zu kommen. Dies erscheint zunächst als außerhalb der Möglichkeiten, doch am Ende fährt Marie mit Felix nach Berlin und bleibt dort mehrere Monate. Es ist schön zu sehen, wie unerschütterlich Marie an ihr Kind glaubt und wie sich der junge Psychiater, den das beeindruckt, dann engagiert, trotz der institutionellen Rahmenbedingungen, die nicht immer förderlich sind. Er nähert sich der Welt des Kindes an, über das Hantieren mit Glasmurmeln, Hölzern und anderen Materialien baut er eine Brücke zu Felix und kann so die Eigenaktivität und schließlich auch die Kommunikationsbereitschaft des Jungen wecken.

Schrittweise erkennt er, wie die innere Welt des Kindes aufgebaut ist. Für Marie wird das Ganze indes zu einer großen Belastungsprobe. Um die Behandlungskosten in der Klinik, in der Cromer arbeitet, aufzubringen, muss sie abends, bis tief in die Nacht, als Kellnerin, später gar als Bardame im Rotlichtmilieu, arbeiten. Sie wird von der Zimmerwirtin hinausgeworfen, als Felix eines abends wach wird und anfängt verzweifelt zu schreien und nicht wieder aufhört, bis dass die Mutter endlich zurückkommt. Zu der Zeit wurde offenbar eine psychiatrische Behandlung noch nicht von den Krankenkassen übernommen. Paul, ihr Mann, hat einen sehr hohen Kredit aufge- 
nommen, um eine neue Maschine für die Hopfenernte zu finanzieren und steht wirtschaftlich mit dem Rücken zur Wand, als die Brauerei, die sein Hauptabnehmer ist, den vereinbarten Preis für die Ernte nicht zahlt. Das sind die heimtückischen Schachzüge der Regie, damit das Ganze auch möglichst dramatisch wird. Vor dem Hintergrund war Paul auch gegen die Fahrt nach Berlin, aus Sorge, die Rechnungen nicht bezahlen zu können. Am Ende zieht Marie in die Wohngemeinschaft, in der auch Alex lebt, um den finanziellen Druck wenigstens etwas zu mildern. Unter den freien, experimentellen Bedingungen der 68er Bewegung baut Felix Kontakt mit den anderen Kindern in der Wohngemeinschaft auf. Er kommuniziert zwar auf seine eigene Weise, wirkt in gewisser Hinsicht aber erstmalig integriert. Für Marie beginnt sich, in der Berliner Luft, die Welt zu öffnen. Weit weg nun die Versuche der Schwiegermutter mit Pfarrer und Weihrauchfass eine Art Teufelsaustreibung an dem Kind zu versuchen. Im, durch die 68er bewegten, Berlin darf eben jeder anders sein. Dr. Cromer hat inzwischen mit der etablierten, orthodoxen Psychiatrie vollständig gebrochen und sich auch von seiner bisherigen Freundin getrennt, der Tochter eines bekannten und etablierten Psychiaters, über die er sicherlich hätte Karriere machen können, in genau dem wissenschaftlichen Apparat, den er nun überwinden und verändern will. Dr. Cromer arbeitet empathisch verstehend, notiert mit Ruhe, Konzentration, Anteilnahme und Hingabe seine Beobachtungen auf Karteikarten, denkt viel über Felix nach und berät sich auch mit einem älteren, erfahrenen Kollegen. Vielleicht wird der filmische Bogen ein wenig überspannt, als Alex, im Hörsaal der Universität, auf dem Klavier spielt und Felix, mit der Kreide in der Hand, in enormem Tempo die Musik in Zahlen übersetzt, an der Tafel. Doch das ist eben die Filmwelt, sie arbeitet mit Zuspitzungen und eingängigen Bildern. Ebenso müssen Marie und Dr. Cromer, so schön die Szene ja ist, nach all dem, was sie gemeinsam mit Felix durchgestanden haben, in der freien Atmosphäre der Berliner Wohngemeinschaft, sich auch einmal in die Arme nehmen und gemeinsam fallenlassen. Paul, als er schließlich nach Berlin kommt, weil er die Situation in Bayern, ohne Marie, nicht mehr erträgt und auch die beiden anderen Kinder der Familie leiden, weil sie ihre Mutter nicht mehr bei sich haben, und er dann am verhalten bewegten Abschied zwischen Marie und Dr. Cromer den emotionalen Tiefgang des ganzen Berliner Aufenthalts erahnt, akzeptiert es immerhin, schweigend, auch verstehend, wie man meint. Er nimmt Frau und Kind mit zurück auf den bayrischen Hof. Auch Paul hat in der Berliner Wohngemeinschaft übernachtet und gesehen, wie offen dort gelebt wird. Er hat einen schnellen Transformationsprozess durchlebt, man freut sich daran. Nur könnten die Wissenschaften in der nächsten Zeit noch damit aufhören, einem Menschen Etiketten, wie hier Asperger-Autismus, zuzuschreiben. Es ginge ja auch ohne.

\section{"Fack ju Göhte«: Resonante pädagogische Beziehungen}

Wunderbar unterhaltsam, geistreich, erfrischend, witzig, auch systemkritisch, ideologiekritisch, Tabus, Konventionen und derzeitige Sprechgebote sprengend. Über die Filmserie Fack ju Göhte ist schon viel Anerkennendes gesagt worden, zurecht (vgl. Haas, 2017; Lühmann, 2014; Uslar, 2013). Die »Feuerzangenbowle 4.0« oder auch der »Club der toten Dichter für die bildungsfernen Schichten«, wie in der ZEIT geschrieben wurde. Aber ist das wirklich eine »Teenagerkomödie« (vgl. Seifert, 2015)? Kaum. Eher 
ist es eine Schulkomödie, eine Satire über unser Schulsystem, über die Gesellschaft als Ganzes, über ihre Ideologien und Herausforderungen, von Bildungsgerechtigkeit über Inklusion bis Hochbegabtenförderung, von PISA bis Lehrer_innen-Burnout, eine Zuspitzung und Abrechnung, ein Durcharbeiten und Neu-Entwerfen. Als Pädagoge, der selbst viele Jahre im Schuldienst tätig war, als Lehrer, als Schulleiter, kann ich nur sagen: Ich habe mich beim Ansehen aller drei Teile von Fack ju Göhte köstlich amüsiert. Die Filme haben, trotz vieler fiktiver Elemente, Realitätsbezug, denn sie bringen etliche komplexe, symbolträchtige Szenen und haben insgesamt viel transformatives Potenzial. Natürlich, die Story ist ein wenig zu sehr zusammengebastelt. Etwa dass Zeki Müller den Job als Aushilfslehrer an der Goethe-Gesamtschule eher durch ein Missverständnis bekommt. Er wollte sich auf eine Hausmeisterstelle bewerben, allerdings nicht, um sich dann um ein Schulgebäude zu kümmern. Er nimmt den Lehrer-Job nur an, um durch nächtliche Grabungen an das, unter der Turnhalle lagernde, Geld zu kommen, das seine Partnerin, die Prostituierte Charlie, dort, auf dem Gelände hinter der Schule, damals noch eine Baustelle, nach dem gemeinsamen Banküberfall, vergraben hat. Oder die Machenschaften des Schiller-Gymnasiums und die Jagd nach den Diamanten in Thailand. Irgendwie gehört das alles nun mal dazu, um die nötige Leichtigkeit und den Drive bei der ganzen Sache zu erzeugen.

Die Methoden des Zufalls-Lehrers Müller sind überaus rabiat und gerade dadurch brechen sie das ganze Bildungsgetue gehörig auf, das wir uns seit Jahrzehnten ansehen und anhören müssen. Da lösen sich endlich die, durch jahrzehntelanges, andächtiges Nachbeten von pädagogischen Konzepten aufgebauten Spannungen. Zeki Müller, der delinquent gewordene charmante underdog, selbst von der Schule nicht adäquat gefördert, ja verkannt, wird von der Chaosklasse, die er schließlich übernimmt, anfangs ordentlich rangenommen. Doch er zahlt doppelt zurück. Auf die verbalen Provokationen der Jugendlichen setzt er immer noch eins oben drauf. Hier werden sie alle auf die Schippe genommen: Lehrer_innen, die sich mit ihren überkommenen Rollen überidentifizieren, die nicht wissen, wie sie auf den gesellschaftlichen Wandel reagieren sollen, aber auch die sog. bildungsfernen Schichten, die Harzer Milieus, die rechtsradikalen Milieus, die kriminellen Milieus, die Rotlichtmilieus, die Jugendwelten mit ihren medialen Orientierungen, ihren Sprachmustern von Türk-Deutsch bis Hip Hop. Aber auch die Schulbehörden, die Maschinerie der Leistungstests, das Konkurrieren zwischen den Schulen, die politisch bestellten, ideologisch unterfütterten, pädagogischen Konzepte. All das wird karikiert. Eine Klassenfahrt muss also in ein Schwellenland, hier nach Thailand, gehen, um der betreffenden Schule Fördergelder und Wettbewerbsvorteile zu verschaffen. Kriterium: Es muss da Probleme mit Menschenrechten geben. Das bringt der Schule Punkte, Ansehen und Geld. Auch muss die Fahrt inklusiv sein, also muss mindestens ein Schüler mit Förderbedarf dabei sein. Das ist in diesem Fall der, überaus sympathisch rüberkommende, Etienne. Der Junge verhält sich dann und wann etwas ungewöhnlich. Ihm wird das sog. Asperger-Syndrom zugeschrieben. Inklusiv erscheint der Umgang der anderen Jugendlichen mit Etienne in jedem Fall, allerdings auf sehr unkonventionelle, unverkrampfte Art und Weise. Es ließe sich vielleicht sogar etwas davon für die pädagogische Realität lernen. Der deutsch-türkische Drehbuchautor und Regisseur Bora Dagtekin schreckt hier vor keinem Tabu zurück. Hier wird nichts mehr mit der nötigen Andacht ausbuchstabiert. 21 Millionen Zuschauer gingen in die Kinos, um die drei Folgen zu sehen und ihren Spaß zu haben. Knallbunt das Ganze, viel Rhythmus und Abwechslung in der Handlung 
aller drei Teile. Gedreht in München und in Berlin, teils in Plattenbauvierteln in Neukölln, teils in einer Schwimmhalle in Schöneberg, teils in Thailand. Reichlich nervig die Rolle der Lehrerin Schnabelstedt, zu weinerlich, zu angepasst, zu sehr Opfer, um es im Jugendjargon zu sagen. Pragmatisch, abgebrüht die Schulleiterin. Sie beschafft Zeki Müller, der zum Starpädagogen der Schule und der Kampagne des Ministeriums geworden ist, das fehlende Abiturzeugnis und kommentiert die, von Zeki Müller vorgenommene und von ihr selbst zu Ende geführte, Urkundenfälschung mit dem Satz: »Wir werden hier den ganzen Tag verarscht. Jetzt verarschen wir mal zurück.«

Eine vielsagende Szene, als Chantal, die dabei ist, sich eine Karriere als Influencerin aufzubauen und von Thailand aus ihre Follower auf YouTube mit dem Neuesten versorgt, mit ihren silbernen, wirklich sehr hohen Plateau-Schuhen die Leiter in der Bibliothek nach oben steigt, jetzt wo die Kids endlich erkannt haben, dass Bücher relevantes Wissen enthalten. Ganz oben, im Fokus der Kamera, was für ein filmischer Schachzug, einige Bände von Michel Foucault. Chantal wird schwindlig. Sie fällt mit dem staubigen und schweren Buch, nach dem sie gegriffen hat und das sie nun in der Hand hält, nach hinten. Zum Glück fällt sie Danger, dem männlichen Enfant Terrible der Klasse, in die Arme. Wer selbst lange Jahre im schulischen Schwerpunkt der emotionalen und sozialen Entwicklung gearbeitet hat, wird Danger und die anderen Jugendlichen allerdings eher niedlich finden. Sehr schnell schwenken sie um, nach anfänglicher Rebellion, in Anbetracht der raubeinig verpackten Beziehungs- und Überraschungspädagogik von Zeki Müller. Sie werden schnell anhänglich, auch wenn es noch mal ein paar Vertrauenskrisen und Verhaltensrückschritte bei dem Ganzen gibt. Aber hier nun auch ein paar Einwände: So heldenhaft das ja alles ist, auch die Kids aus den dargestellten Milieus zum Abitur zu bringen, denn das stellt die Filmserie ganz und gar nicht in Frage. Es wird in diesen drei Filmen so ziemlich alles in Frage gestellt und aufs Korn genommen, aber dieses eine hier nicht. Dadurch, dass man als Lehrer_in an sie glaubt, all diese Bildungsträume aus den 70er Jahren, ja, das ist ganz fundamental wichtig in einer guten Pädagogik. Aber muss wirklich jeder, mit pädagogisch-didaktischen Kopfständen von Lehrer_innenseite, zum Abitur gebracht werden, um dann mit einer 4,0 oder 3,7 in welche Zukunft zu starten? Fack ju Göhte wagt leider noch nicht, die Existenz dieser Art von Schulsystem, inklusive der dort angestrebten und vergebenen Schulabschlüsse, generell in Frage zu stellen. Im Massenbetrieb staatlicher Universitäten kann das, was Zeki Müller macht, sicherlich nicht in der Art fortgesetzt werden, auch wenn sich das die Landesregierungen und Ministerien, die derzeit verzweifelt versuchen, an Absolvent_innen, speziell von sonder- und inklusionspädagogischen Lehramtsstudiengängen, zu kommen, sicher fiebernd wünschen würden. Sollten wir aber nicht besser endlich für eine gesellschaftliche Rehabilitierung der praktischen, handwerklichen Arbeit sorgen, statt weiter für eine gesellschaftlich unvernünftige Total-Akademisierung zu werben? Und wie weit kommt so eine quereinsteigende Lehrkraft im Schulsystem wirklich, ohne fundierte soziologische, philosophische Reflexionshintergründe und ohne pädagogische und didaktische Fachkenntnisse? Letztlich sind das aber die falschen Fragen an diese Filmreihe.

Gegen Johann Wolfgang von Goethe und die von ihm verkörperten Bildungsideale, wie der Titel ironisch nahelegt, geht das hier alles aber keineswegs. Ganz im Gegenteil. Die Filme führen eher neu zu Goethe hin, wenngleich Goethe und Gesamtschule, das ist ja nun mal Teil der ganzen filmischen Provokation, in der Tradition dieses Schultyps und hinsichtlich der traditionellen, vermutlich jedoch viel zu einseitigen, tradierten 
Goethe-Bilder, nicht recht zusammenzupassen scheinen. Aber im Grunde war Goethe vermutlich viel unkonventioneller, innovativer, ausgeflippter als all die Studienräte, die über Jahrzehnte das verstaubte, altbackene Goethe-Bild geprägt haben. Fack ju Göhte macht Goethe neu lebendig, doch müssen wir die Erarbeitung der traditionellen Bildungsinhalte jetzt eben ein wenig anders einrahmen. Das Ganze muss einfach zeitgemäß übersetzt und neu verknüpft werden. Insofern geht es auch hier um eine Art lebensweltorientierte Didaktik. Fack ju Göhte 1-3, das ist im Grunde ein großer Bildungsroman, zugleich schelmisch und subversiv. Zeki sei für die Schüler_innen sowas wie »ein Arsch mit Herz«, meint Charlie, die Freundin aus dem Rotlichtmilieu. Sollen wir diese Filmserie nun in der Lehrer_innenbildung an Universitäten thematisieren? Ja unbedingt, denn das schafft Gesprächsanlässe, beschleunigt Reflexion, bringt viel in Bewegung. An der Universität Köln, so ist in einem der genannten ZEIT-Artikel (vgl. Seifert, 2015) zu lesen, haben die Filme schon Eingang in die Seminare gefunden, in der Pädagogischen Psychologie. Da werden die Filme nun in Szenen zerlegt und dann Querverbindungen etwa zur, bis zum Überdruss zitierten, Hattie-Studie hergestellt, zum Beispiel bezüglich des Lehrer-Schüler-Verhältnisses oder der aktiven Lernzeit, die ja von Hilbert Meyer als eines von mehreren Kriterien guten Unterrichts benannt wurde. Besonders die aktive Lernzeit wird ja heute auf eine erdrückende und ermüdende Weise von Fachleitungen, Schulleitungen, Stufenleitungen, Seminarleitungen oder Qualitätsprüfer_innen als Messlatte für guten Unterricht angesehen, ausgegeben und eingefordert, zum Leidwesen der in den Klassen tätigen Lehrkräfte, besonders aber der sich in Abhängigkeit befindlichen Lehramtsaspirant_innen, die nicht einmal ein paar Minuten durchatmen können, weil sonst kostbare Lernzeit verloren gehen könnte. Aber geht nicht gerade durch diese ständige Anspannung etwas verloren? Auch wird in dem genannten Artikel über die hochschuldidaktische Arbeit in Köln festgestellt, dass es optimal sei, den motivierenden Stil von Zeki Müller mit der planenden Systematik der Lehrerin Schnabelstedt zu verbinden. Dabei wird so getan, als handle es sich bei den Drehbüchern um ein Fallmaterial aus der schulischen Praxis.

Doch die Filme sind Kunstwerke und wollen mit Sicherheit keine Anleitung für die schulische Praxis sein. Wir können ja auch nicht mit Farbbeuteln auf unterrichtsverweigernde Schüler schießen, noch ihnen Chips unter die Haut implantieren, um fortan ihren Aufenthaltsort zu bestimmen und sie vom Stehlen von Lippenstiften in Drogerien abzuhalten. Noch können wir sie hinten ans Auto binden und zur Schule schleifen, selbst wenn wir dies alles gerne einmal tun würden. Das sind symbolhafte, allerdings sehr erfrischende, Filmbilder. Das hochschuldidaktische Aufgreifen muss folglich ein wenig anders, mehr in übergeordneten, philosophischen Zusammenhängen geschehen. Es müssen sich jetzt nicht Lehrer_innen bemühen darzulegen, wie im Magazin Spiegel geschehen, dass sie aber viel mehr Zeit für die Vor- und Nachbereitung des Unterrichts am Schreibtisch verbringen, als das bei Zeki Müller sichtbar wird, womöglich aus der Sorge heraus, jemand könnte denken, sie führten ein so freies Leben wie dieser pädagogische Rebell. Irgendwas wurde hier falsch verstanden. Kunst und Realität sollen zwar aufeinander bezogen werden, aber nicht im 1:1 Abgleich. Kunstwerke, wie diese Filme, wollen Impulse geben, zum Nachdenken anregen, verfestigte Wahrnehmungs-, Denk- und Handlungsmuster irritieren und nebenher auch noch unterhalten. Goethe selbst hätte diese Form der filmischen Thematisierung sicher sehr begrüßt, nachdem er sich die jüngere Geschichte und die Gegenwart unserer Schulpädagogik und unserer Gesellschaft erst einmal genauer angesehen hätte. Als 
nächstes brauchen wir sowas, wenn ich das einmal satirisch ein wenig zuspitzen darf, über die Welt der Academia, um die dort anzutreffenden Spiele auf die Schippe zu nehmen, den Wahnsinn der Modularisierung, die Politik der Akkreditierung, die Monetarisierung, die immer engere Steuerung, das immer direktivere Durchregieren, bis hin zu einer Neuen Despotie, wie Keane es nennt, die anwachsende Bürokratisierung, die Kompetenzorientierung, die Frauen- und Quotenpolitik, die Berufungspolitik und die Politik der Begutachtung von Professor_innen, die Politik der Forschungsförderung und des Generierens von Drittmitteln, die Strippenzieherei, das Entstehen von neuen höfischen Strukturen, das Antichambrieren, das Einfädeln von Intrigen, das Schmieden von Komplotten, die schrittweise Verwandlung von freigeistigen Professor_innen in Lehrknechte und Lehrmägde, die in den Bildungswissenschaften an immer mehr Orten evidenzbasiertes, apparatives Steuerungswissen produzieren sollen, Professor_innen, denen man versucht die Flügel zu stutzen und die man dazu anhält, am Stutzen ihrer Flügel selbst mitzuwirken. Titelvorschlag für eine solche Filmstaffel: Humbollt ju bitsch. 


\section{Das ländliche Westdeutschland zur ersten Hälfte des 20. Jahrhunderts: Soziokulturelle Rekonstruktionen}

\section{Generationenübergreifendes, narratives Lernen in einer dörflichen Community}

Dieses Kapitel untersucht zunächst die Biografien von sieben, zwischen 1896 und 1909 auf einem Dorf in Südwestfalen als Kinder eines Landarbeiters und einer Müllerstochter geborenen, Geschwistern. Dabei wird gefragt, welche Möglichkeiten des sozialen Aufstiegs, der kulturellen Partizipation und der Selbstgestaltung von Geschlechterrollen in den Lebensgeschichten dieser Mädchen und Jungen sichtbar werden. Diese drei Faktoren, so meine Hypothese, sind zugleich Einflussfaktoren für eine ausgeglichene emotionale und soziale Entwicklung. Das zugrundeliegende Material wurde im Rahmen eines, in der dörflichen Community angesiedelten, narrativ angelegten, generationenübergreifenden Lern- und Forschungsprojektes generiert. Aus diesem Projekt werden am Ende des Kapitels einige exemplarische Bilddokumente hinzugefügt. Gemeinsam mit Janet Painter und Joyce Davis habe ich einen Teil des Materials bereits ausgewertet, unter der Fragestellung, welche politische, demokratische Bedeutung in den gesammelten Erzählungen liegt. 2017 haben wir dazu im International Journal of Lifelong Education veröffentlicht. Doch im vorliegenden Kapitel sollen speziell die Lebensläufe der sieben Geschwister betrachtet werden, unter den genannten Aspekten. Während zwei der Söhne die Möglichkeit zum sozialen Aufstieg bekamen, verblieben die beiden Töchter und die anderen drei Söhne im Rahmen ihres Herkunftsmilieus. Die Aufstiegschancen für die beiden Jungen waren jedoch eng gekoppelt an die Ziele des nationalsozialistischen Regimes. Während der eine als Ingenieur in den deutschen Ostgebieten das Anlegen von Wiesen und das Bauen von Straßen vorantreiben sollte, übernahm der andere, begünstigt durch das Reichserbhofgesetz, einen Großgrundbesitz, auf dem er zuvor als Knecht gearbeitet hatte. Die Möglichkeiten der kulturellen Partizipation im Dorf waren schicht- und milieuspezifisch begrenzt. Kulturelle Bezugs- und Handlungsfelder wurden durch die katholische Kirche, die Volksschule, einen Fußballverein, einen Gesangsverein, einen Schützenverein und einen Theaterverein konstituiert. Eine der Töchter fand in der Welt des Theaters ihr bevorzugtes Aktionsfeld. Die Ausgestaltung der Geschlechterrollen bei den sieben Kindern lief, den sozialen und normativen Vorgaben jener Zeit entsprechend, zunächst einmal auf konventionellen Bahnen. Bei einer der Töchter und beim jüngsten Sohn der Familie deuteten sich allerdings erste Versuche an, die heteronormativen Identitätskonstruktionen zu überschreiten. Vor allem die Welt des Laientheaters bot hierfür Raum. Das von 2011 
bis 2014 laufende, biografisch orientierte, generationenübergreifende Forschungsprojekt, umgesetzt in Eichertshagen ${ }^{1}$, einem in Südwestfalen gelegenen Dorf von ca. 2000 Einwohner_innen, war zum einen angeregt durch die Geschichte von unten (vgl. z. B. Ehalt, 1994; Paul und Schoßig, 1986) und die Oral History (vgl. z. B. Bergmann und Kuhn, 1984; Shopes, 2011). Zum anderen gewann das qualitativ ausgerichtete Projekt seine Orientierung aus Life History-Ansätzen (vgl. etwa Goodley et al. 2004; Merrill und West, 2009). Der narrative Zugang (vgl. Chase, 2011) und die Arbeit mit Dokumenten (vgl. Patton, 2002) wurden verknüpft mit Modellen des Community-based Learning und des Learning Across Generations (vgl. Schmidt-Hertha et al., 2014).

Im Kern handelte es sich darum, dass etwa 30 ältere Menschen aus einer großen und verzweigten Familie, geboren zwischen 1930 und 1945, über 2,5 Jahre hinweg, ihre Lebenserfahrungen in verschiedenen kommunikativen Formationen, von freien, unstrukturierten Gruppengesprächen, über thematisch strukturierte Fokusgruppen, bis hin zu Einzelinterviews, mit einer Reihe von jüngeren Personen aus Eichertshagen und mir, als Projektleiter, rekonstruierten und reflektierten. Eine zentrale Rolle spielte dabei das Sammeln und Aufschreiben von Anekdoten und Geschichten sowie das Zusammentragen und gemeinsame Betrachten von Photografien, Briefen, Tagebüchern und weiteren Materialien wie z. B. Militärpässen, Stammbüchern etc. Dies alles wurde von mir auf einen Tonträger aufgenommen oder, je nach Situation, auch mit der Hand notiert, abgeschrieben und gemeinsam mit den eingescannten Dokumenten zu einer Art kollektivem Tagebuch zusammengestellt. Dieses wurde in verschiedenen Entwurfsfassungen vervielfältigt und wiederum zurück an die Teilnehmenden gegeben und von diesen weiterbearbeitet, ergänzt und fortentwickelt. Die dabei zur Sprache kommenden biografischen Erfahrungen drehten sich zum einen um die Zeit des Nationalsozialismus, den Zweiten Weltkrieg und die Nachkriegszeit. Zum anderen wurden auch die Lebensverhältnisse der davor lebenden, um 1900 geborenen, Generation, rekonstruiert und reflektiert, auf der Basis der weitergegebenen Erzählungen und der vorhandenen Dokumente und Materialien. Somit gab es auch Einblicke in Biografien und Lebenskontexte des wilhelminischen Deutschland und der Weimarer Republik. Das Projekt hatte beides im Blick: Die individuelle Lebensgeschichte und die historischen, gesellschaftlichen und politischen Zusammenhänge, in denen die einzelne Lebensgeschichte steht. Bisher gibt es zwei Veröffentlichungen zu dem genannten Projekt: Einen 400-seitigen Materialband (vgl. Bröcher, 2014), der aus dem kollektiven Tagebuch entstanden ist, das zugleich in seinen prozesshaften Entwurfsfassungen die materielle Grundlage der biografischen Reflexionen darstellte sowie einen Artikel, der die Ziele, Methoden und Ergebnisse des Gesamtprojektes darlegt und für die internationale Forschungscommunity zusammenfasst (vgl. Broecher et al., 2017). Dabei wurde das Material anhand der folgenden Themen analysiert: Das Arbeits- und Familienleben, die großen Meilensteine des Lebens, das Leben der Frauen zwischen Abhängigkeit und Selbstbestimmung, sozialer Zusammenhalt und kommunale Strukturen der Selbsthilfe und gegenseitigen Unterstützung, das Theaterleben im Dorf Eichertshagen als Form des selbstorganisierten kulturellen Lebens, Schule und Erziehung sowie Informations- und Meinungsfreiheit und Alltagsleben in einem totalitären Staat. Es kristallisierten sich in den Erzählungen der, am Projekt

1 Alle Namen von Orten und Personen wurden geändert, mit Ausnahme der regionalen Bezeichnungen Südwestfalen und Siegerland. 
teilnehmenden, Frauen und Männer, die ja zwischen 1930 und 1945 geboren waren, besonders sieben, zwischen 1896 und 1909 geborene, Geschwister heraus, die allesamt Väter, Mütter, Onkel und Tanten der Teilnehmenden waren. Die biografische Entwicklung dieser sieben Geschwister, von denen einige, im Laufe der rekonstruierenden Arbeit, als besonders markante Charaktere hervortraten, soll nun genauer betrachtet werden.

\section{Ein Landarbeiter, eine Müllerstochter und ihre sieben Kinder}

Heinrich (1865-1935) war in Eichertshagen als einfacher Landarbeiter oder als Knecht für wohlhabendere Bauern, die etwas besaßen, tätig. Im Jahre 1895 heiratete er Anna (1869-1944), die einen kleinen Hof, mit einigen Wiesen und Feldern, geerbt hatte. Durch diese Heirat war Heinrich in der Lage, eine Familie zu gründen und die Familie hatte ein respektables Haus, in dem sie leben konnte. Zu jener Zeit hatte das Dorf etwas über 400 Einwohner_innen. Mit ins Haus zogen eine unverheiratete Schwester von Anna und eine unverheiratete Schwester von Heinrich. Anna's Vater war ein Müller, der einige Dörfer weiter eine Mühle betrieb. Das Anna überschriebene Fachwerkhaus war gemeinsam mit der Dorfkapelle um 1650 gebaut worden. Das Gebäude-Ensemble hatte früher einmal zu einem Adelssitz im Siegerland gehört und die Müllerstochter hatte den kleinen Hof von ihrem Großvater mütterlicherseits geerbt. Geld war indes nicht viel vorhanden, so dass sich Heinrich, neben der kleinen Landwirtschaft, die er betrieb, weiter auf anderen Höfen als einfacher Landarbeiter und Knecht verdingen musste, vor allem in Schwarzbrock, einem, einsam an einer alten Landstraße gelegenen, Gutshof. Dieses, zwischen 1810 und 1820 errichtete, Anwesen wurde von Martha, der ledig gebliebenen Erbin einer vermögenden Industriellenfamilie, bewirtschaftet. Teile von Marthas Familie hatten Erzgruben betrieben, andere waren als hohe Beamte in den Gemeindeverwaltungen der Gegend tätig gewesen. Nachdem Marthas Eltern und auch sämtliche Brüder und Schwestern gestorben waren, lenkte sie die Geschicke des Gutshofs schließlich allein. Arbeitskräfte holte sie sich aus dem benachbarten Eichertshagen. Einer von ihnen war Heinrich und später auch zwei seiner Kinder: Frieda und Friedrich. Heinrich und Anna bekamen zwischen 1896 und 1909 insgesamt sieben Kinder: Paul (1896-1973), Hermann (1900-1978), Richard (1902-1970), Frieda (19031994), Otto (1905-1985), Friedrich (1907-1989) und Bertha (1909-1941). Zwei Portraits der Familie, in ihren Sonntagsanzügen, sind erhalten geblieben. Das eine stammt von 1912 und das andere von 1925, jeweils aufgenommen von einem professionellen Photografen. $\mathrm{Zu}$ allen sieben Geschwistern und ihren Familien existieren weitere Bilder, in den verschiedensten Konstellationen. $\mathrm{Zu}$ allen wurde, im Verlauf des Projekts, reichlich anekdotisches Wissen zusammengetragen, auch Dokumente wie Stammbäume, Briefe, Militärpässe etc. Zur jüngsten Tochter Bertha, die 1941 im Kindbett verstorben war und deren Ehemann und einziger Sohn später durch Unfälle mit Militärfahrzeugen, im Rahmen des Zweiten Weltkriegs, ums Leben kamen, fiel das Zusammengetragene nicht so umfangreich aus. Wegen der hohen Gegenwartsbedeutung dieser Themen, soll die Betrachtung dieser sieben Biografien nun unter den folgenden drei Aspekten erfolgen: Zum einen mit Blick auf die Möglichkeit zum sozialen Aufstieg, zweitens unter der Perspektive der kulturellen Partizipation und drittens in Bezug auf die jeweils sichtbar werdenden Geschlechterrollen. 


\section{Chancen zum sozialen Aufstieg}

Alle sieben Kinder der Familie besuchten die Volksschule im Dorf Eichertshagen. Bis auf den an zweiter Stelle geborenen Hermann, gingen sie auf keinerlei weiterführende Schulen. Außer Hermann war Richard der einzige, der eine solide Berufsausbildung bekam. Er machte eine Lehre als Huf- und Wagenschmied, im Siegerland, arbeitete dort noch eine Weile als Geselle und machte sich dann als Schmiedemeister in Eichertshagen mit einer eigenen Schmiede selbstständig. Er baute seine Schmiede und ein Wohnhaus gleich neben dem elterlichen Hof. Die anderen fünf Kinder mussten sich als ungelernte Arbeitskräfte durchschlagen. Alles, was sie an Bildung im Gepäck hatten, waren die in 7-9 Jahren Volksschulbesuch erworbenen Kenntnisse. Der 1896 geborene Paul kam als Viehhändler und Händler für Futtermittel über die Runden. Er hatte in einen kleinen Hof in einem Nachbardorf eingeheiratet und fand so ein Dach über dem Kopf. Frieda arbeitete als Haushälterin und landwirtschaftliche Hilfskraft, zunächst auf dem Gutshof Schwarzbrock, später in anderen Haushalten und Fabriken. Otto ernährte seine Familie durch abhängige Lohnarbeit als ungelernter Arbeiter in einem Walzwerk im Siegerland. Die bereits mit 32 Jahren verstorbene Bertha hatte ihre Arbeitskraft in die Bewirtschaftung des elterlichen Hofes eingebracht. Der 1907 geborene Friedrich half als Knecht auf dem Gutshof Schwarzbrock, genauso wie seine Schwester Frieda und einige andere junge Männer aus dem Dorf Eichertshagen. Während Paul, Richard, Frieda, Otto und Bertha im Rahmen der sozialen Schicht, in die sie hineingeboren waren, verblieben und sich darin einrichteten, bewegten sich Hermann und Friedrich auf der sozialen Stufenleiter nach oben. Der 1900 geborene Hermann besuchte im benachbarten Siegerland eine Fachschule, in der es um die Vermittlung von Kenntnissen im Wiesenbau ging. Wahrscheinlich hatte ein Volksschullehrer die Fähigkeiten des Jungen erkannt und den Eltern empfohlen, ihn weiter die Schule besuchen zu lassen. Diese, etwa um die Jahre 1915-1917 erworbene, Fachschulbildung ermöglichte ihm später eine berufliche Karriere, wie sie nicht nur für die betreffende Familie, sondern für das gesamte Dorf Eichertshagen zu jener Zeit ganz ungewöhnlich war. Hinzu kam, dass er eine Frau heiratete, die aus der oberen Mittelschicht, aus Köslin, Pommern, stammte und die über ausgeprägte Bildungshintergründe verfügte. Rosa und Hermann schrieben sich, bevor sie heirateten, regelmäßig Briefe, wenn Hermann nach Eichertshagen zu seinen Eltern reiste und sich dort stets für einige Tage oder Wochen aufhielt. Rosa verfasste ausführliche Tagebücher, in denen sie auf der einen Seite Zeitgeschichtliches festhielt und auf der anderen Seite ihre eigenen Emotionen und Erfahrungen reflektierte.

Auch sammelte und archivierte sie sorgfältig alle biografisch relevanten Materialien und nahm diese auf den Gutshof Schwarzbrock mit, wo sie ihre letzten Jahre verbrachte, nachdem ihr Mann Hermann verstorben war. Dort lagerten die Materialien viele Jahre unbeachtet in Kartons und in Koffern aus den 1920er Jahren. Sie überdauerten sogar einen großen Brand auf dem Gutshof in den 1970er Jahren. Hermann wurde zunächst als Soldat in den Ersten Weltkrieg geschickt und kämpfte in Frankreich. Nach Kriegsende wurde er nach Pommern bzw. Westpreußen berufen, konkret nach Flatow und Deutsch Krone, wo er als Kulturbaumeister leitende Aufgaben im Wiesenbau, später auch im Straßenbau bekam. In Köslin lernte Hermann auch seine zukünftige Frau Rosa kennen. Der Briefwechsel zwischen Rosa und Hermann legt nahe, dass er kein überzeugter Nationalsozialist gewesen ist, obwohl er Mitglied der NSDAP 
war. Er beklagt etwa in einem der Briefe, dass der katholische Dorfpriester von Eichertshagen nicht mehr frei predigen dürfe, bisher habe er nämlich vielerlei Kritik am nationalsozialistischen Regime in der Kirche geäußert und dass der Pfarrer seine Predigten ab sofort niederschreiben müsse, um sie von einer bestimmten nationalsozialistischen Stelle genehmigen zu lassen. Anschließend müsse er die Predigt dann vom Blatt ablesen. Hermann ist besorgt und notiert dies in einem Brief an seine Frau, dass sein Bruder Richard, der Dorfschmied, weitere Konsequenzen der Nationalsozialisten zu fürchten habe. Er habe sich in der Dorfkneipe über Hitler und die Nazis wiederholt kritisch geäußert und lustig gemacht, sei dann offensichtlich denunziert und für neun Tage ins Gefängnis geworfen worden. Der Dorfpfarrer habe durch seine Intervention verhindern können, dass der Bruder nach Düsseldorf abtransportiert und interniert worden sei. Hermann dürfte sich also mit dem nationalsozialistischen Staat und dessen Ideologie nicht überidentifiziert haben. Trotz allem erscheint sein gesamter biografischer Weg opportunistisch und systemkonform. Er war nicht nur Mitglied der NSDAP. Wir fanden in seinem Nachlass auch eine Ariermappe, ohne deren lückenlose Dokumentation aller relevanten Stammbäume und biografischer Linien er in dem nationalsozialistischen Machtapparat niemals hätte aufsteigen können. Hermann war als Ingenieur Mitglied der Organisation Todt, einer technischen Spezialeinheit, die mit der Errichtung kriegsrelevanter Anlagen, wie z. B. Luftschutzanlagen, Raketenabschussrampen, unterirdischer Produktionshallen etc. zu tun hatte. An welchen konkreten Projekten Hermann beteiligt war, ließ sich nicht herausfinden. Er hatte als hoher Beamter ein gutes Einkommen. Seine Frau und er schickten in Abständen Pakete mit Lebensmitteln an die Familien der Geschwister in Eichertshagen. Nach Kriegsende und der Vertreibung der Deutschen aus den Ostgebieten wurde Hermann zunächst in einem britischen Gefangenenlager festgesetzt und verhört, wohl wegen seiner Mitgliedschaft in der NSDAP und in der Organisation Todt. Nach vermutlich einem halben Jahr wurde er jedoch freigelassen. Ab etwa 1946 wurde er wiederum als hoher Beamter in Westdeutschland tätig, wo er die Leitung einer Behörde übernahm, die mit Straßen- und Landschaftsbau zu tun hatte.

Eine andere Form des sozialen Aufstiegs realisierte sich im Leben des 1907 geborenen Friedrich. Nach Abschluss der Volksschule, etwa 1922, arbeitete er gemeinsam mit dem Vater und einigen anderen jungen Männern aus Eichertshagen als Knecht auf dem Gutshof Schwarzbrock. Seine Arbeitgeberin war Martha (1868-1936), alleinstehende und von der Familie als einzige übrig gebliebene Alleinerbin. Sie war auf Arbeitskräfte aus dem benachbarten Dorf angewiesen, um den Gutshof zu bewirtschaften. Im Jahr 1922 war Martha 54 Jahre. Als sie älter wurde, traf sie testamentarische Regelungen, wonach der Gutshof und die dazugehörigen Ländereien, nach ihrem Tod, an ein, etwa 15 Kilometer entfernt liegendes, Kloster gehen sollten. Dies wurde jedoch durch das, von den Nationalsozialisten erlassene, Reichserbhofgesetz verhindert. Danach musste ein solcher Gutshof an einen deutschen Mann vererbt werden, der gerade geheiratet hatte oder im Begriff war dies zu tun und der glaubhaft machen konnte, dass er gemeinsam mit seiner Frau ausreichend Nachkommen zeugen und einen solchen Hof bewirtschaften könne. Im Rahmen des Projekts tauchte umfangreiche Korrespondenz von Rechtsanwälten und Behörden auf, auch Rechnungen und Bücher, in denen die Einnahmen und Ausgaben des Hofes, inklusive der Gehälter der Knechte und Mägde, fein säuberlich notiert waren. Auch detaillierte Auflistungen des Besitzes, von der Anzahl des Viehs, über das Tafelsilber, bis hin zu den Stoffballen, die in 
den Truhen auf den Fluren des Wohngebäudes lagerten, wurden aus den Familienarchiven von Friedrichs Kindern hervorgeholt. Martha, inzwischen 66 oder 67 Jahre alt, hatte mit Vehemenz versucht, ihren eigenen testamentarischen Plan gegen die Nationalsozialisten durchzusetzen, erfolglos. Schließlich, nachdem sie hatte einlenken müssen, den Hof an einen der Männer aus Eichertshagen zu vererben, und ihre nicht gerade freie Wahl dann auf Friedrich gefallen war, hatte sie über ihren Rechtsbeistand $\mathrm{zu}$ erreichen versucht, dass sie immerhin ihr Barvermögen an einige Cousinen und Freundinnen, alles gebildete und besser gestellte Frauen, mit denen sie einen regen Briefwechsel unterhalten hatte, vererben konnte. Auch hierzu gab es einen sich länger hinziehenden Rechtsstreit, weil Friedrich, der nun schon als Besitzer des Hofes im Grundbuch eingetragen war, argumentierte, dass er ohne jedes Barvermögen den Hof nicht bewirtschaften könne. Martha kämpfte indes um ihr Recht auf Selbstbestimmung. Sie unterlag schließlich. Als sie 1936 mit 68 Jahren starb, ging ihr kompletter Besitz an Friedrich. Zunächst bewirtschaftete er den Hof allein, 1938 heiratete er. Für den 29-jährigen Knecht bedeutete die Übernahme von Schwarzbrock einen enormen sozioökonomischen Aufstieg. Der etwa 1820 als repräsentatives Steingebäude errichtete Gutshof, mit seinen hohen Zimmerdecken, stilvollen Fenstern und ausgedehnten Stallungen und Wirtschaftsgebäuden, stand, allein schon architektonisch, im allergrößten Kontrast zu den einfachen, niedrigen Fachwerkhäusern von Eichertshagen, die hinter dem Hügel lagen und denen man die Armut und das schlichte Leben ihrer Bewohner_innen ansehen konnte.

Nach und nach baute sich Friedrich ein neues soziales Netzwerk auf. Er verkehrte nun in anderen Kreisen als seine Geschwister, teils gab er diesen nun Aufträge, insbesondere Richard, dem Dorfschmied. Das Beziehungsverhältnis zwischen den beiden und ihren Familien wurde allerdings als ambivalent beschrieben. Teils blieben enge freundschaftliche Beziehungen erhalten, insbesondere zu Hermann und zu dessen Frau Rosa, die später ihren Lebensabend auf Schwarzbrock verbringen sollte. Friedrich, der neben Hermann, als einziger in der Familie über die notwendigen finanziellen Mittel verfügte, holte, nach dem Tod seines Vaters, auch seine Mutter und deren ledige Schwester nach Schwarzbrock, wo sie bis zu ihrem Tod lebten. Auf diese Weise wurde der Gutshof zu einem Mehrgenerationenprojekt. Trotz allem bleibt das, in den Erzählungen und gemeinsamen biografischen Rekonstruktionen, von Friedrich gezeichnete Bild sehr zwiespältig. Wenn er bei einem größeren Fest, so wurde berichtet, viel getrunken hatte und in guter Laune war, dann konnte es durchaus sein, dass er ein ganzes Fass Bier ausgab. Ansonsten wird er als wenig freigebig und misanthropisch beschrieben. Die Nachfahren des Dorfschmieds Richard berichteten etwa, dass Friedrich sie schroff abgewiesen habe, als ihre Mutter sie während der Kriegszeit, als diese kaum wusste, wie sie ihre acht Kinder satt bekommen sollte, zum Gutshof geschickt habe, um dort etwas Mehl zum Backen zu erbitten. Ein Sohn des Schmieds berichtete, wie er einmal in einen der Apfelbäume hinter dem Gutshof geklettert sei, um sich einen Apfel zu pflücken und Friedrich, erbost über die Eigenmächtigkeit des Neffen, ihn wutentbrannt, mit einer Peitsche, aus dem Baum herausgetrieben habe. Als Friedrichs jüngster Sohn mit seiner jungen Frau, nach durchtanzter Hochzeitsnacht, in den frühen Morgenstunden, nach Hause kam, und die beiden sich zunächst ein wenig schlafen legen und erst später in den Kuhstall gehen wollten, sei der Vater wutentbrannt mit einer Axt auf sie losgegangen und hätte auf sofortigem Arbeitsbeginn im Stall bestanden. 


\section{Möglichkeiten der kulturellen Partizipation}

Das Kulturleben im Dorf Eichertshagen war, ab 1900 bis in die 1970er Jahre hinein, insbesondere durch die katholische Kirche geprägt. Die Kirche rahmte die großen Lebensereignisse ein und unterlegte diese mit Sinnbezügen. Durch ihre sinnlichen Inszenierungen gab sie zugleich kulturelle Impulse. Alle sieben Geschwister verblieben ihr Leben lang in diesem vorgegebenen Bezugsrahmen. Doch allein Frieda übernahm aktiv Aufgaben im Kontext des religiösen Lebens, indem sie eng mit dem Pfarrer zusammenarbeitete bei der Gestaltung von öffentlichen Ereignissen, Feiern oder kirchlichen Festen. Otto engagierte sich in seiner Freizeit als Schiedsrichter bei Fußballspielen in den Dörfern der Region und war in der Welt des Fußballs ein geschätzter Mann. Richard, der Dorfschmied, war bekannt für seinen Humor und Witz. Er war ein Geschichtenerzähler und viel in den Kneipen unterwegs, um an Aufträge zu kommen. Er prägte, auf seine unverwechselbare Weise, eine bestimmte Form der mündlichen, regional verwurzelten Erzählkultur. In diesen Erzählungen werden Werte wie geistige Freiheit, Autonomie und Widerständigkeit transportiert, ein Hintergrund, aus dem der Dorfschmied auch seine mutige, teils leichtsinnige Haltung während des Dritten Reiches schöpfte. Ein Repräsentant der NSDAP hatte etwa verlangt, dass ein Bild von Adolf Hitler in der Schmiede, wo ja mehr oder weniger das ganze Dorf verkehrte, platziert wurde. Richard fragte den Mann: »Wat maaken mij dann mit dämm? Summen upphangen ördder an de Wand ställn?« (Was machen wir denn mit dem? Sollen wir ihn aufhängen oder an die Wand stellen?) Und ein anderes Mal hatte Richard in einer Dorf kneipe gesagt: "Schitte is uch brujn (Scheiße ist auch braun). Hermann gewann durch seine Frau Zugang zu einer Bildungswelt, die normalerweise für die Kinder aus Eichertshagen nicht erreichbar war. Rosa las Romane, schrieb Briefe und verfasste Tagebücher. Auf Photografien sehen wir sie fein gekleidet, mit Pelzkragen und elegantem, breitem Hut. Wenn sie mit nach Eichertshagen kam, verbreitete sie dort eine Atmosphäre von Eleganz und Weltgewandtheit. Der Kontrast hätte nicht größer sein können, wenn man die einfachen Menschen sah, die dort ihre Kühe hüteten und mit Holzschuhen auf den unbefestigten Dorfwegen liefen. Das kinderlos bleibende Paar kam für die damaligen Verhältnisse viel herum, reiste zwischen Pommern und Südwestfalen, mit dem Zug, über Berlin. Wer von den einfachen Menschen im Dorf war jemals mit einem Schnellzug gefahren? Wer von ihnen hatte jemals Berlin, Stettin oder die Ostsee gesehen? Die Menschen in Eichertshagen kannten bis dahin nur Fuhrwerke, vor die ein Ochse gespannt wurde. Friedrich gewann durch seinen neuen Status als Großgrundbesitzer Zugang zu höhergestellten Kreisen. Dazu gehörten Industrielle, mit denen gemeinsam er Jagden, auch auf seinen eigenen Ländereien, organisierte. Es existieren Photografien von solchen Ereignissen und den anschließenden Festlichkeiten im Saal des Dorfgasthofs. Zugleich blieb Friedrich seiner Herkunft treu, indem er bei den wichtigen Dorffesten teilnahm, etwa Schützenfesten, Familienfeiern usw.

Eine besondere Rolle spielte im Kulturleben des Dorfes Eichertshagen das Theater. 1919, im freieren Klima der Weimarer Republik, wurde ein Theaterverein gegründet, der allerdings seine Tätigkeit während des Dritten Reiches wieder einstellen musste. Geprobt wurde in einer Scheune. Die Aufführungen fanden im Saal der Dorfgaststätte statt, wo auch sämtliche anderen wichtigen Ereignisse des Dorflebens, von Hochzeiten bis Beerdigungskaffees, ihren Raum hatten. Frieda, zu dem Zeitpunkt 16 Jahre alt, protokollierte die Gründung des Theatervereins. Auf einer Photografie von 1920 se- 
hen wir 25 jüngere Frauen und Männer, darunter auch Frieda und ihre Brüder Richard und Hermann. Dieser Theaterverein bestand bis weit in die 6oer Jahre. Vor allem für Frieda eröffnete sich hier ein Aktionsfeld von ganz besonderer Bedeutung. Sie übernahm, gemeinsam mit einem der Männer, eine führende Rolle bei den Theateraktivitäten und stand auch in engem Kontakt mit Lehrer und Pfarrer. Diese halfen den Theaterleuten an Texte zu kommen und diese für die Arbeit im Dorf zu erschließen und so umzuschreiben, das man/frau diese auf die Bühne bringen konnte. Hinzu kam, dass Frieda, über die Theaterproben und Theateraufführungen hinaus, eine führende Rolle im kulturellen Leben des Dorfes Eichertshagen einnahm, indem sie eine gefragte Rednerin bei allen nur denkbaren dörflichen Ereignissen wurde. Sie sprach bei Hochzeiten, Beerdigungen, Schützenfesten, Kirchenfesten, eigentlich immer dann, wenn gefeiert oder getrauert wurde, wenn jemand wichtiges im Dorf begrüßt, empfangen oder in ein Amt eingeführt wurde oder ein Jubiläum hatte. Frieda trat auf, moderierte, kommentierte, unterhielt oder sie trug Verse, Gedichte und Balladen vor. Eine ihrer Nichten hat ihren gesamten Nachlass von Texten bekommen und aufgehoben, inklusive der bei diesen Gelegenheiten verwendeten Requisiten, das heißt Hüten, Taschen, Schals, Jacken, Perücken usw. Was Frieda tat, hatte auch Bedeutung für die Dorfbewohner_innen. Sie setzte sich in ihren, teils selbst verfassten, teils von anderen übernommenen und umgeschriebenen oder weiterentwickelten, Texten mit lebensgeschichtlichen Ereignissen auseinander, mit Liebe und Sexualität, mit dem Verhältnis der Geschlechter zueinander, mit Geburt, Älterwerden und Tod, mit dem Großziehen von Kindern und den damit verbundenen Schwierigkeiten, mit Schule, Religion, oder mit den gesellschaftlichen Veränderungen, auch mit sozialen Klassengegensätzen. Diese thematisierte sie besonders gerne aus der Perspektive eines aufmüpfigen Dienstmädchens.

\section{Gefangensein in tradierten Geschlechterrollen}

Das Geschehen um den Gutshof Schwarzbrock ist, unter der Perspektive der Geschlechterrollen, von einiger Dramatik. Martha, als alleinstehende, ältere, gebildete Frau und als letzte Erbin einer wohlhabenden Dynastie von Erzgruben betreibenden Industriellen und hohen Beamten, wird, in Ermangelung eines geeigneten Erben aus der eigenen Verwandtschaft, von der niemand mehr lebt, durch das nationalsozialistische Regime gezwungen, den Gutshof und ihr Barvermögen an einen einfachen Mann aus dem Volk, der gerade einmal über die elementarste Schulbildung verfügt, $\mathrm{zu}$ vererben. Es geht hier jedoch nicht um eine Auseinandersetzung zwischen Frauen und Männern, sondern um einen ideologischen Kampf. Der Gutshof soll nicht an die Kirche fallen, sondern in Zukunft dazu dienen, die nationalsozialistische Blut-undBoden Politik zu verwirklichen. Auf diese Weise wird Marthas Recht auf Selbstbestimmung außer Kraft gesetzt. So ist Friedrich zwar in der partriarchalischen Welt der 1930er Jahre zwar einerseits der Alleinerbe des Hofes. Doch die, an seiner Seite stehende, junge Bauerntochter, die er heiratet, ist als Kinder gebärende und den Hof bewirtschaftende Mutter bei diesem Geschlechtermodell der Nationalsozialisten stets mitgedacht. Friedrich ist zwar der patriarchalische, zeugende Mann, aber er ist dies nur durch die Gleichzeitigkeit der gebärenden, arbeitsamen Frau an seiner Seite. Es kommt daher, im Übergang vom wilhelminischen Deutschland und der Weima- 
rer Republik in die Zeit des Nationalsozialismus, in Zusammenhang mit dem Gutshof Schwarzbrock, zu einer Verschiebung, ja zu einer regelrechten Verkehrung der weiblichen Geschlechterrolle. Wo zuvor eine hochgebildete, alleinlebende, kinderlose Frau das gesamte Anwesen verwaltete, zieht nun eine Frau ein, die allein zum Gebären, zum Großziehen von Kindern und zum praktischen Wirtschaften vorherbestimmt ist, an der Seite eines bäuerlichen Mannes, der lediglich über die allernötigste Volkschulbildung verfügt und dem sie an die Seite gestellt und letztlich unterstellt ist. Aber auch Friedrichs Schwester Frieda hätte möglicherweise, in der retrospektiven Betrachtung, mindestens so wie ihr Bruder Friedrich, die Motivation, die Fähigkeit und die Durchsetzungskraft gehabt, die Geschicke des Gutshofs Schwarzbrock zu lenken. Auch Frieda war ja mit den Arbeitsabläufen auf Schwarzbrock sehr gut vertraut. Doch 1936 konnte, bei dem durch die Nationalsozialisten propagierten Frauen- und Männerbild, nur ein Mann der Erbe eines solchen Gutshofes sein. Zwischen Frieda und Friedrich entwickelte sich dadurch, in den Jahren ab 1936, eine gewisse Rivalität. Jahrelang war sie ja ebenfalls gemeinsam mit Vater Heinrich zum Gutshof gegangen, um dort unter der Regie von Martha zu arbeiten. Nach Marthas Tod war nun Friedrich der Besitzer und Frieda eine untergeordnete Hilfskraft. Sie kämpfte noch mit ihrem Bruder um eine finanzielle Ausgleichszahlung, die er ihr zumindest teilweise gewährte, verließ den Hof und suchte sich andere berufliche Tätigkeiten, in Haushalten, teils in Fabriken.

Paul, Hermann, Richard, Otto und Friedrich heirateten, ihrer Zeit entsprechend, Frauen, wie die beiden Töchter Frieda und Bertha Männer heirateten. Somit verblieben alle sieben Geschwister innerhalb der sozial vorgezeichneten Geschlechterrollen. Bis auf Hermann hatten alle Kinder. Paul hatte mit seiner Frau fünf Kinder, Richard acht, Otto, nach vier Fehlgeburten, drei und Friedrich fünf. Bertha und Frieda hatten jeweils einen Sohn. Der in einem Walzwerk, einer traditionellen Männerdomäne, als ungelernter Arbeiter tätige Otto, tauchte in seiner Freizeit in die Welt des Fußballs ein, die zu jener Zeit ebenfalls ein männlich dominiertes Handlungs- und Erlebnisfeld darstellte. Zugleich berichteten die Teilnehmenden von der Sanftmut dieses Mannes. Eher wurde Ottos Frau als durchsetzungsstark, dominant und teils andere einengend beschrieben, auch ihm selbst gegenüber. Dominanz und Unterordnung befinden sich hier folglich nicht im erwarteten geschlechtsrollenspezifischen Schema. Dasselbe wurde bezüglich des Beziehungsverhältnisses zwischen Paul und seiner Frau, der ja als Nichts-Besitzender eine Etwas-Besitzende geheiratet hatte, sowie Hermann und seiner Frau, deren Allgemeinbildung seine allgemeine Bildung weitaus übertraf, berichtet. Abgesehen von diesen teils unerwarteten Dominanzverhältnissen in den ehelichen Beziehungen gab es jedoch keine Hinweise darauf, dass Paul, Hermann, Richard, Otto und Bertha Aktivitäten entfaltet hätten, oder etwas mitgeteilt hätten, was auf eine Abwandlung, Variation, temporäre Veränderung oder gar dauerhafte Umkehrung ihrer Geschlechterrolle, oder zumindest den Wunsch danach, verwiesen hätte. Anders verhielt es sich bei der 1903 geborenen Frieda und bei dem 1907 geborenen Friedrich. Frieda wird als eine Frau beschrieben, die teils auch maskuline Züge hatte und die bei ihren öffentlichen Auftritten, bei Winterfeiern, Theaterabenden oder Hochzeiten, auch gerne eine Art Cross-Dressing vornahm und in Männerkleidern, mit Smoking, Weste und Zylinderhut auftrat. Es gab diverse männliche Rollen, die sie, je nach Anlass und Kontext, wechselte und immer wieder, über die Jahre, in Szene setzte. Zugleich hatte Frieda einen einfachen Mann aus dem Volk geheiratet, der eines Tages 
mit dem Fahrrad am Hof Schwarzbrock mit dem Fahrrad vorbeigekommen war und um ein Glas Wasser gebeten hatte. In der Welt des Theaters und der Welt der Dorfkultur lebte Frieda jedoch ihre, über die sozial zugewiesene Rolle hinausgehenden, Persönlichkeitsanteile aus.

Friedrich hatte eine, von einem anderen, größeren Hof stammende, loyal zu ihm stehende, Frau geheiratet. Doch zugleich wurde berichtet, dass die beiden eine eher lockere Ehemoral praktizierten. Auch lag zwischen Schwarzbrock und dem Dorf Eichertshagen ein Hügel, so dass man auf dem Gutshof die katholische Kirche, die die Menschen der Region ethisch-moralisch lenkte, nicht sehen und die Kirchenglocken nur entfernt hören konnte. Aus diesen besonderen sozialgeografischen Lagebedingungen haben einige der am Projekt Teilnehmenden abgeleitet, dass es auf Schwarzbrock ab 1938 in Fragen der Moral etwas freier zuging. Friedrichs Frau hatte demzufolge, nach Ablauf der ersten Ehejahre, auch einen Verehrer aus einem nach der anderen Seite gelegenen Dorf, der ihr bei der vielen Arbeit auf dem Gutshof unter die Arme griff, insbesondere dann, wenn Friedrich geschäftlich unterwegs und für einige Tage abwesend war. Als fünftes in der Reihe ihrer Kinder, empfing sie möglichweise, wie von einigen der am Projekt Teilnehmenden spekuliert wurde, einen Jungen von diesem Mann, was auch in Eichertshagen kein Geheimnis blieb. Dieser Junge wurde allerdings auf völlig natürliche Weise, in Vorwegnahme heutiger Familienverhältnisse, und ohne dass Friedrich dies weiter thematisiert hätte, mitgroßgezogen und in allen Fragen als legitimer Sohn behandelt. Da sich Friedrich, der zu jähzornigen Ausbrüchen neigte, mit seinem erstgeborenen, leiblichen Sohn, auf Dauer überwarf, und die drei Mädchen, von denen auch noch eine im Alter von vierzehn Jahren starb, zeitbedingt nicht als Erbinnen des Gutshofes in Betracht kamen, sollte er diesem, höchstwahrscheinlich von einem anderen Mann stammenden, Sohn sogar den Hof vererben. Friedrich, ein ansehnlicher Mann, zog derweil regelmäßig mit zwei befreundeten Jägern in der Landschaft umher, von denen einer nach übereinstimmender Einschätzung der am Projekt Teilnehmenden dem männlichen Geschlecht zugeneigt war. Zwar wurde sich über alles Weitere ausgeschwiegen, doch ausführlich der tragische Unfall geschildert, $\mathrm{zu}$ dem es bei einem dieser Jagdausflüge kam. Friedrich, der sonst im familiären und verwandtschaftlichen Umfeld als raubeinig und abweisend galt, weshalb man ihn auch den Bär nannte, und den Berichten zufolge, höchstens emotionaler, weicher, gesprächiger wurde, wenn er zuvor gehörig Bier oder andere Alkoholika konsumiert hatte, hatte jenen Freund, der mangels geeigneter Stiefel, nicht durch einen vor ihnen liegenden Bach waten wollte, huckepack auf seinen Rücken genommen. Zugleich hing aber auch sein Gewehr über der Schulter. Ein Schuss löste sich und tötete den Freund. Dieser verblutete im Wiesengrund. Man kann viel in diese Szene hineininterpretieren, aber sie könnte am Ende doch für eine verborgene Sehnsucht des Großgrundbesitzers stehen und für die Vergeblichkeit der offenbar zwischen den beiden Männern bestehenden Zuneigung. Aus seinen späteren Jahren wird berichtet, dass Friedrich in den Gaststätten oftmals spontan einen Frauenkittel oder einen Pelzmantel anzog, oder sich ein Kopftuch umband und eine Art Steggreif-Show in Szene setzte, wie schon seine Schwester Frieda, also ein umgekehrtes Cross-Dressing vornahm. So weichte er ein wenig die starren Geschlechterrollen auf, wenn auch nur in Kneipen oder bei ausgelassenen Feiern, unter dem Einfluss von Alkohol. 


\section{Diskussion und Schlussfolgerungen}

In diesem Kapitel wurden die Biografien von sieben, zwischen 1896 und 1909 geborenen und zwischen 1941 und 1994 verstorbenen, Geschwistern unter den folgenden Aspekten betrachtet: Erstens: Welche Möglichkeiten des sozialen Aufstiegs boten sich ihnen? Fünf der sieben Kinder, das heißt drei Jungen und zwei Mädchen, verblieben im Rahmen der, durch eine erhebliche soziale Ungleichheit charakterisierten, Gesellschaft jener Jahre in dem sozialen Milieu und in der sozialen Schicht, in die sie hineingeboren worden waren. Es gab lediglich kleine Differenzierungen im Hinblick auf die Frage, ob sie dann selbstständig arbeiteten wie Richard, der Dorfschmied oder Paul, der Viehhändler, oder in abhängiger Lohnarbeit in einem Walzwerk, wie Otto, in Haushalten oder Fabriken, wie Frieda. Prekär lebten sie alle. Nur zwei der sieben Kinder erschlossen sich tatsächliche, das heißt wirklich signifikante soziale und ökonomische Aufstiegsmöglichkeiten. Friedrich profitierte von der, durch die Nationalsozialisten eingeführten, sozialen Umverteilungsmaßnahme Reichserbhofgesetz. So konnte ein junger Mann, der lediglich über einige Jahre Volksschulbildung verfügte und nicht einmal ein Handwerk gelernt und lediglich als Knecht in der Landwirtschaft gearbeitet hatte, von heute auf morgen zum Großgrundbesitzer werden. Sein älterer Bruder Hermann profitierte von einer speziellen, im weitesten Sinne ingenieursorientierten Fachschulausbildung, die der Volksschule folgte. Sicher kamen ihm, unter den damaligen Bedingungen, auch seine Erfahrungen und Verdienste beim Militär, im Ersten und im Zweiten Weltkrieg, zugute, ebenso der Expansionswille des wilhelminischen und später des nationalsozialistischen Deutschlands in den Ostgebieten, ferner seine Fähigkeit, sich strategisch und opportunistisch zu verhalten, wozu auch gehörte, in die NSDAP und die Organisation Todt einzutreten. Aufgrund des wilhelminischen wie auch des nationalsozialistischen Frauenbildes, standen die genannten Aufstiegsund Karrierewege lediglich Männern offen. Frauen wurden als Mütter konstruiert, die ihre Aufgaben im Führen von Haushalten und im Großziehen von Kindern hatten. Sie konnten folglich nur an der Seite eines Ehemanns aufsteigen. Die Männer wurden zugleich nicht als schöpferische, selbstbestimmte Individuen gefördert, sondern als gesellschaftliche und politische Werkzeuge, die dabei zu helfen hatten, die Blut-undBoden-Politik der Nationalsozialisten umzusetzen, Friedrich als Großbauer und Hermann als Ingenieur im Bau von Straßen und im Urbar-Machen von Land, zunächst in Pommern, und perspektivisch, das heißt nach Umsetzung der geplanten Eroberung weiterer Gebiete im Osten, insbesondere dort. Beide Männer stiegen zwar sozial auf, doch taten sie dies auf engen, ideologisch eingerahmten, Wegen. Sie wurden einerseits gefördert, doch zugleich wurden sie instrumentalisiert.

Zweitens: Welche Möglichkeiten der kulturellen Partizipation boten sich den sieben Geschwistern? Mit dem sozialen Aufstieg konnten sich Hermann und Friedrich teils auch andere kulturelle Welten erschließen. Im Fall von Hermann, der als einziger aus der Familie den geografischen Raum Südwestfalens überschritt, resultierte dieser kulturelle Aufstieg, zu großen Teilen, aus seiner Ehe mit einer gebildeten Frau aus der oberen Mittelschicht, denn sie erschloss ihm neue kulturelle Bezüge. Der zum Großgrundbesitzer gewordene Friedrich schuf sich, durch sein Engagement auf dem Gebiet der Jagd, ein neues soziales Netzwerk. Hierzu gehörten auch Industrielle, wodurch ein anderer sozialer Umgang zustande kam. Besitz und materieller Reichtum und eine neue soziale Bezugsgruppe erzeugten einerseits ein prachtvolles Bild, 
brachten aber andererseits keinen Zugang zur Hochkultur mit sich, denn dafür fehlten Friedrich und seiner Frau die Bildungsvoraussetzungen. Martha, das letzte weibliche Mitglied der auf Schwarzbrock lebenden Dynastie aus Industriellen und hohen Beamten, die zugleich über eine höhere Bildung verfügt hatten, war verstorben. Nach dem nationalsozialistisch erzwungenen Neubeginn, wurden abends auf dem Gutshof keine Romane mehr gelesen, keine Tagebücher und Briefe mehr geschrieben. In den hohen Räumen des Anwesens lebten jetzt Menschen von bäuerlicher Einfachheit. So absurd uns heute das Reichserbhofgesetz der Nationalsozialisten erscheinen mag, so müssen wir doch auch nach der Herkunft der finanziellen Mittel für den ursprünglichen Erwerb und den Aufbau eines solchen Anwesens, wie es mit Schwarzbrock kurz nach 1800 errichtet wurde, fragen. Marthas Vorfahren hatten ihr Vermögen durch das Betreiben von Erzgruben, in dieser Region Südwestfalens, verdient. Die Männer, die auf den Dörfern eine Kleinstlandwirtschaft mit einer Kuh und zwei Schweinen betrieben, wenn sie den Hof übernehmen konnten, oftmals jedoch, als jüngere Brüder, gar nichts erbten, waren gezwungen, mit der Spitzhacke in den lebensgefährlichen Stollen eben dieses Erzgestein loszuschlagen und nach oben zu befördern. Viele kamen, den Quellen nach zu urteilen, durch unterirdische Einstürze oder Gasexplosionen ums Leben. Andere starben früh durch die körperliche Erschöpfung oder durch eine Staublunge. Der Gutshof Schwarzbrock steht daher auch für die Gewinnmaximierung dieser frühen Generation von Unternehmern. Natürlich war Martha eine gebildete Frau von edlem Charakter, die Friedrich, der den Hof dann übernahm, geistig und moralisch sicher weit überlegen war. Auch hatte sie in den 1920er Jahren das Geld für eine neue Kirchenglocke gestiftet und dafür ein größeres Stück Wald verkauft. Trotz allem: Das Anwesen, mit seinen ausgedehnten Ländereien, muss in seinen komplexen historischen, sozialen und politischen Zusammenhängen gesehen werden. Dass der Hof schließlich in den 7oer Jahren niederbrannte, ist von ungeheurer Symbolik.

Im Dorf Eichertshagen blühte indes eine volkstümliche Kultur, zwischen katholischer Kirche, Gesangsverein, Fußballverein und Theaterverein. Mehrere der Geschwister spielten hier von 1919 bis 1933 Theater, und dann wieder ab 1945, vor allem Frieda. Wir könnten auch sagen, dass sie hier ihr eigentliches Aktionsfeld fand, vielleicht auch in Kompensation für die nicht vorhandenen Möglichkeiten zu schulischer Bildung oder zu beruflichem Aufstieg, quasi im Sinne autodidaktischer Selbstbildung, teils in Kooperation mit dem Pfarrer und dem Lehrer. Hier übernahm Frieda eine führende Rolle, nicht nur auf der Theaterbühne im engeren Sinne, sondern auch im weiteren sozialen und öffentlichen Leben des Dorfes. Sie war es, die bei öffentlichen Ereignissen und Festlichkeiten, die oftmals rauen Lebensumstände spiegelte, die den einfachen Menschen mit ihren Texten und Balladen half, ihre Lebenserfahrungen zu reflektieren und die sich auch nicht scheute, Zeitereignisse und politische Ereignisse $\mathrm{zu}$ kommentieren und humorvoll Kritik an sozialen Ungerechtigkeiten zu üben. Sie war es auch, die unter dem dritten Aspekt, den hier sichtbar werdenden Geschlechterrollen, eine gewisse Experimentierfreude zeigte, indem sie bei vielen kulturellen Anlässen in Männerkleidung auftrat. Nun war dieses Cross-Dressing möglicherweise ein strategisches Aufschließen mit den damals noch im öffentlichen Leben dominanten Männern, doch immerhin besteht auch die Möglichkeit, dass es sich um erste Versuche der spielerischen Überschreitung des eigenen, sozial zugewiesenen, Geschlechts handelte. Der freiere Geist der Weimarer Republik könnte dies ja durchaus befördert haben. Die jüngste Tochter der Familie verstarb bei der Geburt ihres ersten Kindes in 
ihrer häuslichen Schlafstube, einerseits ein naturgegebenes, tragisches Ereignis, das jedoch mit hoher Wahrscheinlichkeit durch die unzureichende Geburtshilfe und mangelhafte ärztliche Versorgung in jenen ländlichen Regionen mitverursacht worden sein könnte. So gesehen handelt es sich auch um eine soziale Frage, da die Zugänge zu fachlich qualifizierter Geburtshilfe und ärztlicher Versorgung eben auch schichtspezifisch, das heißt sozial ungerecht, verteilt waren.

Paul, Otto und Hermann erfüllten, auf der Basis der Erzählungen nicht die Erwartung, an hegemonialen Männlichkeitskonzepten orientiert gewesen zu sein, im Gegenteil: Sie wurden als eher sanftmütig und nachgiebig, ihre Frauen dagegen als überaus dominant, beschrieben. Friedrich gibt indes die größten Rätsel auf. Einerseits dürfte auf ihn die Charakterisierung der hegemonialen Männlichkeitsorientierung am allermeisten zutreffen, dies in Kombination mit Jähzorn, Gewaltausbrüchen, hohem Alkoholkonsum. Friedrich erinnert in vielen Aspekten an Heathcliff in Emily Brontes Roman Wuthering Heights. Doch er war es auch, der Mutter, Tante und Schwägerin auf den Gutshof holte, damit sie dort ihr hohes Alter verbringen konnten, bis zum Tod, und so eine Art familiäres Mehrgenerationenprojekt schuf. In Einzelgesprächen mit einem Teil seiner Nachfahren und aufgrund der Analyse von Photografien eröffneten sich, darüber hinaus, tiefergehende, an das Geheime in den Biografien rührende, interpretative Zugänge. Diese hatten mit Friedrichs Jagdausflügen mit einem Freund zu tun, den er versehentlich durch einen Gewehrschuss tötete. Auch sein Cross-Dressing in Kneipen und bei Feierlichkeiten, so gesehen spiegelbildlich zu seiner Schwester Frieda, deutete auf zaghafte Versuche, der heteronormativen Zwangsstruktur jener Jahre, zumindest für wenige Augenblicke, zu entkommen und diese in rauschhaften Momenten zu überschreiten. Es stellt sich auch die Frage, wieviel väterliche Zuwendung Friedrich noch erhalten hat, nachdem bereits vier ältere Brüder vor ihm geboren waren. Bei seiner Geburt war der Vater bereits 42 Jahre alt. Es ist immerhin denkbar, dass er sich schon früh enger an die Mutter anschloß, was dann seine ganze Charakterentwicklung beeinflusst haben könnte. Friedrich hatte weder die Möglichkeit sich in einer der vielen Online-Communities zu orientieren, wie sie heute existieren, noch konnte er in queere Nachtclubs, in Köln oder Berlin, eintauchen und sich dort umsehen. Er war völlig auf sich gestellt, ohne eine Bezugsgruppe, mit der er sich hätte austauschen können, ohne theoretische oder literarische Bezüge, die er hätte heranziehen können. Die dargestellten Biografien erscheinen abschließend als soziale Konstrukte, mit ungleich verteilten, Frauen benachteiligenden, Aufstiegschancen, teils auch in Zusammenhang mit nationalsozialistischen Ideologien. Es boten sich den sieben Geschwistern teils diverse kulturelle Betätigungs- und Partizipationsfelder, die einerseits individuelle Ausformungen ermöglichten, die im Ganzen jedoch milieu- und schichtspezifisch und durch die abgelegene ländliche Lage bedingt, limitiert waren und in Ansätzen lediglich durch Hermann, durch die Eheverbindung mit einer gebildeten Frau, überschritten wurden. Die Geschlechterrollen, wie sie sich hier manifestieren, waren $\mathrm{ab} 1900$ bis in die 6oer Jahre hinein noch überwiegend männlich hegemonial und heteronormativ zementiert und gaben weder den Frauen, noch den Männern, in solchen dörflichen Welten viel Spielraum. Friedrich wirkt in seinem Aufbegehren gegen diese Einengungen, auf der Basis der narrativen Rekonstruktionen und Interpretationen der vorhandenen Materialien, in seinen Wutausbrüchen und in seinem hohen Alkoholkonsum, eher zerrissen und verloren. Eine gewisse Vergeblichkeit und unerfüllte Sehnsucht bleibt im Raum stehen, wenngleich wir vieles, was geschehen ist, 
oder geschehen sein könnte, nicht ans Licht bringen können. Insofern müssen wir die Begrenztheit der eigenen Interpretation vor Augen haben. Friedas Experimentieren mit ihrer Geschlechterrolle, bei ihren öffentlichen Auftritten im Saal des Dorfes oder auf der Theaterbühne, erscheint dagegen eher produktiv und konfliktarm. Trotz ihrer wirtschaftlich prekären Lage wirkt ihr gesamter Auftritt sogar heiter. 

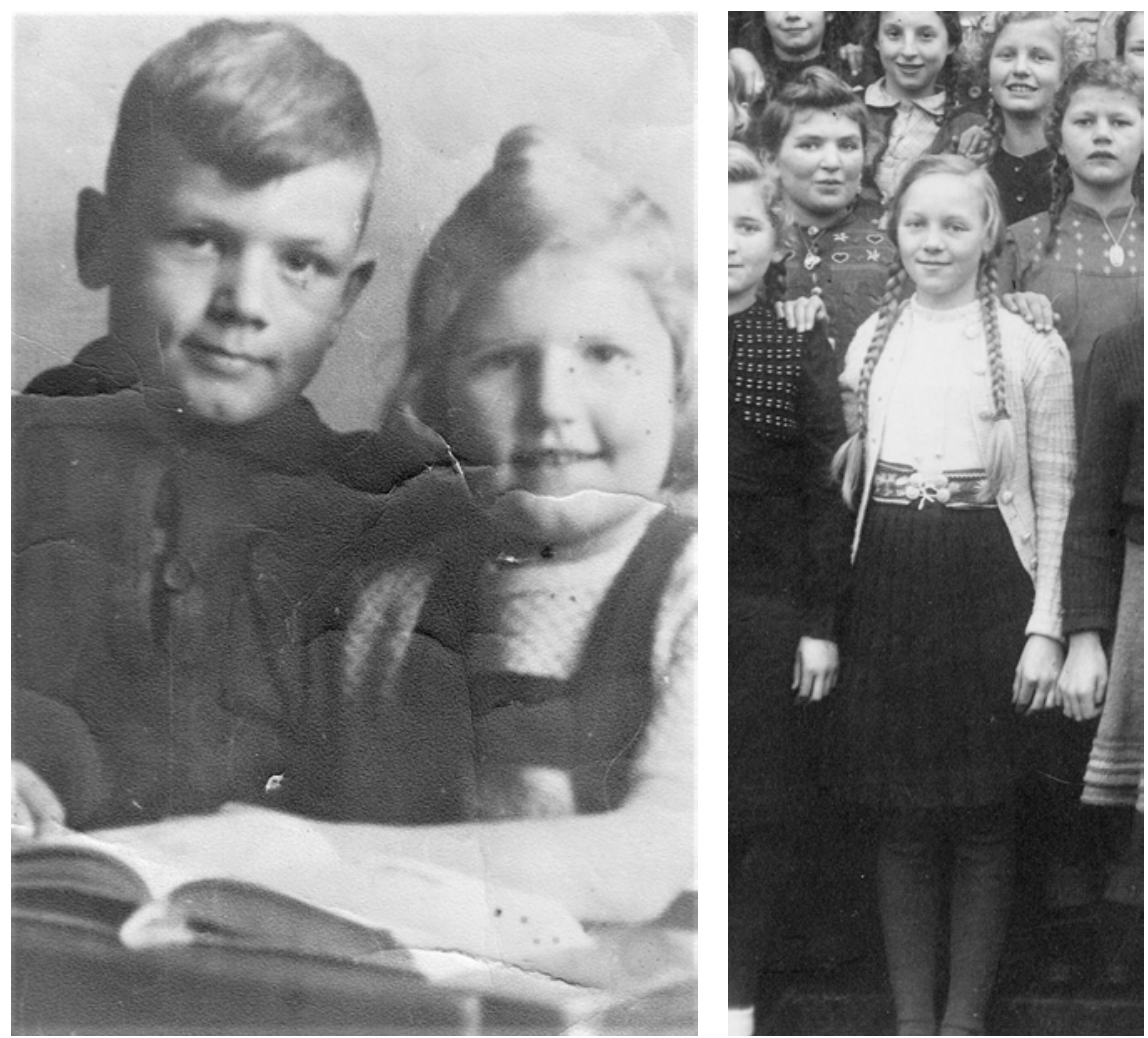

Abb. 49 und 50: Der Volksschule in Eichertshagen kam in den 1940er Jahren eine enorme Bedeutung für die Bildung der dortigen Kinder zu. Das Photo links zeigt die beiden jüngsten Kinder des Dorfschmieds Richard. Der Junge lernte später ein metallverarbeitendes Handwerk, arbeitete teils auch in der Schmiede und sammelt noch heute alte Schullesebücher und liest darin. Die Mädchen auf dem Photo rechts mussten die Schule nach der 7. Klasse verlassen, um in den elterlichen Haushalten zu helfen, zu denen auch eine kleine Landwirtschaft gehörte. Glücklich waren sie, nach ihrer eigenen Aussage, darüber nicht. Cerne hätten sie mehr Bildung erhalten und ein Handwerk, wie z. B. das Schneidern, gelernt. ${ }^{2}$

2 Die Photos in diesem Bildteil, Abb. 49-65, stammen aus den persönlichen Beständen der Projektteilnehmer_innen. Diese gaben ihr Einverständnis zur Veröffentlichung. 


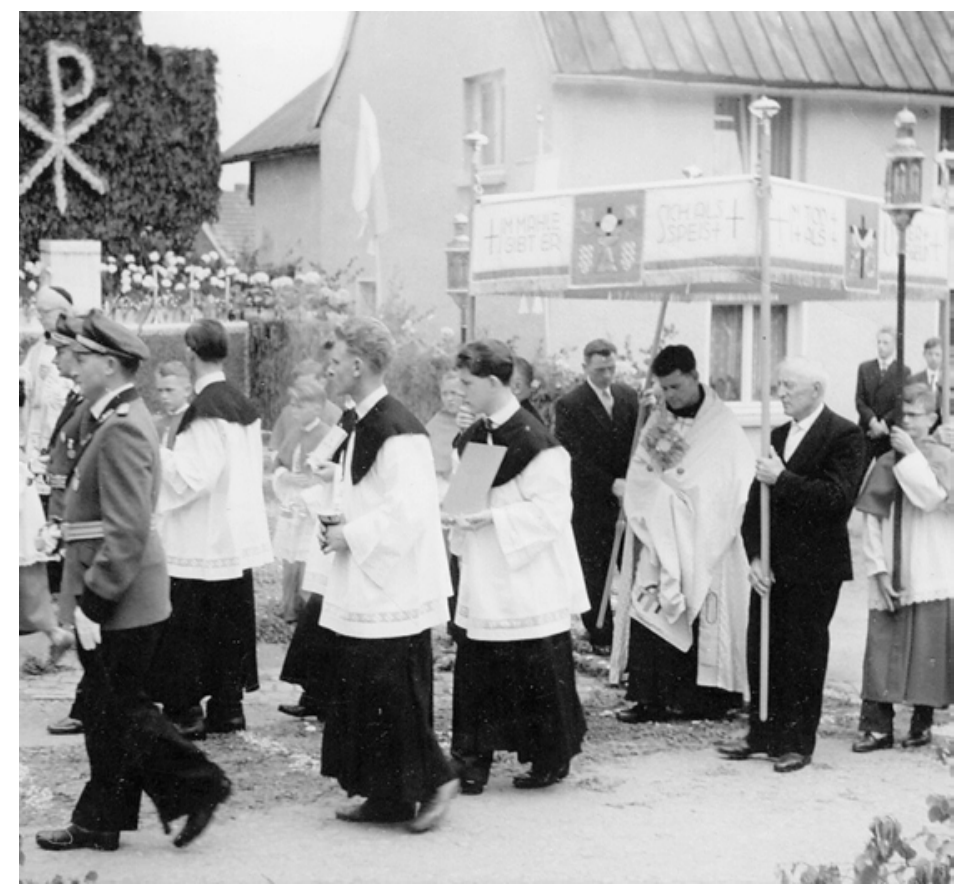

Abb. 51: Die katholische Kirche rahmte das Leben der Menschen auf den Dörfern Südwestfalens ein und versah es mit Sinnbezügen. Doch für viele Lebensentwürfe gab es in dieser Welt keinen Raum. Die negative Sicht der katholischen Kirche auf Fragen des Körpers und der Sexualität hatte vielerlei problematische Folgen für die Menschen. Erst einige der Enkelkinder von Richard dem Dorfschmied fingen dann an, durch die verbesserten Bildungszugänge in den 7oer Jahren, Texte von Wilhelm Reich, Erich Fromm oder Theodor Adorno zu lesen und die Strukturen des ganzen sozioökonomischen und soziokulturellen Zusammenhangs zu erkennen. So lösten sie sich schrittweise aus dieser Welt und beteiligten sich am Entwerfen einer offeneren und freieren Cesellschaft. 

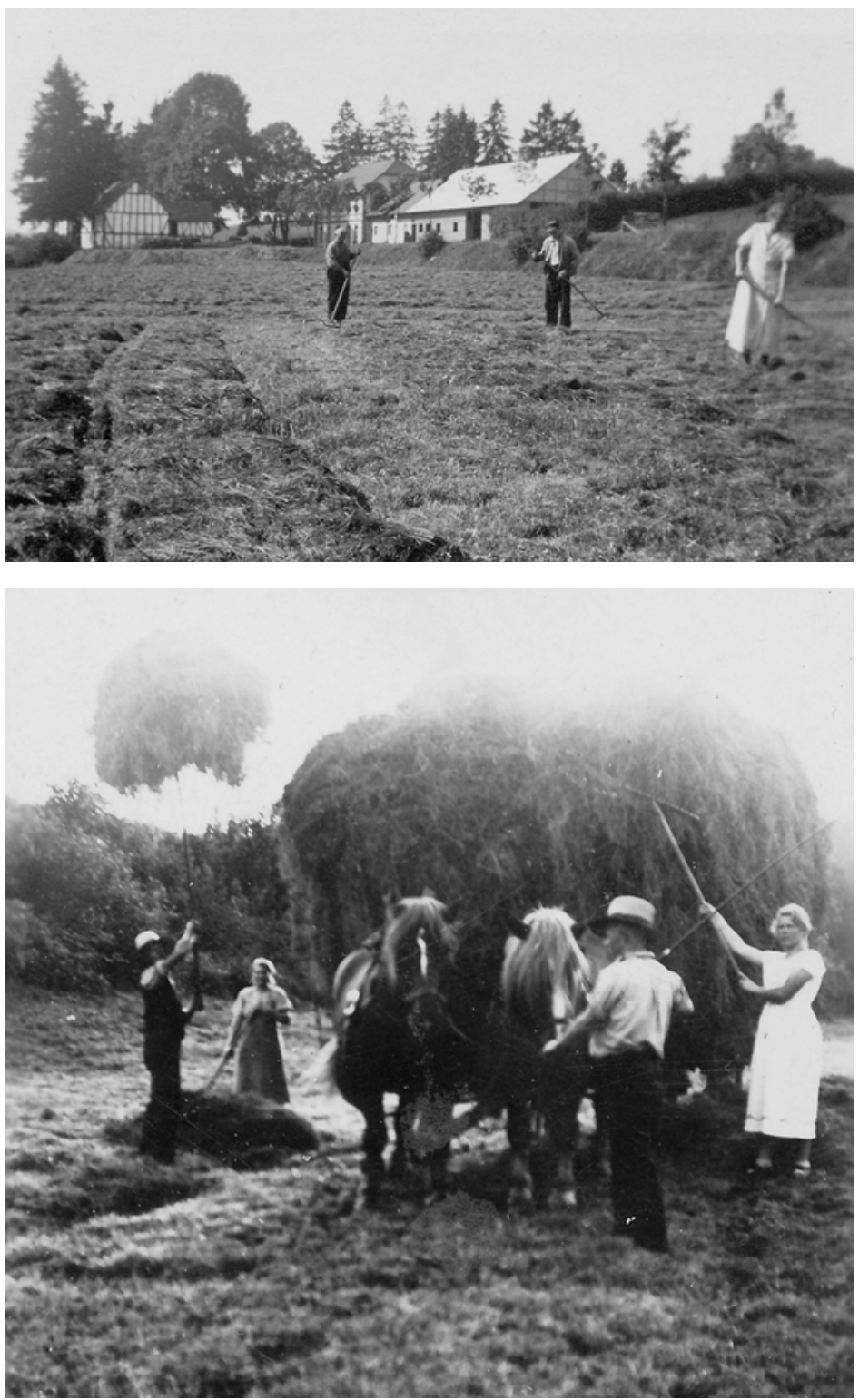

Abb. 52 und 53: Friedrich war durch die nationalsozialistische Umverteilungsmaßnahme Reichserbhofgesetz zum Großgrundbesitzer geworden und erfuhr so einen enormen sozioökonomischen Aufstieg. Zuvor hatte er als Knecht auf dem Gutshof Schwarzbrock gearbeitet, zusammen mit seinem Vater und seiner Schwester Frieda. 

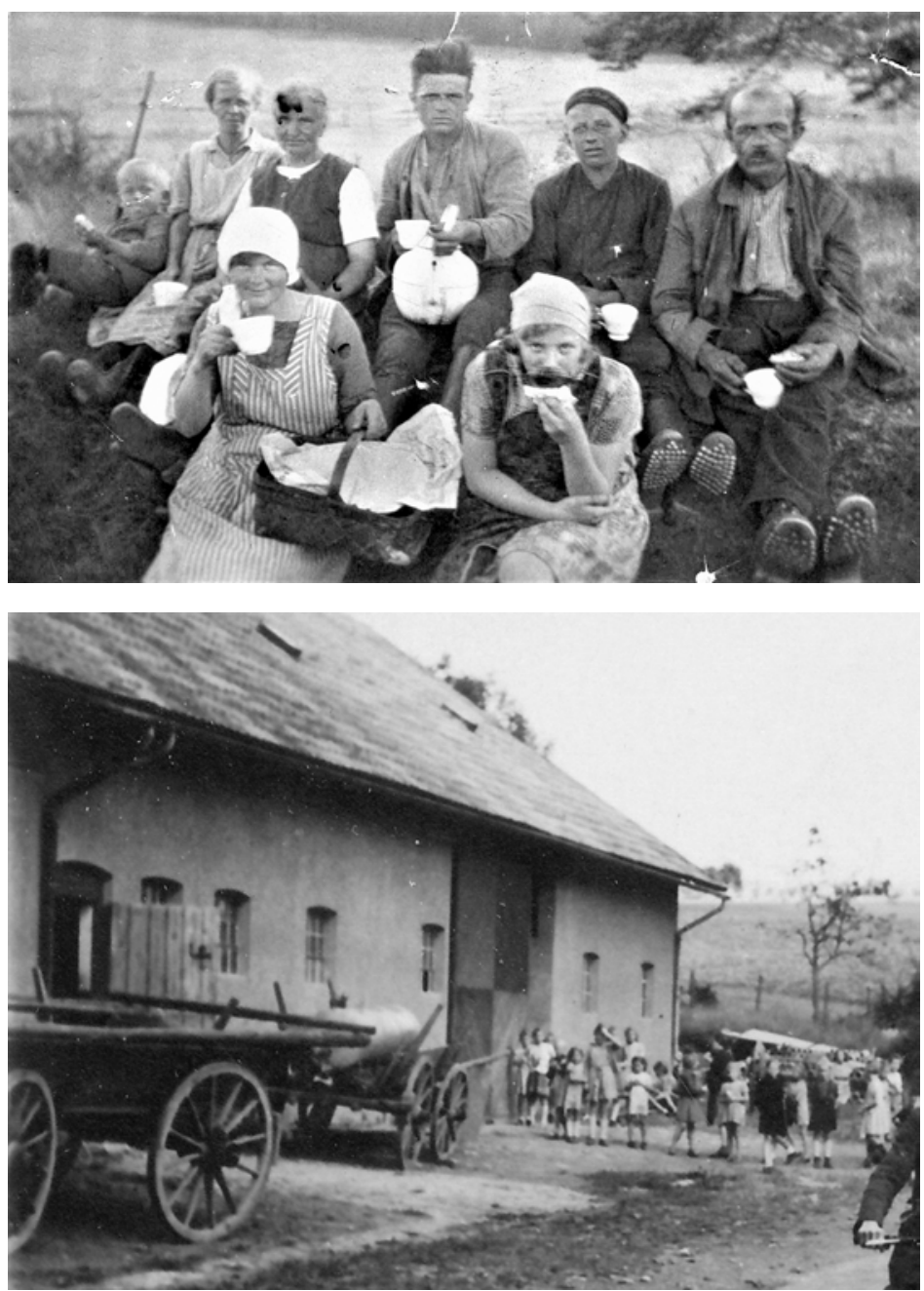

Abb. 54 und 55: Das obere Photo stammt aus dem Jahr 1929 und zeigt Heinrich und seine Familie bei der Kartoffelernte. In der hinteren Reihe, in der Mitte, sehen wir Friedrich, den jüngsten Sohne der Familie, als jungen Mann. Anna, die Mutter, die zu seiner rechten Seite sitzt, hatte einen kleinen Hof mit etwas Land geerbt. Bargeld war allerdings kaum vorhanden. Das untere Photo zeigt ein Stallgebäude des Gutshofes Schwarzbrock aus den 1940er Jahren. Eine Gruppe von Kriegswaisen und Flüchtlingskindern war mit ihren Betreuerinnen dort hingekommen, um auf dem Heuboden zu übernachten. 

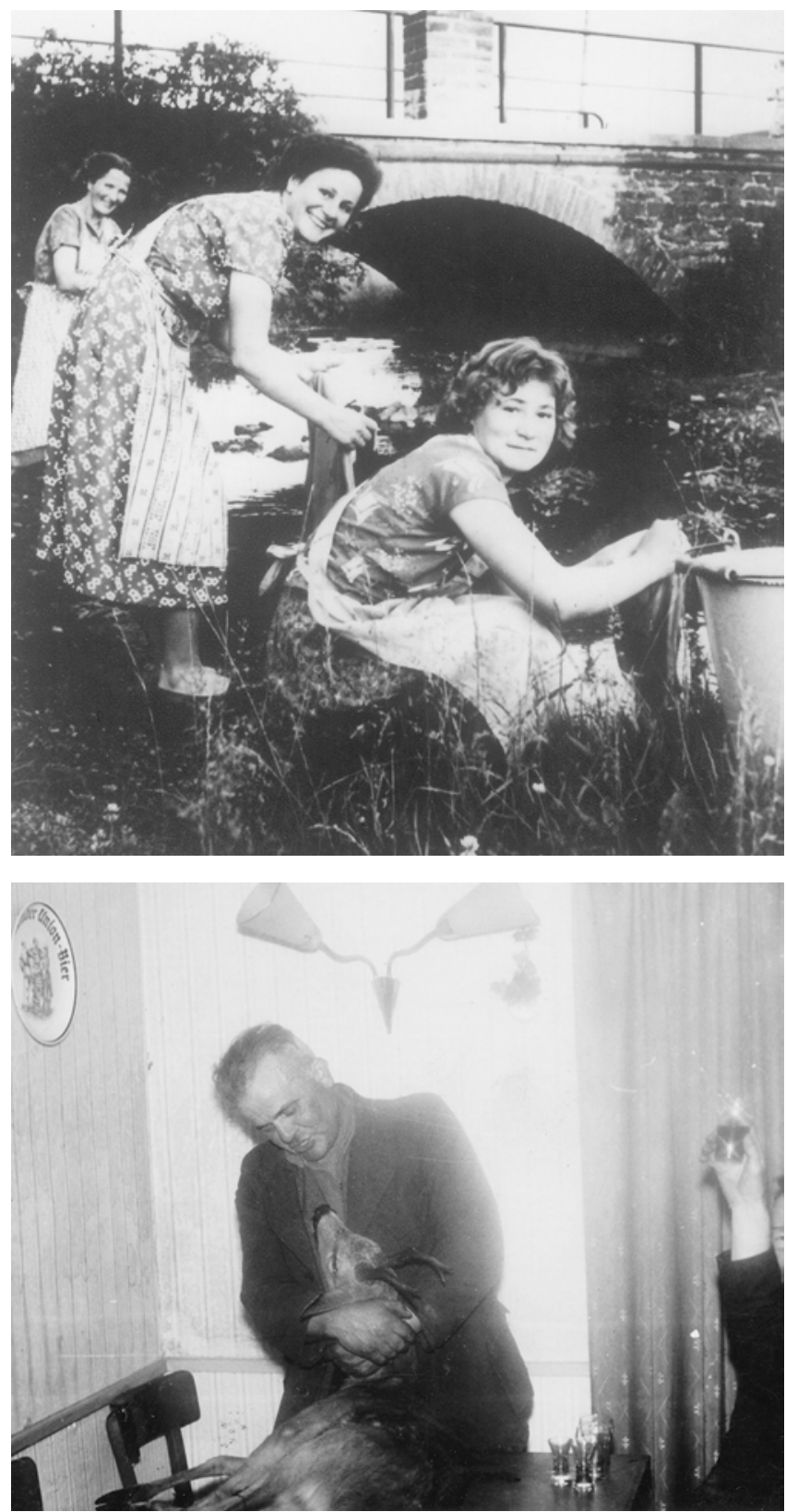

Abb. 56 und 57: Die weibliche Rolle in den Dörfern Südwestfalens beinhaltete, wie das obere Photo aus den 1940er Jahren anschaulich zeigt, unter anderem das Waschen der Wäsche am Bach. Auf dem Photo unten sehen wir Friedrich, in den 1950er Jahren, in einer Dorfkneipe, nach der Jagd, einen zuvor erlegten Rehbock umarmend, während ihm seine Trinkkumpane mit Schnapsgläsern zuprosten. Die beiden Szenen markieren entgegengesetzte Enden damaliger Geschlechterkonstruktionen und Rollenvorstellungen. Weiblichkeit wirkt hier hell und die Dinge klärend, Männlichkeit dagegen abgründig und in sich zerrissen. 

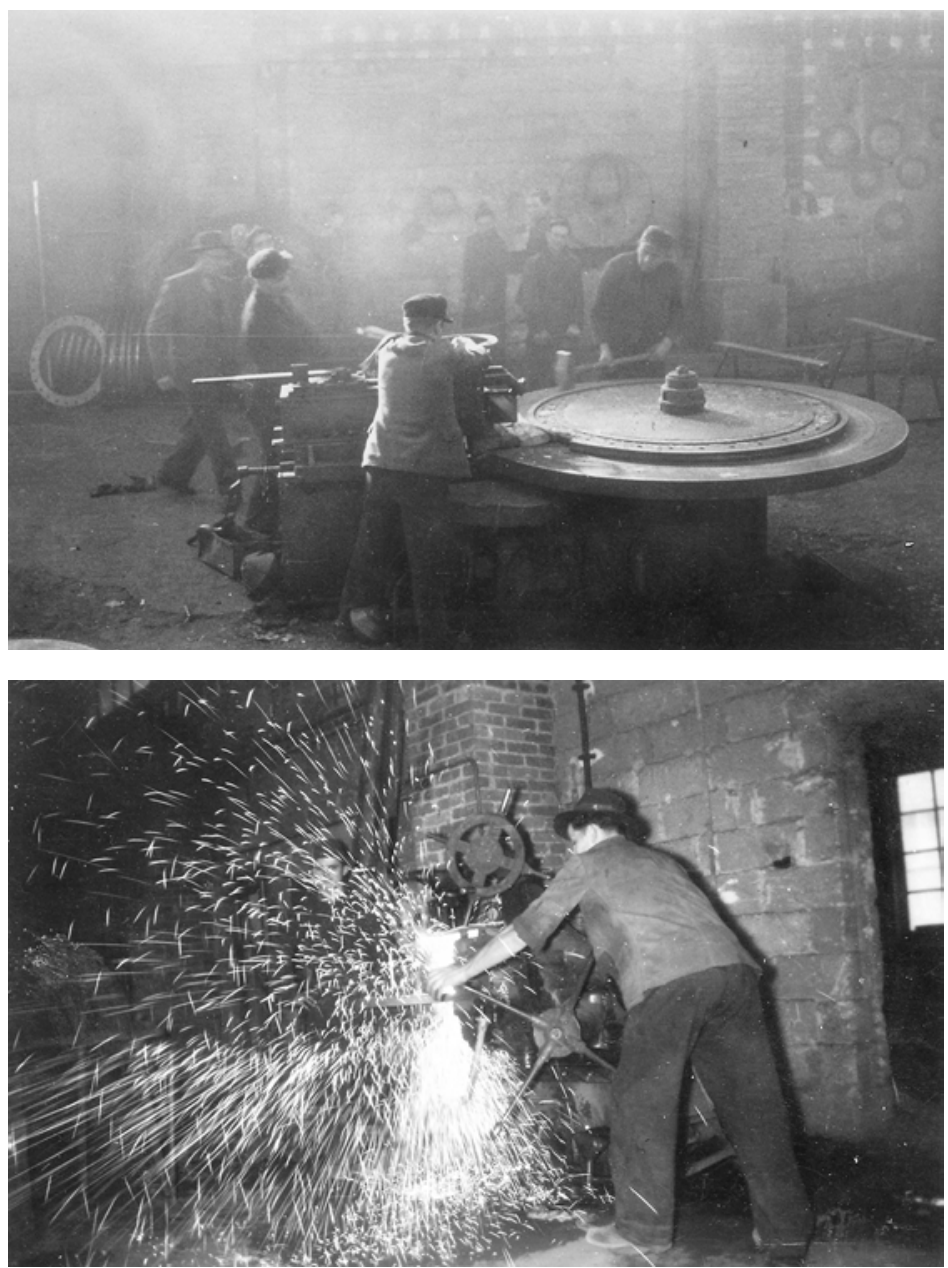

Abb. 58 und 59: Eine solche Arbeitswelt, wie sie sich in den Photos aus einer Siegerländer Flanschenschmiede, aus den Jahren 1953 bis 1955, wiederspiegelt, war eine Männerwelt. Sie war charakterisiert durch Lärm, Schmutz und Hitze, Eisen und Stahl. Sicher war es auch eine entfremdete Arbeit, im Sinne von Karl Marx. Zugleich war diese Art von industrieller Arbeit ein Fortschritt gegenüber dem Betreiben von kleinen Landwirtschaften und dem gleichzeitigen, riskanten Graben und Hacken in den Erzgruben, wo viele der Vorfahren dieser Männer ums Leben gekommen waren oder, aufgrund der körperlichen Auszehrung, früh gestorben waren. Die sich, unter solch harten Bedingungen, ausformenden Masculinities konnten kaum etwas Sanftes und Weiches beinhalten. In Zeiten von Industrie 4.0, digitaler Revolution und Smart Data ist inzwischen alles anders geworden. Solche Arbeitsplätze dürften kaum noch existieren. 


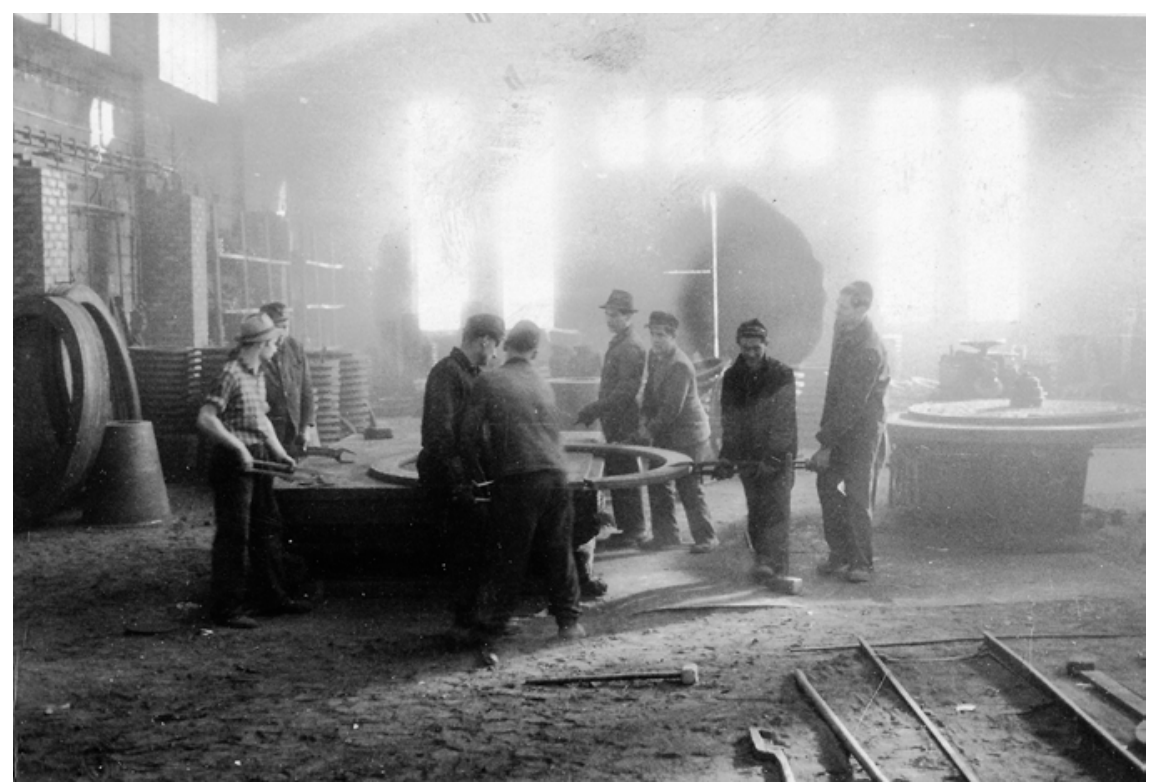

Abb. 60: Ziehen wir einmal Paul Willis' Texte zu den handlungsleitenden Werten und Überzeugungen der britischen Arbeiter heran, so können wir vielleicht ermessen, in welchen sozioökonomischen und soziokulturellen Kontexten diese Männer in einer Flanschenschmiede im Siegerland arbeiteten und lebten und welche Auswirkungen dies auf ihr Denken, Fühlen und Handeln hatte. Das, zwischen 1953 und 1955 entstandene, Photo gibt Anlass, über die Rolle dieser Männer als Ehemänner, Väter und Bürger, einer zumeist dörflichen Community, nachzudenken. 

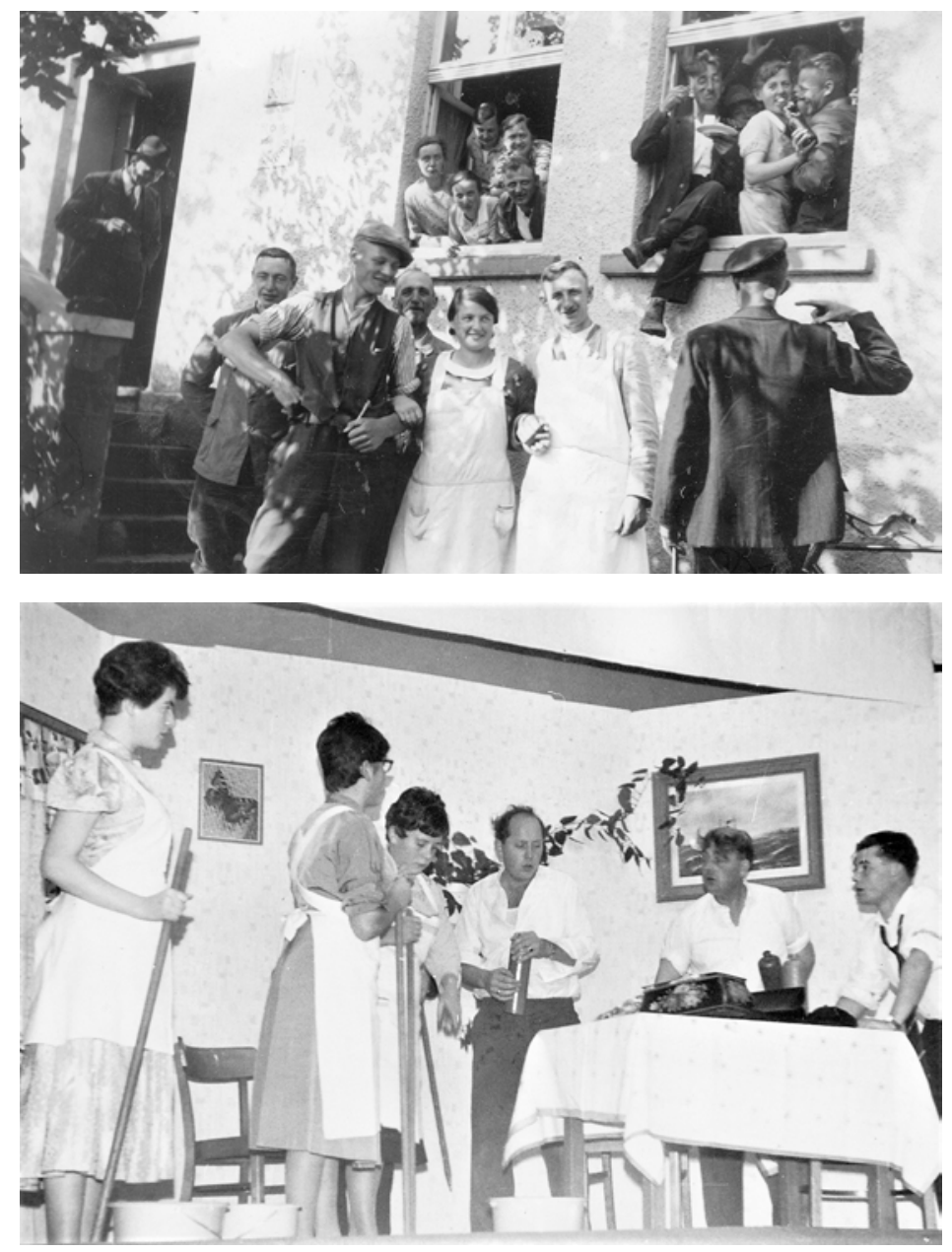

Abb. 61 und 62: Das obere Photo zeigt eine Szene aus Eichertshagen, aus dem Jahr 1934, ein Jahr nach der Machtergreifung der Nationalsozialisten. Wir sehen den Dorfgasthof, als Ort ausgelassenen sozialen Lebens. Rechter Hand grenzte ein großer Saal mit Theaterbühne an, das kulturelle Zentrum, sagen wir, unter Babylon Berlin-Fans, das Moka Efti des Dorfes. Der Theaterverein wurde allerdings bald durch die Nationalsozialisten verboten. Soviel freigeistiges Experiment war verdächtig und staatsbedrohend. Ab 1945 blühte das Theaterleben in Eichertshagen wieder auf. Das untere Photo zeigt eine Theaterszene aus den 6oer Jahren. Links im Bildzentrum sehen wir, in eine weiße Schürze gekleidet, die jüngste Tochter von Richard dem Dorfschmied. 


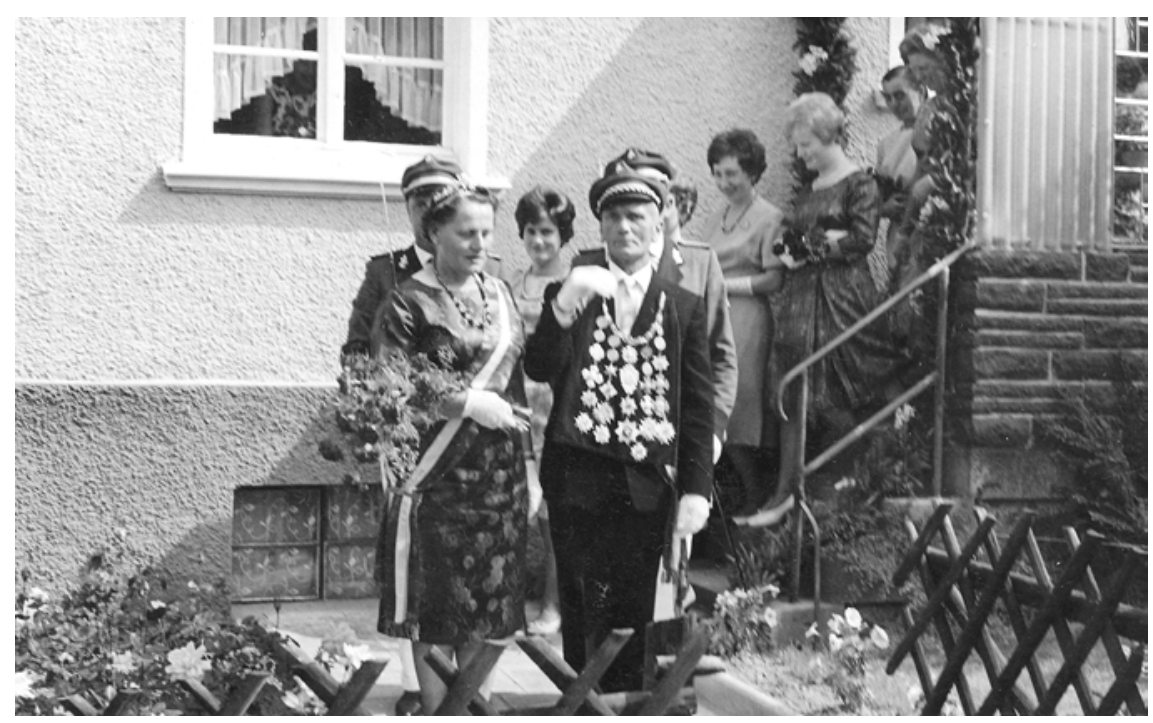

Abb. 63: Auch die sog. kleinen Leute hielten Hof, insbesondere im Rahmen der, mit großem Ernst und mit viel Aufwand gefeierten, Schützenfeste. Höfische Strukturen zu schaffen und diese anschaulich, sinnlich in Szene zu setzen, das beherrschten die Menschen hier und sie genossen dieses Spiel in vollen Zügen. Dass die einfachen Menschen Männer und Frauen aus ihren Reihen zu König_innen machten, wie hier Otto und seine Frau, Anfang der 6oer Jahre, hatte ja auch etwas Subversives, so als wollten sie sagen: Was die da oben tun, das können wir hier unten auch. Zusätzliche Impulse gab nicht nur das Militär, sondern auch die katholische Kirche mit Blumenschmuck, Prozessionen, würdevollem Schreiten in bestimmten, festgelegten Formationen und Choreografien. Nehmen wir nun vorrangig das höfische Element, so scheint es zugleich ein tiefes Bedürfnis danach in den Menschen zu geben. Man/frau kann es sogar an den heutigen Schulen und Universitäten beobachten. Auch hier bilden sich, fast automatisch, immer wieder höfische Strukturen und entsprechende Inszenierungen und Spiele heraus. 


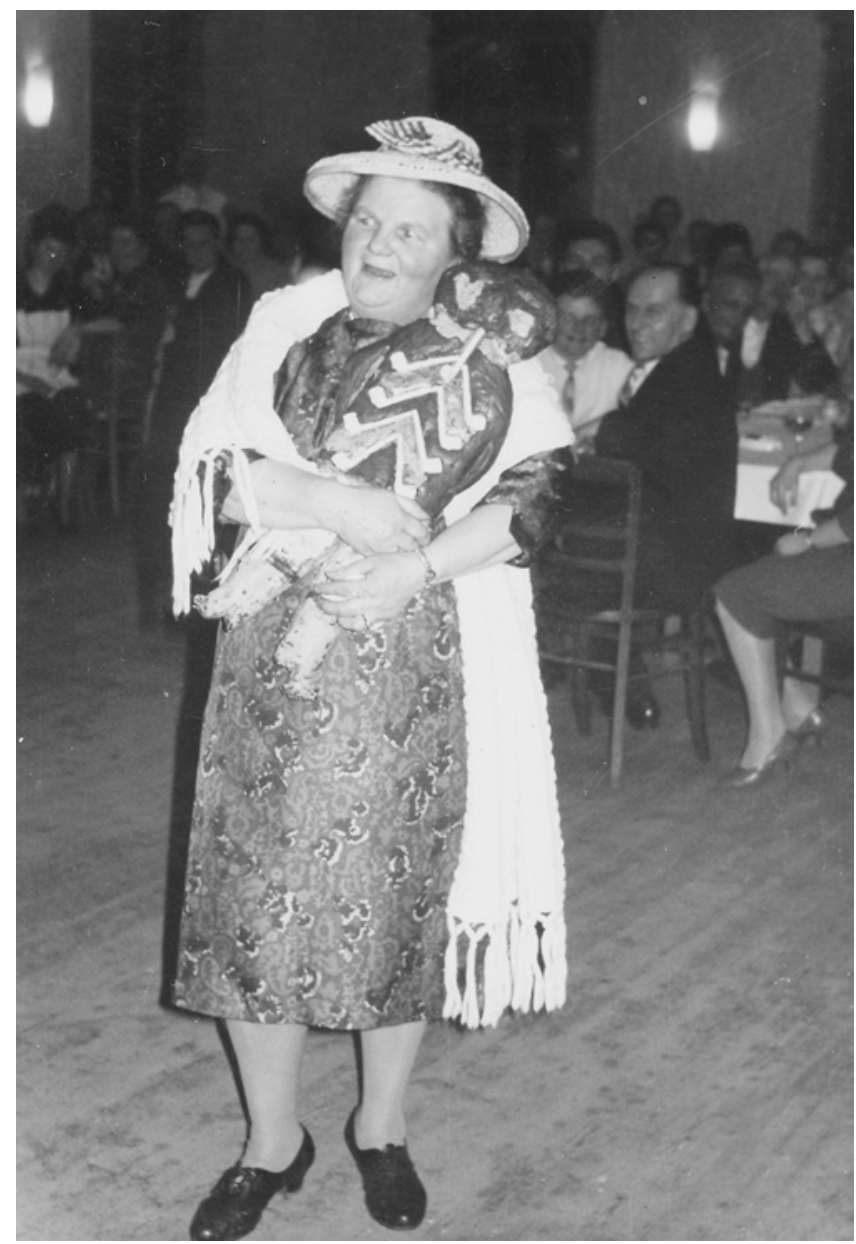

Abb. 64: Das, von etwa 1960 stammende, Photo zeigt Frieda in ihrer bevorzugten Rolle, nicht nur als Theaterschauspielerin, sondern auch als Kommentatorin von Lebensereignissen, von gesellschaftlichen Strukturen und Veränderungsprozessen sowie als Kritikerin von sozialer Ungleichheit und Ungerechtigkeit. Im Saal des Gasthofes von Eichertshagen zog Frieda schließlich alle Register, von humorvoller bis beißend scharfer Machtkritik, bis hin zu Cross-Dressing. An formaler Schulbildung besaß sie einen Volksschulabschluss, doch lernte sie autodidaktisch weiter, im Kontext der Theaterarbeit. Sie prägte das kulturelle Leben im Dorf wie sonst niemand anders. 


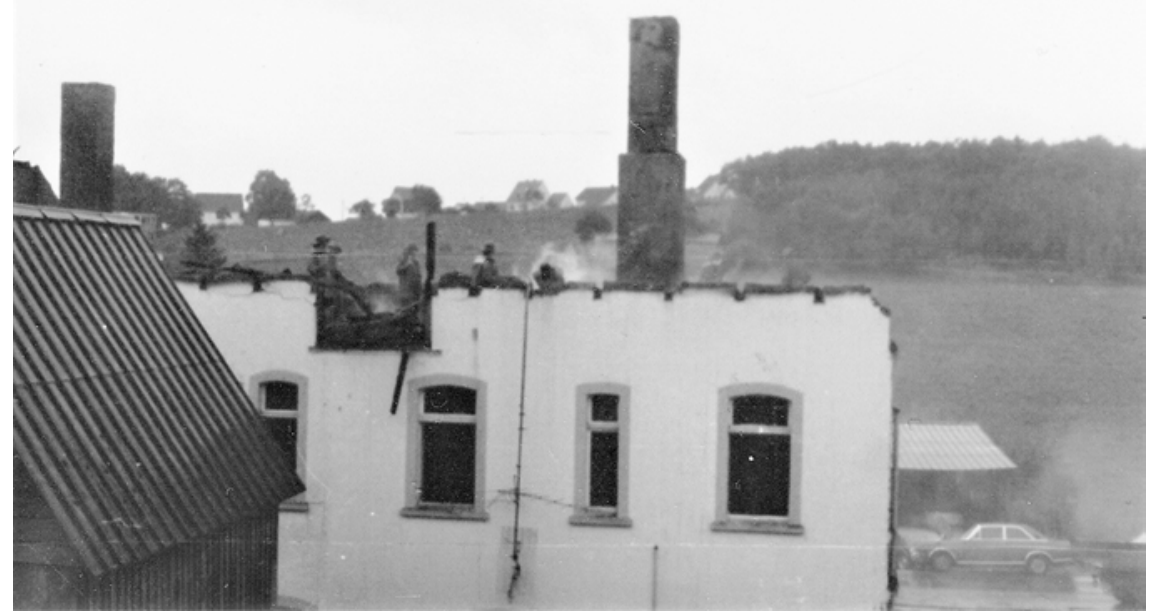

Abb. 65: Als hätte das Schicksal wiederum für einen gerechten Ausgleich sorgen wollen. Zumindest wirkte es auf viele Menschen in Eichertshagen und den umliegenden Dörfern so, als 1975 der Gutshof Schwarzbrock brannte. Ausgelöst durch Gase, die sich im, dicht unter den Dächern gestopften, Heu gebildet hatten, standen, innerhalb kürzester Zeit, sämtliche Dachgeschosse, über den langgestreckten Cebäuden, vom Wohnhaus über die Stallungen hinweg, in hellen Flammen. Friedrich war 1936 durch das Reichserbhofgesetz der Nationalsozialisten an den Croßgrundbesitz gelangt, der sonst, nach dem Tod der letzten, ledigen und kinderlosen Besitzerin, an ein Kloster vererbt worden wäre. Auch hatte sich Friedrich, innerlich zerrissen, wie er vermutlich war, durch seinen Jähzorn, seinen Geiz und seine unberechenbare Haltung, selbst im Umgang mit seiner engeren und weiteren Familie, wenig Freunde gemacht. Zugleich darf nicht vergessen werden, dass die finanziellen Überschüsse, aus denen der Gutshof ursprünglich, um etwa 1800, errichtet worden war, aus dem Erzabbau stammten. Die Mehrheit der Männer der Region arbeiteten, unter menschenunwürdigen Bedingungen, in den Stollen. Viele sind dabei umgekommen. 

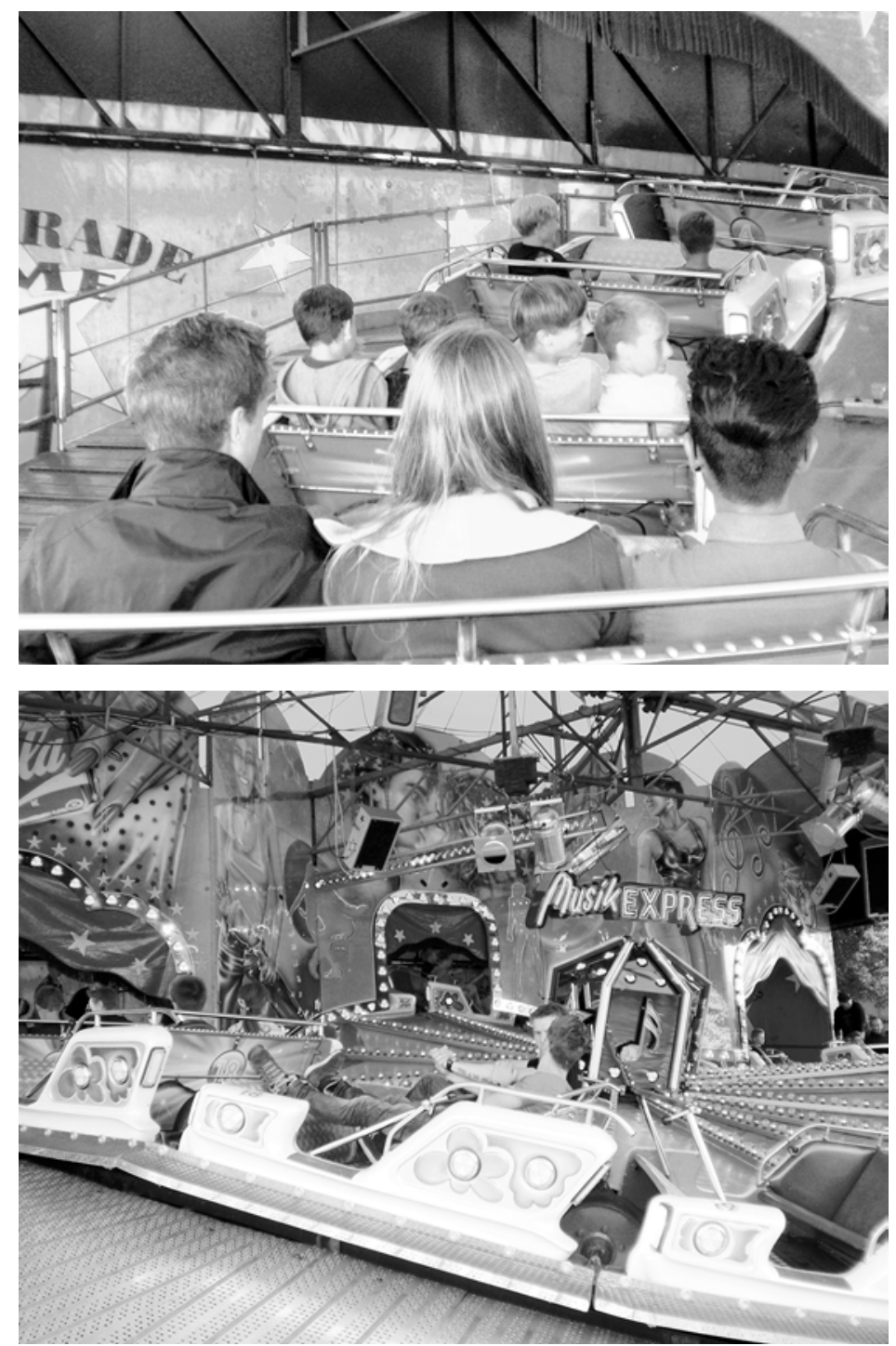

Abb. 66 und 67: Es gab nicht gerade viele Momente von Leichtigkeit und Unbeschwertheit im Leben der einfachen Menschen, wie sie in den Dörfern Südwestfalens lebten. Sie arbeiteten hart für ihren Lebensunterhalt und für eine bessere Zukunft ihrer Kinder, unter sehr herausfordernden Bedingungen. Die stets Mitte August stattfindende Wendener Kirmes und Tierschau war, neben den kirchlichen Festen, sicherlich ein Höhepunkt im Jahreslauf. Wohl kaum ein Fahrgeschäft auf dem Kirmesgelände war, seit den 6oer Jahren bis heute, so populär wie der Musikexpress. Dieser dürfte Leichtigkeit und Unbeschwertheit wohl am allermeisten verkörpern, dazu die jeweils beliebteste Popmusik und das Aroma von gebrannten Mandeln und Zuckerwatte. Ein Hauch von dolce vita, in der rauen und kargen Welt Südwestfalens. 


\section{7. "Bodies under Glass«: Erkundungen in virtuellen Räumen}

\section{Masculinities zwischen Hegemonialität und Vulnerabilität}

Sexuelle Kulturen und Identitäten heutiger Jugendlicher lassen sich nur begreifen, wenn wir vielerlei Komponenten mitbedenken. In historischer Perspektive vor allem die Befreiung der Sexualität aus den engen kirchlichen Moralvorstellungen und dem rigiden Erziehungsapparat der traditionellen Kleinfamilie. Sodann müssen wir die heutige Breite der Sexualität in den Blick nehmen, aber auch die Bedeutung, die digitale Repräsentationen von Sexualität und virtuelle Kommunikations- und Auseinandersetzungsprozesse mittlerweile auf diesem Gebiet haben und die Frieda und Friedrich, mit denen wir uns, im Kapitel zuvor, beschäftigt haben, eben noch nicht hatten. Männliche Identitäten und Rollenschemata, oder Masculinities (vgl. Connell, 2005), sind für den Bereich der emotionalen und sozialen Entwicklung überaus zentral, weil es in diesem pädagogischen Feld ja in erster Linie um Jungen und junge Männer geht. Es gibt natürlich auch einen, wenn auch deutlich kleineren Bereich, in dem mit Mädchen und jungen Frauen in diesem Feld pädagogisch gearbeitet wird. $\mathrm{Zu}$ den Mädchen und jungen Frauen etwas Qualifiziertes zu sagen, möchte ich jedoch lieber den Kolleginnen in den verschiedenen, berührten Wissenschaftsdisziplinen überlassen, weil es mir hier schlicht an pädagogisch-praktischer Erfahrung fehlt. Mirja Silkenbeumer (2006, 2007) hat etwa in diesem Themenfeld geforscht. Die Dinge, mit denen uns die männlichen Heranwachsenden im pädagogischen Feld oftmals konfrontieren, müssen dabei in größeren kulturellen und sozialen Kontexten gesehen werden. Männliche Jugendliche setzen sich mit dem Thema der Geschlechterrolle auseinander, teils direkt, teils indirekt, oftmals jedoch verbunden mit seelischen Spannungen, Ängsten und Konflikten, selbst wenn nach außen ein sehr dominantes oder aggressives, an traditionellen Jungen- oder Männerrollen ausgerichtetes, Verhalten gezeigt wird. Ich kann hier nicht eine umfassende Analyse dieses Themenzusammenhangs unternehmen, doch möchte ich immerhin auf einige, mir zentral erscheinende, Aspekte zu sprechen kommen. Wir haben hier mit einem Nicht-Thema zu tun, einer Art Schatten-Thema, um es mit Carl Gustav Jung zu sagen, nämlich mit der männlichen Homosexualität. Das einerseits angstbesetzte, zum anderen provokative verbale und gestische Spiel mit der männlichen Homosexualität ist etwas, was die pädagogischen Handlungsfelder im Schwerpunkt der emotionalen und sozialen Entwicklung in besonderer Weise durchzieht. Aus diesem Grund habe ich einige Erkundungen speziell zu diesem Themenkomplex unternommen, quasi um Hintergründe und Tiefenschichten auszuleuchten, die das pädagogische Geschehen, insbesondere in Zusammenhang mit Jugendlichen, 
mal mehr und mal weniger beeinflussen können. Obwohl es bezogen auf das Thema der männlichen Homosexualität in den westlichen Ländern inzwischen große politische und gesellschaftliche Fortschritte gegeben hat, immer länger wird die Liste der homosexuellen Politiker, Künstler, Musiker, Schauspieler, und damit auch die Liste möglicher gesellschaftlicher Vorbilder, steht die Schulpädagogik hier noch immer vor enormen Herausforderungen.

Immerhin wächst der Bestand an pädagogischer und wissenschaftlicher Literatur, in der es um die Beratung von Jugendlichen mit homosexueller oder bisexueller Orientierung geht. Transgender-Thematik an Schulen, Integration dieses Themenspektrums in das schulische Curriculum, Auseinandersetzung mit diesen Themen im Rahmen des Lehramtsstudiums, Rolle und Bedeutung von Lehrkräften mit offen gelebter homosexueller Identität in Schulkollegien, mann-männliche Prostitution oder kulturelle und pädagogische Arbeit mit männlichen Prostituierten, sind weitere Themen in dieser Literatur. Auch wenn dies schwer mit Daten belegt werden kann, vieles spricht dafür, dass Schulhöfe und Schulklassen oftmals noch immer Orte sind, an denen kein entspannter Umgang mit männlicher Homosexualität möglich ist, trotz der zahlreichen Diversity-Kampagnen seitens der Politik, der öffentlich-rechtlichen Medien und der Ministerien. Schon vermeintlich feminine Lerngegenstände, wie Kunst, Ästhetik oder Poesie, werden von einer Reihe von Jungen und jungen Männern, die in engeren Rollenkonzepten und identitätsbildenden Mustern gefangen sind, radikal abgewehrt, obwohl Kenntnisse und Fähigkeiten auf diesen Gebieten ja im Zeitalter der Creative Industries von hohem praktischen Nutzen sind. Nicht umsonst werden viele dieser Jungen und jungen Männer zu Bildungsverlierern. Dies könnte also geradezu damit zu tun haben, dass sie ihre vermeintlich weiblichen, das heißt schöpferischen, kreativen Anteile nicht entwickeln, nicht zeigen und nicht kultivieren. Wenn aber oftmals Masculinities bei jungen Männern mit einer emotionalen und sozialen Hintergrundthematik handlungsleitend sind, die mit einer Abspaltung und Negierung von allem, was mit Kreativität in Verbindung steht, einhergehen, dann erweisen sich diese verinnerlichten Rollenschemata, Muster und Orientierungen im Hinblick auf unsere veränderte Arbeits- und Wirtschaftswelt, in der die Creative Industries eine immer wichtigere Rolle spielen, als kontraproduktiv, ganz zu schweigen von der sozialen Welt. Aus der Sicht der Lads, deren Lebenskontext Paul Willis in den 7oer Jahren, in seinen ethnografischen Studien, untersucht hat, galten Fleiß und Konformität in der Schule als unmännlich, eben als feminin. Die Männlichkeitskonzepte dieser Jugendlichen leiteten sich vielmehr von den Tätigkeiten und Handlungszusammenhängen körperlich arbeitender Männer in den Fabriken und Werkstätten ab. Die in den Schulen der 7oer und soer Jahren anzutreffende Gegenkultur war, so Willis, zugleich verbunden mit einer maskulinen Kultur des politischen Widerstands, dem Versuch der Arbeiter, informell die Kontrolle über die Produktion zu bekommen. Dieser Mechanismus, wenngleich diese britische Studie ja nun schon ein gewisses Alter hat, scheint auch in der Gegenwart in einigen sozialen Milieus noch wirksam zu sein. Genau diese Definition von Männlichkeit, wenngleich es den Aspekt des politischen Kampfes nicht mehr in so starker Ausprägung gibt, scheint bis in die Gegenwart überdauert zu haben. Es dürfte auch keine einfachen Strategien geben, die Angst vieler Jungen und junger Männer vor den eigenen weiblichen und damit auch vor homosexuellen Anteilen, und die daraus entstehende Homophobie, aus der Welt zu schaffen. $\mathrm{Zu}$ verunsichernd erscheint vielen männlichen Jugendlichen, wie auch jungen Männern, die sich in ihren Peer-Welten 
mit einer traditionell maskulinen Identitätskonstruktion zu behaupten suchen, die Vorstellung, sie könnten selbst weibliche Anteile oder homosexuelle Wünsche haben. Folglich stecken viele der Jungen und jungen Männer, die wir im Feld emotionalen und sozialen Lernens antreffen, einen enormen Energieaufwand in Inszenierungen, die allen anderen in dem betreffenden Umfeld klarmachen sollen, dass sie harte Kerle und eben nicht bisexuell, homosexuell oder transgender sind. Bei diesen Versuchen schießen massive, provokative oder destruktive Verhaltensweisen oftmals weit übers Ziel hinaus. Wenn es sein muss, wird zu diesem Zweck auch einmal ein Schultisch an die Wand geworfen, ein Messer gezogen oder ein Mitschüler ins Gesicht geschlagen.

Jungen und junge Männer, die sich dagegen als homosexuell, bisexuell oder transgender erleben, finden im Kontext Schule selten ein günstiges Klima für die eigene psychosoziale Entwicklung vor. Die Auseinandersetzung mit dem Thema verlagert sich daher in städtische Subkulturen und ins Internet, in die Welt der Pornos und der Dating-Apps bzw. der sozialen Netzwerke, in denen sich teils sehr unterschiedliche Communities, Körperkonzepte, Identitätskonzepte, erotisch-sexuelle Stile, Muster, Skripte, Drehbücher und Kommunikationsformen herausgebildet haben. Gerade weil das Thema derart von Spannungen besetzt ist, die mit den Tiefen und Untiefen unserer eigenen Kultur und zusätzlich mit Spannungsfeldern zwischen verschiedenen Kulturen zu tun haben, könnte es zu den Aufgaben von Lehrkräften und anderen Pädagog_innen im Feld des emotionalen und sozialen Lernens gehören, geeignete Zugänge zu erschließen. Auch in Anbetracht dieser Schwierigkeiten muss ja versucht werden, eine Auseinandersetzung mit den Licht- und Schattenseiten des komplexen Themenfeldes zu ermöglichen, Angst und Abwehr gegenüber dem Ganzen zu verringern und vielleicht sogar die Jugendlichen zu ermutigen, neue Erfahrungen im Leben zu machen und einfach einmal etwas anderes auszuprobieren. Ein Werbeplakat der Berliner Verkehrsbetriebe zeigt zwei leger, in schwarzes Leder, gekleidete Männer in einer UBahn. Darüber steht als Slogan: »Wir bringen Dich ans andere Ufer.«Was die Berliner BVG kann, das müssten Schulen doch auch können. In den Erziehungswissenschaften ist das Thema aber noch nicht im erforderlichen Maße angekommen und die Sonderpädagogik hat es, bis auf einige versprengte Publikationen, eher vernachlässigt. Wer liefert also Konzepte und Impulse, außer den Gender- und Queer Studies? Die liberale Reformpädagogik mit ihren, in einigen Fällen nachweislich, fließenden Übergängen ins mann-männlich Erotisch-Sexuelle sieht sich seit einigen Jahren heftiger Kritik ausgesetzt. Sie muss erst einmal die vorgekommenen sexuellen Verstrickungen, in deren Zentrum die Odenwaldschule stand, aufklären und sich dann neu ausrichten. Insofern kommen von dieser Seite derzeit keine nennenswerten Vorschläge, wie wir pädagogisch in Fragen der Sexualität weitermachen können. Eine rein verhaltensorientierte, an evidenzbasierten, psychologischen Diagnostik- und Interventionssystemen orientierte Inklusions- und Sonderpädagogik, wie sie den Schwerpunkt der emotionalen und sozialen Entwicklung in Deutschland und den USA immer mehr beherrscht, wird sich ebenso wenig als Bezugsmodell eignen, weil sie über gar keine Reflexionshintergründe und Konzepte verfügt, um die emotionalen Tiefen und die kulturellen Grundierungen des Themas zu erfassen. Folglich lassen sich von hier aus keine Modelle entwickeln, um die, von den Jugendlichen artikulierten, sich um Liebe und Erotik, Identität und Sexualität drehenden, Lebensthemen pädagogisch bzw. didaktisch zu rahmen und im Idealfall sogar noch mit sachbezogenem Lernen zu verknüpfen, wie ich es etwa im Rahmen der Lebensweltorientierten Didaktik versucht habe. 
Impulse lassen sich jedoch aus kulturwissenschaftlichen, historiografischen, soziologischen und philosophischen Diskursen beziehen, ebenso aus der autobiografischen und biografischen Literatur, aus Romanen und Erzählungen, aus Filmen, Kunst und Photografie, wenngleich das allermeiste davon nicht 1:1 im Unterricht oder in anderen pädagogischen Formaten verwendet werden kann und mehr der Hintergrundvorbereitung von Lehrkräften und Pädagog_innen dient. Meine eigenen schulischen und außerschulischen Praxiserfahrungen sprechen auch dafür, eher indirekt am Thema zu arbeiten, dabei niemanden festzulegen und stärker den Einzelnen übergreifende Reflexionshorizonte zu öffnen. Es geht eher darum, ermutigende, manchmal auch starre Denkmuster irritierende Impulse zu geben, Ängste abzubauen, ein Nachdenken und Neu-Denken in Identitätsfragen sowie eine Transformation von überkommenen, einengenden normativen Männlichkeitskonzepten anzuregen, wie sie etwa noch in der Welt des Fußballs herrschen. So lässt sich schrittweise zu einer Akzeptanz diverser Persönlichkeitsanteile und zu einem tieferen Verständnis alles Menschlichen gelangen, allerdings in sehr kleinen Schritten. Erschwerend kommt hinzu, dass sich in den homosexuellen Kulturen und Subkulturen wiederum teils starre Männlichkeitskonzepte herausbilden, die auf die gesellschaftlichen Auseinandersetzungsprozesse mit männlicher Homosexualität zurückwirken, etwa die starke Betonung von jungen, kantigen und trainierten Körpern, wie sie vor allem Tom of Finland gezeichnet hat. Diese Modelle haben zum einen männliche Homosexualität von der Reduzierung auf Tuntiges und Effeminiertes befreit. Zum anderen haben sie aber auch zu einer Diskriminierung von all jenen männlichen Körpern geführt, die als feminin, dick oder alt kategorisiert werden. Gegen diesen Trend formierten sich schon seit den 70er Jahren wiederum neue Subkulturen, mit emanzipatorischer Absicht, etwa im Rahmen des Big Men's oder Girth \& Mirth Movement, wobei selbstbewusst kräftigere, dickere oder gar übergewichtige Körper gezeigt und zelebriert worden sind. Dabei fand teils eine Orientierung an den eher stämmigen, korpulenten, kräftigen Männertypen der früheren Arbeiterklasse statt. Auf diese Weise wurden neue homosexuelle Masculinities, wie der kräftige, haarige Bär, oftmals mit einem Bierbauch, der dicklich weiche Chubby oder Superchub, der ältere, erfahrene Daddy, oder Mischungen aus alldem, geschaffen und mit je eigenen Narrativen umgeben. Besonders die Existenz der Bärenszene ermöglichte nun auch Männern ein Outing, die sich, bei einer weiteren Dominanz von eher femininen Männlichkeitskonzepten im öffentlichen, gesellschaftlichen Bild, niemals geoutet und eher im Verborgenen gehalten hätten. Diese Renaissance proletarischer Männlichkeitsmodelle erzeugte parallel einen neuen wertschätzenden Blick nicht nur auf männliche Muskelmasse, sondern zugleich auch auf männliches Körperfett. Mit der Thematisierung von männlichem Körperfett gelangen wir aber nun in ein hochgradig emotional besetztes Gelände, denn Fett steht, wir wissen es seit Joseph Beuys' Kunstschöpfungen, für Wärme, für Leben und Überleben. Es liegt nahe, dass es in bestimmten homosexuellen Subkulturen eine sehr starke Sehnsucht nach diesen, mit Fett assoziierten, emotionalen Qualitäten gibt. Zugleich haben wir in der Gesellschaft mit einer Diskriminierung von Fett zu tun. Doch in den geschützten Räumen digitaler Subkulturen kommen Bedürfnisse zum Ausdruck, die im Alltagsleben verborgen bleiben müssen.

Für die Jungen und männlichen Jugendlichen im pädagogischen Feld, die sich oft wenig sachbezogen mit all diesen Aspekten beschäftigt haben, könnten solche Hintergrundkenntnisse immerhin zu einer differenzierteren Einschätzung der Lage beitragen. Für viele ist es oftmals eine Überraschung, von solchen Ausdifferenzierungen 
der homosexuellen Szenen etwas zu hören. Auch war es so, das viele der Jugendlichen, mit denen ich im Feld der emotionalen und sozialen Entwicklung gearbeitet habe, sich an solchen Männlichkeitskonzepten, wie wir sie nicht nur in der Wrestling-Szene, sondern eben auch in der Bären-Szene antreffen, ausrichteten, allerdings abzüglich der homosexuellen Komponente. Trifft man diese Gruppe etwa in den Fitnessstudios, sind sie zumeist damit befasst, teils auch durch unterstützende Einnahme von Hormonen und Anabolika, Masse aufzubauen. Masse ist aus ihrer Sicht männlich. Ein gutes Thema für pädagogische Reflexionen ist daher die Frage nach dem Wesen von Männlichkeit und welche Rolle dabei Muskelmasse und Körperfett spielen. Vorläufig bloß in Nebensätzen lässt sich dabei auf Bären, Chubs, Super Chubs etc. und die sich um sie rankenden Erzählungen anspielen. In diesen delikaten, jedoch zumeist mit enormer Motivation besetzten, Themenfeldern haben die kleinsten Andeutungen schon überaus große Wirkung. Ohne dass ich allzu viel erzählen müsste, kommt viel in den Jugendlichen in Bewegung, denn die meisten haben in den digitalen Welten mehr gesehen als wir Pädagog_innen. Unsere Aufgabe bzw. Rolle ist dann nicht das informative Schildern von Details, sondern das Einordnen des Gesehenen in größere Zusammenhänge und das Aufzeigen von Ebenen der Analyse und des tiefergehenden Verstehens. Zugleich trete ich nicht als jemand auf, der schon alles weiß und alles gesehen hat, wie könnte ich auch, sondern als jemand, der mit geöffneten Augen durch die Welt geht, der Fragen stellt, der denkt und der nach tieferen Bedeutungen sucht. Größer sind die Schwierigkeiten, wenn wir Hinweise auf aggressives Sexualverhalten von Jugendlichen bekommen, auf das Austesten oder Überschreiten von Grenzen, auf Kindheitstraumata und damit in Verbindung stehende sexuelle Auffälligkeiten. Natürlich können wir sagen, dass liege alles jenseits unserer professionellen Reichweite als Pädagog_innen und sei etwas für speziell ausgebildete Psychotherapeut_innen. Das ist es auch, doch was machen wir, wenn die betreffenden Jugendlichen diesen Konfliktstoff, oder bloß Teile davon, vor unseren Augen in Szene setzen, oder wenn sie diese Dinge in irgendwelchen Randbereichen des Schullebens ausleben und sie aber weder zu einer Psychiater_in noch zu einer Psychotherapeut_in gehen? Es ist allemal gut, sich Wissenshintergründe zu verschaffen, um die Dinge einordnen zu können, um dann eventuell an andere Stellen verweisen oder etwas empfehlen zu können, auch um sich selbst und die anderen Jungen bzw. jungen Männer, und natürlich die Mädchen und jungen Frauen im Umfeld, zu schützen und vorbereitet zu sein. Ein Konzept, das wir vielleicht kennen sollten, nennt sich Imprinted Arousal Pattern (vgl. King, 2000). Dabei handelt es sich um eine Art Muster, das die Heranwachsenden in mehr oder weniger traumatischen, oder zumindest für sie sehr belastenden, Situationen ausgebildet haben und das nun zu Erregungszuständen durch Situationen führt, die den Traumatisierungsumständen ähneln. Das können sowohl selbst erlebte als auch mitangesehene Misshandlungen anderer, oder auch schwer verdauliche sexuelle Handlungen oder Verhaltensweisen anderer gewesen sein. Solche verinnerlichten Muster können dazu führen, dass Jugendliche oder junge Männer andere sexuell missbrauchen oder dass sie sich sehr stark sadistisch, oder auch masochistisch, verhalten. Masochismus lässt sich dann als Ergebnis eines problematischen Selbsterlebens verstehen. Ein Mensch mit einem solchen Muster spürt sich nur durch Schmerz, Fesselung, Demütigung, in der Interaktion mit einem dominant-sadistisch agierenden Gegenüber. Der italienische Psychoanalytiker Franco De Masi (2018) hat sich detailliert mit diesem Themenzusammenhang beschäftigt. 


\section{Körper, Identität, Emotion und Sehnsucht in der digitalen Welt}

Die Identitätsentwicklung und die sexuelle Entwicklung von Jugendlichen ist heute nicht mehr ohne die Auseinandersetzung mit den Körpern und Praktiken im virtuellen Raum denkbar. Eine besondere Rolle spielen dabei Online-Communities und Dating-Apps. Das hier angesprochene Geschehen beinhaltet eine Reihe von Themen und Aspekten, die aber erst nach und nach Eingang in die Forschung finden, etwa das Kommen und Gehen in den Apps, das Umgehen mit Ungewissheit, das Umgehen mit Widersprüchen, verbunden sein und zugleich nicht verbunden sein, die Konfrontation mit falschen Identitäten, Täuschungen oder Cyberbullying, die Risiken digital zustandegekommener sexueller Begegnungen, die Sorge um Privatheit und Datenschutz oder die mann-männliche Prostitution über das Internet und damit einhergehend die Selbstpräsentation, Selbstvermessung und Selbstvermarktung des eigenen Körpers. Das virtuelle Sehen und Gesehen-Werden wird für viele junge Männer zu einem lebensbestimmenden Themenfeld, zu einer Quelle der Bestätigung oder des Unbehagens und des seelischen Leidens, oder beidem. Über die Bedeutung dieser gegenseitigen Blicke im virtuellen Raum ließe sich, etwa ausgehend von Jean-Paul Sartres Überlegungen, wie wir sie in seinem Buch Das Sein und das Nichts finden, auch mit den Jugendlichen selbst philosophieren. Wir haben es mit neuen Formen der Interaktion, Typisierung und Kategorisierung zu tun, mit der digitalen Vermessung und Selbstvermessung, mit der Vergegenständlichung und Verdinglichung von Körpern, mit der Selbstvermarktung. Gesichts- und Körperphotos spielen bei der digitalen Selbstpräsentation der Körper unter Glas (vgl. Penney, 2014), wie auch bei der dann folgenden Kommunikation, eine wichtige Rolle. Eine hervorgehobene Bedeutung kommt dem unbekleideten männlichen Torso zu. Bei diesen Formen der Präsentation und Performance in den virtuellen Räumen der Dating-Apps geht es etwa um die Suche nach der eigenen männlichen Identität und die Produktion von Männlichkeit. Dabei fällt auf, dass in etlichen homosexuellen Apps Geschlechterrollen propagiert, betont und forciert werden, die zum einen sehr stark am Konzept der hegemonialen Männlichkeit ausgerichtet sind. Die hegemoniale, auf Dominanz und Unterwerfung ausgerichtete, Männlichkeit benötigt aber immer einen Gegenpol, jemanden, der unterworfen und dominiert werden kann und der, in der Regel, auch dominiert werden will. Passiv zu sein, sich hinzugeben, sich unterzuordnen, ist zur Konstitution des Aktiven, Erobernden und Dominanten unerlässlich.

In den Apps und Dating-Plattformen sehen wir nun auf der einen Seite die rezeptiv-passiven Bottoms oder Subs und auf der anderen Seite die aktiven, das Geschehen bestimmenden Doms oder Tops. Dabei kommt es in etlichen Apps zu einer Abwertung, ja regelrechten Diskriminierung femininer Tendenzen, zu anti-femininer Sprache, außerdem zu einer Abwertung und Entmännlichung von übergewichtigen Männern. Wir haben also mit Apps zu tun, wo alles Feminine, Dicke, Weiche diskriminiert und zugleich instrumentalisiert und verstärkt wird. Trotz allem werden diese Körpermanifestationen ja gebraucht, zu Zwecken der Identitätskonstruktion über Abgrenzung. Selbststabilisierung und Identitätsgewinnung erfolgen durch das, was ich eben nicht bin oder nicht sein will, durch das Andere, was ich mir gegenüberstelle. Zugleich haben sich, in Zusammenhang mit der Big Man's Bewegung, Online-Communities und Dating-Apps etabliert, wo wir nun Männern aller Altersstufen begegnen, die sich aus diesen stereotypen Masculinities herausbewegen. Sie versuchen Stigmata zu über- 
winden, die mit einem erhöhten Körpergewicht zu tun haben, wie etwa in der bereits erwähnten Subkultur der Bären und Chubs. Doch es gibt mittlerweile weitere Differenzierungen und Spielarten. Im vergangenen Jahrzehnt haben sich eine Reihe von internationalen Online-Communities etabliert, in denen sich, trotz der damit einhergehenden gesundheitlichen Risiken, um das Thema Fettfetischismus, eine neue homosexuelle Subkultur entwickelt hat, auch bekannt unter dem Namen Feederism. Was hier geschieht, ist für unser pädagogisches Fachgebiet, in dem es oftmals ja auch um Essen geht, denken wir an das Thema Magersucht, an die hohe Bedeutung von Süßigkeiten in der psychoanalytischen Pädagogik von Fritz Redl und Bruno Bettelheim, oder an Marjorie Boxalls Nurture Groups, die ja das Füttern schon im Namen tragen, in mehrfacher Hinsicht aufschlussreich. Die auf diesen Plattformen anzutreffenden Personenprofile, Selbstbeschreibungen und allgemeinen, insbesondere aber auch die dialogisch-privaten, Kommunikationen geben ungeahnte Einblicke in die Tiefendimensionen männlicher Identitäten, Körperkonzepte, sexueller Präferenzen und Emotionen. Mit Namen nennen will und kann ich die besuchten Plattformen aus Gründen der Diskretion und des Datenschutzes nicht. Die allermeisten dieser Plattformen erlauben auch keine systematische, wissenschaftliche Forschung, aus naheliegenden Gründen.

Von einer Forschung im engeren Sinne will ich bei meinen Versuchen, in diesen Welten einen ersten, groben Überblick zu bekommen, auch nicht sprechen. Auch werde ich keinerlei Daten oder Kommunikationen im Detail wiedergeben. Ich habe keine Screenshots gemacht, nichts ausgedruckt, und alle Dialoge zusammen mit den diversen Accounts komplett wieder gelöscht. Ich habe keinerlei Materialien dieser Erkundungen und Explorationen zurückbehalten. In den Apps werden auch durchgängig von den beteiligten Männern keine echten Namen verwendet, sondern durchweg Phantasienamen. Erst wenn Vertrauen aufgebaut worden ist, und das wird in der Regel eine ganze Weile dauern, werden im privaten Chat-Bereich die echten Namen und gegebenenfalls sogar Kontaktinformationen ausgetauscht. Soweit bin ich jedoch in keinem einzigen Fall gekommen bzw. gegangen. Doch eines sei hervorgehoben: Diese Plattformen sind alle legal. Wer sich anmeldet, muss unterzeichnen, dass er mindestens 18 Jahre alt ist. Allerdings hatte ich bei einigen wenigen Profilen den Eindruck, dass auch 17-jährige unter den Nutzern gewesen sein könnten. Wer will das überprüfen? Gesichtsbilder sind zunächst eher rar. Manchmal finden sie sich in den private pics, für die man erst einmal freigeschaltet werden muss. Manchmal werden sie auch nur im privaten Chat geteilt, oftmals, aus Vorsicht, auch gar nicht. Zunächst ist jedoch festzuhalten, dass diese Online-Communities Männern Kommunikationsmöglichkeiten anbieten, einen explorativen Raum, um das eigene Körpererleben, emotionale oder psychosexuelle Erleben in Beziehung zu anderen Männern zu setzen, dadurch Resonanz zu erhalten, sich selbst zu erkennen und mehr Klarheit bezüglich der eigenen Rolle und Orientierung zu bekommen und sich gegebenenfalls neu auszurichten. Aus dem allgemein und übergreifend laufenden Kommunikationsprozess heraus, bilden sich einzelne Dyaden, das heißt kommunikative, teils intime und persönliche Blasen, um es mit Peter Sloterdijk zu beschreiben. Einige der Apps bieten fast wissenschaftlich wirkende Kriterienlisten, mit denen jeder Mann, der sich hier anmeldet, eine Art persönliches Profil erstellen und ebensolche Suchfilter kreieren kann, um aus der weltweiten Community genau diejenigen Männer herauszufiltern, die am ehesten zu den eigenen Bedürfnissen passen könnten und die, je nach Leitmotiv der 
jeweiligen Community, an demselben Fetisch interessiert sind. Fetisch kann sich hier auf eine ganze Reihe von Komponenten beziehen, von bestimmten Materialien wie Leder, Gummi bis hin zu spezifischen Rollenspielen oder Skripten, oder eben Körperfett oder Muskelmasse. In gewisser Weise wirken einige dieser Plattformen wie regelrechte Selbsterfahrungsgruppen, allerdings ohne professionelle Leitung oder Moderation.

Gerne hätte ich das Geschehen in diesen virtuellen Welten einmal mit Carl Rogers, dem Begründer der Encountergruppen, gemeinsam angeschaut und besprochen. Zentrale Themen können sein Dominanz und Unterwerfung, Abhängigkeit und $\mathrm{Zu}$ neigung, körperliche Verschmelzung, die Einbettung von Begegnungen in warmherzige Beziehungen oder die eher emotionslose, pure sexuelle Begegnung, per Chat, $\mathrm{Vi-}$ deo-Chat oder real in der Wirklichkeit. Bei einer Plattform geht es zusätzlich um das Thema Essen, das sich gegenseitig Füttern, bis hin zu einem regelrechten Mästen des anderen. Teils geht es um den Aufbau von Muskeln und die kleinschrittige Begleitung eines anderen Mannes bei diesem Prozess, den er dann durch das Hochladen neuer Photos seines Körpers dokumentiert. Teils geht es, bei diesen körperlichen Transformationsprozessen, auch um das Zulegen von reinem Fett oder einer bestimmten Mischung von Muskeln und Fett. Es gibt Männer, die sich tagelang, wochenlang, monatelang mit nichts anderem beschäftigen als mit der Frage, wie sie die, für sie richtige, Mischung hinbekommen und dazu weltweit in die Kommunikation gehen, mit Männern, die eben genau das interessiert. Hierdurch entstehen ganz neue Formen der Intimität und es bildet sich eine neue Form des körperbezogenen und psychosexuellen Wissens. Es werden eine ganze Reihe von Szenarien und Rollenspielen sichtbar, die über Filter gewählt werden können, um mit Männern in Kontakt zu kommen, die nicht nur die gewünschten körperlichen Eigenschaften, sondern auch die passenden Präferenzen haben. Mit fast wissenschaftlich zu nennender Detailliertheit wurden hier Merkmalslisten und Skalen erstellt, zum einen was die physische Beschaffenheit des eigenen Körpers, wie auch des, beim Gegenüber, gewünschten Körpers anbelangt, zum anderen welche Themen auf der Handlungsebene im Vordergrund stehen sollen. Solche Rollenspiele drehen sich sehr häufig um Vater und Sohn, Onkel und Neffe, gelegentlich um Arzt und Patient oder um die Interaktion mit einer Autoritätsfigur wie z. B. einem Polizisten, oder mit einer traditionell hypermaskulinen Figur wie einem Soldaten. Teils drehen sich diese Skripte um bestimmte Formen der Kleidung, etwa Unterwäsche, Militär- oder Polizeiuniformen, Gummi oder Leder, eng um dicke Bäuche gespannte Hemden, aufplatzende Hemdknöpfe oder um nasse Kleidung, die den Körper durchscheinen lässt. Ein weiteres Skript bezieht sich auf das Thema Essen und Füttern, wobei es darum gehen kann, jemanden regelmäßig zu füttern oder sich selbst füttern zu lassen. Oder es geht darum, einen Mann auch dann weiter zu füttern, wenn er schon eigentlich nicht mehr essen kann. Es kommen also Fragen der Macht und der Dominanz ins Spiel, wie auch der Unterwerfung. Ein häufig anzutreffendes Thema ist, einen anderen Mann durch exzessives Mästen, teils einvernehmlich, teils auch gegen seinen Willen, völlig handlungs- und bewegungsunfähig und damit von sich abhängig zu machen und unter Kontrolle zu bringen, oder eben sich selbst, aus der passiven Haltung heraus, genau danach zu sehnen. Andere Skripte sind Pig Play oder Messy Eating. Dort, wo dicke Bäuche zum Fetisch werden, sind diese entweder durch massives Essen und Trinken real erzeugt, teils kurzfristig durch das Trinken von sehr viel Flüssigkeit, die im Körper gehalten wird oder sie werden mit Luft regelrecht aufgepumpt. 
In mehr oder weniger ausführlichen Photodokumentationen lassen sich diese körperlichen Transformationsprozesse in den Profilen, im allgemeinen Newsfeed oder in der dyadischen, mehr privaten Kommunikation, nachvollziehen. Wer noch mehr Details sehen will, kann den jeweiligen Akteur um Freischalten seiner privaten Bilder bitten oder sich per Videochat verabreden. Hier kann jedem kleinen Interesse und jeder kleinen, noch so verborgenen Lust nachgegangen und sich darüber ausgetauscht werden, solange beide Dialogpartner das gegenseitige Interesse aufrechterhalten. Natürlich lässt sich virtuelle Kommunikation jederzeit abbrechen oder beenden. Auch das geschieht, den Beiträgen im Newsfeed nach zu urteilen. Viele Männer verarbeiten solche Erlebnisse durch ein allgemeines Sharing und hoffen vielleicht auf guten Zuspruch aus der Community, vielleicht auch auf neue Kontaktmöglichkeiten, die sich hieraus wiederum ergeben können. Irgendwo auf der Welt fühlt sich jemand von dem Geschriebenen angesprochen und reagiert. Auf eine Stimme aus Manchester antwortet jemand aus Sydney. Ein Beitrag aus Warschau findet sein Echo aus New York. Recht häufige Skripte, die sich in mehreren Online-Communities wiederfinden, sind um die Ausscheidungsvorgänge zentriert, etwa Watersports genannt, die in die sexuellen Spiele einbezogen werden oder aber selbst als Fetisch im Vordergrund der Begegnung zwischen zwei Männern stehen. In einem etwas ungewöhnlichen Fall präsentierte sich ein Mann auf allen Photos mit einer Windel, wie sie Babies tragen. Nun ist das Tragen einer solchen Einweg-Windel für ihn hochgradig lustbesetzt, wie wir in seiner Selbstbeschreibung erfahren. Er wünscht sich Männer, die pausenlos mit ihm über das Tragen und Wechseln der Windel in Kommunikation sind. Reale Begegnungen sollen sich ebenfalls um dieses Thema drehen. Es wird gegessen und getrunken, und irgendwann ist es soweit, der Mann muss die Windel abnehmen, sich entleeren und eine neue Windel anlegen. Gelegentlich macht er sein Geschäft in die Windel, was natürlich noch mehr Aufregung erzeugt, die dann gerne mit einem anderen Mann aus der Nähe geteilt wird. Ein weiteres, wenn auch nicht allzu oft anzutreffendes Skript, das dann als Rollenspiel regelrecht gelebt wird, ist die männliche Schwangerschaft. Hierbei entwickelt einer der beiden Partner die Phantasie, dass er das Kind eines anderen Mannes in sich trägt oder beide kultivieren wechselweise diese Phantasie. Um das Ganze glaubhafter zu machen, wird der Bauch bis auf die notwendige Größe gebracht, durch Essen, Trinken oder Aufpumpen. Ein sehr häufiges Skript ist in Verbindung mit Feeding und Stuffing das sog. Belly Play.

Ein gelegentlich anzutreffendes Skript dreht sich darum, sich einen anderen Mann regelrecht durch Essen einzuverleiben bzw. selbst gegessen zu werden. Dies mag in den meisten Fällen auf einer reinen Phantasieebene bleiben. Ein Mann Mitte 20 war jedoch tatsächlich auf der Suche nach einem väterlichen Mann, der ihn in der Realität zerlegen und sich einverleiben sollte. In seinem Profil befanden sich eine Reihe von Photomontagen, wo er Selbstportraits verkleinert und in Bilder eingefügt hatte. Auf einem der Bilder lag er auf dem Grill, wie ein knusprig gebratenes Hähnchen. Bei einem anderen Bild saß er nackt auf einem Salatblatt, auf wieder einem anderen sahen wir ihn, wie einen Fötus, im Bauch eines anderen Mannes kauernd. Es dürfte sich sicher um eine ernstzunehmende Form von passivem Kannibalismus gehandelt haben. Ein Gespräch per Chat über seine biografischen Hintergründe blockte dieser junge Mann rigoros ab, auch meine Empfehlung sich psychotherapeutische Hilfe zu suchen. Stattdessen ging er ganz in der Beschreibung möglicher Szenarien auf, wie er sich seine eigene Transformation an den gewünschten Ort, nämlich das Innere 
eines Mannes, der sein Vater sein könnte, vorstellte. Ein anderer Fall war ein Student, Anfang 20, der von einem dominanten Mann mittleren Alters entführt, eingesperrt, gemästet und dann sexuell benutzt werden wollte. Er selbst phantasierte sich dabei völlig passiv. Der ältere, dominante Mann sollte regelmäßig prüfen, ob er auch tatsächlich an Körpergewicht zunehme. Täglich sollte er das neu hinzugekommene Fett befühlen. In dem Maße, wo der entführte junge Mann an Gewicht zunimmt, wird in dieser Story nun die sexuelle Erregung des Entführers gesteigert. Hier kam es, ohne besondere Anstrengung, zu einer tieferen Exploration des biografischen Hintergrunds und des emotionalen Erlebens meines Chat-Partners. Dieser junge Mann war mit einem beruflich sehr erfolgreichen Vater aufgewachsen, der während seiner Kindheits- und Jugendjahre jedoch überwiegend nicht präsent gewesen war. Wenn der Vater bei der Familie war, war er emotional kaum zugänglich. Auch hatte er seinem Sohn vor allem vermittelt, dass es im Leben um schulische und berufliche Leistung ging. Niemals habe der Vater den Jungen während seiner Kindheit liebevoll in den Arm genommen, schreibt der Student im Chat. Nun befindet sich der junge Mann an einer internationalen Eliteuniversität und verzehrt sich nachts in solchen Phantasien. Diese Entführungsphantasie tauchte häufiger auf, auch in Kombination mit dem Einsperren und Mästen, so dass ich davon ausgehe, dass es sich um ein recht verbreitetes Skript handeln könnte, das freilich noch allerlei Abwandlungen, Variationen und Differenzierungen erfahren kann.

Ein Skript, das mir allerdings noch häufiger begegnete, ist der Fall eines jungen Mannes, in einigen Fällen handelte es sich dabei auch um Männer im mittleren oder höheren Alter, die an der schrittweisen Feminisierung ihres Körpers arbeiteten, um das sexuelle Begehren eines anderen Mannes auf sich zu lenken. So ein junger Mann kultiviert nun üppige, weiche Formen, durch eine bestimmte Art der fettreichen Ernährung, der reduzierten Bewegung, teils auch durch die Einnahme von Hormonen. Zusätzlich werden dem Körper Geräte, etwa Penis-Käfige oder Penis-Schlösser angelegt, die die phallische Sexualität zurückdrängen, ja schließlich ganz zum Erliegen bringen sollen. Anscheinend bewirken diese Maßnahmen auch eine Art Translokation der sexuellen Lustzentren in andere Körperzonen, die mehr mit dem passiven Erleben von Sexualität in Einklang stehen. Im Unterschied zu Transgender-Persönlichkeiten wollen diese Männer durchaus in ihrem männlichen Körper verbleiben. Sie erleben diese partielle Verwandlung als hochgradig aufregend. Diese Männer scheinen einem inneren Skript oder Drehbuch zu folgen, das das Leben für sie geschrieben hat und das sich um die Verwandlung ihres sexuellen Erlebens und Begehrens dreht. Sie sehnen sich nach männlicher Eroberung und Dominanz. In ihren Chats sind sie zumeist sehr kommunikativ und phantasievoll. Wie sich in den Online-Communities erkennen lässt, finden sie auch eine große Resonanz in der Männerwelt. Viele Männer suchen eben etwas Weibliches, aber ohne dass es, in aller Konsequenz, tatsächlich eine Frau ist. Wieder eine andere Gruppe, speziell von jungen Männern im Bereich 20 bis $25 \mathrm{Jah}-$ re, wollen einen väterlichen Mann stürmisch erobern und leben insofern ihre phallische Sexualität offensiv aus, teils in der Vorstellung, teils in der Realität. Doch was bei näherer Betrachtung deutlich wurde war, dass sie sich im Grunde danach sehnen, auf Bauch und Brust eines väterlichen Mannes einfach nur zu liegen und liebevoll gehalten $\mathrm{zu}$ werden. Hinter dem sexuellen Begehren verbirgt sich ein tiefes, bisher unerfüllt gebliebenes, emotionales Bedürfnis. Die meisten von ihnen wuchsen ohne Vater auf und wenn sie ihren Vater überhaupt kennen, dann hat er sich ihnen nicht liebevoll zu- 
gewandt. Ein wenig aus der Reihe fällt ein Student, der stets auf der Suche nach devoten Männern im Vater-Alter war. $\mathrm{Zu}$ einem Chat war er allerdings nicht aufgelegt und blockte sämtliche Fragen ab. Er sah sich als Dom, als Top, als Master. Als solcher beantwortete er eben keine Fragen. Vielmehr gab er Anweisungen. Soviel zu seiner Objektwahl: Es handelte sich um Männer in der Mitte des Lebens, auch reifere Männer, die sein Vater hätten sein können. Er erwartete von ihnen absolute Unterwürfigkeit und Folgsamkeit. Man sollte sich mit ihm per Video-Chat verabreden und dann seinen weiteren Anweisungen strikt Folge leisten. Er selbst zeigte sich prinzipiell nicht per Kamera, sondern fand seine Erfüllung darin, aus der Anonymität heraus dem Mann, der seinen Köder geschluckt hatte, Befehle zu geben, diesen etwa zu bitten, sich vor laufender Kamera zu entkleiden, auf allen Vieren herumzulaufen, sich vor den Augen des Studenten zu befriedigen und anderes mehr.

Wie es aussah, hatte dieser junge Mann seine Follower. Aus aller Welt bekam er Likes zu den Posts, mit denen er auf sich aufmerksam machte. Es gibt auch eine recht verbreitete Phantasie, die sich auf Männer mit quasi weiblichen, üppigen Brüsten richtet, aus denen die Männer, die dieser Phantasie folgen, sich satt trinken können (Man Tits, Nipple Play). Ein ursprünglich von Müttern zu erfüllendes Bedürfnis wird nun auf Männer übertragen. Dieser Wunsch, gestillt zu werden, kann sich genauso auf die Genitalien von Männern richten, wir wissen das schon seit Sigmund Freuds Studie zu Leonardo da Vinci, teils in Kombination mit dem Trinken aus den Männerbrüsten. Gerne hätte ich gemeinsam mit Sigmund Freud, Wilhelm Reich, Theodor Adorno, Richard Louv oder Judith Butler vor dem Bildschirm gesessen, mich über die gesehenen Profile und die selbst geführten Chats mit diesen Wissenschaftler_innen ausgetauscht, um tiefergehend zu verstehen, worum es sich handelt und was die Bedeutungsebenen des Ganzen sein könnten. Manches liegt zwar auf der Hand, anderes ist aber schwerer zu entschlüsseln. Was hätte Krishnamurti dazu gesagt? Nehme ich das, was ich in diesen Online-Communities gesehen und gelesen habe, zusammenfassend in den Blick, sehe ich den roten Faden, egal ob es sich um junge oder Männer im mittleren oder höheren Alter handelt, gleichgültig ob diese Männer irgendwo in den Vereinigten Staaten, in Kanada oder Großbritannien, in Deutschland, Polen oder Tschechien, in der Schweiz oder in Australien leben, dass sie in den meisten Fällen nicht nach rein sexuellen Kontakten suchen, sondern dass sie in erster Linie angetrieben werden von einer tiefen, ungestillten Sehnsucht nach männlicher, und oftmals indirekt auch weiblicher, auf die männlichen Körper übertragener, emotionaler Zuwendung. Es dürfte ihnen am allermeisten um körperliches und emotionales Gehaltenwerden gehen, um Resonanzerfahrungen, Beachtetwerden, Gesehenwerden. Sehr viele jüngere Männer suchen nach Zuneigung von älteren, das heißt eher väterlichen Männern. Ältere Männer suchen sich oftmals einen jüngeren Mann, dem sie dann die Zuwendung zukommen lassen wollen, die sie vermutlich selbst in dem Alter gesucht haben und gebraucht hätten. Einige jüngere Männer suchen auch nach einem sog. Sugar Daddy, das heißt sie wollen einen väterlichen Mann im mittleren oder etwas höheren Alter sexuell beglücken und zugleich finanzielle Zuwendungen dafür bekommen.

Solche Fälle gab es gelegentlich auch unter meinen Schülern an urbanen Förderschulen. Geld und emotionale Zuwendung dürften in ihrem tieferen Bedeutungskern allerdings dabei verschmelzen, denn es gibt ja immer auch andere Geldquellen als einen solchen Sugar Daddy. Zugleich entstehen in der virtuellen Welt neue Geschäftspraktiken, die aus den erotisch-sexuellen Skripten und Vorlieben abgeleitet werden, 
insbesondere im Bereich des Feederism. Über die großen Online-Händler können einem anderen Mann Lebensmittelpakete zugesandt werden. Wer sein Wunschessen im Netz bestellt, bezahlt und ihnen zukommen lässt, kommt in den Genuss von privaten Photos oder Video-Chats, in denen das Paket dann geöffnet oder die Nahrung vor laufender Kamera zu sich genommen wird und gegebenenfalls weitere Wünsche erfüllt werden, etwa sich während des Essens schrittweise auszuziehen etc. Wieder andere Protagonisten schalten, nach Zahlung mit Kreditkarte, ihre selbst erstellten Filme frei, in denen genau die Dinge inszeniert werden, um die es dem Interessenten geht. Auf diese Weise vermarkten sie sich selbst, in einer Art Business. Soweit es sich in Erfahrung bringen lässt, sind die Männer in diesen Online-Communities in allen möglichen beruflichen Feldern tätig. Sofern sie studieren, sind technische Studiengänge stark vertreten, vielleicht gerade weil dort, anders als in gesellschafts- und bildungswissenschaftlichen Studiengängen, kaum inhaltliche Auseinandersetzungsmöglichkeiten mit den relevanten Lebensthemen gegeben sind. An den Datierungen der geposteten Beiträge lässt sich erkennen, dass viele dieser Männer, teils über etliche Jahre hinweg, ein- und dieselbe Story verfolgen. Viele scheinen regelrecht gefangen in den jeweiligen Skripten. Seit Jahren schon wirft etwa ein aggressiv auftretender Master bzw. Feeder seinen Köder aus und erhält, wie sich an den Likes und Kommentaren zu seinen Posts nachvollziehen lässt, aus der ganzen Welt Resonanz von devoten, masochistisch orientierten Männern, die ihre eigene Männlichkeit vollständig aufgegeben haben und sich danach sehen, von einem sadistischen Mann dominiert zu werden. Doch es gibt auch selbstreflexive und kritische Profile und Beiträge. Diese Männer versuchen, eine Metaperspektive einzunehmen, wo das gesamte kommunikative Geschehen auf der jeweiligen Plattform kritisch analysiert und überdies mit gesellschaftlichen Fragen in Verbindung gebracht wird. Seltener werden die innerhalb der betreffenden Community praktizierten Skripte in Frage gestellt. Die Betreiber der Plattformen scheinen solche Kommentare auch nicht sonderlich zu mögen. Im Code of Conduct gibt es Formulierungen, die so etwas nahelegen. Vermutlich werden solche Beiträge auch gelöscht. Doch immerhin einmal las ich einen allgemeinen Beitrag im Newsfeed, wo ein Mann schrieb, dass es unverantwortlich seitens der sadistischen Feeder sei, einen masochistisch orientierten übergewichtigen Mann zu beeinflussen, bis zur völligen Unbeweglichkeit weiter zu essen. Doch manch einer dort scheint auch früh sterben zu wollen.

Es muss also bei etlichen dieser Männer eine Art Lebensüberdruss, eine Verzweiflung, ein seelisches Leiden geben, dass sie sich buchstäblich zu Tode essen und genau darin die allergrößte sexuelle Lusterfüllung sehen. Die geposteten Bilder können einen teils erschrecken, wenn man sieht, was sie mit ihren Körpern angerichtet haben. Immer wieder schreiben Männer, dass sie sich von der jeweiligen Online-Community abgemeldet haben, weil sie die Wucht der thematischen Auseinandersetzung dort nicht mehr ertrugen und dann doch, nach einer gewissen Zeit, wieder zurückkehren mussten, weil sie ohne die dortigen Kommunikationsmöglichkeiten nicht leben konnten. Sie scheinen zwanghaft an die betreffende Community gebunden zu sein. O'Donohue würde sicher sagen, dass sie sich in einer Art inneren Gefängnis befinden, in einem Käfig, aus dem sie nicht herausfinden. Manche wollen ja auch regelrecht von einem anderen Mann in einen Käfig gesperrt und dort gefangen gehalten werden. Eine bestimmte Gruppe lässt sich, wie bereits erwähnt, kleine Käfige oder Schlösser anlegen, deren Schlüssel ein anderer Mann in Verwahrung nimmt, um ihre phalli- 
sche Sexualität zu kontrollieren, niederzudrücken oder gar völlig auszulöschen oder das Ganze wird virtuell als bloßes Rollenspiel inszeniert, in Ermangelung realer Umsetzungsmöglichkeiten oder zu großer Entfernung des anderen beteiligten Mannes. Der Käfig wird hier zu einer Art Symbol auf so vielen Ebenen. Auch in dem Film Wir Kinder vom BahnhofZoo, den ich, weiter vorne im Buch, besprochen habe, spielten ja die Käfige, mit den darin flatternden Vögeln, eine bedeutsame Rolle. Auch hier das Gefangen-Sein in problematischen Lebens-Skripten und biografisch unterfütterten, teils auf traumatischen Erfahrungen basierenden, Drehbüchern. Immer wieder sind auch Männer anzutreffen, die durchaus an biografischen Reflexionen und Rekonstruktionen interessiert sind, um die eigene Lebensgeschichte, das eigene Gewordensein besser zu verstehen. An solchen Punkten geht es ja schon in Richtung einer Encountergruppe oder einer Selbsterfahrungsgruppe, wie sie von Carl Rogers in den 7oer Jahren ins Leben gerufen wurde. In einigen Fällen wird auf den Plattformen auch gezeichnet, gemalt oder es werden mithilfe von Computerprogrammen Bildschöpfungen kreiert, die sich natürlich um den männlichen Körper und die Interaktionen zwischen Männern drehen. Es ist sicherlich erst einmal wichtig, dass es in einer offenen Gesellschaft die gefahrlose Möglichkeit gibt, all diese Facetten von Kontaktbedürfnissen, emotionalen und sexuellen Präferenzen zur Sprache zu bringen, all diese Vielfalt an Themen, verbal und in einigen Fällen sogar gestalterisch. Manches geht allerdings auch einher mit erheblichen körperlichen und seelischen Risiken. Es entsteht daher ein ambivalentes Bild, auf das es von pädagogischer Seite keine einfache Antwort gibt. Wie wollen wir als Gesellschaft damit umgehen? Wie groß ist am Ende der Leidensdruck, der Handlungsbedarf und was bedeutet all dies für die Zukunft der Gesellschaft? Die dargelegten Phänomene sind ja nicht in vollem Umfang einfach genetisch vorherbestimmt, wenngleich es sicherlich die eine oder andere anlagebedingte Disposition gibt, so dürfte das allermeiste, was wir hier zu sehen bekommen, sich durch bestimmte Sozialisationsprozesse, Interaktionserfahrungen in der Familie und kulturelle Einflussfaktoren entwickelt haben. Zugleich zerfällt diese Gesellschaft immer weiter in Bereiche, die unverbunden nebeneinander existieren. Auch das scheint sich hier auszuwirken.

Wenn auf eine durch professionelle Fachkräfte betreute Krippenkindheit und eine entfremdete Schulzeit noch ein entfremdeter Bürojob folgt, wenn nicht gar ein durch Medienkonsum und Onlinespiele gefülltes, von sozialen Transferleistungen abhängiges und beruflich perspektiveloses Leben geführt wird, in Kombination mit einem fragmentierten Privatleben, ohne besondere Einbettungen in eine weitere, lebendige Community, mit realen Menschen, dann können die wahren Sehnsüchte von Männern in der virtuellen Welt eben so in Erscheinung treten, wie sie es hier tun. Die nunmehr weltweit vernetzten Körper unter Glas (vgl. Penney, 2014) bringen sich zur Sprache. Sie entfalten sich in all ihrer, grundsätzlich erst einmal zu bejahenden und nicht in Frage zu stellenden, Diversität. Doch in vielen Fällen inszenieren jüngere und ältere Männer, vermutlich während der Kindheit verinnerlichte, Skripte, die sich oftmals zu rigiden Mustern oder Schemata verfestigt haben. Gelegentlich bleiben diese Drehbücher an frühesten Entwicklungsstufen hängen und entwickeln sich kaum weiter und treten am Ende ganz auf der Stelle. Oftmals sieht es auch so aus, dass diese Skripte mit Imprinted Arousal Patterns (vgl. King, 2000) verknüpft sind, wie sie in traumatisch wirkenden Stresssituationen entstehen können. Diese Männer treten nun miteinander in Kommunikation. Auch wenn sich gelegentlich Partner fürs Leben finden, um die 
persönliche Story dann in der Realität tatsächlich auszuleben, so dürfte sich die Mehrheit dieser Männer doch verzehren in einer ungestillten Sehnsucht. Die Frage ist, ob wir als Gesellschaft dabei stehen bleiben wollen und ob es nicht doch Möglichkeiten gäbe, die Weichen beim Aufwachsen von Kindern, insbesondere von Jungen und jungen Männern, mit deren Vulnerabilität ich mich ja hier beschäftige, anders zu stellen, um eine risikoärmere emotionale, geistige, körperliche und sexuelle Erfüllung, durchaus auch in ungewöhnlicheren Konstellationen, möglich zu machen. Dafür sollten wir mitnichten zur bürgerlichen Kleinfamilie, wie sie von Wilhelm Reich dekonstruiert wurde, zurückkehren, mit all ihren Verdrängungen, Irritationen, unguten Unterströmungen und all den neurotischen Verstrickungen, die hieraus für Kinder und Jugendliche resultieren konnten. Problematisch erscheinen mir allein zwei Komponenten: Dass es sich bei sehr rigiden Skripten, von denen wir uns nun einige exemplarisch angeschaut haben, um einen Verlust von Freiheit handelt, auch andere Dinge im Leben zu versuchen und dass es bei einigen Praktiken gegen den eigenen Körper und die eigene Seele geht. Psychoanalytisch gerahmt würde dies bedeuten, dass sich Eros und Thánatos gelegentlich zu stark mischen und Thánatos, in der jeweiligen Melange, teils zu sehr die Oberhand gewinnt. Das kann aber nicht das Ziel des Lebens sein und die Pädagogik sollte die Aufgabe haben, dem entgegenzusteuern. Kritiker_innen könnten es eventuell voyeuristisch finden, überhaupt in solche Online-Plattformen zu gehen und sich umzuschauen. Doch wir müssen schon hinschauen, wenn wir verstehen wollen, was derzeit geschieht und wenn wir noch Versuche machen wollen, die Situation, von der pädagogischen und gesellschaftlichen Seite aus, zu beeinflussen. Niemals können diese Dinge, die oftmals schon im Ansatz in vielen Jungen und jungen Männern, in je eigentümlichen Mischungen angelegt sind, die aber vielleicht noch in ihnen schlummern und sich erst nach und nach entfalten, allzu direkt im pädagogischen Kontext thematisiert werden. Es erscheint mir jedoch wichtig, erst einmal Vorstellungen zu entwickeln, was alles sein könnte, was alles in den Tiefenschichten der jugendlichen männlichen Psyche eingelagert sein könnte, wenn ein junger Mann von fünfzehn Jahren etwa Sätze wie »Verpiss Dich Du dreckige Schwuchtel!«, »Ich fick Dich auseinander!« oder »Sie können mir mal die Keule schmatzen!« in die Schulklasse schreit. Verschaffen wir uns Verstehenshintergründe, wie ich sie in diesem Kapitel versuchsweise erschlossen habe, dürfte die Wahrscheinlichkeit wachsen, dass wir als Pädagog_innen, in solchen Situationen, geeignete Antworten finden. 


\section{Europäische Lernräume: Pädagogischer Austausch zwischen Polen und Deutschland zur Zeit des Kalten Krieges}

Mit Piotr Toczyski, Maria Grzegorzewska Universität Warschau

\section{Die Ursprünge einer zukunftsweisenden pädagogischen Philosophie}

Ich habe dieses Kapitel hier aufgenommen, um zu zeigen, welche Bildungsphilosophie für mich handlungsleitend ist. Unsere pädagogischen Bemühungen müssen in größeren historischen, politischen und kulturellen Zusammenhängen stehen. Nachdem ich immer wieder nach Westen geblickt habe, also über Großbritannien und Irland bis hin zu den Vereinigten Staaten, will ich mich auch Osteuropa zuwenden. Hinzu kommt das Einbeziehen einer historischen Tiefendimension, die sich anhand der polnischdeutschen Beziehungen besonders anschaulich darlegen lässt. Solche Hintergrundüberlegungen sind auch für die später zu entwerfenden transformativen CommunityProjekte von hoher Bedeutung. Diese sollen nicht nur lokal verankert sein, sondern auch auf europäischer Ebene eine Rolle spielen. Das Kapitel wird auch deutlich machen, aus welchen tieferen Quellen ich bei meiner pädagogischen Ideenentwicklung schöpfe. Auf dem Rückflug von Krakau, im Januar 2020, saß ich neben einem Studenten, der im Rahmen des Erasmus-Programms gerade ein Auslandssemester an der dortigen Jagiellonen-Universität verbracht hatte. Der junge Mann schwärmte, wer wollte es ihm verdenken, von Krakaus Kellerkneipen, wie sie sich um den Rynek, den großen Marktplatz im Zentrum der Altstadt, finden und von den urigen Lokalen in Kazimierz, dem ehemals jüdischen Viertel, sodann von den guten Bieren und der Klezmermusik. Als er dann hörte, wie die Situation noch in den 8oer Jahren in Polen gewesen und wie schwer es zu der Zeit gewesen ist, überhaupt nach Polen einzureisen und sich innerhalb von Polen zu bewegen, wirkte er überrascht. Einige Vorträge seitens der Krakauer Universität zu kulturellen und historischen Themen, wie sie speziell Erasmusstudierenden angeboten werden, waren vermutlich recht abstrakt und schwer greifbar für den Studenten gewesen. Jetzt, wo die gehörten Geschichten einen persönlichen Bezug bekamen, wurden bei dem jungen Mann Gedanken und Fragen ausgelöst. So erfuhr er während dieses Fluges vom Engagement von Andrzej Jaczewski und Karl-Josef Kluge auf dem Gebiet der deutsch-polnischen Inklusions- und Sonderpädagogik während der Zeit des Kalten Krieges. Er sah es als willkommene Ergänzung und Abrundung seiner Erfahrung in Polen. Doch was genau unternahmen Jaczewski und Kluge seit 1969, dem Jahr, in dem sie sich erstmals begegneten? Wofür engagierten 
sie sich? Vor welchem historischen und gesellschaftspolitischen Hintergrund geschah all dies? Wie gestaltete sich der von ihnen initiierte pädagogische Austausch? Welche Herausforderungen stellten sich ihnen?

Teils face-to-face, teils telefonisch führten wir biografische und narrative Interviews (vgl. Küsters, 2009; Mayer, 2013; Nohl, 2009) mit den beiden Protagonisten. Wir legen offen, dass wir in persönlichen Beziehungen zu den beiden Professoren standen oder noch stehen, um deren Wirken es hier geht. Ich selbst war, als Student und Doktorand, an den hier rekonstruierten Projekten aktiv beteiligt. Piotr Toczyski lernte Jaczewski Anfang der 9oer Jahre in Warschau kennen, als er sich einer Pfadfindergruppe anschloss, der letzten Gruppe, die dieser leitete, bevor er sich 1992 von seiner Führungsrolle bei den Warschauer Pfadfindern zurückzog. Jaczewski gab aber weiter, in größeren Abständen, Seminare an der Warschauer Universität. Piotr besuchte einige von ihnen, unterstützte Jaczewski beim Aufbau seiner Medienpräsenz und analysierte seine digitalen Beiträge, über mehrere Jahre hinweg, unter der Frage, wie sich Weisheit in der digitalen Welt manifestiert (z. B. Toczyski, 2019). Es kam auch zu gemeinsamen Publikationen, etwa zu den Herausforderungen, die die digitale Welt für das Aufwachsen von Jugendlichen darstellt (Jaczewski und Toczyski, 2015). Piotr und ich haben uns, nach einem ausführlichen Arbeitstreffen in Berlin im Jahr 2019, $\mathrm{zu}$ dieser gemeinsamen Recherche entschlossen, weil es bisher keine übergreifende Veröffentlichung zu den von Jaczewski und Kluge initiierten deutsch-polnischen Austauschaktivitäten zur Zeit des Kalten Krieges gibt und weil wir davon überzeugt sind, dass das, was Kluge und Jaczewski in Gang gebracht haben, auch für die Gegenwart und die Zukunft der europäischen Gesellschaften von Bedeutung ist. Wir kombinierten Dokumentenanalysen (vgl. Hoffmann, 2018) mit mehrsprachigen Gruppendiskussionen (vgl. Kühn und Koschel, 2011) an Andrzej Jaczewskis Wohnort Ropki, in Südpolen, im Januar 2020. Ergänzend analysierten wir Gruppendiskussionen in einem von Jaczewski unterhaltenen Internetforum (vgl. Ullrich und Schiek, 2014). Zum einen stand uns ein begrenzter Fundus an veröffentlichtem Dokumentationsmaterial zu den damaligen Projekten zur Verfügung, teils in deutscher (vgl. Bröcher et al., 1987a, b; Depta, 1993; Fitting und Kluge, 1989), teils in polnischer Sprache (vgl. Jaczewski, 1993, 2015, 2018). Zusätzlich zogen wir unveröffentlichte Texte, Briefe und Photos heran. Außerdem werteten wir die polnischsprachigen Podcasts in Jaczewskis Internetforum aus, darunter Erinnerungen und Rückblicke, aber auch Stellungnahmen $\mathrm{zu}$ früheren politischen Ereignissen und aktuellen gesellschaftlichen Fragen in Polen. Auch die Kommentare und Diskussionsbeiträge, die hierzu aus seinem wissenschaftlichen Netzwerk und aus der weiteren polnischen Gesellschaft erfolgt sind, gingen in diese Analyse ein.

\section{Die Vergegenwärtigung der besonderen Historie der deutsch-polnischen Beziehungen}

Bevor wir in die Beskiden, das heißt nach Ropki, fuhren, um uns mehrere Tage mit Andrzej Jaczewski und weiteren Personen aus seinem Umfeld auszutauschen, verbrachten Piotr und ich einige Zeit in Krakau, zu Recherchen. Als wir durch die winterliche Universitätsstadt gingen, sprachen wir über die lange und wechselvolle Geschichte, die Polen und Deutschland miteinander verbindet (vgl. Bingen et al., 2016; Bömelburg 
und Kizik, 2014; Hackmann und Kopij-Weiß, 2014; Ruchniewicz, 2005). Jan Ostroróg, Schriftsteller und Berater der polnischen Könige, schrieb etwa um 1500: „Oh welcher Nachteil und Verruf für Polen! An vielen Orten wird in Gotteshäusern deutsch gepredigt ... Weil aber zwischen diesen beiden Sprachen ... schon die Abstammung ewigen Unfrieden und Haß eingibt, ermahne ich in dieser Sprache nicht zu predigen. Soll Polnisch lernen wer in Polen leben will!« (zit. n. Dedecius, 2011, S. 37). Der Schriftsteller Bolesław Prus notierte 1907, also 400 Jahre später: »Werden uns die Deutschen ausrotten oder uns die nationale Identität rauben?« (zit. n. Dedecius, 2011, S. 212). Doch Prus äußerte auch Respekt vor den Leistungen der deutschen Kultur: »Wer die Deutschen kennenlernen möchte, schaue sich ihre vorbildlich bebauten Felder an, ihre sauberen Häuser, Straßen und Ställe, ihre Museen und Ausstellungen, ihre Schulen, Universitäten und Bibliotheken ...« (a.a. O., S. 214). Weiter schreibt Prus: »Es ist wahr, die Deutschen haben uns Unrecht getan: die Teilung des Landes, eine gemeine Politik in Galizien ... Doch man denke, ohne das Schlechte zu vergessen, auch an das Gute ... Gibt es bei uns ein Handwerk, das nicht die Deutschen mitgebracht hätten?« (ebd.).

Mit Blick auf diese Hintergründe versuchten wir eine ausgewogene Sicht auf die beiden Nationen einzunehmen, aber die Position des Deutschen, der im Burghof des Wawel steht und sich mit Hans Frank und seiner Schreckensherrschaft über das Generalgouvernement auseinandersetzen muss, stellt in diesem Dialog eine ziemliche Herausforderung dar. Tatsächlich wurden in den Bloodlands wie Timothy Snyder (2016) das von Zentralpolen bis nach Westrussland reichende Gebiet nennt, einschließlich der Ukraine, Weißrusslands und der Baltischen Staaten, 14 Millionen Menschen ermordet, zwei Drittel von den Deutschen, das andere Drittel von Stalin. In den vergangenen 1000 Jahren gab es teils ein friedliches Miteinander von Deutschen und Polen, teils erhebliche Konflikte bis hin zu Kriegen. Ins kollektive Gedächtnis eingebrannt haben sich die drei polnischen Teilungen, an denen auch Deutschland beteiligt war, die erste 1772, die letzte 1795. Polen verschwand für 123 Jahre von der Landkarte, als es zwischen Preußen, Russland und Österreich aufgeteilt wurde. Die polnische Nation überlebte im Exil und in der Literatur, weshalb die polnische Literatur auch einen so ausgeprägt politischen Charakter hat und zugleich der Bewusstwerdung und Identitätsbildung der Polen diente (Lettenbauer und Kijowska, 1996, S. 410). Erst 1918 war Polen wieder eigenständig, bis dass die Deutschen im September 1939 einmarschierten und das Land bis Januar 1945 besetzt hielten. Ostpolen wurde zeitgleich, seit September 1939, von der Sowjetunion besetzt und entlang der Molotow-Ribbentrop-Linie aufgeteilt (vgl. Snyder, 2016, S. 135-167). Hitler und Stalin hatten im Geheimen vereinbart, dass jeweils die Hälfte des Landes an eine Seite fallen sollte. Die Grausamkeiten gegenüber der polnischen Bevölkerung während des Überfalls auf Polen und während der Zeit der deutschen Besatzung waren unvorstellbar. Kazimierz Brandys (1988) Roman Rondo dreht sich um den Widerstand im Warschau des Dritten Reiches und spiegelt die Atmosphäre jener Zeit wider. Die Deutschen veranlassten Umsiedlungen, Deportationen und Vertreibungen innerhalb von Polen (vgl. Pohl, 2008, S. 272). Die Deportierten lebten unter katastrophalen Bedingungen. Wohnungen in den Städten wurden für deutsche Beamte beschlagnahmt.

Auch in Ostpolen gab es Terror, Massenerschießungen und Deportationen. Mit der Kriegserklärung Deutschlands an die Sowjetunion im Juni 1941 wurde Ostpolen ebenfalls von den Deutschen kontrolliert. Andrzej Jaczewski war 1939 zehn Jahre alt. Er war bei den Pfadfindern, die sich teils politisch organisierten und gemeinsam mit seinem 
Vater, dem die Polen später ein Denkmal für seine Leistungen im Widerstand gesetzt haben, war er ab 1943, also bereits ab dem 14. Lebensjahr, im Warschauer Widerstand aktiv. Zum einen wurden Aktivitäten gegen die Deutschen, zum anderen gegen die Russen unternommen. Zugleich herrschte Hans Frank, geboren 1900, früherer Rechtsberater und Wegbegleiter von Adolf Hitler, mit sehr weitreichenden gesetzgeberischen Befugnissen im Generalgouvernement. Er verwaltete diesen Teil von Polen als eine Art Reichsnebenland oder Kolonie (vgl. Pohl, 2008, S. 268). Frank ist für die Ermordung von hunderttausenden Polen verantwortlich, für die Beschlagnahmung ihres Eigentums, für die systematische Ausbeutung und Ausplünderung der beherrschten polnischen Gebiete, für die Deportation von etwa einer Millionen Arbeiter_innen in deutsche Fabriken, für die Verschleppung der polnischen Juden in Gettos und ihre Ermordung in Konzentrationslagern. Steven Spielberg hat diese Geschehnisse auf bewegende Weise in seinem Film Schindlers Liste zum Thema gemacht. Während die polnische Bevölkerung im Generalgouvernement hungerte, rafften Hans Frank und seine Frau Kunstund Wertgegenstände und landwirtschaftliche Erzeugnisse im Übermaß zusammen und transportierten diese in ihrem luxoriösen Salonwagen, per Eisenbahn, zum bayrischen Erstwohnsitz. Ihr Sohn Niklas, geboren 1939, der als Kind all dies aus der Nähe miterlebte, hat sich in Buchform mit den, von seinem Vater begangenen, Verbrechen auseinandergesetzt (vgl. Frank, 2014). Unter dem Namen Sonderaktion Krakau (vgl. August, 1997; Schenk, 2010, S. 52 ff.) wurden am 6. November 1939, während Niklas als Kind von 8 Monaten oben auf dem Wawel in einer Wiege lag, 183 Wissenschaftler_innen der Krakauer Jagiellonen-Universität zu einem Vortrag einbestellt, jedoch unmittelbar verhaftet und interniert. Ein Teil der Akademiker_innen starb während der Zeit der Internierung. Der größte Teil wurde, wegen der internationalen Proteste, innerhalb von zwei Jahren wieder freigelassen. Allerdings konnten die Wissenschaftler_innen, die diese Schikanen überlebt hatten, ihre Arbeit nicht fortsetzen, denn die Krakauer Universität war inwischen zu einer deutschen Lehranstalt umfunktioniert worden. Es fand eine systematische Auslöschung der polnischen Intelligenz statt. Es gab Massenmorde an Politikern, Priestern und Lehrer_innen (vgl. Pohl, 2008, S. 274). Es existieren Photos von Lehrer_innen, die mit erhobenen Händen bis an den Rand von ausgehobenen Erdgräben geführt wurden, um sie dann zu erschießen.

Die deutschen Besatzer schlossen alle literarischen Institutionen, was zu einer weitgehenden Zerstörung des Schriftstellermilieus, teils auch zu einer Abwanderung in den Untergrund führte. Ein Teil der Schriftsteller_innen ging ins Exil nach London, Paris und New York (vgl. Kiowska, 1996, S. 149). 1939-1945 wurde eine konsequente Germanisierungspolitik im besetzten Polen betrieben, dazu gehörte nicht nur die Schließung aller polnischen Universitäten, sondern auch eine germanisierende Erziehungs- und Schulpolitik (vgl. Hansen, 2006; Ommler und Harten, 1996). Kein Pole sollte mehr über den Rang eines Industriemeisters hinauskommen. Die Deutschen wollten die Polen als bloße Arbeitskräfte, nicht als Denker_innen. Der Schriftsteller Stefan Zeromski hatte dies bereits Ende des 19. Jahrhunderts kommen sehen: »Du kennst die Deutschen nicht! Das ist kein Volk, sondern ein schrecklicher Orden, klug und schamlos organisiert, um solche Ackerbauern und Traumtänzer wie uns auzurotten ...« (Zeromski, 1886-1887, zit. n. Dedecius, 2011, S. 233). Nach der Niederlage Deutschlands am Ende des Zweiten Weltkrieges am 7. Mai 1945, Jaczewski war nun 16 Jahre alt, Kluge war da ein 12-jähriger Junge und lebte in Essen, im Ruhrgebiet, verschob die Sowjetunion den polnischen Staat nach Westen. Genau in diesem Jahr 1945 notierte die Lyri- 
kerin und spätere Nobelpreisträgerin Wisława Szymborska und wird dabei auf die 173 Jahre der Teilungen, der Auslöschung der polnischen Nation, des deutschen und des sowjetischen Überfalls und der dann folgenden Okkupation und Grenzverschiebung zurückgeblickt haben: »Die Geschichte hat uns keine Siegerfanfare geschmettert: Sie hat uns schmutzigen Sand in die Augen gestreut. Weite und blinde Straßen lagen vor uns, bitteres Brot, vergiftete Brunnen« (Szymborska, 1996 a, S. 203). Doch noch hatten die Polen weitere herausfordernde 45 Jahre vor sich. Die deutsche Bevölkerung, die in den östlichen Provinzen des wilhelminischen Reiches, etwa in Schlesien, gelebt hatte, wurde vertrieben. Es kam zu Racheakten und Grausamkeiten an den Deutschen. Schlesien und das kulturelle Zentrum Breslau, heute Wroclaw, haben in dieser Hinsicht eine hochkomplexe, wechselvolle Geschichte (vgl. Davies, 2003). Während der nachfolgenden Jahrzehnte von 1945 bis 1990, der Zeit des Kalten Krieges (vgl. Dülffer, 2004; Gärtner, 2017; Stöver, 2017; Westad, 2019), war die Welt aufgeteilt in zwei sich feindselig gegenüberstehende Blöcke, in West und Ost. Auf der einen Seite die USA und die Nato, auf der anderen Seite die Sowjetunion und der Warschauer Pakt, dazwischen der "Eiserne Vorhang«, wie Winston Churchill diese unüberwindbare Grenze genannt hatte. Zur Konkurrenz der Wirtschaftssysteme und politischen Ideologien kamen Wettrüsten und das Anhäufen von Atomwaffen.

Die politische Situation in der Volksrepublik Polen war durch ökonomische Schwierigkeiten und Einschränkungen der Bürger- und Menschenrechte gekennzeichnet. Die Kommunikation zwischen den Blöcken war extrem schwierig. Trotz allem gab es bestimmte Reisekorridore zwischen Westdeutschland und West-Berlin. Durch die DDR fuhren die Züge mit bewaffneten Soldaten an den Türen. Ich habe 1981 eine solche Fahrt nach West-Berlin unternommen. Genauso war es bei den internationalen Zügen, die in Paris oder Ostende starteten, in Köln und Berlin hielten und dann, durch die DDR, bis nach Warschau und weiter bis nach Moskau bzw. Leningrad fuhren. Eine solche Fahrt nach Polen habe ich im Sommer 1986 erstmals unternommen. Am Bahnhof Berlin-Friedrichstraße standen Grenzsoldaten und überwachten die Ankunft und Weiterfahrt der Züge. Trainierte Hunde suchten nach versteckten Passagieren. Die Pässe der polnischen Bürger_innen wurden, wie Andrzej Jaczewski aus eigener Erfahrung berichtet, von staatlichen Stellen verwahrt und mussten dort abgeholt werden, wenn jemand reisen wollte. Von 1956 bis 1990 agierten in Polen eine Geheimpolizei und ein Geheimdienst. Diese waren vergleichbar der Staatssicherheit der DDR. Regimekritische Menschen wurden beschattet, verhaftet, teilweise ermordet. Briefe zwischen Ost und West wurden von den kommunistischen Geheimdiensten geöffnet und auf systemkritische Mitteilungen oder Fluchtabsichten hin überprüft. Willy Brandts Ostpolitik brachte kleine Verbesserungen, doch die Deutschen blieben gespalten hinsichtlich der polnischen Grenze. Im Rahmen des Moskauer Vertrags hatten die Sowjetunion und Deutschland die bestehenden Grenzen zwar anerkannt. Das Verhältnis zwischen Deutschland und Polen war jedoch weiter angespannt. 1969, inmitten dieser politischen Turbulenzen, begegneten sich Jaczewski und Kluge zum ersten Mal.

1970 ging das Bild mit Willy Brandt um die Welt, als er vor dem Ehrenmal für die Toten des Warschauer Gettos kniete. Brandts Kniefall, als Demutsgeste gedacht, hatte international große Wirkung. In Deutschland brachte ihm dies aber auch die Kritik derjenigen Kreise ein, die die deutsch-polnische Grenze in der Form nicht hinnehmen wollten. So kam es $1972 \mathrm{zu}$ einem Misstrauensvotum gegen Brandt, wegen seiner auf Versöhnung, Verständigung und Entspannung gerichteten Ostpolitik und seiner Ab- 
sicht, die Oder-Neiße-Linie als deutsch-polnische Grenze endgültig anzuerkennen. In Ryszard Krynickis, zwischen 1978 und 1985 entstandenen, Notizen ist zu lesen: „Wenn ich zu rufen habe >Es lebe Polen! - in welcher Sprache werde ich es tun müssen? « (zit. n. Dedecius, 2011, S. 357). Unterdessen entwickelte sich in Polen die Situation weiter. Die 1980 aus einer Streikbewegung heraus entstandene Gewerkschaft Solidarność (vgl. Kühn, 2002) war letztlich Wegbereiter der großen politischen Umbrüche, die dann 1989 einsetzten. Doch bis dahin war es noch ein weiter, steiniger Weg. Um die mit der Solidarność aufkommende Demokratisierungsbewegung zu unterdrücken und die Gewerkschaft zu zerschlagen, verhängte die polnische Regierung Jaruzelski am 13. Dezember 1981 das Kriegsrecht (vgl. Hey, 2010). Kazimierz Brandys (1996) hat in seinem Warschauer Tagebuch das gesellschaftliche und politische Klima der Jahre 1978 bis 1981 festgehalten. Diese, bis Juli 1983 andauernde, Situation war verbunden mit Grenzschließungen, mit einer Militarisierung von Verwaltung, Wirtschaft und Medien, der Aufhebung von Bürgerrechten sowie einer das ganze Land erfassenden Verhaftungs- und Repressionswelle. Zahlreiche Gewerkschaftsmitglieder und Personen aus ihrem Umfeld wurden interniert. Obwohl auch Jaczewski dazugehörte, blieb er verschont. Seine Reputation als Kinderarzt, der sich sehr um die Menschen in Südpolen verdient gemacht hatte, gab ihm einen gewissen Schutz. Er kehrte gerade aus Köln nach Polen zurück, kurz bevor das Kriegsrecht verhängt wurde. Um Verlagsangelegenheiten in Zusammenhang mit Buchübersetzungen zu besprechen, war Jaczewski von Köln über Wien und die Tschechoslowakei gefahren und sah in der Grenzregion verzweifelte polnische Familien, die versuchten, den Ostblock noch, vor Verhängung des Kriegsrechts, zu verlassen und nach Österreich auszureisen. Sie wurden jedoch von den polnischen Grenzkontrolleuren nicht durchgelassen. Jaczewski litt sehr darunter, die Notlage dieser Menschen aus der Nähe mitanzusehen und nichts für sie tun zu können.

Es gab eine große Welle der Solidarität deutscher mit polnischen Bürger_innen nach der Einführung des Kriegsrechts und dem Verbot der unabhängigen Gewerkschaft Solidarnosc (vgl. Cöllen et al., 2012). Die Versorgungssituation der polnischen Bevölkerung wurde zunehmend schlechter. Jaczewski sagte während der Interviews in Ropki: „Wir gingen zu der Zeit mit löchrigen Schuhen und zerrissener Kleidung.» Es seien dann Winterkleidung, Essen, Früchte, medizinische Artikel etc. aus Deutschland nach Polen geschickt worden, auch Kleinbusse für die Pfadfinder, über das Netzwerk, dass Kluge und Jaczewski bis dahin aufgebaut hatten. Ab dem Jahr 1986, dem Jahr meiner ersten Polenreise, setzte in der Sowjetunion die Politik der Perestroika unter Michail Gorbatschow ein. Die deutsch-deutsche Mauer fiel im November 1989. Es folgte die deutsche Wiedervereinigung im Oktober 1990 und die endgültige Anerkennung der polnischen Westgrenze, seitens der Regierung Kohl. 1991 kam es zu einer Auflösung von Sowjetunion und Warschauer Pakt. Diese politischen und gesellschaftlichen Hintergründe müssen wir uns in Erinnerung rufen, um das, was Jaczewski und Kluge unternahmen, während der Jahre 1969 bis 1990, einordnen und würdigen zu können. Über die Bedeutung des kulturellen, akademischen und pädagogischen Austauschs, während des Kalten Krieges und darüberhinaus, herrscht in der Literatur Einigkeit (vgl. Barwinska, 2004; Borisova und Simons, 2012; Bu, 1999; Henderson, 2012; Marburger und Riesner, 1996; Richmond, 2003). Doch vor 1990 gab es nicht viel an solchen Aktivitäten. Der Deutsche Akademische Austauschdienst unterhielt zwar seit 1958 Verbindungen zu Polen, doch eine Systematisierung des Austauschs begann 
erst mit der Eröffnung einer DAAD-Außenstelle in Warschau im Jahr 1997. EU-basierte Sokrates-Erasmus-Programme begannen zwar im Juli 1987, doch brauchten sie noch anderthalb Jahrzehnte, bis dass sie sich zu den Strukturen entwickelten, die wir heute kennen. Das Deutsch-Polnische Jugendwerk wurde erst durch die Regierungen von Deutschland und Polen 1991 gegründet. Die Deutsch-Polnische Gesellschaft existiert erst seit 1996 als Bundesverband. Sie ging aus regionalen Gesellschaften hervor, die sich zuerst 1987 zusammengeschlossen hatten. Die Europäische Union schuf erst in den 9oer und 2000er Jahren Strukturen für einen systematischen kulturellen Austausch (vgl. Olsen, 2002). Viele Programme und Institutionen, die heute als selbstverständlich gelten, existierten daher vor 1990 entweder noch nicht oder sie steckten noch in den Kinderschuhen. Das Feld des deutsch-polnischen Dialogs hing in den 7oer und 8oer Jahren vor allem von mutigen und engagierten Einzelpersonen ab. Diese handelten als Pioniere, das heißt ohne institutionellen Rückhalt, auch was Fragen der Finanzierung anbelangt, während sich zugleich langsam die großen politschen Umwälzungen vorbereiteten.

\section{Die Achse Köln-Warschau während der Zeit des Kalten Krieges}

Zwei dieser engagierten Einzelpersonen waren Andrzej Jaczewski, geboren 1929, Kinderarzt und später Professor an der pädagogischen Fakultät der Universität Warschau sowie Ehrenprofessor an der Universität Krakau, und Karl-Josef Kluge, geboren 1933, Professor an der Heilpädagogischen Fakultät der Universität zu Köln. Jaczewski war zunächst praktisch tätig, in den ländlichen Regionen Südpolens, wo er noch heute den Rufhat, zu einer erheblichen Absenkung der Kindersterblichheit beigetragen zu haben. Später wurde er als Professor an die Universität Warschau berufen und war dort in der pädagogischen Fakultät tätig. Jaczewski veröffentlichte speziell zu Fragen der Sexualität von Kindern und Jugendlichen (vgl. Jaczewski, 2014) und zur Pubertät von Jungen (vgl. Jaczewski, 2019). Ein Teil seiner Bücher erschien schon in den 7oer und 8oer Jahren und wurde immer wieder aktualisiert und neu aufgelegt. Über das Radio, wo er regelmäßig sprach, gab er der polnischen Bevölkerung viele Jahre Informationen und Empfehlungen zur Kinderpflege und zu Erziehungsfragen. Sein ganzes Leben lang war Jaczewski als Pfadfinder aktiv und hatte innerhalb dieser Organisation leitende und koordinierende Rollen inne, speziell auch bei den Seepfadfindern, die ihr Handlungsfeld auf den Masurischen Seen hatten. Einer der von uns Befragten berichtete, dass Jaczewski besonders darauf achtete und sich auch gut darauf verstand, Jugendliche in Krisen oder schwierigen Lebenssituationen in die gruppenpädagogischen und erlebnispädagogischen Aktivitäten der Pfadfinderarbeit einzubinden. Jaczewski hatte bereits durch seine frühe Tätigkeit als Kinderarzt eine sehr starke Bindung an den polnischen Süden entwickelt. Als er dann als Professor an der Warschauer Universität tätig war und dort auch eine Wohnung bezog, erwarb er 1984 ein Grundstück in Ropki, in den Beskiden, einem Vorgebirge der Karpaten, wo er zuvor Pfadfindertreffen veranstaltet hatte. In Ropki baute er sich ein Holzhaus. Dieses diente zunächst als Sommersitz und später als Alterssitz. Es gehört zur besonderen Geschichte der Beskiden, dass dort, bis zu der durch das kommunistische Regime im Jahre 1947 veranlassten Zwangsumsiedlung, das bereits im Mittelalter aus den Karpaten eingewanderte Hirtenvolk der Lemken siedelte. Nun hat sich Jaczewski in besonderer Weise für die Lem- 
ken und ihre Rückkehr in die Beskiden (vgl. Schwanitz, 2007 a, b) eingesetzt und lebte mit zweien von ihnen in Wohngemeinschaft auf dem Anwesen in Ropki. Die Lemken richten ihr Leben traditionell nach der orthodoxen Kirche aus, so dass auch Jaczewski den Kontakt zu den geistigen Führungspersonen dieser Kirche pflegte. Auch hat er ein Denkmal gestiftet, dass an das Unrecht erinnert, das dem Volk der Lemken angetan worden ist. Jaczewski hielt ferner intensive Verbindung nach Russland und zur russischen Kultur. Sein Großvater war Professor in St. Petersburg. In seinem Blockhaus befanden sich eine Reihe von Originalmöbeln und Ikonen aus diesem Zusammenhang. Einerseits lebte Jaczewski nun mit 91 Jahren ein zurückgezogenes Leben. Zum andern pflegte er regen Kontakt $\mathrm{zu}$ seinem wissenschaftlichen Netzwerk, das ihn zu seinem 90. Geburtstag mit einer Festschrift geehrt hat (vgl. Wojtyczy, 2019). Sein Leben lang befasste sich Jaczewski mit Musik. Im Sommer 1986 legte er für uns Studierende, in seiner Warschauer Wohnung, Schallplatten mit polnischer Barockmusik auf und erläuterte deren Besonderheiten. Jan Piekarski (2019) schreibt in seinen Erinnerungen an die 6oer Jahre, dass Jaczewski ihm und den anderen Jugendlichen, im Rahmen der Pfadfinderarbeit, klassische Musik von Schallplatten vorgespielt hat. Im Januar des Jahres 2020 sprach Jaczewski über seine Leidenschaft für Richard Wagners Musik. Als Gastgeschenk hatte er sich von mir eine bestimmte Aufnahme des Rings der Nibelungen gewünscht. Die von mir angesprochene Nähe Wagners zum Dritten Reich fegte er mit lässiger Geste vom Tisch. Hier trenne er Kunst und Politik, sagte er. Auf keinen Fall wolle er Wagner der nationalsozialistischen Vereinnahmung überlassen.

Karl-Josef Kluge war zunächst Leiter eines heilpädagogischen Heimes am Niederrhein, dann ab 1968 Professor für Verhaltensauffälligenpädagogik an der Universität zu Köln und arbeitete etwa an historischen Rekonstruktionen zu dieser Disziplin (Flissikowski et al., 1980), an Adaptierungen des klientenzentrierten Ansatzes für den Bereich der schulischen und außerschulischen Erziehungshilfe (z. B. Fitting et al., 1981), am Thema Begabungsförderung (z. B. Kluge und Suermondt-Schlembach, 1981) oder an der Entwicklung von integrativen bzw. inklusiven europäischen oder internationalen Sommerworkshops (Bröcher, 1989; Bröcher et al., 1987a, b; Fitting und Kluge, 1989). Kluge gründete, gemeinsam mit seiner Frau Eva, das erew-Institut, später umbenannt in Kolleg für Therapeutik. Unter diesem Dach fanden nicht nur zahlreiche Aktivitäten im Feld der Familienberatung, der Erstellung von Gerichtsgutachten und der Kinder- und Jugendtherapie statt, sondern auch Weiterbildungsprogramme für Menschen aus psychosozialen Arbeitsfeldern. Die bundesweit besuchten Lehrgänge drehten sich um Kommunikation und Beratung, Supervision oder Leiten und Führen. Eine Festschrift zu Kluges 60. Geburtstag (Fitting und Saßenrath-Döpke, 1993) spiegelt die Vielfalt seiner Tätigkeitsfelder wider. Das letzte international ausgerichtete Sommercamp, unter seiner und seiner Frau Leitung, fand 2010 statt. Seiner Lehrtätigkeit an der Universität zu Köln geht Kluge auch mit 87 Jahren weiter nach, ebenso der Familienberatung. Wie entwickelte sich nun die Zusammenarbeit zwischen Kluge und Jaczewski? Es begann nach den Erzählungen der beiden 1969 während einer Tagung zum Dialog zwischen Ost und West, im Harz, in der Grenzregion zur DDR. Diese Tagung wurde veranstaltet von einer politischen Institution, welche genau es war, ließ sich nicht mehr ergründen. Kluge, frisch berufener Universitätsprofessor, war da 36 and Jaczewski 40 Jahre alt. Das Verhältnis zwischen Ost und West und speziell das deutsch-polnische Verhältnis waren, wie ich einleitend aufgezeigt habe, konfliktbe- 
lastet. Kluge mochte die Art, wie Jaczewski sich während der Konferenz einbrachte. Die beiden stellten fest, dass sie eine ähnliche Perspektive einnahmen, nämlich auf eine Verständigung und Aussöhnung zwischen Polen und Deutschen gerichtet. Schon während der Tagung nahmen sie sich vor, den Austausch und die Begegnung der Menschen zu fördern, wie festgefahren und spannungsgeladen die politische Situation auch sein sollte. Gleich im Anschluss lud Kluge seinen polnischen Kollegen nach Deutschland ein und schickte ihm Flugtickets. Jaczewski sagte, dass Kluge vermutlich nicht im vollem Umfang klar gewesen sei, wie kompliziert die Situation tatsächlich in Polen gewesen sei, hinsichtlich einer Reise nach Deutschland. Denn er besaß noch längst keine Genehmigung aus Polen auszureisen. Es mussten zunächst eine Reihe von Personen in den Ministerien kontaktiert und mit diesen verhandelt werden. Schließlich konnte Jaczewski nach Deutschland reisen. Dort besuchte er Jugendeinrichtungen in Viersen, auch das erew-Institut und anschließend die Universität zu Köln. Noch in demselben Jahr machte Kluge seinen ersten Besuch in Warschau und traf dort Kolleg_innen der pädagogischen Fakultät. Kluge betont, wie groß die Herausforderungen waren. In diesen Jahren sei in Polen alles von den staatlichen Stellen kontrolliert worden, doch Jaczewski sei es gelungen, den Dialog mit Westdeutschland weiterzuführen und schrittweise auszubauen. Kluge sagte weiter, das kommunistische Regime in Polen habe Jaczewskis guten Ruf als Kinderarzt genutzt, um das eigene Image aufzuhellen. Jaczewski sei beides für das Regime gewesen, zum einen anerkannt und zugleich verdächtig.

Kluge kam auch auf die Radiosendungen zu sprechen, bei denen Jaczewski zu Erziehungsfragen Stellung genommen und der polnischen Bevölkerung Rat und Orientierung gegeben habe. Diese Radiosendungen hätten ihn im ganzen Land bekannt gemacht. Als Kluge und seine Frau Eva einmal mit dem Zug nach Polen reisten, so erzählt er beim Telefoninterview, habe der Grenzbeamte seine Einreisepapiere kontrolliert. Als er dann das von Jaczewski unterzeichnete Einladungsschreiben gelesen habe, habe er mit einiger innerer Bewegung gesagt: »Oh, Professor Andrzej Jaczewski! Er ist der Mann, der mein Aufwachsen wie kein anderer förderte! Meine Mutter stand vor der schwierigen Aufgabe, mich alleine aufzuziehen. Regelmäßig hörte sie sich die Radiosendungen mit Professor Jaczewski an. Ich verdanke ihm soviel und ich bin so dankbar, dass meine Mutter seine Ideen und Anregungen aufgegriffen hat."Was an Jaczewskis Stil in der Beratung und in der Vermittlung anders gewesen sei? fragte ich Karl-Josef Kluge. »Er förderte eine offenere Diskussion der Themen, offener als es sonst zu der Zeit üblich war«, erwiderte er. Der von Jaczewski (2019) veröffentlichte Ratgeber O chłopcach dla chłopców (deutsch: Über Jungen für Jungen) wurde denn auch immer wieder aktualisiert und neu aufgelegt. Für Kluge galt es nun, finanzielle Mittel für die Reisen und die Aufenthalte der polnischen Teilnehmer_innen nach Westdeutschland $\mathrm{zu}$ akquirieren, wobei ihm auch einige Personen in der polnischen Botschaft und im Bonner Ministerium zuarbeiteten, wie er sagte, Menschen, die, wie er selbst und wie Jaczewski, teils einen Pfadfinderhintergrund hatten. Die gemeinsame, länderübergreifende Pfadfinderphilosophie hat hier, nach Aussagen beider Protagonisten, Vertrauen geschaffen und vieles möglich gemacht. Kluges Rolle beinhaltete ferner, die Sommercamp-Programme, die ja eine zentrale Säule des deutsch-polnischen Austauschs waren, in Gang zu bringen und in Gang zu halten, engagierte Studierende und bereits berufserfahrene Pädagog_innen zu finden, zu trainieren und $\mathrm{zu}$ begleiten, die dann die Camps und Sommerworkshops mit Inhalt füllten und die 
mit hoher Motivation an die deutsch-polnischen Begegnungen und das gemeinsame Lernen herangingen. Jaczewski musste unterdessen eng mit Personen aus dem Staats- und Parteiapparat der Volksrepublik Polen kooperieren und Vertrauen aufbauen. Dies war unverzichtbar. Barbara Proszynska, Repräsentantin des Warschauer Kultur- und Jugendpalasts war eine solche Schlüsselfigur. Ich lernte sie bei meiner Polenreise im Sommer 1986 kennen. Wir wurden die ganze Zeit von wechselnden Personen aus dem Partei- und Staatsapparat begleitet. Es gab nur sehr wenige Situationen, wo wir offener sprechen konnten. Etwa in Danzig, als uns Andrzej die Werften zeigte, wo sich die Mitglieder der Solidarnosc im Verborgenen formierten. Jaczewski sagte im Januar 2020, dass er sehr froh sei, dass sich niemand bei den Reisen nach Westdeutschland absetzte und etwa Asyl beantragte, denn das hätte das Ende des Austausches bedeutet. Schritt für Schritt bauten Jaczewski und Kluge ein deutschpolnisches Netzwerk auf. So entstand allmählich ein Dialog, an dem mehr und mehr Personen teilhatten. Wissenschaftler_innen und praktisch tätige Pädagog_innen, auch Psycholog_innen, die mit Erziehungsfragen befasst waren, Studierende der Universitäten in Warschau, Posen und Krakau auf der einen Seite, Studierende und Lehrende der Universität Köln auf der anderen Seite. Eine ganze Reihe von Personen brachten sich aktiv in den von Kluge und Jaczewski iniitierten Austausch ein. Auf deutscher Seite etwa Uta Sievert-Przybilski, auf der polnischen Seite Anna Radzik oder Artur Sieroszewski. Zwei Dutzend Mitglieder der Warschauer Universität und Wissenschaftler_innen aus deren Umfeld reisten im Rahmen dieser Austauschbeziehungen nach Deutschland.

In Köln traf Jaczewski auch auf Dov Gafni, ehemals Bernhard Weintraub, einen aus Polen nach Israel ausgewanderten Juden. Durch diesen Kontakt wurde, wie er sagte, sein Interesse am polnischen Judentum geweckt und dauert bis in die Gegenwart an. Natürlich müsse sich auch die polnische Bevölkerung mit ihrem ambivalenten Verhältnis zu den Juden kritisch auseinandersetzen, sagte Jaczewski. Wir sprachen in dem Zusammenhang über Władysław Reymonts Roman Die Bauern, für den Reymont 1924 den Literatur-Nobelpreis erhalten hat. Lebendig geschrieben und spannend $\mathrm{zu}$ lesen, zeichnet das Buch doch ein sehr negatives Bild der polnischen Juden, aus der Sicht der einfachen Landbevölkerung. Durch Dov Gafni kamen nun auch Jugendliche aus Israel in die Sommercamps und die pädagogischen Projekte. So begegneten sich dort mehrere Nationen, die historisch betrachtet, viel aufzuarbeiten hatten. An der Universität zu Köln gab Jaczewski unterdessen Seminare im Schnittfeld von Sonderpädagogik, Sexualerziehung und Familienberatung. Später kam noch Janusz Korczak als thematischer Schwerpunkt dazu, weil die Kölner Studierenden mehr über dessen Leben und Werk erfahren wollten. Jaczewski stellte große Unterschiede zwischen den Warschauer und den Kölner Studierenden fest. Während er die polnischen Studierenden als eher passiv erlebte, machte er in Köln die Erfahrung, dass die Studierenden sehr aktiv diskutierten und nahezu alles hinterfragten, was für ihn teils herausfordernd war. Die Kölner Studierenden hätten seine Ausführungen unterbrochen und frei ihre eigenen Erfahrungen, Gedanken und Überlegungen, auch Kritikpunkte mitgeteilt. Ein solcher studentischer Kommunikationsstil sei an den polnischen Universitäten vor 1990 undenkbar gewesen. Zwei Studenten hätten etwa die Frage nach Korczaks homosexuellen bzw. pädophilen Neigungen aufgeworfen. Die jungen Männer hätten dann, wir müssen uns in die frühen 8oer Jahre zurückversetzen, wie folgt argumentiert: »Wie kann es sein, dass uns einerseits Korczak als Vorbild hinge- 
stellt wird, und wir andererseits, wenn wir selbst homosexuell sind, mit erheblichen Schwierigkeiten rechnen müssen, wenn wir im Schuldienst als Lehrer arbeiten wollen?« So begann Jaczewski sich intensiver mit Korczak zu beschäftigen und die den damaligen Diskurs dominierenden, teils ideologisch eingefärbten, Korczak-Bilder zu hinterfragen (vgl. auch Smolinska-Theiss, 2013, S. 99). Über zwei Jahrzehnte hinweg lehrte Jaczewski zweimal im Jahr an der Universität zu Köln, bis 1992. Stellen wir uns also vor, wie er, selbst unter den angespanntesten politischen Rahmenbedingungen, Polen verließ und nach Westdeutschland einreiste, etwa in den Jahren 1981 bis 1983, als die kommunistische Regierung das Kriegsrecht in Polen verhängte. Aufschlussreich, dass er mir in Ropki gerade ein Kölner Vorlesungsverzeichnis aus dem Jahr 1983 in die Hand drückte, in dem er als Honorarprofessor gelistet ist (Der Rektor der Universität zu Köln, 1983, S. 132).

Jaczewski konnte auch konfrontativ im Umgang mit den Studierenden sein. »Wann waren Sie zuletzt in der Oper?« Solche Fragen stellte er mitunter in seinen Lehrveranstaltungen. Wenn die Studierenden etwa sagten: „Gar nicht«, konnte es sein, dass er antwortete: »Kommen Sie wieder, wenn Sie eine Oper angesehen haben.«Viele Studierende der Kölner Sonderpädagogik der 8oer Jahre kamen nicht gerade aus den sozialen Schichten, in denen die Kinder im Geist der Hochkultur sozialisiert werden. Auch war diese Generation von Studierenden stark durch den Geist der 68er Bewegung geprägt. Entsprechend wenig Respekt wurde teils der Hochkultur entgegengebracht. Als Piotr und ich diesen Punkt besprachen, sagte er, dass Polen eben auch keine so ausgeprägte 68er Bewegung gehabt habe und dass das in seinem Land bis heute vermutlich fehlen würde. Der polnischen Gesellschaft seien so wichtige Impulse vorenthalten worden, was sich auch in der Gegenwartsgesellschaft widerspiegle. Kluge erklärte dazu, für Jaczewski sei der breite kulturelle Hintergrund von Pädagog_innen eben wichtig gewesen, egal aus welchen sozialen Schichten sie stammten. So vertiefte ich mich, vor meiner Polenreise im Januar 2020, besonders in die polnische Literatur, las Władysław Reymont, Stefan Żeromski, Kazimierz Brandys, Wiesław Myśliwski, Olga Tokarczuk und Wisława Szymborska. Auch hörte ich, auf Piotrs Empfehlung, Opern von Stanisław Moniuszko, die er mir mit nach Berlin gebracht hatte. Außerdem beschäftigte ich mich intensiv mit Richard Wagner. Jaczewskis Stil sei in gewisser Weise konfrontativ gewesen, wandte ich beim Interview mit Karl-Josef Kluge ein. Dieser antwortete darauf: »Andrzej war immer konfrontativ.«Jaczewski fiel die sexuelle Freiheit und teilweise Promiskuität im Deutschland der 8oer Jahre auf. Solche Themen kamen wohl auch in seinen Blockseminaren mit Studierenden zur Sprache. Jaczewski sah sich in Deutschland um, auch in Zusammenhang mit der AIDS-Epidemie. Er besuchte Einrichtungen, beschäftigte sich mit Präventionsprogrammen und nahm Anregungen nach Polen mit, wo das Thema, vor dem Fall des Eisernen Vorhangs und bei den eingeschränkten Reisemöglichkeiten, noch nicht im Bewusstsein der Bevölkerung war. Jaczewski sagte, in Polen sei AIDS erst sechs Jahre später angekommen, mit der Grenzöffnung, mit dem Fall des Eisernen Vorhangs. Seine Vorschläge zur Prävention wurden in Polen teils ignoriert, doch immerhin von einigen Personen seien sie aufgegriffen worden. Vor allem im Bereich der Pfadfinderarbeit sorgte er selbst für Aufklärung und Information. 


\section{Das Aufspannen von europäischen Lernräumen über Sommerworkshops und erlebnispädagogische Aktivitäten}

Seit Anfang der 7oer fand unter dem Namen Europa-Kontakt eine 12-tägige Sommerfreizeit für Menschen mit und ohne Behinderung statt, stets in enger Kooperation von Kluge und Jaczewski und in Verbindung mit Einrichtungen und engagierten Einzelpersonen aus anderen europäischen Ländern. Das Camp fand zunächst am Niederrhein statt, nicht weit von Viersen, wo Kluge lebte. Jeden Sommer nahmen hier polnische Jugendliche und junge Erwachsene mit diversen Behinderungen teil. Jaczewski und Kluge begannen klein und bauten das Projekt Europa-Kontakt von Jahr zu Jahr weiter aus. Kluge lud auch Studierende und bereits praktizierende Pädagog_innen und Psycholog_innen aus Polen ein, im Team mitzuarbeiten. Klaus Fitting, ein damaliger wissenschaftlicher Mitarbeiter von Kluge, hat sich sehr um dieses Projekt verdient gemacht und es viele Jahre geleitet. Ich engagierte mich hier als Student, im Sommer 1983, in Emstal. Der Ort lag nicht weit von der Grenze zur DDR. Etwa in der Mitte der zwei Wochen unternahmen wir eine Exkursion. Wir hielten nah an der Grenze, wo wir den Todesstreifen sehen konnten. In nicht zu großen Abständen standen Wachtürme, oben bewaffnete Posten. Grenzsoldaten fuhren in Jeeps den eingezäunten Streifen auf und ab oder waren mit Schäferhunden zu Fuß unterwegs. Diese Bilder führten zu großer Betroffenheit und manchen Diskussionen innerhalb der Camp-Community. 1985 gründete Kluge das Kreative Sommercamp, später auch Universitäres Sommercamp und Skylight-Campus genannt. Dieses, auf die Förderung von Begabungen, Kreativität und hoher Lernmotivation ausgerichtete, vierwöchige internationale Programm, das stets von einer einwöchigen Trainingswoche für die Mitarbeiter_innen eingeleitet wurde, lief bis 2010. Dieses Camp, es wanderte von Wegberg, Niederrhein über Arnsberg, Sauerland nach Südtirol, später dann nach Schloß Rohlstorf bei Lübeck und schließlich nach Herchen, Sieg. Es wurde durchgängig auch von polnischen Jugendlichen besucht. Neben Kölner Studierenden und Doktorand_ innen arbeiteten dort regelmäßig polnische Studierende, Pädagog_innen und Psycholog_innen mit. Auch Israel war hier, über das Netzwerk von Dov Gafni, mehrere Jahre beteiligt. 1986 bis 1988 brachte Kluge noch ein weiteres, etwas kleineres deutschpolnisch-französisches Camp für junge Menschen mit und ohne Behinderung an den Start, in Eichendorf, Niederbayern, auf einem, zum Schullandheim umfunktionierten Bauernhof. Alle drei Sommercamps setzten auf Inklusion, Partizipation, handlungsorientiertes, interkulturelles, emotional-soziales Lernen, Erlebnispädagogik und interkulturelle Begegnung. Am Kreativen Sommercamp nahmen auch taubstumme oder blinde Jugendliche aus Polen teil. Wenn Kluge von der Förderung von Begabungen sprach, meinte er das in einem sehr weiten Sinne. Obwohl er sich zunächst an der Struktur des amerikanischen HighScope-Camps (vgl. Bröcher, 2015 b) orientierte, definierte er die Zielgruppe deutlich weiter. Jede Form der Kategorisierung war tabu. Zwar versuchten wir die Lebenskontexte der einzelnen Menschen zu verstehen und mit unseren pädagogischen Angeboten darauf Bezug zu nehmen. Aber Formen der gezielten Diagnostik oder problemzentrierten Förderung, wie es heute in der Sonder- und Inklusionspädagogik gang und gäbe ist, hatten bei diesen Sommerfreizeiten keinerlei Raum und gehörten weder zum Programm noch zur pädagogischen Philosophie. Insofern waren Kluge und Jaczewski einerseits Vorreiter der De-Kategorisierung, zum anderen des Aufspannens von motivierenden Lernräumen. Die Einbindung von 
Teilnehmer_innen aus Polen hatte für Kluge immer höchste Priorität. Er sagte dazu: »Wenn wir eine Gruppe von fünfzig Teilnehmer_innen hatten, aus Deutschland und anderen Ländern, dann fügte ich immer zehn Plätze für Teilnehmer_innen aus Polen dazu.« In einem Sommer stellten uns die Jugendlichen aus Israel vor größte Herausforderungen. Sie waren alle unter 18 Jahren, hatten am Abend das Gelände verlassen und saßen auf einem benachbarten Campingplatz bei Jugendlichen im Zelt, die wir nicht kannten und nicht einschätzen konnten. Karl Kluge bat mich, die Jugendlichen zurückzuholen. Sie weigerten sich, diskutierten sehr herausfordernd und äußerten den Vorwurf, unsere vom HighScope-Camp abgeleiteten Regeln seien »wie in einem Konzentrationslager«. Schließlich schickte Dov Gafni seine Tochter an den Niederrhein. Smadar half uns, mit den Jugendlichen aus Tel Aviv wieder ins Gespräch zu kommen und Lösungen zu entwickeln.

All diese Auseinandersetzungs- und Klärungsprozesse erlebten auch die polnischen Teilnehmer_innen und Team-Mitglieder mit und nahmen ihre Beobachtungen, Erfahrungen und Erkenntnisse mit nach Polen. Die dokumentierten Materialien, wenngleich nicht viel aus jenen Jahren vorhanden ist, zeigen zumindest im Ansatz, dass die Sommercamps einen bedeutsamen Raum der Erfahrung für die polnischen Teilnehmer_innen boten. Dazu gehörte auch, die eigenen Überzeugungen und Vorannahmen zu überprüfen. Eine im Warschauer Jugendpalast tätige Pädagogin schrieb: "Die Zeit, die wir im Kreativen Sommercamp für die hochbegabten Jugendlichen verbracht haben, war für uns eine interessante pädagogische und soziale Erfahrung. Wir hatten auch die Gelegenheit unsere täglichen Tätigkeiten im Jugendpalast mit dem arnsbergschen Experiment zu vergleichen. Die Vielfalt von Fachdisziplinen und relative Freiheit bei der Wahl der Aktivitäten befriedigten die künstlerischen und wissenschaftlichen Interessen der Jugend. Von besonderem Wert war die Unterstützung der Kreativität, Innovation und Personalität der Campteilnehmer. Daß sich die Methoden der Entwicklung kreativer Fähigkeiten von unseren unterscheiden inspiriert uns zum Nachdenken, manche bleiben für uns unannehmbar« (Gonezpin, 1987, S. 311). In den Workshops des Kreativen Sommercamps gab es unter anderem kreativen Ausdruckstanz, Meditiations- und Yogaübungen, Musikmalen oder expressives Malen. Diese Dinge waren für die polnischen Pädagog_innen teils neu, in einigen Fällen vielleicht irritierend. Die polnischen Jugendlichen griffen die ihnen gebotenen Möglichkeiten der Selbsterkundung und des Ausdrucks jedoch gerne auf. Adam Borowicz, Psychologe von der Universität Posen, der im Arnsberger Team 1986 mitarbeitete, notierte: »Bevor ich nach Arnsberg kam, fragte ich mich, auf welche Weise meine deutschen Kollegen die strengen Prinzipien deutscher Kultur mit dem warmen Klima, das zur Entwicklung von Kreativität notwendig ist, versöhnen wollen. Ich war bisher der Meinung: Die deutsche Kultur beinhaltet starre Prinzipien für jemanden, der aus einem anderen Kulturkreis kommt«(Borowicz, 1987, S. 312). Weiter schreibt er: „Einige Counselors gaben mir Gelegenheit, an ihren Arbeitsprogrammen teilzunehmen. Dadurch durfte ich die faszinierenden Beziehungen beobachten, die sich zwischen den Counselors und den Campern bei den verschiedenartigsten Angeboten wie Musik, Kunst, Chemie, Biologie entwickelten. Die Counselors eines jeden Arbeitsbereiches zeigten dabei denselben warmherzigen Stil. Sie halfen den Campern bei Fragestellungen; durch die Anregung zu einer großen Offenheit ermöglichten sie, daß sich neue Horizonte auftaten«(Borowicz, 1987, S. 313). Neu für ihn war, dass es zwar ein klares Regelsystem gab, dieses jedoch ohne Strafen auskam, und zumindest, wie er schreibt, was 
die Kurse und Workshops betraf, von den Kindern und Jugendlichen auch eingehalten worden sei. Darüber hinaus jedoch nicht immer, denn für einige sei das Programm $\mathrm{zu}$ »hart" gewesen, in der intellektuellen Erwartung. Da wären eventuell mehr Entspannungsphasen besser gewesen. Aber eine kleine Gruppe von Camper_innen hätte auch nicht wirklich Verantwortung für ihr eigenes Lernen übernehmen wollen und wäre nicht aus ihrer Abhängigkeit von den Counselor_innen herausgekommen. Die stärker schöpferischen Kinder und Jugendlichen hätten das Angebot aber sehr zu schätzen gewusst und hätten ihr eigenes Lernen in die Hand genommen. Adam Borowicz (1987, S. 317) notierte: »Ich kann behaupten, daß es meinen deutschen Kollegen gelungen ist, die Prinzipien der deutschen Kultur mit schöpferischer Flexibilität zu verbinden.«

Was geschah unterdessen in Polen? Andrzej Jaczewski ging mit den deutschen Studierenden in Warschau in die Oper oder ins Theater. In Krakau zeigte er ihnen das mittelalterliche Collegium Maius oder er machte mit ihnen Exkursionen auf Korczaks Spuren. Unter Einbindung von lokalen Pfadfindergruppen, die teils auch an den deutschen Camps teilnahmen, wurde auf den Masurischen Seen gesegelt oder in den Beskiden gewandert. In meiner Erinnerung höre ich melancholische Akkordeonklänge. Im Sommer 1986 zeigte Jaczewski uns nicht nur Danzig, die Seebäder Gdingen und Sopot sondern auch die Marienburg und die abgelegensten Dörfer an der russischen Grenze. Auf den ungeteerten Straßen Pferdefuhrwerke, Hühner, Kleinbauern in schwarzer Kleidung. In einem Dorf stiegen wir aus, um uns eine Marienprozession anzusehen. Jaczewski zeigte uns Warschau, sprach auch von der Zerstörung der Stadt durch die Deutschen im Zweiten Weltkrieg und von seiner Zeit im Widerstand. Dank der auf dem Schwarzmarkt getauschten Zloty konnten wir Restaurants besuchen, wenngleich sich das planwirtschaftliche Angebot an Speisen in Grenzen hielt. Auch konnten wir mit unseren D-Mark in Pewex-Shops einige Flaschen französischen Rotwein kaufen. In Warschau übernachteten wir auf Feldbetten, im Kulturpalast. In Gdingen schliefen wir in einer Gruppenunterkunft im Hafen. Jaczewski gab dem Concierge etwas Geld, damit er uns morgens eine Kanne frisch gebrühten Kaffee brachte. Dazu aßen wir die verbliebenen Tomaten, Pilze und Erdbeeren, die wir am Tag zuvor von einer Bäuerin am Straßenrand gekauft hatten. Von den restlichen, auf dem Schwarzmarkt getauschten Zloty kauften wir uns einige Chopin-Platten, Klaviernoten oder Ledersachen. Der Nachtzug zurück nach Deutschland rollte aus Leningrad ein. Die Zollbeamten im Warschau-Paris-Express schikanierten uns regelrecht, als hätten wir die Sachen gestohlen. Kluge sagte dazu beim Interview: »Das war Ausdruck des noch nicht wiedererlangten Vertrauens uns Deutschen gegenüber.« Rufen wir uns den eingangs skizzierten historischen Hintergrund in Erinnerung, ist das ruppige Verhalten der Zollbeamten zumindest zu erklären. Wir waren in ihren Augen die Nachkommen von Hans Frank, Robert Ley und all den anderen und nahmen nun erneut Sachen aus Polen mit nach Deutschland, egal ob wir etwas dafür bezahlt hatten. Es war einfach nicht rechtmäßig, erneut etwas aus Polen mit nach Deutschland zu nehmen. Es war noch zu früh. Das ganze Hintergrundgeschehen war noch nicht verarbeitet. Im Jahr 1986, als wir diese Reise durch Polen machten, begann die Lyrikerin Wisława Szymborska eines ihrer Gedichte wie folgt: »Wir sind Kinder der Zeit. Die Zeit ist politisch« (abgedruckt in Szymborska, 1996a, S. 27). 


\section{Deutsch-polnische Lernerfahrungen und Community-Projekte der Zukunft}

Trotz der angespannten politischen Lage während der Zeit des Kalten Krieges gelang es Kluge und Jaczewski die deutsch-polnische Grenze etwas durchlässiger zu machen und menschliche Begegnungen und gemeinsames Lernen im Rahmen von Sommerworkshops und erlebnispädagogischen Exkursionen zu ermöglichen. Dabei wurden bewusst Menschen mit Behinderung einbezogen. Ferner gelang es diesen beiden Pionieren, einen fachlichen Austausch von Wissenschaftler_innen und Praktiker_innen aus den Bereichen Inklusions- und Sonderpädagogik, Psychologie und Kindermedzin im deutsch-polnischen Feld auf den Weg zu bringen. Insgesamt waren, nach Einschätzung der Protagonisten, zwischen 1969 und 1990 etwa 600 Personen an den hier rekonstruierten deutsch-polnischen Austauschaktivitäten beteiligt. Wenn deutsche Gruppen nach Polen reisten, waren es zahlenmäßig jedoch weniger als umgekehrt. Der Drang der Polen nach Westen war definitiv größer als die Neugier der Deutschen auf den Osten. Kluge und Jaczewski debattierten nicht über bestimmte pädagogische Modelle oder wissenschaftstheoretische Ansätze oder Methodologien. Jaczewski wusste, wie er sagte, nicht viel über Kluges Verankerung im klientenzentrierten Ansatz oder über seine anfängliche Orientierung an der HighScope-Pädagogik. Kluge sagte, dass besonders das Pfadfinderwesen eine enorm verbindende Kraft gehabt habe, bei alldem. An handlungsleitenden Pfadfinderwerten nannte er: Hilfsbereitsschaft, gegenseitiges Vertrauen, mindestens eine gute Tat am Tag, auch Anforderungen und Härten durchzustehen, wenn es wirklich schwierig wird, seine eigenen Bedürfnisse zurückzustellen sowie Freundschaft aufzubauen aus Notwendigkeit. Es wurden weder gezielte Forschungsfragen formuliert noch systematisch Daten erhoben. Es ging weder Kluge noch Jaczewski um Begriffe oder Konzepte, noch um Diskurse und Debatten. Das hier war eine angewandte Pädagogik. Im Zentrum des Ganzen stand allein die menschliche Begegnung. Das gesamte Handlungsgeschehen war so dicht, dass sich keiner der Beteiligten die Zeit nahm, alles detailliert niederzuschreiben und systematisch zu dokumentieren. Entscheidend war für Jaczewski und Kluge, dass die Menschen mit Reisepapieren ausgestattet wurden, dass sie die fast undurchlässige Grenze, eben den Eisernen Vorhang, überhaupt passieren konnten, dass die menschlichen Begegnungen zustandekamen und dass sie konstruktiv, mit gegenseitiger Wertschätzung, gestaltet wurden. Kluge war viel mit der Finanzierung der Austauschaktivitäten beschäftigt. Aufgrund des für die Polen sehr nachteiligen Wechselverhältnisses zwischen Zloty und D-Mark, musste die deutsche Seite für sämtliche Kosten auf deutschem Boden aufkommen. Zugleich erfuhren die beteiligten Deutschen bei den Polen-Aufenthalten eine überwältigende Gastfreundschaft. Die pädagogische Programmgestaltung in Deutschland entwickelte Kluge zwar mit, gab den Kölner Studierenden und Doktorand_innen jedoch sehr viel Spielraum und Selbstverantwortung in der Umsetzung. Dieses der jungen Generation entgegengebrachte Vertrauen erzeugte eine äußerst hohe Motivation. Kluge sagte beim Interview: »Diese Arbeit war weniger logisch oder analytisch, sondern mehr im Sinne von gegenseitigem Vertrauen. Wir werden nie genau verstehen, wer genau was auslöste und welche Ideen im Einzelnen die Unternehmungen und Projekte prägten. Es war alles auf Großzügigkeit und Gastfreundschaft aufgebaut, immer dem Prinzip folgend, dass nicht die Politik entscheidend ist, sondern die menschliche Begegnung. «aczewski bestätigte dies bei den Gesprächen in den Beskiden, im Januar 2020. Er merkte hierzu an: »Ziel war 
Vertrauen aufzubauen und Misstrauen abzubauen. Die polnische Bevölkerung hatte noch nicht realisiert, wie sehr sich Deutschland in den 7oer und 8oer Jahren verändert hat.«Aus dem, was Jaczewski und Kluge bewegt haben, sind nicht nur zahlreiche professionelle, sondern auch persönliche Beziehungen entstanden, die teils mehrere Jahrzehnte andauerten oder gar bis in die Gegenwart fortbestehen. Im Oktober 2020 ist Andrzej Jaczewski im Alter von 91 Jahren verstorben. In meiner Zehlendorfer Küche steht ein kleines Wodka-Fässchen, dass er mir bei meinem letzten Besuch in Ropki geschenkt hat. Er hat den Wodka eigens mit einer ganz bestimmten Kräutermischung aus den Beskiden veredelt und in ein spezielles Holzfässchen eingelagert. Im Zuge der handwerklichen Arbeiten, bei dem inzwischen in Sachsen-Anhalt begonnenen Community-Projekt, könnte sich ja bald eine Gelegenheit ergeben, das Fässchen zu öffnen. Das wäre zugleich eine Art symbolischer Gründungsakt, denn dieses neue Projekt schöpft auch aus dem, was Karl-Josef Kluge und Andrzej Jaczewski in jenen Jahren an Humanität, an Erfahrungen und Erkenntnissen auf den Weg gebracht und ermöglicht haben. So lässt sich diese besondere Gabe, aus der Hand von Andrzej, mit anderen teilen und dann auch von dem ganzen Hintergrund, um den es in diesem Kapitel hier geht, erzählen. 


\section{Von der Kontrollgesellschaft zur Zivilgesellschaft der Entrepreneur_innen}

\section{Bildungssystem und Neue Steuerung}

Die, mit der Postmoderne in Verbindung gebrachte, Vielfalt an wissenschaftlichen Strömungen und praktischen Handlungsansätzen, wie sie noch für die 9oer Jahre für die Pädagogik der emotionalen und sozialen Entwicklung kennzeichnend war, wenngleich sich diese Strömungen teils in einem wahllosen Eklektizismus verloren haben, hat sich inzwischen wiederum enorm verengt. Zwar gibt es in unserem Fach noch qualitative, gesellschaftskritische Diskurse, doch sind diese in sich überaus heterogen und zersplittert. Sie entfalten daher insgesamt keine Schlagkraft, sicherlich auch deshalb nicht, weil die betreffenden Stakeholder_innen keinen übergreifenden theoretischen Rahmen, nicht mal einen losen Theoriezusammenhang geschaffen haben, auf den sich mehr oder weniger alle beziehen könnten. Ein weiterer Grund für den Niedergang der qualitativen und gesellschaftskritischen Forschung in unserem Fach ist, dass die Protagonist_innen auf dieser Szene, bis auf kleine Netzwerke, die sich untereinander Listenplätze und Lehrstühle oder empfehlende Gutachten für Publikationen, Drittmittel- und Projektanträge zuschieben, vielfach gegeneinander arbeiten. Eine Analyse der Publikationen aus diesem Feld zeigt, dass etwa die Texte von Kolleg_innen in den eigenen Veröffentlichungen selbst dann ignoriert und nicht diskutiert werden, wenn sie die eigene Argumentation stützen würden. Es wirkt so, als ginge es in erster Linie darum, den betreffenden Kolleg_innen keine Beachtung und keine Anerkennung und damit keine Bedeutung zukommen zu lassen, im Kampf um die Lehrstühle, im Game of Thrones, dieser sonderpädagogischen Sparte. Hand aufs Herz, wer hat nicht alles die Dominanz der Evidenzbasierung und der Psychologie sowie den Mangel an pädagogischen Bezügen und emanzipatorisch-kritischen Ansätzen beklagt? Und wer hat dann einmal auf die von mir entwickelte Lebensweltorientierte Didaktik, die ja genau in diesen Kontexten steht, verwiesen, oder diese Texte gar aufgegriffen und weiterentwickelt? Diese eher trostlos zu nennende Situation hat ein in den 8oer Jahren in Deutschland noch gar nicht existierendes, verhaltensorientiertes Netzwerk enorm gestärkt, eine Wissenschaftscommunity, die sich über die Kernkonzepte evidence-based und data-driven, analog der US-amerikanischen Behavior Community, definiert. Wenn dann aus dieser Szene heraus ein »systematischer Überblick über deutschsprachige schulbasierte Maßnahmen« im »Bereich der Sekundarstufe I« (vgl. Casale et al., 2014) erstellt wird, kommt darin immerhin die Positive Peer Culture vor, allerdings nicht die Lebensweltorientierte Didaktik. Wenn man also Handlungsmo- 
delle ignorieren will, kann man leicht die Auswahlkriterien so und so setzen. Für mich gilt allerdings erst einmal das, was oben als Titel drüber gesetzt wird. Daran messe ich schließlich den inhaltlichen Gehalt eines Textes. Aber wollen wir uns denn wirklich auf Tier III, der Ebene, wo im Rahmen von School-wide Positive Behavior Support die Arbeit mit denjenigen Heranwachsenden stattfindet, deren Lern-, Arbeits- und Sozialverhaltens als sehr herausfordernd eingestuft worden ist, allein auf funktionsbasierte Analysen und Interventionen beschränken lassen?

Hier könnten doch ebenso Hip Hop und Rap-Projekte laufen, in denen Lebenserfahrungen und soziale Problematiken zur Sprache kommen. Natürlich könnten wir hier auch mit den Kindern und Jugendlichen über ihre Lebensthemen philosophieren. Ausgehend von Sartre könnten wir etwa mit einem Jugendlichen über die Faktizität, also das derzeit in seinem Leben Gegebene, sprechen und überlegen, was Transzendenz für ihn sein könnte, im Sinne des Horizonts, in den hinein er sich entwickeln möchte. Wir könnten auch die Philosophie der Transfiguration alles Seelischen, wie sie O'Donohue $(1997,1998)$ entworfen hat, zum Ausgangspunkt der pädagogischen Gespräche mit den Jugendlichen machen. Auch könnte das Konzept der Resonanz (vgl. Rosa, 2019), bei dem es um das Herstellen von lebendigen Austauschbeziehungen zwischen Menschen geht, in den kooperativ mit den Lernenden zu entwerfenden Lernräumen eine Rolle spielen. Sollen wir das alles bleiben lassen, weil das so schwer zu greifen, zu operationalisieren und im kompetenzorientierten Sinne zu überprüfen ist und weil eine bestimmte Wissenschaftscommunity, die zu weiten Teilen die Lehrstühle erobert hat und nun vielerorts die deutschen Universitätsinstitute dominiert, davon abrät, weil das deren engem, auf Evidenzbasierung reduziertem Wissenschaftsbild, das diese Stakeholder_innen allerdings selten einmal über, sagen wir zehn oder fünfzehn Jahre in der pädagogischen Praxis verifiziert haben, nicht entspricht? Ich hätte in meinen 18 Jahren an den Schulen wohl wenig bewirkt, wenn ich mich in meinen pädagogischen Handlungsmöglichkeiten derart hätte einschränken lassen. Tier III, wenn ich da noch einmal auf das RTI-Vokabular zurückgreifen darf, würde jedenfalls durch philosophische und kulturelle, auch subkulturelle Bezüge, mit enormer Energie und ganz neuen Bedeutungsebenen aufgeladen. Auch Thomas Kuhn rät uns ja zu Abweichungen von den tradierten Wegen, wenn wir wissenschaftliches Neuland entdecken wollen. Da müssen wir schon ein wenig mutiger werden. Wer sollte uns auch daran hindern, wenn nicht wir selbst? Niemals werden Wissenschaftler_innen Neuland entdecken, die sich ängstlich an ein paar Grundsätze klammern, sich immer nur in selbst auferlegter, ganz unnötiger Konformität in einer allzu engen Denkbahn bewegen. Was sie aber schaffen werden, ist ein enger und enger werdendes Gesellschaftssystem, ein immer enger werdendes Bildungssystem am Laufen zu halten, zumindest noch eine Zeitlang, doch auch nicht mehr für lange, weil diese Systeme auf einen Punkt zusteuern, wo es nicht mehr weitergeht. Bildungsstandards, Lernstandserhebungen, Leistungsvergleiche, Kompetenzmessungen und Kompetenzorientierung (vgl. Schott und Azizi-Ghanbari, 2008), eigenverantwortliche Schule, Schulinspektion, Qualitätsentwicklung, Zielvereinbarungen, Evaluation, Akkreditierung, all diese Technologien der Neuen Steuerung, der Educational Governance (vgl. Altrichter et al., 2007; Altrichter und Maag Merki, 2016; Bellmann, 2006; Nebel, 2011; Recum, 2006), haben inzwischen eine enorme Macht über sämtliche im Bildungssystem befindlichen Menschen gewonnen. Kleinstkinder werden schon kurz nach der Geburt in den pädagogischen Einrichtungen kompetenzorientiert gefördert. Dies zieht sich dann weiter über 
alle Schulstufen und Schularten hinweg bis hin zu Fachhochschulen und Universitäten, wo die Professor_innen im Rahmen der Entwicklung und Akkreditierung von Studiengängen von Qualitätsstäben angehalten werden, die Module und Teilmodule in den Studienprogrammen kompetenzorientiert zu konzipieren und auszuarbeiten. Dies schließt didaktische Überlegungen genauso ein wie Prüfungsformen.

Nun muss eine solche Didaktisierung der Hochschullehre an sich für die Studierenden noch nicht von Nachteil sein. Das Problem ist eher, dass das Ganze einem einheitlichen, durchaus einengenden, Konstruktionsschema unterworfen wird und die Professor_innen einem kleinschrittigen Monitoring seitens der Qualitätsstäbe und der Akkreditierungsagenturen oder, bei einigen Studiengängen, auch Vorgaben aus den Ministerien, unterliegen. Je nachdem, wer da gerade Minister_in oder Staatssekretär_in ist, oder je nachdem, wer da als externe Expert_in in einer Akkreditierungskommission sitzt, kann es zu teils erheblichen Differenzen hinsichtlich der wissenschaftstheoretischen Grundierung von pädagogischen Studiengängen kommen. Den Inhaber_innen einer Professur kann heutzutage abverlangt werden, ein Studienprogramm insgesamt, keineswegs nur einzelne Modulbeschreibungen, anders zu verfassen, als sie es, im Sinne der Freiheit von Forschung und Lehre, eigentlich gerne tun würden. Für die freigeistigen Hochschullehrer_innen der 8oer Jahre wäre all dies sicher völlig undenkbar, nicht vorstellbar und ganz und gar unzumutbar gewesen. Ich denke in dem Zusammenhang etwa an eine Reihe von Professor_innen der Universität zu Köln. Einer von ihnen schritt, als eine Art Wiedergänger von Joseph Beuys, über den Campus und entwarf auch genauso frei seine ästhetisch-therapeutischen Theorien. In seinen Seminaren bekam man aber Luft. Da öffneten sich eben geistige und emotionale Räume. Aber allzu viel widersprechen konnte man/frau einem solchen Guru natürlich auch nicht. Es gab also auch eine gewisse Selbstherrlichkeit, einen gewissen Narzissmus bei einem solchen Professor. Aber als Studierende fühlten wir uns trotz allem eher inspiriert und schon gar nicht eingeengt. Ein Professor in der Psychologie bearbeitete die fundamentalen Daseinsthemen, Tod und Trauer und anderes mehr. Auch war er dafür bekannt, dass er sich immer wieder länger in Italien aufhielt und dort alte Fresken restaurierte. Das adelte ihn irgendwie aus studentischer Sicht. Der Italienbegeisterung vieler Kölner Studierender kam das natürlich sehr entgegen, nicht nur im Fach Kunst. Italien war in den 8oer Jahren absoluter Kult. In den damaligen Kölner Hipster-Bars traf man smarte, junge, polyglotte Goldschmiede, die ihr Handwerk in Florenz gelernt hatten. Auch ich machte gleich nach Ablauf des ersten Semesters eine längere Italienreise, mit dem Rucksack, mit nicht allzu viel Geld in der Tasche. Zumeist schliefen wir auf Stränden oder auf Zeltplätzen. Gelegentlich gab es aber auch Pensions- oder Hotelzimmer für wenig Geld. Diese Generation von Professor_innen hatte jedenfalls noch diese ganz speziellen Profile, ungewöhnliche Interessen, vielleicht auch Marotten. Jedenfalls waren es Originale mit Ecken und Kanten. Für Schule und Unterricht interessierte sich der, italienische Fresken restaurierende, Professor jedenfalls nicht. Kam man mit schulbezogenen Themen in seine Sprechstunde, um sich für eine Prüfung anzumelden, wurde man regelrecht aus seinem Büro hinausgeworfen. Schule und Unterricht waren für ihn ein abzuwehrender Alptraum. Über Italien und die Kunst wäre ich sicherlich mit ihm ins Gespräch gekommen, aber ich wusste damals vermutlich nicht genau wie, sprach dann unglücklicherweise das Thema Schule an ... 
Tragisch war das aber nicht, weil wir ja viel Auswahl an Teilgebieten und Professor_innen auf dem Kölner Campus hatten. Die Prüfungsordnung war weit und offen aufgespannt. Wir mussten nur in dem riesigen erziehungswissenschaftlichen Feld eine bestimmte Anzahl von Prüfungen, am Ende des Studiums, durchlaufen, ob in Philosophie, Soziologie, Psychologie, Schulpädagogik, Allgemeiner Didaktik usw., war mehr oder weniger uns überlassen. Wir bewegten uns inhaltlich in wirklich sehr weit gesteckten, eigentlich grenzenlosen Feldern, für manch einen waren sie vielleicht $\mathrm{zu}$ weit, so dass sich einige Studierende auch darin verloren, wie im dichten Nebel, und dann irgendwann ganz bei ihrem Taxi-Job oder Hilfsjob beim Film oder im Medienbusiness hängenblieben. Für mich waren diese Felder jedoch gerade weit genug. So inspirierten mich Professoren wie Wilhelm Salber, der in seinen Büchern Kunst, Psychologie, Behandlung oder Psychologie in Bildern ein ganz neues geistiges Universum eröffnet. Das sind Texte die einfach alle bisherigen Kategorien sprengen. Wenn man so etwas gelesen hat, wird man für enge institutionelle Strukturen und kleinkariertes, eindimensionales Denken kaum noch etwas übrig haben. In der Gegenwart der Universitäten ist zwar immer noch Raum für Situatives, Überraschendes und Ungeplantes in den Lehrveranstaltungen, also für genau das, was durch die jeweils zustande kommenden Dialoge und Gedankenentwicklungen eine einzelne Seminarveranstaltung oftmals einzigartig und inspirierend werden lässt. Doch entsteht nun das Bild einer Schieflage, wenn die Dozent_innen vom eigentlichen Lehrplan und den kompetenzorientierten Beschreibungen der Modulpläne abweichen, wenn sie eben so arbeiten, wie es noch vor einigen Jahrzehnten an Universitäten, zumindest in bildungsund geisteswissenschaftlichen Bereichen, durchaus üblich war. Auch gibt es nun eine Gruppe von Studierenden, die genau das von den Lehrenden einfordert, was nunmal in den Modulbeschreibungen steht. Durch ein solches Monitoring von unerwarteter Seite geraten Hochschullehrer_innen unter den Druck, auf eine bestimmte Art und Weise ihre Lehrveranstaltungen halten zu müssen, wie sie es bei weiter freien Lehrbedingungen niemals getan hätten. Was man den Studierenden, die sowas tun, allerdings auch sagen muss: Damit werden sie nicht etwa besser vorbereitet auf ihren Beruf als Lehrer_in.

Es ist gar nicht mal so klar, was am Ende wirklich das Wichtigste ist, um diese Arbeit längerfristig tun zu können und dabei geistig und seelisch gesund und lebendig zu bleiben, ob es also die Aneignung von eng definiertem anwendungsbezogenem Wissen ist oder die Erschließung von übergeordneten kulturellen, soziologischen und philosophischen Bezügen. Wenn ich als Student vor die Wahl gestellt würde, entweder ein Referat über das Good Behavior Game zu halten oder aber über die Kunsttheorie, wie sie Umberto Eco in seinem Buch Opera Aperta niedergeschrieben hat, würde ich mich für Eco entscheiden, weil ich hierin eine größere Bedeutung für meine zukünftige Unterrichtsgestaltung und die lebendige Entfaltung der mir anvertrauten Kinder und Jugendlichen erkennen würde als bei dem Dressurspiel, das schon in den 60er Jahren in den USA entwickelt wurde. Vieles spricht aber dafür, dass wir am besten beides tun, auch um kritikfähig zu werden. Wir brauchen auch konkrete Modelle und Handlungsansätze um etwa in Schulen zu arbeiten. Das Good Behavior Game lässt sich sehr gut nehmen, um bestimmte Steuerungstechnologien der Kritik zu unterwerfen. Auch könnte es als eine Art Selbsterfahrungsübung gespielt und dann auf der Meta-Ebene mit den Kindern reflektiert werden. Auch haben viele Studierende begonnen, regelrecht mit den Lehrenden zu verhandeln, wenn es um das Maß ihres aktiven Engagements 
und ihre Einsatzes geht, um etwa diese oder jene Credits zu erlangen. Auf diese Weise übertragen sie die Gesetzmäßigkeiten der kapitalistischen Wirtschaftsordnung auf das Universitätsstudium. Parallel dazu arbeiten die Professor_innen, hier ist freilich noch einmal nach ihren konkreten Besoldungsgruppen und nach Bundesland zu differenzieren, mit abgesenkten Grundgehältern und können oder müssen, wenn sie aus bestimmten Gründen darauf angewiesen sind, oder, aufgrund irrationaler Überzeugungen, Selbstkonditionierungen und nicht erkannter eigener Muster, bloß meinen, sie müssten dies tun, weil sie sich nicht mit niedrigeren Gehältern arrangieren wollen, sich finanzielle Zulagen durch jahrelangen, mühevollen Einsatz, nach bestimmten Kriterien definiert und im Rahmen von Zielvereinbarungen niedergeschrieben, erst noch hinzuverdienen. Gefragt sind jetzt nicht mehr freie, innovate Denker_innen, sondern Wissensarbeiter_innen, die sich unter dem Joch dieser neuen Vorgaben beugen und sich im Rahmen solcher Anreizsysteme von Ministerien und Universitätsleitungen punktgenau steuern lassen. Statt aus Leidenschaft und mit Herzblut an den ihnen wichtigen Themen $\mathrm{zu}$ arbeiten, entwickeln sie einen Instinkt für Themen und Forschungsformate, die lukrativ sind und für die es Geld und Aufstiegschancen gibt. Jetzt wird keiner mehr auf die Idee kommen nach Italien zu reisen und dort alte Fresken zu restaurieren. Zwar kann ich mich jetzt noch als eine Art Joseph Beuys in der Academia bewegen, aber unter den heute geltenden Kennziffern, bringt mir das keinen Euro mehr ein, der über ein Grundgehalt hinausgeht.

Durch eine solche Selbstunterwerfung unter ökonomisches Denken (vgl. Wiechmann und Bandelt, 2016), hat aber die kapitalistische Wirtschaftsordnung gleich auf mehreren Ebenen die Universitäten erreicht. Wolfgang Jantzen thematisiert in seinem Buch Behindertenpädagogik als synthetische Humanwissenschaft, ausgehend von Karl Marx, die »reelle Subsumtion der lebendigen Arbeit unter das Kapital« (vgl. Marx, 1969; Jantzen, 2019, S. 95). Da wären wir wohl nun auch im Wissenschaftsbetrieb, und niemand sollte glauben, dass sich die Sonder- und Inklusionspädagogik hier auch nur im Geringsten von Betriebswirtschaft oder Business Administration unterscheidet, angelangt und was Marx und Engels schrieben, dürfte nunmehr die gegenwärtige Situation trefflich charakterisieren: "Die Bourgeoisie hat alle bisher ehrwürdigen ... Tätigkeiten ... entkleidet. Sie hat den Arzt, den Juristen ... den Mann der Wissenschaft in ihre bezahlten Lohnarbeiter verwandelt« (vgl. Marx und Engels, 1972, S. 464 f., zit. n. Jantzen, 2019, S. 95). Man will einen Professor nicht mehr als Denker und Philosophen, sondern als Modulmanager, Drittmittelakquisiteur, Datenanalytiker und Lehrbeauftragten, dessen Arbeit sich messen, quantifizieren, evaluieren und steuern lässt. Er hat auch keine persönliche Sekretärin mehr, sondern er schreibt jetzt seine Briefe, Artikel und Bücher selbst. Wenn er nicht aufpasst, lässt man ihn, wie es an einigen Universitäten schon üblich ist, in akribischer Detailarbeit, die unzähligen Noten, die er immer mehr Studierenden in all den Teilmodulen und Modulen geben muss, selbst in die Online-Systeme einpflegen. Das heißt es wird immer weiter rationalisiert und Dinge, die einst von Assistent_innen, Sekretär_innen, Mitarbeiter_innen in der Verwaltung und Prüfungsämtern erledigt wurden, machen Professor_innen heute zunehmend selbst. Dadurch, auch durch die vielen Mails von Studierenden, die es versäumt haben, sich zu bestimmten Prüfungen anzumelden oder die noch irgendetwas aus einem vergangenen Modul oder Teilmodul nachholen müssen, ist er viel beschäftigt und kann schon nicht so viele unbequeme Gedanken entwickeln oder unwillkommene Fragen aufwerfen. Will er Personal einstellen, das ihm hilft, muss er Drittmittel einwerben, um es 
zu bezahlen. Durch das Schreiben von Anträgen, durch das Verhandeln, und später, falls das gelingt, durch das dann anfallende Personal- und Finanzmanagement, hat er dann noch mehr Arbeit und noch weniger Zeit für die eigentlichen Dinge, oder sagen wir für das, was für ihn die eigentlichen Dinge sind. Für die moderne Universität ist eben genau dieses Finanzmanagement, das Personalmanagement und das geschickte Jonglieren mit, strategisch ausgewählten, Forschungsthemen, Drittmittelanträgen und Daten längst das Eigentliche geworden. Es kommt nicht mehr darauf an, dass ich ein guter Denker bin. Wenn ich das nicht monetarisieren kann, erscheint das bloße Denken unter heutigen Bedingungen sinnlos. Universitätsprofessor_innen werden nach diesem neoliberalen Verständnis auf ihre bloße, im Feld des Sichtbaren und Messbaren liegende, Arbeitskraft reduziert. Ihnen wird ein bestimmter, stets steigerbarer Marktwert zugemessen, freilich nur bei Vorliegen geeigneter Netzwerkkontakte, die auf der akademischen Hinterbühne, unsichtbar für die Zivilgesellschaft, die erforderlichen Strippen ziehen, beim Begutachten und Platzieren von Bewerber_innen auf Berufungslisten, beim Zuschieben von Drittmitteln, oder beim Durchwinken von Fachzeitschriftenartikeln beim Peer Review.

Professor_innen, wie sie im Rahmen der Neuen Steuerung bzw. in Zusammenhang mit Educational Governance als neue hochschuldidaktische Typen entworfen und dann gelenkt werden, sollen diese neoliberale, an Fremdsteuerung, Selbststeuerung und Selbstoptimierung ausgerichtete Haltung nun an die Lehramtsstudierenden weitergeben, die diesen, auf Funktionalisierung und Anpassung zielenden, Geist dann wiederum in die Schulen bringen und in diesem Sinne die ihnen zugewiesenen Kinder und Jugendlichen erziehen und sozialisieren, damit diese es schließlich genauso machen. Die sprachliche und zugleich konzeptionelle Verbindung zwischen beiden Ebenen offenbart sich zunächst im Konzept der Kompetenz. In Hochschulpädagogik, Schulpädagogik, Sonder- und Inklusionspädagogik tauchen immer mehr Kompetenzbegriffe auf, etwa emotionale und soziale Kompetenz (z. B. Hartmann, 2004; Hillenbrand et al., 2015; Petermann et al., 2016), Kompetenzscreening (z. B. Hartmann und Methner, 2015), Lesekompetenz (z. B. Bertschi-Kaufmann und Graber, 2016; Groeben und Hurrelmann, 2009), auch Beziehungskompetenz (z. B. West-Leuer, 2007) und Beratungskompetenz (z. B. Buchinger und Klinkhammer, 2003). Der Kompetenz-Begriff bezeichnet Fähigkeiten, die sichtbar, messbar, vergleichbar und in ihrem weiteren Verlauf beobachtbar sind. Dadurch ist Kompetenz zu einem der wichtigsten Schlüsselbegriffe der kapitalistisch unterfütterten Neuen Steuerung im Bildungssystem geworden. Doch es gibt auch Kritik an der Kompetenzorientierung (z. B. Hanschmann, 2017; Ladenthin, 2010; Wiechmann und Bandelt, 2016). Speziell in der Sonderpädagogik hat Wolfgang Jantzen scharfe Kritik an der Reduktion des Menschen auf seine Fähigkeiten und auf seine damit einhergehende Arbeitskraft geübt (vgl. Jantzen, 2019, S. 141 ff.). Eine weitere zentrale Komponente, im Rahmen der neuen Steuerungstechnologien, ist das Monitoring. Wir haben derzeit mit einer immer stärker zunehmenden Überwachung in der Gesellschaft tun, speziell im Bereich der Telekommunikation und der digitalen Welt. Aufzeichnung, Tracking, Beobachtung, wo wir uns auch bewegen und was wir auch machen. Ständig hinterlassen wir Spuren, ständig dokumentieren wir unsere Aktivitäten. So werden schrittweise Infrastrukturen der Überwachung und immer ausgefeiltere Überwachungstechnologien aufgebaut. Der Transponder, mit dem wir die Türen von Schulen, Universitäten und anderen öffentlichen Gebäuden durchqueren, sorgt für die kontinuierliche Abspei- 
cherung unserer Aufenthaltsorte und der Dauer unseres Aufenthalts in den jeweiligen Räumen, wie auch das Login und das Logout an den Geräten, mit denen wir arbeiten. Dass sämtliche Computer, Tablets und Smartphones pausenlos unser Verhalten dokumentieren und Profile über uns erstellen, weil bestimmte Algorithmen analysieren, was wir bestellen, wonach für suchen, wofür wir uns interessieren, woran wir arbeiten, ist längst Alltag, den wir resigniert hingenommen haben. Der Mensch wird zum vermessenen Mensch und das Tragische, ja Absurde ist, dass er selbst immer mehr an dieser Selbstvermessung und Selbstüberwachung mitwirkt. Die Bürger_innen befinden sich aber nicht nur im Blick der großen, das digitale Leben dominierenden Konzerne und Unternehmen, sondern auch im Blickfeld des Staates (vgl. Bächle, 2016; Bauman und Lyon, 2013; Bendrath, 2007; Schaar, 2007). Wer dächte hier nicht an George Orwells Dystopie 1984?

Doch werden die seit etwa 15 Jahren immer mehr dominierenden Steuerungstechnologien auch der Kritik unterworfen (z. B. Eckert, 2017). Kritische Diskurse, ausgehend von Gilles Deleuze, diskutieren den Zusammenhang von Kontrollgesellschaft und schulischer Erziehung (z. B. Patzner, 2005; Rittberger, 2005). Deleuze führte Michel Foucaults Analyse der Disziplinargesellschaft des 18. und 19. Jahrhunderts fort. Danach liegt die Macht jetzt in den Systemen und generiert sich fortwährend neu. Das schulische Bildungssystem wie auch das Universitätssystem lassen sich nun im Kontext neoliberaler Gouvernementalität betrachten. Das staatliche Bildungssystem, wie wir es heute vor uns und um uns haben, ist Teil der Kontrollgesellschaft und steht in Verbindung mit der Kontrollmacht der Produktion und der Finanzmärkte. Das Ganze sieht zwar zunächst einmal freiheitlich aus, doch die Wahrheit ist, dass das Kontrollsystem nur den alten Disziplinarapparat ersetzt hat. Für Deleuze ist es schwer zu beantworten, welches der beiden Systeme das härtere oder erträglichere ist. Jedenfalls stehen sich, aus seiner Sicht, in beiden Systemen, der Disziplinar-wie auch der Kontrollgesellschaft, Befreiungen und Unterwerfungen gegenüber. Es findet eine kontinuierliche Kontrolle im Schul- und Bildungswesen statt. Auch der Zwang zur permanenten Weiterbildung bedeutet für Deleuze Kontrolle. Man wird heutzutage nie mit etwas fertig. Alles muss immerzu fortentwickelt und optimiert werden. Nun haben sich unsere Schulen und Bildungsreinrichtungen ja, in gewisser Weise, auch im Positiven weiterentwickelt. Lehrer_innen schlagen nicht mehr mit dem Zeigestock auf Finger und Hände, werfen nicht mehr mit dem Schlüsselbund, schreien nicht mehr ungehemmt auf Schüler_innen ein, geben keine Ohrfeigen mehr. Schulen haben sich durch das Installieren von Gremien, durch das Festschreiben von Beteiligungs- und Beschwerderechten im Schulgesetz, zweifelsohne weiter demokratisiert. Nur selten kommt es noch zu wirklich schwerwiegenden Rückschritten, Entgleisungen, Zuspitzungen, wie in Zusammenhang mit dem abgründigen Schulmatriarchat, das ich unter dem Kunstnamen Schwarzegg ausführlich dokumentiert und analysiert habe und wo sämtliche schulgesetztlich verankerte Partizipation und Mitwirkung ausgehebelt war und eine Schulleiterin, nach Art einer gefühllosen Gutsherrin, die Schule autokratisch regierte. Trotz allem bleibt das Schulsystem als Ganzes noch weit hinter dem zurück, was unsere heutige offene und demokratische Gesellschaft tatsächlich möglich machen und erlauben würde. 1976 veröffentlichten Bowles und Gintis ihr Buch Schooling in capitalist America. Darin können wir etwa die folgende Passage lesen: »Why saddle our youth with the burden of authoritarian schools? Why ought the better part of a young person's days pass in an atmosphere of powerlessness, of demeaning and dicta- 
torial rigidity, perpetual boredom, and behavior modification? Why, in a democratic society, should an individual's first contact with a formal institution be so profoundly antidemocratic?" (vgl. Bowles und Gintis, 2011, S. 250 f.).

Natürlich ist das eine scharfe Kritik. Das Schulsystem hat sich seit dieser Zeit sicher in einigen Punkten erfreulich weiterentwickelt. Doch die konstituierenden Grundlagen des öffentlichen Schulsystems sind noch immer dieselben. Es gibt kaum wirkliche Partizipation, schon gar nicht bezüglich des Lehrplans, bezüglich der Anwesenheit, der formalen Abläufe, der Prüfungen und Sanktionen. Die gesamte Art, wie Schulen, aufgrund der geltenden Schulgesetze, eben organisiert sind, ist nach wie vor vorgegeben. Partizipation durch Schüler_innen und Eltern bzw. Erziehungsberechtigte ist oftmals eine Schein-Partizipation. Es ist mehr Rhetorik und heiße Luft als Realität. Aria frittata nennt man das in Italien. Stets hat es eine Gruppe von Schüler_innen gegeben, die dagegen rebelliert hat, die in die Verweigerung gegangen ist, die sich an diesem System aufgerieben hat. Genau für diese Zielgruppe soll die Sonder- und Inklusionspädagogik des Schwerpunkts emotionale und soziale Entwicklung nun aber Konzepte entwickeln, damit auch diese Heranwachsenden in die vorgezeichneten Bahnen zurückfinden, dass sie darin gehalten werden, dass sie nicht erneut ausscheren. Doch wer spricht heute, im Zeitalter von Neuer Steuerung, Kompetenzorientierung, Monitoring und Educational Governance, noch von der Notwendigkeit, dass auch die Bildungssysteme selbst sich ändern müssten? Das gesamte Schulleben hat einen hochkomplexen bürokratischen Überbau. Jede kleine, pädagogisch relevante Entscheidung, wirklich alles, ist in immer detaillierter werdenden Schulgesetzen und ergänzenden Verordnungen geregelt. An die Aufhebung der Schulpflicht wagt sich in Deutschland jedoch noch immer kaum jemand heran, obwohl diese in einer offenen, freiheitlichen, demokratischen Gesellschaft keineswegs zwingend wäre und durch neue, nachhaltigere, zukunftsorientiertere Formate, etwa eine selbstgestaltete Bildungspflicht, die sich ja durchaus verwirklichen ließe, ersetzt werden könnte. Dadurch würde der enorme Druck aus dem System genommen und es würden sich neue Räume öffnen, für kreativeres, freieres Lernen (vgl. hierzu auch Siegmund und Wildermuth, 2012, S. 1521). Statt also an der fortwährenden Verfeinerung des Kontrollwissens mitzuarbeiten, indem wir immer neue psychodiagnostische Tests, Rating-Tools, verhaltensbezogene Checklisten oder Kompetenzraster, Verlaufsdiagnostiken usw. entwickeln, um vermeintliche emotionale und soziale Problematiken bzw. Verhaltensprobleme erfassen, beschreiben und durch gezielte Interventionen beeinflussen zu können, sollten wir eher das derzeit dominierende Bildungssystem und das darin verwendete Kontrollwissen in Frage stellen und durch kritische Analyse überwinden helfen, um für die einzelnen Heranwachsenden und für die Gesellschaft insgesamt etwas Besseres zu erreichen. Das neue Selbstverständnis der Pädagogik im Schwerpunkt der emotionalen und sozialen Entwicklung sollte eher sein, zum Bestandteil der gesellschaftlichen Transformation zu werden, die sich seit einigen Jahren auf verschiedenen Gebieten, von der Ökologie, über die Politikwissenschaft, bis hin zum Urban Design, abzuzeichnen beginnt. Natürlich muss das Schritt für Schritt und immer auf der Basis der demokratischen Gesellschaftsordnung vorangehen. 


\section{Funktionalisierung und Entfremdung}

Ziehen wir John O'Donohues $(1997,1998)$ philosophische Texte erneut heran, so können diese auch dabei helfen, den tieferen Bedeutungen von Funktionalisierung und Entfremdung auf den Grund zu gehen. Problematisch ist, wenn wir das aus der allgegenwärtigen Technologie abgeleitete funktionalistische Denken auf alles Menschliche übertragen. Menschen werden für Zwecke benutzt, ohne dass sie selbst als Menschen noch eine Bedeutung haben. Funktionalisierung und Kontrolle gehen dabei Hand in Hand. Die Systeme haben die Kontrolle übernommen. Die Menschen lassen sich verführen, diese Systeme am Laufen zu halten, weil sie selbst nach Besitz, nach Status oder Macht streben. Der ständige Vergleich und Wettbewerb in einer funktionalistischen Welt führt jedoch zu Einsamkeit. Die aus Kapitalismus und Funktionalismus bestehende Ideologie, die unser Alltagsleben und unser berufliches Leben, auch in den Schulen und Universitäten, immer stärker beherrscht, ist destruktiv, weil sie vielen Menschen schadet und die gesamte Gesellschaft immer weiter in eine sehr problematische Richtung treibt. Je nach Kontext können Arbeitsplätze, im Feld von Pädagogik und Wissenschaft, sehr stark auf Wettbewerb ausgerichtet sein, wobei oftmals Menschen gezielt gegeneinander ausgespielt werden, mit dem Ergebnis, dass diejenigen, die eigentlich meine Kolleg_innen sein könnten, zu meinen Gegner_innen werden. Es werden durch solche Systeme und durch die Führungskräfte, die sie bedienen und die an den Schaltstellen der Macht sitzen, Spannungen regelrecht künstlich erzeugt, oftmals regelrecht angeheizt, indem man etwa Menschen für dieselbe Arbeit ganz erheblich unterschiedlich besoldet. Man kann Menschen auf diese Art sehr subtil beherrschen und untereinander in einen fortwährenden Konkurrenzkampf treiben. Statt sich miteinander als Gleiche zu solidarisieren und etwa gegen unzumutbare Forderungen seitens der Systeme aufzubegehren, rivalisieren die Menschen, auch Professor_innen, jetzt miteinander um Geld, Ressourcen, Personal oder Status. Oft genug bekämpfen sie sich dabei auch persönlich, wodurch Atmosphären entstehen, wie aus den verschiedenen Regionen Deutschlands immer wieder zu hören und zu lesen ist, die sich unter Rückgriff auf Peter Sloterdijks Sphären-Philosophie als toxisch, das heißt kaum lebbar, erweisen. Im Grunde ist es ja genau das, was von Systemseite intendiert und gewünscht ist. Doch solche Unternehmens- und Organisationsphilosophien haben etwas ethisch Verwerfliches. Es wird höchste Zeit, dies alles zu durchbrechen und $\mathrm{zu}$ beenden, denn das ist alles Red Ocean. Dies gelingt aber nur durch eine aktivere Rolle der Zivilgesellschaft. Es ginge ja auch anders und in den Community-Projekten, die in der Zukunft in unserem Land zu Tausenden entstehen werden, soll es auch anders sein, das heißt schöpferisch und im Geist der gemeinsamen Unternehmung, der gemeinsamen Zielsetzung, des gemeinsamen gesellschaftlichen, ökologischen und globalen Anliegens. Wenn wir aber etwas Substantielles verändern wollen, dann müssen wir umdenken und auch im Tausch gegen unsere wiedergewonnene Freiheit auf einige Dinge verzichten, etwa auf teure Autos, Flugreisen, Hotelurlaube, Kreuzfahrten und anderes mehr. Dann brauchten wir auch nicht mehr so viel zu arbeiten und nicht mehr so viel Zeit im Berufsverkehr, beim Pendeln und auch nicht in spannungsgeladenen Meetings zu verbringen.

Dazu müssten natürlich die Sozialsysteme reformiert werden, inklusive der Zahlung eines bedingungslosen Grundeinkommens. Es muss jedoch unbedingt ein bedingungsloses, garantiertes, lebenslanges Grundeinkommen sein und nicht eine vorüber- 
gehende Zahlung, die nur dazu dienen soll, sich möglichst schnell wieder in das alte System einzufädeln. Das ist etwas völlig anderes, weil das gegenwärtige System dabei ja gar nicht in Frage gestellt wird. Es ist eine Mogelpackung, den Leuten so etwas anzubieten. Es klingt nur besser als Hartz IV und hat vielleicht den Vorteil, dass man das Geld nicht ständig neu beantragen muss. Aber im Grunde ist es dasselbe. Mir geht es um die Veränderung des Systems als Ganzes. Es müssen tatsächlich neue Arbeitsund Lebenskontexte entstehen, die mehr lokalen Bezug und weniger Mobilität mit sich bringen. Die Zukunftsentwürfe des Berliner Architekten und Urban Designers Max Schwitalla zeigen hier Möglichkeiten auf. So wird eine ganz andere Lebensqualität und auch eine andere Beziehungsqualität entstehen. Das wäre der Blue Ocean. Zunehmend wird der, in unserer Gesellschaft dominierende, Leistungsbegriff, auf dem derartige Praktiken und Systemstrukturen ja beruhen, hinterfragt. Herbert Marcuse (2012) veröffentlichte bereits vor 50 Jahren seine Kritik an der durch Medien, Politik und Industrie unternommenen Manipulation der Bürger_innen, an der Entfremdung, die sich unter den geltenden gesellschaftlichen Bedingungen ergibt, an der Flucht in Empirie und quantitatives Denken, am Aufbau eines technokratischen Herrschaftswissens. Marcuse plädierte für eine qualitative Reflexion der gesellschaftlichen Probleme. Aus seiner Sicht nimmt der Wohlfahrtsstaat der Bevölkerung die kritischen und revolutionären Reflexe. Die Arbeitswelt ist für Marcuse zu einer Herrschaftssphäre der Entfremdung geworden. In den Medien und in der Politik dominiert zugleich eine funktionalisierende Sprache. Sprache wird zu einem Instrument der Verschleierung und an dieser Verschleierung wirkt die Inklusions- und Sonderpädagogik zu weiten Teilen in unhinterfragter Betriebsamkeit mit, indem sie hilft, ein längst überkommenes Gesellschafts- und Wirtschaftssystem am Laufen zu halten. Wir müssen also stets die Gesellschaft, auf der einen Seite, und das Bildungssystem, auf der anderen Seite, in den Blick nehmen, einschließlich der Wechselwirkung zwischen beiden.

Kritik am Wissenschaftsbetrieb, den die zukünftigen Lehrkräfte und Pädagog_ innen ja durchlaufen und der diese in ihren späteren Denk- und Handlungsweisen prägt, lässt sich ferner aus systemtheoretischen Überlegungen (vgl. Luhmann, 2012) ableiten. Viele Universitätsinstitute und Abteilungen, speziell in den Bildungs- und Erziehungswissenschaften sind zu selbstreferentiellen, sich selbst zum Maßstab nehmenden, um sich selbst kreisenden Systemen, zu in erster Linie sich selbst reproduzierenden, wie Niklas Luhmann es nennt: autopoietischen Systemen geworden, die letztlich mehr mit ihrer Selbsterhaltung und mit der Anhäufung von Ressourcen und Statusvermehrung beschäftigt sind. Die eigentlichen, gesellschaftlich relevanten Fragestellungen, mit deren Lösung sie ursprünglich einmal von den Bürger_innen, die dafür ihre Steuergelder aufwenden, beauftragt worden sind, geraten dabei teils völlig aus dem Blick. Oftmals haben die jeweiligen Protagonist_innen in den universitären Abteilungen und Instituten gar kein Bewusstsein dafür, was draußen in der Gesellschaft tatsächlich passiert und welchen Veränderungsbedarf es dort wirklich gibt. Sie tauchen in die Analyse austauschbarer Daten ein, eben in das, wofür es gerade Geld gibt, folglich in das, was von der Politik und den Verwaltungen vorgegeben wird und in das, was am allermeisten der eigenen Karriere im monetären Sinne und im Sinne von sozialem Status dient. Kritik an den Zwängen und der Übermacht speziell der Schulpädagogik wurde bereits vielfach geübt und zugleich für die Freiheits- und Selbstbestimmungsrechte, für die Entwicklungsautonomie des einzelnen Kindes und Jugendlichen argumentiert, etwa seitens der antiautoritären Erziehung (z. B. Neill, 
1998). Teils stehen diese Strömungen unter dem Einfluss der Kapitalismuskritik und des Freudomarxismus, teils unter dem Einfluss der Reformpädagogik. Kritik an Entmündigung und Manipulation gab es auch seitens der Antipädagogik (vgl. Braunmühl, 2006), ferner seitens der von den USA ausgehenden De-schooling- oder Entschulungsbewegung (vgl. Goodman, 1971, 2012; von Hentig, 1972; Illich, 2000; Reimer, 1972; Vetter und Scheidler, 2014). Für Paul Goodman, den sicherlich prominentesten Vertreter dieser kritischen Bewegung, werden die Jugendlichen nicht erwachsen, weil sie im falschen Umfeld aufwachsen. Die Schule bereitet sie lediglich auf ein entfremdetes Leben unter Leistungs- und Konsumdruck vor. Der heimliche Lehrplan, den die Schule verfolgt, zielt nach Goodmans Auffassung auf die bloße Einfügung der Heranwachsenden in die bestehenden Lebens- und Arbeitsformen. Es erfolgt eine politische Erziehung nach den jeweils machthabenden Regierungen. Besser wäre es jedoch, so Goodman, offenere kommunikative Netzwerke und Einrichtungen zu schaffen, und so Freiheit und Autonomie zu fördern.

Doch in den deutschen Schulen der Gegenwart, speziell im Bereich der Sekundarstufe I, haben wir seit geraumer Zeit eine nicht zu kleine Gruppe von Heranwachsenden, die in dieser Art von Bildungssystem nicht zurechtkommen und die in irgendeiner Form aus dem Felde gehen oder sich entziehen. Wieviele Lehrkräfte, die unter den Bedingungen eines solchen Schulsystems arbeiten, kommen im Laufe ihrer Dienstjahre an den Punkt, dass sie nicht mehr können oder wollen? Oftmals, insbesondere dann, wenn sie einen Beamtenstatus haben und nicht ohne weiteres kündigen können, bietet sich ihnen kein adäquater Ausweg, das System wieder zu verlassen, ohne den allergrößten Teil ihrer Altersversorgung wieder zu verlieren. Ähnliches gilt für Professor_ innen, die auch nicht frei in andere Berufsfelder oder bloß an eine Universität im Ausland wechseln können. Der rote Faden in alldem ist nicht nur die Beschränkung der individuellen Freiheit, zugunsten der Systemstabilität und Systemkontinuität, Prinzipien, wie sie noch aus dem alten Preußen stammen, sondern zugleich auch, um dieses, durch Karl Marx geprägte, Leitmotiv aufzugreifen: Entfremdung. David Prechts (2020) Plädoyer lautet denn auch, lieber erfüllter und selbstbestimmter zu leben, zu arbeiten und sich selbst zu verwirklichen, statt den ganzen Tag über in einem Büro vor einem Rechner zu sitzen und Daten zu analysieren oder unternehmensinterne Abläufe zu optimieren, die einen persönlich nicht im Geringsten interessieren oder anderen Menschen Produkte zu verkaufen, die diese nicht brauchen. Nicht immer mehr Effizienzsteigerung und Perfektionierung, sondern kreative Selbstverwirklichung. Für Hüther et al. (2020) wandelt sich derzeit durch die globalen Umbrüche unsere Vorstellung von Arbeit. Weil die Bildungseinrichtungen, darunter die Schulen und die pädagogischen Fachbereiche der Universitäten, sich jedoch zu weiten Teilen dieser Erkenntnis verweigern, behindern sie teils eine zukunftsorientierte Bildung. Aus dieser Sicht muss die Zivilgesellschaft, verstehen wir hierunter die Gesamtheit der aufgeklärten und engagierten Bürger_innen dieses Landes, demnächst eine viel wichtigere Rolle übernehmen, als es derzeit unter der Vorherrschaft von Politik, Regierungen und Bildungsinstitutionen der Fall ist. Precht sieht eine Massenarbeitslosigkeit auf uns zukommen, in Zusammenhang mit der Digitalisierung. Er schlägt daher, wie viele andere auch, ein bedingungsloses Grundeinkommen für jeden Menschen vor. In der Schule und in den parallel entstehenden Community-Projekten sollten Motivation und signifikantes Lernen gefördert werden. Die befreite Gesellschaft, ohne repressive Arbeit und ohne die Unterdrückung des Lustprinzips, wie sie Herbert Marcuse (1982) beschrieben hat 
und zugleich eine Gesellschaft wie sie Erich Fromm (1976) entworfen hat, in der es auf Sein, philosophische Tiefe und ein qualitativ erfülltes, solidarisches Miteinander und nicht auf Haben, Besitzen, Rivalisieren und das Anhäufen von Statussymbolen oder das Ausüben von Kontrollmacht über andere Menschen ankommt.

Das seelische Leid in der Schule Schwarzegg war nur so lange möglich, weil die Schüler_innen, als auch die Lehrkräfte, durch gesetzliche Rahmenbedingungen gezwungen waren, dort zu bleiben bzw. täglich in diesen Käfig zurückzukehren. Die Schulleiterin beauftragte eine Kollegin damit, einen Schüler aus einer anderen Klasse immer in der 6. Stunde, wenn der Junge schon nicht mehr die beste Konzentrationsleistung zeigen konnte, mit einem diagnostischen Verfahren $\mathrm{zu}$ testen, um ihm $\mathrm{zu}$ geringe Intelligenz nachzuweisen und ihn dann an eine Förderschule Lernen abschieben zu können. Lehrkräfte, die keine Beamt_innen sind, hätten einfach gehen oder relativ kurzfristig kündigen können und wären durch ein Grundeinkommen nicht sogleich ins wirtschaftliche Chaos gestürzt worden. Schüler_innen und Eltern hätten sich ebenfalls aus dieser Schule zurückziehen und nach einem alternativen Projekt suchen können, um sich dort einzuschreiben. So hätten sich alle, die hier zu Opfern von Mobbing, Schikanen und seelischen Misshandlungen wurden, der Führungsclique an jener Förderschule für emotionale und soziale Entwicklung unmittelbar entziehen können. Erst der Zwangscharakter des gegenwärtigen Systems setzte die betroffenen Kinder, Jugendlichen, Eltern und Lehrkräfte dort regelrecht fest. Die schließlich durchgesetzten Reformen benötigten fünf ganze Jahre, wegen diverser Verstrickungen und Verwicklungen, wozu auch Personen aus der oberen Schulaufsicht und der Landespolitik gehörten. Fünf Mal sahen die betroffenen Kinder, Jugendlichen, Eltern und Lehrkräfte den Sommer kommen und gehen, ebenso den Winter, bis das sich endlich etwas änderte, obwohl ein Kreis von Personen unentwegt gegen die Missstände ankämpfte. Unsere demokratische Gesellschaft mit ihren teils rigiden, bürokratischen Institutionen und Aufsichtsbehörden und den auf den oberen Rängen befindlichen Funktionsträger_innen, trägt die Verantwortung für dieses Versagen gegenüber den betroffenen Menschen. 2009 stellte ich das Material erstmalig zur Diskussion, auf einem Kongress der Deutschen Gesellschaft für Erziehungswissenschaften, zum Thema Kulturen der Bildung, an der TU Dresden. Es gab einen, von mehreren Akteur_innen gestalteten, Workshop zum Thema Unkulturen der Bildung und hier brachte ich meine Sache ein. Es gab einen regelrechten Eklat, weil etliche der dort Anwesenden nicht ertrugen, dass ich das Material zunächst einmal ungefiltert, wenn auch bloß exemplarisch, vorstellte, ohne sogleich Theoretisierungen anzubieten und das düstere Material sogleich damit wieder zuzudecken. Das gipfelte in der kecken Frage eines Professors, welchen Nutzen das Material, das ich hier soeben vorgestellt hätte, denn nun für die Erziehungswissenschaften hätte? Ich war recht erstaunt, dass jemand das überhaupt von der Seite betrachten könnte. So fragte ich denn zurück, was denn der Nutzen sei, den eine so malträtierte Schule aus den Erziehungswissenschaften ziehen könne, denn diese Schule brauche ja nun eine solide fachliche Orientierung und gut ausgebildete Lehrkräfte und hätte dies, trotz der Existenz der deutschsprachigen Erziehungswissenschaften mit all ihren lehrkräftebildenden Studiengängen, alles offenbar nicht zur Verfügung gehabt.

Hier muss sich dringend etwas ändern. Ich setze auf die junge Generation der politischen und gesellschaftlichen Aktivist_innen und möchte ihnen Mut machen, die Veränderung jetzt voranzutreiben. Gibt man den Menschen ihre Freiheit zurück, än- 
dert sich in der Regel alles sehr schnell. Die Texte von Erich Fromm besitzen für solche zukunftsorientierten Entwürfe eine besondere Bedeutung. Zu Fromms Buch The Fear of Freedom hat Noam Chomsky das Folgende gesagt: "Erich Fromm speaks with wisdom, compassion, learning and insight into the problems of individuals trapped in a social world that is needlessly cruel and hostile." Unsere Gesellschaft ist also ohne Grund und ohne Not in vielen Bereichen grausam und feindselig, weil sie an überkommenen Strukturen festhält und bisher bedauerlicherweise reformunwillig ist. Tom Hodgkinsons (2007) Buch How to be free enthält eine ganze Reihe inspirierender Ansatzpunkte und für John Locke ist Freiheit eine Art Naturzustand des Menschen. Der Mensch ist für Locke »von jeder höheren Macht auf Erden frei«. Er untersteht »nicht dem Willen oder der Gesetzesgewalt eines Menschen« und er ist »keinem fremden Willenszwang und keiner Einschränkung seiner Rechte ausgesetzt« (vgl. Decher, 2012, S. $97 \mathrm{f}$.). Doch wie sieht das denn in der derzeitigen gesellschaftlichen und pädagogischen Wirklichkeit aus? Ist das schon so? Für Immanuel Kant geht es vor allem darum, dass die Menschen zu einem öffentlichen Gebrauch der Vernunft und zu gedanklicher Freiheit gelangen und dass sie den Mut haben, sich ihres Verstandes zu bedienen (vgl. Decher, 2012, S. 130). Was hindert uns also noch daran? Immer mehr ist die Rede von der gesellschaftlichen Transformation in Richtung einer Postwachstumsgesellschaft (vgl. Welzer und Wiegand, 2014; Wright, 2017). Durch ein bedingungsloses Grundeinkommen, das jeder Mensch ein Leben lang bezieht, ohne dass er irgendwelche Anträge stellen und ohne dass er Bittgänge unternehmen muss, ließe sich die Handlungsautonomie aller Akteur_innen vergrößern, insofern liegt darin ein enormes emanzipatorisches Potenzial. Es fände auch eine Machtverschiebung von den staatlichen Institutionen zur Zivilgesellschaft statt. Zugleich könnten all die sozialen Transferleistungen, wie sie in der Gegenwart gezahlt werden, etwa Wohngeld, Erziehungsgeld, Arbeitslosengeld II und all die Hilfen, wie sie etwa während der Corona-Krise an die Menschen verteilt worden sind, beendet werden. Es könnten sehr umfassende, kostenintensive Verwaltungsapparate, Deutschland verfügt über eine enorm aufgeblähte, teure Sozialbürokratie, geschlossen werden. Das eingesparte Geld könnte auf die Menschen verteilt werden, nur eben anders. Die nach der Abwicklung unnötiger Sozialbürokratie leerstehenden Immobilien können verkauft und umgebaut werden, damit insbesondere in den großen Städten mehr Wohnraum entsteht.

Der aufgeblähte Bundestag müsste endlich deutlich verkleinert werden, denn an den immer mehr Abgeordneten hängen ganze Stäbe von Mitarbeiter_innen mit einem gewaltigen Gebirge aus Gehältern, Zulagen, Reisekosten, Trennungsgeldern, Immobilienkosten, Betriebskosten und Pensionsansprüchen. Überall haben wir Lean Management, aber seltsamerweise nicht hier. Offenbar denkt auch der größere Teil der politischen Kaste in erster Linie systemerhaltend, selbstreferentiell und autopoietisch, um erneut Luhmanns Begrifflichkeiten heranzuziehen. Wichtig wäre, dass jeder Mensch, gleichgültig, was er/sie darüberhinaus dann arbeitet, schafft, entwirft oder produziert und dann noch hinzuverdient, dass er/sie dieses Geld wirklich lebenslang bezieht. Dadurch würden sich die Ängste vor Altersarmut deutlich verringern, die Kriminalität könnte sinken, das Selbstwertgefühl der vielen Menschen, die jetzt von sozialen Transferleistungen abhängig sind, könnte steigen, indem zugleich eine neue Philosophie in der Gesellschaft zum Leben erweckt wird. Menschen, die sich in der Gegenwart ausgegrenzt und abgeschrieben fühlen und teils aggressiv oder destruktiv geworden sind, würden so eine Wertschätzung erfahren und das Signal bekommen, 
dass auch sie Teil dieser Gesellschaft sind und dass wir daran glauben, dass auch sie etwas Konstruktives aus ihrem Leben machen können. Sie würden sich dann auch eher mit unseren demokratischen Werten identifizieren. Wir dürfen von unseren Politiker_innen erwarten, dass sie stärker philosophisch agieren. Die Zahlung eines Grundeinkommens sollte jedoch nicht als Einladung zum Nichtstun verstanden werden, sondern zum eigenen, selbstbestimmten Engagement, auf allen möglichen Ebenen der Gesellschaft, beflügeln. Diese Zahlung sollte ein Ansporn zur Entfaltung der eigenen Kreativität, eine Bestärkung, auf dieser Basis dann zu sehen, was der eigene gesellschaftliche und globale Beitrag sein kann. Vor allem soll das Grundeinkommen dazu beitragen, die starren, rigiden, menschenfeindlichen Vorstellungen von Arbeit zu überwinden. Arbeit muss wieder als etwas Schöpferisches, Erfüllendes, Selbstbestimmtes entworfen und von innen heraus mit neuer Motivation aufgeladen werden. Das Grundeinkommen sollte steuerfrei gezahlt werden, damit auch die Mittelschicht, die zu weiten Teilen darüberhinaus aktiv sein will, auch etwas davon hat und nicht ein großer Teil des Geldes wiederum durch Steuern aufgefressen wird. Aber auch etliche Menschen aus der Mittelschicht, die seit Jahrzehnten besonders hart im Rädchen der Arbeitswelt laufen und unsere Gesellschaft mit ihren Steuerzahlungen am Leben erhalten, möchten vielleicht ihre Arbeitsstunden reduzieren, um dann teils schöpferische Dinge zu tun. Eine Bankmitarbeiterin will vielleicht an einem Tag in der Woche malen, in einem neu eingerichteten Atelier. Ein Lehrer will vielleicht Stunden reduzieren und teils in der ökologischen Landwirtschaft tätig sein.

Das alles wird die Berufszufriedenheit erhöhen und die Krankheitskosten in diesem Land senken. In Kürze läuft auch eine großangelegte Längsschnittstudie zum bedingungslosen Grundeinkommen an, unter der Leitung von Jürgen Schupp, vom Institut der deutschen Wirtschaft. Die zentrale Frage, die diese Studie, für die sich zahllose Bewerber_innen gemeldet haben, lautet, ob die Menschen auch während des Bezugs eines Grundeinkommens produktiv bleiben. Wenn wir also endlich die Schulpflicht in eine selbstgestaltete Bildungspflicht umwandeln würden, somit den jungen Menschen und ihren Familien ihre Freiheit zurückgeben würden, selbst zu entscheiden, wie diese, so bedeutsamen Jahre, mit Lernaktivitäten gefüllt werden, also den rigiden Schulzwang endlich abschaffen würden, hätte dies sicherlich enorm positive Effekte. Zahlreiche Publikationen legen ja auch nahe, dass wir über Unschooling und selbstgesteuertes und selbstbestimmtes Lernen ebenfalls, oder gar viel besser und nachhaltiger, zu neuen Formen der Wissensaneignung gelangen (vgl. z. B. Stern, 1993, 2006, 2016). Wichtig wäre natürlich auch, darauf zu verzichten, am Ende der selbstgestalteten Bildungsjahre eine einheitliche Prüfung abzuhalten. Wofür sollte diese auch gut sein? Das ist alles altes Denken! Es geht jetzt darum, den jungen Menschen endlich ihre Freiheit und ihr tatsächliches Recht auf Bildung zurückzugeben. Wir sollten mit diesen peinlichen Kontrollen einfach aufhören. Dazu muss der Staat, hier in Gestalt der Bundesländer, sein Monopol in Bildungsfragen aber aufgeben. Universitäten und weiterführende Schulen können dann ihre eigenen Aufnahmetests machen. Das sollten sie tatsächlich tun und sehen, ob jemand, mit seinem Kenntnisstand, in der Lage sein wird, ein Studium erfolgreich abzuschließen. Davon sollte auch nicht abgerückt werden, insbesondere wenn es um technische, medizinische oder juristische oder vergleichbare Studiengänge geht. Es sind die diversen Schulabschlüsse, die jetzt in Frage gestellt werden müssen. Es ist das Abitur, auf das wir am ehesten verzichten könnten, denn die Studierfähigkeit garantiert es schon lange nicht mehr. 
Diese Klage war ja in den vergangenen Jahren immer wieder aus der Universitätswelt $\mathrm{zu}$ hören. Zunehmend haben wir ja auch junge Menschen mit einem Schulabschluss Klasse 10 und ein paar Jahren Berufserfahrung an den Universitäten. Das Abitur hat ohnehin längst seine Strahlkraft verloren, in dem Moment schon, wo es von immer mehr jungen Menschen erreicht wird. Oftmals wird den Jugendlichen aber während der gymnasialen Oberstufe auch Gewalt angetan, durch erzwungene Fächerkombinationen, die ihren Neigungen nicht entsprechen und folglich keine optimale Verwirklichung von Lerninteressen erlauben. Was die jungen Leute aber gelernt haben ist, dass sie sich anpassen und fügen müssen und dass es eben nicht darum geht, dass sie ihr ganz eigenes Lebensprojekt angehen können. Mit so etwas sollten wir aufhören.

In zahlreichen anderen europäischen und anderen Ländern, in Großbritannien, in der Schweiz, in den Niederlanden, in den USA, in Australien oder Brasilien haben wir schon freiere Formen sich zu bilden, jenseits von Schulpflicht und Schulzwang, etwa in Form einer Unterrichts-, Lern- oder Bildungspflicht, der auch in Form von Homeschooling oder Unschooling nachgekommen werden kann. Jan Edel (2008) hat einen Überblick über die Situation in Europa gegeben. Die freie Bildungspflicht scheint mir ideal, auch mit Blick auf die Community-Projekte, um die es mir geht, nicht aber das selbstständige Lernen eines staatlich vorgegebenen Curriculums, etwa im Homeschooling, selbst wenn das schon ein Fortschritt zum Schulzwang sein mag. Die Bildungspflicht wird in dem Artikel von Edel folgendermaßen definiert: »Die Eltern sind verpflichtet, für eine ausreichende und der Schule mindestens gleichwertige Bildung ihrer Kinder zu sorgen. Die Wahl der Methode und des Ortes bleibt frei. Die Eltern können wählen, ob das Kind durch Unterrichtung gebildet wird, oder ob es beispielsweise durch selbstbestimmte Lernformen zu seiner Bildung gelangt« (a.a. O., S. 20). Das können dann eben in Zukunft die transformativen Community-Projekte sein, in denen genau diese selbstbestimmten Lernformen stattfinden. Es ist erstaunlich, dass gerade Deutschland, ein Land dass sonst so große Stücke auf seine fortschrittliche, freiheitliche Demokratie hält, diese längst fällige Reform bisher nicht unternimmt und die Freiheit seiner Bürger_innen so massiv einschränkt. Würde die Schulpflicht aufgehoben, würden sich automatisch die Schulen verkleinern. Die Kosten für die staatlichen Schulen würden auch beträchtlich sinken. Es brauchten weniger Lehrkräfte eingestellt $\mathrm{zu}$ werden. Dies wiederum müsste den Landesregierungen helfen, die derzeit kaum noch genügend Lehrkräfte für ihr inklusives Schulsystem bekommen können, das offenbar an Attraktivität bei der jüngeren Generation verloren hat. Den nachrückenden jungen Generationen ist ja nicht verborgen geblieben, wie anstrengend das Unterrichten an Schulen, insbesondere unter den veränderten gesellschaftlichen Bedingungen, geworden ist. Immer seltener wählen junge Menschen daher einen Lehramtsstudiengang. Es gibt kaum eine Landesregierung, kaum ein Bildungsministerium, die derzeit nicht auf das Etablieren von Schnellmaßnahmen des Quereinstiegs, des Seiteneinstiegs oder des dualen Studiums drängen, um rasch an Lehrkräfte zu kommen. Doch wie nachhaltig ist das? Zwar werden nun Personengruppen mit den vielfältigsten beruflichen Vorerfahrungen und Studienrichtungen für den Schuldienst rekrutiert, teils, indem man sie schon während des Studiums bezahlt, was sicher zum einen zu einer Erweiterung der schulinternen Perspektiven führen wird, doch zugleich wissen wir nichts darüber, wie lange diese, im Schnellverfahren ausgebildeten, Lehrkräfte die pädagogische Arbeit in den überregulierten staatlichen 
Schulen tatsächlich durchhalten werden. Letztlich muss sich das System ändern. Die staatlichen Schulen können in der jetzigen Form nicht mehr lange weitermachen. Würden wir die Schulpflicht aufheben, brauchten auch weniger Lehramtsstudierende an den Universitäten ausgebildet zu werden. So oder so würden weniger Menschen an die Universitäten strömen, wenn wir zugleich ein bedingungsloses Grundeinkommen einführen würden, weil Bachelor- und Masterabschlüsse bei vielen jungen Menschen an Bedeutung für die eigene Lebensgestaltung verlieren würden.

Es wäre plötzlich ein Leben denkbar und vorstellbar jenseits solcher Abschlüsse, jenseits von Credits, Modulen, Modulprüfungen, Teilmodulprüfungen, oftmals versäumten Anmeldungen und all dem Trouble, der daraus entsteht, auch für die Lehrenden. In den neuen transformativen Projekten, die freilich noch genauer beschrieben und definiert werden müssten, würde auch das Handwerk eine Renaissance erfahren. Völlig zu Unrecht ist in den vergangenen Jahren die Akademisierung zum allein richtigen Weg und zu einem alles beherrschenden beruflichen Leitmotiv hochstilisiert worden. Praktische Arbeit und Handwerk wurden dagegen abgewertet. Es wird nun höchste Zeit, diesen schwerwiegenden Fehler wieder gut zu machen. Nicht nur befanden sich in den vergangenen Jahren viele junge Menschen an Universitäten, die dort eigentlich nicht hingehören, weil sie nämlich nicht gerne lesen, debattieren, Konzeptpapiere oder Abhandlungen schreiben und sich nicht mit der nötigen Leidenschaft in theoretische Diskurse hineinarbeiten. Bedauerlich aber ist, dass sie, unter dem Einfluss der unangemessenen Gewichtung akademischer Abschlüsse seitens der Politik und der Medien, nicht mehr erleben konnten, wie erfüllend stattdessen der Umgang mit Werkzeug oder Material im Handwerk und der sonstigen praktischen Arbeit sein kann. Vermutlich gehen diese Irreführungen darauf zurück, dass viele, aus den unteren Sozialschichten aufgestiegene, Politiker_innen und Wissenschaftler_innen eben dieses Muster des Aufstiegs durch Akademisierung so massiv propagiert haben, weil sie ihre eigene Geschichte zum Maßstab genommen haben, weil sie sich mit dieser eigenen Story überidentifizieren und sich selbst nichts anderes mehr vorstellen können. Genau das aber ist jetzt im Umbruch. Das Muster funktioniert nicht mehr. Es ist nicht nur überholt, ja es wird zunehmend kontraproduktiv. Dies auch deshalb, weil die Menschen, die all diese akademischen Abschlüsse erworben haben, erstens nicht alle beständig aufsteigen können, oftmals auch in der Arbeitslosigkeit landen und sich dann, mit Verspätung, andere berufliche Wege suchen müssen. Zum anderen ist es auch so, dass diese Inhaber_innen von akademischen Abschlüssen nun auch nicht automatisch mehr Lebensglück ausstrahlen. Im Gegenteil, auf den Ebenen, die sie erreichen, geht es oftmals sehr kalt, rivalisierend, verbissen und geistig überaus eng zu (vgl. hierzu auch Siegmund und Wildermuth, 2012, S. 133-162). Viele Arbeitskontexte sind durch ein hohes Maß an Entfremdung gekennzeichnet. Trotz allem ist es im Hinblick auf die transformativen Zukunftsprojekte, wie auch für die ja noch fortbestehenden, aber sich reformierenden, Schulen wichtig, dass sich eine bestimmte Gruppe von Menschen mit Soziologie, Philosophie, Kulturwissenschaften, Pädagogik, Sozialarbeit und den diversen Unterrichtsfächern usw. im wissenschaftlichen Kontext beschäftigt und dafür sicher auch Universitäten besucht. Universitäten sollen ja vom Kern her weiter bestehen, aber quantitativ betrachtet, deutlich zurückgefahren werden und dadurch auch deutlich weniger Ressourcen verbrauchen. Dasselbe sollte für die staatlichen Schulen gelten. 


\section{Von der Kontrollgesellschaft zur aktiven Zivilgesellschaft}

Warum ist diese Gesellschaft eigentlich nicht in der Lage, noch mehr Menschen so weit zu motivieren, dass sie von sich aus danach streben, ihre individuellen Möglichkeiten zu erkunden und zu verwirklichen und zum anderen zugleich konstruktive Beiträge zum gesellschaftlichen und globalen Ganzen zu leisten? Natürlich gibt es viele, die das schon jetzt tun, aber viele tun es auch nicht, was diverse soziale Institutionen, darunter die Schulen, auf den Plan ruft, daran etwas zu ändern. Aber warum wird jetzt immer stärker auf Steuerung, Monitoring und Governance gesetzt? Warum nicht auf Eigeninitiative, Motivation und Kreativität? In weiten Teilen der Pädagogik im Schwerpunkt emotionales und soziales Lernen geht es denn auch um das Antrainieren von Sozialverhalten, um das Steuern von Verhalten, um Behavior Management. Was wir hier seit den 8oer Jahren an Publikationen zur Verhaltensmodifikation und Verhaltenstherapie hatten, war durchaus noch überschaubar. Doch inzwischen hat es sehr viel Input aus den USA gegeben und dadurch haben sich auch in Deutschland vielfältigere Forschungsaktivitäten und Konzeptentwicklungen in diesem Segment ergeben (vgl. die Übersicht von Blumenthal et al., 2020). Die Internetseiten des Council for Children with Behavioral Disorders (CCBD) und der Association for Positive Behavior Support (APBS) geben hier umfassende Informationen. Die verschiedenen Aspekte der emotionalen und sozialen Entwicklung werden aus diesen Theoriewelten heraus in der Regel mithilfe psychometrischer Testverfahren, Screenings, Behavior Ratings (vgl. z. B. Casale et al., 2015 b, 2019; Huber und Rietz, 2015; Kalberg et al., 2011; Kilgus et al., 2018; Lane, Bruhn et al., 2010; Lane, Kalberg et al., 2010; Mutzeck et al., 2017) oder unter Rückgriff auf Inventare (z. B. Stadler et al., 2004) oder Checklisten eingeschätzt. Im Sinne von Diagnostik bzw. Förderdiagnostik (z. B. Mutzeck, 2002, 2004; Ricken, 2003) werden Informationen über ein Kind bzw. einen Jugendlichen gesammelt, etwa zum Thema Angst, zum Verhalten generell, zum aggressiven Verhalten, zur sozialen und emotionalen Entwicklung und diesbezüglichen Kompetenzen, zu den Familienbeziehungen, zur Emotionsregulation, zu emotionalen und sozialen Schulerfahrungen, zu Neurotizismus- und Extraversion, zu Impulsivität, Risikoverhalten und Empathie, zum Sozial- und Lernverhalten aus der Sicht von Lehrkräften, zu Stärken und Schwächen aus der Sicht von Kindern und Jugendlichen einerseits und Lehrkräften andererseits, zum schulischen Selbstkonzept, zu Entwicklungsrisiken oder zum Umgang der Heranwachsenden mit Stress.

Sodann werden auf dieser Datenbasis Förderpläne (vgl. z. B. Popp et al., 2017) entwickelt. Integriert in die Förderung wird oftmals eine kontinuierliche Verlaufsdiagnostik (vgl. z. B. Casale et al., 2015 a; Huber und Rietz, 2015) betrieben. Interventionen, wie sie unter dem Dach von School-wide Positive Behavior Support systematisiert worden sind, die zuvor bereits als Einzelinterventionen vorhanden waren und somit bereits eine längere Geschichte haben, lassen sich natürlich auch für sich betrachten. Das allermeiste, was wir in diesem theoretischen Feld antreffen, ist verhaltensorientiert, seltener geht es bei diesen Forschungen und Konzeptentwicklungen um Emotionen (vgl. z. B. bei Petermann et al., 2016). Natürlich sind Emotionen auch schwerer greifbar. Gerne wird daher die Regulation von Emotionen zum Forschungsgegenstand genommen. Hier lassen sich einige objektivierbare Beobachtungen anstellen. Nicht aber die Bedeutung dieser Emotionen selbst steht im Vordergrund. Sodann stoßen wir auf zahlreiche Publikationen zum Thema Classroom Management (vgl. z. B. 
Brozio, 2015; Eichhorn, 2019; Klaffke, 2018; Marzano, 2003; Marzano et al., 2005; Syring, 2017; Toman, 2017), wenngleich diese Bezeichnung vieles beinhalten kann, was in den soer Jahren noch der allgemeinen Didaktik zugerechnet wurde, etwa Fragen der geschickten Eröffnung und Beendigung einer Unterrichtsstunde, das Gestalten von Übergängen, die Gestaltung der pädagogischen Beziehung zwischen Lehrkraft und Kindern bzw. Jugendlichen. Gelegentlich werden auch neue Interventionen erprobt und geprüft, etwa das Tootling (vgl. Hintz et al., 2014). Hier werden Schüler_innen von anderen Schüler_innen bei einer guten Tat beobachtet und mit positivem Feedback versehen. Dies erscheint jedoch nicht als unproblematisch, denn hier wird die Gruppe der Gleichaltrigen mit Kontrollmacht und Definitionsmacht ausgestattet, was einzelne Kinder und Jugendliche sehr unter Anpassungsdruck und Konformitätszwang setzen könnte. Überhaupt wird, durch eine solche Intervention, die kindliche und jugendliche Wahrnehmung von inhaltlich definierten Lernprozessen weg auf die Ebene eines verhaltensbezogenen Monitorings gelenkt. So verinnerlichen die Heranwachsenden schon früh die Mechanismen der sie umgebenden Kontrollgesellschaft (vgl. Deleuze, 1993). Alle Kinder werden schrittweise in das systemimmanente Monitoring, die Educational Governance, die Neue Steuerung hineinsozialisiert und sie werden darin trainiert, sich gegenseitig zu beobachten und zu kontrollieren. Eine affirmative, kaum systemkritische, pragmatische Sonder- und Inklusionspädagogik wird dabei zum bereitwilligen Multiplikator, indem sie derlei Praktiken wissenschaftlich legitimiert, auf Tagungen und in Publikationen verbreitet und somit in den Schulen verankern hilft. Während PBIS in Deutschland zunächst kaum Beachtung oder Anwendung fand, anders als etwa in Norwegen oder den Niederlanden, wo man bereits seit etlichen Jahren damit arbeitet, hat sich seit 2003 überraschenderweise ein anderes schulweites Programm, das Trainingsraum-Programm (TRP) (vgl. Balke, 2003; Bründel und Simon, 2013; Claßen und Nießen, 2006) an deutschen Schulen verbreitet. Beim TRP handelt es sich um ein Time-out Modell, das auf dem ebenfalls amerikanischen Responsible Thinking Process (RTP) basiert, welches jedoch, interessanterweise, in den USA selbst keine besondere Beachtung gefunden hat. Im Zuge der Umsetzung der UN-Konvention empfahlen gar Schulverwaltungen und Wissenschaftler_innen, etwa Ulf Preuss-Lausitz und Klaus Klemm, die Einrichtung des TRP an deutschen Schulen, um insbesondere den Erfolg der inklusiven Beschulung im Bereich der emotionalen und sozialen Entwicklung zu sichern. Formale Inklusion und schulinterne, temporäre Exklusion werden im Rahmen des TRP miteinander verschränkt. Dies, obwohl bisher kein überzeugender empirischer Nachweis für die Effektivität des TRP vorliegt (vgl. Hövel et al., 2020).

Qualitativ gewonnene Daten sprechen sogar dafür, dass sich durch die Anwendung des TRP eine negative Auswirkung auf das Lehr-Lern-Geschehen in den Klassen und auf die Kultur einer Schule insgesamt ergibt. Während das TRP das Ziel verfolgt, die Disziplin im Klassenzimmer zu erhöhen und die Lehrkräfte zu entlasten, dürfte das Programm in Wahrheit jedoch die Entwicklung einer stärkenorientierten und partizipativen Lernkultur nachhaltig verhindern. Auch das auf Anpassung und Konformität beruhende Menschenbild und Bildungsideal des TRP werfen erhebliche Bedenken auf. Das ist der Hauptgrund, der gegen das TRP spricht, nicht seine mangelnde Wirksamkeit. Ich habe mich weiter vorne im Buch schon ausführlich mit dieser Problematik beschäftigt, anhand der Publikation von Hövel, Zimmermann et al. (2020). Es bleibt die, bisher unbeantwortete, Frage im Raum stehen, wie es sein kann, dass Schulver- 
waltungen und teils auch Wissenschaftler_innen den Schulen, trotz der von wissenschaftlicher Seite veröffentlichten kritischen Stellungnahmen (vgl. z. B. Jornitz, 2004; Pongratz, 2010), etwas so Problematisches wie das TRP überhaupt empfehlen konnten? Etwa aus bloßer Unkenntnis und versäumter Lektüre der nationalen und internationalen Literatur, wo man/frau Besseres und Effektiveres hätten finden können? Auch die Frage, warum so viele Schulen dieses fragwürdige Modell überhaupt installiert haben? War es der bloße Griff nach dem rettenden Strohhalm? Dürfte man aber von Schulleitungen, Schulrät_innen und Lehrerkollegien nicht auch einen Blick in die Literatur erwarten können, im Sinne beständiger Weiterbildung und schulischer Organisationsentwicklung?

School-wide Positive Behavior Interventions and Supports (SW-PBIS oder PBIS) bezeichnet nun ein daten- und evidenzbasiertes schulübergreifendes System der Verhaltenssteuerung und des Verhaltenstrainings für inklusive allgemeine Schulen. Viele PBIS-Elemente werden zugleich auch im spezialisierten, separativen Förderschulbereich angewendet. PBIS funktioniert, wie die datenbasierte Lernförderung, nach dem dreistufigen Response-to-Intervention-Modell (RTI) (vgl. Blumenthal und Voß, 2016; Hartke, 2017; Huber und Grosche, 2012; Voß et al., 2016). Dabei zeigt die systematische Erhebung und Auswertung von Daten, welche Schüler_innen eine intensivere, individuellere Förderung bekommen sollen. Bei diesen 3-Stufen-Modellen arbeitet nun die gesamte Schule auf mehreren Ebenen der Intervention. Es dürfen nur Interventionen verwendet werden, die als ausreichend empirisch geprüft, das heißt als evidenzbasiert gelten, wobei hier ganz bestimmte Kriterien Anwendung finden, was die Größe der Stichproben und was die Qualität der quantitativen, empirischen, statistischen Forschung anbelangt. Mehrere Forscher_innen müssen, unabhängig voneinander und an verschiedenen Orten, zu denselben Ergebnissen gekommen sein. Es müssen Wiederholungsprüfungen und Metaanalysen vorliegen usw. Ich erinnere an die diesbezüglichen, bereits erwähnten, Erläuterungen der Kollegin aus Ohio und ihre Flugzeug-Metapher. Jede der drei Stufen beinhaltet eine Serie von Einzelinterventionen. Alle schulinternen Entscheidungsprozesse beruhen auf der Erhebung und Auswertung von Daten. Auf der ersten Ebene, auch Tier I genannt, finden präventive Maßnahmen für alle Schüler_innen der Schule statt. Diese Interventionen haben pädagogischen und didaktischen Charakter. Sie finden im Klassenverband mehr oder weniger, je nach Entwicklungsstand und Klassensituation, mit allen Schüler_innen der Schule statt, etwa klare Verhaltenserwartungen, die zunächst vermittelt werden (Clear Behavioral Expectations), das systematische Einsetzen von verhaltensspezifischem Lob (Behavior-specific Praise), das Good Behavior Game, Schüler_innen coachen sich untereinander, während sie Lernaufgaben lösen (Classwide Peer Tutoring) oder didaktische Modifizierungen als verhaltensbezogene Interventionen (Instructional Adaptations). Da oftmals Lern- und Leistungsrückstände bei Schüler_innen mit einer emotionalen und sozialen Problematik vorliegen, wird in der Literatur davon ausgegangen, dass ein großer Teil des unterrichtsabgewandten Verhaltens von Schüler_innen durch Vermeidungsstrategien verursacht und aufrechterhalten wird, weil diese fürchten, die unterrichtlichen Aufgaben nicht bewältigen zu können und folglich vor den erforderlichen geistigen Anstrengungen ausweichen. Insofern müssen hier schulische Leistungsfähigkeit und emotionale und soziale Problematik zugleich in den Blick genommen werden. Die Abwehr gegenüber dem Unterrichtslernen kann sich zu einem Muster oder einer Haltung verfestigen. Somit kommt den eingesetzten 
didaktischen Strategien und Methoden eine hohe Bedeutung zu. Didaktische Interventionen erscheinen daher als eine sinnvolle Antwort auf das Problemverhalten. Eine solche Intervention ist, die Lernaufgaben in kleine Schritte zu zerlegen (Breaking up the Task Components), eine weitere, das direkte oder explizite Unterrichten (Direct or Explicit Teaching). Eine dritte Intervention auf dieser Ebene ist das Anbieten von Wahlmöglichkeiten beim Lernen (Choice-making), um Lernwiderstände abzubauen. Das kann bedeuten eine Lernaktivität aus einem angebotenen Spektrum an Lernaktivitäten auszuwählen, innerhalb einer vorgegebenen Lernaktivität zu wählen, oder aber, als Schüler_in, selbst über die Reihenfolge in der Bearbeitung vorgegebener Aufgaben zu entscheiden. Beim gezielten Anbieten von Antwortmöglichkeiten (Opportunities to Respond) werden Schüler_innen Gelegenheiten geboten, ihre Gedanken mitzuteilen und sich aktiv in den Unterricht einzubringen, wodurch sich automatisch Problemverhalten verringern soll.

Auf der zweiten Ebene, auch Tier II genannt, kommen spezielle Trainings zu sozialen Fähigkeiten oder sozialpädagogische Maßnahmen für die at-risk Schüler_innen zur Anwendung, das heißt für diejenigen Kinder und Jugendlichen, die etwa auf der Basis der Student Risk Screening Scale (SRSS), mit 4-8 Punkten bewertet wurden. Ein entscheidendes Merkmal von Tier II-Interventionen ist, dass alle Kinder bzw. Jugendlichen in der betreffenden Gruppe exakt dieselbe standardisierte Intervention bekommen. Die Dauer der Anwendung beträgt einige Wochen bis hin zu einigen Monaten. Das Trainieren sozialer Fähigkeiten kann in kleinen Gruppen außerhalb oder ergänzend zum Klassenunterricht stattfinden. Denkbar sind auch Interventionen, die integriert in das Klassengeschehen stattfinden, je nach Unterrichtsform, Unterrichtsfach und pädagogischem Stil einer Lehrkraft. Zu beachten ist, dass in der Literatur nicht immer einheitlich verfahren wird, wenn es um die Zuordnung von einzelnen Interventionen zu den Stufen I und II geht. So finden sich etwa Class-wide Peer Tutoring oder das Good Behavior Game teils auf Stufe I, teils auf Stufe II. Die Interventionen, die üblicherweise mit Stufe II verbunden werden bzw. dort zum Einsatz kommen sollen, sind die Daily Behavior Report Card, Check-In/Check-Out, auch Behavior Education Program genannt, Check \& Connect, das aktive Einbinden von Eltern und Erziehungsberechtigten und die Social Skills Trainings. Ein großer Teil der Publikationen in diesem Feld befasst sich mit dem Training von Selbstregulation, Selbstkontrolle (vgl. z. B. Polsgrove und Smith, 2004), Selbstmanagement (vgl. z. B. Schramm, 2018; Smith und Sugai, 2000), Selbstbeobachtung (Self-monitoring, z. B. Kalis et al., 2007; Levendoski und Cartledge, 2000; Todd et al., 1999) oder Selbstkontrolle (Polsgrove und Smith, 2004). Andere Programme richten sich speziell auf die Fähigkeit der Kinder und Jugendlichen mit Frustration und daraus resultierendem Ärger umzugehen. Natürlich gibt es teils auch wertvolle Komponenten in einigen PBIS-Interventionen. Es gilt sie sorgfältig herauszufiltern. In einem nächsten Schritt müssten sie allerdings dann in eine erweiterte, offenere Struktur einer freieren Pädagogik integriert, teils auch abgewandelt und verändert werden. Auf der dritten Ebene, auch Tier III genannt, werden durch das schulinterne Behavior Support Team individuelle, auf die einzelnen Schüler_innen mit high risk (SRSS-Punkte 9-21) zugeschnittene Interventionen entwickelt. Allerdings verlaufen diese Bemühungen in sehr engen Bahnen. Im ersten Schritt wird auf der Basis der Grundannahme, dass jedes Verhalten einen Zweck erfüllt, dass es eine Funktion für das Kind oder den Jugendlichen hat, eine funktionsbezogene Verhaltensanalyse (Function-based Assessment) (vgl. z. B. Chandler und Dahl- 
quist, 2010; Scott und Eber, 2003; Smith und Sugai, 2000; Sugai und Lewis-Palmer, 2004; Waller, 2009) unternommen. Hierbei werden Verhaltensauslöser (Antecedents), das Verhalten begleitende und begünstigende Rahmenbedingungen (Setting Events), das Problemverhalten (Target Behavior) und die sich hieraus im Kontext Schule ergebende Konsequenz (Consequence) hypothetisch bestimmt und genauer betrachtet. Es wird in der Literatur eine einfachere Basisversion der funktionsbasierten Verhaltensanalyse (Function-based Assessment) von einer komplexeren Variante unterschieden. Die Basisversion wird bei leichten bis mittleren Problematiken angewandt und kann von schulinternem Personal (Behavior Support Team) allein durchgeführt werden, solange es sich nicht um gefährliches Verhalten handelt oder um ein Problemverhalten, dass sich in allen möglichen Lebensbereichen manifestiert. Die komplexere Version wird dagegen bei mittleren bis schwerwiegenden oder gefährlichen Verhaltensweisen angewandt und impliziert eine intensive Arbeit mit der Familie und die Kooperation mit anderen Instanzen wie Jugendamt, externen Psychotherapeut_innen, Verhaltensspezialist_innen aus Psychologie, Sonderpädagogik oder Polizei. Auf der Basis der Verhaltensanalyse wird nun ein Interventionsplan (Behavior Support Plan) entwickelt. Auf dieser Basis werden funktionsbezogene Interventionen (Function-based Interventions) definiert und umgesetzt. Dabei werden die Eltern bzw. Erziehungsberechtigen eingebunden. Auch die interprofessionelle Kooperation spielt hier eine zentrale Rolle (School-based Wraparound, Collaboration with Other Agencies, Systems of Care, Family-driven Care).

School-wide Positive Behavior Support ist datenbasiert und erfordert eine systematische und kontinuierliche Erhebung von diagnostischen Daten. Schulweite Erhebungen etwa mit der Student Risk Screening Scale (SRSS und SRSS-IE) gelten international als bewährt und anerkannt, da dieses Instrument nicht nur sehr gut durch Forschung abgesichert ist (vgl. z. B. Kilgus et al., 2018; Lane, Bruhn et al., 2010; Lane, Kalberg et al., 2010), sondern zugleich einfach, praktikabel, über eine Einschätzung durch die Lehrkräfte schnell durchzuführen und kostenlos zu haben ist. Eine weitere Möglichkeit zur Datensammlung und Datenauswertung sind die archivierten Verweise eines Schülers zur Schulleitung (Office Discipline Referrals). PBIS ist data-based bzw. data-driven. Dies bedeutet, dass kontinuierliche Datenerhebungen absolut zentral sind bei der Installierung und schulinternen Anwendung und Weiterentwicklung von PBIS. Qualitätsentwicklung erfolgt durch Training und Coaching, Selbst-Beobachtung, in Unterricht, Beratung oder Förderung, durch regelmäßige, strukturierte, angeleitete kollegiale Besprechungen und Beratungen, auch Unterrichtshospitationen, um etwa die Häufigkeit des von einer Lehrkraft angewandten verhaltensspezifischen Lobs zu erheben und dieser anschließend ein Feedback zu geben. Dabei kann auch die Besprechung der gesamten Arbeitssituation mit einer Lehrkraft, bezüglich ihrer Motivation, Klassenführung oder fachlichen Weiterentwicklung, und ein mögliches Coaching diesbezüglich, eine wesentliche Rolle spielen. Schulen, die PBIS erst einmal kennen, werden sich immerhin mit dem Trainingsraum-Programm, oder mit all den daraus entwickelten Inselräumen, Lernbüros, Freiräumen usw., nicht mehr aufhalten wollen und können, weil diese Modelle ja alle implizieren, dass Schüler_innen aus dem Klassenzusammenhang und damit aus dem curricularen Lernzusammenhang herausgenommen werden und selbst Hövel, Zimmermann et al. (2020) schlagen das ja noch vor, obwohl ja inzwischen längst ausreichend Modelle vorliegen, wie wir in den Klassen anders arbeiten könnten, etwa im Sinne der Lebensweltorientierten Didaktik 
(vgl. Bröcher, 1997, nachgedruckt 2013) und sei es, je nach Standpunkt und Überzeugung, auch mit PBIS, oder mit einer Verknüpfung von beidem. PBIS stößt, wie die RTI-Modelle insgesamt, allerdings nicht nur auf Zustimmung (vgl. z. B. Ferri, 2012; Willmann, 2018). »Protegiert durch ein gesteigertes politisches Interesse an technologischem Wissen, ist mittlerweile eine Forschungsindustrie entstanden«, schreibt Marc Willmann (2020, S. 223). Es lässt sich darin letztlich auch eine eine raffinierte Steuerungsapparatur sehen, die Konformität und Anpassung erzeugt, bei Schüler_innen wie bei Lehrkräften, und in der umfassend Daten erhoben werden. Ein Land mit der Bevölkerung Norwegens könnte es in Kürze geschafft haben, sämtliche PBIS-bezogenen Schuldaten in seinen Aufsichtsbehörden und Ministerien zusammenzuführen und zentral in den Blick zu bekommen. Dies dürfte in Deutschland jedoch Schwierigkeiten bereiten, nicht nur wegen der höheren Bevölkerungszahl, sondern auch wegen der Widerständigkeit hiesiger Schulkollegien, zumindest von Teilen davon, aber auch in den jeweiligen Landesregierungen, in den einzelnen Bundesländern, dürfte sowas nicht überall mehrheitsfähig sein, weil wir mittlerweile eine kritische Zivilgesellschaft haben, die hier ihr Veto einlegen wird. Gäbe es also kulturelle Adaptierungsmöglichkeiten, evtl. auch von Bestandteilen von PBIS, die, trotz dieser Einschränkungen, in die deutsche Bildungslandschaft passen würden? Ließe sich PBIS im Grundsatz übernehmen und stärker mit einem freiheitlichen Bildungsideal und partizipativen, prozesshaften, auch qualitativen Elementen der Schulentwicklung variieren? Philosophie, Experiential Education, Outdoor, Adventure, Martial Arts, Creative Arts oder Lebensweltorientierte Didaktik auf Tier II und Tier III? Das Good Behavior Game dann mehr als Selbsterfahrungsübung, um etwas über das Thema Macht und Steuerung zu lernen? Mit solchen, freilich für die Behavior-Welt schwer zu akzeptierenden, Veränderungen und Verkehrungen könnte es doch gehen. Die Diskussion hat begonnen, auf europäischer Ebene. Dabei kristallisieren sich zwei Positionen heraus: Zum einen: PBIS kann auch in Europa nur zu 100\% evidenzbasiert angewandt werden, also keine Variationen. Zum anderen: Wir variieren das strenge PBIS-System nach eigenen Maßstäben, aber nach welchen?

In Großbritannien haben sich zudem einige weitergehende verhaltensbezogene Monitoring-Systeme für den Kontext Schule etabliert. Eines davon läuft unter dem Namen Behavior Watch und wurde von Eduspot, Leicester, UK entwickelt. Auf deren Internetseite lesen wir: »What happens in the classroom, sports hall and playground matters - so we keep all of your snippets of information in one place.« Das im wesentlichen auf einer speziellen Software beruhende System wird als »straightforward behaviour management « definiert, »because what your child does between 8.30 am and 3.30 pm five days a week shouldn't be a mystery." Mithilfe der Software, die kontinuierlich von den Lehrkräften mit Daten gefüllt und von der Schulleitung überwacht und ausgewertet wird, wird ein nahezu lückenloses Tracking oder Monitoring sämtlicher Verhaltensweisen eines Kindes oder Jugendlichen möglich: »Behaviour Watch fills the void between home and school, so no more missing report cards. It lets parents and teachers know how pupils are getting on at school. With real time attendance monitoring, issues can be flagged the moment they arise. Behaviour Watch also caters for children with special educational needs and extra curricular activities. $\aleph^{1}$ Ein weiteres Programm dieser Art wurde von der School Software Company, St. Johns Innova-

1 https://eduspot.co.uk/product/behaviourwatch/ (25.10.2020) 
tion Centre, Cambridge, UK, unter der Federführung von Tom Vodden entwickelt und läuft unter dem Namen Sleuth. Ich lernte Vodden kennen, bei der Jahreskonferenz von SEBDA, der britischen Social, Emotional and Behavioural Difficulties Association, im Marriott Hotel in Leeds, im März 2013. Er hatte dort hochprofessionelle Informationswände aufgestellt in einem Foyer, wo sich die Konferenzteilnehmer_innen zu einem cup of tea trafen. Es gab Hochglanzbroschüren zu Sleuth und Vodden kam rüber wie ein smarter Finanzberater. Er hatte früher einmal eine akademisch-pädagogische Laufbahn eingeschlagen, die aber irgendwie nicht so recht weitergegangen war. Dann kam die Idee mit Sleuth. Mehrfach saßen Vodden und ich beim Essen im Marriott zusammen und sprachen über Sleuth und alle Fragen, die damit zu tun haben. Ich hatte zunächst nicht den Eindruck, dass Sleuth von seinem ganzen Ansatz und von seiner Zielrichtung her unbedingt zur Philosophie von SEBDA passte. Nirgendwo in den Publikationen dieser Gesellschaft, oder in denen von einzelnen SEBDA-Protagonist_innen, soweit ich diese kenne, finden sich solche Bezüge. Ich hatte in Leeds etwa an einem Workshop über die Bedeutung von Hunden in der pädagogischen Arbeit an Schulen teilgenommen. Das war nun wahrlich eine andere Perspektive, als sie bei Sleuth eingenommen wird. Ich erklärte es mir so, dass die Gesellschaften, die ja zumeist chronischen Geldmangel haben, Firmen die Möglichkeit geben, ihre Produkte gegen Gebühr auszustellen und dafür Werbung zu machen. Wenn man also mit John Visser spricht, einem der SEBDA Pioniere und Stakeholder von besonderem Renommée, ich hatte ihn zunächst 2002, in Hamburg, bei einer von Birgit Herz organisierten Tagung zum Thema Schulverweigerung, kennengelernt, denkt man eher an das Gegenteil von Sleuth. John Visser, der ja auch umfangreiche Praxiserfahrung hat, setzt auf gute pädagogische Bindungen, die Stärkung von sozialen Communities, auf die Herstellung von Lebensweltbezügen in der pädagogischen und didaktischen Arbeit und er hat eine kritische Haltung gegenüber Behavior Management und datenbasierten Interventionen.

Doch was steckt nun hinter dem Namen Sleuth? Übersetzen können wir das englische Wort sleuth zunächst mit Detektiv oder Spürhund. Als Verb bedeutet es auch schnüffeln, jemandes Spur verfolgen oder jemandem nachspüren. Damit haben wir aber auch schon den wesentlichen Kern des Ganzen erkannt. Es läuft ähnlich wie auch bei Behavior Watch: "Sleuth is a highly effective software tool for tracking student behaviour and their personal and social development. It is used by thousands of staff in hundreds of mainstream and special schools ... In 1-click Sleuth provides leaders and teachers with high quality information that is used to: Communicate what's going on, who is involved and how staff have responded, identify individuals and groups that need support and help you plan intervention strategies, monitor the impact of interventions and provision, evidencing progress and improvement ... The most effective school leaders use Sleuth to empower their staff with targeted information so that they always know what's going on, are able to collaborate with colleagues and develop practice that makes a real and sustainable difference to the behaviour and personal development of every student. $\aleph^{2}$ Bei Behaviour Watch und Sleuth geht es also um die systematische Dokumentation und um die kontinuierliche Auswertung sämtlicher verhaltensrelevanter Ereignisse im Kontext Schule. Schulleitungen und übergeordnete Schulbehörden können unmittelbar sehen, was es, gemessen an den

2 https://schoolsoftwarecompany.com/ (25.10.2020) 
für schulisches Verhalten gültig erklärten Normen und Standards, an Abweichungen und Besonderheiten gibt. Solche Programme machen Lehrkräfte jedoch zu Kontrolleur_innen. Diese Programme ermöglichen ein totales Monitoring, bezogen auf sämtliche am Schulleben beteiligten Personen und werden so zum Bestandteil einer fortgeschrittenen Kontrollgesellschaft, wie sie schon in den 9oer Jahren von Gilles Deleuze vorausgesehen wurde. Wenn wir einmal auf die bereits 1964, unter dem Titel One-dimensional Man. Studies in the Ideology of Advanced Industrial Society, erschienene Kritik von Herbert Marcuse zurückgreifen, so wird durch diese Form der sozialen Kontrolle nicht nur Einförmigkeit und Konformität im Charakter der jungen Menschen erzeugt, sondern auch auf seiten der beteiligten Lehrkräfte, die Stunde um Stunde diese Daten eingeben.

Die Mehrheit der Menschen in Deutschland, Großbritannien und den meisten anderen europäischen Ländern lebt heutzutage, so die Argumentation von Marcuse, unter relativ komfortablen Bedingungen. Aus diesem Grund bildet sich kaum noch ein gesellschaftskritischer Impuls innerhalb der Bevölkerung, um gegen die zunehmenden Kontrollmechanismen und die unterschwelligen Konditionierungen und Manipulationen, die in solchen Systemmechanismen liegen, aufzubegehren und etwa mehr Freiheit und Selbstbestimmung zu fordern und sich zu erkämpfen. Aldous Huxley hat in seinem, 1932 erschienenen, Buch Brave New World, in deutscher Übersetzung Schöne neue Welt, eine solche Entwicklung im Sinne einer Dystopie auf die Spitze getrieben. In seinem Roman beschreibt er eine Kontrollgesellschaft, die zugleich für Wohlstand und Vergnügungen sorgt, in der die programmierten und konditionierten Menschen ihr Sklavendasein lieben und sich einreden, sie seien frei. Am Ende könnten wir, wenn wir nicht aufpassen, wie es Erich Fromm genannt hat, bei einer solchen Pathologie der Normalität landen. Programme wie Behaviour Watch oder Sleuth sind zugleich hochkompatibel mit dem in China verwendeten Social Credit System (SCS). Hierbei handelt es sich um ein digitales Überwachungssystem, ein datengestütztes Rating- und Bonitätssystem, bei dem jeder Schritt und jede Bewegung der einzelnen Menschen, rund um die Uhr, aufgezeichnet, ausgewertet und öffentlich gemacht wird, im schulischen, beruflichen, öffentlichen und privaten Leben (vgl. ARD, 2020; ZDF, 2020; Strittmatter, 2018). Allgegenwärtige Kameras sind mit Gesichtserkennung, Body-Scans und dem Aufzeichnen von Bewegungsprofilen beschäftigt. All diese Daten werden mit persönlichen Daten und Online-Verhalten verknüpft. Wer sich nicht systemkonform verhält, dazu gehören etwa das Nicht-Zahlen von Steuern, Verstöße gegen Verkehrsregeln, systemkritische Äußerungen u.a., wird in seiner Mobilität und in seinen sozialen Kontaktmöglichkeiten eingeschränkt, das heißt es dürfen keine Flugtickets oder keine Tickets für Hochgeschwindigkeitszüge mehr gebucht werden, Accounts von sozialen Netzwerken werden gesperrt usw. Unangepasste Menschen müssen damit rechnen in ein Umerziehungslager eingewiesen $\mathrm{zu}$ werden. Solche Einrichtungen werden $\mathrm{Be}$ rufsbildungszentren o. ä. genannt, ihr wahrer Zweck wird somit durch sprachliche Einkleidung verschleiert. Allein schon der Kontakt zu Personen, die als unzuverlässig bzw. nicht konform gelten, wirkt sich schädlich auf den eigenen Punkte-Score aus. Wer auf den sog. schwarzen Listen landet, kann sich kaum noch in der Stadt oder im Land bewegen. Technologiefirmen optimieren die Aufzeichnung und Auswertung der Daten immer weiter. Philippe Calderon und Caroline Benarrosh (2017) haben Huxleys und Orwells Dystopie zueinander in Beziehung gesetzt, diese verglichen und hinsichtlich ihrer Gegenwarts- und Zukunftsbedeutung untersucht, nicht nur im Hinblick auf die 
chinesische Gesellschaft, sondern auch im Hinblick auf Donald Trump und seinen Umgang mit Sprache und mit der Wirklichkeit. Speziell in Orwells Dystopie 1984 wird Sprache manipulativ gebraucht und die Geschichte wird nach ideologischen Gesichtspunkten umgeschrieben.

\section{Communities der Zukunft}

Aus der Literatur wissen wir um die hohe Bedeutung von Schüler_innen-Partizipation, ebenso Eltern-Partizipation für die Schulentwicklung, für das Aufbauen einer guten Schulkultur und eines guten Schulklimas. Ebenso von hohem Stellenwert sind intensive und produktive Beziehungen zwischen Schule und umgebender Community (vgl. z. B. Klein, 2000). Auch die enge Kooperation mit der sozialpädagogischen Kinder- und Jugendhilfe, ebenso eine Auseinandersetzung mit den Theorielandschaften und Handlungsmodellen der Sozialen Arbeit, vom Konzept des Sozialen Raums, über die Hilfen zur Erziehung, die Hilfeplanung, die Schulsozialarbeit, die Heimerziehung, die Kriminalpädagogik bis hin zur sozialpädagogischen Arbeit mit Randgruppen in Straßenszenen und sozialen Brennpunkten (vgl. z. B. Marquardt, 2001) erscheint hier sinnvoll und notwendig. Nur so lassen sich produktive Antworten auf problematisches Verhalten im Kontext Schule, aber auch auf Schulverweigerung und Schulabsentismus (vgl. z. B. Thimm, 2000) finden. Die Schulentwicklung, das heißt die gemeinsame Entwicklung und kooperative Umsetzung von pädagogischen, didaktischen, sozialpädagogischen Handlungsmodellen und Konzepten, wie auch die Erfahrungsverarbeitung, sollte sich als prozesshaft verstehen, auf das Prinzip Dialog (vgl. Bohm, 1998) setzen, die Kolleg_innen aus allen beteiligten Berufsgruppen partizipativ einbinden und somit den dauernden Wandel aktiv gestalten (vgl. z. B. Bridges, 2009; Doppler und Lauterburg, 2002; Kotter, 2012). Schulen sollten sich dabei als lernende, sich selbst reflektierende Organisationen (vgl. z. B. Senge, 2006; Senge et al., 1994, 2012) verstehen, in denen frei gedacht werden kann und wo die brennenden Fragen tatsächlich angesprochen werden können, wo kooperative Strukturen aufgebaut werden, etwa in Form von gemeinsamer Beratung, Fallberatung oder Co-Teaching und wo Raum für Kreativität und Innovation entsteht, wo organisatorische Transformationsprozesse reflektiert werden (vgl. z. B. Fatzer, 2005; Schein, 2005 a, b). Kollektives Lernen benötigt Aufmerksamkeit, Raum und Wertschätzung, etwa anhand der Learning History oder Lerngeschichte (vgl. Kleiner und Roth, 2005; Roth, 1996). Das hiermit verbundene sich selbst Hinterfragen wird dann an einer Schule leichter sein, wenn die dortigen Leitungskräfte, neben dem transaktional-organisierenden Know-how, das sie natürlich auch benötigen, um ihren vielen Aufgaben gerecht zu werden, über transformative und philosophische Führungsfähigkeiten verfügen. Solche Führungskräfte werden auf die konsequente Unterstützung und das Empowerment der Kolleg_innen setzen und die Weiterentwicklung des gesellschaftlichen und globalen Ganzen im Blick haben.

Die Entwicklung einer lernenden Organisation erfordert daher einen ganz bestimmten Führungsstil. Doch diese Voraussetzungen sind nicht immer gegeben, weshalb es ratsam ist, sich auch mit Mikropolitik und Macht in Organisationen zu beschäftigen (vgl. z. B. Ball, 2012; DeCelles et al., 2012; Greene, 2004; Lindle, 1994; Neuberger, 1995), speziell auch mit Aggression, Destruktivität und Mobbing in Lehrerkollegien und 
anderen pädagogischen Organisationen (vgl. z. B. Baron und Neuman, 1996; Keashley, 1998, 2001; Leymann, 1990; Neuman und Baron, 1998; Schnall, 2009) sowie mit den dunklen Seiten schulischer Führung (vgl. z. B. Blase und Blase, 2002, 2003; Blase et al., 2008), speziell in autoritären, teils paramilitärischen pädagogischen Systemen (vgl. z. B. Archer, 1999), in denen eine Ideologie des hart Durchgreifens (vgl. z. B. Zirkel et al., 2011) vorherrscht. Gelegentlich sind besondere Anstrengungen nötig, das Schulganze konstruktiv zu beeinflussen. Eine wichtige Komponente ist dabei die Professionalisierung der Lehrkräfte. In dem Maße, wo sich diese als handlungsfähig und selbstwirksam erleben, werden sie weniger zu Machtmissbrauch und Gewaltanwendung neigen (vgl. z. B. Khoury-Kassabri, 2012). Humor und Satire können starre Strukturen aufbrechen. Doch mit all diesen Überlegungen und Weiterentwicklungen kommen Schulen in der Gegenwart immer mehr an ihre Grenzen. Die politischen und administrativen Steuerungsmechanismen werden immer umfassender und raffinierter, wodurch der Druck auf die Schulen wächst. Schulen haben derzeit zusätzlich Aufgaben zugewiesen bekommen, die früher zum Familienleben gehörten, etwa Ganztagsbetreuung oder das Servieren eines Mittagessens. Vielfach sind Schulen, insbesondere im Nachmittagsbereich, zu bloßen Aufbewahrungsorten für Kinder geworden. Das, was sie dort machen, ist oftmals mehr Beschäftigung als aktives Lernen. Das ist kein Vorwurf an die pädagogischen Fachkräfte, die an den langen Nachmittag all die Stunden irgendwie gestalten müssen. Häufig werden diese Stunden aber mit niedrigschwelligen Aktivitäten gefüllt, weil es auch gar nicht anders geht. Wer hätte die Kraft etwas anderes zu versuchen? Meine Kritik richtet sich gegen das System, dass sowas überhaupt gemacht wird, dass sowas überhaupt als notwendig erscheint und kein Mensch über Alternativen nachzudenken scheint. Eine größer werdende Gruppe von Kindern und Jugendlichen zeigt zugleich eine mangelnde Anpassungsbereitschaft und teils breit gefächerte emotionale und soziale Problematiken. Diese anwachsenden Schwierigkeiten lassen sich, neben vielen anderen Faktoren, die hier einwirken, zum einen als Ergebnis mangelnder Verankerung in stabilen sozialen Kontexten, zum anderen auch als Widerstand gegen die Zunahme systemimmanenter Kontrollmacht interpretieren. Ein Ausweg aus diesem Dilemma könnte die Aufhebung der Schulpflicht und deren Umwandlung in eine selbst auszugestaltende Bildungspflicht sein. Wichtig ist, dass der Druck aus dem System herausgenommen wird. Dieser, ohnehin schon massive, Druck ist noch einmal enorm angewachsen, durch die politische Forcierung der Inklusion, insbesondere in Zusammenhang mit emotionalen und sozialen Problematiken. Hätten wir geeignete, bildungsorientierte Projekte außerhalb der curricularen Enge des Schulsystems, könnten all diejenigen, die darin nicht zurecht kommen oder denen die dortigen Strukturen zu einengend erscheinen, sich Alternativen suchen. Durch die Erfahrung der Selbstbestimmung und Selbstgestaltung des eigenen Lebens würden diese Heranwachsenden auch zu neuer Lernmotivation gelangen. O'Donohue (1998, S. 9) entwickelt einige recht bedeutsame Gedanken zum Thema der sozialen Community. Zunächst gilt es, die Idee, solche neuartigen Communities entstehen zu lassen, überhaupt erst einmal zu beleben. Sodann führt er aus, welches enorme Potenzial er in einer Community sieht, in der sich Menschen freiwillig zusammengeschlossen haben. Communities müssen jedoch mit Sorgfalt entwickelt werden. Sie bauen sich quasi langsam von innen auf. Da jede Community eine gewisse Anpassung von uns fordert, gilt es auch, seinen eigenen Raum zu wahren und der Community keinen alles beherrschenden Stellenwert zu geben. Es muss eine gute Balance gefunden werden 
zwischen kollektivem und individuellem Raum. Es müssen daher, aus der Sicht von O’Donohue, bei aller Wertschätzung des Community-Gedankens, auch individuelle, persönliche Räume aufrechterhalten bleiben, in die sich jeder zurückziehen kann.

\section{Kreativität und Imagination}

Entwerfen wir für die Zukunft neue gesellschaftliche Formationen, in denen nicht nur gelernt, sondern zugleich auch gearbeitet und gelebt wird, Projekte, in die junge Menschen gehen können, wenn sie in den überregulierten staatlichen Schulen der Gegenwart nicht mehr zurechtkommen oder dort kaum eine Passung mit ihren eigenen Lernbedürfnissen feststellen. Diese Projekte könnten zunächst über bedingungslose Grundeinkommen, die alle beteiligten Menschen ja beziehen, sowie einige ergänzende staatliche Starthilfen in Gang kommen. Vergleichbare Gelder zum Anschub von Projekten werden ja auch jetzt schon in zahlreiche gesellschaftliche Bereiche investiert. Mit der Zeit können sich die neuen Projekte etablieren und aus eigener Kraft weiterentwickeln, ein eigenes Profil ausprägen, sich drehend etwa um ein bestimmtes Handwerk, eine Dienstleistung, eine industrielle Fertigung, eine bestimmte Form der Landwirtschaft, des ökologischen Anbaus, eine künstlerische oder schöpferische Produktion. So werden in den verbleibenden öffentlichen, wie auch in diesen neu anlaufenden Projekten, Kreativität, Innovation und Entrepreneurship eine herausgehobene Rolle spielen. Schon in der Gegenwart lassen sich, in einer Metropole wie Berlin, experimentelle Räume für Ideenentwicklung, Denkfabriken, Creative Labs ausfindig machen, auch in vielen anderen Städten und ländlichen Regionen in Deutschland. Nur, all diese kreativen, zukunftsorientierten Projekte können noch nicht von Kindern, Jugendlichen und Erwachsenen als Bildungs- und Lebensorte gewählt werden. Das jedoch würde all diesen Projekten enormen Auftrieb geben. Es gilt daher, mehr denn je, Kreativität und zugleich unternehmerisches Denken in interdisziplinärer Sicht zu betrachten, über alle Fachgebiete hinweg (vgl. z. B. Ambrose, 2017; Kaufman et al., 2017), Kreativität im kulturellen Kontext zu sehen (vgl. z. B. Glaveanu, 2017) und weiter zu entwickeln, aber auch Kreativität in Schulklassen zu fördern (vgl. z. B. Beghetto et al., 2015) etwa über Teaching Outside of the Lines (vgl. Johnson, 2015). Was wir im Moment jedoch überwiegend haben, ist das genaue Gegenteil. Alle Menschen, die sich in schulischen oder schulbezogenen Bildungssystemen befinden, gleichgültig auf welcher Ebene, sollen, immer noch stärker, in immer noch engere Bahnen, hineinsozialisiert werden. Teaching Outside of the Lines, wie Johnson es nennt, erscheint da regelrecht therapeutisch für ein staatliches System, das daran gewöhnt ist, alles vorzuschreiben. Ich gebe dieser überkommenen Mentalität auch keine 15 Jahre mehr. Das alles wird anfangen zu bröckeln und sich schrittweise verändern. Was wir aber dringend benötigen, sind Menschen die eigenverantwortlich und schöpferisch denken und handeln und die nicht bloß vorgegebene Regeln befolgen. Anders als bei der funktionalistischen, auf Kontrolle gerichteten Denkweise gilt daher Imagination als ein wichtiger Schlüssel, denn sie öffnet Möglichkeitsräume und ist offen für das Unbekannte. In den Texten von John O'Donohue können wir sehr viel Bedeutsames zur Imagination lesen. Menschen mit einer ausgeprägten Imaginationsgabe können Multiplikator_innen bei der Transformation der Bildungs- und Arbeitswelt in Richtung von mehr Inspiration und Engagement sein. 


\section{Selbstentfaltung statt Selbstoptimierung}

Die Tätigkeit als Lehrer_in an den heutigen Schulen wird in der öffentlichen Wahrnehmung, aber auch in der Literatur, generell mit einem hohen Stresslevel verknüpft, denn diese Arbeit stellt hohe Anforderungen an die eigene Fachlichkeit und Resilienz. Dies gilt speziell für die Tätigkeit im Schwerpunkt der emotionalen und sozialen Entwicklung, gleichgültig, ob es sich um ein inklusives oder ein spezialisiertes, separatives schulisches Setting handelt. Ein Teil dieser Anforderungen resultiert aus den besonderen Merkmalen der Zielgruppe von Kindern und Jugendlichen mit einer emotionalen und sozialen Thematik. Ein weiterer Teil dieser Anforderungen ergibt sich aus der ständigen Notwendigkeit mit Kolleg_innen, Dienstvorgesetzten auf den verschiedenen Ebenen, Eltern und professionellen Partner_innen in benachbarten psychosozialen Feldern zusammenzuarbeiten und sich auf all diese Menschen und ihre Erwartungen einzustellen und sich mit ihnen fachlich auszutauschen. Neben das fortwährende Unterrichten, Beraten, Ermutigen, Lenken, Intervenieren, Kontrollieren oder Beaufsichtigen und all die, sich hieraus ergebende, Dauerkommunikation, tritt die schulische Mikropolitik, das kollegiale Miteinander, das Aushandeln der Richtung, in die die Schule gemeinsam gesteuert werden soll. Dieser Prozess verlangt manchmal klare Positionierungen von uns, manchmal auch Anpassung und Mitschwimmen mit einer Mehrheit, oder die bloße Akzeptanz der Entscheidungen von Politik, Schulaufsicht, Schulverwaltung oder Hochschulleitung. Wieviel Freiheit und Selbstbestimmung sind also möglich in Anbetracht der gegebenen Systemzwänge, um diesen von Hartmut von Hentig (1969) geprägten Begriff hier erneut ins Spiel zu bringen? Allgemeine Dynamiken, die in der Gesellschaft, in Politik und Verwaltung sowie im Schulsystem herrschen, wirken sich ebenfalls aus. Aus Anforderungen können Belastungen und Stress resultieren, bis hin zu Burnout und persönlichen Krisen. In Deutschlands schulbezogenen Verwaltungen lagern, freilich im Verborgenen, gewaltige Bestände an diesbezüglichen Berichten, Stellungnahmen, Gutachten. Sie könnten einmal anonymisiert, gesammelt und dann wissenschaftlich ausgewertet werden. Eine umfangreiche Literatur legt nahe, solchen Tendenzen schon frühzeitig entgegenzuarbeiten, durch Selbstreflexion und Selbst- und Stressmanagement. Dabei können Coaching und Supervision helfen, auch das Verfassen von Tagebüchern, oder die künstlerische Verarbeitung. Es gilt, sich Kraftquellen oder Gegenwelten zu erschließen, durch Aktivitäten mit Partner_innen, Freund_innen, den eigenen Kindern, Sport, Kunst, Musik, Literatur, Film, Mode, Reisen, Hausbau, Gartengestaltung, Kochen, Philosophie, Religion, Yoga, Meditation oder Tai Chi. Für mich waren das, unter anderem, Aufenthalte im entschleunigten Süden Italiens, auf Procida oder Ischia, Wanderungen in Cornwall, Südwestirland oder in den Bergen um Sils-Maria.

Auch der kontinuierlichen, weiteren fachlichen Professionalisierung, im Sinne von Lifelong Learning, wird in der Literatur eine hohe präventive Bedeutung zugemessen, zur Stärkung der Resilienz. Denn wer sich als handlungskompetent und selbstwirksam erlebt in seiner pädagogischen Arbeit, hat, aus der Sicht der Forschungsliteratur, schon weniger Stress zu erwarten, weil er/sie besser zurechtkommt, in der Bewältigung der sich stellenden Anforderungen. Aber das heißt auch, sich immer weiterbilden, lesen, denken, neu entwerfen, immer am Ball bleiben, niemals sich auf einem einmal angeeigneten Wissen ausruhen, immer neue Perspektiven einnehmen und sich klarmachen, dass der Wissensstand von heute schon morgen überholt ist. Man- 
che Lektüren, die wir unternehmen, ändern soviel. Warum soll ich Prousts Aufder Suche nach der verlorenen Zeit erst im vermeintlichen Ruhestand lesen? Etwa, weil ich jetzt keine Zeit dafür finde? Was für ein Universum uns Proust eröffnet! Wenn wir das jetzt kennen, werden wir auch eine andere Perspektive auf unser Leben und unsere Arbeit einnehmen. Eine Gegenwelt also, zu all dem Stumpfsinn in den Institutionen erschließt sich in diesem, scheinbar endlosen, Roman! Ein Grand Hotel in Balbec, irgendwo am Atlantik und seitenlange Beschreibungen des Himmels und des Wassers und des Lichts und des Spiels der Wolken, da draußen vor dem Balkon, über dem Meer. Zeit im Überfluss. Nur wir laufen hier so im Rädchen. Faszinierend Elsa Morantes Roman über Arturo, der über das Inselchen Procida, ein wahres Refugium im Golf von Neapel, streift, der gar nicht zur Schule geht und autodidaktisch in Büchern liest und sich so selbst bildet. Eine Büchersammlung, die sich in einem barocken Palazzo befindet, der durch einen unerwarteten Erbfall in die Hand des Vaters gekommen ist. Allerdings ist der Vater viel abwesend. Der Junge hat sehr viel Autonomie, einen Hund hat er auch und die vielen Bücher. Diese Art des autodidaktischen, selbstbestimmten Lesens und Studierens ist ja auch Thema von Nassim Nicholas Taleb (2020), in seinem Buch Antifragilität. Ja wir sollten mehr lesen, aber immer auch außerhalb unserer eigentlichen Fachgebiete, autodidaktisch, selbstbestimmt, eigenwillig. Wieviele Protagonist_innen in Wissenschaft und Praxis sind aber in längst überholten Denkwelten hängengeblieben! Es gibt Akteur_innen die auch 2020 noch dieselbe empirischquantitative Verengung der Sonderpädagogik verkörpern, wie sie bei einer Teil-Szene des Faches schon in den 8oer Jahren sichtbar wurde. Bei einem Berufungsverfahren bestand eine Mittelbauvertreterin darauf, dass die neu zu berufende Professor_in in erster Linie die systemische Beratung zu betreiben hätte, vermutlich nur weil der Vorgänger, an den sie sich gewöhnt hatte, das komplette Studium im Feld der emotionalen und sozialen Entwicklung eben mit systemischer Beratung bestritten hatte. Selbst wenn die systemische Beratung auch weiterhin ein wertvoller Baustein in dieser pädagogischen Arbeit ist und sein wird, so erscheint es doch, bei dem komplexen Wissen, das wir heute in unserem Fach haben, nicht länger zulässig, dieses allein von hier aus $\mathrm{zu}$ entwerfen und letztlich darauf zu beschränken. Die pädagogische und psychologische Forschung hält nun Anregungen für die aktive Bewältigung der Anforderungen bereit, die der Lehrberuf an Schulen mit sich bringt, unter Stichworten wie Mindfulness oder Self Awareness.

Impulse für eine kritische Reflexion, die auch die eigene Motivation und Rolle und das gesamte System, mit seinen teils engen, konditionierenden Strukturen, hinterfragt, in dem Lehrer_innen funktionieren müssen, gibt uns dagegen die Philosophie. Konzepte wie Gelassenheit, etwa ausgehend von Epiktet oder Kohelet, aber auch $\mathrm{Hu}$ mor, erscheinen als hilfreich, in Anbetracht der nie endenden Anforderungen und Erwartungen, die an Lehrkräfte gestellt werden und die an die Situation des Sysiphos erinnern. Es kann jedoch in Zukunft nicht mehr allein darum gehen, dass Lehrkräfte oder Pädagog_innen immer noch resilienter werden, dass sie sich immer weitergehend optimieren, dass sie sich immer effektiver managen, damit ein reformbedürftiges Bildungssystem fortbestehen kann. Bedauerlicherweise ist die Selbsterfahrungsbewegung, die mit dem Psychoboom der 7oer und frühen 8oer Jahre und einer regelrechten Therapeutisierung der Gesellschaft einherging, mittlerweile zu weiten Teilen durch die Neue Steuerung vereinnahmt worden. Was einst unter der Flagge der Selbstbefreiung, der Emanzipation, der Systemkritik, der Demokratisierung begann, mün- 
dete inzwischen ein in eine Technologie der immer weiteren Selbstoptimierung und Ökonomisierung des Selbst. Es ist nun an der Zeit, das staatliche Bildungssystem auf allen Ebenen zu überdenken und zu verändern, es zu öffnen, es menschlicher, kreativer, schöpferischer, entspannter, gesünder und damit auch nachhaltiger zu machen. Deshalb sollten wir lieber von Selbstsorge im Sinne von Seneca oder Foucault sprechen und das Ganze nicht länger als Selbstoptimierung oder Resilienztraining, nicht mehr als Selbstmanagement auffassen, um den, immer weiter steigenden, Anforderungen gewachsen zu sein und immer perfekter den Erwartungen zu entsprechen, die das System an uns stellt. Allein die Begriffe Selbstoptimierung, Resilienztraining und Selbstmanagement sind schon kritisch zu hinterfragen. Das ist eine technische Sprache, eine Wirtschaftssprache, eine funktionalistische Sprache, die den Menschen und seinen Körper instrumentalisiert und zum Objekt macht. Wir müssen vielmehr die strukturellen Entstehungszusammenhänge dieser Anforderungen in den Blick nehmen, um diese zu verändern und durch Besseres und Anderes zu ersetzen. Es erscheint an dieser Stelle sinnvoll sich mit der Philosophie als einer Kunst der Lebensführung, als einer Lebenskunst zu beschäftigen, damit das Ringen um ein selbstbestimmtes Leben tatsächlich Erfolg und die Sorge um sich eine Chance hat. Als ungünstig erscheint aus der Sicht von Seneca, in dem Zusammenhang, eine unersättliche materialistische Habsucht, eine mühevolle Geschäftigkeit, das Verschwenden unserer Zeit an nutzlose Aufgaben und ein übersteigerter Ehrgeiz, der immer auch vom Urteil anderer abhängt (vgl. Decher, 2012, S. 68). Zur menschlichen Natur gehört sowohl das aktive Arbeiten, Herstellen, Handeln, im Sinne von vita activa, wie auch das untätige Betrachten, im Sinne von vita contemplativa. Es gilt beides in ein gutes Verhältnis zu bringen (vgl. Arendt, 2002; Decher, 2012, S. 75).

Während das Konzept der Kontemplation, denken wir an Meister Eckhart, historisch betrachtet, auch eine ausgeprägte christlich-geistliche Richtung bekommen hat, wird in neueren Publikationen die Bedeutung der Muße und Langeweile hervorgehoben (vgl. z. B. Decher, 2000, 2020; Hodgkinson, 2005, Simon, 2007). Arbeit und der dadurch mögliche Konsum werden in der Leistungsgesellschaft oft genug zu zwanghaften Lebensprogrammen, ja regelrecht zu Fetischen, die ein betrachtendes, meditatives, untätiges, reflexives und dadurch auch schöpferisches Leben verhindern. Henry David Thoreau hat mit der 1854 erschienenen Niederschrift von Walden wichtige Impulse gegeben, aber auch Heinrich Böll mit seiner 1963 veröffentlichten Anekdote zur Senkung der Arbeitsmoral. Friedhelm Decher (2020) analysiert in seinem Essay Eine Gesellschaft, die keine Zeit hat, lebt nicht den Zusammenhang zwischen Zeitnot, Ökonomie und Muße. Greifen wir erneut auf Senecas, aus der römischen Antike stammenden, Anleitungen zur Lebenskunst zurück, so gilt es, den Augenblick zu genießen und sich immer auch mit dem Sterben zu befassen (vgl. Decher, 2012, S. 75). Wir sollten versuchen Körper und Geist, soweit wie möglich, gesund zu erhalten und uns in die Umstände schicken, aber nicht zu Sklaven werden (Decher, 2012, S. 68 f.). In einem sehr lesenswerten Buchkapitel hat Friedhelm Decher (2020, S. $47 \mathrm{ff}$.), unter Rückgriff auf Arbeiten des Schweizers Ivo Muri, den Unterschied zwischen der »Zeit der Uhren«, der "Zeit des Lebens« und der »Zeit der Wirtschaft« dargelegt. Nach seiner Analyse leben wir allzusehr in der Zeit der Wirtschaft, wobei Zeit mit Geld gleichgesetzt wird und auch die Kompetenzorientierung und Standardisierung, die wir zunehmend im Bildungssystem, durchaus auf allen Ebenen, feststellen können, resultiert ja aus der hieraus entspringenden Rastlosigkeit, indem wir meinen, jede Minute Lernzeit ausnut- 
zen zu müssen. Leider schauen wir dabei zuwenig in den Himmel und in die Sterne. "Gestern betrug ich mich schlecht im Kosmos. Den ganzen Tag lebte ich, ohne zu fragen, ohne mich über etwas zu wundern«, notierte Wisława Szymborska (2012, S. 32). Ausgehend von Michel Foucault und Bertrand Russell kommt Decher zu dem Schluss, das es jetzt mehr darauf ankomme, eine Art schöpferischer Muße zu kultivieren und »dem Dasein Fülle zu geben« (a.a. O., S. 61). Viele von uns haben dies schon lange verlernt. Aus Thoreaus, in der Einsamkeit des Waldes und am Walden See geschriebenen, Tagebuch lässt sich da einiges an Anregungen schöpfen. Alles, was ich hier herangezogen, diskutiert und niedergeschrieben habe, impliziert jedoch, dass ich durch eigene mentale Veränderungen, und daraus resultierend, durch meine Haltung, die von mir verwandten Denkmuster und eingesetzten Strategien, etwas bewirke.

Ich muss jedoch auch in Betracht ziehen, dass mein Bewusstsein durch meine materiellen Lebensumstände, durch die sozialen und ökonomischen Rahmenbedingungen, unter denen ich eben lebe und arbeite, geprägt ist. Dieser Zusammenhang wurde von Marx und Engels wie folgt auf den Punkt gebracht: »... nicht das Bewusstsein bestimmt das Leben, sondern das Leben bestimmt das Bewusstein« (vgl. Marx und Engels, 1983, S. 27; zit. n. Jantzen und Lanwer, 2012, S. VII). Der Begriff Leben ist an dieser Stelle gleichzusetzen mit den gesellschaftlichen Reproduktionsbedingungen, die eben auf die Bewusstseinsprozesse der Akteur_innen wirken und diese prägen. Aus diesem Zusammenhang lässt sich weiter ableiten, dass wir andere Rahmenbedingungen zum lernen, arbeiten und leben brauchen, als wir sie derzeit haben, um andere Bewusstseinszustände bei den Bürger_innen dieses Landes zu erreichen. Egon Friedell (1996, S. 60), ursprünglich notiert wurden diese Zeilen ja in den Jahren 1927 bis 1931, beschreibt das Problem unseres ambivalenten Verhältnisses zur vergehenden Zeit wie folgt: »...flüchtig und unheimlich, gestaltlos und unergründlich, ein Schnittpunkt zwischen zwei drohenden Ungewißheiten: einer Vergangenheit, die nicht mehr ist und trotzdem noch immer in unser Jetzt hineinragt, und einer Zukunft, die noch nicht ist und dennoch bereits beängstigend auf unserem Heute lastet; die Gegenwart aber fassen wir nie. Die Zeit also ... gehört uns nicht. Wir wollen sie besitzen, und stattdessen sind wir von ihr besessen, rastlos vorwärts gehetzt nach einem Phantom, das wir >morgen nennen und das wir niemals erreichen werden. Aber gerade darum ist der Mensch unermüdlich bemüht, die Zeit zu dividieren, einzuteilen, in immer kleinere und regelmäßigere Portionen zu zerlegen.«Diese Tendenz haben wir in unserer funktionalistischen, von Kontrolle, Management und Monitoring dominierten, Gesellschaft immer weiter perfektioniert. Jede der 45 Minuten einer Standard-Unterrichtsstunde muss als wertvolle Lernzeit genutzt werden. Wenn ich unter heutigen Bedingungen wieder Schulleiter geworden wäre, was ich noch zwischen Oktober 2019 und Februar 2020 in Betracht gezogen habe, sagen wir, weil mir gewisse Prozesse und Strukturen in der akademischen Welt einen gewissen Überdruss bereitet haben, dann hätte ich immerzu dafür Sorge tragen müssen, dass die Lehrer_innen an der von mir geleiteten Schule auch die Lernzeit effektiv nutzen. Und andere, höher gestellte Funktionsträger_innen hätten dafür gesorgt, dass ich da auch für sorge und nicht etwa als ein freigeistiger Voltaire eine dieser Schulen, für die ich mich interessierte, geleitet hätte, sagen wir: auf meine philosophische Art. Ich hätte ins Rädchen springen müssen und jemand hätte draußen neben mir gestanden und mit einer Peitsche geknallt. Doch was ist, wenn draußen, vor dem geöffneten Fenster des Klassenzimmers ein warmer Sommerregen niedergeht? Oder wenn ein Windstoß nach innen weht oder 
wenn Wolken sich, in nie dagewesenen Formationen, am Himmel auftürmen, und einige Schüler_innen dies wahrnehmen und darin versinken? Könnten solche Phänomene und ihre Wahrnehmung nicht die Imagination beflügeln? Entstehen nicht oftmals auf diese Weise große Poesie und Musik? Kommen auf solchen Wegen nicht gelegentlich entscheidende Eingebungen, die bei der Erforschung von naturwissenschaftlichen Phänomenen eine Rolle spielen? Doch woran habe ich all das als Lehrer_in erkannt? Wie kann ich es im kompetenzorientierten Sinne, im Sinne effektiv genutzter Lernzeit, glaubhaft machen? »Am I interrupting the progress of knowledge?«, fragt der Zauberer M. L'Estrange, in Brian Friels (1999, S. 25) Kurzgeschichte The Illusionists, als er die Grundschulklasse, in einem abgelegenen Dorf, im irischen Donegal, betritt. Wie kann ich nachweisen, messen, dokumentieren, dass es womöglich eine Inspiration, eine Stimulierung der Imagination, in dem Augenblick gegeben hat, und ich sogar selbst staunend innehielt, weil ich meinte, all dies zu erkennen, einschließlich der möglichen Wirkung auf einen Teil der Schüler_innen, zumindest auf einige von ihnen? Wurden diese 10 Minuten Lernzeit nun adäquat genutzt? So ist aber die Denkweise in den heutigen Staatsschulen, genau so werden die Lehramtsanwärter_innen und Quereinsteiger_innen trainiert. Doch wird das alles nicht zu guten Ergebnissen führen. Das Gegenteil ist der Fall. »Erfunden die Gestalt, eingebildet die Eile, « notierte Wisława Szymborska (2012, S. 32).

\section{Gesellschaftliche Transformation, globale Veränderung und nachhaltige Entwicklung}

Betrachten wir nun die globalen Herausforderungen in bezug auf lokale Problematiken, Risiken, Prozesse, soziale Dynamiken und politische Implikationen, so geht es in Zukunft, um es mit Gert Hofstede (2017) zu sagen, darum global zu handeln, aber lokal zu denken. Zunehmend hat die Digitalisierung Einfluss auf ganze Staaten. Regierungen stehen mehr und mehr in Rivalität mit privaten Protagonist_innen, die sich in der digitalen Welt äußern (vgl. Boehme-Neßler, 2009) und das Geschehen beeinflussen, über ihre Twitter-, YouTube- oder Instagram-Präsenzen, über Blogs, oder über die Open Access-Publikation von Aufsätzen und Büchern. Dies kann problematisch sein, weil Staaten so weniger Macht haben, insbesondere dann, wenn sie instabil sind. Es kann aber auch von Vorteil sein, wenn Staaten stabil genug sind, oder gar dazu neigen zuviel zu regulieren. Denn durch das Engagement einzelner Protagonist_innen, entstehen neue Gestaltungsräume für die Zivilgesellschaft, das heißt für Einzelpersonen und Zusammenschlüsse von Personen. Wir beobachten den Kampf um Boden bzw. Land, das sog. Landgrabbing (vgl. z. B. Bommert, 2012; Daniel und Mittal, 2009), um die Ressource Wasser (vgl. z. B. Cless, 2014; Kamski, 2015), sodann Ressourcenkonflikte (vgl. z. B. Denninghoff, 2015) und Sicherheitsrisiken (vgl. z. B. Fröhlich, 2015) die daraus entstehen können. Der gesamte Problemzusammenhang von Klimawandel, Dürre, Bodenerosion, Abnahme von Biodiversität, Fluchtmigration (vgl. z. B. Brzoska und Fröhlich, 2016; Johler und Lange, 2019; Scheffran et al., 2012; Scheffran, 2017) muss hier mitbedacht werden, ebenso die Problematiken von fragilen Staaten, Krieg, Bürgerkrieg, Korruption, Ausbeutung von Staaten, Demokratieverfall, eskalierenden ethnischen Konflikten und Staatszusammenbrüchen (vgl. z. B. Goldstone, 2008; Rotberg, 2004). Wollen wir wirklich einen gesellschaftlichen Neuentwurf, zugleich mit globaler, 
nachhaltiger Perspektive, dann müssen wir auf so vielen Ebenen gleichzeitig ansetzen und etwa für eine nachhaltige Landwirtschaft und Ernährung (Slow Food) eintreten (vgl. z. B. Bommert und Landzettel, 2017; Engler et al., 2016). In globaler Perspektive rücken auch die lokale Welt und der Übertourismus in den Blick. Wir brauchen hier veränderte Perspektiven und Konzepte (vgl. z. B. Pechlaner, 2019; Scherle, 2020). Wenn immer mehr Kreuzfahrtschiffe die Luft und die Meere verpesten und kulturell sensible und ökologisch vulnerable Orte mit Touristenmassen überschwemmt werden, weil bestimmte wohlhabende Schichten immerzu Spaß, Abwechslung und Zerstreuung suchen, spiegelt das die gesamte Misere wider, in der wir uns befinden. Menschen, die vermutlich unter wenig sinnstiftenden Bedingungen ihr Geld verdient haben, wenn sie es nicht bloß geerbt oder passiv vermehrt haben, buchen oftmals solche an externer Animation orientierten Reisen. Diese Reisekonzepte dürften aber kaum dazu beitragen, die stereotype Wahrnehmung von anderen Kulturen zu durchbrechen und sich tatsächlich tiefergehend mit den sozialen und kulturellen Besonderheiten der besuchten Ländern zu beschäftigen, indem man/frau sich ihnen wirklich aussetzt. Eher werden unterhaltsame, oberflächliche Stippvisiten oder aber reine Wellnessaufenthalte unternommen, bevor man/frau zum Buffett, Deckchair oder Pool zurückkehrt. So wie viele dieser Menschen unter entfremdeten Bedingungen arbeiten und leben, so reisen sie auch unter entfremdeten Bedingungen. Dadurch halten sie Wirtschaftssysteme in Gang und bescheren anderen geografischen Räumen zugleich vielerlei Nachteile, einmal ganz abgesehen von den generellen globalen Problemen, die diese Art des Reisens fürs Klima und für die Ökosysteme nach sich zieht.

Zumindest die Teile der heranwachsende Generation, die sich etwa im Rahmen der Fridays for Future Bewegung (vgl. dazu Haunss und Sommer, 2020) engagiert haben, wollen diesen ökologisch schädlichen Lebensstil nicht mehr weiter fortführen. In den 8oer Jahren hatte meine Generation die Bände Anders Reisen aus dem Rowohlt-Verlag im Rucksack. Pauschalreisen ohne kritischen, explorativen Anspruch erschienen den jungen, alternativ reisenden Menschen schon zu jener Zeit als problematisch. Abgesehen davon, dass damalige Schüler_innen und Studierende die, noch recht teuren, Pauschalreisen auch gar nicht hätten bezahlen können, wurde bewusst auf Komfort bei den unternommenen Reisen verzichtet. Gereist wurde überwiegend mit Zügen, oftmals mit dem legendären Interrail-Pass, teils auch per Anhalter oder mit Bussen. Trotz allem waren die jungen Rucksackreisenden nicht in allen Ländern gerne gesehen, weil sie, im Vergleich zu den Pauschaltouristen, oder einer kleineren Gruppe von sehr wohlhabenden Individualreisenden, weniger Geld ins Land brachten, oftmals gar auf Stränden schliefen. Aber zumindest brauchten für sie keine Flugzeuge gechartert und keine Betonburgen gebaut zu werden. Sie suchten bevorzugt nach kleinen, preiswerten Pensionen, Trattorien, Cafés und Lebensmittelläden. Statt ihr Geld großen Reisekonzernen zu geben, unterstützte diese Generation von anders Reisenden kleine, lokale Läden und Familienbetriebe. Die Situation hat sich inzwischen durch die Digitalisierung und durch das reiche Angebot an preiswerten Flügen, etwa ab 2002 setzte das ja ein, und durch ein immer größeres Angebot an Kreuzfahrten usw. vollkommen verändert, ja zugespitzt. Niemals zuvor wurde von Overtourism gesprochen, doch inzwischen hören wir von etlichen Orten, unter anderem Venedig oder Barcelona, die hoffnungslos überlaufen sind. Als immer drängender erscheint die Notwendigkeit, dem Klimawandel entgegenzuarbeiten. Der Club of Rome setzt sich bereits seit 1968 für Nachhaltigkeit, für den Schutz von Ökosystemen ein und verweist, in 
den von ihm beauftragten Berichten, auf die Grenzen des Wachstums (vgl. Meadows, 1972; Meadows et al., 2015), ebenso die Global Marshall Plan Initiative. Jetzt gilt es solches Denken seitens der Wissenschaftsdisziplinen aufzugreifen. Es besteht also ein subtiler Zusammenhang zwischen konsumorientierten Reisekonzepten, Formen der Geldanlage, die etwa Landgrabbing und Gentrifizierungsprozesse vorantreiben und den raffinierten Steuerungs- und Kontrollmechanismen, denen wir in unseren Bildungssystemen unterliegen, und bei denen unsere Mitarbeit als Pädagog_innen und Wissenschaftler_innen erwartet wird. Das sind ja genau diejenigen Prozesse, die dazu dienen, uns alle miteinander in genau diese konsumorientierte, unökologische, funktionalistische, entfremdete Arbeits- und Lebensweise hineinzusozialisieren.

Wollen wir die Heranwachsenden, seien es Kinder im Grundschulalter, Jugendliche an Sekundarschulen oder Universitätsstudierende, wirklich auf diese Art in die Spur bringen und zu diesem Zweck unsere raffinierten Techniken des Behavior Managements einsetzen? Wollen wir weiter an ihrer Konditionierung mitwirken und ihnen ihre Flügel stutzen? Wollen wir ihnen systematisch das kritische Denken abgewöhnen, indem wir sie durch, eng entworfene Lerncurricula und Wissensmodule schleusen? Wollen wir ihnen beibringen egoistisch nach vorne zu drängen, die Ellbogen zu spreizen und sich durchzukämpfen, um dann später, mit den angehäuften Geldern, in Landgrabbing, in die Gentrifizierungsprozesse in den großen deutschen Metropolen oder in Kreuzfahrten investieren zu können? Wollen wir zusehen, wie sie gleichzeitig passiv und abhängig werden? Wie sie einfach damit aufhören, selbstständig zu denken und mögliche Risikoszenarien durchzuspielen, indem sie, selbst während der Covid-19-Krise, Pauschalreisen buchen und dann erwarten, dass sich die Bundesregierung, liebevoll sorgenden Eltern gleich, sie alle wieder ins sichere Deutschland zurückfliegt? Besser wir betrachten die anwachsende Unlust von immer mehr jungen Menschen, sich in diese Bahnen hineinpressen zu lassen, als etwas sehr Wertvolles und Produktives. Dasselbe gilt für das Aufbegehren von vielen Jugendlichen in unzähligen Schulen, die sich dort verweigern und nicht mehr mitmachen wollen. Oftmals ohne Plan, sind sie einfach nur dagegen. Schließlich bleiben sie ganz weg und streunen irgendwo in der Stadt herum, weil niemand erkennt, welche Art von Gespräch und Orientierung sie wirklich brauchen. Auch das verdient unsere Aufmerksamkeit. Allerdings müssen wir mit diesen Heranwachsenden jetzt etwas Neues entwickeln. Die bloße Anwesenheit in der Schule und lernen zu wollen, im Sinne des derzeitigen Curriculums, kann dabei kaum zum pädagogischen Förderziel erklärt werden (wie etwa bei Ricking und Dunkake, 2017). Vorher muss sich substantiell etwas an den Bedingungen und den Kontexten des Lernens ändern. Es ist auch nicht damit getan, auf bloßes ontask behavior hinzuarbeiten (z. B. bei Sutherland et al., 2000). Das allein kann niemals der Sinn und der Zweck der Bildung sein. Wer gibt auch die Aufgaben vor? Werden sie überhaupt als sinnvoll erlebt? Das Gegenteil ist der Fall. Es gibt in dem ganzen pädagogischen Vokabular eigentlich kein funktionalistischeres Begriffspaar als on-task und off-task. Es geht bei diesem Schema nicht mehr um inhaltliche Sinnbezüge, es geht nur noch darum, dass ein Kind oder ein Jugendlicher die Aufgabe bearbeitet und sich konform verhält, das heißt still sechs Stunden oder gar länger, auf einem Stuhl, am Tisch, vor Arbeitsblättern, Büchern, Heften oder einem Tablet oder Laptop sitzt.

Mit den sich verweigernden Heranwachsenden müssen wir jetzt aber andere Dinge tun. Dinge, die eben darüber hinausgehen, die die derzeitigen, überaus engen, institutionellen Handlungsrahmen weit übersteigen. Je mehr das Good Behavior Game in 
deutschen Schulen gespielt wird, umso besser wird sich ein großer Teil der Deutschen benehmen, denken wir vielleicht. Ein großer Teil aber auch nicht. Wenn dann niemand mehr daneben steht und ein lückenloses Monitoring garantiert und beständig verstärkende Creditpoints zuweist, läuft es bekanntermaßen, in den meisten Fällen, ganz anders. Ich könnte Hunderte von Seiten mit Dingen füllen, die alle anzeigen, dass das Alltagsleben, selbst unter Erwachsenen, voller problematischer Verhaltensweisen sein kann. Ein Heer von Rechtsanwält_innen und eine Vielzahl von Gerichten sind pausenlos damit beschäftigt, all das, was diesbezüglich in der Gesellschaft geschieht, zu regulieren und zu lösen. Gutes, verantwortliches, rücksichtsvolles Verhalten basiert auf guten Charakteren, auf stabilen Persönlichkeiten, auf dem Bilden von inneren Werten, nicht aber auf der äußerlichen, apparativen Verhaltenssteuerung, nicht auf Behavior Management. Die Menschen passen sich in Anbetracht solcher Systeme nur so lange an, wie sie es müssen, weil sie sonst sanktioniert werden. Aber sie werden auch zu passiven, ängstlichen, oftmals auch unterschwellig aggressiven, jedenfalls nicht selbstständig nachdenkenden Individuen. Solche Menschen ahnen zwar, dass sie ihre ureigene Freiheit aufgegeben haben. Dafür erwarten sie aber eine Totalversorgung. Mindestens zwei Mal im Jahr, wenn nicht gar öfter, eine Flugreise buchen, irgendwo im Süden, am Meer, in einem Hotel absteigen, dort ein passives Strandleben, ein konsum- und animationsorientiertes Nachtleben führen, sich einmal richtig austoben und gehenlassen usw. Den übrigen Teil des Jahres fügt man/frau sich zu Hause in ein eher ödes und entfremdetes Arbeitsleben ein. Es geht jetzt darum, im Rahmen einer vernünftigen Pädagogik die jungen Menschen wachzurütteln, damit sie anfangen Fragen zu stellen. Die gesellschaftliche Transformation (vgl. Brie und Klein, 2011; Dörre et al., 2019; Reißig, 2019; Sommer und Welzer, 2014) hat also begonnen, in Anbetracht der globalen und lokalen Herausforderungen und die Pädagogik sollte, in Fortführung ihrer allerbesten kritischen Traditionen, ein Teil dieser Transformation sein. Als Grundlage für diesen Neuentwurf lässt sich die Agenda 2030 für nachhaltige Entwicklung heranziehen. Zu ihren Zielen gehört vor allem die Armut und den Hunger zu beenden. Es muss eine Ernährungssicherheit und eine bessere Ernährung für alle erreicht werden, in Verbindung mit einer nachhaltigen Landwirtschaft. Für alle Menschen, egal welchen Alters, gilt es, eine gute Gesundheit und Wohlbefinden zu fördern, eine qualitativ hochwertige, inklusive und gerechte Bildung bereitzuhalten und ihnen lebenslanges Lernen zu ermöglichen. Es ist von hoher Bedeutung, Frauen und Mädchen zur Selbstbestimmung zu befähigen.

Aber auch die in den westlichen Gesellschaften zunehmend marginalisierten Jungen und Männer, ich erinnere an die Phänomene, wie ich sie im Rahmen der Erkundung von virtuellen Welten beschrieben habe, ich erlaube mir diese Ergänzung des Zielkatalogs der Vereinten Nationen, dürfen nicht aus dem Blick geraten. Es gilt sauberes Wasser und Sanitäranlagen für alle verfügbar zu machen, in Verbindung mit einer nachhaltigen Bewirtschaftung. Von Bedeutung sind ferner eine ökologische, dezentralere Energiebereitstellung, die für die Menschen bezahlbar und verlässlich ist. Wichtig natürlich ein nachhaltiges Wirtschaftswachstum, in Verbindung mit menschenwürdiger Arbeit. Statt Vollzeitarbeit sollten allerdings Teilzeitbeschäftigung und ehrenamtliche Tätigkeiten in Zukunft im Vordergrund stehen, in Kombination mit dem bedingungslosen Grundeinkommen. Ein weiteres Ziel ist das Aufbauen von widerstandsfähigen Infrastrukturen und einer nachhaltigen Automatisierung, ebenso die Förderung von entsprechenden Innovationen. Die Ungleichheiten zwischen den 
Ländern sollen verringert werden. Es geht auch um die Entwicklung von inklusiven, sicheren und nachhaltigen Städten und Siedlungen. Wir benötigen ferner eine nachhaltige Produktion und einen verantwortungsbewussten Konsum. Zentrale Themen sind auch die Bekämpfung des Klimawandels, die Bewahrung und nachhaltige Nutzung der Ozeane, der Schutz und die Wiederherstellung der Landökosysteme und deren nachhaltige Nutzung, die nachhaltige Bewirtschaftung der Wälder, die Bekämpfung der Wüstenbildung und der Bodenerosion, das Erhalten der biologischen Vielfalt. Von hoher Bedeutung sind ferner die Förderung friedlicher und inklusiver Gesellschaften, das Schaffen von Zugang zum Recht für alle, das Aufbauen von leistungsfähigen, rechenschaftspflichtigen und inklusiven Institutionen auf allen Ebenen, schließlich das Aufbauen von Partnerschaften, um all diese politischen Ziele für eine nachhaltige globale Entwicklung zu erreichen, wie sie durch die Vereinten Nationen (2016) formuliert worden sind und wie sie am 1.1.2016 mit einer Laufzeit von 15 Jahren, mit Gültigkeit für alle Mitgliedsstaaten, in Kraft getreten sind.

Es geht in der Tat darum, unsere Welt neu zu denken, die Natur und das Leben neu zu betrachten, den technologischen Fortschritt, den Konsum, den Markt, den Staat, das Gemeingut, die Gerechtigkeit anders zu entwerfen (vgl. dazu auch Göpel, 2016, 2020; Kahlenborn et al., 2019). Die neuen transformativen Projekte, um die es mir hier geht, und die alternative Lernorte für Kinder und Jugendliche sein können, die im derzeitigen staatlichen Schulsystem unglücklich sind, nicht zurechtkommen und sich nicht hinreichend verwirklichen können, sind diverse, nachhaltige, inklusive Communities, im Sinne von EcoJustice (vgl. z. B. Martusewicz et al., 2015), auf der Basis demokratischer Prinzipien. Diese Projekte sind offen, zugänglich, transparent, selbstreflexiv, selbstkritisch, dialogisch, partizipativ und prozesshaft. Sie arbeiten und entwickeln sich fernab von starren Ideologien, dogmatischen Programmen, religiösen Beeinflussungen, Einflussnahmen von politischen Parteien, Kirchen, Sekten, Splittergruppen, fernab von allen Formen der Ausbeutung, Unterdrückung, Freiheitsbeschränkung, Konditionierung, Einschüchterung, Machtspielen, Selbstinszenierungen vermeintlicher Anführer, Gurus oder sonstiger Sektenführer. Kinder und Jugendliche können sich bewerben und begründen, warum sie bei einem bestimmten Projekt dabei sein wollen und was sie dort einbringen und mitnehmen bzw. lernen wollen. Einen Anspruch auf Aufnahme in einem speziellen Projekt kann es jedoch nicht geben. Nur wer in einem solchen Projekt aufgenommen wird oder in einer Art Homeschooling oder Privatunterricht von hinreichend gebildeten Eltern oder anderen Personen unterrichtet wird, sollte die staatliche Schule verlassen können. Wer nicht an einem solch neuartigen Projekt teilnehmen will, verbleibt in der Staatsschule, bis dass sich ein passendes alternatives Projekt gefunden hat oder ein solches gegründet worden ist. Natürlich kann es nicht darum gehen, dass Kinder und Jugendliche einfach auf den Straßen und Plätzen herumhängen oder in ihren Wohnungen, ohne soziale, pädagogische und kulturelle Bezüge, womöglich nur noch vor Bildschirmen sitzen. Sie müssen glaubhaft machen, zu welchem Projekt sie gehören und was sie dort tun. Die transformativen Community-Projekte müssen sich von kritischen Bürger_innen und entsprechenden Supervisionsbehörden kontrollieren lassen, sicherlich auch von staatlichen Stellen überblickt werden, damit sich nicht so merkwürdige Dinge herausbilden wie etwa die Colonia Dignidad in Chile.

Es wird also nicht ohne staatliche Aufsicht gehen. Irgendwo muss vermerkt sein, wer sich in welchem Projekt befindet und an was dort gearbeitet wird, was dort für 
ein Handwerk betrieben wird, was dort die Philosophie ist und wer dort die Gesamtverantwortung trägt. Rein sonderpädagogisch ausgerichtete Projekte kann es von der Idee schon nicht geben. Aber es werden mit der Zeit viele Projekte entstehen, die im jetzigen schulischen Sinne weniger anpassungsbereiten Jugendlichen körperliche Aktion und Handlung ermöglichen, etwa in landwirtschaftlich orientierten Feldern oder im Bereich von Technik und Handwerk. Man/frau kann sich auf Zeit oder längerfristig in diese transformativen Projekte einbringen. Die neuen transformativen Projekte sollten ein komprimiertes Programm und eine Philosophie entwickeln, niederschreiben und veröffentlichen. Nur so werden sie auch Menschen für sich interessieren und gewinnen können. Sie sollen transparent machen, woran sie arbeiten und wofür sie sich einsetzen und dokumentieren, was sie bisher erreicht haben und mit welchen Herausforderungen sie dabei zu tun haben, ohne aber Hunderte von Zielformulierungen und kompetenzorientierte Beschreibungen aufs Papier bringen und einreichen zu müssen. Wir wollen es ja jetzt einmal etwas offener und freier angehen als eben in der Staatsschule, die wir im Moment noch haben. Die Projekte müssen auch ihre Finanzierung offenlegen, am besten zur Kontrolle durch die aufgeklärte Zivilgesellschaft ihre Finanzverwaltung im Internet transparent machen. Dasselbe sollte übrigens für Schulen, Universitäten, Unternehmen und Organisationen gelten. Die Bürger_innen sollten in Zukunft wissen, wofür ihr Geld konkret verwendet wird. Nur so lassen sich Verschwendung von Mitteln und Korruption verhindern und vermeiden. Wir werden uns nicht allein auf die jetzt zuständigen Landes- und Bundesrechnungshöfe verlassen können. Die derzeitigen Systeme sind diesbezüglich intransparent. Wir wissen als Zivilgesellschaft nicht wirklich, was mit all dem Geld geschieht, das wir, über unsere Arbeit und die von uns gezahlten Steuern, aufgebracht haben. Die transformativen Projekte sind handlungs- und projektorientiert, wenn es sich anbietet, interdisziplinär oder transdisziplinär. Sie beenden Ausgrenzung und Isolation, indem auch Menschen mit Behinderung und ältere bzw. alte Menschen integriert werden, denn die Beziehung des Menschen zur Welt ändert sich tiefgreifend durch die fehlende soziale Einbettung wie Wolfgang Jantzen (2019, 2020 a) schreibt. Stattdessen arbeiten diese Projekte, um es erneut mit Jantzen zu sagen, an der Stabilisierung des menschlichen Selbst durch Dialoge und durch das Herstellen von Sinn (Jantzen 2012 b), möglichst unter Einbindung aller Lebensalter. Geht es erst einmal stärker um Emotionen und die Seele, so werden, um mit Jantzen zu sprechen, neue Resonanzerfahrungen möglich.

Kunst und Musik, auch im kollektiven oder regionalen Sinne, können bei alldem eine wichtige Rolle spielen. Ein schönes Beispiel ist für mich die Aktion, die im Küstenstädtchen Diamante, in Kalabrien, in den 8oer Jahren, zur Problematik des italienischen Südens und der Auswanderung von dort in die Vereinigten Staaten stattgefunden hat (vgl. Bröcher, 1999). Natürlich war das kein transformatives Community-Projekt, sondern eine temporäre Aktion. Aber mir geht es hier um diese Art von Bezügen und Sinnebenen, wie sie in Diamante erfahrbar wurden. Transformative Projekte können ferner Elemente von Community Learning (vgl. z. B. Field, 2011) und generationenübergreifendem Lernen (vgl. z. B. Schmidt-Hertha et al., 2014) beinhalten. Dort wo Kinder und Jugendliche beteiligt sind, können Travel Schooling wie auch das Lernen in Museen, sei es mehr im Bereich Kunst, sei es mehr im Feld der Naturwissenschaften und der Technik, eine wichtige Rolle spielen. Immer geht es um aktive Exploration und themenbezogene Interaktion. Blicken wir erneut auf Menschen 
mit Behinderungen, so ermöglichen die transformativen Projekte weitere Fortschritte auf dem Weg der Deinstitutionalisierung. Viele Menschen könnten aus den Einrichtungen der Behindertenhilfe herausgeholt und sofern sie es wünschen, eingebunden und wieder stärker ins allgemeine gesellschaftliche Leben integriert werden (Jantzen 2020 a). Dasselbe gilt für die vielen älteren und alten Menschen, die teils in Pflegeheimen isoliert vor sich hin leben. Auch sie ließen sich hier einbinden und mit ihrer Lebenserfahrung wieder stärker wertschätzen, als es jetzt der Fall ist. O'Donohue zeigt auch auf, dass ältere Menschen viel Erfahrung, ja Weisheit, in solche Communities einbringen können. Je nach Projekt, ließen sich dort auch einige alte Menschen bis zum Tod pflegen. Enrique Dussel hat sehr treffend zum Ausdruck gebracht, dass es hierbei aber keineswegs um das geht, was bisher unter dem reichlich verbrauchten und bis zum Überdruss verwendeten Wort Inklusion verstanden wird: »Die Ausgeschlossenen sollen nicht ins alte System eingeschlossen werden ... sondern als Gleiche in einem neuen institutionellen Moment ... partizipieren. Man kämpft nicht für die Inklusion, sondern für die Transformation « (vgl. Dussel, 2013, These 14.13; zit. n. Jantzen, 2019, S. 283).

Das ist hier eben der entscheidende Punkt: Es wird etwas Neues geschaffen und das alte System wird dabei transformiert. Letztlich müssen wir, um erneut mit Enrique Dussel zu sprechen, »alle politischen Systeme, Handlungen und Institutionen als nicht zukunftsfähig kritisieren und verwerfen, unter deren negativen Auswirkungen Opfer als Unterdrückte und als Ausgeschlossene leiden!« (Dussel, 2013, S. 107; zit. n. Jantzen, 2019, S. 144). Dies trifft in weiten Teilen auch auf die heutigen Staatsschulen zu. In ihnen gibt es immer noch viel Unglück und seelisches Leiden. Doch es existiert oftmals kein gangbarer Weg nach draußen. Vor allem kann eine Zwangsinklusion, unter ungeeigneten systemstrukturellen Bedingungen, schon gar nicht die Lösung sein. Dabei kommen dann solch merkwürdige Dinge wie das TrainingsraumProgramm heraus, oder all die außerhalb von Klassenzimmern liegenden Inselräume, Lernoasen oder Lernbüros. Viele Familien können aber diesem, immer ungemütlicher werdenden, System der Staatsschule nicht entfliehen. Eine Privatschule können sich nicht alle leisten und selbst die Privatschulen befinden sich noch unter staatlicher Schulaufsicht. Sie können zwar etwas anders, aber nicht völlig anders arbeiten als die Staatsschulen, denn sie müssen letztlich dieselben Ziele erreichen wie die öffentlichen Schulen. Gerald Hüthers Publikationen bieten eine ganze Reihe von Anknüpfungspunkten für neue Entwürfe. Hüther verbindet mit dem Lernen in der Kommune, in der Gemeinschaft und im Dorf große Chancen. Seine Beschreibungen ähneln in vielem den von mir gemeinten transformativen Projekten. Hüther sieht in solchen sozialen Formationen die wahren Lernorte, wo Kinder und Jugendliche Verantwortung übernehmen und eine neue Art der Beziehungskultur erfahren können (vgl. Hüther, 2013). Für Hüther $(2016,2018)$ geht es darum, dass die Heranwachsenden die Freude am Lernen wieder entdecken, die in den staatlichen Bildungseinrichtungen teils zerstört und verloren gegangen ist. Es ist absurd, dass wir für die Sommerernten Menschen vorübergehend aus anderen Ländern anwerben müssen. Würden wir uns im eigenen Land anders organisieren, könnten das große, aufregende, abenteuerliche Dinge werden, wenn wir dies, unter Einbindung von schulmüden Heranwachsenden, ja überhaupt von Kindern und Jugendlichen, wieder selbst in die Hand nehmen würden. Trotz allem könnten wir dann noch ein wenig Arbeit an Menschen aus östlichen Nachbarländern abgeben und diese am besten, soweit wie es eben geht, in die Arbeit 
und das Leben der Community-Projekte einbinden. So würde das Ganze noch zu einer kulturellen, länderübergreifenden Begegnung.

Deutschland ist schon längst zu einem multikulturellen Einwanderungsland geworden. Die transformativen Projekte müssen daher kultursensibel sein, denn die verschiedenen Kulturen, mit denen wir mittlerweile in Deutschland, in Europa und in der Welt zu tun haben, gingen bisher unterschiedlich mit Individualismus und Kollektivismus, mit Gleichheit und Verschiedenheit, mit Macht, mit Maskulinität und Feminität um (vgl. dazu Hofstede et al., 2010). Als ganz besonders wichtig erscheint aber der sensible und reflektierte Umgang mit Macht. Dazu muss eine gute Kommunikations- und Reflexionskultur aufgebaut werden. Dort, wo Menschen Kinder großziehen, wird es auch auf Elternbildung, durchaus im Kontext der Einwanderungsgesellschaft, ankommen. Ferner geht es um das Entwickeln einer konstruktiven Konfliktkultur, in Familie und Gesellschaft, in den Projekten und in den interkulturellen und interreligiösen Übergangsräumen, die hier entstehen. Bei der Entwicklung von urbanen und ruralen Communities muss in Zukunft auch daran gedacht werden, vulnerable Orte und Kontexte besonders zu stärken, soziale Diversität zu fördern, Bildungszugänge für alle zu schaffen und sozialen Zusammenhalt zu unterstützen.

Die aktive Vaterschaft (vgl. hierzu Louv, 1993) wird in diesen Projekten eine ganz neue Bedeutung erlangen, auch mit Blick auf die ungestillte Sehnsucht der vielen jüngeren und älteren Männer, wie sie sich derzeit in den virtuellen Welten artikuliert, und wie wir in dem Kapitel Körper unter Glas exemplarisch gesehen haben. Wir sollten damit aufhören, den Mangel an Männern in der Pädagogik zu beklagen und stattdessen andere soziale Strukturen schaffen, damit Männer wieder natürlicher Bestandteil des Aufwachsens von Kindern sind. Heutige Väter, wie auch zunehmend die Mütter, sind mittlerweile in einem oftmals erbarmungslosen Konkurrenzkampf um Stellen, Geld, sozialen Status und ökonomisches Überleben verstrickt. Führt das aber zum persönlichen Glück? Wohl kaum. Was leben diese Eltern ihren Kindern vor? Paul Goodman (2012, S. 113) schreibt in seinem Buch Growing up Absurd: »... do the children have a father, if he is running a Rat Race? Into what world do the small children grow up in such a home? « Statt um Wettbewerb sollte es in Zukunft um Kooperation gehen, um den Ausdruck dessen, was in jedem einzelnen Menschen verborgen ist. Arbeit sollte der sozialen Community dienen, nicht allein dem Profitstreben von Unternehmen. Auch die echte, das heißt von den einzelnen wirklich so erlebte, Zugehörigkeit zu einem Arbeitskontext sollte in den transformativen Community-Projekten möglich sein. Nur bei einem entfremdeten Arbeitskontext müssen wir, wie in all den Work-Life-Balance Ratgebern geschrieben wird, so viel Wert auf die Trennung von Arbeit und Freizeit bzw. Regenerationszeit legen. Bei den neuen Community-Projekten wird die Notwendigkeit solcher Abgrenzungen nicht mehr so stark gegeben sein.

\section{Offene, variable Strukturen in Lern- und Lebensräumen}

Wo alle immer Ordnung, Regelmäßigkeit, Planbarkeit usw. wollen, gerade in Zusammenhang mit schulischen Fragen, Bildungsfragen, gesellschaftlichen Fragen oder in Fragen des Lernens und des Verhaltens, so ist doch auch alles Widersprüchliche, Nicht-Kontinuierliche und Unordentliche wichtig für kreative Entwicklungen. Richard Sennett schreibt in seinem Buch Building and Dwelling: Ethics for the City über 
die geschlossene, segregierte, reglementierte und kontrollierte Stadt, wie sie sich vom globalen Norden bis in die explodierenden Megastädte des globalen Südens ausgebreitet hat. Als Alternative entwirft er die offene Stadt, die ihre innere Vielfältigkeit bejaht und aktiv gestaltet. In dem, gemeinsam mit dem Architekten Pablo Sendra verfassten, Buch Designing Disorder. Experiments and Disruptions in the City führt er diese Argumentation fort und greift zugleich das Leitmotiv seines, zuerst 1970 erschienenen, Werkes The Uses of Disorder. Personal Identity and City Life wieder auf. Aus meiner Sicht ist es mit einer zukunftsweisenden, communitybasierten Pädagogik und dann auch, im nächsten Schritt, innerhalb der sich verändernden und öffnenden Schulen so ähnlich wie in der Stadtentwicklung und dem Entwerfen von innovativer Architektur. Unsere derzeitige Gesellschaft erfordert jetzt mehr ein Design of Disorder. Die neuen transformativen Projekte sollten von einer solchen kreativen Unordnung geprägt sein. Ähnlich ist es ja auch in frisch gegründeten Unternehmen, Organisationen, Start-ups oder Creative Labs. William Bridges (2009) beschreibt diesen Geist sehr schön in seinem Buch Managing Transitions. Er hält auch fest, was in der Endphase von Organisationen passiert, wenn sie immer bürokratischer, rigider, enger und kontrollierender werden. Dann steuern sie auf ihr Ende zu, zumindest ihr Ende in dieser Form. Die einzige Möglichkeit besteht dann darin, dieses Zuviel an Institutionalisierung, Regulierung, Geschlossenheit und Bürokratisierung, genau das also, was wir derzeit bei Schulen und Universitäten beobachten, zu überwinden und wieder zum Anfang zurückzukehren, zur Phase der Gründung, Motivation und kreativen Unordnung. Auch der Städtebau der vergangenen Jahrzehnte folgte ja solchen Prinzipien. Der Architekt Sendra und der Soziologe Sennett verbinden ihre kritische Analyse des Städtebaus mit Kapitalismuskritik und einer Kritik des Neoliberalismus. Die Städte des 20. Jahrhunderts wurden nach dem Prinzip der Arbeitsteilung entworfen, ähnlich der Wirtschaftswelt. Die Stadt wurde zum Produkt gemacht, das sich vermarkten lässt. So ist es inzwischen auch mit den allermeisten Formen von Unterricht und universitärer Lehre. Statt echtes, freies Denken zu inspirieren, in lebendigen Diskursen, müssen Wissenspakete nach bestimmten Kriterien geschnürt und als Modulinhalte präsentiert und kompetenzorientiert abgeprüft werden. Signifikantes Lernen ist aber etwas anderes.

In einer Art Gegenbewegung, ich wechsle erneut in die Welt des Städtebaus und der Stadtentwicklung, gilt es nun Unterbrechungen und Diskontinuitäten in den urbanen Raum einzufügen. Auf der Ebene der Menschen stellen Sendra und Sennett sich das so vor, dass diese, angeregt durch ein offeneres urbanes Umfeld, auch von ihrem Denken und Fühlen her beweglicher werden und starre Überzeugungen und Muster aufgeben. Es geht auch darum, mehr informelle Räume zu schaffen und dadurch Experimente und die Auflösung starrer Ordnungen zu ermöglichen. Das Leitmotiv der offenen Stadt hat Richard Sennett von Jane Jacobs übernommen. Um uns ein lebendiges Beispiel für eine offene und eine geschlossene Stadt zu geben, nennen Sendra und Sennett zum einen Neapel und zum anderen Frankfurt a. M. Meine eigenen Erfahrungen und Eindrücke in den beiden Städten decken sich exakt mit dieser Einschätzung. Besonders die Altstadt von Neapel ist ein suggestiver, die Imagination und Kommunikation fördernder Ort. Welche konkreten Formen sind es nun, die die offene Stadt erzeugen? Zum einen sind das Passagen, offene Durchgänge, womit ich wiederum bei dem von Walter Benjamin übernommenen Leitmotiv meiner eigenen Forschungen und Überlegungen angelangt wäre, sodann unvollständige Objekte sowie nicht-lineare Erzählungen (vgl. Sendra und Sennett, 2020, S. 27). Interessant ist 
nun, was Sendra und Sennett über Mauern in Städten schreiben, wenn es um die Passagen und offenen Durchgänge geht. Mauern stehen für Geschlossenheit. Sie verhindern Passagen und Durchquerungen. Ähnlich ist es mit den Bildungswissenschaften. Wenn ich mein pädagogisches Fach als etwas in sich Geschlossenes entwerfe, dann besteht nicht die Möglichkeit zu solchen explorativen Passagen, durch die allein wir uns die Stadtlandschaft, um noch ein wenig in der analogen Welt der Urban Studies $\mathrm{zu}$ bleiben, als Ganzes aneignen und aus vielen verschiedenen Perspektiven betrachten können. Dasselbe gilt für Schulen, die sich abriegeln und keinerlei Durchlässigkeit zur umgebenden Community aufweisen, weder räumlich materiell, noch von den Austauschbeziehungen betrachtet. Ferner existieren in Verbindung mit solchen Passagen lebendige urbane Übergangszonen, von Sendra und Sennett (2020, S. 29) border genannt, wo die verschiedensten Gruppen miteinander interagieren. Die Stadtforscher ziehen an dieser Stelle einen Vergleich zur Ökologie. Border bezeichnet einen lebendigen Grenz- und Übergangsraum, ähnlich einer mittelalterlichen Stadtmauer, an die vielerlei Werkstätten gebaut waren und wo sich Händler aufhielten und folglich vielerlei Kommunikation stattfand. Boundary ist dagegen eine Art Rand, wo die Dinge enden. Übertragen wir dies einmal auf die urbanen oder ländlichen Zonen, in denen sich unsere derzeitigen Schulen befinden, so liegen diese zumeist abgeriegelt hinter Mauern und hohen Zäunen, ohne jedes Leben um sie herum und auch im übertragenen Sinne gibt es oft auch kaum eine Durchlässigkeit.

Kommen wir zu der zweiten, von Sendra und Sennett genannten Komponente einer offenen Stadt, den unvollständigen Formen. Ihre Bedeutung besteht nun darin, dass sie die Imagination und die Kreativität herausfordern. Sie stimulieren das Entwickeln von Ideen und neuartigen Lösungen. Unsere staatlichen Schulen, wie auch die Universitäten sind jedoch deutlich überorganisiert und überreguliert. Es gibt nichts Unvollständiges mehr, wo die Stakeholder_innen des Schullebens noch etwas anbauen oder entwickeln könnten. Es ist immer alles schon da. Es gibt nur noch überaus geringe Spielräume. Das macht es auch immer schwerer, in vielen Fällen nahezu unmöglich, Heranwachsende mit einer emotionalen und sozialen Thematik in den Schulen unterzubringen. In offeneren, variableren Strukturen, in denen vieles unfertig und in Bewegung ist, wäre dies viel leichter. Projekte, die im Aufbau sind und die sich ständig verändern, je nachdem, welche Erfordernisse gegeben sind und wer in ihnen gerade mitarbeitet, bieten diese Art der unvollständigen, fragmenthaften Form, wo sich Heranwachsende auch tatsächlich einbringen können, wo sie gefordert sind, sich etwas einfallen zu lassen, die Initiative zu ergreifen, an der Entwicklung von Ideen und Lösungen mitzuarbeiten. Ich selbst habe solche Arbeitsatmosphären in den Sommercamps der 8oer Jahre, im internationalen HighScope Camp in Michigan, mit David Weikart und seinem Team von Studierenden, im Kreativen Sommercamp mit KarlJosef Kluge und seinem Team, später auch Universitäres Sommercamp oder SkyLightCampus genannt, in den integrativen oder inklusiven Sommercamps mit polnischen, französischen, ungarischen und deutschen Jugendlichen und jungen Erwachsenen erlebt. Etliche von ihnen brachten irgendein Handicap mit. Andrzej Jaczewski, von der Universität Warschau, war hieran in einem besonderen Maße beteiligt. Schon zur Zeit des Kalten Krieges ermöglichte er polnischen Gruppen über die Grenze nach Deutschland zu gelangen. Umgekehrt organisierte er für deutsche Gruppen erlebnispädagogische Aufenthalte und Reisen innerhalb von Polen, verhandelte mit den polnischen Behörden, dass wir einreisen konnten usw. Wir hatten viel inhaltlichen Spielraum 
in diesen Camps. Das erzeugte eine enorme Motivation, ja einen regelrechten Aufbruchsgeist. Dieses Gefühl hatte ich in den Schulen, in 18 Jahren, nur selten. Warum eigentlich? In den curricular definierten Gegenwartsschulen ist fast alles bereits vorgegeben und wird mit Macht unverrückbar und unveränderbar vor die Heranwachsenden, wie auch vor die Lehrkräfte, hingestellt, mit der klaren Erwartungshaltung, jetzt genau dieses vorgefertigte Schema zu akzeptieren, genau in dieses eine Laufrad einzusteigen und, wie alle anderen auch, brav darin vorwärtszulaufen, sich anzupassen und zu fügen. Von der Sonderpädagogik des Schwerpunkts emotionale und soziale Entwicklung wird nun Mithilfe genau an diesem Punkt erwartet. Dazu sollen wir allerhand kleine Listen und Tricks aus dem Ärmel schütteln, dass die Kinder und Jugendlichen nun endlich über das Stöckchen springen. Aber noch ist niemand bereit, das gesamte Bildungsprojekt einmal ganz anders aufzuziehen.

Die dritte Komponente, die für die offene Stadt von Bedeutung ist, neben Passagen und unvollständigen Formen, sind nicht-lineare urbane Erzählungen. Das staatliche Schulwesen und auch die darauf ausgerichteten universitären Lehramtsstudiengänge setzen jedoch immer voraus, dass es eine lineare Erzählung von Bildung gibt, dass es eine bestimmte Art der Vorbereitung auf das Erwerbsleben, in dieser ganz bestimmten Gesellschaft, mit den derzeit noch dominierenden Arbeits- und Wirtschaftsformen gibt, und dass sich die Kinder und Jugendlichen in staatlich regulierten Schulen genau darauf vorzubereiten haben, dass sie sich ganz bestimmte Wissensinhalte und Kompetenzen anzueignen haben, für die jeweiligen beruflichen Wege. Das ist aber schon jetzt immer weniger der Fall. Vieles, was sich die Heranwachsenden am Ende ihrer jeweiligen Schullaufbahnen angeeignet haben, haben sie sich keineswegs in der Schule, sondern mehr in informellen Kontexten, durch Eigeninitiative, durch autodidaktische Studien, durch Reisen, Projekte, durch ihr Leben in den digitalen und virtuellen Welten angeeignet, durch explorative Streifzüge, Teilnahme an OnlineSeminaren von Universitäten in der ganzen Welt, durch das Spielen von komplexen Online-Games, durch Stöbern in Datenbanken aller Art, durch das Anschauen von informativen Filmen auf so vielen Kanälen, von YouTube über Amazon Prime bis Netflix. $\mathrm{Zu}$ bedenken ist auch, dass ein Teil der Jugendlichen die konstruktive Teilnahme am Unterricht der staatlichen Schulen regelrecht verweigert und dies durch destruktives Verhalten oder Fernbleiben zum Ausdruck bringt. Es erscheinen immer wieder Lageberichte, dass ein bestimmter Prozentsatz der Schüler_innen die Schule ohne relevante Kenntnisse und ohne entsprechenden Abschluss verlässt. Die Passung zwischen ihnen und dem System ist in diesen Fällen offenbar nicht gegeben. Vermutlich sind das Setting und die Atmosphäre nicht geeignet, dass auch diese Heranwachsenden dort lernen könnten. Wer also nun dazu neigt, den Sinn solch offenerer Lernstrukturen, wie ich sie hier aufzeige, in Frage zu stellen, dem lässt sich leicht entgegenhalten: Das sorgfältig definierte Paket aus anzueignendem Wissen und zu lernenden Kompetenzen kommt bei einem bestimmten Prozentsatz von Heranwachsenden auch jetzt, unter den derzeit geltenden schulischen Bedingungen, nicht an. Wir können dies auch nicht erzwingen. Keine sonderpädagogische oder psychologische Beeinflussungsmethode, was auch immer es sein mag, wird diese Schwierigkeiten abschließend und, vor allem, mit langfristigem Effekt, lösen können. Das Erreichen einer kurzfristigen Verhaltensanpassung ist kein Beleg für einen nachhaltigen Lerneffekt oder für eine wirklich substantielle Veränderung, auch wenn viele Studien das behaupten. Wer sich das einredet, macht sich etwas vor. Wir sollten daher etwas Neues versuchen, indem 
wir zunächst eine Alternative zur bestehenden Schule schaffen. Hierdurch wird sich langfristig auch die Schule selbst verändern, im Sinne von mehr Öffnung und Variabilität. Auch hochmotivierte, autodidaktische Lerner mit hoher Eigeninitiative, junge Querdenker und kreative Denker werden dankbar für eine Alternative zur staatlichen Schule sein, denn sie werden oftmals gemobbt und schikaniert, besonders von ihren männlichen Peers. Die drei genannten Komponenten, von Sendra und Sennett Infrastructures of Disorder genannt, erzeugen aus deren Sicht einen demokratischen Raum, wo die Beteiligung der Bürger_innen erwünscht und möglich ist. So sollte es ja auch für die Heranwachsenden und ihre Bezugspersonen in pädagogischen Kontexten, also auch in den transformativen Community-Projekten, später dann ebenfalls in den veränderten Schulen, sein.

\section{Die Einzelnen und das Ganze}

Wenn ich hier also Kritik an Kapitalismus und staatlicher Bevormundung übe, die Neue Steuerung im Bildungssystem einem kritischen Diskurs unterziehe, die übertriebene Akademisierung der vergangenen Jahre in Frage stelle und stattdessen für die Beteiligung der Pädagogik des Schwerpunkts emotionale und soziale Entwicklung an der gesellschaftlichen Transformation eintrete, wie sie sich derzeit in vielen Ländern dieser Welt vorbereitet und wie sie längst begonnen hat, und communitybasierte Projekte entwerfe, in denen in Zukunft, parallel zu dem derzeit noch dominierenden Schul- und Bildungssystem, gelebt, gelernt und gearbeitet werden kann, so ist dies ja alles, für sich betrachtet, nicht neu. Schon andere haben dies vor mir getan oder tun dies zeitgleich. Ohne Theodor Adorno, Herbert Marcuse, Paul Goodman, Paul Willis, Carl Rogers oder Erich Fromm, ohne Aldous Huxley und George Orwell, wären wir mit unserer Ideenentwicklung nicht da, wo wir jetzt sind. Und was Gerald Hüther, Wolfgang Jantzen, Richard David Precht, Wilfried Bommert, Maja Göpel und viele andere in der Gegenwart veröffentlichen, zielt sämtlich auf die gesellschaftliche und globale Transformation, wenn auch jeder und jede der Genannten jeweils bestimmte Teilaspekte besonders beleuchtet. Es ist allerdings nicht ganz unproblematisch von der Großen Transformation zu sprechen, wie es jetzt öfter zu lesen ist. Karl Polanyi (1973) gebrauchte den Begriff bereits 1944, ich verdanke den Hinweis Wolfgang Jantzen, und zwar zunächst in dem Sinne, dass er damit den Übergang von integrierten Gesellschaften, in denen das Wirtschaftsleben noch in einen übergeordneten kulturellen Rahmen eingebettet war, zu dem nicht länger integrierten Modell der freien Marktwirtschaft bezeichnete. Im Grunde geht es mir und vielen anderen heute ja genau um das Gegenteil davon. Dass nämlich Wirtschaftsleben, Kultur und Gesellschaft wieder stärker miteinander verschmolzen werden, dass Arbeitsteilung und Entfremdung möglichst wieder aufgehoben werden, in einer verlangsamten, ökologisch verträglicheren, nachhaltigeren Art und Weise zu leben und zu arbeiten, wie ich sie hier mit den transformativen Community-Projekten verbinde. Es ist in Zukunft mehr theoretische Auseinandersetzung erforderlich mit dem Thema der gesellschaftlichen Transformation und mit dem, was wir insbesondere unter der Großen Transformation verstehen wollen (vgl. dazu auch Ther, 2019).

"Die fruchtbaren neuen Ideen stammen nie von einzelnen, sondern immer von der Zeit. Es ist geradezu der Prüfstein ihres Wertes, daß sie von vielen gleichzeitig 
gedacht werden« notierte Egon Friedell (1996, S. 47). In seiner Kulturgeschichte der Neuzeit schreibt Friedell (a. a. O., S. 53) weiter: »... die guten Gedanken ... sind das Werk des Kollektivbewussteins eines ganzen Zeitalters. Es handelt sich darum, wer sie am schärfsten formuliert, am klarsten durchleuchtet, am weitesten in ihren möglichen Anwendungen verfolgt hat." Mit einem solchen Anspruch will ich hier aber sicher nicht auftreten. Mir ging es darum, eine nur noch angelehnte, aber nicht mehr verschlossene Tür noch ein wenig weiter aufzustoßen. Es wird weiterer Anstrengungen in dieser Richtung bedürfen. Besonders die noch ganz junge Generation, die sich unter dem Motto Fridays for Future formiert hat, dürfte das Potenzial haben, das Neue zu entwerfen. In der nächsten Zeit sollten einmal die bereits existierenden Initiativen in Deutschland und darüberhinaus recherchiert, aufgelistet, zusammenfassend dargestellt und vergleichend analysiert werden. Die jungen Leute sollten sich nicht von den alten Ordnungen beirren lassen. In Politik und Gesellschaft ist schon viel möglich geworden, was in den 7oer und 8oer Jahre kaum jemand für möglich gehalten hätte. Die autoritäre, patriarchalische Kleinfamilie existiert nicht mehr. Die Wehrpflicht wurde abgeschafft. Ich erinnere daran, dass um 1980 herum Wehrdienstverweigerer noch regelrecht kriminalisiert wurden. Das ist 40 Jahre später nicht mehr vorstellbar. Kaum jemand erinnert sich noch daran, außer meiner Generation, die direkt davon betroffen war. Die großen Kirchen haben ihre absolute Autorität verloren. Das war in den 6oer Jahren auch nicht vorstellbar. Jetzt ist es aber Realität. Homosexuell orientierte Menschen können jetzt offen zusammenleben und heiraten. Statt enger heteronormativer Identitätskonzepte und Geschlechterrollen wird nun auf allen gesellschaftlichen Ebenen sexuelle Vielfalt propagiert, Menschen können das Geschlecht wechseln. In den 8oer Jahren führten die meisten homosexuellen Männer noch ein Doppelleben und tauchten im Verborgenen in die Subkulturen der großen Metropolen ein. Keiner konnte sich vorstellen, dass das einmal anders würde. Doch es ist anders geworden. Spirituelle, holistische, ganzheitliche Philosophien und Praktiken sind mittlerweile in der Breite der Gesellschaft angekommen. Als wir, als Studierende in den 8oer Jahren in Köln mit Katja Seebaum Yoga und mit Meinolf Schnier Meditationsübungen machten und an Breathing-Workshops teilnahmen, waren diese Formen der Selbsterfahrung lediglich in einer kleinen gesellschaftlichen Avantgarde akzeptiert. Deutschland ist überdies ein multikultureller Staat geworden, ein Land, in das Menschen aus der ganzen Welt gerne einwandern. Kaum noch jemand sorgt sich um die Vormachtstellung deutschen Kulturguts im Feld der Bildung. Die Menschen haben erkannt, dass auch in anderen Kulturen und Sprachen enormes Potenzial liegt. Auch das war in den 8oer Jahren noch nicht vorstellbar. Ich weiß natürlich um die Spannungsfelder und Herausforderungen, mit denen wir unter anderem auch zu tun haben.

Nun muss nur noch die Schulpflicht, im Sinne des Schulzwangs, aufgehoben werden. Das erscheint den allermeisten Bürger_innen, in der Gegenwart, noch nicht vorstellbar. Doch in fünfzehn Jahren, wenn der Schulzwang aufgehoben sein wird, werden alle sagen, dass wir das doch nicht weiter hätten fortführen können, das sei doch schließlich der letzte Zwang gewesen, den wir noch in unserer demokratischen, offenen, diversen Gesellschaft gehabt hätten. Wozu hätten wir auch daran festhalten sollen? Und aus dem, was früher Sozialhilfe hieß, und was jetzt Hartz IV oder Grundsicherung genannt wird, wird spätestens in fünfzehn Jahren ein bedingungsloses Grundeinkommen geworden sein. Bis dahin werden alle politischen Debatten im Bundestag und in der Zivilgesellschaft diesbezüglich, auch bezüglich der Umwand- 
lung der Schulpflicht in eine selbst zu gestaltende Bildungspflicht abgeschlossen sein. Damit hätten wir, ich schaue nun natürlich ein wenig visionär in meine Glaskugel, die Voraussetzungen für die Entwicklung der neuen, transformativen communitybasierten Lern-, Arbeits- und Lebensformen und auch kulturellen Formen, in größerer Zahl, geschaffen. Was würde Friedell, der uns, in seinem lebendig geschriebenen Überblick über die Epochen, die entscheidenden thematischen Strömungen der vergangenen 600 Jahre aufzeigt und der kenntnisreich mit den Jahrhunderten jongliert und sie voneinander absetzt, hinsichtlich ihres Bewusstseins, ihrer Praktiken, ihrer sozialen, wirtschaftlichen, kulturellen und geistigen Formen, Schlüsselthemen und Strömungen, was würde er also über unsere jetzige Zeit sagen und wie würde er mögliche Weiterentwicklungen antizipieren und entwerfen? Ich bin sicher, dass auch er die gesellschaftliche Transformation, von der mittlerweile so viele sprechen, am Horizont heraufdämmern sähe. Ich möchte mit diesem Buch die Geschicke des eigenen pädagogischen Faches mit diesen übergreifenden Diskursen und utopischen Neuentwürfen verknüpfen und so zu einer disziplinübergreifenden, nachhaltigen globalen Veränderung beitragen. Bezogen auf die Jugendlichen und seien sie noch so überrascht am Anfang, wenn ich sie so frage, geht es vor allem darum, sie nach ihrem eigenen Anliegen zu fragen. Das wäre doch das Entscheidende, das worauf es am allermeisten ankommt in einer guten Pädagogik. Was willst Du tatsächlich mit Deinem Leben anfangen? Wofür willst $\mathrm{Du}$ Dich einsetzen? „Werden Sie sich einfach wie ein Zahnrad in die Maschinerie einfügen? Was wird aus Ihnen werden in Bezug auf die Welt?« fragt Jiddu Krishnamurti (2009, S. 31) seine Schüler. Nicht immer können die Heranwachsenden gleich erkennen, welchen Weg sie einschlagen sollen und was ihre besondere Begabung ist und was ihr persönlicher Beitrag zum Ganzen sein könnte.

Es ist eine so fundamental wichtige Erfahrung für Kinder und Jugendliche, die bisher einen schwierigen Weg hatten, sei es im familiären Umfeld, im Raum der Schule oder an der Universität, dass ich ihnen als Pädagoge ein solches Engagement, eine solche Verwirklichung ihrer selbst zutraue und sie pädagogisch dabei begleite. Für viele Kinder und Jugendliche, wie auch für viele Erwachsene, ist es zunächst einmal eine Herausforderung über die Verbundenheit und den tieferen Sinn aller Dinge nachzudenken, so wie O'Donohue es eben in seinen philosophischen Texten tut. Es ist gut, mit ihnen viel Philosophie zu betreiben (vgl. auch Siegmund, 2019). Wir haben uns an ein naturwissenschaftliches Weltbild gewöhnt und trennen zwischen Materie und Geist bzw. Seele, wenn wir den zweiten Aspekt überhaupt noch gedanklich zulassen. Warum haben die acht Staffeln der Serie Game of Thrones besonders bei den jüngeren Generationen eine solche Faszination ausgelöst? Vermutlich genau wegen dieser Verknüpfung. Was für eine wunderbare Szene, als die dem Herrn des Lichts dienende Melisandre, durch einen Zauber, die Schwerter der, für Winterfell, den Norden und zugleich für das ganze Land kämpfenden, Reiter entflammt, bevor die Krieger dem, im Dunkeln lauernden, Nachtkönig entgegenreiten. Was uns die gekonnte Einarbeitung magischer Figuren und Handlungselemente bei GoT und die weltweite Faszination, die dies ausgelöst hat, doch lehrt, dass die Menschen nicht nur ein tiefes Bedürfnis nach diesen Dingen haben, sondern dass sie ihre Existenz in gewisser Weise auch ahnen. Dies würde zugleich einen anderen Blick auf das ermöglichen, was wir derzeit für die Wirklichkeit halten. Die den Nachtkönig umgebende Dunkelheit könnte auch für die Unwissenheit steht und für die Gefahren, die uns von dort aus drohen. Ein vergleichbares Beispiel stellt Otfried Preußlers Jugendroman Krabat dar. Auch hier 
werden, auf gekonnte Art und Weise, magische Elemente eingearbeitet. Die geheimnisvolle Mühle, in der das Geschehen spielt, inspiriert auch zu einigen interessanten Zukunftsprojekten, wie sie speziell in der Oberlausitz entstehen könnten. Ich stelle mir Jugendliche vor, die in einer solchen Mühle leben, arbeiten und lernen, gemeinsam mit Handwerker_innen, Pädagog_innen, einem Sozialarbeiter oder einer Sozialarbeiterin, und noch einigen Menschen, die etwas von Kunst, Musik und Philosophie, Wirtschaft und Technik verstehen und dem ganzen Unternehmen gemeinsam einen Bildungscharakter geben könnten. Was wären das für Jugendjahre! Könnten sie nicht eine ganz neue Qualität haben? Nehmen wir Preußlers Mühle einmal als Modell, so gibt es in den Landschaften der Oberlausitz zusätzlich magische Erzählungen, die das Ganze mit Spannung aufladen. Diese Dinge verweisen auf das große Unbekannte.

Eines der bestechendsten Bilder in O'Donohues philosophischen Texten ist die Metapher des Wanderers, der sich fortwährend auf dem Weg der Exploration befindet. So könnten, in der nahen Zukunft, die Heranwachsenden in Deutschland von einem Community-Projekt zum nächsten ziehen. Sie arbeiten ein Jahr beim House of One in Berlin $^{3}$ oder auf dem Friedenshof in Neustadt am Rübenberge ${ }^{4}$ mit, lernen dort und ziehen dann, nach einer gewissen Zeit, zu der Mühle in der Oberlausitz weiter. Je nach individuellen Interessen könnten sie auch ein Jahr in Auroville ${ }^{5}$, das heißt in Indien, verbringen. Wenn sie gelernt haben, was es bei einem Projekt zu lernen gab, packen sie ihren Rucksack und ziehen weiter. Durch das bedingungslose Grundeinkommen haben sie die ökonomische Unabhängigkeit dies zu tun. Das Grundeinkommen sollte gezahlt werden, sobald ein Junge oder ein Mädchen mit einer solchen Wanderschaft beginnt. Was für ein Abenteuer! Wenn es in dieser überregulierten Gesellschaft, wo viele Eltern sogar ihre 16-jährigen Kinder noch mit dem SUV am liebsten gleich in den Schulflur oder ins Klassenzimmer hineinfahren würden, wieder solche Wanderjahre gäbe! Deutschland würde, auf einer ganz neuen Ebene, wieder zu etwas sehr Kostbarem zurückfinden, was es in seiner Vergangenheit zurückgelassen hat. Schauen wir jetzt noch einmal auf dieses oftmals so unproduktive Gezerre um das Lern-, Arbeitsund Sozialverhalten von vielen Jugendlichen in den heutigen Staatsschulen. Packt Euren Rucksack! möchte ich ihnen zurufen, und: Begebt Euch auf Wanderschaft! Und den Schulbehörden und der Politik möchte ich zurufen: Lasst sie gehen! Lasst sie Erfahrungen machen, außerhalb von engen Lerncurricula, Klassenräumen und Schulgebäuden! Bei alldem lässt sich auch dem Rätsel des eigenen Lebens und den tiefsten existentiellen und transzendentalen Fragen auf die Spur kommen. Was wir Kindern und Jugendlichen aber am allermeisten geben müssen, sind haltende Strukturen, damit sie die rätselhafte Weite und Unbestimmtheit des Universums aushalten können. Einfach nur ein bisschen Spaß haben dürfte als Leitmotiv für das eigene Leben nicht mehr ausreichen, nicht bei unserem heutigen Wissensstand und unserem Bewusstsein von den Dingen. Zur Verbreitung dieser Einsicht sollte eine engagierte Pädagogik schon etwas beitragen. Doch der Blick in die Unendlichkeit des Universums löst bei ängstlicheren Naturen auch Unruhe und Ängste aus. In aller Regel wird sich dann durch eskapistische Aktivitäten und sonstige irdische Aktivität, oftmals Hyperaktivität, von Online-Games bis Fußball, abgelenkt und so der innere Spannungszustand kompen-

\footnotetext{
3 https://house-of-one.org/de (25.10.2020)

4 www.friedenshof.org/ (25.10.2020)

5 https://www.auroville.de/ (25.10.2020)
} 
siert. Ein wichtiger Schritt, in Anbetracht all des Unbekannten, könnte vorläufig sein, die Situation auf diesem Planeten, sei es in ökologischer oder sozialer Hinsicht, jetzt durch gemeinsame Anstrengung zu verbessern und auf eine höhere Entwicklungsstufe zu bringen. Dazu müssen aber möglichst viele Mitglieder dieser Gesellschaft zu selbstständigen, freien Denker_innen und Akteur_innen werden, was auch immer sie sonst tun, ob sie Gemüse anbauen oder eine Schafsherde hüten, ob sie die Windparks weiter verbessern oder an neuen Formen der Mobilität arbeiten. Auf Bachelor- und Masterabschlüsse kommt es hier nicht mehr an. Die Menschen der Zukunft können, auch ohne solche Zertifizierungen, selbstbewusste, aufgeklärte, reflektierte Autodidaktiker_innen und klare, scharfe Denker_innen sein, die sich nicht, durch enge Lerncurricula und institutionelle Ritualisierungen, die Flügel haben stutzen lassen. Vielleicht ist das Durchlaufen von standardisierten Lern- und Bildungsprogrammen in vielen Fällen auch kontraproduktiv, weil die jungen Menschen dann aufhören, selbst die Initiative zu ergreifen und eigenständig zu denken. Wichtig aber wäre den eigenen Bildungsprozess selbst zu entwerfen und den eigenen Lebensweg stärker selbst zu definieren. Die Menschen der Zukunft denken kritisch in Bezug auf steuernde Systeme und Ideologien und setzen ihren eigenen klaren, scharfen zivilgesellschaftlichen Verstand dagegen, so in der Art, wie wir es von Jiddu Krishnamurti lernen können, wenn wir aufmerksam seine Texte lesen. Diese neue Generation von Menschen blickt nicht nur auf ihr eigenes Leben, sondern zugleich auf den Zustand des Planeten Erde und auf die Lage der Weltbevölkerung insgesamt. Sicher, ein weiter Weg, aber lesen wir Friedells brillante Rückschau zu dem, was seit dem Jahr 1400 alles in Europa passiert ist, so kann man auch mit einem gewissen Optimismus sagen: Wir haben schon viel hinter uns gelassen, was die Menschen in diesen vergangenen Epochen für unveränderlich, für auferlegt und gegeben gehalten haben. 



\section{Ein Community-Projekt im ländlichen Raum Ostdeutschlands: Dokumentation des Anfangs}

In Städten und ländlichen Regionen könnten in Zukunft eine Vielfalt an transformativen Community-Projekten entstehen. In den Neuen Bundesländern gibt es verlassene Höfe mit Ländereien, die sich hierfür eignen. Gemeinsam mit meinem Sohn habe ich begonnen, ein solches Anwesen und ein wenig dazu gehörendes Land, in der Region von Zerbst, Anhalt, in Richtung eines solchen Projektes zu entwickeln und aufzubauen. Wir betrachten das gerade begonnene Vorhaben als Experimentierfeld, zu dem so vieles gehört: Handwerkliche und landwirtschaftliche Arbeit im Sinne ökologischen Anbaus, technische Entwicklung in Richtung nachhaltiger Gebäudesanierung und Energiegewinnung sowie das Herstellen von sozialen, pädagogischen und kulturellen Bezügen. Inspiration und Anregung gab mir Dagmar Görnhardt, die die historische, im Bergischen Land gelegene, Dorfschule in Niederbreidenbach zu einem Ort der handwerklichen, künstlerischen und sozialen Kreativität gestaltet und immerfort umgestaltet. Anregungen gab mir auch Siggi Neuhaus-Omintara, dessen Gehöft in Astert, Westerwald, schon seit den frühen 8oer Jahren, ein Refugium für Menschen aus dem Rheinland war und wo neue Lebensformen erprobt werden konnten. Anna Salz berichtete mir von Projekten der Permakultur und der Gemeinwohlökonomie, die sie insbesondere in Österreich gesehen hat. Wir beginnen nun in allem von vorne, langsam und auch mit bescheidenen finanziellen Mitteln. Wir haben das alte Gehöft im Oktober des Jahres 2020 erworben und während die Umschreibeformalitäten noch liefen, begannen wir mit den ersten Planungen. 


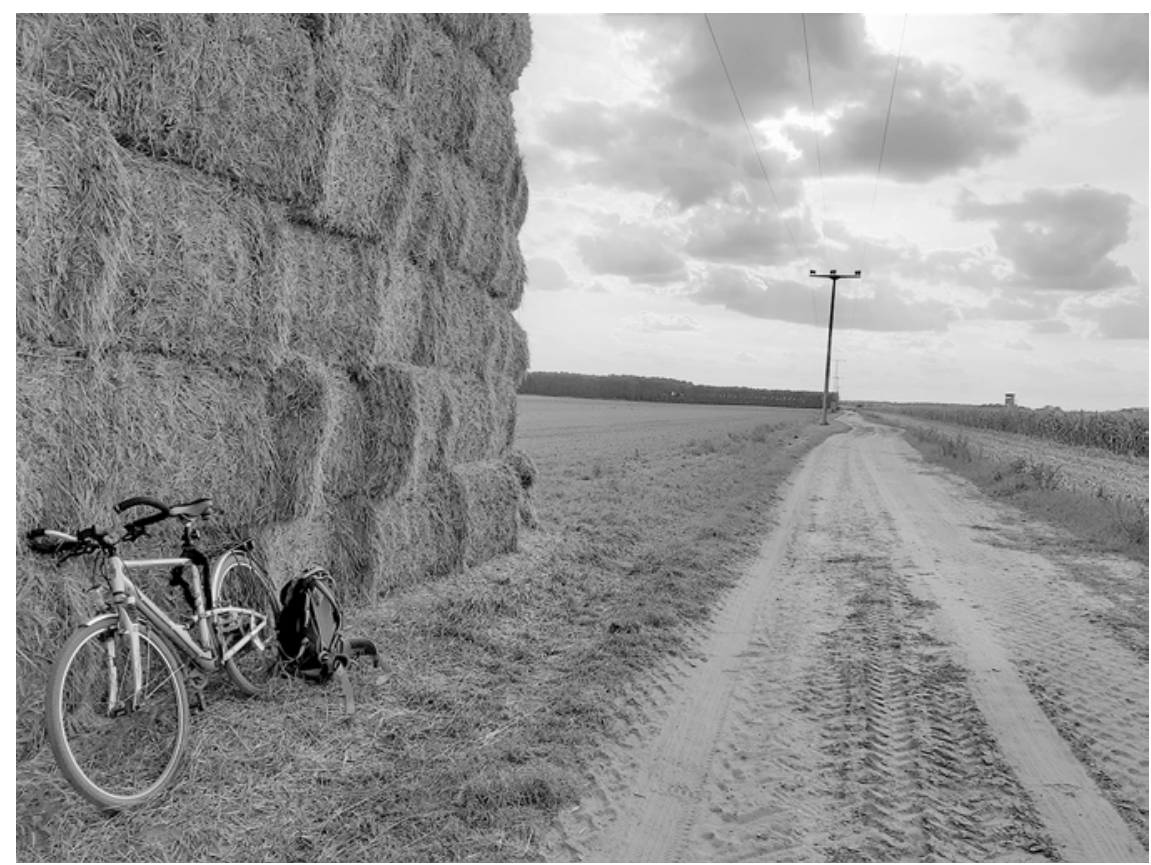

Abb. 68: Die landschaftlichen Weiten Ostdeutschlands bieten viel Raum für das Gründen von transformativen Community-Projekten, es gibt viel Land, bei einer vergleichsweise niedrigen Bevölkerungsdichte, teils auch verlassene Gehöfte und Gebäude. Ich suchte eine ganze Zeitlang in Mecklenburg-Vorpommern, Sachsen, Brandenburg, Thüringen und Sachsen-Anhalt nach einem geeigneten Gelände. Fündig wurde ich schließlich in Sachsen-Anhalt, in der Nähe von Zerbst, Anhalt, in einem Landschaftsraum, in dem sich, in früheren Jahrhunderten, bedeutende Handelsstraßen kreuzten. Dass die Wahl gerade auf Sachsen-Anhalt fiel, ging sicher auch auf die vier Jahre zurück, die ich von 2008 bis 2012 in der Altmark verbrachte, wenn auch im Sinne einer Nebenexistenz, in Zusammenhang mit meiner Lehrtätigkeit an der Hochschule Magdeburg-Stendal, auf dem Campus in Stendal. Schon während dieser Jahre entwickelte sich eine intensive Bindung zu diesem historisch und geografisch hochinteressanten Landschaftsraum, wie auch zu den Menschen, die hier leben. 


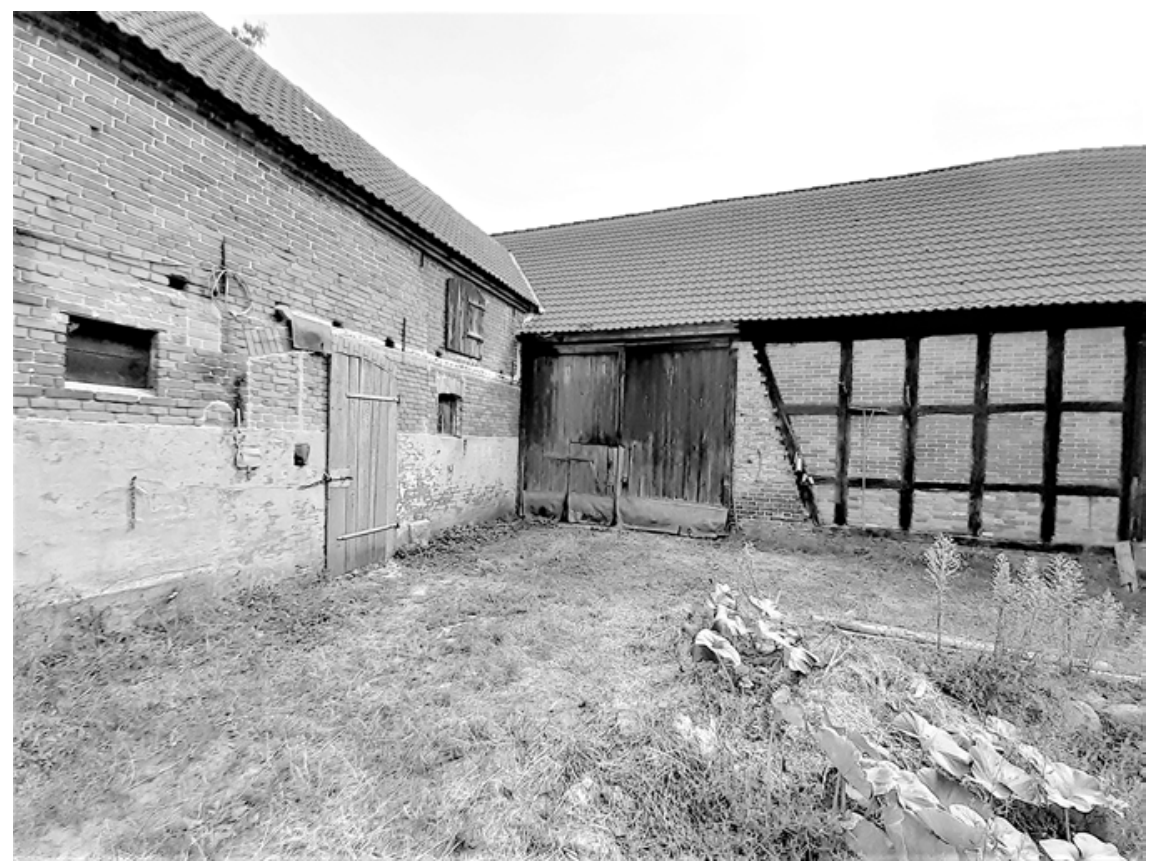

Abb. 69: Dieser in Anhalt, am Rand des südwestlichen Fläming, gelegene Hof stammt aus dem Jahre 1884. Während der Jahre der DDR lebte und wirtschaftete hier eine Bauernfamilie mit drei Kindern. Die Adressbezeichnung aus der Zeit der DDR lautete Straße der deutsch-sowjetischen Freundschaft, wie es auch im Grundbuch noch zu lesen ist. Interessanterweise ist es bisher auch noch nicht geändert worden. Ein hochaktueller Name für eine Straße in Ostdeutschland, der ein Thema von besonderer Priorität anspricht. Schließlich blieb nur noch der jetzt 95-jährige Vater auf dem Anwesen wohnen, bevor er im Sommer 2020 in einem Pflegeheim untergebracht wurde. Der Besitzer hielt zuletzt nur noch Hühner und bewirtschaftete einen Gemüsegarten. In seiner Werkstatt fertigte er Teile für die Reparatur von Türen und Toren an. Modernisiert wurde hier jedoch nichts mehr, weder im Wohnhaus, nicht in den Ställen, nicht in der Scheune und auch nicht in der angrenzenden Werkstatt. Alles, was wir vorfinden ist in die Jahre gekommen. Es gibt Handlungsbedarf auf allen Ebenen. 


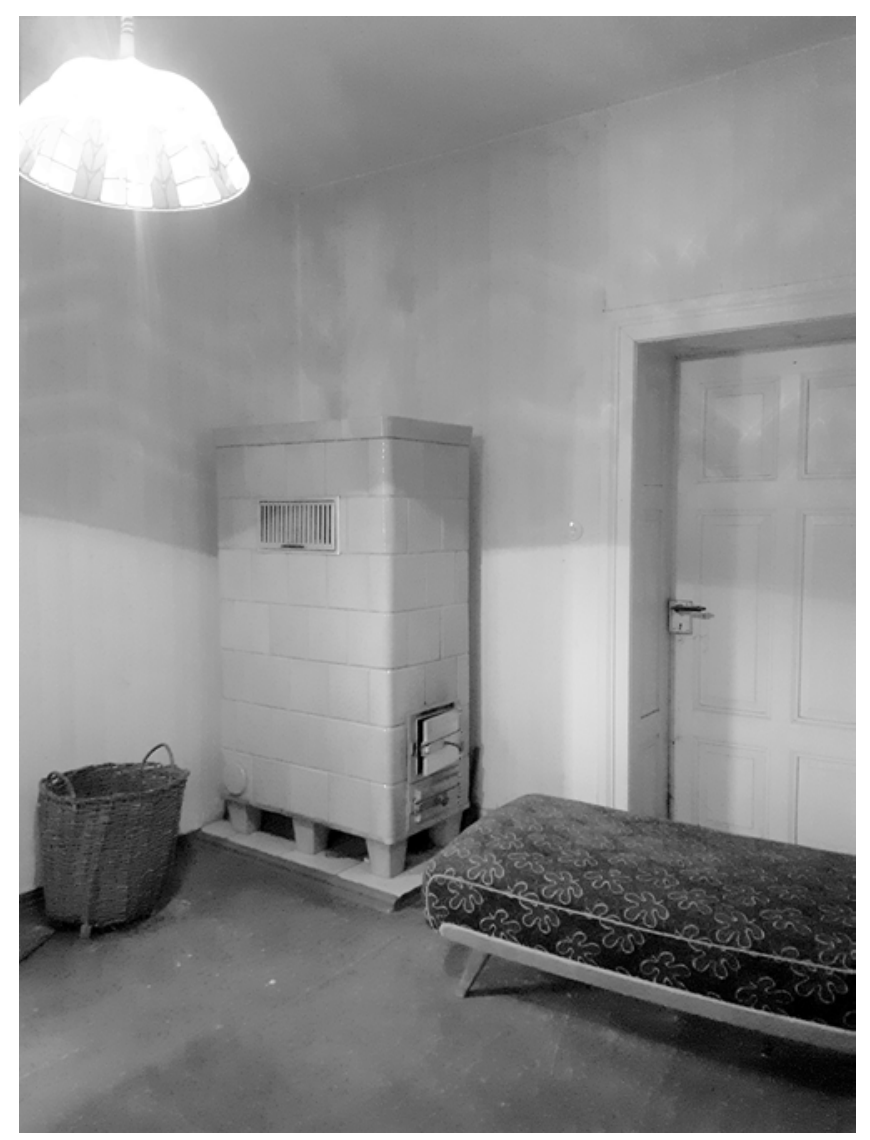

Abb. 70: »Es wird Zeit, die Feuer anzuzünden«, notierte Wisława Szymborska (1996a, S. 17) in ihrem Gedichtband, und »Winter is coming«, sagt Jon Snow, in Game of Thrones. Öfen sind so etwas wie die Seele eines Hauses. Dieses, aus vier Zimmern, einer kleinen Küche und einem nachträglich angebauten Bad bestehende, Wohnhaus ist aus dem Jahr 1884. Es ist aus schlichten Ziegelsteinen gemauert. Zu etwa zwei Dritteln ist das Haus unterkellert. Das aus Bruchsteinen bestehende Kellergewölbe ist feucht. Diese Feuchtigkeit ist teils nach oben in die Mauern gezogen. Ein Teil des Hauses steht lediglich auf einer Balkenkonstruktion, die auf Sand gesetzt ist. Darüber befinden sich Holzdielen und PVC-Böden. Geheizt wird mit drei Kachelöfen, einem weiteren kleinen Ofen in dem vierten Zimmer und zusätzlich können Nachtspeicheröfen verwendet werden. Der Dachboden wurde zum Lagern von Getreide genutzt. Auf einer Seite der Dachetage wurde eine Stube abgetrennt und ausgebaut. Dort befindet sich die elektrische Schaltzentrale für den gesamten Hof. Das Dach ist nicht wärmeisoliert, genausowenig die lediglich dünn verputzen Mauern aus Ziegelsteinen. Die doppelverglasten Fenster sind vertikal gesetzte Rechtecke aus weißem Kunststoff. Ließe sich dieses Haus sanieren? Mit welchen Methoden und zu welchen finanziellen Konditionen? Wie könnte ein neues, nachhaltiges Energie- und Cebäudekonzept aussehen? Es gibt viel zu überlegen, zu entwickeln und zu planen. 

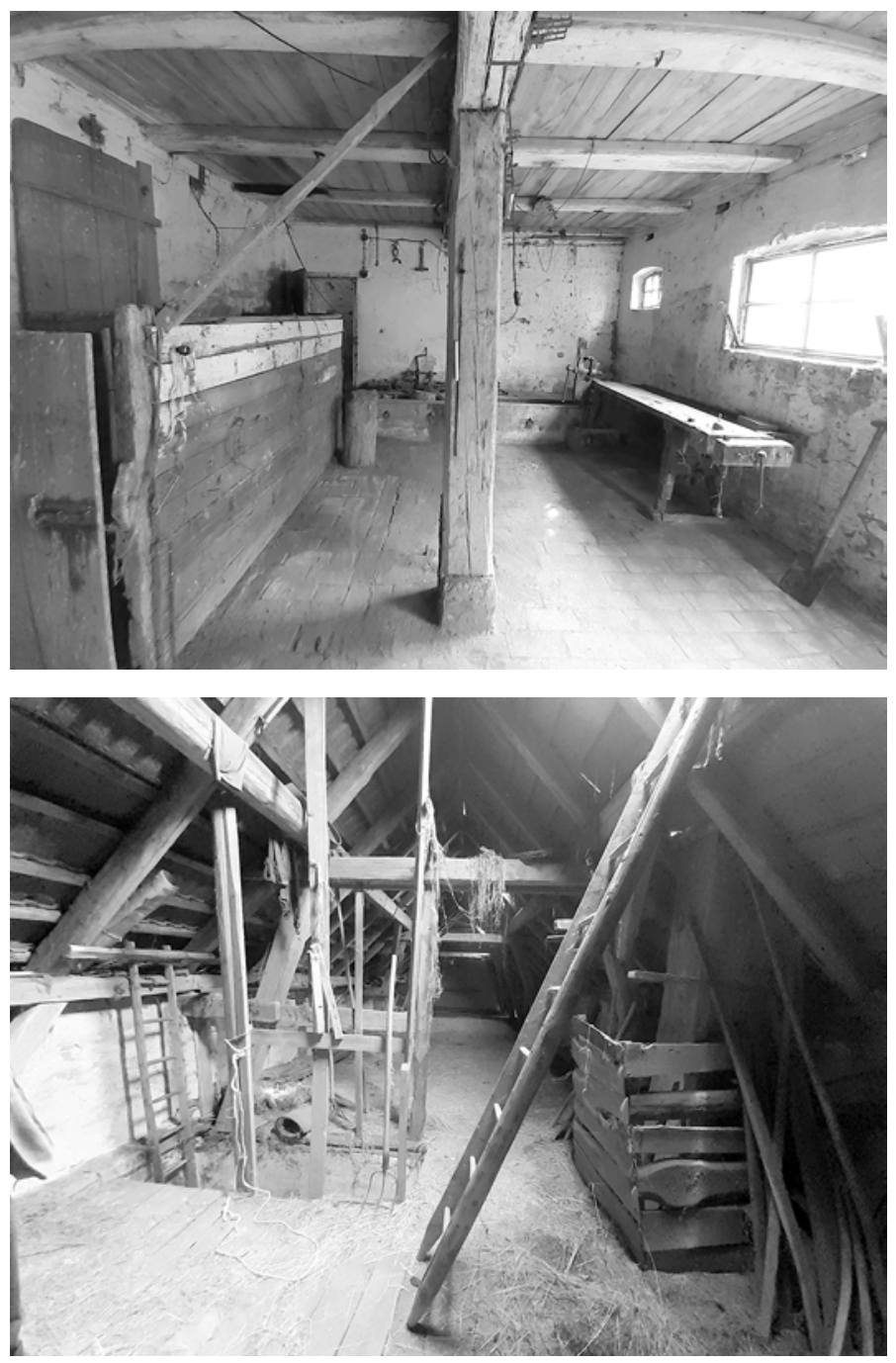

Abb. 71 und 72: In früheren Jahren waren in diesen Ställen Kühe, Pferde und Schweine untergebracht. Oben auf dem Boden lagerte Heu. Was wären nun die Möglichkeiten? Könnte hier eine neue, eine ökologische Landwirtschaft entstehen oder sollte der Raum für soziale, pädagogische und kulturelle Dinge genutzt werden oder beides? Wäre das Raum für Schlafstuben, um dann Seminare und Workshops für Menschen aus Berlin zu geben? Wie lässt sich hier klug investieren und wie sähe ein zukunftsweisendes Konzept aus? Welche unmittelbaren Instandhaltungsarbeiten sind hier erforderlich und wie lassen sich die finanziellen Mittel dafür generieren? Mit wem ließe sich hier zusammenarbeiten und gemeinsam etwas entwickeln? Es wird jetzt darum gehen, viel nachzudenken, sich mit Menschen auszutauschen, mit Menschen aus der Region Anhalt und mit innovativ denkenden Menschen aus anderen Teilen Deutschlands, Europas und der Welt. 


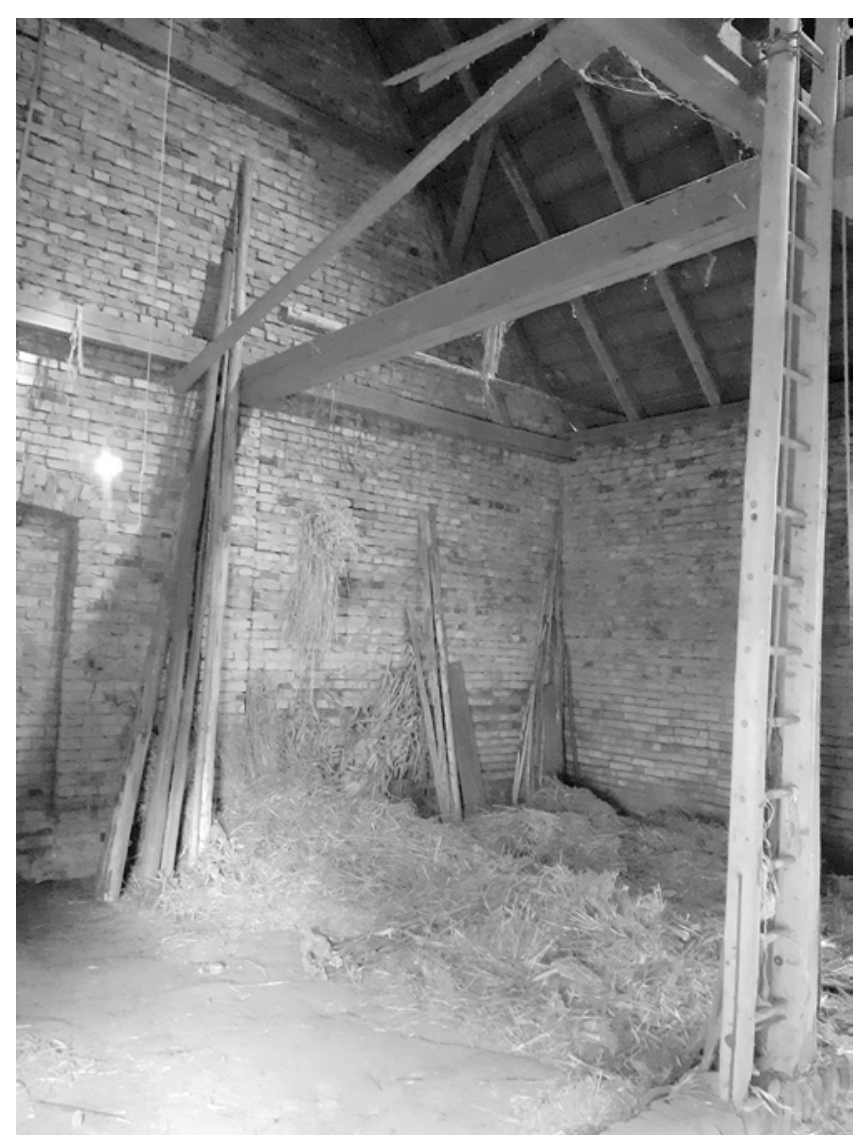

Abb. 73: In dieser Tenne wurde zu früheren Zeiten das Getreide gedroschen. Hier standen Heuwagen und allerlei Gerät. Dieser hohe und weite Raum könnte in Zukunft für vieles andere dienen. Hier könnten nicht nur Konzerte, Lesungen, Seminare, Workshops und Diskussionen stattfinden, sondern auch gesellige Ereignisse. Es könnten hier auch Dinge gefertigt und in alle Welt versandt werden, was auch immer es ist, und wer auch immer dabei mitarbeitet, und seiner Kreativität und seinem unternehmerischen Talent freien Lauf lässt. Öffnet man die hinteren Scheunentüren, schaut man weit in die Landschaft. Das wäre auch etwas für Poet_innen, für Philosoph_innen und Menschen, die mit spirituellen Praktiken arbeiten oder für Menschen, die ein bestimmtes Handwerk ausüben wollen. Workshops zu musikalischer Improvisation, deutsch-polnische Literaturzirkel, kreativer Ausdruckstanz, Yoga und Meditation? Seminare für alleinerziehende Mütter und Väter, während auch die Kinder auf dem Hof aktiv beschäftigt sind mit dem Bauen von Buden, mit Naturbeobachtungen oder dem Backen von Stockbrot an einem Feuer? Vieles erscheint möglich. 

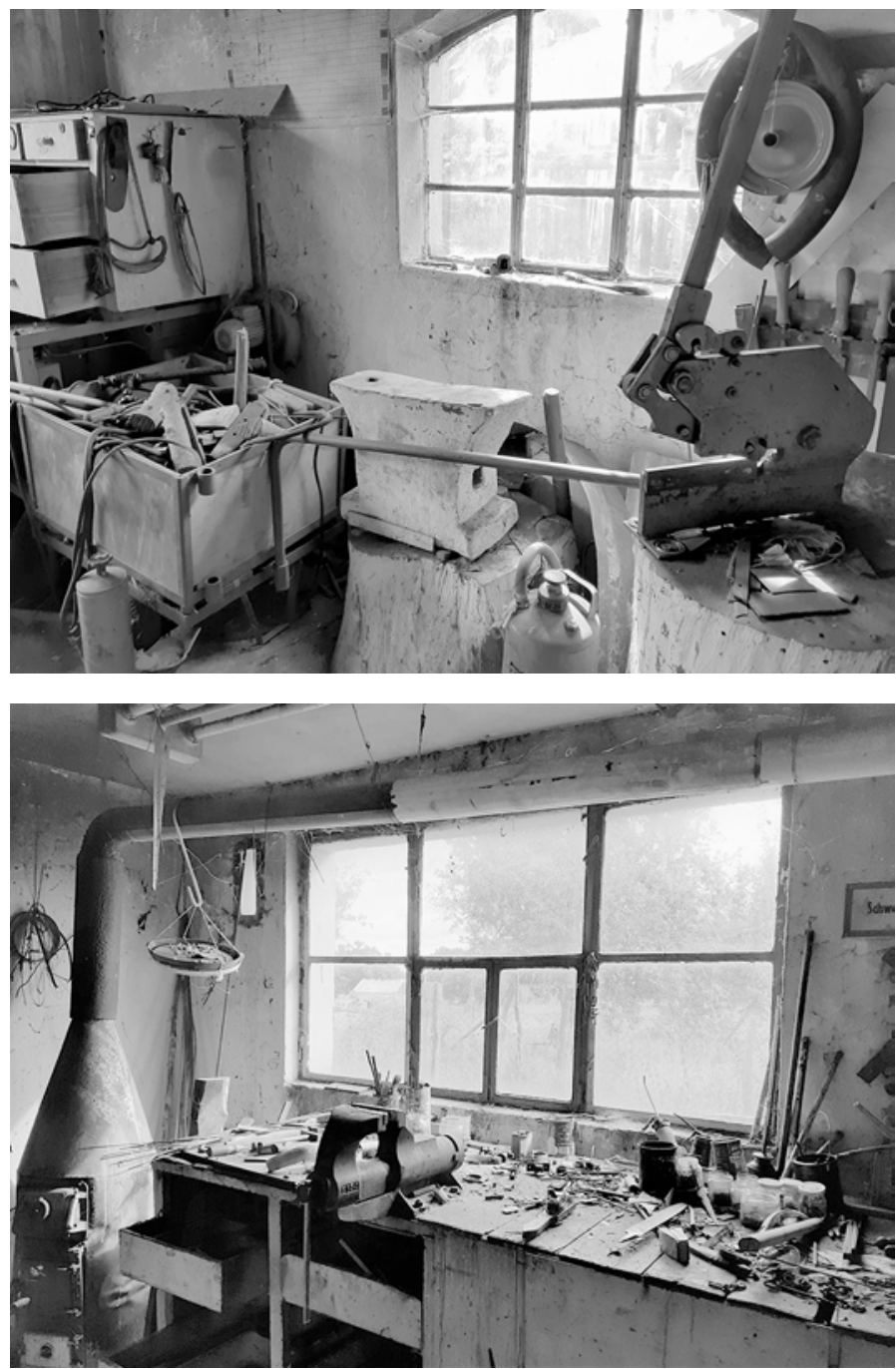

Abb. 74 und 75: Amboss, Schmiedefeuer, Schneidemaschine und Schraubstock. Die Atmosphäre dieser Werkstatt ist von einem besonderen Reiz. Es gibt sicher Werkzeuge darin, die auch in der Gegenwart, wie auch in der Zukunft, noch von Bedeutung sein können, Dinge, die weiter Verwendung finden können. Manches verweist eher auf die Vergangenheit und wird keine Rolle mehr spielen, jedenfalls nicht, wenn man an Industrie 4.0., Smart Data oder das Internet der Dinge (vgl. dazu Schaeffer, 2017) denkt. Oder wird es hier eine Renaissance des alten Handwerks geben? Körbe flechten, Drechseln oder Töpfern? Nach und nach wird es zu einer Bestandsaufnahme kommen, zu einer neuen Art von Systematisierung und zu einer Weiterentwicklung, bis hin zu dem Zeitpunkt, in der Zukunft, wo sich hier neue Richtungen abzeichnen. 

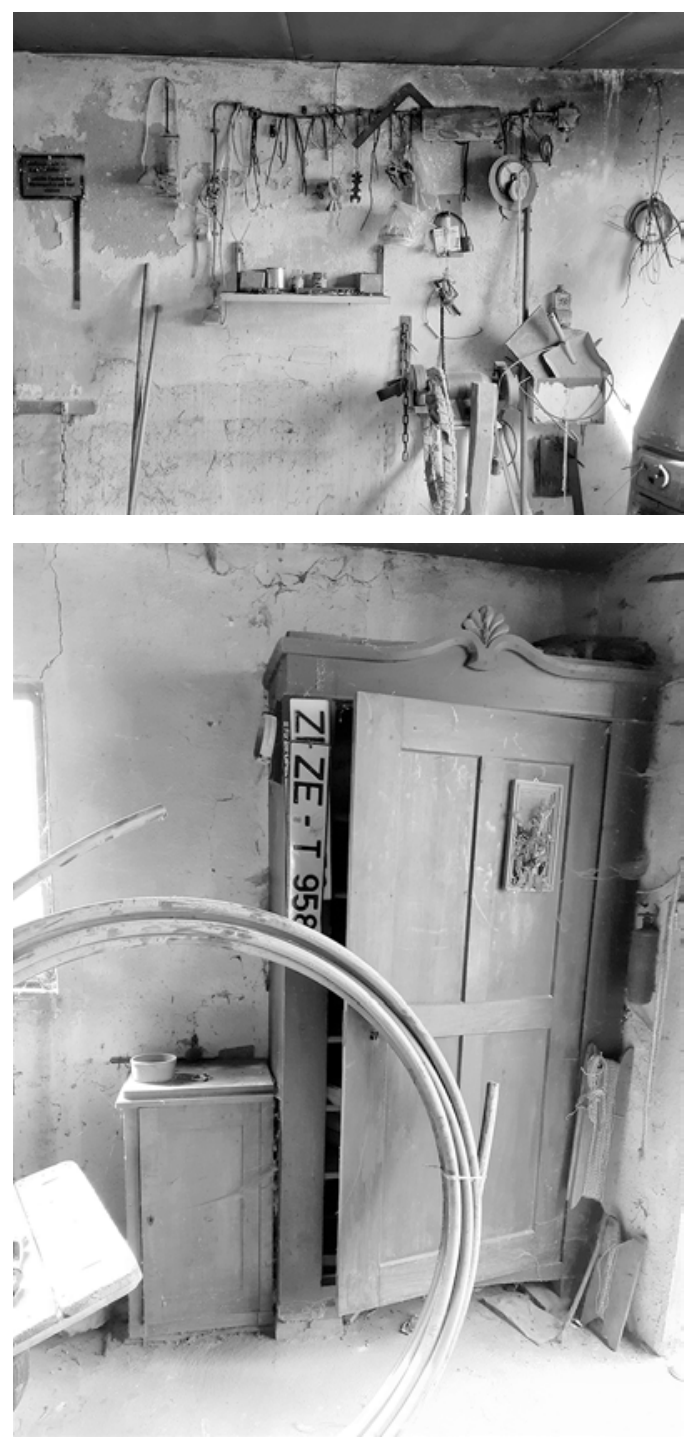

Abb. 76 und 77: Manche Einrichtungsgegenstände, Werkzeuge und Materialien in dieser Werkstatt sind originelle Fundstücke, anderes wirkt funktional oder alltäglich. Ich beginne zu rekonstruieren, was wozu gebraucht wurde und aus welchem Zusammenhang die Dinge stammen könnten. Fast alles hat eine Patina angesetzt, auch die Wände und die Möbel. Das künstlerisch geschulte Auge freut sich daran. Über allem liegt der Schleier der Zeit. Das Gehöft stammt aus dem wilhelminischen Deutschland, erlebte die Weimarer Republik, das Dritte Reich, die Nachkriegszeit, die Zeit der DDR, die Wende, den Jahrtausendwechsel. Wir übernahmen das Anwesen im Alter von 136 Jahren. In welche Zukunft wird sich all dies nun nach und nach verwandeln? Welche neuen Kräfte werden hier nun freigesetzt? Was werden die Dynamiken sein und was werden die Richtungen sein, in die sich das Canze nun bewegt? Werden das Refugien für das Verfassen von Literatur, Studios für das Drehen von Filmen, Ateliers für Handwerk oder Creative Arts, oder Experimentierräume im Sinne von Industrie 4.0? 


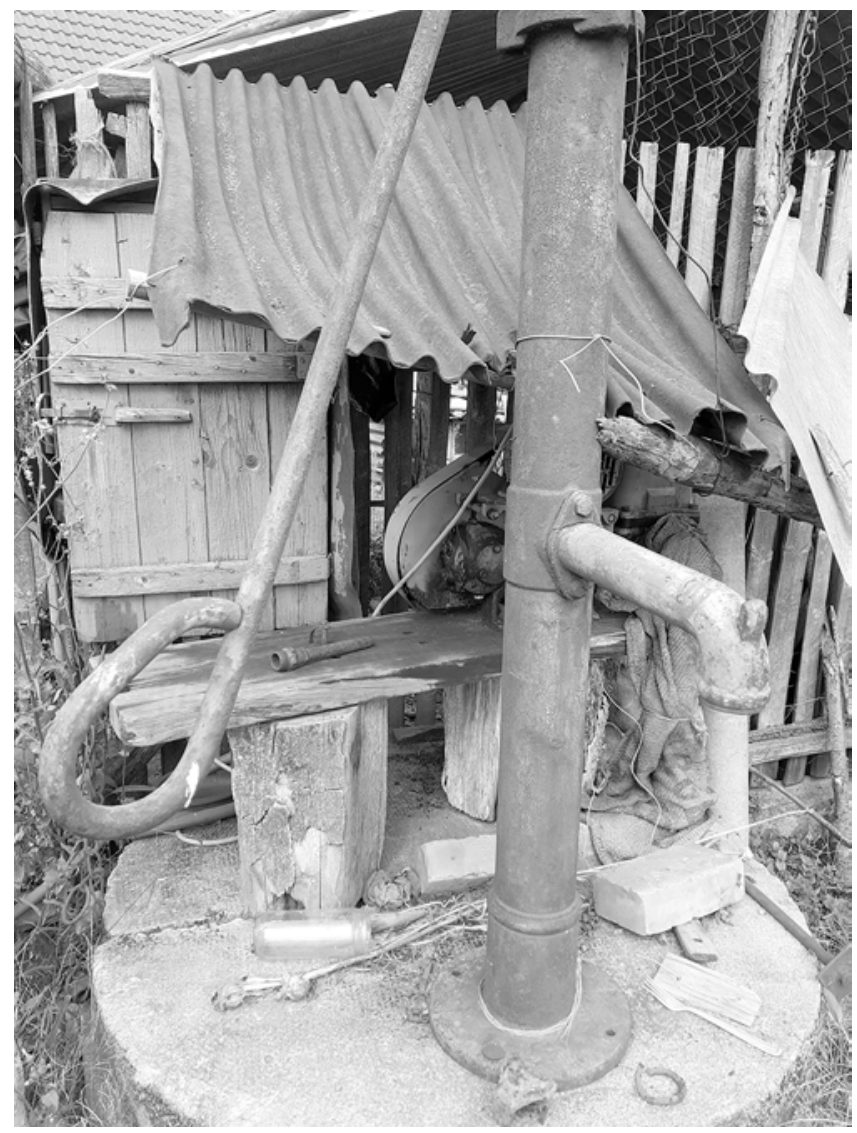

Abb. 78: Hinter den Gebäuden, in Richtung der Felder, befindet sich ein Brunnen, dessen Wasser zur Bewässerung des Cemüsegartens verwendet werden kann. Ein weiterer Brunnen befindet sich vorne neben dem Wohnhaus. Die manuelle Pumpe funktioniert nicht mehr. Auf dem horizontalen Holzbrett befindet sich ein Motor zum Hochpumpen des Wassers. Er stammt noch aus der Zeit der Deutschen Demokratischen Republik. Gemäß der Bedienungsanleitung von 1987 wurde er vom VEB Kombinat Pumpen und Verdichter in Salzwedel hergestellt. Durch welche neuen Techniken und Geräte lässt sich diese, in die Jahre gekommene, Installation ersetzen? Die immer trockener werdenden Sommer in Ostdeutschland werfen die Frage nach sinnvollen Anbau- und Bewässerungsmethoden auf. 


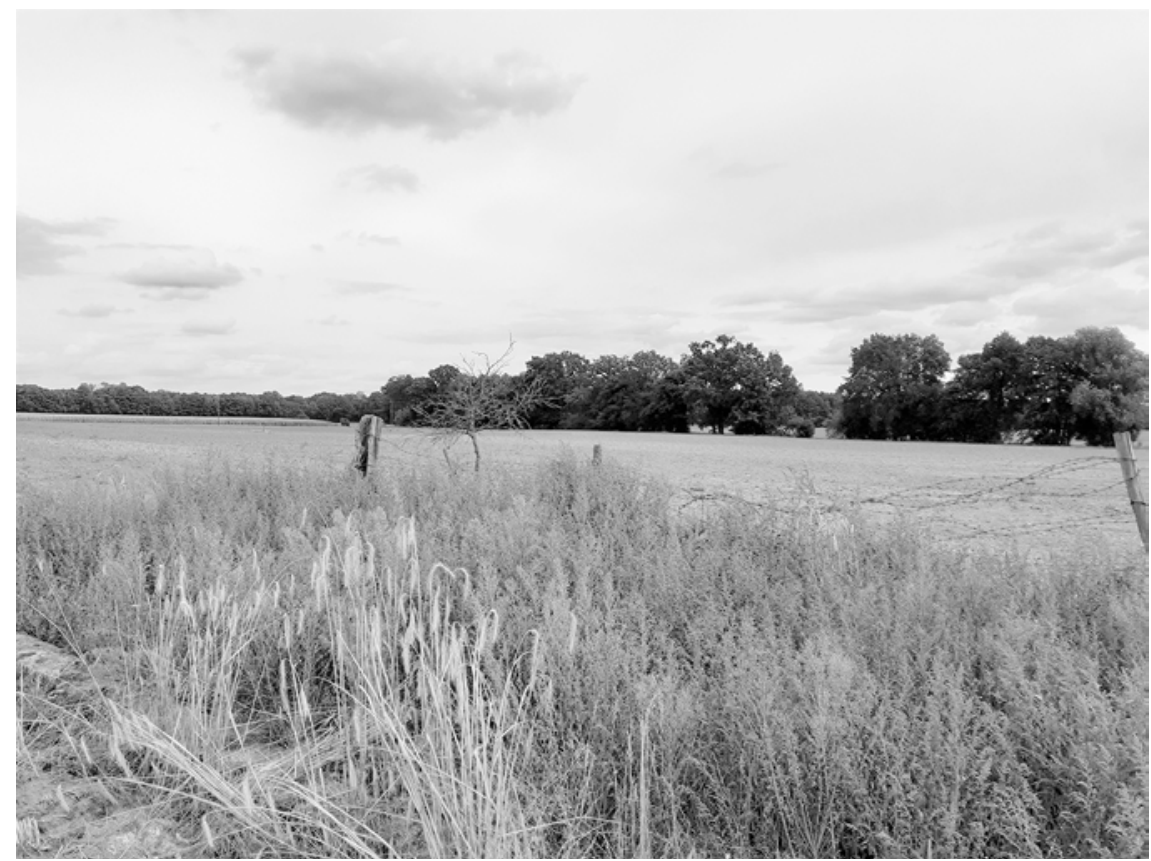

Abb. 79: Ein ausreichend großes Stück Land gehört bei einem solchen Projekt dazu. Für die Familie, die hier früher lebte, war die Bewirtschaftung der Felder die hauptsächliche Existenzgrundlage. Für uns ist der Kontext nun ein anderer. Der Boden soll uns nun nicht mehr in der Hauptsache mit Kartoffeln, Roggen oder Rüben, die er hervorbringt, ernähren, sondern er soll jetzt, gemeinsam mit den darauf befindlichen Gebäuden, zu einem Treibhaus neuer gesellschaftlicher Entwicklung werden. Derzeit ist dieses Land noch an einen lokalen Bauern verpachtet. Entlang der Bäume fließt ein kleines Bächlein, eher ein Rinnsal. Vieles könnte hier in Zukunft möglich werden. Auf welche Art und Weise dies geschehen kann, ist noch offen und bedarf vielerlei Überlegungen und des Austauschs mit Menschen im Bereich der Gemeinwohl-Ökonomie ${ }^{1}$, wie sie sich derzeit in verschiedenen europäischen und lateinamerikanischen Ländern etabliert, oder im Bereich Permakultur, wie sie von den Australiern Bill Mollison und David Holmgren begründet und von zahlreichen Stakeholder_innen (vgl. z. B. Otterpohl, 2017), bis in die Gegenwart hinein, weiterentwickelt worden ist. Auch das Lesen der nationalen und internationalen Literatur wird uns helfen. Wir werden den Winter über erste Ideen und Konzepte entwickeln.

1 https://www.ecogood.org/ (23.11.2020) 


\section{Epilog: Mit Zuversicht und Optimismus die Zukunft gestalten}

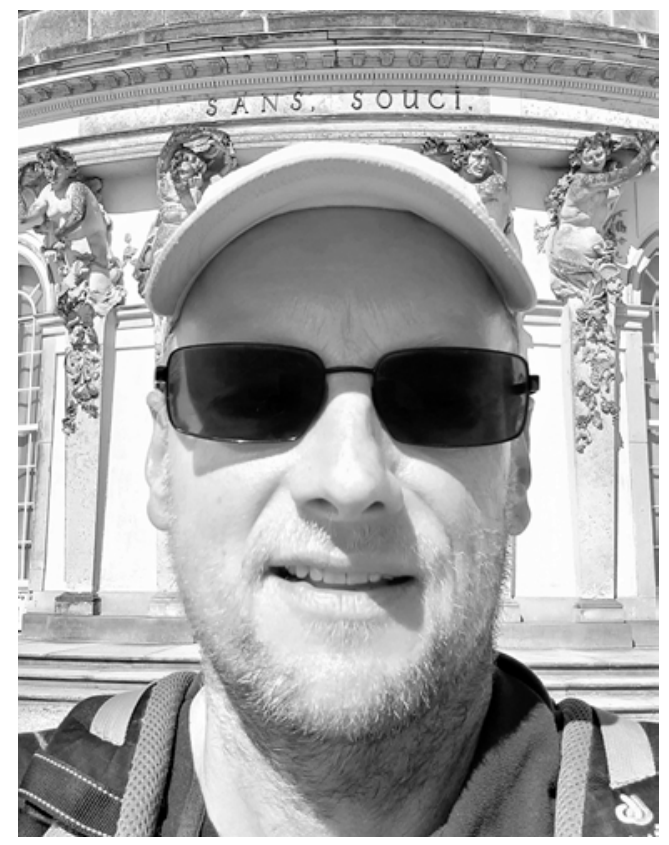

Abb. 80: Die Landschaftsparks, Architekturen und Seen im Berliner Südwesten und im Nordosten von Potsdam waren, zu weiten Teilen, die Orte und Räume der Entwicklung dessen, was ich hier in diesem Buch, nach ersten Entwürfen und etlichen Überarbeitungen, schließlich niedergeschrieben habe. Gerade Sans Souci und die sich um dieses Schlösschen rankenden Erzählungen sollen, im exemplarischen Sinne, für diese imaginationsfördernden Atmosphären stehen, daher also das Photo, genau hier. Mit John O'Donohues Büchern Eternal Echoes oder Anam Cara auf dem sonnengewärmten Marmor im Säulengang des Marmorpalais im Neuen Garten, oder bei der Orangerie sitzen, nachdenken und nachsinnen und wieder lesen, und, vor dem Rückweg nach Zehlendorf, das Fahrrad an einen Baum gelehnt, im Heiligen See schwimmen, immer noch mit Blick auf das Marmorpalais, das wie eine Fata Morgana über dem Wasser zu schweben scheint. Wo ließe sich besser über die Weite des Universums und über unsere bescheidenen Versuche, auf dem Planeten Erde etwas Vernünftiges aufzubauen, nachdenken. Sei ohne Sorge, dieser Satz ist auch von einem sehr lebenserfahrenen chinesischen Meister des Tai Chi überliefert. 



\section{Quellenverzeichnis}

\section{Literatur aus Inklusions-, Sozial- und Sonderpädagogik}

Abelein, P. und Stein, R. (2017). Förderung bei Aufmerksamkeits- und Hyperaktivitätsstörungen. Stuttgart: Kohlhammer.

Ahrbeck, B. (2020). Bildungsungerecht? Herausforderungen und Grenzen schulischer Inklusion. Forschung \& Lehre, 27 (4), 304-306.

Ahrbeck, B., Dörr, M., Göppel, R., Krebs, H. und Wininger, M. (Hg.) (2016). Innere und äußere Grenzen: Psychische Strukturbildung als pädagogische Aufgabe. Jahrbuch für Psychoanalytische Pädagogik 24. Gießen: Psychosozial.

Ahrbeck, B. und Willmann, M. (2010). Pädagogik bei Verhaltensstörungen. Stuttgart: Kohlhammer.

Balke, S. (2003). Die Spielregeln im Klassenzimmer. Das Handbuch zum Trainingsraum-Programm. Bielefeld: Karoi.

Bakken, J. P., Obiakor, F. E. und Rotatori, A. F. (Hg.) (2012). Behavioral disorders: Identification, assessment and instruction of students with EBD. Bingley: Emerald, https://doi.org/10.1108/S0270-4013(2012)22.

Bertschi-Kaufmann, A. und Graber, A. (2016). Lesekompetenz, Leseleistung, Leseförderung: Grundlagen, Modelle und Materialien. Seelze: Kallmeyer.

Blumenthal, Y., Casale, G., Hartke, B., Hennemann, T., Hillenbrand, C. und Vierbuchen, M.-C. (2020). Kinder mit Verhaltensauffälligkeiten und sozial emotionalen Entwicklungsstörungen. Förderung in inklusiven Schulklassen. Stuttgart: Kohlhammer.

Blumenthal, Y. und Voß, S. (2016). Effekte des Response to Intervention-Ansatzes auf die emotionale und soziale Situation von Grundschülern der vierten Jahrgangsstufe. Empirische Pädagogik, 30 (1), 81-97.

Bowman-Perrott, L. (2009). Classwide peer tutoring. An effective strategy for students with emotional and behavioral disorders. Intervention in School and Clinic, 44 (5), 259-267, https://doi.org/10.1177/1053451208330898.

Bröcher, J. (1997). Lebenswelt und Didaktik. Unterricht mit verhaltensauffälligen Jugendlichen auf der Basis ihrer (alltags-)ästhetischen Produktionen (Nachdruck 2013). Heidelberg: Universitätsverlag Winter.

Bröcher, J. (2005 a). »Ab in den Trainingsraum!« Zur Kritik der »neuen« Disziplinierungspädagogik. PÄD Forum: unterrichten, erziehen, 33/24 (3), 139-145.

Bröcher, J. (2005 b). Die Grenzen der Disziplinierung. In J. Bröcher, Didaktische Variationen bei Schulverweigerung und Verhaltensproblemen. Impulse für Schul- und 
Unterrichtsentwicklung, sozialpädagogische Projekte und Coaching. Bd. 1: Beziehungsaufnahmen (2. Aufl., zuerst erschienen 2004, S. 148-193). Niebüll: Videel (2004), Norderstedt: Books on Demand (2005).

Bröcher, J. (2007 a). Anders unterrichten, anders Schule machen. Beiträge zur Schulund Unterrichtsentwicklung im Förderschwerpunkt Lernen. Heidelberg: Universitätsverlag Winter.

Bröcher, J. (2007b). Zur Kritik der Neuen Disziplinierungspädagogik. In J. Bröcher, Anders unterrichten, anders Schule machen. Beiträge zur Schul- und Unterrichtsentwicklung im Förderschwerpunkt Lernen (S. 108-139). Heidelberg: Universitätsverlag Winter.

Bröcher, J. (2010). Trainingsraum Kritik. Bedenken zu einem fragwürdigen Modell schulischer Disziplinierung. Norderstedt: Books on Demand.

Bröcher, J. (2011 a). Trainingsraum Kritik. Bedenken zu einem fragwürdigen Modell schulischer Disziplinierung (2. überarb. und erweit. Aufl.). Norderstedt: Books on Demand.

Bröcher, J. (2011 b). Das Trainingsraum-Programm. In J. Bröcher, Schule, Unterricht und Sozialpädagogik bei herausforderndem Verhalten: Nationale und internationale Ansätze zur pädagogischen Beziehungsgestaltung, zum Aufbau von Lernmotivation und zur Verhaltensstabilisierung, Teil I. Stendaler Studienmaterialien, Bd. 3 (S. 141-193). Norderstedt: Books on Demand.

Bröcher, J. (2011 c). Eros, Herrschaft, Missbrauch: Grenzüberschreitungen und Abgründe in der (Schul-)Pädagogik. Fallrekonstruktionen, Analysen und Perspektiven der Transformation (2. Aufl.). Stendaler Studienmaterialien, Bd. 7. Norderstedt: Books on Demand.

Bröcher, J. (2012). Collage-unterstützt Bilder machen. Kunstunterricht bei eingeschränkten Darstellungsfähigkeiten und Misserfolgserwartungen: Spielerisch zu komplexen Bildkompositionen mit dem Mobilen Layout (2. Aufl.). Norderstedt: Books on Demand.

Bröcher, J. (2014a). Das Ineinander von formaler Inklusion und interner Exklusion: Wie das »Trainingsraum«-Programm an deutschen Schulen die Disziplin im Klassenzimmer erhöhen will und dabei die Entwicklung einer stärkenorientierten und partizipativen Lernkultur verhindert (3. Aufl.). Norderstedt: Books on Demand.

Broecher, J. (2014 b). The interconnection between formal inclusion and internal exclusion: How the »Training Room« program in German schools seeks to improve classroom discipline, but in doing so inhibits the development of a participative and empowering learning culture. Norderstedt: Books on Demand.

Broecher, J. (2015 a). Implementing School-Wide Positive Behavioral Interventions and Supports (PBIS) in German schools: The challenge of knowledge politics, education cultures and teacher perspectives. In B. Higgins (Hg.), Goal setting and personal development: Teachers' perspectives, behavioral strategies and impact on performance (S. 101-151). New York: Nova Science Publishers, Open Access.

Broecher, J. (2016). The long struggle to turn around an inhumane, corrupt, paramilitary school specialized for students with emotional and behavioral difficulties. In R. Nata (Hg.), Progress in Education, Vol. 38 (S. 39-72). New York: Nova Science Publishers, Open Access.

Broecher, J. (2019a). Creating learning spaces: Experiences from educational fields. Bielefeld: transcript, https://doi.org/10.14361/9783839448878. 
Broecher, J. (2019 b). Accessing art with Movable Layout. In J. Broecher, Creating learning spaces: Experiences from educational fields (S. 55-72). Bielefeld: transcript, https://doi.org/10.14361/9783839448878.

Broecher, J. (2019c). Challenging disabling school policies. In J. Broecher, Creating learning spaces: Experiences from educational fields (S. 73-90). Bielefeld: transcript, https://doi.org/10.14361/9783839448878.

Brozio, P. (2015). Umgang mit schwierigen Schülern: Intervention, Prävention, Classroom Management. München: Oldenbourg.

Bründel, H. und Simon, E. (2013). Die Trainingsraum-Methode (3. Aufl., zuerst 2003). Weinheim: Beltz.

Burns, B. J. und Goldman, S. K. (1999). Promising practices in wraparound for children with serious emotional disturbances and their families: Systems of care. Promising Practices in Children's Mental Health, 1998 Series, Volume IV. Washington, D. C.: Center for Effective Collaboration and Practice, The American Institutes for Research.

Casale, G., Hennemann, T. und Hövel, D. (2014). Systematischer Überblick über deutschsprachige schulbasierte Maßnahmen zur Prävention von Verhaltensstörungen in der Sekundarstufe I. Empirische Sonderpädagogik, 1, 33-58.

Casale, G., Hennemann, T., Huber, C. und Grosche, M. (2015 a). Testgütekriterien der Verlaufsdiagnostik von Schülerverhalten im Förderschwerpunkt Emotionale und Soziale Entwicklung. Heilpädagogische Forschung, 41 (1), 37-54.

Casale, G., Hennemann, T., Volpe, R. J. und Grosche, M. (2015 b). Generalisierbarkeit und Zuverlässigkeit von Direkten Verhaltensbeurteilungen des Lern- und Arbeitsverhaltens in einer inklusiven Grundschulklasse. Empirische Sonderpädagogik, 7 (3), 258-268.

Casale, G., Huber, C., Hennemann, T. und Grosche, M. (2019). Direkte Verhaltensbeurteilung in der Schule. Eine Einführung für die Praxis. München: Reinhardt.

Chandler, L. K. und Dahlquist, C. M. (2010). Functional assessment. Strategies to prevent and remediate challenging behaviors in school settings (3. Aufl.). Upper Saddle River, New Jersey: Pearson Education.

Claßen, A. und Nießen, K. (2006). Das Trainingsraum-Programm. Unterrichtsstörungen pädagogisch auflösen. Mülheim: Verlag an der Ruhr.

Clough, P., Garner, P., Pardeck, J. T. und Yuen, F. (Hg.) (2005). Handbook of emotional and behavioural difficulties. London: Sage.

Cole, T., Daniels, H. und Visser, J. (2013). The Routledge international companion to emotional and behavioural difficulties. Milton Park: Routledge, https://doi.org/ 10.4324/9780203117378.

Dilling, H., Mombour, W. und Schmidt, M.H. (2015). Internationale Klassifikation psychischer Störungen. ICD-10 Kapitel V (F), klinisch-diagnostische Leitlinien (10. Aufl.). Göttingen: Hogrefe.

Eber, L. und Keenan, S. (2004). Collaboration with other agencies: Wraparound and systems of care for children and youths with emotional and behavioral disorders. In R. B. Rutherford Jr, M. M. Quinn und S. R. Mathur (Hg.), Research in emotional and behavioral disorders (S. 502-516). New York: Guilford.

Eichhorn, C. und Sucholetz, A. v. (2019). Chaos im Klassenzimmer: Classroom-Management: Damit guter Unterricht noch besser wird (4. Aufl.). Stuttgart: KlettCotta. 
Emerson, E. und Einfeld, S. L. (2011). Challenging behaviour. Cambridge, UK; New York: Cambridge University Press, https://doi.org/10.1017/CBO9780511861178.

Ennis, R.P. und Jolivette, K. (2014). Existing research and future directions for self-regulated strategy development with students with and at risk for emotional and behavioral disorders. The Journal of Special Education, 48 (1), 32-45, https://doi. org/10.1177/0022466912454682.

Falkai, P. und Wittchen, H.-U. (Hg.) (2018). Diagnostisches und statistisches Manual psychischer Störungen, DSM-5 (2. Aufl.). Göttingen: Hogrefe, https://doi.org/10.10 26/02803-000.

Ferri, B. A. (2012). Undermining inclusion? A critical reading of response to intervention (RTI). International Journal of Inclusive Education, 16 (8), 863-880, https://doi. org/10.1080/13603116.2010.538862.

Fingerle, M. (2008). Einführung in die Entwicklungspsychopathologie. In B. Gasteiger-Klicpera, H. Julius und C. Klicpera (Hg.), Sonderpädagogik der sozialen und emotionalen Entwicklung. Handbuch Sonderpädagogik, Bd. 3 (S. 67-80). Göttingen: Hogrefe.

Fitting, K. und Kluge, K.-J. (1982). Aspekte erziehungstherapeutischen Unterrichts bei verhaltensgestörten Kindern und Jugendlichen. Hagen: Studienbrief Fernuniversität Hagen.

Fitting, K. und Kluge, K.-J. (Hg.) (1989). Brücken zueinander. Europa in integrativen Jugendseminaren: Eine Text- und Bilddokumentation der Europa-Jugendseminare 1977-1987. Bonn: Reha-Verlag.

Fitting, K., Kluge, K.-J. und Steinberg, D. (1981). »Sich auf seine Schüler einlassen.« Zur Konfliktregelung und Kommunikationsverbesserung im erziehungstherapeutischen Unterricht. München: Minerva Publikation.

Fitting, K. und Saßenrath-Döpke, E.-M. (Hg.) (1993). Pädagogik und Auffälligkeit. Impulse für Lehren und Lernen bei erwartungswidrigem Verhalten. Festschrift zum 60. Geburtstag von Karl-Josef Kluge. Weinheim: Deutscher Studien Verlag.

Flissikowski, R., Kluge, K.-J. und Schauerhammer, K. (1980). Vom Prügelstock zur Erziehungsklasse für »schwierige« Kinder: Zur Sozialgeschichte abweichenden Verhaltens in der Schule. München: Minerva Publikation.

Garner, P., Kaufman, J. und Elliott, J. (2014). The Sage handbook of emotional and behavioural difficulties. Los Angeles: Sage, https://doi.org/10.4135/9781446247525.

Gasteiger-Klicpera, B., Julius, H. und Klicpera, C. (Hg.) (2008). Sonderpädagogik der sozialen und emotionalen Entwicklung. Handbuch Sonderpädagogik, Bd. 3. Göttingen: Hogrefe.

Göppel, R. (2002). »Arizona« - ein Programm zur Förderung der »Eigenverantwortung« oder ein Disziplinierungsinstrument? In Institut für Weiterbildung der $\mathrm{PH}$ Heidelberg, Informationsschrift, No. 26, S. 52.

Goetze, H. (1994). Pädagogik bei Verhaltensstörungen: Innovationen. Bad Heilbrunn: Klinkhardt.

Goetze, H. und Neukäter, H. (Hg.) (1993). Pädagogik bei Verhaltensstörungen. Handbuch Sonderpädagogik, Bd. 6 (2. Aufl.). Berlin: Marhold.

Gresham, F. M. (2007). Response to intervention and emotional and behavioral disorders: Best practices in assessment for intervention. Assessment for Effective Intervention, 32 (4), 214-222, https://doi.org/10.1177/15345084070320040301. 
Gresham, F. M. und Elliott, S. N. (2014). Social skills assessment and training in emotional and behavioral disorders. In H. M. Walker und F. M. Gresham (Hg.), Handbook of evidence-based practices for emotional and behavioral disorders (S. 152172). New York: Guilford.

Groeben, N. und Hurrelmann, B. (Hg.) (2009). Lesekompetenz. Bedingungen, Dimensionen, Funktionen. Weinheim, Basel: Beltz Juventa.

Hänsel, D. und Schwager, H. J. (2003). Einführung in die sonderpädagogische Schultheorie. Weinheim: Beltz.

Hartke, B. (2017). Handlungsmöglichkeiten schulische Inklusion. Das Rügener Modell kompakt. Stuttgart: Kohlhammer.

Hartmann, B. (2004). Entwicklung von Screeningverfahren zur Erfassung sozialer Kompetenzen von Schülerinnen und Schülern. In W. Mutzeck und P. Jogschies (Hg.), Neue Entwicklungen in der Förderdiagnostik (S. 186-193). Weinheim: Beltz.

Hartmann, B. und Methner, A. (2015). Leipziger Kompetenzscreening für die Schule (LKS). Diagnostik und Förderplanung: Soziale und emotionale Kompetenzen, Lern- und Arbeitsverhalten. München: Reinhardt.

Hawken, L. S., Vincent, C. G. und Schumann, J. (2008). Response to intervention for social behavior: Challenges and opportunities. Journal of Emotional and Behavioral Disorders, 16 (4), 213-225, https://doi.org/10.1177/1063426608316018.

Heilmann, J., Eggert-Schmid Noerr, A. und Pforr, U. (Hg.) (2015). Neue Störungsbilder. Mythos oder Realität? Psychoanalytisch-pädagogische Diskussionen zu ADHS, Asperger-Autismus und anderen Diagnosen. Gießen: Psychosozial, https://doi. org/10.30820/9783837968262.

Hillenbrand, C. (2003). Didaktik bei Unterrichts- und Verhaltensstörungen (2. Aufl.). München: Reinhardt.

Hillenbrand, C. (2008). Einführung in die Pädagogik bei Verhaltensstörungen (4. Aufl.). München: Reinhardt.

Hillenbrand, C., Hennemann, T., Hens, S. und Hövel, D. (2015). »Lubo aus dem All!« 1. und 2. Klasse: Programm zur Förderung sozial-emotionaler Kompetenzen (3. Aufl.). München: Reinhardt.

Hintz, A.-M., Krull, J., Paal, M., Schirmer, R., Boon, R. T. und Burke, M. D. (2014). »Du wurdest bei einer guten Tat beobachtet!« Förderung positiven Verhaltens durch Tootling. Zeitschrift für Heilpädagogik, 12, 440-453.

Hövel, D. C., Zimmermann, D., Meyer, B. und Gingelmaier, S. (2020). »Und bist du nicht willig, so brauch ich Gewalt.« Der Trainingsraum: Empirische Befunde, theoretische Perspektiven, pädagogische Alternativen. Sonderpädagogische Förderung heute, 65 (3), 291-305.

Huber, C. und Grosche, M. (2012). Das Response-to-Intervention-Modell als Grundlage für einen inklusiven Paradigmenwechsel in der Sonderpädagogik. Zeitschrift für Heilpädagogik, 63, 312-322.

Huber, C. und Rietz, C. (2015). Direct Behavior Rating (DBR) als Methode zur Verhaltensverlaufsdiagnostik in der Schule: Ein systematisches Review von Methodenstudien. Empirische Sonderpädagogik, 7 (2), 75-98.

Jantzen, W. (Hg.) (2012 a). Kulturhistorische Didaktik. Rezeption und Weiterentwicklung in Europa und Lateinamerika. Berlin: Lehmanns Media.

Jantzen, W. (2012 b). Am Anfang war der Sinn. Zur Naturgeschichte, Psychologie und Philosophie von Tätigkeit, Sinn und Dialog (2. Aufl.). Berlin: Lehmanns Media. 
Jantzen, W. (2012 c). Diagnostik, Dialog und Rehistorisierung: Methodologische Bemerkungen zum Zusammenhang von Erklären und Verstehen im diagnostischen Prozess. In W. Jantzen und W. Lanwer (Hg.), Diagnostik als Rehistorisierung. Methodologie und Praxis einer verstehenden Diagnostik am Beispiel schwer behinderter Menschen (2. Aufl., S. 9-32). Berlin: Lehmanns Media.

Jantzen, W. (2012 d). Kulturhistorische Didaktik und soziokulturelle Situation - Ein Bericht aus einem Forschungsprojekt in Brasilien. In W. Jantzen (Hg.), Kulturhistorische Didaktik. Rezeption und Weiterentwicklung in Europa und Lateinamerika (S. 367-416). Berlin: Lehmanns Media.

Jantzen, W. (2018). »Es kommt darauf an sich zu verändern ...« Zur Methodologie und Praxis rehistorisierender Diagnostik und Intervention (2. Aufl.). Gießen: Psychosozial.

Jantzen, W. (2019). Behindertenpädagogik als synthetische Humanwissenschaft. Sozialwissenschaftliche und methodologische Erkundungen. Gießen: Psychosozial, https://doi.org/10.30820/9783837974812.

Jantzen, W. (2020 a). »... die da dürstet nach Gerechtigkeit.« Deinstitutionalisierung in einer Großreinrichtung der Behindertenhilfe. Berlin: Lehmanns Media.

Jantzen, W. (2020 b). Seele, Sinn und Emotionen. Essays zu Grundfragen der Humanwissenschaften. Gießen: Psychosozial, https://doi.org/10.30820/9783837976663.

Jantzen, W. und Lanwer, W. (Hg.) (2012). Diagnostik als Rehistorisierung. Methodologie und Praxis einer verstehenden Diagnostik am Beispiel schwer behinderter Menschen (2. Aufl.). Berlin: Lehmanns Media.

Jimerson, S. R., Burns, M. K. und van der Heyden, A. M. (Hg.) (2015). Handbook of Response to Intervention. The science and practice of multi-tiered systems of support: New York: Springer.

Jornitz, S. (2004). Der Trainingsraum: Unterrichtsstörung als Bumerang. Pädagogische Korrespondenz, 33, 98-117.

Kaiser, B. und Rasminsky, J. S. (2012). Challenging behavior in young children: Understanding, preventing, and responding effectively (3. Aufl.). Boston, MA: Pearson.

Kalberg, J. R., Lane, K. L., Driscoll, S. und Wehby, J. (2011). Systematic screening for emotional and behavioral disorders at the high school level: A formidable and necessary task. Remedial and Special Education, 32 (6), 506-520, https:/doi.org/ 10.1177/0741932510362508.

Kalis, T. M., Vannest, K. J. und Parker, R. (2007). Praise counts: Using self-monitoring to increase effective teaching practices. Preventing School Failure, 51, 20-27, https://doi.org/10.3200/PSFL.51.3.20-27.

Kavale, K. A., Mathur, S. R., Forness, S. R., Rutherford, R. B. und Quinn, M. M. (1997). Effectiveness of social skills training for students with behavior disorders: A meta-analysis. In T. E. Scruggs und M. A. Mastropieri (Hg.), Advances in learning and behavioral disabilities (Vol. 11, S. 1-26). Greenwich, CT: JAI.

Kavale, K. A., Mathur, S. R. und Mostert, M. P. (2004). Social skills training and teaching social behavior to students with emotional and behavioral disorders. In R. B. Rutherford, M. M. Quinn und S. R. Mathur (Hg.), Handbook of research in emotional and behavioral disorders (S. 446-461). New York: Guilford.

Kilb, R., Weidner, J. und Gall, R. (2013). Konfrontative Pädagogik in der Schule: AntiAggressivitäts- und Coolness-Training. Weinheim: Beltz Juventa. 
Kilgus, S. P., Eklund, K., Maggin, D. M., Taylor, C. N. und Allen, A. N. (2018). The Student Risk Screening Scale: A reliability and validity generalization meta-analysis. Journal of Emotional and Behavioral Disorders, 26 (3), 143-155, https://doi.org/10.11 77/1063426617710207.

Killu, K. (2008). Developing effective behavior intervention plans: Suggestions for school personnel. Intervention in School and Clinic, 43 (3), 140-149, https://doi.org/ 10.1177/1053451207311610.

Klaffke, T. (2018). Klassen führen - Klassen leiten: Beziehungen, Lernen, Classroom Management (2. Aufl.). Seelze: Klett, Kallmeyer.

Klein, R. (2000). West Walker Primary School, Newcastle: And finds a school bringing new hope to a demoralized community. Improving Schools, 3 (2), 18-21, https://doi. org/10.1177/136548020000300203.

Kluge, K.-J. und Suermondt-Schlembach, K. (1981). Hochintelligente verhaltensauffällig gemacht? München: Minerva Publikation.

Landrum, T. J. (2000). Assessment for eligibility: Issues in identifying students with emotional or behavioral disorders. Assessment for Effective Intervention, 26 (1), 41-49, https://doi.org/10.1177/073724770002600106.

Lane, K. L., Bruhn, A. L., Eisner, S. L. und Kalberg, J. R. (2010). Score reliability and validity of the Student Risk Screening Scale: A psychometrically-sound, feasible tool for use in urban middle schools. Journal of Emotional and Behavioral Disorders, 18, 211-224, https://doi.org/10.1177/1063426609349733.

Lane, K. L., Kalberg, J. R., Lambert, W., Crnobori, M. und Bruhns, A. (2010). A comparison of systematic screening tools for emotional and behavioral disorders: A replication. Journal of Emotional and Behavioral Disorders, 18, 100-112, https://doi. org/10.1177/1063426609341069.

Levendoski, L. S. und Cartledge, G. (2000). Self-monitoring for elementary school children with serious emotional disturbances: Classroom applications for increased academic responding. Behavioral Disorders, 25, 211-234, https://doi.org/10.1177/ 019874290002500308.

Lever, C. (2011). Understanding challenging behavior in inclusive classrooms. Harlow, UK: Longman, https://doi.org/10.4324/9781315833347.

Lewis, T. J. und Newcomer, L. L. (2004). Reducing problem behavior through schoolwide systems of Positive Behavior Support. In P. Clough, P. Garner, J. T. Pardeck und F. Yuen (Hg.), Handbook of Emotional \& Behavioral Difficulties (S. 261-272). London: Sage, https://doi.org/10.4135/9781848608146.n16.

Linderkamp, F. (2008). Lerntheoretische Interventionen: Konditionierung und Verhaltensmodifikation. In B. Gasteiger-Klicpera, H. Julius und B. Gasteiger-Klicpera (Hg.), Sonderpädagogik der sozialen und emotionalen Entwicklung. Handbuch Sonderpädagogik, Bd. 3 (S. 471-486). Göttingen: Hogrefe.

Lueken, G.-L. (2010). Paradigma/Paradigmenwechsel. In D. Horster und W. Jantzen (Hg.). Wissenschaftstheorie (Enzyklopädisches Handbuch der Behindertenpädagogik, Bd. 1, S. 162-166). Stuttgart: Kohlhammer.

Marquardt, A. (2001). Zwischenwelten. Jugendliche zwischen Schule und Straße. Münster, Hamburg, London: Lit.

Marzano, R. J. (2003). Classroom management that works. Research-based strategies for every teacher. Alexandria, VA: Association for Supervision and Curriculum Development. 
Marzano, R. J., Gaddy, B. B., Foseid, M.C., Foseid, P. und Marzano, J.S. (2005). A handbook for classroom management that works. Alexandria, VA: Association for Supervision and Curriculum Development.

Michie, G. (Hg.) (2005). See you when we get there: Teaching for change in urban schools. New York: Teachers College Press.

Michie, G. (2009). Holler if you hear me: The education of a teacher and his students (2. Aufl.). New York: Teachers College Press.

Minahan, J. und Rappaport, N. (2012). The behavior code: A practical guide to understanding and teaching the most challenging students. Cambridge, MA: Harvard Education Press.

Müller, T. (2018). Kinder mit auffälligem Verhalten unterrichten. Fundierte Praxis in der inklusiven Grundschule. München: Reinhardt.

Mutzeck, W. (2000 a). Förderdiagnostik bei Lern- und Verhaltensstörungen: Konzepte und Methoden. Weinheim: Deutscher Studienverlag.

Mutzeck, W. (2000 b). Verhaltensgestörtenpädagogik und Erziehungshilfe. Bad Heilbrunn: Klinkhardt.

Mutzeck, W. (2002). Förderdiagnostik: Konzepte und Methoden (3. überarb. Aufl.). Weinheim: Beltz.

Mutzeck, W. (2004). Neue Entwicklungen in der Förderdiagnostik: Grundlagen und praktische Umsetzungen. Weinheim: Beltz.

Mutzeck, W., Fingerle, M. und Hartmann, B. (2017). Screening für Verhaltensauffälligkeiten im Schulbereich. Als Anhang in K. Popp, C. Melzer und A. Methner. Förderpläne entwickeln und umsetzen (S. 160-164). München: Reinhardt.

Mutzeck, W. und Pallasch, W. (Hg.) (1992). Integration von Schülern mit Verhaltensstörungen: Praktische Modelle und Versuche. Weinheim: Deutscher Studienverlag.

Myschker, N. und Stein, R. (2018). Verhaltensstörungen bei Kindern und Jugendlichen (8. Aufl.). Stuttgart: Kohlhammer.

Netzel, D. M. und Eber, L. (2003). Shifting from reactive to proactive discipline in an urban school district: A change of focus through PBIS implementation. Journal of Positive Behavior Interventions, 5(2), 71-79, https://doi.org/10.1177/109830070300 50020201.

Opp, G. (2000). Ko-Morbidität: Überschneidungen zwischen Gefühls- und Verhaltensstörungen und speziellen Lernstörungen/Aufmerksamkeitsstörungen als pädagogische Herausforderung an die Schule. In S. Rolus-Borgwardt, U. Tänzer und M. Wittrock (Hg.), Beeinträchtigung des Lernens und/oder Verhaltens. Unterschiedliche Ausdrucksformen für ein gemeinsames Problem (S. 11-18). Oldenburg: Didaktisches Zentrum der Carl von Ossietzky Universität Oldenburg.

Petermann, F., Petermann, U. und Nitkowski, D. (2016). Emotionstraining in der Schule: Ein Programm zur Förderung der emotionalen Kompetenz. Göttingen: Hogrefe, https://doi.org/10.1026/02687-000.

Polsgrove, L. und Smith, S.W. (2004). Informed practice in teaching self-control to children with emotional and behavioral disorders. In R. B. Rutherford, M. M. Quinn und S. R. Mathur (Hg.), Handbook of research in emotional and behavioral disorders (S. 399-425). New York: Guilford.

Popp, K., Melzer, C. und Methner, A. (2017). Förderpläne entwickeln und umsetzen. München: Reinhardt. 
Reid, R., Gonzalez, J. E. W., Nordness, P. D., Trout, A. L. und Epstein, M. H. (2004). A meta-analysis of the academic status of students with emotional/behavioural disturbance. Journal of Special Education, 38, 130-143, https://doi.org/10.1177/002246 69040380030101.

Reinke, W. M., Lewis-Palmer, T. und Merrell, K. (2008). The classroom check-up: A classwide consultation model for increasing praise and decreasing disruptive behavior. School Psychology Review, 37, 315-332, https://doi.org/10.1080/02796015.2 008.12087879 .

Reinke, W.M., Herman, K.C. und Sprick, R. (2011). Motivational interviewing for effective classroom management: The classroom check-up. New York: Guilford.

Ricken, G. (Hg.) (2003). Diagnose: Sonderpädagogischer Förderbedarf. Lengerich: Pabst Science Publ.

Ricking, H. und Dunkake, I. (2017). Wenn Schüler die Schule schwänzen oder meiden: Förderziele Anwesenheit und Lernen-wollen. Baltmannsweiler: Schneider Hohengehren.

Rutherford, R. B., Quinn, M. M. und Mathur, S. R. (Hg.) (2004). Handbook of research in emotional and behavioral difficulties. New York: Guilford.

Sailor, W., Dunlap, G., Sugai, G. und Horner, R. (Hg.) (2009). Handbook of Positive Behavior Support. New York: Springer, https://doi.org/10.1007/978-0-387-09632-2.

Schramm, S. A. (2018). Selbstmanagement-Therapie. In G.W. Lauth und F. Linderkamp (Hg.), Verhaltenstherapie mit Kindern und Jugendlichen (4. Aufl., S. 696705). Weinheim: Beltz.

Scott, T. M. und Eber, L. (2003). Functional assessment and wraparound as systemic school processes: Primary, secondary, and tertiary systems examples. Journal of Positive Behavior Interventions, 5(3), 131-143, https://doi.org/10.1177/10983007030 050030201.

Silkenbeumer, M. (2006). Entwicklungswege weiblicher Jugendlicher in die Gewaltbereitschaft. In W. Heitmeyer und M. Schröttle (Hg.), Gewalt (S. 318-324). Bonn: Schriftenreihe der Bundeszentrale für politische Bildung.

Silkenbeumer, M. (2007). Biografische Selbstentwürfe und Weiblichkeitskonzepte aggressiver Mädchen und junger Frauen. Münster: Lit.

Simpson, R. L. (2004). Inclusion of students with behavior disorders in general education settings: Research and measurement issues. Behavioral Disorders, 30 (1), 19-31, https://doi.org/10.1177/019874290403000104.

Smith, B.W. und Sugai, G. (2000). A self-management functional assessment-based behavior support plan for a middle school student with EBD. Journal of Positive Behavior Interventions, 2 (4), 208-217, https://doi.org/10.1177/109830070000200405.

Stadler, C., Janke, W. und Schmeck, K. (2004). Inventar zur Erfassung von Impulsivität, Risikoverhalten und Empathie bei 9-14 jährigen Kindern. Göttingen: Hogrefe.

Stein, R. (2008). Grundwissen Verhaltensstörungen. Baltmannsweiler: Schneider Hohengehren.

Stein, R. (2012). Förderung bei Ängstlichkeit und Angststörungen. Stuttgart: Kohlhammer.

Stein, R. und Kranert, H.-W. (2020). Transition Schule-Beruf für Jugendliche mit psychischen Störungen - ein Theoriemodell. In R. Stein und H.-W. Kranert (Hg.), Inklusion in der Berufsbildung im kritischen Diskurs (S. 121-155). Berlin: Frank \& Timme. 
Sugai, G. und Lewis-Palmer, T. (2004). Overview of a function-based approach to behavior support within schools. Assessment for Effective Intervention, 30 (1), 1-5, https://doi.org/10.1177/073724770403000101.

Sutherland, K., Wehby, J.H. und Copeland, S. R. (2000). Effect of varying rates of behavior-specific praise on the on-task behavior of students with EBD. Journal of Emotional and Behavioral Disorders, 8 (1), 2-8, 26, https://doi.org/10.1177/106342 660000800101.

Syring, M. (2017). Classroom Management: Theorien, Befunde, Fälle. Hilfen für die Praxis. Göttingen: Vandenhoeck \& Ruprecht, https://doi.org/10.13109/9783666701856.

Theunissen, G. (1992). Heilpädagogik und Soziale Arbeit mit verhaltensauffälligen Kindern und Jugendlichen. Freiburg i. Br.: Lambertus.

Theunissen, G. (2003). Erwachsenenbildung und Behinderung. Impulse für die Arbeit mit Menschen, die als lern- und geistig behindert gelten. Bad Heilbrunn: Klinkhardt.

Theunissen, G. (2013). Empowerment und Inklusion behinderter Menschen. Eine Einführung in Heilpädagogik und Soziale Arbeit (3. Aufl.). Freiburg i. Br.: Lambertus.

Thimm, K. (2000). Schulverweigerung. Zur Begründung eines neuen Verhältnisses von Sozialpädagogik und Schule. Münster: Votum.

Todd, A., Horner, R. H. und Sugai, G. (1999). Self-monitoring and self-recruited praise: Effects on problem behavior, academic engagement, and work completion in a typical classroom. Journal of Positive Behavior Interventions, I (2), 66-76, 122, https:// doi.org/10.1177/109830079900100201.

Toman, H. (2017). Classroom-Management: Praxishilfen für das Classroom-Management (3. aktual. Aufl.). Baltmannsweiler: Schneider Hohengehren.

Trout, A. L., Nordness, P. D., Pierce, C. D. und Epstein, M. H. (2003). Research on the academic status of children with emotional and behavioral disorders: A review of the literature from 1961 to 2000 . Journal of Emotional and Behavioral Disorders, 11, 198-210, https://doi.org/10.1177/10634266030110040201.

Trowell, J. und Etchegoyen, A. (Hg.) (2002). The importance of fathers. A psychoanalytic re-evaluation. New York: Routledge.

Tsai, K. H., Yeh, M. und Slymen, D. (2015). Strain in caring for youths meeting diagnosis for disruptive behavior disorders. Journal of Emotional and Behavioral Disorders, 23 (1), 40-51, https://doi.org/10.1177/1063426613503498.

Vaughn, S. R., Kim, A., Morris Sloan, C. V., Hughes, M. T., Elbaum, B. und Sridhar, D. (2003). Social skills interventions for young children with disabilities: A synthesis of group design studies. Remedial and Special Education, 24, 2-15, https://doi. org/10.1177/074193250302400101.

Voß, S., Blumenthal, Y., Mahlau, K., Marten, K., Diehl, K., Sikora, S. und Hartke, B. (2016). Der Response-to-Intervention-Ansatz in der Praxis. Evaluationsergebnisse zum Rügener Inklusionsmodell. Münster: Waxmann.

Walker, H. M. und Gresham, F. M. (2014). Handbook of evidence-based practices for emotional and behavioural disorders: Applications in schools. New York: Guilford.

Waller, R. J. (2009). The teacher's concise guide to Functional Behavioral Assessment: Thousand Oaks, CA: Corwin.

Wehby, J. H., Lane, K. L. und Falk, K. B. (2003). Academic instruction for students with emotional and behavioral disorders. Journal of Emotional and Behavioral Disorders, 11, 194-197, https://doi.org/10.1177/10634266030110040101. 
Weidner, J. und Kilb, R. (Hg.) (2010). Konfrontative Pädagogik. Konfliktbearbeitung in Sozialer Arbeit und Erziehung (4. Aufl.). Wiesbaden: VS Sozialwissenschaften, https://doi.org/10.1007/978-3-531-92406-9.

Weidner, J. und Kilb, R. (Hg.) (2011). Handbuch konfrontative Pädagogik: Grundlagen und Handlungsstrategien zum Umgang mit aggressivem und abweichendem Verhalten. Weinheim, München: Juventa.

Weisser, J. (2010). Diskursanalyse. In D. Horster und W. Jantzen (Hg.), Wissenschaftstheorie (Enzyklopädisches Handbuch der Behindertenpädagogik, Bd. 1, S. 284288). Stuttgart: Kohlhammer.

West-Leuer, B. (2007). Coaching an Schulen: psychodynamische Beratung zur Stärkung professioneller Beziehungskompetenz. Gießen: Psychosozial.

Willmann, M. (2018). Vermessung des Verhaltens, Normierung zur Inklusion? RTI als evidenzbasierte Pädagogik - eine Kritik. Zeitschrift für Grundschulforschung. Bildung im Elementar- und Primarbereich, 11(1), 101-114, https://doi.org/10.1007/ s42278-018-0006-4.

Willmann, M. (2020). Deutungsmacht der Forschung, Ohnmacht in der Praxis? - Evidenzbasierte Sonderpädagogik als Exklusionsrisiko. ESE: Emotionale und Soziale Entwicklung in der Pädagogik der Erziehungshilfe und bei Verhaltensstörungen, 2 (2), 222-232.

Wittrock, M. und Vernooij, M. (Hg.) (2008). Verhaltensgestört? Perspektiven, Diagnosen, Lösungen im pädagogischen Alltag (2. Aufl.). Paderborn: Schöningh.

Wollenweber, K.U. (2013). Evaluation des Trainingsraum-Programms. Umsetzung des Programms an Schulen und dessen Auswirkungen auf die Aufmerksamkeit und das Störverhalten von Schülern, ihre Einschätzung des Schul- und Klassenklimas sowie auf die Berufszufriedenheit und Arbeitsbelastung von Lehrkräften. Dissertation, Europa-Universität Flensburg.

Zimmermann, D. (2016). Traumapädagogik in der Schule. Pädagogische Beziehungen mit schwer belasteten Kindern und Jugendlichen. Gießen: Psychosozial.

\section{Übergreifende Literatur}

Adamo, N. (2012). Bedingungsloses Grundeinkommen. Sozialromantik oder Zukunft des Sozialstaats? Darmstadt: Büchner.

Adorno, T. W. (1971). Erziehung zur Mündigkeit. Frankfurt a. M.: Suhrkamp.

Adorno, T. W. (2018). Studien zum autoritären Charakter. Frankfurt a. M.: Suhrkamp.

Arendt, H. (2002). Vita Activa oder: Vom tätigen Leben. München: Piper.

Altrichter, H., Brüsemeister, T. und Wissinger, J. (Hg.) (2007). Educational Governance. Handlungskoordination und Steuerung im Bildungssystem. Wiesbaden: VS Sozialwissenschaften, https://doi.org/10.1007/978-3-531-90498-6.

Altrichter, H. und Maag Merki, K. (Hg.) (2016). Handbuch Neue Steuerung im Schulsystem (2. Aufl.). Wiesbaden: VS Sozialwissenschaften, https://doi.org/10.1007/978-3531-18942-0.

Ambrose, D. (2017). Interdisciplinary invigoration of creativity studies. The Journal of Creative Behavior, 51 (4), 348-351, https://doi.org/10.1002/jocb.205. 
Archer, D. (1999). Exploring »bullying« culture in the paramilitary organization. International Journal of Manpower, 20 (1), 94-105, https://doi.org/10.1108/0143772 9910268687.

August, J. (1997). "Sonderaktion Krakau« - Die Verhaftung der Krakauer Wissenschaftler am 6. November 1939. Hamburg: Hamburger Edition.

Bächle, T. C. (2016). Digitales Wissen, Daten und Überwachung. Hamburg: Junius.

Ball, S. J. (2012). The micropolitics of the school. Towards a theory of school organization. New York: Routledge, https://doi.org/10.4324/9780203808733.

Baron, R. A. und Neuman, J. H. (1996). Workplace violence and workplace aggression: Evidence on their relative frequency and potential causes. Aggressive Behavior, 22 (3), 161-173, https://doi.org/10.1002/(SICI)1098-2337(1996)22:3<161::AID-AB1>3.0.CO;2-Q.

Barwińska, D. (2004). Varia: Deutsch-polnischer Jugendaustausch als Beitrag zu einer Europa-orientierten Erziehung. Bildung und Erziehung, 57 (2), 215-230, https://doi. org/10.7788/bue.2004.57.2.215.

Bauman, Z. und Lyon, D. (2013). Daten, Drohnen, Disziplin. Ein Gespräch zur flüchtigen Überwachung. Berlin: Suhrkamp.

Becker, U. (2016). Die Inklusionslüge. Behinderung im flexiblen Kapitalismus (2. Aufl.). Bielefeld: transcript, https://doi.org/10.14361/9783839430569.

Beghetto, R.A., Kaufman, J.C. und Baer, J. (2015). Teaching for creativity in the common core classroom. New York: Teachers College Press.

Bellmann, J. (2006). Bildungsforschung und Bildungspolitik im Zeitalter »Neuer Steuerung«. Zeitschrift für Pädagogik, 52 (4), 487-504.

Bendrath, R. (2007). Der gläserne Bürger und der vorsorgliche Staat: Zum Verhältnis von Überwachung und Sicherheit in der Informationsgesellschaft. kommunikation@ gesellschaft, 8, urn:nbn:de:0228-200708035.

Benjamin, W. (2015). Das Passagen-Werk (Bd. 1 und 2, 9. Aufl.). Frankfurt a. M.: Suhrkamp.

Bennett, K., Cochrane, A., Mohan, G. und Neal, S. (2015). Listening. Emotion, Space and Society, 17, 7-14, https://doi.org/10.1016/j.emospa.2015.10.002.

Bergmann, K. und Kuhn, A. (1984). Oral history, kommunikative Geschichte, Geschichte von unten. Düsseldorf: Schwann.

Berndt, C. und Pütz, R. (Hg.) (2007). Kulturelle Geografien. Zur Beschäftigung mit Raum und Ort nach dem Cultural Turn. Bielefeld: transcript, https://doi.org/10.14 361/9783839407240.

Bingen, D., Bömelburg, H.-J., Klamt, A. und Loew, P.-O. (Hg.) (2016). Die Deutschen und die Polen. Geschichte einer Nachbarschaft. Darmstadt: Theiss Verlag (WBG).

Blase, J. und Blase, J. (2002). The dark side of leadership: Teacher perspectives of principal mistreatment. Educational Administration Quarterly, 38 (5), 671-727, https:// doi.org/10.1177/0013161X02239643.

Blase, J. und Blase, J. (2003). Breaking the silence: Overcoming the problem of principal mistreatment of teachers. Thousand Oaks, CA: Corwin.

Blase, J., Blase, J. und Du, F. (2008). The mistreated teacher: A national study. Journal of Educational Administration, 46 (3), 263-301, https://doi.org/10.1108/095782308108 69257.

Boehme-Neßler, V. (2009). Das Ende des Staates? Zu den Auswirkungen der Digitalisierung auf den Staat. Zeitschrift für öffentliches Recht, 64, 145-199, https://doi. org/10.1007/s00708-009-0024-8. 
Bömelburg, H.-J. und Kizik, E. (2014). Deutsch-polnische Geschichte - Frühe Neuzeit: Altes Reich und alte Republik. Deutsch-polnische Beziehungen und Verflechtungen 1500-1806. Darmstadt: Wissenschaftliche Buchgesellschaft.

Bohm, D. und Nichol, L. (1998). Der Dialog. Stuttgart: Klett-Cotta.

Bolz, N. (2000). Machiavelli Consulting: Über das Innovative des Bösen. In J. Weidner und Y. M. Koller-Tejeiro (Hg.), Mit Biss zum Erfolg! Durchsetzungsstärke und positive Aggression im Management (3. Aufl., S. 43-53). Bad Godesberg: Forum.

Bommert, W. (2012). Bodenrausch. Die globale Jagd nach den Äckern der Welt. Frankfurt a. M.: Eichborn.

Bommert, W. und Landzettel, M. (2017). Verbrannte Mandeln. Wie der Klimawandel unsere Teller erreicht. München: dtv.

Bono, E. de (1986). Denkschule. Zu mehr Innovation und Kreativität. Landsberg am Lech: mvg.

Bono, E. de (1992). Chancen. Das Trainingsmodell für erfolgreiche Ideensuche. Düsseldorf, Wien: Econ.

Borowicz, A. (1987). Rapport über meine Beobachtungen, Erlebnisse und Erkenntisse. In J. Bröcher, N. Griffel und K.-J. Kluge (Hg.), Mit Vergnügen Forschen und Lernen 1986: Außergewöhnliches Lernen in universitären Sommercamps (S. 312-317). München: Minerva Publikation.

Borisova, T. und Simons, W. B. (2012). The legal dimension in Cold-War interactions. Some notes from the field. Leiden, NL and Boston, MA: Martinus Niehoff Publishers.

Bowles, S. und Gintis, H. (2011). Schooling in capitalist America. Educational reform and the contradictions of economic life (Reprint der Ausgabe von 1976). Chicago, IL: Haymarket.

Braunmühl, E. v. (2006). Antipädagogik. Studien zur Abschaffung der Erziehung (Reprint der Ausgabe von 1975). Leipzig: tologo.

Bridges, W. (2009). Managing transitions. Making the most of change (3. Aufl.). Philadelphia, PA: Da Capo.

Brie, M. und Klein, D. (2011). The second great transformation: Towards a solidarity society. International Critical Thought, 1(1), 18-28.

Bröcher, J. (1989). Kreative Intelligenz und Lernen. Eine Untersuchung zur Förderung schöpferischen Denkens und Handelns, unter anderem in einem Universitären Sommercamp. München: Minerva Publikation.

Bröcher, J. (1999). Die »Murales« in Diamante. Die Leidensgeschichte des Mezzogiorno, dargestellt in den Wandbildern zeitgenössischer Künstler. Musik-, Tanz- und Kunsttherapie, 10 (4), 186-196, https://doi.org/10.1026//0933-6885.10.4.186.

Bröcher, J. (2014). Die Bräijder und ihre Zeit: Familien-, Kultur- und Gesellschaftsgeschichte im Wendener Land, Südwestfalen, 1495-1970, rekonstruiert im generationenübergreifenden Dialog, in Fotografien und Erzählungen. Neue Formen des intergenerationalen Lernens. Norderstedt: Books on Demand.

Broecher, J. (2015 b). How David P. Weikart's HighScope Summer Camp for (Gifted) Teenagers became a sustainable model for my later work in special education and inclusive education. Gifted Education International, 31(3), 244-256, https://doi. org/10.1177/0261429414526655.

Broecher, J., Davis, J.H. und Painter, J.F. (2017). Rediscovering the political dimension of the personal life story: Results from an intergenerational narrative learning 
project with older adults in South Westphalia. International Journal of Lifelong Education, 36 (4), 471-485, https://doi.org/10.1080/02601370.2017.1285361.

Bröcher, J., Griffel, N. und Kluge, K.-J. (Hg.) (1987a, b). Mit Vergnügen Forschen und Lernen 1985/1986: Außergewöhnliches Lernen in universitären Sommercamps (2 Bände). München: Minerva Publikation.

Broecher, J. und Painter, J.F. (2021). Throwing out a net over Berlin: Educators in search of the metropole's creative potential. Progress in Education, Vol. 66. New York: Nova Science Publishers, Open Access.

Broecher, J., Painter, J. F., Davis, J.H. und Williams, A. (2017). Professional growth through guided autobiografical reflection: A case study from pre-service teacher education. In R. Nata (Hg.), Progress in Education, Vol. 43 (S. 153-196). New York: Nova Science Publishers, Open Access.

Brzoska, M. und Fröhlich, C. (2016). Climate change, migration and violent conflict: Vulnerabilities, pathways and adaptation strategies. Migration and Development, 5 (2), 190-210, https://doi.org/10.1080/21632324.2015.1022973.

$\mathrm{Bu}, \mathrm{L}$. (1999). Educational exchange and cultural diplomacy in the Cold War. Journal of American Studies, 33 (3), 393-415, https://doi.org/10.1017/So021875899006167.

Buchinger, K. und Klinkhammer, M. (2003). Beratungskompetenz: Supervision, Coaching, Organisationsberatung. Stuttgart: Kohlhammer.

Chase, S. E. (2011). Narrative inquiry: Still a field in the making. In N. K. Denzin und Y.S. Lincoln (Hg.), The Sage handbook of qualitative research (4. Aufl.) (S. 421-434). Thousand Oaks, CA, London, UK: Sage.

Cless, K. (2014). Menschen am Brunnen. Ethnologische Perspektiven zum Umgang mit Wasser. Bielefeld: transcript, https://doi.org/10.14361/transcript.9783839429020.

Cöllen, B., Dudek, B. und Ruchniewicz, K. (Hg.) (2012). Polenhilfe - Pomoc dla Polski: Als Schmuggler für Polen unterwegs - Zostali przemytnikami dla Polaków. Dresden: Neisse Verlag.

Connell, R. W. (2005). Masculinities (2. Aufl., zuerst erschienen 1995). Cambridge, UK: Polity Press.

Daniel, S. und Mittal, A. (2009). The great land grab - Rush for world's farmland threatens food security for the poor. Oakland: The Oakland Institute.

Dank, B. M. (1971). Six homosexual siblings. Archives of Sexual Behavior, 1, 193-204, https://doi.org/10.1007/BFo1541682.

Davies, N. (2003). Microcosm: Portrait of a central European city. London, UK: Random House (Pimlico).

DeCelles, K. A., DeRue, D. S., Margolis, J. D. und Ceranic, T. L. (2012). Does power corrupt or enable? When and why power facilitates self-interested behavior? Journal of Applied Psychology, 97 (3), 681-689, https://doi.org/10.1037/a0026811.

Decher, F. (2000). Besuch vom Mittagsdämon. Philosophie der Langeweile. Lüneburg: zu Klampen.

Decher, F. (2012). Die Schule der Philosophen. Große Denker über Bildung und Erziehung. Darmstadt: Lambert Schneider.

Decher, F. (2020). »Eine Gesellschaft, die keine Zeit hat, lebt nicht.«Zeitnot, Ökonomie und Muße. In K. Farokhifar und H.-G. Neugebauer (Hg.), Nachlese. Philosophische Miszellen. Nachdenken, Bd. 9 (S. 41-64). Rheinbach: cmz.

Deimann, M. (2019). Open Education. Auf dem Weg zu einer offenen Hochschulbildung. Bielefeld: transcript, https://doi.org/10.14361/9783839444962. 
Depta, H. (1993). Ein Sommercamp für einen Professor oder Universitäre Sommercamps für Jugend aus aller Welt. In K. Fitting und E.-M. Saßenrath-Döpke (Hg.), Pädagogik und Auffälligkeit. Impulse für Lehren und Lernen bei erwartungswidrigem Verhalten. Festschrift zum 60. Geburtstag von Karl-Josef Kluge (S. 437-445). Weinheim: Deutscher Studien Verlag.

Deleuze, G. (1993). Postskriptum über die Kontrollgesellschaften. In G. Deleuze, Unterhandlungen, 1972-1990 (S. 254-262). Frankfurt a. M.: Suhrkamp.

De Masi, F. (2018). The sadomasochistic perversion: The entity and the theories. New York: Routledge, https://doi.org/10.4324/9780429483073.

Denninghoff A. (2015). Ressourcenkonflikte als globales Sicherheitsrisiko? In T. Jäger (Hg.), Handbuch Sicherheitsgefahren. Globale Gesellschaft und internationale Beziehungen (S. 21-32). Wiesbaden: Springer VS, https://doi.org/10.1007/978-3-65802753-7_2.

Der Rektor der Universität zu Köln (Hg.) (1983). Vorlesungsverzeichnis für das Wintersemester 1983/84. Hürth, Rheinland: Drei-Kronen-Druck.

Dörre, K., Rosa, H., Becker, K., Bose, S. und Seyd, B. (Hg.) (2019). Große Transformation? Zur Zukunft moderner Gesellschaften. Wiesbaden: Springer VS, https://doi. org/10.1007/978-3-658-25947-1.

Doppler, K. und Lauterburg, C. (2002). Change Management. Den Unternehmenswandel gestalten (10. Aufl.). Frankfurt a. M.: Campus.

Dülffer, J. (2004). Europa im Ost-West-Konflikt 1945-1991. München: Oldenbourg, https://doi.org/10.1524/9783486701203.

Dussel, E. (2013). 20 Thesen zur Politik. Münster: Lit.

Duxbury, N., Garrett-Petts, W. F. und MacLennon, D. (Hg.) (2015). Cultural mapping as cultural inquiry. New York, London: Routledge, https://doi.org/10.4324/97813157 43066.

Eckardt, F. (2014). Stadtforschung. Gegenstand und Methoden. Wiesbaden: Springer VS, https://doi.org/10.1007/978-3-658-08354-0.

Eckert, M. (2017). Vom Sinn und Unsinn neuer Steuerungsinstrumente im Bildungssystem - Kritik und Perspektiven. In A. Bolder, H. Bremer und R. Epping (Hg.), Bildung für Arbeit unter neuer Steuerung (S. 389-403). Wiesbaden: Springer VS, https://doi.org/10.1007/978-3-658-15412-7_19.

Edel, J. (2008). Schulpflicht und Bildungsfreiheit in Europa. Unerzogen, 3, 14-21.

Ehalt, H.C. (1994). Geschichte von unten. Fragestellungen, Methoden und Projekte einer Geschichte des Alltags. Wien: Böhlau.

Engler, S., Stengel, O. und Bommert, W. (Hg.) (2016). Regional, innovativ und gesund. Nachhaltige Ernährung als Teil der Großen Transformation. Göttingen: Vandenhoeck \& Ruprecht, https://doi.org/10.13109/9783666300592.

Fairclough, N. (1989). Language and power. London: Longman.

Fairclough, N. (1992). Discourse and social change. Cambridge, UK: Polity.

Fairclough, N. (2013). Critical discourse analysis: The critical study of language. London, New York: Routledge, https://doi.org/10.4324/9781315834368.

Fatzer, G. (Hg.) (2005). Nachhaltige Transformationsprozesse in Organisationen. Bergisch Gladbach: EHP.

Fehrenbach, H. G. (2020). Machtmissbrauch in der Wissenschaft. Fünf Mythen. Forschung \& Lehre, 27 (4), 322-324.

Feyerabend, P. (1995). Wider den Methodenzwang (5. Aufl.) Frankfurt a. M.: Suhrkamp. 
Field, J. (2011). Lifelong Learning and community. In P. Jarvis (Hg.), The Routledge international handbook of lifelong learning (S. 153-162). New York: Routledge.

Florida, R. (2002). The rise of the creative class: ... and how it's transforming work, leisure, community, \& everyday life. New York: Basic Books.

Florida, R. (2005). Cities and the creative class. New York, London: Routledge, https:// doi.org/10.4324/9780203997673.

Florida, R. (2017). The new urban crisis: How our cities are increasing inequality, deepening segregation, and failing the middle class, and what we can do about it. New York: Basic Books.

Flusser, V. (1995). Die Revolution der Bilder. Mannheim: Bollmann.

Flusser, V. (1994). Ins Universum der technischen Bilder (4. Aufl.). Göttingen: European Photografy.

Foucault, M. (1976). Mikrophysik der Macht. Über Strafjustiz, Psychiatrie und Medizin. Berlin: Merve.

Foucault, M. (1981). Archäologie des Wissens. Frankfurt a. M.: Suhrkamp.

Foucault, M. (1989). Wahnsinn und Gesellschaft (8. Aufl.). Frankfurt a. M.: Suhrkamp.

Foucault, M. (1991). Sexualität und Wahrheit III: Die Sorge um sich. Frankfurt a. M.: Suhrkamp.

Foucault, M. (1992). Überwachen und Strafen (10. Aufl.). Frankfurt a. M.: Suhrkamp.

Foucault, M. (2001). Räderwerke des Überwachens und Strafens. In M. Foucault, Short cuts (S. 56-80). Frankfurt a. M.: Zweitausendeins.

Frank, N. (2014). Der Vater: Eine Abrechnung (2. Aufl). Ecklak: Eigenverlag Brigitte Frank unsel. Erben.

Frei, N. (2008). 1968. Jugendrevolte und globaler Protest. München: dtv.

Friedell, E. (1996). Kulturgeschichte der Neuzeit. Die Krisis der europäischen Seele von der schwarzen Pest bis zum ersten Weltkrieg (Reprint der drei Bände von 19271931). München: C. H. Beck.

Fröhlich, C. (2015). Wasser als Machtinstrument: Internationale und sub-staatliche Konflikte um Wasser. In T. Jäger (Hg.), Handbuch Sicherheitsgefahren. Globale Gesellschaft und internationale Beziehungen (S. 75-82). Wiesbaden: Springer VS, https://doi.org/10.1007/978-3-658-02753-7_7.

Fromm, E. (2009). Die Pathologie der Normalität: Zur Wissenschaft vom Menschen (3. Aufl.). Berlin: Ullstein.

Fromm, E. (2017). Haben oder Sein: Die seelischen Grundlagen einer neuen Gesellschaft (44. Aufl.). München: dtv.

Gärtner, H. (2017). Der Kalte Krieg. Bündnisse - Krisen - Konflikte. Wiesbaden: Marixwissen, Verlagshaus Römerweg.

Gebauer, K. und Hüther, G. (2012). Kinder brauchen Wurzeln. Neue Perspektiven für eine gelingende Entwicklung (8. Aufl.). Düsseldorf: Patmos.

Glaveanu, V. P. (2017). A culture-inclusive, socially engaged agenda for creativity research. The Journal of Creative Behavior, 51(4), 338-340, https://doi.org/10.1002/ jocb.198.

Göpel, M. (2016). The great mindshift. How a new economic paradigm and sustainability transformations go hand in hand. Cham: Springer, https://doi.org/10.1007/9783-319-43766-8.

Göpel, M. (2020). Unsere Welt neu denken. Eine Einladung. Berlin: Ullstein. 
Goldstone, J. A. (2008). Pathways to state failure. Conflict management and peace science, 25 (4), 285-296, https://doi.org/10.1080/07388940802397343.

Gonezpin, J. (1987). Bericht zum Aufenthalt der Gruppe von Pädagogen aus dem Jugendpalast, Warszawa in Arnsberg, 6. August - 26. August 1986. In J. Bröcher, N. Griffel und K.-J. Kluge (Hg.), Mit Vergnügen Forschen und Lernen 1986: Außergewöhnliches Lernen in universitären Sommercamps (S. 311). München: Minerva Publikation.

Goodley, D., Lawthom, R., Clough, P. und Moore, M. (2004). Researching life stories: Method, theory and analysis in a biografical age. London, New York: Routledge-Falmer.

Goodman, P. (1975). Das Verhängnis Schule. Frankfurt a. M.: Fischer Athenäum.

Goodman, P. (1972). Aufwachsen im Widerspruch. Über die Entfremdung der Jugend in der verwalteten Welt. Darmstadt: Darmstädter Blätter.

Greene, R. (2004). Power. Die 48 Gesetze der Macht. München: dtv.

Haas, D. (2017). Wie der Faust aufs Auge. Laut, schrill und schlau: »Fack ju Göhte 3« mischt die Bildungsdebatte auf, dass es wehtut. Die ZEIT Nr. 44, 25. Oktober 2017.

Hackmann, J. und Kopij-Weiß, M. (Hg.) (2014). Deutsch-polnische Geschichte 19. Jahrhundert: Nationen in Kontakt und Konflikt. Deutsch-polnische Beziehungen und Verflechtungen 1806-1918. Darmstadt: Wissenschaftliche Buchgesellschaft.

Hanschmann, F. (2017). Kompetenzorientierung oder die Reduktion des staatlichen Bildungs- und Erziehungsauftrages. Kritische Vierteljahresschrift für Gesetzgebung und Rechtswissenschaft, 100 (2), 76-100, https://doi.org/10.5771/2193-78692017-2-76.

Hansen, G. (2006). Schulpolitik im besetzten Polen 1939-1945. Bildungsforschung, 3(1), Abgerufen am 1.10.2020 unter www.bildungsforschung.org/Archiv/2006-01/ polen/.

Haunss, S. und Sommer, M. (Hg.) (2020). Fridays for Future - Die Jugend gegen den Klimawandel. Konturen der weltweiten Protestbewegung. Bielefeld: transcript, https://doi.org/10.14361/9783839453476.

Henderson, J. (2012). Talking across the fence: Cold-War academic cooperation in the legal sphere. In T. Borisova \& W. B. Simons (Hg.), The legal dimension in Cold-War interactions. Some notes from the field, 1-40. Leiden, NL and Boston, MA: Martinus Niehoff Publishers, https://doi.org/10.1163/9789004203334_003.

Hentig, H. v. (1969). Systemzwang und Selbstbestimmung. Über die Bedingungen der Gesamtschule in der Industriegesellschaft. Stuttgart: Klett.

Hentig, H. v. (1972). Cuernavaca oder Alternativen zur Schule? (2. Aufl.). Stuttgart: Klett; München: Kösel.

Hey, P. (2010). Die sowjetische Polenpolitik Anfang der 1980er Jahre und die Verhängung des Kriegsrechts in der Volksrepublik Polen: Tatsächliche sowjetische Bedrohung oder erfolgreicher Bluff? Münster: Lit.

Hirsch Hadorn, G., Hoffmann-Reim, H., Biber-Klemm, S., Gorssenbacher-Mansuy, W., Joye, D. und Pohl, C. (Hg.) (2008). Handbook of transdisciplinary research. New York: Springer, https://doi.org/10.1007/978-1-4020-6699-3.

Hodgkinson, T. (2005). How to be idle. London: Penguin.

Hodgkinson, T. (2007). How to be free. London: Penguin. 
Hoffmann, N. (2018). Dokumentenanalyse in der Bildungs- und Sozialforschung. Weinheim: Beltz Juventa.

Hofstede, G. (2017). Lokales Denken, globales Handeln: Interkulturelle Zusammenarbeit und globales Management (6. Aufl.). München: dtv.

Hofstede, G., Hofstede, G. J. und Minkov, M. (2010). Cultures and organizations: Software of the mind. Intercultural cooperation and its importance for survival. New York: McGraw-Hill.

Honneth, A. (1990). Die zerrissene Welt des Sozialen. Sozialphilosophische Aufsätze. Frankfurt a. M.: Suhrkamp.

Hüther, G. (2013). Kommunale Intelligenz. Potenzialentfaltung in Städten und Gemeinden. Hamburg: Edition Körber.

Hüther, G. (2016). Mit Freude lernen - ein Leben lang. Weshalb wir ein neues Verständnis von Lernen brauchen. Göttingen: Vandenhoeck \& Ruprecht, https://doi. org/10.13109/9783666701825.

Hüther, G. (2018). Etwas mehr Hirn bitte. Eine Einladung zur Wiederentdeckung der Freude am eigenen Denken und der Lust am gemeinsamen Gestalten. Göttingen: Vandenhoeck \& Ruprecht.

Hüther, G., Heinrich, M. und Senf, M. (2020). \#Education For Future. Bildung für ein gelingendes Leben. München: Goldmann.

Huntington, S. P. (2002). Kampf der Kulturen. Die Neugestaltung der Weltpolitik im 21. Jahrhundert. München: Goldmann.

Illich, I. (2017). Entschulung der Gesellschaft: Eine Streitschrift (7. Aufl.). München: C. H. Beck.

Jacobs, J. (2015). Tod und Leben großer amerikanischer Städte. Basel: Birkhäuser; Gütersloh, Berlin: Bauverlag, https://doi.org/10.1515/9783035602128.

Jaczewski, A. (1993). Über meine Kontakte und Freundschaft mit Karl-Josef Kluge. In K. Fitting und E.-M. Saßenrath-Döpke (Hg.), Pädagogik und Auffälligkeit. Impulse für Lehren und Lernen bei erwartungswidrigem Verhalten. Festschrift zum 60. Geburtstag von Karl-Josef Kluge (S. 680-682). Weinheim: Deutscher Studien Verlag.

Jaczewski, A. (2014). Seksualność dzieci i młodzieży. Pół wieku badań i refleksji (Sexualität von Kindern und Jugendlichen. Ein halbes Jahrhundert Forschung und Reflexion). Warschau: Difin.

Jaczewski, A. (2015). Współpraca moja i Wydziału Pedagogicznego Uniwersytetu Warszawskiego z Uniwersytetem w Kolonii (Rückblick auf die Zusammenarbeit der Fakultät für Bildungswissenschaften der Universität Warschau und der Heilpädagogischen Fakultät der Universität zu Köln). Kwartalnik Pedagogiczny, 237 (3), 188-198.

Jaczewski, A. (2018). Książka moich wspomnień (Ein Buch meiner Erinnerungen). Radom: Instytut Technologii Eksploatacji.

Jaczewski, A. (2019). O chłopcach dla chłopców (Über Jungen für Jungen). Warschau: PZWL-Verlag.

Jaczewski, A. und Toczyski, P. (2015). Przemiany cywilizacyjne a współczesne zagrożenia wychowawcze okresu dojrzewania (Zivilisationsveränderungen und zeitgenössische Herausforderungen bei der Bildung der Jugend). Rocznik Towarzystwa Naukowego Płockiego, Vol. 7, 323-331. 
Johler, R. und Lange, J. (Hg.) (2019). Konfliktfeld Fluchtmigration. Historische und ethnografische Perspektiven. Bielefeld: transcript, https://doi.org/10.14361/9783839 447666.

Johnson, D. (2015). Teaching outside of the lines: Developing creativity in every learner. Thousand Oaks, CA; London, UK: Sage, Corwin, https://doi.org/10.4135/978 1483390000.

Kahlenborn, W., Clausen, J., Behrendt, S. und Göll, E. (Hg.) (2019). Auf dem Weg zu einer Green Economy. Wie die sozialökologische Transformation gelingen kann. Bielefeld: transcript, https://doi.org/10.14361/9783839444931.

Kamski, B. (2015). Wasserressourcen als Konfliktfaktor großflächiger Landtransaktionen. In T. Jäger (Hg.), Handbuch Sicherheitsgefahren. Globale Gesellschaft und internationale Beziehungen (S. 83-92). Wiesbaden: Springer VS, https://doi. org/10.1007/978-3-658-02753-7_8.

Kaufman, J. C., Glaveanu, V. P. und Baer, J. (Hg.) (2017). The Cambridge handbook of creativity across domains. Cambridge, UK; New York: Cambridge University Press.

Keane, J. (2020). The new despotism. Cambridge, MA: Harvard University Press, https://doi.org/10.4159/9780674246713.

Keashley, L. (1998). Emotional abuse in the workplace: Conceptual and empirical issues. Journal of Emotional Abuse, 1(1), 85-118, https://doi.org/10.1300/J135v01n01_05.

Keashley, L. (2001). Interpersonal and systemic aspects of emotional abuse at work: The target's perspective. Violence and Victims, 16 (3), 233-268, https://doi.org/10.18 91/0886-6708.16.3.233.

Ketterer H. (2019). Bedingungsloses Grundeinkommen als materielle und symbolische Ermöglichungsstruktur von Praktiken für die gesellschaftliche Transformation. In K. Dörre, H. Rosa, K. Becker, S. Bose und B. Seyd (Hg.), Große Transformation? Zur Zukunft moderner Gesellschaften (S. 333-348). Wiesbaden: Springer VS, https://doi.org/10.1007/978-3-658-25947-1_18.

Khoury-Kassabri, M. (2012). The relationship between teacher self-efficacy and violence toward students as mediated by teacher's attitude. Social Work Research, 36 (2), 127-139, https://doi.org/10.1093/swr/svsoo4.

Kijowska, M. (1996). Die polnische Gegenwartsliteratur: Vom Zweiten Weltkrieg bis zu den neunziger Jahren. In W. Jens (Hg.), Kindlers Neues Literaturlexikon, Bd. 20 (S. 419-425). München: Kindler.

Kim, W.C. und Mauborgne, R. (2016). Der blaue Ozean als Strategie. Wie man neue Märkte schafft, wo es keine Konkurrenz gibt (2. Aufl.). München: Carl Hanser.

Kim, W.C. und Mauborgne, R. (2018). Blue Ocean shift. Jenseits des Wettbewerbs. München: Franz Vahlen, https://doi.org/10.15358/9783800656622.

King, N. (2000). Childhood sexual trauma in gay men. Social context and the Imprinted Arousal Pattern. Journal of Gay \& Lesbian Social Services, 12 (1), 19-35, https:// doi.org/10.1300/J041v12no1_02.

Klafki, W. (1985). Neue Studien zur Bildungstheorie und Didaktik. Beiträge zur kritisch-konstruktiven Didaktik. Weinheim: Beltz.

Kleiner, A. und Roth, A. (2005). Lerngeschichten von Organisationen. Wie sich Erfahrungen in der Firma nutzen lassen. In G. Fatzer (Hg.), Nachhaltige Transformationsprozesse in Organisationen (S. 29-39). Bergisch Gladbach: EHP.

Klemperer, V. (2018). LTI. Notizbuch eines Philologen. Ditzingen: Reclam. 
Kohelet/Salomo (2016). Der Prediger Salomo (Kohelet). In Die Bibel, Lutherübersetzung (S. 687-694). Stuttgart: Deutsche Bibelgesellschaft.

Kotter, J. (2012). The heart of change: Real life stories of how people change their organizations. Boston, MA: Harvard Business Review.

Krishnamurti, J. (2009). Wahre Bildung. Freiamt im Schwarzwald: Arbor.

Krishnamurti, J. (2019). Vollkommene Freiheit (10. Aufl.). Frankfurt a. M.: Fischer.

Kühn, H. (2002). Das Jahrzehnt der Solidarnosc: Die politische Geschichte Polens 1980-1990. Berlin: BasisDruck.

Kühn, T. und Koschel, K.-V. (2011). Gruppendiskussionen. Ein Praxis-Handbuch. Wiesbaden: VS-Verlag für Sozialwissenschaften, https://doi.org/10.1007/978-3-531-93243-9.

Küsters, I. (2009). Narrative Interviews. Grundlagen und Anwendungen (2. Aufl). Wiesbaden: VS Verlag für Sozialwissenschaften.

Kuhn, T.S. (2012). The structure of scientific revolutions (4. Aufl.). Chicago, London: The University of Chicago Press, https://doi.org/10.7208/chicago/9780226458144. 001.0001.

Ladenthin, V. (2010). Kompetenzorientierung als Indiz pädagogischer Orientierungslosigkeit. Vierteljahresschrift für wissenschaftliche Pädagogik, 86(3), 346-358, https://doi.org/10.30965/25890581-08603006.

Ladenthin, V. (2020). Kann man Wissenschaft evaluieren? Nur eine zweckfreie Forschung ist nütztlich. Forschung \& Lehre, 27 (10), 828-829.

Lang, D. J., Wiek, A., Bergmann, M., Stauffacher, M., Martens, P., Moll, P., Swilling, M. und Thomas, C. J. (2012). Transdisciplinary research in sustainability science: Practice, principles, challenges. Sustainability Science, 7 (1), Supplement, 25-43, https://doi.org/10.1007/s11625-011-0149-x.

Lange, B. (2006). From Cool Britannia to Generation Berlin? Geografies of culturepreneurs and their creative milieus in Berlin. In C. Eisenberg, R. Gerlach and C. Handke (Hg.), Cultural industries: The British experience in international perspective. Berlin: Humboldt University Berlin, Edoc-Server: http://edoc.hu-berlin.de.

Lange, B. (2007). Die Räume der Kreativszenen. Culturepreneurs und ihre Orte in Berlin. Bielefeld: transcript, https://doi.org/10.14361/9783839406793.

Lange, B. (2010). Wertschöpfung in der Kreativwirtschaft. Der Fall der elektronischen Klubmusik. Zeitschrift für Wirtschaftsgeografie, 54(1), 46-68, https://doi. org/10.1515/zfw.2010.0004.

Lange, B., Kalandides, A., Stöber, B. und Mieg, H. A. (2008). Berlin's creative industries: Governing creativity? Industry and Innovation, 15 (5), 531-548, https://doi. org/10.1080/13662710802373981.

Lanz, S. (2013). Berlin diversities. The perpetual act of becoming of a true metropolis. In M. Bernt, B. Grell und A. Holm (Hg.), The Berlin reader. A compendium on urban change and activism (S. 207-222). Bielefeld: transcript, https://oi.org/10.14361/ transcript.9783839424780.207.

Lettenbauer, W. und Kijowska, M. (1996). Die polnische Literatur. In W. Jens (Hg.), Kindlers Neues Literaturlexikon, Bd. 20 (S. 410-419). München: Kindler.

Leymann, H. (1990). Mobbing and psychological terror at workplaces. Violence and Victims, 5 (2), 119-126, https://doi.org/10.1891/0886-6708.5.2.119.

Lindle, J. C. (1994). Surviving school micropolitics: Strategies for administrators. Lancaster: Technomic Publ. 
Lohmer, M. (2008). Psychodynamische Organisationsberatung. Konflikte und Potenziale in Veränderungsprozessen (2. Aufl.). Stuttgart: Schäffer Poeschel.

Lohmer, M. und Möller, H. (2019). Psychoanalyse in Organisationen: Einführung in die psychodynamische Organisationsberatung (2. Aufl.). Stuttgart: Kohlhammer.

Louv, R. (1993). Fatherlove: What we need, what we seek, what we must create. New York, London: Pocket Books.

Louv, R. (2012). Das Prinzip Natur. Grünes Leben im digitalen Zeitalter. Weinheim, Basel: Beltz.

Lühmann, H. (2014). Voll frontal ins Klischee gehauen: »Fack ju Göhte« erklärt, FAZ 23.1.2014.

Luhmann, N. (2012). Soziale Systeme (15. Aufl.). Frankfurt a. M.: Suhrkamp.

Lynn, D. B. (1976). Fathers and sex-role development. The Family Coordinator, 25 (4), 403-409, https://doi.org/10.2307/582854.

Machiavelli, N. (2018). Der Fürst (Original von 1532). Hamburg: Nikol.

Marburger, H. und Riesner, S. (Hg.) (1996). Jugend und deutsch-polnische Nachbarschaft: Bilder vom Andern, Austausch- und Migrationserfahrungen, grenzüberschreitende Projekte und Kooperationen. Frankfurt a. M.: IKO-Verlag für Interkulturelle Kommunikation.

Marcuse, H. (1982). Triebstruktur und Gesellschaft. Ein philosophischer Beitrag zu Sigmund Freud. Frankfurt a. M.: Suhrkamp.

Marcuse, H. (2014). Der eindimensionale Mensch. Studien zur Ideologie der fortgeschrittenen Industriegesellschaft. Lüneburg: zu Klampen.

Martusewicz, R.A., Edmundson, J. und Lupinacci, J. (2015). EcoJustice. Toward diverse, democratic, and sustainable communities (2. Aufl.). New York: Routledge.

Marvin, S., Bulkeley, H., Mai, L., McCormick, K. und Voytenko Palgani, Y. (Hg.) (2018). Urban living labs: Experimenting with city futures. London, New York: Routledge.

Marx, K. (1969). Resultate des unmittelbaren Reproduktionsprozesses. Frankfurt a. M.: Neue Kritik.

Marx, K. (2009). Ökonomisch-philosophische Manuskripte (3. Aufl.). Frankfurt a. M.: Suhrkamp, https://doi.org/10.28937/978-3-7873-2079-0.

Marx, K. und Engels, F. (1972). Manifest der kommunistischen Partei. MEW 4, 459-493.

Mayer, H.O. (2013). Interview und schriftliche Befragung. Grundlagen und Methoden empirischer Sozialforschung (6. Aufl.). München: Oldenbourg, https://doi. org/10.1524/9783486717624.

Meadows, D. H. (1972). Die Grenzen des Wachstums. Bericht des Club of Rome zur Lage der Menschheit. Stuttgart: DVA.

Meadows, D., Randers, J. und Meadows, D. (2015). Grenzen des Wachstums. Das 30-Jahre Update (5. Aufl.). Stuttgart: Hirzel.

Merrill, B. und West, L. (2009). Using biografical methods in social research. Thousand Oaks, CA, London, UK: Sage, https://doi.org/10.4135/9780857028990.

Meyer, T. und Vornholt, U. (Hg.). (2017). Bedingungsloses Grundeinkommen in Deutschland und Europa? Bochum: Projekt.

Milgram, S. (2012). Das Milgram-Experiment: Zur Gehorsamsbereitschaft gegenüber Autorität (17. Aufl.). Reinbek: Rowohlt.

Mitchell, D. (2000). Cultural geografy. A critical introduction. Malden, MA, Oxford, UK: Blackwell. 
Mussen, P. und Distler, L. (1959). Masculinity, identification, and father-son relationships. The Journal of Abnormal and Social Psychology, 59(3), 350-356, https://doi. org/10.1037/hoo44529.

Nebel, J.A. (2011). Schulprogramme als innovative Steuerungsinstrumente im System des allgemeinen Verwaltungsrechts. Berlin: Berliner Wissenschafts-Verlag.

Neill, A. S. (1998). Theorie und Praxis der antiautoritären Erziehung. Das Beispiel Summerhill (zuerst 1969). Reinbek: Rowohlt.

Neuberger, O. (1995). Mikropolitik. Der alltägliche Aufbau und Einsatz von Macht in Organisationen. Stuttgart: Enke.

Neuman, J. H. und Baron, R.A. (1998). Workplace violence and workplace aggression: Evidence concerning specific forms, potential causes, and preferred targets. Journal of Management, 24 (3), 391-419, https://doi.org/10.1177/014920639802400305.

Nohl, A.-M. (2009). Interview und dokumentarische Methode (3. Aufl). Wiesbaden: VS Verlag für Sozialwissenschaften, https://doi.org/10.1007/978-3-531-91539-5.

Norton, W. (2006). Cultural geography: Environments, landscapes, identities, inequalities (2. Aufl.). Ontario, Oxford, New York: Oxford University Press.

O'Donohue, J. (1997). Anam cara. Spiritual wisdom from the Celtic world. London, New York: Bantam.

O'Donohue, J. (1998). Eternal echoes. Exploring our hunger to belong. London, New York: Bantam.

Olsen, J.P. (2002). The many faces of europeanization. Journal of Common Market Studies, 40 (5), 921-952, https://doi.org/10.1111/1468-5965.00403.

Ommler, N. und Harten, H.-C. (1996). De-Kulturation und Germanisierung. Die nationalsozialistische Rassen- und Erziehungspolitik in Polen 1939-1945. Frankfurt a. M., New York: Campus.

Osho (1997). Das Buch der Kinder: Von der Freiheit Du selbst zu sein. München: Heyne.

Otterpohl, R. (2017). Das neue Dorf. Vielfalt leben, lokal produzieren, mit Natur und Nachbarn kooperieren. München: oekom.

Owen, H. (2011). Open Space technology. Ein Leitfaden für die Praxis (2. Aufl.). Stuttgart: Schäffer Poeschel.

Patton, M. Q. (2002). Qualitative research and evaluation methods (3. Aufl.). Thousand Oaks, CA: Sage.

Patzner, G. (2005). Schule im Kontext neoliberaler Gouvernementalität. Schulheft, 30 (118), 53-71, https://doi.org/10.1007/s11614-006-0064-z.

Paul, G. und Schoßig, B. (Hg.) (1986). Die andere Geschichte. Geschichte von unten, Spurensicherung, ökologische Geschichte, Geschichtswerkstätten. Köln: Bund.

Pechlaner, H. (2019). Destination und Lebensraum. Perspektiven touristischer Entwicklung. Wiesbaden: Springer Gabler, https://doi.org/10.1007/978-3-658-28110-6.

Penney, T. (2014). Bodies under glass: Gay dating apps and the affect-image. Media International Australia, 153 (1), 107-117, https://doi.org/10.1177/1329878X1415300113.

Pfeifer, W. (Hg.) (2004). Etymologisches Lexikon des Deutschen (7. Aufl.). München: dtv. Piekarski, J. (2019). Wspomnienia różne (Erinnerungen anders). In J. Wojtyczy (Hg.), O harmonijny rozwój człowieka. Myśl pedagogiczna Profesora Andrzeja Jaczewskiego (S. 83-95). Krakau: Krakowska Akademia.

Piketty, T. (2016). Das Kapital im 21. Jahrhundert (8. Aufl.). München: C. H. Beck.

Piketty, T. (2020). Ökonomie der Ungleichheit (3. Aufl.). München: C. H. Beck, https:// doi.org/10.17104/9783406750038. 
Pohl, D. (2008). Herrscher und Unterworfene. Die deutsche Besatzung und die Gesellschaften Europas. In D. Süß und W. Süß (Hg.), Das »Dritte Reich«. Eine Einführung (S. 267-285). München: Pantheon.

Polanyi, K. (1973). The Great Transformation. Politische und ökonomische Ursprünge von Gesellschaften und Wirtschaftssystemen (14. Aufl.). Frankfurt a. M.: Suhrkamp.

Pongratz, L.A. (2010). Einstimmung in die Kontrollgesellschaft. Der Trainingsraum als gouvernementale Strafpraxis. Pädagogische Korrespondenz, 41, 63-74.

Popper, K. R. (2003). Die offene Gesellschaft und ihre Feinde. Bd. 1: Der Zauber Platons. Bd. 2: Falsche Propheten: Hegel, Marx und die Folgen (8. Aufl.). Tübingen: Mohr Siebeck.

Pratt, A.C. (2010). Creative cities: Tensions within and between social, cultural and economic development. A critical reading of the UK experience. City, Culture and Society, 1, 13-20, https://doi.org/10.1016/j.ccs.2010.04.001.

Pratt, A.C. (2011). The cultural contradictions of the creative city. City, Culture and Society, 2, 123-130, https://doi.org/10.1016/j.ccs.2011.08.002.

Precht, R. D. (2020). Jäger, Hirten, Kritiker. Eine Utopie für die digitale Gesellschaft. München: Goldmann.

Ratiu, D. E. (2013). Creative cities and/or sustainable cities: Discourses and practices. City, Culture and Society, 4, 125-135, https://doi.org/10.1016/j.ccs.2013.04.002.

Recum, H. v. (2006). Steuerung des Bildungssystems. Entwicklung, Analysen, Perspektiven. Berlin: Berliner Wissenschafts-Verlag.

Reimer, E. (1972). Schafft die Schule ab! Befreiung aus der Lernmaschine. Reinbek: Rowohlt.

Reißig, R. (2019). Transformation von Gesellschaften. Eine vergleichende Betrachtung von Geschichte, Gegenwart und Zukunft. Marburg: Schüren.

Richmond, Y. (2003). Cultural exchange and the Cold War: Raising the Iron Curtain. University Park, PA: Pennsylvania State University Press, https://doi.org/10.5325/j. ctv14gp21b.

Rittberger, M. (2005). Kontrollgesellschaft und schulische Erziehung. Schulheft, $30(118), 110-121$.

Roberts, L. (Hg.) (2012). Mapping cultures. Place, practice and performance. New York: Palgrave Macmillan, https://doi.org/10.1057/9781137025050.

Rogers, C.R. (2006). Entwicklung der Persönlichkeit: Psychotherapie aus der Sicht eines Therapeuten (16. Aufl.). Stuttgart: Klett-Cotta.

Rogers, C. R. (1984). Lernen in Freiheit. Zur Bildungsreform in Schule und Universität. München: Kösel.

Rogers, C. R. (1974). Encounter-Gruppen: Das Erlebnis der menschlichen Begegnung. München: Kindler.

Rogers, C. R. (1985). Die Kraft des Guten: Ein Appell zur Selbstverwirklichung. Frankfurt a. M.: Fischer.

Rogers, C. R. (2017). Der neue Mensch (11. Aufl.). Stuttgart: Klett-Cotta.

Rosa, H. (2019). Resonanz. Eine Soziologie der Weltbeziehung. Berlin: Suhrkamp.

Rotberg, R. (Hg.) (2004). When states fail: Causes and consequences. Princeton, NJ:

Princeton University Press, https://doi.org/10.1515/9781400835799.

Roth, G. (1996). Learning History Manual. Boston: MIT Press. 
Ruchniewicz, K. (2005). Zögernde Annäherung: Studien zur Geschichte der deutschpolnischen Beziehungen im 20. Jahrhundert. Dresden: Thelem.

Sartre, J.-P. (1991). Das Sein und das Nichts. Versuch einer phänomenologischen Ontologie. Reinbek: Rowohlt.

Schaar, P. (2007). Das Ende der Privatsphäre. Der Weg in die Überwachungsgesellschaft. München: Bertelsmann.

Scheffer, E. (2017). Industry X. O. Digitale Chancen in der Industrie nutzen. München: Redline.

Scheffran, J. (Hg.) (2017). Migration und Flucht zwischen Klimawandel und Konflikten. Hamburg: Institut für Geografie der Universität Hamburg.

Scheffran, J., Brzoska, M., Brauch, H. G., Link, P. M. und Schilling, J. (2012). Climate change, human security and violent conflict. Berlin, Heidelberg: Springer, https:// doi.org/10.1007/978-3-642-28626-1.

Schein, E. H. (2005 a). Organisationskultur ernst nehmen. In G. Fatzer (Hg.), Nachhaltige Transformationsprozesse in Organisationen (S. 40-53). Bergisch Gladbach: EHP.

Schein, E. H. (2005 b). Wann lernen wir? In G. Fatzer (Hg.), Nachhaltige Transformationsprozesse in Organisationen (S. 113-124). Bergisch Gladbach: EHP.

Schenk, D. (2010). Krakauer Burg. Die Machtzentrale des Generalgouverneurs Hans Frank 1939-1945. Berlin: Ch. Links.

Scherle, N. (2016). Kulturelle Geografien der Vielfalt. Von der Macht der Differenzen zu einer Logik der Diversität. Bielefeld: transcript, https://doi.org/10.14361/97838 39431467.

Scherle, N. (2020). Im Spannungsfeld von Klimawandel, Overtourism und Agenda 2030 - Tourismus in Destinationen des globalen Südens. In E. Herlyn und M. Lévy-Tödter (Hg.), Die Agenda 2030 als magisches Vieleck der Nachhaltigkeit (S. 199229). Wiesbaden: Springer Gabler, https://doi.org/10.1007/978-3-658-25706-4_11.

Schloen, B. (2019). Grundeinkommen und Menschenwürde. Ein Weckruf für mehr Selbstbestimmung, Solidarität und Plutokratieabwehr. Wiesbaden: Springer, https://doi.org/10.1007/978-3-658-24262-6.

Schmidt-Hertha, B., Jelenc Krasovec, S. und Formosa, M. (Hg.) (2014). Learning across generations in Europe: Contemporary issues in older adult education. Rotterdam, Boston, Taipei: Sense, https://doi.org/10.1007/978-94-6209-902-9.

Schnall, R.S. (2009). When teachers talk: Principal abuse of teachers, the untold story. Las Vegas, NV: Goldenring.

Schoolman, E. D., Guest, J. S., Bush, K. F. und Bell, A. R. (2012). How interdisciplinary is sustainability research? Sustainability Science, $7(1), 67-80$, https://doi.org/ 10.1007/s11625-011-0139-z.

Schott, F. und Azizi Ghanbari, S. (2008). Bildungsstandards, Kompetenzdiagnostik und kompetenzorientierter Unterricht zur Qualitätssicherung des Bildungswesens. Eine problemorientierte Einführung in die theoretischen Grundlagen. Münster: Waxmann.

Schwanitz, M. (2007a). Die Rückkehr der Lemken. Polnische Minderheit kommt zurück in die Heimat. Deutschlandfunk, 23.10.2007. Abgerufen am 13.02.2020 unter https://www.deutschlandfunk.de/die-rueckkehr-der-lemken.795.de.html?dram: article_id $=117082$.

Schwanitz, M. (2007b). Besuch bei einem vergessenen Volk. Die Lemken im Südosten Polens. Deutschlandfunk, 28.10.2007. Abgerufen am 13.02.2020 unter https:// 
www.deutschlandfunk.de/besuch-bei-einem-vergessenen-volk.1242.de.html? dram:article_id=189070.

Shopes, L. (2011). Oral history. In N. K. Denzin und Y. S. Lincoln (Hg.), The Sage handbook of qualitative research (4. Aufl.) (S. 451-465). Thousand Oaks, CA, London, UK: Sage.

Schwegmann, R. (2016). Nacht-Orte. Eine kulturelle Geografie der Ökonomie. Bielefeld: transcript, https://doi.org/10.14361/9783839432563.

Seifert, L. (2015). »Chantal, du bist hochbegabt!« Die Teenagerkomödie »Fack ju Göhte 2 « läuft derzeit in den Kinos. Der erste Teil wird inzwischen in der Lehrerausbildung eingesetzt. Lernt man da was? Die ZEIT, Nr. 36, 3.9.2015.

Sendra, P. und Sennett, R. (2020). Designing disorder. Experiments and disruptions in the city. London, New York: Verso.

Seneca (2011). Vom glücklichen Leben. Berlin: Insel.

Senge, P. (2006). Die fünfte Disziplin. Kunst und Praxis der lernenden Organisation (10. Aufl.). Stuttgart: Klett-Cotta.

Senge, P. M., Kleiner, A., Roberts, C., Ross, R. B. und Smith B. J. (1994). The fifth discipline fieldbook: Strategies and tools for building a learning organization. London: Nicholas Brealey.

Senge, P., Cambron-McCabe, N., Lucas, T., Smith, B., Dutton, J. und Kleiner, A. (2012). Schools that learn: A fifth discipline fieldbook for educators, parents, and everyone who cares about education. New York: Crown Business.

Sennett, R. (1992). The uses of disorder. Personal identity and city life (Reprint der Ausgabe von 1970). New York, London: W. W. Norton.

Sennett, R. (2018). Die offene Stadt. Eine Ethik des Bauens und Bewohnens. Berlin: Hanser.

Siegmund, M. (2019). Die besten 123 Fragen zum Philosophieren mit Kindern und Jugendlichen. Norderstedt: Books on Demand.

Siegmund, M. und Wildermuth, H. (2012). Die Neu-Erfindung der Schule. Die Befreiung der Menschen von staatlicher Bevormundung durch Permation und Autonomie. Norderstedt: Books on Demand.

Sievers, B., Ohlmeier, D., Oberhoff, B. und Beumer, U. (Hg.) (2003). Das Unbewusste in Organisationen: Freie Assoziationen zur psychosozialen Dynamik von Organisationen. Gießen: Psychosozial.

Simon, F. B. (2007). Organisationen brauchen Langeweile. Mehr Zeit für Nichts! wirtschaft \& weiterbildung, 7/8, 16.

Sloterdijk, P. (1998). Sphären I: Blasen. Frankfurt a. M.: Suhrkamp.

Sloterdijk, P. (2004). Sphären III: Schäume. Frankfurt a. M.: Suhrkamp.

Smolinska-Theiss, B. (2013). Universalität und Aktualität der Ideen Korczaks. In M. Liebel (Hg.), Janusz Korczak. Pionier der Kinderrechte. Ein internationales Symposium (S. 95-100). Münster: Lit.

Snyder, T. (2016). Bloodlands. Europa zwischen Hitler und Stalin (3. Aufl.). München: C. H. Beck.

Sommer, B. und Welzer, H. (2014). Transformationsdesign. Wege in eine zukunftsfähige Moderne. München: oekom.

Stern, B. (1993). Schule? Nein danke! Für ein Recht auf freie Bildung! In Kristian Kunert (Hg.), Schule im Kreuzfeuer. Auftrag - Aufgaben - Probleme. Ringvorlesung zu Grundfragen der Schulpädagogik an der Universität Tübingen (S. 20-43). Baltmannsweiler: Schneider Hohengehren. 
Stern, B. (2006). Schluß mit Schule! - das Menschenrecht, sich frei zu bilden. Leipzig: Tologo.

Stern, B. (2016). Zum Ausbruch aus der Beschulungsideologie: Gute Gründe, auch juristisch den Schulverweigerern unser prospektives Vertrauen zu schenken. In Matthias Kern (Hg.), Selbstbestimmte und selbstorganisierte Bildung versus Schulpflicht. Leipzig: Tologo.

Stöver, B. (2017). Der Kalte Krieg. Geschichte eines radikalen Zeitalters 1947-1991 (5. Aufl.). München: C. H. Beck, https://doi.org/10.17104/9783406706127.

Strittmatter, K. (2018). Die Neuerfindung der Diktatur: Wie China den digitalen Überwachungsstaat aufbaut und uns damit herausfordert. München: Piper.

Taleb, N. N. (2018). Antifragilität. Anleitung für eine Welt, die wir nicht verstehen (2. Aufl.). München: Knaus.

Tannert, C. (Hg.) (2018). Berlinzulage. West-Berlin, Kunst, 1980er Jahre. Berlin: Künstlerhaus Bethanien.

Ther, P. (2019). Das andere Ende der Geschichte. Über die Große Transformation. Berlin: Suhrkamp.

Thoreau, H. D. (2016). Walden, or life in the woods (Original von 1854). New York: Penguin, Random House, https://doi.org/10.5962/bhl.title.146169.

Toczyski, P. (2019). Jak mądrość cyfrowa w powiązaniu z mądrością życiową umożliwia realizację archetypu mędrca w internecie: przykład bloga prof. Andrzeja Jaczewskiego (Wie digitale Weisheit in Zusammenhang mit der Lebensweisheit die Umsetzung des Weisheitsarchetypen im Internet ermöglicht: Das Beispiel von Prof. Andrzej Jaczewski). In J. Wojtyczy (Hg.), O harmonijny rozwój człowieka. Myśl pedagogiczna Profesora Andrzeja Jaczewskiego (S. 83-95). Krakau: Krakowska Akademia.

Ullrich, C. G. und Schiek, D. (2014). Gruppendiskussionen in Internetforen. Zur Methodologie eines neuen qualitativen Erhebungsinstruments. Kölner Zeitschrift für Soziologie und Sozialpsychologie, 66 (3), 459-474, https://doi.org/10.1007/s11577-o1 4-0279-0.

United Nations (2016). Transforming our world: The 2030 agenda for sustainable development, https:/www.un.org/sustainabledevelopment/sustainable-development-goals/.

Uslar, M. von (2013). »Geisterkranker!« Die Teenagerkomödie »Fack ju Göhte« ist der erfolgreichste deutsche Film des Jahres. Eine Sprachkritik. Die ZEIT Nr. 50, 5.12.2013.

Vetter, A. und Scheidler, F. (2014). Lernen ohne Wachstumszwang. Entschulung als Weg zu einem anderen Wirtschaften. Unerzogen, 1, 41-43.

Vivant, E. (2013). Creatives in the city: Urban contradictions of the creative city. City, Culture and Society, 4, 57-63, https://doi.org/10.1016/j.ccs.2013.02.003.

Wahler, P., Tully, C. J. und Preiß, C. (2008). Jugendliche in neuen Lernwelten. Selbstorganisierte Bildung jenseits institutioneller Qualifizierung. Wiesbaden: Springer VS, https://doi.org/10.1007/978-3-531-91983-6.

Welzer, H. und Wiegandt, K. (2014). Wege aus der Wachstumsgesellschaft (2. Aufl.). Frankfurt a. M.: Fischer.

Wende, W.W. und Koch, L. (Hg.) (2010). Krisenkino. Filmanalyse als Kulturanalyse: Zur Konstruktion von Normalität und Abweichung im Spielfilm. Bielefeld: transcript, https://doi.org/10.14361/9783839411353.

Westad, O.A. (2019). Der Kalte Krieg. Eine Weltgeschichte. Stuttgart: Klett-Cotta.

Wiechmann, R. und Bandelt, H.-J. (2016). Die Selbstunterwerfung unter ökonomisches Denken. Pädagogische Korrespondenz, Heft 53, 26-47. 
Willis, P. (1979). Spaß am Widerstand. Gegenkultur in der Arbeiterschule. Frankfurt a. M.: Syndikat.

Willis P. (1981). Profan Culture: Rocker, Hippies. Subversive Stile der Jugendkultur. Frankfurt a. M.: Syndikat.

Willis, P. (2017). Learning to labor (Original von 1977). New York: Columbia University Press.

Wirth, H.-J. (2011). Narzissmus und Macht. Zur Psychoanalyse seelischer Störungen in der Politik (4. Aufl.). Gießen: Psychosozial.

Wojtyczy, J. (Hg.) (2019). O harmonijny rozwój człowieka. Myśl pedagogiczna Profesora Andrzeja Jaczewskiego (Harmonische menschliche Entwicklung. Der pädagogische Gedanke von Professor Andrzej Jaczewski). Krakau: Krakowska Akademia.

Wood, B. E. (2013). Young people's emotional geographies of citizenship participation: Spatial and relational insights. City, Culture and Society, 9, 50-58, https://doi.org/ 10.1016/j.emospa.2013.02.004.

Wright, E. O. (2017). Reale Utopien. Wege aus dem Kapitalismus. Berlin: Suhrkamp.

Zimbardo, P. (2017). Der Luzifer-Effekt: Die Macht der Umstände und die Psychologie des Bösen. Berlin, Heidelberg: Springer.

Zirkel, S., Bailey, F., Bathey, S., Hawley, R., Lewis, U., Long, D., et al. (2011). »Isn't that what sthose kids need? « Urban schools and the master narrative of the »tough, urban principal«. Race, Ethnicity and Education, 14 (2), 137-158.

\section{Belletristische Literatur}

Böll, H. (1994). Anekdote zur Senkung der Arbeitsmoral. In H. Böll, Romane und Erzählungen 4, 1961-1970 (S. 267-269). Köln: Kiepenheuer \& Witsch.

Brandys, K. (1996). Warschauer Tagebuch. Die Monate davor, 1978-1981. Frankfurt a. M.: Suhrkamp.

Brandys, K. (1988). Rondo. Darmstadt: Luchterhand.

Bronte, E. (1986). Sturmhöhe (Original: Wuthering Heights). Ditzingen: Reclam.

Burgess, A. (1992). Uhrwerk Orange (10. Aufl.). München: Heyne.

Dedecius, K. (2011). Meine polnische Bibliothek. Literatur aus neun Jahrhunderten. Berlin, Leipzig: Insel.

Forster, E. M. (2005). Maurice. London: Penguin.

Friel, B. (1999). The illusionists. In H.-C. Oeser (Hg.), Contemporary Irish short stories (S. 23-44). Ditzingen: Reclam.

Genet, J. (1974). Querelle. Reinbek bei Hamburg: Rowohlt.

Golding, W. (2017). Herr der Fliegen. Frankfurt a. M.: Fischer.

Hesse, H. (1980). Unterm Rad. Frankfurt a. M.: Suhrkamp.

Huxley, A. (2014). Schöne neue Welt (7. Aufl.). Frankfurt a. M.: Fischer.

Isherwood, C. (2010). A single man. London: Vintage.

Jahnn, H. H. (1994). Perrudja. Hamburg: Hoffmann und Campe.

Mann, T. (1988). Tonio Kröger. Frankfurt a. M.: Fischer.

Martin, G. R. R. (1996). A game of thrones (A song of ice and fire series, Bd. 1). New York: Bantam.

Martin, G. R. R. (1999). A clash of kings (A song of ice and fire series, Bd. 2). New York: Bantam. 
Martin, G. R. R. (2000). A storm of swords (A song of ice and fire series, Bd. 3). New York: Bantam.

Martin, G. R. R. (2005). A feast of crows (A song of ice and fire series, Bd. 4). New York: Bantam.

Martin, G. R. R. (2011). A dance with dragons (A song of ice and fire series, Bd. 5). New York: Bantam.

Morante, E. (2002). Arturos Insel. Berlin: Wagenbach.

Musil, R. (2008). Die Verwirrungen des Zöglings Törleß (61. Aufl.). Reinbek: Rowohlt.

Orwell, G. (1978). 1984. Berlin: Ullstein.

Ostroróg, J. (1994). Memoriał w sprawie uporządkowania Rzeczypospolitej. Łódzkie: Towarzystwo Naukowe.

Pasolini, P. P. (2001). Vita Violenta. München, Zürich: Piper.

Pasolini, P. P. (2009). Ragazzi di vita. Berlin: Wagenbach.

Preußler, O. (1988). Krabat. Stuttgart: Thienemann.

Proulx, A. (2009). Brokeback Mountain. Geschichten aus Wyoming (S. 305-348). München: btb, Random House.

Reymont, W. S. (2017). Die Bauern: Herbst - Winter - Frühling - Sommer (poln. Original: Chłopi, 1901-1908). Berlin: Hofenberg.

Salinger, J. D. (1988). Der Fänger im Roggen. Reinbek: Rowohlt.

Sapphire (2009). Push. A novel. New York: Vintage.

Schneider, R. (1995). Schlafes Bruder (12. Aufl.). Leipzig: Reclam.

Schönherz, R. und Fleer, A. (2002). "In meinem wilden Herzen«, Rilke-Projekt. München: BMG Ariola Classics.

Scholochow, M. A. (1993). Der stille Don. München: dtv.

Schwanitz, D. (1994). Der Campus. Frankfurt a. M.: Eichborn.

Sillitoe, A. (2007). Die Einsamkeit des Langstreckenläufers. Zürich: Diogenes.

Szymborska, W. (1996a). Hundert Freuden. Frankfurt a. M.: Suhrkamp.

Szymborska, W. (1996b). Auf Wiedersehn. Bis morgen. Frankfurt a. M.: Suhrkamp.

Szymborska, W. (2012). Glückliche Liebe und andere Gedichte. Berlin: Suhrkamp.

Torberg, F. (1979). Der Schüler Gerber (6. Aufl). München: dtv.

Vidal, G. (1994). The city and the pillar. London: Abacus.

Zeromski, S. (1954). Dzienniki, II, 1886-1887 (Tagebücher). Warschau: Czytelnik.

\section{Dokumentarfilme}

ARD (2020). Totale Kontrolle - Chinas Sozialkreditsystem. Plusminus, 15.1.2020.

Calderon, P. und Benarrosh, C. (2017). George Orwell, Aldous Huxley. 1984 oder Schöne neue Welt? Frankreich.

Dupuy, J. (2020). Das notwendige Böse. Frankreich.

Fitsch, M. (2019). Flexible Räume - Die Zukunft des Bauens. Deutschland.

Schmitt, T. (1981). Randale und Liebe. Deutschland.

Schmitt, T. (1985). Cooltur. Deutschland.

ZDF (2020). Das überwachte Volk - Chinas Sozialkredit-System. ZDF-info, 16.10.2020. 


\section{Spielfilme}

Akel, M. (2006). Chalk. USA.

Akin, F. (2002). Solino. Deutschland, Italien.

Altman, R. (2001). Gosford Park. USA, Großbritannien, Italien.

Alvarez, K. P. (2015). The Stanford prison experiment. USA.

Ang, L. (2005). Brokeback Mountain. USA, Canada (basierend auf einer Erzählung von Annie Proulx).

Angel, H. (2016). Die Grundschullehrerin (Primaire). Frankreich.

Barratier, C. (2004). Die Kinder des Monsieur Mathieu (Les choristes). Frankreich.

Becker, L. (2006). Der beste Lehrer der Welt. Deutschland.

Benioff, D. und Weiss, D. B. (2011-2019). Game of Thrones (73 Episoden in 8 Staffeln). USA, Großbritannien.

Benton, R. (2003). Der menschliche Makel (The Human Stain). USA (basierend auf einem Roman von Philip Roth).

Bergman, I. (1972). Schreie und Flüstern (Viskningar och rop). Schweden.

Bergman, I. (1982). Fanny und Alexander (Fanny och Alexander). Schweden.

Bolognini, M. (1959). Wir von der Straße (La notte brava). Italien (basierend auf einem Roman von Pier Paolo Pasolini).

Brusati, F. (1979). Vergiß Venedig. Italien.

Cantet, L. (2008). Die Klasse (Entre les murs). Frankreich.

Capuano, A. (1996). Pianese Nunzio, 14 im Mai. Italien.

Chabrol, C. (1985). Hühnchen in Essig (Poulet au vinaigre). Frankreich.

Chabrol, C. (2003). Die Blume des Bösen (La fleur du mal). Frankreich.

Chabrol, C. (2004). Die Brautjungfer (La demoiselle d'donneur). Frankreich.

Coixet, I. (2017). Der Buchladen der Florence Green (The Bookshop). Großbritannien, Spanien, Deutschland (nach dem Roman von Penelope Fitzgerald).

Dagtekin, B. (2013). Fack ju Göhte. Deutschland.

Dagtekin, B. (2015). Fack ju Göhte 2. Deutschland, Thailand.

Dagtekin, B. (2017). Fack ju Göhte 3. Deutschland.

Daldry, S. (2000). Billy Elliot: I will dance. Großbritannien.

Daniels, L. (2009). Precious - Das Leben ist kostbar (Precious). USA.

Dick, A. (2019). Teacher. USA.

Edel, U. (1981). Christiane F.: Wir Kinder vom Bahnhof Zoo. Deutschland.

Fabrick, J. (2011). Der kalte Himmel (2 Teile). Deutschland.

Fassbinder, R.W. (1980). Berlin Alexanderplatz (14 Episoden). Deutschland (basierend auf dem Roman von Alfred Döblin).

Fassbinder, R.W. (1982). Querelle. Deutschland, Frankreich (basierend auf dem Roman von Jean Genet).

Faure, C. (2000). Nur eine Frage der Liebe (Juste une question d'amour). Frankreich, Belgien.

Faure, C. (2005). Un amour à taire (A love to hide). Frankreich.

Fellini, F. (1973). Amarcord. Italien.

Fingscheidt, N. (2019). Systemsprenger. Deutschland.

Fleck, R. (2006). Half Nelson. USA.

Ford, T. (2009). A single man. USA (basierend auf einer Erzählung von Christopher Isherwood). 
Gallenberger, F. (2015). Colonia Dignidad - Es gibt kein zurück. Deutschland, Luxemburg, Frankreich.

Gansel, D. (2008). Die Welle. Deutschland.

Geschonnek, M. (1997). Der Schrei der Liebe. Deutschland.

Gilbert, B. (1997). Oscar Wilde. Deutschland, Japan, Großbritannien.

Gluck, W. (2010). Einfach zu haben (Easy A). USA.

Grube, T. und Sánchez Lansch, E. (2004). Rhythm is it! Deutschland.

Hiller, A. (1984). Die Aufsässigen (Teachers). USA.

Hirschbiegel, O. (2001). Das Experiment. Deutschland.

Hirst, M. (2013-2020). Vikings (89 Episoden in 6 Staffeln). Kanada, Irland.

Hitchcock, A. (1960). Psycho. USA.

Hitchcock, A. (1963). Die Vögel (The birds). USA.

Hook, H. (1990). Lord of the flies. USA (basierend auf einem Roman von William Golding).

Howard, R. (2001). A beautiful mind: Genie und Wahnsinn. USA.

Hughes, J. (1985). Der Frühstücksclub (The breakfast club). USA.

Hughes, J. (1986). Ferris macht blau (Ferris Bueller's day off). USA.

Huntgeburth, H. (1997). Das Trio. Deutschland.

Ivory, J. (1987). Maurice. Großbritannien (basierend auf einem Roman von E. M. Forster).

Jarman, D. (1991). Edward II. Großbritannien.

Jarman, D. (1992). Wittgenstein. Großbritannien.

Johnson, M. (2013). The dirties. Kanada.

Johnston, J. (1999). October Sky. USA.

Kablitz-Post, C. (2016). Lou Andreas-Salomé (The audacity to be free). Deutschland, Österreich, Italien, Schweiz.

Kokkinos, A. (1998). Kopfüber (Head On). Australien.

Kraume, L. (2018). Das schweigende Klassenzimmer. Deutschland (nach einem Roman von Dietrich Garstka).

Laccant, S. (2013). Freier Fall. Deutschland.

LaGravenese, R. (2007). Freedom writers. USA.

Link, C. (2013). Exit Marrakech. Deutschland, Marokko.

Linklater, R. (2004). School of rock. USA, Deutschland.

McGregor, E. (2016). Amerikanisches Idyll (American pastoral). USA (basierend auf einem Roman von Philip Roth).

Menéndez, R. (1988). Stand and deliver. USA.

Mention Schaar, M.-C. (2014). Die Schüler der Madame Anne (Les héritiers). Frankreich.

Miller, C. (1988). Die kleine Diebin (La petite voleuse). Frankreich.

Miller, C. (1998). Die Klassenfahrt (La classe de neige). Frankreich.

Minghella, A. (1999). Der talentierte Mr. Ripley (The talented Mr. Ripley). USA, Italien (nach einem Roman von Patricia Highsmith).

Montaldo, G. (1987). Brille mit Goldrand (Gli occhiali d'oro). Italien, Frankreich.

Muccino, G. (2006). The pursuit of happyness (Das Streben nach Glück). USA.

Nyholm, K. (2017). Taboo (8 Episoden in einer ersten Staffel). Großbritannien.

O'Connor, P. (1998). Tanz in die Freiheit (Dancing at Lughnasa). Irland, USA, Großbritannien. 
Özpetek, F. (1997). Hamam. Das türkische Bad (Il bagno turco). Italien, Türkei, Spanien.

Pasolini, P. P. (1968). Teorema. Geometrie der Liebe (Teorema). Italien.

Pasolini, P. P. (1974). Erotische Geschichten aus 1001 Nacht (Il fiore delle mille e una notte). Italien.

Pasolini, P. P. (1975). Die 120 Tage von Sodom (Salò o le 120 giornate di Sodoma). Italien. Philibert, N. (2002). Sein und haben (Etre et avoir). Frankreich.

Praunheim, R. v. (1971). Nicht der Homosexuelle ist pervers, sondern die Situation, in der er lebt. Deutschland.

Ripploh, F. (1980). Taxi zum Klo. Deutschland.

Röhl, C. (2014). Die Auserwählten. Deutschland.

Rosenmüller, M. H. (2008). Räuber Kneißl. Deutschland.

Schamus, J. (2017). Empörung (Indignation). USA (basierend auf einem Roman von Philip Roth).

Schlöndorff, V. (1966). Der junge Törless. Deutschland (basierend auf einem Roman von Robert Musil).

Schwochow, C. (2019). Deutschstunde (nach dem Roman von Siegfried Lenz). Deutschland.

Sehr, P. (1993). Kaspar Hauser. Deutschland.

Smith, J. N. (1995). Dangerous minds (Wilde Gedanken). USA.

Strouse, J. (2014). Teacher of the year. USA.

Tarkovski, A. (1983). Nostalgia (Nostalghia). Sowjetunion, Italien.

Truffaut, F. (1957). Die Unverschämten (Les mistons). Frankreich.

Truffaut, F. (1959). Sie küssten und sie schlugen ihn (Les quatre cents coups). Frankreich.

Truffaut, F. (1968). Geraubte Küsse (Baisers volés). Frankreich.

Truffaut, F. (1970). Der Wolfsjunge (L'enfant sauvage). Frankreich.

Truffaut, F. (1972). Ein schönes Mädchen wie ich (Une belle fille comme moi). Frankreich.

Truffaut, F. (1976). Taschengeld (L'argent de poche). Frankreich.

Van Sant, G. (1997). Good Will Hunting (Der gute Will Hunting). USA.

Vilsmeier, J. (1995). Schlafes Bruder. Deutschland (basierend auf einem Roman von Robert Schneider).

Vinterberg, T. (2012). Die Jagd. Dänemark.

Weir, P. (1989). Der Club der toten Dichter (Dead Poet Society). USA.

Weiss, H. (1944). Die Feuerzangenbowle. Deutsches Reich.

Wortmann, S. (2015). Frau Müller muss weg! Deutschland. 


\section{Pädagogik}

\section{Kay Biesel \\ Felix Brandhorst, \\ Regina Rätz, \\ Hans-Ullrich Krause \\ Deutschland schützt \\ seine Kinder! \\ Eine Streitschrift \\ zum Kinderschutz \\ [ranseript] $\times \cdots \times$}
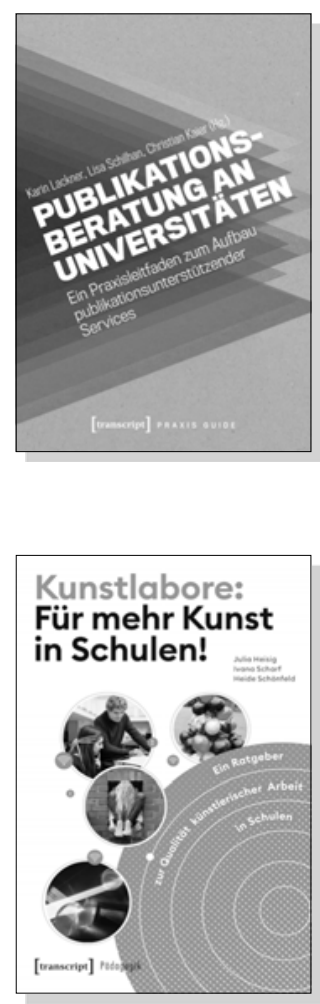

Kay Biesel, Felix Brandhorst, Regina Rätz, Hans-Ullrich Krause Deutschland schützt seine Kinder!

Eine Streitschrift zum Kinderschutz

2019, 242 S., kart., 1 SW-Abbildung

$22,99 €(D E), 978-3-8376-4248-3$

E-Book: 20,99€ (DE), ISBN 978-3-8394-4248-7

EPUB: $20,99 €(D E)$, ISBN 978-3-7328-4248-3

Karin Lackner, Lisa Schilhan, Christian Kaier (Hg.)

Publikationsberatung an Universitäten

Ein Praxisleitfaden zum Aufbau

publikationsunterstützender Services

2020, 396 S., kart., 14 SW-Abbildungen

39,00€ (DE), 978-3-8376-5072-3

E-Book: kostenlos erhältlich als Open-Access-Publikation

PDF: ISBN 978-3-8394-5072-7

ISBN 978-3-7328-5072-3

Julia Heisig, Ivana Scharf, Heide Schönfeld

Kunstlabore: Für mehr Kunst in Schulen!

Ein Ratgeber zur Qualität künstlerischer Arbeit in Schulen

2020, 216 S., Klappbroschur, durchgängig vierfarbig

27,99€ (DE), 978-3-8376-4985-7

E-Book: kostenlos erhältlich als 0pen-Access-Publikation

PDF: ISBN 978-3-8394-4985-1 


\section{Pädagogik}

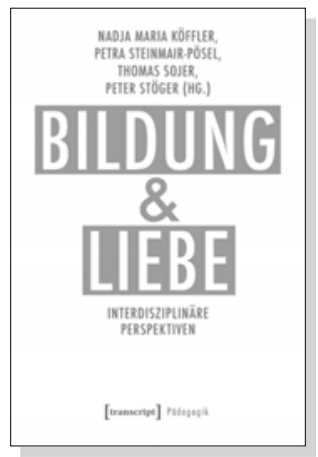

Nadja Köffler, Petra Steinmair-Pösel,

Thomas Sojer, Peter Stöger (Hg.)

Bildung und Liebe

Interdisziplinäre Perspektiven

2018, 412 S., kart., 11 SW-Abbildungen

39,99 € (DE), 978-3-8376-4359-6

E-Book:

PDF: 39,99€ (DE), ISBN 978-3-8394-4359-0

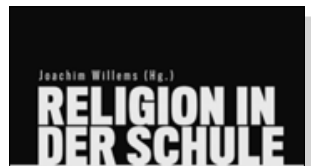

Joachim Willems (Hg.)

Religion in der Schule

Pädagogische Praxis

zwischen Diskriminierung und Anerkennung

2020, 432 S., kart.

39,00€ (DE), 978-3-8376-5355-7

E-Book: kostenlos erhältlich als Open-Access-Publikation

PDF: ISBN 978-3-8394-5355-1

[mancipl] nitase

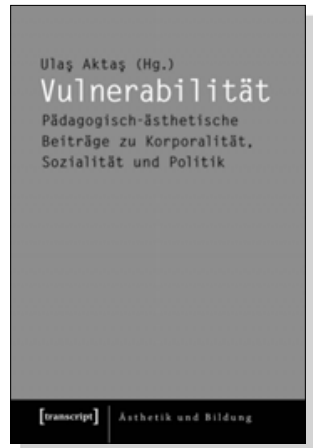

Ulaș Aktaș (Hg.)

Vulnerabilität

Pädagogisch-ästhetische Beiträge

zu Korporalität, Sozialität und Politik

2020, 194 S., kart., 26 SW-Abbildungen, 26 Farbabbildungen 39,00 € (DE), 978-3-8376-5444-8

E-Book:

PDF: $38,99 €$ (DE), ISBN 978-3-8394-5444-2 
